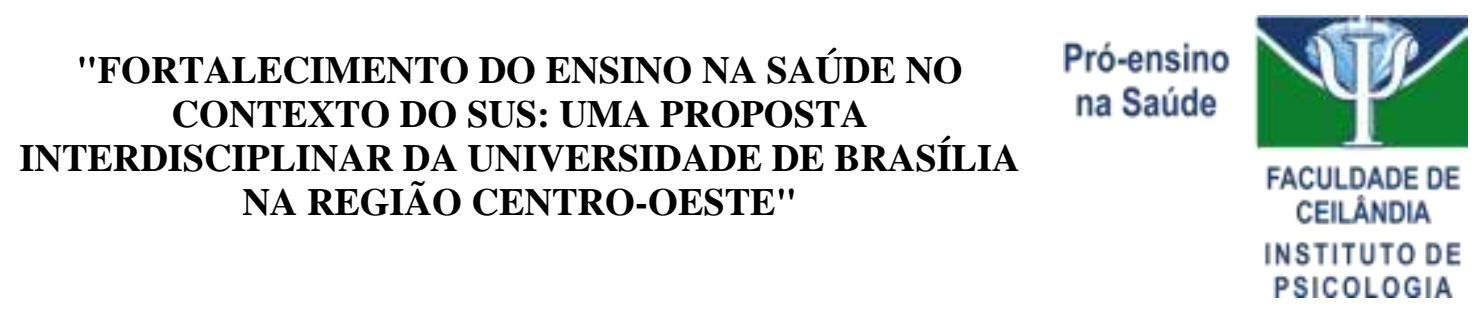

Programa de Pós-Graduação em Psicologia Clínica e Cultura

\title{
Políticas Indutoras (Pró-Saúde) e a Reorientação da Formação de Profissionais da Área da Saúde para o fortalecimento do SUS
}

Doutoranda: Denise de Lima Costa Furlanetto Orientadora: Diana Lúcia Moura Pinho 
UNIVERSIDADE DE BRASÍLIA

"FORTALECIMENTO DO ENSINO NA SAÚDE NO

CONTEXTO DO SUS: UMA PROPOSTA

INTERDISCIPLINAR DA UNIVERSIDADE DE BRASÍLIA

NA REGIÃO CENTRO-OESTE"

Pró-ensino na Saúde

FACULDADE DE CEILÂNDIA INSTITUTO DE PSICOLOGIA

Programa de Pós-Graduação em Psicologia Clínica e Cultura

\section{Políticas Indutoras (Pró-Saúde) e a Reorientação da Formação de Profissionais da Área da Saúde para o fortalecimento do SUS}

Denise de Lima Costa Furlanetto

Tese apresentada ao Programa de Pós-Graduação em Psicologia Clínica e Cultura do Instituto de Psicologia da Universidade de Brasília como requisito parcial para obtenção do título de Doutor em Psicologia Clínica e Cultura, sob a orientação da

Professora Doutora Diana Lúcia Moura Pinho 


\title{
POLÍTICAS INDUTORAS (PRÓ-SAÚDE) E A REORIENTAÇÃO DA FORMAÇÃO DE PROFISSIONAIS DA ÁREA DA SAÚDE PARA O FORTALECIMENTO DO SUS
}

\author{
Denise de Lima Costa Furlanetto
}

\section{BANCA EXAMINADORA}

Profa . Dra. Diana Lúcia Moura Pinho - Orientadora - Presidente

Prof. Dra. Eliana Goldfarb Cyrino - Membro Externo - UNESP- Botucatu

Prof. Dra. Dais Gonçalves Rocha - Membro Externo - DSC - UnB

Prof. Dra. Elizabeth Queiroz - Membro Interno - IP - UnB

Prof. Dra. Clelia Maria de Sousa Ferreira Parreira - Membro Efetivo - FCE -UnB

Prof. Dr. Oviromar Flores - Membro Suplente - PPGCTS/FCE -UnB 


\section{DEDICATÓRIA}

Dedico esta tese aos meus pais, meus filhos e meu esposo, por todo sacrifício a que foram submetidos para que esse trabalho fosse desenvolvido e concluído. 


\section{AGRADECIMENTOS}

À minha orientadora, Dra. Diana Lúcia Moura Pinho, por ter me acolhido e conduzido essa caminhada com muita sabedoria e otimismo. Uma capacidade admirável de desatar nós.

À professora Dra. Clélia Maria de Sousa Ferreira Parreira por todo apoio oferecido, especialmente nos momentos de dificuldade. E também pela grande presteza na condução do projeto junto ao CNPq.

Ao prof. Dr. Adriano de Almeida de Lima pelo apoio nas análises estatísticas desse trabalho.

Ao grupo gestor do Pró-Ensino na Saúde pela colaboração ao longo desses anos.

Aos bolsistas de apoio técnico, Mábia Milhomem Bastos e Jetro Williams Silva Júnior, meu carinho especial, pelo profissionalismo, presteza e companheirismo durante o desenvolvimento dessa pesquisa.

Aos professores da banca examinadora, Dra. Dais Gonçalves Rocha, Dra. Eliana Goldfarb Cyrino, Dra. Elizabeth Queiroz e Dr. Oviromar Flores, pela disponibilidade em trazer suas contribuições para a conclusão desse trabalho.

Aos colegas do Pró-Ensino na Saúde, pelos momentos de crescimento que compartilhamos. Especial agradecimento à colega e amiga Marilac Meireles.

Aos colegas de trabalho pelo incentivo, apoio e compreensão nos momentos de ausência, especialmente ao prof. Dr. Arlindo Abreu de Castro Filho.

Pelo apoio financeiro do Conselho Nacional de Desenvolvimento Científico e Tecnológico (CNPq), com a aprovação desse projeto no Edital MCTI/CNPQ/MS-Decit 08/2013. E pela bolsa de doutorado concedida pela Capes, através do Projeto PróEnsino na Saúde.

À minha família, irmãos, sobrinhos, enfim, todos aqueles que me apoiaram e apoiam sempre.

Ao meu amado pai, pelo exemplo de vida que sempre foi e será para mim. 


\section{RESUMO}

A formação profissional na área de saúde é de extrema importância para a construção, manutenção e consolidação de modelos de saúde. Busca-se atualmente obter um profissional com o perfil que atenda as necessidades em saúde das pessoas. Dentre diversas políticas indutoras de mudanças na formação, uma importante iniciativa foi a implantação do Programa Nacional de Reorientação da Formação Profissional em Saúde (Pró-Saúde) em 2005. O Programa Pró-Saúde busca induzir a integração ensinoserviço, com o foco na reorientação da formação profissional em saúde, assegurando uma abordagem integral do processo saúde-doença com ênfase na Atenção Primária. Este estudo tem por objetivo avaliar a implementação das ações do Pró-Saúde em três cursos de graduação, Enfermagem, Medicina e Odontologia, que representam as áreas que compõem a equipe mínima da Estratégia Saúde da Família (ESF). Este trabalho foi dividido em etapas, sendo que inicialmente foi realizada revisão da literatura. $\mathrm{Na}$ segunda etapa foi construído e validado um instrumento, com escala de Likert, baseado nos eixos temáticos propostos no Programa Pró-Saúde. A terceira etapa consistiu na aplicação do instrumento aos acadêmicos e docentes dos cursos de graduação de Odontologia, Enfermagem e Medicina da IES incluída no estudo. Na quarta etapa, foi realizado um aprofundamento da análise das experiências com a implementação do PróSaúde, por meio da realização de entrevistas. Os resultados quantitativos do presente estudo demonstraram que cada curso vivencia momentos diferentes de reestruturação curricular. Há por parte de professores e estudantes dos três cursos analisados, o reconhecimento de que mudanças estão ocorrendo, ainda que de forma tímida em algumas dimensões, e de que o Pró-Saúde tem o potencial de ser uma referencial de apoio importante nessa missão. Os cursos de Enfermagem e Odontologia, quando comparados ao curso de Medicina, apresentam uma tendência maior à transição do perfil especialista para o perfil profissional de especialista para o perfil generalista. Quanto ao currículo, observou-se que há convergência entre os três cursos em relação à necessidade de discussões e reformulação curricular. Além disso, constatou-se que quanto maior o quantitativo de reformulação ocorrida, observa-se mais avanço em direção à reorientação da formação. Da análise qualitativa, pôde-se apreender que, apesar desse reconhecimento, os nós críticos ainda são fortes e se manifestam na forma de barreiras, dificuldades, resistência e equívocos, os quais devem ser considerados na elaboração de ações de enfrentamento ao cenário. As diferenças observadas entre os três cursos são pertinentes ao momento de cada curso no processo de reestruturação. Entretanto, é importante destacar as similaridades verificadas entre eles. A abertura ao diálogo, as discussões presentes e as inquietações manifestadas, demonstram o importante momento de abertura na busca de uma aproximação entre todos os envolvidos. Verificou-se ainda, avanços em que outras frentes, como a integração entre áreas, cursos e entre a universidade e os serviços de saúde. A mudança de perfil profissional ainda requer outras estratégias para o fortalecimento, já que essas requerem transformações de maior complexidade. Pode-se concluir que apesar de existirem ações em andamento para que se coloque em prática todas as propostas do Pró-Saúde, ainda há muito a ser feito para se alcançar uma formação profissional para os cursos de graduação em Enfermagem, Medicina e Odontologia que atendam as necessidades do SUS.

Descritores: Ensino na saúde; Pró-Saúde; Avaliação do ensino na saúde; Políticas indutoras; Formação profissional em saúde. 


\begin{abstract}
The health professional qualification is extremely important for the construction, maintenance and consolidation of health models. The current proposal is to obtain a professional with the profile that meets these changes and that can meet people's health needs. Among other health professional training inducing policies, a major initiative was the implementation of National Programme for Re-orientation of Health Professional (Pro-Saúde) in 2005, which is a joint action between the Ministry of Health and Ministry of Education. The Pro-Saúde Programme intend to promote the teaching-service integration, in order to promote changes in the teaching-learning process and reorientation of professional training in health, ensuring a comprehensive approach to the health-disease process with an emphasis on primary care. This research project aims to evaluate the implementation of Pro-Saúde proposals in three undergraduate courses, Nursing, Medicine and Dentistry, which represent the areas that initially composed the staff of the Family Health Strategy (ESF). This research project was developed in stages. The first stage included the literature review. In the second stage the construction and validation of an instrument was made, a Likert scale questionnaire, based on the themes proposed in the Pro-Saúde Programme. The third stage of the study refers to the instrument's application to students and lecturers of Dentistry, Nursing and Medicine undergraduate courses of the university where the research was developed. In the fourth stage, was conducted a deeper analysis of the experiences with the implementation of the Pro-Saúde, with semi-structured interviews. The quantitative results of this study demonstrated that each course experiences different moments of curricular reorientation. The lecturers and students from the three courses analyzed recognize that changes are taking place, even if in slow paces in some aspects, and that the Pro-Saúde has the potential to be an important support for that mission. The Nursing and Dentistry degree courses, when compared to Medicine, present trends to transition from the specalist professional profile to the general practitioner profile. Regarding the curriculum, it was observed that there is agreement among the three courses that there is a need for discussions a curricular reformulation. Besides, it could be seen that the greater the curricular restructuration, more advances were observed into the direction of professional re-orientation. From the qualitative analysis could be drawn that, despite this recognition, we still have the critical force that it appears as barriers, difficulties, resistance and misunderstanding, which should be considered for the development of proposals to address this scenario. Comparing, there are expected The differences seen in the three courses should consider the timing of each course within the restructuring process. However, it is important to note the similarities found among them. The ongoing dialogues, discussions and concerns demonstrate an important moment to bring together all those involved. It was found that other approaches, as the integration between areas, integration between university and health services, as well as the changes in the professional profile require further strategies, as these issues involves changes that are more complex to be achieved. The study results suggest that although there are actions underway, in order to put into practice all the proposals of the Pro-Health, much remains to be done to achieve a professional training for undergraduate courses in Nursing, Medicine and Dentistry that meet the needs of the SUS.
\end{abstract}

Keywords: Pro-Teaching Health Programme; National Programme for Re-orientation of Health Professional; Health Teaching Evaluation; Inducing Politics; Health Professional Training. 


\section{SUMÁRIO}

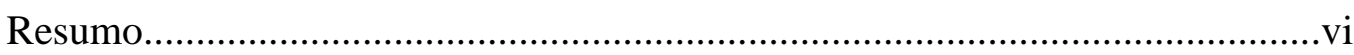

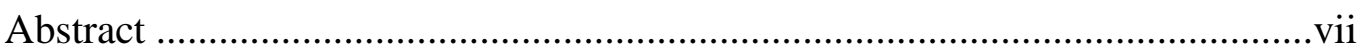

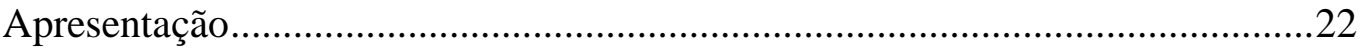

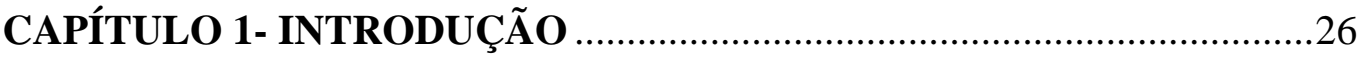

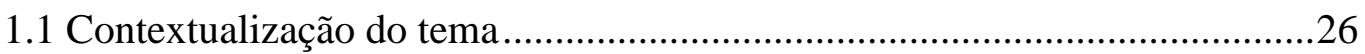

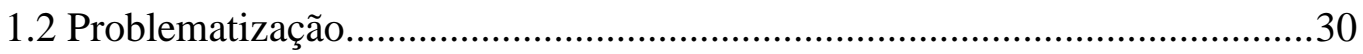

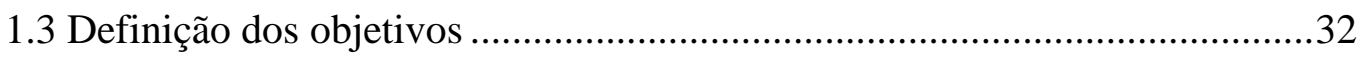

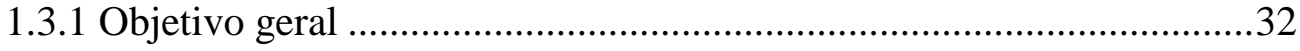

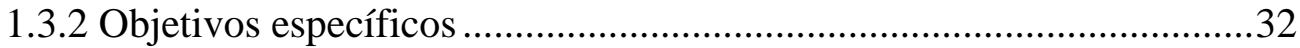

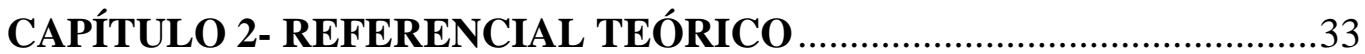

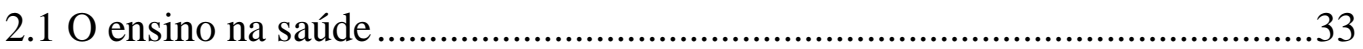

2.1.1 Um breve histórico do cenário mundial...............................................33

2.1.2 O contexto do ensino na saúde no Brasil - ênfase para a Medicina,

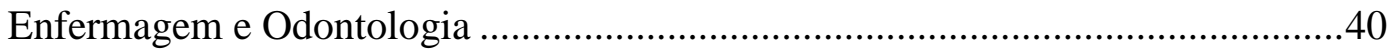

2.2 Bases conceituais das Diretrizes Curriculares Nacionais para os cursos de

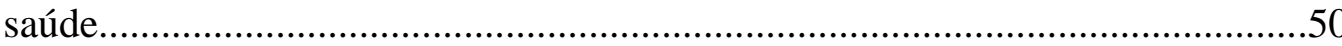

2.3 Políticas indutoras de transformações na formação em saúde .63

2.4 Programa Nacional de Reorientação da Formação Profissional em Saúde (Pró-Saúde)

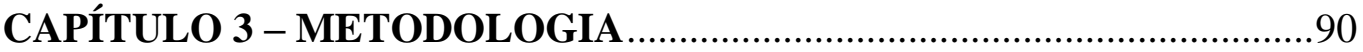

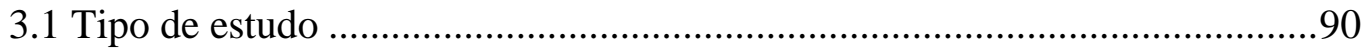

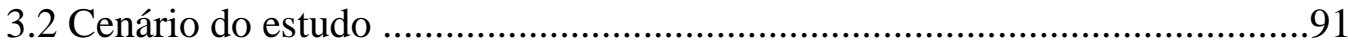

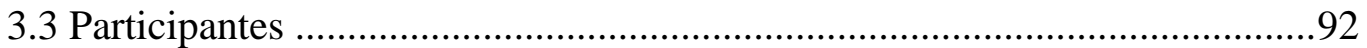

3.4 Descrição das etapas e procedimentos de coleta de dados ............................92

3.4.1 Análise de validade do instrumento .................................................101

3.4.1.1 Agrupamento dos itens do instrumento ........................................101

3.4.1.2 Confiabilidade do instrumento .....................................................104 
3.5 Procedimentos para análise dos dados

CAPÍTULO 4 - RESULTADOS

4.1 Artigo 1

4.2 Artigo 2

4.3 Artigo 3

CAPÍTULO 5 - DISCUSSÃO E CONCLUSÕES

5.1 Análise comparativa entre os estudos 1, 2, e 3

5.2 Considerações finais

Anexo B - Termo de Consentimento Livre e Esclarecido

Anexo C - Versão final do instrumento aplicado aos estudantes

Anexo D - Versão final do instrumento aplicado aos professores

Anexo E - Roteiro de entrevista

\section{APÊNDICES} 196

Apêndice A - Estudo 1 - Odontologia .196

1. Análise descritiva dos dados coletados dos estudantes na Seção 1dados sociodemográficos e acadêmicos 196

2. Análise descritiva dos dados coletados dos professores na Seção 1dados sociodemográficos e profissionais 203 
3. Análise descritiva da Seção 2 - parte específica do instrumento ...210

3.1 Dimensão teórica - estudantes .............................................210

3.2 Dimensão cenário de práticas - estudantes ............................211

3.3 Dimensão reorientação da formação - estudantes...................213

3.4 Dimensão pedagógica - estudantes .......................................214

3.5 Dimensão teórica - professores ............................................215

3.6 Dimensão cenário de práticas - professores ...........................216

3.7 Dimensão reorientação da formação - professores .................218

3.8 Dimensão pedagógica - professores......................................219

3.9 Comentários/sugestões de professores e acadêmicos sobre os itens respondidos no instrumento

4. Pontuação e codificação dos itens e blocos para interpretação das tendências atitudinais

5. Análise de conteúdo das entrevistas

Apêndice B - Estudo 2 - Enfermagem .246

1. Análise descritiva dos dados coletados dos estudantes na Seção 1dados sociodemográficos e acadêmicos

2. Análise descritiva dos dados coletados dos professores na Seção 1dados sociodemográficos e profissionais 252

3. Análise descritiva da Seção 2 - parte específica do instrumento ..259

3.1 Dimensão teórica - estudantes .259

3.2 Dimensão cenário de práticas - estudantes .261

3.3 Dimensão reorientação da formação - estudantes 262

3.4 Dimensão pedagógica - estudantes .263

3.5 Dimensão teórica - professores...........................................264

3.6 Dimensão cenário de práticas - professores.........................265

3.7 Dimensão reorientação da formação - professores ...............267

3.8 Dimensão pedagógica - professores. .267

3.9 Comentários/sugestões de professores e acadêmicos sobre os itens respondidos no instrumento

4. Pontuação e codificação dos itens e blocos para interpretação das tendências atitudinais

5. Análise de conteúdo das entrevistas 
Apêndice C - Estudo 3 - Medicina 292

1. Análise descritiva dos dados coletados dos estudantes na Seção 1dados sociodemográficos e acadêmicos

2. Análise descritiva dos dados coletados dos professores na Seção 1 dados sociodemográficos e profissionais .298

3. Análise descritiva da Seção 2 - parte específica do instrumento.304

3.1 Dimensão teórica - estudantes 304

3.2 Dimensão cenário de práticas - estudantes .306

3.3 Dimensão reorientação da formação - estudantes. 307

3.4 Dimensão pedagógica - estudantes 308

3.5 Dimensão teórica - professores 309

3.6 Dimensão cenário de práticas - professores 310

3.7 Dimensão reorientação da formação - professores 312

3.8 Dimensão pedagógica - professores 313

3.9 Comentários/sugestões de professores e acadêmicos sobre os itens respondidos no instrumento

4. Pontuação e codificação dos itens e blocos para interpretação das tendências atitudinais

5. Análise de conteúdo das entrevistas 323 


\section{LISTA DE TABELAS}

Tabela 1 - Consistência interna para a escala de atitudes

Tabela 2 - Coeficiente alfa de Cronbach da escala de atitude construída nesta pesquisa.

Tabela 3 - Consistência interna para cada dimensão da escala de atitudes. 106

Tabela 4 - Coeficiente Alfa de Cronbach na dimensão teórica da escala de atitude

Tabela 5 - Coeficiente Alfa de Cronbach na dimensão cenário de práticas da escala de atitude

Tabela 6 - Coeficiente Alfa de Cronbach na dimensão reorientação da formação da escala de atitude.

Tabela 7 - Coeficiente Alfa de Cronbach na dimensão pedagógica da escala de atitude 108

Tabela 8 - Comparação entre resultados obtidos nos itens 4 e 10 nos três

cursos

Tabela 9 - Caracterização dos acadêmicos de Odontologia quanto aos dados sócio-demográficos sexo e faixa etária

Tabela 10 - Perfil sociodemográfico e acadêmico dos estudantes de Odontologia participantes do estudo 202

Tabela 11 - Caracterização dos professores do curso de Odontologia quanto aos dados sociodemográficos sexo e faixa etária 204

Tabela 12 - Frequências de respostas obtidas dos estudantes em cada item da dimensão teórica. 
Tabela 13 - Frequências de respostas obtidas dos estudantes em cada item da dimensão cenário de práticas.

Tabela 14 - Frequências de respostas obtidas dos estudantes em cada item da dimensão reorientação da formação

Tabela 15 - Frequências de respostas obtidas dos estudantes em cada item da dimensão pedagógica

Tabela 16 - Frequências de respostas obtidas dos professores em cada item da dimensão teórica.

Tabela 17 - Frequências de respostas obtidas dos professores em cada item da dimensão cenário de práticas

Tabela 18 - Frequências de respostas obtidas dos professores em cada item da dimensão reorientação da formação

Tabela 19 - Frequências de respostas obtidas dos professores em cada item da dimensão pedagógica

Tabela 20 - Pontuação dos itens do bloco 1 em relação aos estudantes

Tabela 21 - Pontuação dos itens do bloco 1 em relação aos professores .225

Tabela 22 - Pontuação dos itens do bloco 2 em relação aos estudantes. .226

Tabela 23 - Pontuação dos itens do bloco 2 em relação aos professores 226

Tabela 24 - Pontuação dos itens do bloco 3 em relação aos estudantes 227

Tabela 25 - Pontuação dos itens do bloco 3 em relação aos professores 227

Tabela 26 - Pontuação dos itens do bloco 4 em relação aos estudantes. 228

Tabela 27 - Pontuação dos itens do bloco 4 em relação aos professores .229

Tabela 28 - Comparação entre as medianas para estudantes e professores nos blocos $1,2,3$ e 4 .230

Tabela 29 - Comparação dos resultados entre professores e estudantes para as quatro dimensões estudadas .230 
Tabela 30 - Caracterização dos acadêmicos de Enfermagem quanto aos dados sócio-demográficos sexo e faixa etária

Tabela 31 - Perfil sociodemográfico e acadêmico dos estudantes de Enfermagem participantes do estudo

Tabela 32 - Perfil sociodemográfico e profissional dos professores de

Enfermagem participantes do estudo

Tabela 33 - Frequências de respostas obtidas dos estudantes em cada item da dimensão teórica.

Tabela 34 - Frequências de respostas obtidas do estudantes em cada item da dimensão cenário de práticas.

Tabela 35 - Frequências de respostas obtidas dos estudantes em cada item da dimensão reorientação da formação

Tabela 36 - Frequências de respostas obtidas dos estudantes em cada item da dimensão pedagógica

Tabela 37 - Frequências de respostas obtidas dos professores em cada item da dimensão teórica.

Tabela 38 - Frequências de respostas obtidas dos professores em cada item da dimensão cenário de práticas

Tabela 39 - Frequências de respostas obtidas dos professores em cada item da dimensão reorientação da formação

Tabela 40 - Frequências de respostas obtidas dos professores em cada item da dimensão pedagógica

Tabela 41 - Pontuação dos itens do bloco 1 em relação aos estudantes 271

Tabela 42 - Pontuação dos itens do bloco 1 em relação aos professores

Tabela 43 - Pontuação dos itens do bloco 2 em relação aos estudantes .272

Tabela 44 - Pontuação dos itens do bloco 2 em relação aos professores .273 
Tabela 45 - Pontuação dos itens do bloco 3 em relação aos estudantes. .273

Tabela 46 - Pontuação dos itens do bloco 3 em relação aos professores .274

Tabela 47 - Pontuação dos itens do bloco 4 em relação aos estudantes. .274

Tabela 48 - Pontuação dos itens do bloco 4 em relação aos professores 275

Tabela 49 - Comparação entre as medianas para estudantes e professores nos blocos $1,2,3$ e 4

Tabela 50 - Comparação dos resultados entre professores e estudantes para as quatro dimensões estudadas 276

Tabela 51 - Caracterização dos acadêmicos de Medicina quanto aos dados sóciodemográficos sexo e faixa etária .294

Tabela 52 - Perfil sociodemográfico e acadêmico dos estudantes de Medicina participantes do estudo

Tabela 53 - Perfil sociodemográfico e profissional dos professores de Medicina participantes do estudo .304

Tabela 54 - Frequências de respostas obtidas dos estudantes em cada item da dimensão teórica.

Tabela 55 - Frequências de respostas obtidas dos estudantes em cada item da dimensão cenário de práticas.

Tabela 56 - Frequências de respostas obtidas dos estudantes em cada item da dimensão reorientação da formação...

Tabela 57 - Frequências de respostas obtidas dos estudantes em cada item da dimensão pedagógica

Tabela 58 - Frequências de respostas obtidas dos professores em cada item da dimensão teórica.

Tabela 59 - Frequências de respostas obtidas dos professores em cada item da dimensão cenário de práticas 
Tabela 60 - Frequências de respostas obtidas dos professores em cada item da dimensão reorientação da formação

Tabela 61 - Frequências de respostas obtidas dos professores em cada item da dimensão pedagógica

Tabela 62 - Pontuação dos itens do bloco 1 em relação aos estudantes

Tabela 63 - Pontuação dos itens do bloco 1 em relação aos professores

Tabela 64 - Pontuação dos itens do bloco 2 em relação aos estudantes

Tabela 65 - Pontuação dos itens do bloco 2 em relação aos professores

Tabela 66 - Pontuação dos itens do bloco 3 em relação aos estudantes 320

Tabela 67 - Pontuação dos itens do bloco 3 em relação aos professores 320

Tabela 68 - Pontuação dos itens do bloco 4 em relação aos estudantes

Tabela 69 - Pontuação dos itens do bloco 4 em relação aos professores

Tabela 70 - Comparação entre as medianas para estudantes e professores nos blocos 1, 2, 3 e 4

Tabela 71 - Comparação dos resultados entre professores e estudantes para as quatro dimensões estudadas 


\section{LISTA DE FIGURAS}

Figura 1 - Resumo das competências e habilidades gerais requeridos aos profissionais, constantes no artigo $4^{\circ}$ das Diretrizes Curriculares Nacionais dos cursos de Enfermagem, Medicina e Odontologia

Figura 1A -Linha do tempo das políticas indutoras de transformação na formação em saúde

Figura 2 - Eixos, vetores e estágios propostos pelo Programa Nacional de

Reorientação da Formação Profissional (Pró-Saúde)

Figura 3 - Instituições integrantes do Pró-Saúde I

Figura 4 - Valores absolutos e percentuais dos cursos de Enfermagem, Medicina e Odontologial

Figura 5 - Valores absolutos e percentuais por Unidade Administrava dos cursos de Enfermagem, Medicina e Odontologia .84

Figura 6 - Cursos de graduação participantes do Pró-Saúde/ PET-Saúde 2013 ...85

Figura 7 - Cursos de Enfermagem contemplados pelo Pró-Saúde I, e suas permanências nos Editais II e III por região do país....

Figura 8 - Cursos de Medicina contemplados pelo Pró-Saúde I, e suas permanências nos Editais II e III por região do país

Figura 9 - Cursos de Odontologia contemplados pelo Pró-Saúde I, e suas

permanências nos Editais II e III por região do país

Figura 10 Valor atribuído a cada item do instrumento de acordo com o nível de concordância do respondente

Figura 11 - Valores atribuídos a cada item da dimensão teórica .96

Figura 12 - Valores atribuídos a cada item da dimensão cenário de práticas .......97

Figura 13 - Valores atribuídos a cada item da dimensão reorientação da .99 
Figura 14 - Valores atribuídos a cada item da dimensão pedagógica

Figura 15 - Classificação e pontuação atribuídas a cada item da dimensão teórica (bloco 1) 102

Figura 16 - Classificação e pontuação atribuídas a cada item da dimensão cenário de práticas (bloco 2) 102

Figura 17 - Classificação e pontuação atribuídas a cada item da dimensão reorientação da formação (bloco 3)

Figura 18 - Classificação e pontuação atribuídas a cada item da dimensão pedagógica (bloco 4) 103

Figura 19 - Fases do processo de construção e validação do instrumento 109

Figura 20 - Esquema das etapas de procedimentos de coleta de dados

Figura 21 - Modelo descritivo do processo de reorientação da formação - PróSaúde, com as categorias obtidas da análise de conteúdo das entrevistas dos estudantes e professores

Figura 22 - Distribuição percentual dos acadêmicos de Odontologia, por semestre, que responderam o instrumento 197

Figura 23 - Acadêmicos matriculados e participantes que compuseram a amostra segundo o semestre 198

Figura 24 - Distribuição percentual dos acadêmicos, segundo graduação concluída em outras áreas

Figura 25 - Distribuição percentual dos acadêmicos bolsistas pelo Pró-Saúde..201

Figura 26 - Distribuição dos acadêmicos em números absolutos em relação ao tempo de participação no Pró-Saúde

Figura 27 - Distribuição percentual dos professores segundo as disciplinas das áreas que ensinam 205 
Figura 28 - Distribuição percentual dos professores conforme as atividades em que orientam os estudantes.

Figura 29 - Distribuição percentual dos professores conforme o tempo de participação em disciplinas inseridas na proposta do Pró-Saúde

Figura 30 - Distribuição percentual dos professores segundo participação em tutoria do Pró-Saúde/Pet-Saúde 208

Figura 31 - Distribuição percentual dos professores em relação ao tempo de participação em tutoria do Pró-Saúde/Pet-Saúde 208

Figura 32 - Distribuição percentual dos professores em relação ao ensino na pósgraduação lato sensu e a área do conteúdo trabalhado

Figura 33 - Distribuição percentual dos professores em relação ao ensino na pósgraduação stricto sensu e a área do conteúdo trabalhado

Figura 34 - Comentários/sugestões dos estudantes sobre os itens respondidos

Figura 35 - Comentários /sugestões dos professores sobre os itens respondidos .....

Figura 36 - Conversão da pontuação dos itens e blocos para conceitos

Figura 37 - Unidades de registro das subcategorias obtidas na análise de conteúdo das entrevistas dos estudantes de Odontologia.....

Figura 38 - Unidades de registro das subcategorias obtidas na análise de conteúdo das entrevistas dos professores de Odontologia.

Figura 39 - Distribuição percentual dos acadêmicos de Enfermagem, por semestre, que responderam o instrumento 246

Figura 40 - Distribuição percentual dos acadêmicos, segundo graduação concluída em outras áreas

Figura 41 - Distribuição percentual dos acadêmicos bolsistas pelo Pró-Saúde..250 
Figura 42 - Distribuição dos acadêmicos em números absolutos em relação ao tempo de participação no Pró-Saúde

Figura 43 - Distribuição percentual dos professores segundo as disciplinas das áreas que ensinam

Figura 44 - Distribuição percentual dos professores conforme as atividades em que orientam os estudantes.

Figura 45 - Distribuição percentual dos professores conforme o tempo de participação em disciplinas inseridas na proposta do Pró-Saúde

Figura 46 - Distribuição percentual dos professores segundo participação em tutoria do Pró-Saúde/Pet-Saúde

Figura 47 - Distribuição percentual dos professores em relação ao tempo de participação em tutoria do Pró-Saúde/Pet-Saúde

Figura 48 - Distribuição percentual dos professores em relação ao ensino na pósgraduação lato sensu e a área do conteúdo trabalhado

Figura 49 - Distribuição percentual dos professores em relação ao ensino na pósgraduação stricto sensu e a área do conteúdo trabalhado 258

Figura 50 - Comentários/sugestões dos estudantes sobre os itens respondidos.......

Figura 51 - Comentários /sugestões dos professores sobre os itens respondidos .....

Figura 52 - Unidades de registro das subcategorias obtidas na análise de conteúdo das entrevistas dos estudantes de Enfermagem .278

Figura 53 - Unidades de registro das subcategorias obtidas na análise de conteúdo das entrevistas dos professores de Enfermagem.

Figura 54 - Distribuição percentual dos acadêmicos de Medicina, por semestre, que responderam o instrumento

Figura 55 - Distribuição percentual dos acadêmicos, segundo graduação concluída em outras áreas 
Figura 56 - Distribuição percentual dos acadêmicos bolsistas pelo Pró-Saúde..296

Figura 57 - Distribuição dos acadêmicos em números absolutos em relação ao tempo de participação no Pró-Saúde

Figura 58 - Distribuição percentual dos professores segundo as disciplinas das áreas que ensinam

Figura 59 - Distribuição percentual dos professores conforme as atividades em que orientam os estudantes.

Figura 60 - Distribuição percentual dos professores conforme o tempo de participação em disciplinas inseridas na proposta do Pró-Saúde

Figura 61 - Distribuição percentual dos professores segundo participação em tutoria do Pró-Saúde/Pet-Saúde

Figura 62 - Distribuição percentual dos professores em relação ao tempo de participação em tutoria do Pró-Saúde/Pet-Saúde

Figura 63 - Distribuição percentual dos professores em relação ao ensino na pósgraduação lato sensu e a área do conteúdo trabalhado 302

Figura 64 - Distribuição percentual dos professores em relação ao ensino na pósgraduação stricto sensu e a área do conteúdo trabalhado

Figura 65 - Comentários/sugestões dos estudantes sobre os itens respondidos

Figura 66 - Comentários /sugestões dos professores sobre os itens respondidos .....

Figura 67 - Unidades de registro das subcategorias obtidas na análise de conteúdo das entrevistas dos estudantes de Medicina.

Figura 68 - Unidades de registro das subcategorias obtidas na análise de conteúdo das entrevistas dos professores de Medicina. 


\section{APRESENTAÇÃO}

Durante o período de minha formação acadêmica na graduação de Odontologia, segui acompanhada de inquietação frente ao sentimento de não compartilhar das mesmas expectativas da maioria de meus pares. Entendia que aquilo que de melhor poderia definir e descrever minha profissão naquele momento me limitava e não me permitia alcançar a plenitude do que eu acreditava que a mesma poderia me oferecer.

Minha experiência profissional me proporcionou a oportunidade de atender alguns de meus anseios. Ao iniciar a carreira, em 1994, dividi meu tempo entre a esfera privada e pública, e nesse momento fui colocada em contato pela primeira vez com um SUS, em que a prática tradicionalista de oferta de saúde predominava. Sempre na certeza de que ações conjuntas podem produzir mudanças mais efetivas, ainda na esfera pública, desenvolvi um projeto de promoção de saúde para toda a rede escolar, em parceria com Secretaria de Educação de um município de pequeno porte no Paraná.

Depois disso, iniciei minha carreira acadêmica como estudante de pós-graduação e vivenciei como usuária, o sistema de saúde britânico, um dos inspiradores da proposta do nosso SUS. O desejo de compartilhar com as pessoas minhas percepções, incertezas e a certeza de que podemos alcançar em nosso país uma proposta de saúde digna, se concretizou na minha inserção no meio acadêmico, onde exerço desde então a profissão docente. Em todo esse processo, fica cada vez mais nítida para mim a necessidade de mudanças profundas que requerem um novo modo de olhar, de pensar e de exercer, por parte de todos e de tudo que de alguma forma possui repercussão na saúde das pessoas. 
Ao me deparar com a proposta do Programa Pró-Saúde, vislumbrei várias possibilidades e tive a certeza de que somos muitos compartilhando das mesmas expectativas e alguns exercendo o papel de abrir caminhos para que ações em prol de mudanças sejam colocadas em prática. $\mathrm{O}$ ingresso no doutorado me oportunizou o aprofundamento, a reflexão e a esperança de alguma contribuição para que alcancemos um SUS melhor.

Nessa perspectiva, o tema de interesse que norteou o desenvolvimento deste estudo é a formação em saúde. As questões que envolvem essa temática têm sido destacadas e encontram-se presentes na agenda de políticas públicas. As mesmas estão pautadas na necessidade crescente de se alcançar uma qualificação e perfil profissional que ofereçam condições de atender as demandas de um sistema de saúde construído em bases que diferem e divergem daquelas oferecidas pela formação tradicional.

Frente ao crescente entendimento do essencial papel que os profissionais podem exercer no fortalecimento e consolidação de modelos de saúde, urge a necessidade de ações conjuntas entre diferentes setores que vislumbrem transformações na forma de pensar e na forma de atuar em saúde, tanto no âmbito das práticas quanto no âmbito da formação daqueles que eventualmente poderão conduzi-las. Dentre algumas iniciativas governamentais conjuntas entre os setores da Educação e Saúde, aqui se insere o projeto Pró-Ensino na Saúde. Este corresponde à formação de mestres e doutores, através de uma parceria entre a Coordenação de Aperfeiçoamento de Pessoal de Nível Superior (Capes) e a Secretaria de Gestão do Trabalho e da Educação na Saúde do Ministério da Saúde. Visa desenvolver a área de ensino na saúde, considerada estratégica para reorientar a formação do profissional de saúde, subsidiando o processo de consolidação do Sistema Único de Saúde (SUS). 
A presente pesquisa está sendo desenvolvida dentro do contexto de uma das propostas do Projeto Pró-Ensino na Saúde, intitulado "Fortalecimento do Ensino na Saúde no Contexto do SUS: uma proposta interdisciplinar da Universidade de Brasília na Região CentroOeste", resultado de uma parceria entre o Instituto de Psicologia e a Faculdade de Ceilândia, da Universidade de Brasília. Dentre as quatro áreas temáticas ofertadas no projeto incluemse a formação e desenvolvimento docente em saúde; políticas de integração entre saúde, educação, ciência e tecnologia; tecnologias inovadoras no ensino na saúde e avaliação do ensino na saúde.

Neste estudo, dentro da linha temática avaliação do ensino na saúde, pretendeu-se analisar a implementação da política indutora de reorientação na formação saúde, denominada Programa Nacional de Reorientação da Formação Profisssional em Saúde (PróSaúde), que busca desenvolver competências gerais no processo de formação dos cursos de graduação que contribuam para desenvolvimento de competências para o trabalho cooperativo e colaborativo. Para isso elegemos cursos de uma Universidade contemplada pelo edital do referido Programa.

A primeira parte do trabalho inclui algumas reflexões sobre a temática formação do profissional de saúde, através de contextualização do tema, seguida da problematização e sua importância, possibilitando a construção do objeto de estudo.

$\mathrm{Na}$ sequência apresentamos o referencial teórico que dará suporte para o desenvolvimento desta pesquisa. A partir disso, foi possível obter-se uma clareza maior na definição do método.

Após a delimitação do objeto de estudo, traçamos o plano de trabalho, para o desenvolvimento da pesquisa, com propostas de procedimentos de coleta e análise dos dados. 
Na sequência são apresentadas na seção de resultados, as produções científicas, com apresentação dos artigos publicados. E para finalizar, é apresentado um capítulo comparativo entre os resultados obtidos no estudo 1 (Odontologia), estudo 2 (Enfermagem) e estudo 3 (Medicina). Os estudos 1, 2 e 3 estão apresentados na íntegra na forma de Apêndices. 


\section{CAPÍTULO 1 \\ INTRODUÇÃO}

\subsection{CONTEXTUALIZAÇÃO DO TEMA}

O ensino superior em saúde segue influenciado pelo paradigma flexneriano, após mais de um século de sua concepção. O Relatório Flexner foi produzido e publicado por Abraham Flexner em 1910 (Flexner, 1910), a partir de um estudo fomentado pela Fundação Carnegie, cujo objetivo inicial era avaliar e propor reformas no ensino médico dos Estados Unidos e Canadá. Este documento foi e ainda segue considerado o grande responsável pela mais importante reforma das escolas médicas de todos os tempos nos Estados Unidos da América (EUA), com profundas implicações para a formação médica e demais áreas da saúde e também para a provisão de saúde no mundo.

Ao adotar o modelo de saúde-doença unicausal, biologicista, a proposta de Flexner reserva pequeno espaço, se algum, para as dimensões social, psicológica e econômica da saúde e para a inclusão do amplo espectro da saúde, que vai muito além da medicina e seus médicos (Pagliosa \& Da Ros, 2008). Outro aspecto relevante refere-se às práticas em saúde. Ocorreu um processo de transformação da clínica, de modo que houve perda de acuidade e percepção integral do indivíduo. Outro ponto de crítica do modelo é a desumanização do atendimento, que pode estar relacionado à fragmentação do trabalho médico e ao consequente comprometimento em relação à responsabilidade sobre o paciente por parte dos profissionais especialistas (Aguiar, 2003). A ênfase no modelo biomédico ou flexneriano, centrado na doença e no hospital, conduziu os programas educacionais a uma visão reducionista.

Entretanto, a ineficácia, a ineficiência e a desigualdade expressa pelas diferenças de classes sociais no que se refere a necessidades de saúde, ao risco de adoecer, morrer ou 
incapacitar e à acessibilidade aos serviços médicos conduzem ao questionamento crescente desse modelo (Mendes, 1985).

Busca-se no Brasil um novo modelo educacional capaz de lidar com as demandas em saúde, que se oriente na construção do paradigma da integralidade, que segundo Campos et al. (2001), teria como imagem-objetivo uma formação mais contextualizada, que associa dimensões sociais, econômicas e culturais da vida da população. Tal proposta busca uma contraposição ao paradigma flexneriano, o qual segue influenciando a formação em saúde desde o início do século XX. Lampert (2009) afirma que o paradigma da integralidade induziria à construção de um novo modelo pedagógico, visando ao equilíbrio entre excelência técnica e relevância social, sustentado na integração curricular, modelos pedagógicos mais interativos, metodologias de ensino e aprendizagem centradas no aluno como sujeito da aprendizagem e no professor como facilitador do processo de construção de conhecimento.

Desde a Constituição Federal de 1988, já se indicava que o SUS deveria cumprir o papel de ordenar o processo de formação profissional na área da saúde. Entretanto, passadas quase três décadas desde a criação do SUS, este papel não se traduziu em prática instituída. Campos (2001) ressalta que o que se visualizou por muito tempo foi uma desarticulação entre as definições políticas dos Ministérios da Saúde e da Educação, o que tem levado a um distanciamento entre o modelo de formação dos profissionais e o modelo de saúde na perspectiva do SUS.

Amplas discussões têm ocorrido em torno da necessidade da educação superior na área da saúde assumir o papel de uma formação que prepare o profissional para atuar nesse contexto (Araújo, 2006). As práticas atualmente recomendadas consideram que o fazer deve resultar da apropriação de conceitos, ideias, valores e condutas pelos profissionais, que visem superar limitações do modelo biomédico ou flexneriano, caracterizado por dar ênfase 
ao biologicismo, ao mecanicismo e estar centrado na doença. É importante pontuar que análises recentes revelam que apesar do Relatório Flexner ressaltar em seu conteúdo a importância da formação médica responder às necessidades da sociedade, o que se extraiu dele e que predominou naquele momento foi os aspectos considerados de maior interesse ou relevante à época (Nunes, 2010). Inegavelmente supriu lacunas e trouxe suas contribuições, como por exemplo o estabelecimento das bases científicas da medicina, que tantos avanços proporcionaram à saúde (Mack, 2010). É de se esperar que por toda a dinâmica que envolve as necessidades em saúde, todo modelo posto se esgota ou requer adaptações que possam atender as demandas de cada momento.

O paradigma alternativo ao flexneriano/biomédico, denominado modelo biopsicossocial, tem enfoque na promoção da saúde, no cuidado e na prevenção das doenças. As ações são voltadas para acompanhamento, cuidado individual e coletivo da população, seguindo pautado em princípios do SUS, como universalidade, integralidade da atenção e práticas de atendimento mais humanizadas (Carvalho \& Ceccim, 2006).

Muitos problemas dos sistemas de serviços de saúde, como a iniquidade ao acesso a serviços, a falta de ênfase à saúde coletiva, a fragmentação do cuidado e dificuldades na gestão, estão relacionados à formação dos profissionais que neles atuam. Esta tem sido marcada pela negação de um processo de trabalho pautado na colaboração e cooperação. Desta forma, as mudanças são necessárias para que se traduzam em ações e práticas profissionais, através da reestruturação dos currículos e das metodologias dos cursos de graduação e pós-graduação em saúde, assim como no desenvolvimento dos profissionais que já estão atuando nos serviços.

Entretanto, é necessário reconhecer que as transformações que se espera nos cursos da área da saúde exigem uma reorientação da lógica do sistema formador. Os movimentos e discussões em prol de mudanças na formação em saúde culminaram em propostas de 
Diretrizes Curriculares Nacionais (DCN) para os cursos de saúde, ocorridas a partir de 2001 (Brasil, 2001). Estas podem ser consideradas um marco, dentro de um cenário refletido por um modelo de formação ultrapassado e que clama por mudanças (Carvalho, 2006). A construção das DCN vislumbrou, além do estímulo ao debate, a possibilidade de mobilizar os setores da saúde para que passassem a influenciar, de forma organizada, o perfil profissional mais adequado às necessidades da população (Gonzalez \& Almeida, 2010). Os autores ressaltam ainda que não se deveria esperar que um processo de reorientação fosse desencadeado espontaneamente, por iniciativas de Instituições de Ensino Superior ou dos serviços de saúde, na direção assinalada pelo SUS.

Para que as ações se concretizem, são imprescindíveis propostas articuladas que facilitem e motivem a implementação das DCN, representando com isso um avanço dos projetos pedagógicos e não uma acomodação de situações existentes (Morita \& Kriger, 2007). A necessidade de articulação entre Educação e Saúde tem se refletido na forma de implementação de políticas públicas que visam estimular mudança de paradigma na formação superior dos profissionais de saúde.

Frente ao exposto, a proposição de um projeto de pesquisa que intencione problematizar as questões que envolvam a formação profissional em saúde, deve considerar toda a complexidade envolvida.

Ao se examinar criticamente as origens da temática para o qual se propõe um aprofundamento teremos um ponto de partida que pode fornecer subsídios nas decisões sobre quais caminhos devam nortear o desenvolvimento da pesquisa. Ao se buscar respostas que envolvam transformações no perfil do profissional de saúde para atendimento às necessidades do SUS, espera-se encontrar um futuro profissional que no processo de sua formação acadêmica desenvolva visão crítico-reflexiva, humanizada, pautada na integralidade da atenção, habilidades e competências para o trabalho em equipe, que saiba 
lidar com a subjetividade dos sujeitos e que busque uma aproximação com o contexto e realidade social (Brasil, 2002).

\subsection{PROBLEMATIZAÇÃO}

Assim como afirma Campos et al. (2001) sobre a necessidade de se obter um novo modelo educacional, em busca do "paradigma da integralidade ou biopsicossocial", objetivase para o profissional de saúde uma formação mais contextualizada, que associe dimensões sociais, econômicas e culturais da vida da população.

As DCN para os cursos de Enfermagem, Medicina e Odontologia reafirmam a necessidade de profissionais com o perfil generalista, humanista, crítica e reflexiva para atuar em todos os níveis de atenção à saúde, com rigor técnico e científico e com comprometimento para com a sociedade (Brasil, 2001a; Brasil 2001b; Brasil, 2002, Brasil, 2014). As dificuldades para implementação das mudanças propostas nas diretrizes determinaram a razão de ser de políticas indutoras, como é o caso do Pró-Saúde, o qual, na realidade, constitui um mecanismo facilitador da parceria ensino-serviço para a real implementação das diretrizes (Ferreira et al, 2007).

O Programa Pró-Saúde, desde sua implementação, em 2005, tem contemplado cursos de Enfermagem, Medicina e Odontologia, com ampliação para os demais cursos, da área da saúde, a partir de seu segundo edital, em 2007. Dada a relevância desta proposta, a qual objetiva alcançar transformações profundas na graduação, torna-se oportuno, oito anos após o início do Programa, uma análise de sua implementação.

Dadas às inúmeras possibilidades de abordagens dentro do campo ensino em saúde envolvendo a implementação do Programa Pró-Saúde, como política indutora para a 
reorientação da formação profissional, neste estudo optou-se por realizar análise de sua implementação com a representação dos cursos de Enfermagem, Medicina e Odontologia.

Pretendemos buscar respostas às seguintes questões norteadoras: o Programa PróSaúde tem induzido mudanças na formação acadêmica em cursos de Enfermagem, Medicina e Odontologia? A política tem contribuído para a construção de um perfil profissional que atenda às demandas atuais do SUS? 


\subsection{DEFINIÇÃO DOS OBJETIVOS}

\subsubsection{Objetivo Geral:}

Analisar a implementação do Programa Nacional de Reorientação da Formação Profissional em Saúde (Pró-Saúde) em cursos de Enfermagem, Medicina e Odontologia, sob a ótica de diferentes sujeitos envolvidos no processo.

\subsubsection{Objetivos específicos:}

1- Descrever e analisar o cenário atual da implantação da política indutora Pró-Saúde e a sua contribuição para a reorientação da formação;

2- Construir e validar uma escala sobre tendências atitudinais com aspectos relacionados ao Programa Pró-Saúde para estudantes e professores;

3- Mensurar as tendências atitudinais de estudantes e professores dos cursos de Enfermagem, Odontologia e Medicina;

4- Apreender a percepção de estudantes e professores em relação às ações do PróSaúde na formação acadêmica;

5- Comparar as tendências atitudinais e percepção entre os cursos de graduação de Enfermagem, Medicina e Odontologia. 


\section{CAPÍTULO 2}

\section{REFERENCIAL TEÓRICO}

Esta etapa da pesquisa visa compor a base teórica dentro da temática na qual este estudo se inscreve, e para tal inclui quatro pilares que merecem um aprofundamento: o ensino na saúde; bases conceituais das diretrizes curriculares nacionais para os cursos da saúde; políticas indutoras de mudanças na formação profissional em saúde e o Programa Nacional de Reorientação da Formação Profissional em Saúde (Pró-Saúde).

Foram conduzidas análises de documentos e revisão da literatura científica nas seguintes bases de dados: Scientific Eletronic Library Online (SCIELO), Biblioteca Virtual em Saúde (BVS) e Literatura Latino-Americana em Ciência e Saúde (LILACS). Além disso, as páginas do Ministério da Saúde do Programa Pró-Saúde também foram fontes de obtenção de relatórios e documentos de interesse para o desenvolvimento deste estudo. O período de busca realizada não incluiu limitação temporal. As palavras-chave incluídas nas buscas são as listadas a seguir: educação médica; educação odontológica; educação na enfermagem; ensino na saúde; formação em saúde; programas de saúde; políticas indutoras; formação profissional em saúde.

\subsection{O ENSINO NA SAÚDE}

\subsubsection{Um breve histórico do cenário mundial}

O processo de formação profissional na área de saúde é importante para a construção e manutenção de modelos de saúde. O desenvolvimento da capacidade de refletir, de agir, de conhecer a complexidade e dinamicidade envolvida nos determinantes do processo saúde-doença são alguns fatores que exemplificam os pontos de relevância em relação ao perfil do profissional inserido em um sistema de saúde, e o reflexo de suas ações na consolidação de propostas de um modelo de saúde (Campos et al., 2001). 
Tomaremos como ponto de partida desta reflexão o século XIX, período em que houve uma aproximação entre a saúde e a ciência, e partir de então o modelo cientifico atuando como determinador das práticas de saúde e de ensino em diversos países do mundo. O avanço científico da época foi marcado por importantes descobertas ocorridas naquele período, e que levaram à substituição do empirismo pelo método científico (Gonzalez \& Almeida, 2010).

Apesar do paradigma da medicina científica exercer influência no ensino médico americano, o início do processo de institucionalização da medicina científica se deu com a criação da Faculdade de Medicina na Universidade Johns Hopkins em 1893. Entretanto, sua consolidação ocorreu em 1910, com a publicação do Relatório Flexner. Este relatório foi produto de uma iniciativa da Fundação Carnegie, a qual convidou o educador Abraham Flexner para realizar um estudo sobre a educação médica nos Estados Unidos e no Canadá. Flexner visitou as 155 escolas de Medicina dos EUA e Canadá durante seis meses. Com base nas avaliações que fez, publicou seu famoso relatório. A medicina científica ou biomédica ou flexneriana passou a determinar mudanças substanciais na prática médica. Tal modelo era pautado em um conjunto de elementos estruturais, descritos por Mendes (1985): mecanicismo, biologicismo, individualismo, especialização, exclusão de práticas alternativas, tecnificação do ato médico, ênfase na medicina curativa e concentração de recursos.

O mecanicismo faz uma analogia do corpo humano com a máquina. O primeiro é interpretado como um sistema em equilíbrio, possuidor de fragilidades que naturalmente geram danos passíveis de intervenção através de métodos químicos, físicos e elétricos. Esse complexo, segundo a visão científica corrente, pode ser fragmentado em partes menores para otimizar a compreensão dos problemas e facilitar o processo de treinamento dos profissionais. 
O biologicismo tenta explicar as causas e consequências das doenças através de alterações biológicas diversas, e sua força vem da descoberta dos microrganismos no século XIX. Pressupõe o reconhecimento crescente e exclusivo da natureza biológica das doenças, de suas causas e consequências. O biologicismo procura isentar os fatores de ordem econômica e social na determinação dos agravos à saúde.

O individualismo está presente na medicina científica devido à eleição do indivíduo como objeto da mesma, em detrimento das coletividades humanas. Assim, é no âmbito pessoal que se preconiza intervir. Pode-se, inclusive, atribuir ao indivíduo a responsabilidade pelo aparecimento de suas enfermidades.

A especialização resultou da troca entre a globalidade do objeto da prática médica e a profundidade do conhecimento de suas dimensões específicas.

A exclusão de práticas alternativas foi necessária para a viabilização da medicina científica. Essa se firmou como eficaz porque era comprovada cientificamente, ao contrário das práticas baseadas no empirismo ou no curandeirismo.

A tecnificação do ato médico legitima o mecanicismo e o biologicismo citados anteriormente ao excluir do processo de trabalho o componente não-científico das relações humanas. A difusão da tecnologia contribui para a progressividade do uso da técnica científica em detrimento da percepção dos sentidos.

A ênfase na medicina curativa interpreta a fisiopatologia como o próprio agravo, e não como sua expressão. Esse elemento reduz consideravelmente o universo de problemas a se confrontar, bem como restringe o universo de intervenções possíveis.

A concentração de recursos se deve às exigências da sociedade industrial e da lógica mercantilista na assistência médica. Os serviços e a tecnologia concentram-se onde há quem possa pagar por eles, e não onde deles se necessita. É uma concepção da saúde 
como mercadoria sujeita às leis de mercado, e sua consequência imediata foi a consolidação do espaço hospitalar como ambiente hegemônico da prática médica.

Esses elementos estruturais reformularam o processo de trabalho na medida em que deslocaram o foco de atenção da sociedade para o indivíduo, tecnificaram a assistência médica e reduziram o universo dos problemas de saúde, os quais passam a ser considerados problemas médicos. As principais propostas de reformas para o ensino contidas no Relatório Flexner foram: definição de padrões de entrada e ampliação, para quatro anos, da duração dos cursos; introdução do ensino laboratorial; estímulo à docência em tempo integral; expansão do ensino clínico, especialmente em hospitais; ênfase na pesquisa biológica; vinculação da pesquisa ao ensino; estímulo à especialização médica; controle do exercício profissional pela profissão organizada.

De acordo com Marsiglia (1998), duas propostas de reformulação do ensino médico marcaram o século XX por exercerem forte influência na organização dos serviços de saúde. Uma delas foi a proposta do Relatório Flexner, a qual iniciou influenciando o ensino médico nos Estados Unidos e Canadá. Por outro lado, merece destaque também a proposta de Bertrand Dawson, em 1920, a qual influenciou a reforma do ensino nas faculdades da Inglaterra e das Repúblicas da União Socialista Soviética dos anos 1940 e 1950.

O modelo dawsoniano, influenciado pela tradição inglesa de legislação de proteção a classes desprivilegiadas e de saúde pública, seguiu um caminho que o diferenciou do modelo flexneriano. Dawson enfatizou a necessidade de reorganização dos serviços de saúde para atendimento a todas as classes sociais e ainda a importância da formação dos profissionais adequar-se a este processo. A forma de reestruturação dos serviços de saúde propostas por Dawson foi descrita a partir de quatro princípios (Marsiglia, 1998):

1) O Estado deveria ser o provedor e controlador das Políticas de Saúde; 
2) Todos os esforços deveriam ser coordenados e o trabalho em equipe deveria ser desenvolvido nos serviços de saúde;

3) Os casos agudos deveriam ser diagnosticados e tratados em instituições especialmente designadas para isso;

4) A Medicina Curativa e a Medicina Preventiva deveriam estar integradas, tanto na organização dos serviços como na educação médica.

Ao criticar a separação entre a Medicina Preventiva e Curativa, Dawson propunha uma atuação coordenada por meio de médicos generalistas. Ao contrário de Flexner, considerava que a formação médica não deveria se dar apenas nos hospitais de ensino especializado, pois o médico generalista deveria exercer funções junto ao indivíduo e à comunidade (Silva Junior, 1998).

O Relatório Dawson não foi implementado assim que proposto na Inglaterra, mas exerceu influência no sistema de saúde da Rússia, após a Revolução de 1917. Após a Segunda Guerra Mundial, foi seguido pela URSS, e pela própria Inglaterra, ao ser implementado o National Health Service (NHS - Serviço Nacional de Saúde), em 1948, a partir do Plano Beveridge (Marsiglia, 1998). A implantação do NHS pressupunha um sistema universal com base na integralidade.

Dawson enfatizava que os currículos das escolas médicas, em vez de se preocuparem excessivamente com a constituição de disciplinas de especialidades, deveriam concentrar seus esforços na formação de um profissional mais generalista, capaz de exercer sua prática em um sistema de saúde regionalizado. Este modelo passou a ser central no modelo de saúde e formação profissional inglês, sendo depois levado a outros países, como Cuba, após a revolução socialista de 1959, e Canadá, no final dos anos 1960. Esses países podem ser 
considerados berços de experiências de medicina familiar no mundo (Hubner \& Franco, 2007).

Na América Latina, a implantação de novos cursos na área de saúde e a reformulação dos já existentes se deu a partir da década de 1940, seguindo as bases do modelo flexneriano. A partir de então, os hospitais passaram a ser estruturados para se tornarem o lócus principal para o ensino (Marsiglia, 1998). Essa ênfase no ensino focado na doença e no hospital conduziram o ensino médico a uma visão reducionista.

Apesar das contribuições do modelo de medicina científica ou flexneriana, como o avanço científico, tecnológico e ferramentas terapêuticas, as novas demandas em saúde deflagram sua dificuldade de sustentação. Mendes (1985) atribui a ineficiência, a ineficácia e a desigualdade como responsáveis pela crise do modelo da medicina científica. A ineficiência é vista pela ausência de correlação entre os investimentos em saúde e os níveis de saúde da população em geral. A ineficácia se refere ao mito de que o padrão de saúde das populações de países desenvolvidos se deve à medicina científica, visto que muitos estudos mostram que os níveis de saúde atuais decorrem muito mais de mudanças no ambiente do que das novas descobertas tecnológicas da medicina e saúde. A desigualdade social expressa diferenças de classes sociais no que tange necessidades de saúde, ao risco de adoecer, morrer ou incapacitar e o acesso aos serviços de saúde.

Ao adotar conceitos de saúde-doença unicausal, biologicista, a proposta de Flexner não deixa espaço para a dimensão social, humanista, econômica da saúde e para a inclusão do amplo espectro da saúde, que vai muito além da medicina e seus médicos (Pagliosa \& Ros, 2008).

O advento de reformulações conceituais sobre saúde, marcados por críticas crescentes ao setor da saúde, aliado aos momentos histórico-políticos vigentes no cenário mundial, remeteram à reformulação de propostas em relação a modelos de saúde de modo 
que estes atendessem às demandas presentes. A partir de então ganham força as ideias propostas pelo modelo da medicina comunitária, cujos elementos estruturais também são descritos por Mendes (1985) e incluem o coletivismo restrito; integração de atividades promocionais, preventivas e curativas; desconcentração de recursos; utilização de tecnologias apropriadas; inclusão de práticas médicas alternativas; implementação de equipes de saúde. A Medicina Comunitária buscava resgatar a medicina anterior ao período de explosão tecnológica. Buscava também a inclusão diferenciada das camadas sociais marginalizadas. Possuía como estratégia principal o estímulo à participação comunitária, especialmente do trabalho voluntário.

Gonzalez e Almeida (2010) destacam importantes movimentos que surgiram, no âmbito da reestruturção da formação superior dos profissionais de saúde, para acompanhar essa nova realidade, como o da Medicina Comunitária e o da Integração DocenteAssistencial (IDA). Os autores destacaram no que tange a reorientação do ensino na saúde, que os projetos de medicina comunitária basicamente pertenciam aos departamentos de medicina preventiva, eximindo os docentes dos departamentos clínicos de qualquer ação conjunta à comunidade. Esta tendência persiste até hoje em muitos lugares, onde as ações extramuros hospitalares são exclusividade dos departamentos de medicina preventiva e social. Isto pode acontecer pela imposição dos próprios departamentos, que se sentem no dever de participar de todas as atividades externas, ou pela omissão dos demais departamentos.

Alguns avanços foram alcançados a partir dos movimentos supracitados, ganhando forças discussões em torno da necessidade de um ensino e uma assistência mais adequada à realidade das sociedades. Um importante marco deste momento foi a Conferência de AlmaAta, em 1978, a qual resultou em avanços de reformas importantes, como a estratégia da Atenção Primária, a figura do Agente Comunitário de Saúde, o trabalho comunitário e o 
trabalho intersetorial. Mattos (2006) relata que a partir disso, ampliou-se o entendimento da saúde como qualidade de vida e identificaram-se como determinantes da saúde também o estilo de vida e o meio ambiente em que se inserem indivíduos e comunidades.

Baltazar (2010) destaca que as discussões sobre as mudanças necessárias no sistema de ensino na área de saúde têm ocorrido em nível mundial. A autora cita como exemplos a União Européia, onde são discutidas competências obrigatórias que devem estar presentes em seus currículos (Scott, 2003).

Propostas em torno do aprendizado baseado em problemas têm sido alvo de atenção na China (Huang et al., 2007). Fiehn (2002) destaca a relevância de se propor mudança de um currículo tradicional (biomédico) para um novo modelo nos países nórdicos. Nos Estados Unidos, discute-se sobre a necessidade de ultrapassar os conceitos contidos no Relatório Gies, concebido na lógica do Flexner, porém específico para a Odontologia (De Paola, 2008).

As discussões estão em torno da necessidade de adequação do ensino profissional em saúde para a sociedade contemporânea. Um relatório foi recentemente publicado por uma comissão composta por membros de 20 países, e foi intitulado - A Formação de Profissionais da Saúde para o século 21, lançado em 2010 (Frenk et al., 2010). A intenção foi marcar o centenário do Relatório Flexner, oferecendo recomendações para as reformas e superações necessárias no ensino profissional na saúde em todo o mundo, que apresenta os mesmo tipos de problemas no que tange a formação e seus reflexos para os sistemas de saúde.

\subsubsection{O contexto do Ensino na Saúde no Brasil para os cursos de Medicina, Enfermagem e Odontologia}


Assim como em outros países da América Latina, o modelo flexneriano começou a ser implantado no Brasil na década de 1940, influenciando os novos cursos de Medicina, Odontologia e Enfermagem, além de reformular os cursos já existentes (Feuerwerker; Marsiglia, 1998).

A crise da medicina científica e as discussões sobre as novas demandas em saúde foram marcadas no Brasil por dois momentos que foram fundamentais para o fortalecimento do processo de construção da saúde sob uma nova lógica: a VIII Conferência Nacional da Saúde em 1986 e a criação do Sistema Único de Saúde (SUS), estabelecido na promulgação da Constituição de 1988. O projeto democrático do movimento da reforma sanitária, iniciado nos anos 80, e que culminou na criação do SUS em 1988, partiu de um entendimento ampliado do conceito de saúde, em que se propõe não reduzi-la à doença e a intervenções médicas ofertadas por serviços de atendimento à população. Buscou-se também expressar a qualidade de vida de uma população, refletindo as suas condições objetivas e suas necessidades subjetivas. Envolveu, portanto, seus determinantes políticos, econômicos, culturais e sociais e a inserção, na política de saúde, de novos espaços sociais como os da educação, meio ambiente, previdência, emprego, habitação, alimentação e nutrição, lazer, esporte, terra e transporte (Mendes, 1996).

Com a criação do SUS, a saúde no Brasil passou a apresentar necessidades de profundas mudanças, que vão muito além do entendimento dos princípios que regem esse novo sistema. Passa-se a ter um modelo de saúde universal e pautado na integralidade. São grandes os obstáculos na consolidação do SUS, apesar de ser o sistema de saúde vigente, amparado na Constituição Federal de 1988 e regulamentado pelas Leis Orgânicas de 1990. Seus princípios democráticos trabalham diretrizes, conceitos e práticas que eram e ainda são contra-hegemônicos na sociedade (Merhy et al., 2006). O sistema hegemônico apresenta a atenção à saúde centrada na assistência curativa, hospitalar e superespecializada, na vertente 
de interesses econômicos e corporativos. A substituição desse sistema pelo sistema universal, que busca modelos de atenção que valorizem a integralidade, o cuidado humanizado e a promoção da saúde, depende do perfil de formação e da prática dos profissionais de saúde (Gonzalez \& Almeida, 2010). Nesse contexto, a qualificação e o comprometimento dos profissionais de saúde tornam-se mais do que simples necessidades à medida que passam a ser aspectos cruciais para a real consolidação do SUS (Ceccim, 2002).

O Relatório Dawson ficou reconhecido no Brasil por exercer forte influência sobre a estrutura das redes de saúde, a respeito da adoção da divisão territorial, da necessidade de articulação entre saúde pública e de saúde individual, bem como a associação entre modelo de organização e gestão de serviços (Kuschnir \& Chorny, 2010). Em relação à influência deste modelo sobre a organização dos sistemas de saúde no Brasil, Carvalho e Ceccim (2006) enfatizaram sua relevância para a gestão e planejamento e também para a saúde pública como um todo. Os autores destacaram que principal diferença entre os relatórios Dawson e o Flexner reside na ênfase do primeiro em relação à incorporação de práticas de cuidados de saúde primários, ao contrário do enfoque em cuidados especializados, e principalmente com base nos serviços de rede comuns como o núcleo, e não apenas hospitais universitários. O Relatório Dawson posiciona o Estado como gestor e regulador das políticas públicas de saúde.

Haddad e Morita (2006) ressaltam que os sistemas de saúde e de educação no Brasil evoluíram com lógicas próprias, ainda que ambos tenham o propósito de construir um país melhor para todos. A seguir destacaremos alguns pontos que marcaram a evolução do ensino da saúde nos cursos de Medicina, da Enfermagem e da Odontologia.

No início do século XIX, o Brasil inaugurou o marco do ensino médico e superior através da implementação das "escolas de cirurgia", onde se formavam profissionais cirurgiões, com a instauração de um novo paradigma, pois até então a arte médico-cirúrgica, 
proveniente da Europa se mesclava com as práticas nativas, exercidas no Brasil principalmente por cirurgiões curiosos e feiticeiros, indígenas e jesuítas (Lampert, 1998). Posteriormente esses cirurgiões completariam sua formação médica na Europa, sobremaneira em Portugal. As “Academias Médicas”, já autônomas à diplomação de seus alunos em meados da década de 1830, iniciaram o processo de incorporação das regras e diretrizes da Escola Médica de Paris, entre as quais a ampliação da duração dos cursos de cinco para seis anos (Batista, 1998).

Até o final do século XIX permaneceu, no Brasil, o formalismo característico da academia francesa-alemã, substituído no início do século XX pelo modelo americano, o qual segue adotado ainda atualmente, caracterizado por incluir semestres iniciais dedicados exclusivamente para o conhecimento biológico do homem; os semestres seguintes para o ensino da clínica (médica, cirúrgica, neurológica, pediátrica, geriátrica e outras); e, por último, serviço, sob supervisão, em internato com duração entre dois e quatro semestres (Souza, 2005).

Até os dias de hoje, a formação médica permanece estruturada a partir de um modelo tecno-científico. No entanto, na contemporaneidade surgem propostas orientadas por um projeto ético-humanista, tendo o Sistema Único de Saúde (SUS) como superfície de emergência de novas demandas que alavancam as transformações requeridas na educação médica brasileira (Nogueira, 2009).

O que ocorre é que desde a sua criação, o SUS tem enfrentado inúmeros obstáculos, dentre os quais se inclui a necessidade de reformulação do modelo assistencial de saúde brasileiro, e para esse processo de reestruturação, a reorganização da atenção primária tornou-se um ponto estratégico. A implementação e expansão do Programa Saúde da Família como estratégia de reorganização da Atenção Básica no Brasil têm gerado alguns desafios conceituais, ao implicar na necessidade de reorientação do processo de trabalho em 
saúde, na busca de uma prática clínica ampliada e integradora das dimensões biopsicossociais do adoecimento e atuação de uma equipe multidisciplinar. Nogueira (2009) ressalta que a partir dessas demandas, constatou-se a carência de médicos aptos para atuar dentro do novo paradigma proposto. Assim, torna-se imprescindível a adoção de medidas voltadas à formação e à capacitação desses profissionais por meio da viabilização de mudanças na graduação que atendam aos interesses apontados por um novo modelo de atenção à saúde.

Em relação ao ensino da Enfermagem, o mesmo teve início no Brasil no final do século XIX, em 1890, com o objetivo de capacitar enfermeiros para atuar em ambientes hospitalares militares e hospícios, baseados em modelos franceses de educação, assim como na medicina à época (Galleguillos \& Oliveira, 2001). Ao longo do tempo, sofreu diversas transformações levando em consideração a conjuntura da sociedade brasileira em diferentes momentos, as necessidades de cada época e as próprias mudanças econômicas, políticas e sociais na educação e na saúde no país e no mundo (Galleguillos \& Oliveira, 2001; Ito et al., 2006).

A partir de início do século XIX, a Enfermagem no país passa a sofrer grande influência norte-americana, caracterizada por ser subordinada à prática médica, e com ações baseadas no modelo assistencial-hospitalar, a exemplo da Escola de Enfermagem, instituída em 1923 (Rizzotto, 1999). Foi a partir desse padrão de centralidade no hospital, que o modelo de ensino estadunidense estava sendo multiplicado de forma bastante enfática no Brasil, influenciando também a organização de ações e serviços de enfermagem nos hospitais (Galleguillos \& Oliveira, 2001).

As transformações ocorridas, decorrentes da implantação do modelo capitalista e do desenvolvimento técnico-científico, provocaram mudanças no setor saúde das décadas de 40 e 50, surgindo novas necessidades em saúde e adaptação dos profissionais de saúde a essa 
nova realidade. O ensino na Enfermagem também acompanhou tais modificações em seu componente curricular, com os trabalhadores da saúde se concentrando cada vez mais nos hospitais, com predominância do modelo curativo (Germano, 2003).

O modelo flexneriano, que orientou as práticas da medicina e outras áreas da saúde, teve influência também no ensino da Enfermagem, estando enraizado em sua prática por muitas décadas (Galleguillos \& Oliveira, 2001). Ocorreram diversas mudanças curriculares no ensino da Enfermagem ao longo do tempo, e ainda assim observa-se o reflexo desse modelo, focado na doença, na cura e no indivíduo, na formação do enfermeiro e no ensino na graduação. Esse modelo curativo/assistencialista permeou outras transformações curriculares até a década de 70 (Ito et al., 2006). Novas propostas de mudança curricular surgem nos anos 80, uma vez que o modelo adotado nos currículos anteriores não dava conta de lidar com as necessidades de saúde que estavam eclodindo no país. Princípios como equidade, universalidade e integralidade, nunca abordados anteriormente, surgem como orientadores das políticas de saúde, gerando uma demanda de profissionais com formação generalista, que deveriam atuar em diferentes níveis de atenção (Ito et al., 2006). Sucessivas modificações no currículo da Enfermagem ocorreram nas décadas seguintes e houve uma maior flexibilização no modelo de ensino e na formação do enfermeiro. Um relevante ponto que deve ser considerado, mencionado por Germano (2003), que influencia positivamente na construção de um novo paradigma na área da saúde e na Enfermagem, diz respeito à relação educação e trabalho, uma ideia amparada por aqueles que defendem a política do SUS e a concretização de seus princípios, com o intuito de melhorar a resolutividade de problemas que permeiam os serviços e a comunidade.

Como descrevem os autores Pinhel e Kurcgant (2007), a prática da Enfermagem não se dissocia da prática do ensino, pois o enfermeiro trabalha nas suas ações de cuidado fazendo uso da metodologia ensino e aprendizado. Suas práticas não estão voltadas apenas 
para pacientes e familiares, mas também para alunos e demais atores envolvidos no processo. Necessita-se, pois, que os enfermeiros sejam dotados de uma competência reflexiva com o intuito de se obter ações que possam ser mais efetivas.

Propõe-se que o ensino na Enfermagem esteja baseado na realidade social, através de um projeto político pedagógico mais flexível, que promova uma interação entre diferentes campos dos saberes dentro da abrangência do curso (Germano, 2003). Almeja-se uma formação dialógica em que o aluno desenvolva um pensamento crítico e uma ação motivada pela ética. Apesar de mais flexibilidade, o modelo deve ser rigoroso, fortemente atrelado ao conhecimento. Pretende-se que a formação possa estimular no futuro enfermeiro o desenvolvimento da criatividade, do raciocínio, da autonomia, da comunicação e a identificação de problemas na área da saúde assim como as soluções para os mesmos (Pinhel \& Kurcgant, 2007).

Observa-se, no entanto, que esse processo de transição no ensino da Enfermagem e nas mudanças curriculares envolvidas poderia enfrentar obstáculos, uma vez que a conjuntura atual na formação do enfermeiro ainda lida com a fragmentação do saber e da prática profissional. Germano (2003) aponta que é importante considerar que a universidade se estrutura de forma bastante arcaica e tradicional, assim como o ensino na saúde, que sempre esteve baseado em um modelo conservador. Essas barreiras estabelecidas podem ser encontradas não só nas Instituições, mas também no modo de pensar do indivíduo que apresenta uma inflexibilidade que limita e dificulta as transformações.

O ensino na Enfermagem, apesar das limitações a serem enfrentadas e das dificuldades de um modelo tradicionalista, precisa ser pautado a partir da integração entre saberes e diferentes áreas do conhecimento que se completam. A formação do enfermeiro necessita desenvolvimento do pensamento crítico e reflexivo para que o futuro profissional seja capaz de lidar com as necessidades em saúde e responder as demandas da sociedade. 
Esse olhar crítico, atrelado com as competências éticas e sociais, a autonomia e a responsabilidade do cuidado, trazem para a prática e para o ensino da Enfermagem, a construção de relações humanas e a capacidade de transformar a realidade dentro da perspectiva do Sistema Único de Saúde (Galleguillos \& Oliveira, 2001; Pinhel \& Kurcgant, 2007).

No que se refere à educação superior na área de Odontologia, o modelo hegemônico no mundo ocidental, ao longo do século XX, segue as propostas contidas no Relatório Gies, de 1926, o qual foi concebido em consonância com o Relatório Flexner, de 1910. Seguindo a mesma lógica de proposição de reformas no ensino, o Relatório Gies abordou especificamente o ensino da Odontologia. De Paola (2004) apontou cinco recomendações extraídas desse relatório: o ensino odontológico e a ciência deveriam ser comparáveis ao ensino médico em qualidade e suporte financeiro; os requisitos e a educação preparatória para os cursos de medicina e odontologia deveriam ser equiparáveis; professores de odontologia deveriam ter um desempenho em ensino e pesquisa comparáveis ao melhor de uma universidade de referência; o currículo de odontologia deveria ser delineado de modo a ser gradativamente aprofundado e concluído em três anos; um quarto ano optativo deveria ser disponibilizado para treinamento clínico e especializações.

A proposta do Relatório Gies caracterizou-se pela migração de um modelo pouco sistematizado para um modelo ancorado na cientificidade, para reorganização da prática odontológica, orientado a partir de então pelo biologicismo, mecanicismo e curativismo (Cordón, 1998). Conforme também destacado por De Paola (2008), tal modelo de formação é pautado na ênfase ao estudo e à pesquisa nas ciências básicas e especializadas; formação centrada na cura; aprimoramento do conhecimento biomédico de modo aprofundado; ensino fragmentado e dissociado do contexto social. 
As propostas de ambos os relatórios, Flexner e Gies, expandiram-se mundialmente e ainda seguem influenciando a formação dos profissionais das diversas áreas da saúde, tanto em países desenvolvidos, quanto em países em desenvolvimento (Baltazar, 2010).

Lampert (2009) também ressalta que na implantação subsequente às propostas de dos referidos relatórios, passa-se a ter uma ênfase ao estudo e à pesquisa nas ciências básicas e especializadas, com aprimoramento do conhecimento biomédico de modo aprofundado, porém, fragmentado e dissociado do contexto social. A ênfase em um modelo construído historicamente apoiado no reparo e na cura, em detrimento do cuidado e da promoção de saúde, relegou aos fatores sociais, culturais e econômicos um papel secundário.

No caso da Odontologia, durante anos, a inserção da saúde bucal e das práticas odontológicas nos sistemas de atenção à saúde ocorreu de forma paralela e afastada do processo de organização dos serviços de saúde no Brasil (Brasil, 2006a). Apesar da criação do Programa Saúde da Família (PSF) em 1994, a implementação de equipes de saúde bucal neste programa ocorreu tardiamente, iniciando-se apenas a partir de 2001 (Brasil, 2000). A inserção da saúde bucal à Estratégia Saúde da Família (ESF), denominação atualizada para PSF, teve como prioridade melhorar a saúde bucal no âmbito da atenção primária à saúde. Entretanto, Kriger e Morita (2004) salientam que tal proposta se defronta com a precária disponibilidade de profissionais que possuam visão humanística e estejam preparados para prestar cuidados contínuos e resolutivos à comunidade. Considerando que dentre as características do modelo proposto para atuação nas equipes da ESF, inclui-se um maior vínculo e humanização na atenção básica, tal cenário se confronta com as deficiências existentes na formação do cirurgião-dentista, tradicionalmente marcada pela pouca valorização da formação humanística, cultural e política (Finkler, 2011).

Outro aspecto relevante é o fato de o mercado de trabalho no século XXI envolver a necessidade de mudanças no perfil profissional. A crescente expansão dos serviços públicos 
em Odontologia tem sido um fator de grande modificação na forma de exercício profissional (Morita et al., 2010). Atualmente, apesar do SUS ser um significativo mercado de trabalho para o cirurgião-dentista, tal fato não produziu o impacto esperado sobre o ensino de graduação (Kriger \& Morita, 2004).

Existem muitos desafios a serem enfrentados, como dificuldades do sistema de educação superior vigente no país e a incipiente participação da Odontologia no SUS.

Algumas propostas e períodos de transformações podem levar a profissão a uma aproximação das dimensões da integralidade que almeja atualmente. A inserção das equipes de saúde bucal na ESF é uma dessas conquistas, além da formulação das DCN para a área. É também relevante o fato de que, pela primeira vez na história das políticas de saúde bucal no país, houve a implementação de uma política pública específica da área, denominado Brasil Sorridente (Brasil, 2004), a qual possui várias frentes de ações e busca de melhorias para a saúde bucal do cidadão brasileiro.

Assim como afirma Moysés (2004), é inquestionável a importância do domínio de aspectos biológicos e clínicos na formação dos profissionais da saúde, mas também é imprescindível aliar a isso o desenvolvimento de competências éticas, políticas, econômicas, culturais e sociais.

Entretanto, o que se observa é que a formação profissional dos cursos visitados neste estudo, possui como eixo comum o modelo biomédico, pautado na habilidade técnica, na visão individualista, na doença e na cura. Isto continua gerando uma lacuna que não permite uma aproximação entre áreas que, embora possuam objetivos comuns (ou deveriam possuir), mantêm-se focadas nos aspectos relacionados às suas especificidades. Por consequência, forma sujeitos com baixa capacidade para protagonizar novas aberturas para a sociedade e para as profissões da saúde. 


\subsection{BASES CONCEITUAIS DAS DIRETRIZES CURRICULARES NACIONAIS PARA OS CURSOS DE SAÚDE}

É consenso o fato de que a formação de recursos humanos é um dos nós críticos para a consolidação do SUS. Por muitos anos, o que se reproduziu foi uma visão com ênfase em procedimentos, superando o pensar saúde. A concepção medicalizadora da saúde ocupou, e segue ocupando um espaço hierarquicamente superior na cultura acadêmica e na concepção do trabalho em saúde (Ceccim \& Bilibio, 2002). O eixo da medicalização necessita ser deslocado para uma atuação interdisciplinar, com base na coletividade, e que ofereça atenção integral, respeitando os princípios do Sistema Único de Saúde. É ponto-chave para este alcance a mudança do perfil dos profissionais que atuam no sistema e possam ser protagonistas destas mudanças.

O perfil dos egressos da formação superior na área da saúde passou, e ainda passa por ampla discussão dentro do cenário brasileiro. A construção das Diretrizes Curriculares Nacionais dos cursos de graduação da área da saúde (DCN) ocorreu em momento privilegiado da nossa sociedade. As discussões em torno dessas necessidades de mudanças envolveram diversos atores sociais que contribuíram para a elaboração das DCN em todo o país. Tal iniciativa foi um avanço importante a ter lugar após décadas de discussões e planejamento coletivo, em andamento desde a Reforma Sanitária Brasileira, na década de 1980, que exigia mudanças na educação profissional em saúde que pudessem incorporar o referencial teórico proposto nos princípios do SUS (Haddad et al., 2010). Em 1991, foi criada a Comissão Interinstitucional Nacional de Avaliação do Ensino Médico (CINAEM), composta por 11 entidades ligadas ao ensino e prática médica no Brasil, que em conjunto, realizaram um processo de avaliação e uma proposta de reformulação para o ensino médico no Brasil (Garcia, 2007). Daí, emergiram redes conceituas estruturantes de um processo no 
campo da educação médica, com significativas propostas de alterações e estruturas de novos sentidos para a formação (Cruz, 2004).

Este debate mobilizou as profissões da área de saúde de maneira expressiva, as quais estavam em concordância quanto à necessidade de ruptura ao modelo de currículo mínimo obrigatório para as carreiras. Os movimentos de mudança na graduação apontavam a noção de diretrizes indicasse como possibilidade a desejável perspectiva transformadora da formação de profissionais de saúde (Ceccim \& Feuerwerker, 2004). E esse processo caminhou em direção ao conceito de integralidade das ações de saúde, em consonância com os princípios do SUS. Ressalta-se que cada profissão teve suas diretrizes publicadas separadamente, sendo que para a maioria dos cursos da área da saúde, foram homologadas entre 2001 e 2004

Rossoni e Lampert (2004) afirmam que as DCN foram resultantes da correlação de forças entre diferentes ideologias. Elas buscavam dar um direcionamento para a construção de um perfil acadêmico e profissional com competências, habilidades e conteúdos de acordo com as necessidades atuais das populações (Gonzalez \& Almeida, 2010). Em seus conteúdos foi antecipada a necessidade de planos de educação em saúde que correspondessem a uma formação acadêmica em consonância com os princípios do SUS. Foi apontada a necessidade de se introduzir metodologias de ensino-aprendizagem inovadoras com foco no desenvolvimento de atividades práticas conjuntas com os serviços de saúde, ao contrário de se ter o espaço das Instituições de Ensino Superior como o cenário principal de aprendizagem durante a formação acadêmica nos cursos de saúde (Brasil, 2001).

Conforme consta no artigo $3^{\circ}$. das Resoluções que instituem as DCN para os cursos de Enfermagem, Medicina e Odontologia (Brasil, 2001a; Brasil, 2001b; Brasil, 2002), existe 
uma similaridade em relação aos perfil geral do formando egresso/profissional que se pretende obter nessas áreas, conforme consta a seguir:

Art. $3^{\circ}$ O Curso de Graduação em Enfermagem tem como perfil do formando egresso/profissional:

Enfermeiro, com formação generalista, humanista, crítica e reflexiva. Profissional qualificado para o exercício de Enfermagem, com base no rigor científico e intelectual e pautado em princípios éticos. Capaz de conhecer e intervir sobre os problemas/situações de saúde-doença mais prevalentes no perfil epidemiológico nacional, com ênfase na sua região de atuação, identificando as dimensões biopsicossociais dos seus determinantes. Capacitado a atuar, com senso de responsabilidade social e compromisso com a cidadania, como promotor da saúde integral do ser humano.

(Novembro de 2001)

\begin{abstract}
Art. $3^{\circ}$ O Curso de Graduação em Medicina tem como perfil do formando egresso/profissional o médico, com formação generalista, humanista, crítica e reflexiva, capacitado a atuar, pautado em princípios éticos, no processo de saúde-doença em seus diferentes níveis de atenção, com ações de promoção, prevenção, recuperação e reabilitação à saúde, na perspectiva da integralidade da assistência, com senso de responsabilidade social e compromisso com a cidadania, como promotor da saúde integral do ser humano.
\end{abstract}

(Novembro de 2001)

\begin{abstract}
Art. $3^{o}$ O Curso de Graduação em Odontologia tem como perfil do formando egresso/profissional o Cirurgião-Dentista, com formação generalista, humanista, crítica e reflexiva, para atuar em todos os níveis de atenção à saúde, com base no rigor técnico e científico. Capacitado ao exercício de atividades referentes à saúde bucal da população, pautado em princípios éticos, legais e na compreensão da realidade social, cultural e econômica do seu meio, dirigindo sua atuação para a transformação da realidade em benefício da sociedade.
\end{abstract}

(Fevereiro de 2002)

$\mathrm{O}$ artigo $4^{\circ}$. das DCN para os três cursos aqui mencionados (apresentado a seguir na íntegra e resumido na Figura 1) estabelece que no processo de formação profissional objetiva-se dotá-lo dos conhecimentos requeridos para o exercício das seguintes competências e habilidades gerais: 
I - Atenção à saúde: os profissionais de saúde, dentro de seu âmbito profissional, devem estar aptos a desenvolver ações de prevenção,

promoção, proteção e reabilitação da saúde, tanto em nível individual quanto coletivo. Cada profissional deve assegurar que sua prática seja realizada de forma integrada e contínua com as demais instâncias do sistema de saúde, sendo capaz de pensar criticamente, de analisar os problemas da sociedade e de procurar soluções para os mesmos. Os profissionais devem realizar seus serviços dentro dos mais altos padrões de qualidade e dos princípios da ética/bioética, tendo em conta que a responsabilidade da atenção à saúde não se encerra com o ato técnico, mas sim, com a resolução do problema de saúde, tanto em nível individual como coletivo;

II - Tomada de decisões: o trabalho dos profissionais de saúde deve estar fundamentado na capacidade de tomar decisões visando o uso apropriado, eficácia e custo efetividade, da força de trabalho, de medicamentos, de equipamentos, de procedimentos e de práticas. Para este fim, os mesmos devem possuir competências e habilidades para avaliar, sistematizar e decidir as condutas mais adequadas, baseadas em evidências científicas;

III - Comunicação: os profissionais de saúde devem ser acessíveis e devem manter a confidencialidade das informações a eles confiadas, na interação com outros profissionais de saúde e o público em geral. A comunicação envolve comunicação verbal, não-verbal e habilidades de escrita e leitura; o domínio de, pelo menos, uma língua estrangeira e de tecnologias de comunicação e informação;

IV - Liderança: no trabalho em equipe multiprofissional, os profissionais de saúde deverão estar aptos a assumirem posições de liderança, sempre tendo em vista o bem estar da comunidade. A liderança envolve compromisso, responsabilidade, empatia, habilidade para tomada de decisões, comunicação e gerenciamento de forma efetiva e eficaz;

' $V$ - Administração e gerenciamento: os profissionais devem estar aptos a tomar iniciativas, fazer o gerenciamento e administração tanto da força de trabalho, dos recursos físicos e materiais e de informação, da mesma forma que devem estar aptos a serem empreendedores, gestores, empregadores ou lideranças na equipe de saúde; $e$

VI - Educação permanente: os profissionais devem ser capazes de aprender continuamente, tanto na sua formação, quanto na sua prática. Desta forma, os profissionais de saúde devem aprender a aprender e ter responsabilidade e compromisso com a sua educação e o treinamento/estágios das futuras gerações de profissionais, mas proporcionando condições para que haja benefício mútuo entre os futuros profissionais e os profissionais dos serviços, inclusive, estimulando e desenvolvendo a mobilidade acadêmico/profissional, 
a formação e a cooperação através de redes nacionais e internacionais.

\begin{tabular}{|c|c|}
\hline $\begin{array}{l}\text { COMPETENCIAS } \\
\text { E HABILIDADES }\end{array}$ & DESCRIÇÃO RESUMIDA \\
\hline Atenção à saúde & $\begin{array}{l}\text { - Desenvolver ações de prevenção, promoção, proteção e reabilitação da saúde } \\
\text { nos níveis individual e coletivo } \\
\text { - Assegurar a prática de forma integrada dentro do sistema de saúde } \\
\text { - Pensar criticamente e analisar os problemas e procurar soluções para os } \\
\text { - Resmos } \\
\text { - Realizar os serviços dentro dos padrões de qualidade e princípios de } \\
\text { - } \text { ética/bioética } \\
\text { Resolver problemas de saúde nos níveis individual e coletivo }\end{array}$ \\
\hline $\begin{array}{l}\text { Tomada de } \\
\text { decisões }\end{array}$ & $\begin{array}{l}\text { - Tomar decisões considerando o uso apropriado da eficácia e custo efetividade, } \\
\text { da força de trabalho, de medicamentos, equipamentos, procedimentos e } \\
\text { práticas. } \\
\text { - Possuir habilidades para avaliar, sistematizar e decidir condutas mais } \\
\text { adequadas } \\
\text { - Basear-se em evidências científicas }\end{array}$ \\
\hline Comunicação & $\begin{array}{l}\text { - Ser acessível } \\
\text { - Manter a confidencialidade das informações } \\
\text { - Comunicar-se de forma verbal e não verbal } \\
\text { - Possuir habilidades de escrita e leitura } \\
\text { - Dominar pelo menos uma língua estrangeira e de tecnologias de comunicação } \\
\text { e informação }\end{array}$ \\
\hline Liderança & $\begin{array}{l}\text { - Estar apto a assumir posições de liderança } \\
\text { - Possuir compromisso, responsabilidade, empatia } \\
\text { - Possuir habilidades para a tomada de decisão } \\
\text { - Ser comunicativo } \\
\text { - Gerenciar de forma efetiva e eficaz }\end{array}$ \\
\hline $\begin{array}{l}\text { Administração e } \\
\text { gerenciamento }\end{array}$ & $\begin{array}{l}\text { - Estar apto a tomar iniciativas, fazer gerenciamento e administração de recursos } \\
\text { humanos, físicos e materiais e informações } \\
\text { - Estar apto a empreender, gerir, empregar ou liderar equipes de saúde }\end{array}$ \\
\hline $\begin{array}{l}\text { Educação } \\
\text { permanente }\end{array}$ & $\begin{array}{l}\text { - Aprender continuamente na formação e na prática } \\
\text { - Aprender a aprender ter responsabilidade e compromisso com a própria } \\
\text { educação e com o treinamento de futuros profissionais } \\
\text { - Estimular e desenvolver a mobilidade acadêmico/profissional, a formação e a } \\
\text { cooperação através de redes nacionais e internacionais }\end{array}$ \\
\hline
\end{tabular}

Figura 1. Resumo das competências e habilidades gerais requeridos aos profissionais, constantes no artigo $4^{\circ}$ das Diretrizes Curriculares Nacionais dos cursos de Enfermagem, Medicina e Odontologia.

Com a recente publicação das DCN para o curso de Medicina, ocorrida em junho de 2014 (Brasil, 2014), a publicação de 2001 para este curso foi revogada. Algumas mudanças ocorreram no componente curricular da atual publicação, como a inclusão do SUS como 
cenário de práticas obrigatório, por meio do estágio curricular, com ênfase na Atenção Básica e no Serviço de Urgência e Emergência. Além disso, os estudantes serão avaliados a cada dois anos durante o processo de formação na graduação. As avaliações ocorridas serão incorporadas como parte do processo de classificação para os exames dos programas de residência médica. Para o alcance do perfil profissional esperado do graduado em Medicina, o atual documento propõe áreas de competências norteadoras da formação, incluindo os eixos atenção em saúde, gestão em saúde e educação em saúde. Estas áreas de competências estão em consonância com as competências e habilidades publicadas anteriormente, conforme observado na Figura 1. O documento atual ressalta que as adequações dos cursos deverão ocorrer até o final de 2018. A Lei 12.871 (Brasil, 2013), que instituiu o Programa Mais Médicos, oferece suporte legal para as mudanças que devem ser incorporadas na formação. Inclui critérios de abertura de novos cursos de Medicina, de modo a atender regiões com maior demanda; implementação do Programa de Residência em Medicina Geral de Família e Comunidade e do Contrato Organizativo da Ação Pública Ensino-Saúde para o estabelecimento e fortalecimento da integração ensino-serviço.

As implementações propostas nas atuais DCN para a Medicina (Brasil, 2014), assim como nas DCN anteriores, para Enfermagem, Medicina e Odontologia (Brasil, 2001a; Brasil, 2001b; Brasil, 2002), reforçam a busca pelo perfil geral desses profissionais, com base em uma formação generalista, humanista, crítico, reflexivo e ético, como consta no artigo $3^{\circ}$ desses documentos.

Neste momento cabe uma reflexão no que tange às bases conceituais que fundamentam o perfil geral proposto pelas DCN para o profissional que se pretende desenvolver durante o processo de formação do futuro profissional da saúde.

Ao se requerer um profissional com formação generalista, humanista, que oferte saúde de forma integral, que mudanças efetivamente se espera desse profissional em relação 
ao profissional de saúde que atua hoje no país? São transformações que visam subtrair, substituir aquilo que antecede o já existente ou buscam-se modificações que possam agregar, acrescentar, adaptar e tornar o profissional mais "completo" em sua formação?

O perfil generalista pressupõe que o profissional seja capaz de ir além do ato técnico (Kriger et al, 2005) para que o mesmo desenvolva as competências gerais que possam suprir lacunas existentes na formação em saúde. As competências específicas inerentes a cada área são fundamentais, devem ser respeitadas e desenvolvidas durante o processo de formação de forma associada às habilidades gerais requeridas para uma boa formação. Esses autores enfatizam que o generalista deve ser capaz de conhecer o indivíduo em sua integralidade, de entender o todo como a base do atendimento das necessidades de saúde das pessoas. A formação tradicional, com ênfase no profissional tecnicista, tende a posicionar o generalista de maneira inferiorizada, incapaz de ser resolutivo. Por outro lado, com os excessos da especialização, atualmente pode-se considerar que uma visão limitada ao específico pode acarretar ao não reconhecimento de problemas maiores, às vezes tanto quanto ou mais importantes que o objeto da atenção especializada em um determinado caso (Brasil, 2007).

É necessário que o profissional esteja apto a lidar com a subjetividade dos sujeitos e com a objetividade de suas condições socioeconômicas e culturais. Fernandes et al. (2005) afirmam que ao se formar um profissional com perfil generalista, o mesmo estará instrumentalizado para atuar nos mais diversos contextos, em oposição à especialização precoce, que pode induzir a visões parciais da realidade.

No que tange a atenção à saúde, a descrição dessa competência nas DCN, afirma que o profissional deve estar apto a desenvolver ações de prevenção, promoção, proteção e reabilitação da saúde, o que nos remete ao conceito de integralidade. É relevante ressaltar a diversidade de sentidos e terminologias utilizadas para definir essa diretriz do SUS, que inclusive, conforme destaca Mattos (2006), não é a expressão utilizada na Constituição 
Federal de 1988, ao prever "atendimento integral, com prioridade para as atividades preventivas, sem prejuízo dos serviços assistenciais” (Brasil, 1988).

Neste estudo adotaremos o conceito de integralidade como "um conjunto articulado e contínuo das ações e serviços preventivos e curativos, individuais e coletivos, exigidos para cada caso em todos os níveis de complexidade do sistema” (Brasil, 2007). A inserção da noção de integralidade busca uma contraposição à dissociação existente entre as práticas assistenciais, fomentadas pela distinção entre serviços de saúde pública e serviços assistenciais (Machado et al., 2005). Na prática, Mattos (2006) descreve integralidade, como a capacidade dos profissionais para responder ao sofrimento manifesto, que gerou determinada demanda espontânea, de forma articulada à oferta de ações de prevenção e de promoção de saúde. Isso significa incluir no cotidiano de trabalho rotinas ou processos de busca sistemática daquelas necessidades mais silenciosas, que antecedem à experiência individual de sofrimento.

Ao se discutir integralidade e sua inserção no processo de formação, é gerada uma zona de tensões à medida que se pressupõe equivocadamente que ao se dar ênfase à Atenção Básica e à Estratégia Saúde da Família durante a formação profissional propõe-se uma modelo de formação com caráter substitutivo, que busca excluir os demais lócus de ensino e aprendizagem. Entretanto, a ideia é expandir para além do que hoje é oferecido e tem demonstrado ser incompleto e ineficaz para a formação. Nesta perspectiva, os hospitaisescola tornam-se um dos lócus (e não o único), assim como os cenários incluídos no campo de atuação da Atenção Primária.

A integralidade das ações de saúde não devem desconsiderar os avanços da tecnologia na saúde. Entretanto, estes devem ser utilizados de forma criteriosa e complementar e não prioritária, com sua indicação bem fundamentada na atenção à saúde, e baseada na melhor evidência científica. A tomada de decisões, incluída dentre as 
competências descritas nas DCN (Brasil, 2001a; Brasil, 2001b; Brasil, 2002; Brasil, 2014), exerce relevante papel neste contexto. O desenvolvimento da habilidade de avaliar, sistematizar, optar pela conduta mais apropriada, requer do sujeito uma formação crítica e reflexiva.

A formação profissional, entendida de um modo geral como o preparo técnico para o exercício de determinadas atividades, privilegia o conhecimento aplicado e informações atualizadas. Entretanto, uma formação básica deve trabalhar conceitos e princípios que regem o núcleo fundamental do saber em determinada área. Neste caso privilegia também um conjunto de conhecimentos essenciais à existência na dinâmica do mundo moderno, ao exercício da cidadania e à vida profissional. Torna-se então imprescindível o desenvolvimento da capacidade de pensar, de acompanhar os avanços e transformações na sociedade (Coelho, 1998). O autor alerta para o possível equívoco de se crer que a inclusão de disciplinas vistas como detentoras de determinadas esferas do conhecimento possam de forma isolada e desconectada com as demais, caracterizar um curso como gerador de uma formação crítica. Defende que os cursos e currículos devem constituir-se em espaços privilegiados da produção do saber, do exercício da reflexão, do debate e da crítica, nos quais ocorram mais dúvidas do que respostas e a livre busca seja uma exigência. Isso coloca os sujeitos envolvidos, tais como professores e estudantes, como condutores de um processo de construção, o qual emerge do repensar, do recriar de ideias e do fazer. Exige desses atores superação de limites e ampliação e realização de possibilidades.

De acordo com Silva e Cunha (2002), ao desenvolver a capacidade de criar, criticar, tomar iniciativas e decisões, o profissional se torna preparado para adaptar-se e agir de acordo com as situações que lhe são impostas e com as mudanças que ocorrem na sociedade. Consideram que a valorização profissional ocorre na medida de sua habilidade para estabelecer relações e assumir lideranças. Uma questão relevante no contexto da sociedade 
atual é que o saber e a comunicação passam a ocupar a maioria das atividades humanas. Os novos profissionais devem ser capazes de operacionalizar seu conhecimento de forma integrada às suas aptidões e vivências culturais.

Ao incluir a educação permanente como uma das competências gerais para os profissionais de saúde, entende-se a importância de preparar o futuro profissional para ter condições de atualizar seus conhecimentos de forma continuada, respondendo aos desafios que o mundo social e do trabalho lhe impuserem.

A Portaria 198/GM de 2004 (Brasil, 2004a) explicita seu entendimento de educação permanente como "aprendizagem no trabalho, onde o aprender e o ensinar se incorporam no cotidiano das organizações e ao trabalho". A implementação da Política Nacional de Educação Permanente, em 2004, segundo Ceccim (2005) demonstrou o esforço de tornar a rede pública de saúde uma rede de ensino-aprendizagem no exercício do trabalho. O autor ressalta que esse conceito foi adotado com o objetivo de dimensionar essa tarefa na ampla intimidade entre formação, gestão, atenção e participação mediante as intercessões promovidas pela educação na saúde, com a oferta de suas tecnologias construtivistas e de ensino-aprendizagem (Ceccin \& Ferla, 2009). O sujeito que obteve uma formação básica sólida adquire autonomia para buscar informações, transferir aprendizagem de uma área para outra, fazer generalizações, estabelecer relações, tirar conclusões e encontrar soluções para problemas com os quais se deparar (Coelho, 1998).

No item VI do artigo $4^{\circ}$. das DCN de 2001 e 2002 anteriormente apresentadas (Brasil, 2001a; Brasil, 2001b; Brasil, 2002) e no item I do artigo $7^{\circ}$. da recente publicação das DCN para a Medicina (Brasil, 2014), os quais discorrem sobre educação permanente, é ressaltada a necessidade de o profissional de saúde ser capaz de aprender a aprender. Esta afirmação está pautada em um dos quatro pilares da Educação estabelecidos em Relatório elaborado pela Comissão Internacional sobre a Educação para o século XXI, da UNESCO, 
em 1996, em que se propõe um novo tipo de educação com enfoque em aprender a conhecer, aprender a fazer, aprender a viver junto e aprender a ser (Delors, 1998).

O pilar aprender a conhecer supõe a necessidade de se exercitar a atenção, a memória e o pensamento. Envolve o aprender a pensar, a buscar a informação, partindo do pressuposto de que o processo de aprendizagem não se esgota durante a formação profissional e, portanto, é necessário que se obtenha autonomia para buscar o conhecimento durante toda a vida profissional.

O aprender a fazer está ligado à questão de como ensinar o estudante a colocar em prática seu conhecimento. A formação não deve ser reduzida apenas à transmissão de práticas rotineiras. Deve implicar no desenvolvimento de competências pessoais que extrapolem a obtenção apenas da qualificação profissional, em seu sentido mais estrito. Envolve adquirir qualidades como o comportamento social, a aptidão para o trabalho em equipe, a capacidade de iniciativa, o gosto pelo risco. Delors (1998) destaca que o aprender a conhecer e o aprender a fazer são indissociáveis, uma vez que aproximam a teoria e a prática.

O aprender a viver junto representa um dos grandes desafios da educação, uma vez que envolve o enfrentamento do individualismo e competitividade do mundo atual. Trata-se de desenvolver a atitude de empatia, o que poderá auxiliar nos comportamentos sociais ao longo da vida. Trata-se de aprender a viver conjuntamente, desenvolvendo o conhecimento dos outros, de sua história, de suas tradições e de sua espiritualidade. Kriger et al. (2005) apontam que o aprender a construir coletivamente é essencial à medida que o conhecimento na área de saúde é multiprofissional e transdisciplinar. Ao se propor a formação do profissional generalista, pressupõe-se, dentre outras habilidades, a capacidade de atuação em equipe. Isso envolve a articulação entre os profissionais de saúde, sendo considerada como uma das estratégias de reorganização das práticas de saúde. Peduzzi (2001) conceitua 
'trabalho em equipe' multiprofissional como uma modalidade de trabalho coletivo que é construído por meio da relação recíproca, de dupla mão, entre as múltiplas intervenções técnicas e a interação dos profissionais de diferentes áreas, configurando, através da comunicação, a articulação das ações e a cooperação. A autora ressalta que a ideia do trabalho em equipe em saúde aparece respaldada pela noção de atenção integral, pautada na coletividade. Costa et al. (2008) destacam os desafios para se organizar essa forma de organização do trabalho, de modo a contemplar a complexidade de saberes, a responsabilidade coletiva e a efetiva interação dos recursos humanos de diferentes áreas profissionais. Incluem enfrentamentos como superação de atuações fragmentadas, isolamento e manutenção de relações de poder entre profissionais e destes com os usuários, dificultando a produção de uma atenção à saúde mais integral e resolutiva. A descoberta do outro e a participação em projetos comuns são apontados pelo Relatório da UNESCO (Delors, 1998, p. 97) como caminhos que podem evitar ou resolver conflitos latentes. Passando à descoberta do outro, necessariamente, passa-se pela descoberta de si mesmo.

O pilar aprender a ser refere-se ao desenvolvimento total do indivíduo. Um Relatório denominado "Aprender a ser" publicado pela Comissão Internacional sobre o Desenvolvimento da Educação (Faure, 1972) já exprimia preocupações com a desumanização do mundo relacionado à evolução técnica. Assim, Delors (1998) assumiu o postulado do referido relatório para descrever esse pilar da educação: “o desenvolvimento tem por objeto a realização completa do homem, em toda a sua riqueza e na complexidade das suas expressões e dos seus compromissos: indivíduo, membro de uma família e de uma coletividade, cidadão e produtor, inventor de técnicas e criador de sonhos". Delors (1998) ressalta que esse desenvolvimento do ser humano é um processo dialético que começa pelo processo de conhecimento de si mesmo para em seguida se abrir para a relação com o outro. O perfil humanista que se espera do profissional de saúde, conforme apontado nas DCN 
requer um retorno à identidade humana, num mundo imerso em novas tecnologias. Moysés (2003) afirma que humanização assume uma alusão à área de humanidades no sentido de posicionar o homem como objeto central de reflexão. Ao entender que a atenção à saúde não se encerra no ato técnico, e sim, na resolução do problema de saúde, tanto em nível individual quanto coletivo, o processo de transformação pode avançar com vistas à humanização.

Para o desenvolvimento do profissional, a educação atua como uma ferramenta que é ao mesmo tempo um processo individualizado e também uma construção social interativa. O pilar aprender a ser integra os demais e cria condições para o desenvolvimento integral da pessoa, com sensibilidade, sentido ético, responsabilidade pessoal, pensamento autônomo e crítico, criatividade, iniciativa e rigor científico (Fernandes et al., 2005).

No Relatório Delors é enfatizado que os quatro pilares da educação anteriormente descritos não se apoiam, exclusivamente, numa fase da vida ou num único lugar. Os tempos e as áreas da educação devem ser repensados, completar-se e interpenetrar-se de maneira que cada indivíduo, ao longo de sua vida, possa tirar o melhor partido de um ambiente educativo em constante ampliação. Moysés (2003) destaca que esses pilares são aspectos fundamentais da aprendizagem significativa, que se contrapõem às propostas educacionais de cunho mercadológico, ao propor uma educação solidária, com aprendizagens inter-relacionadas e que leva a uma educação integral do ser humano.

A intencionalidade ao se propor as DCN foi a de promover a reflexão para que os sujeitos envolvidos no processo de formação construam um novo olhar. Espera-se que os profissionais de saúde desenvolvam com isso a capacidade de visão social e técnica dos problemas reais existentes na população brasileira (Souza et al, 2008). A ideia de suprir a lacuna existente entre o modelo de saúde vigente e a formação profissional daqueles que 
nele atuam é vital para a consolidação de um sistema de saúde que ainda possui muito a caminhar.

Apesar dos avanços em relação à inserção das propostas das DCN nos currículos dos cursos da saúde, vale destacar a citação de Alves et al. (2013) ao afirmar que por trás da racionalidade institucional, existem pessoas reais, para as quais os significados de mudanças educacionais assumem diferentes posicionamentos, e por esta razão elas se tornam favoráveis ou resistentes, de acordo com suas percepções.

\subsection{POLÍTICAS INDUTORAS DE TRANSFORMAÇÕES NA FORMAÇÃO}

\section{EM SAÚDE}

O distanciamento entre os mundos acadêmico e o mundo do trabalho nos serviços em saúde vem sendo apontado, em todo mundo, como um dos responsáveis pela crise do setor da saúde. Essa desarticulação é um dos entraves ao desenvolvimento tanto de um sistema integrado de saúde voltado ao serviço público como também do sistema atual de ensino, o qual não prepara o profissional para atuar na proposta da integralidade na saúde.

O descompasso entre o SUS que se almeja e a formação em saúde que o país oferece não foi superado com a instituição das DCN. O ensino na saúde permanece focado em competências específicas de cada área, em detrimento de avanços no desenvolvimento de competências gerais comuns a todos aqueles que exercerão o papel de protagonistas de transformações na saúde do país. Com isso, um dos maiores desafios ainda enfrentados no Brasil, e por isso considerado como uma das principais questões na agenda das políticas de saúde, é a falta de profissionais preparados para lidar com as exigências postas a partir da implementação do Sistema Único de Saúde, mesmo após mais de uma década de propostas de mudanças curriculares terem sido implementadas por meio das DCN. É necessário, portanto, que ocorram mecanismos facilitadores dessas modificações. 
Estas questões têm sido abordadas com intervenções governamentais implementadas no sentido de incorporar a ênfase no plano de educação em saúde nas competências que atendam aos princípios do SUS. Uma ação que pode ser considerada um marco foi a formalização de parceria estabelecida entre os Ministérios da Saúde e Educação, por meio da Portaria Interministerial $\mathrm{n}^{\circ}$. 2.118, em 2005 (Brasil, 2005). Ressalta-se que atividades e programas importantes já estavam em andamento e novas iniciativas foram lançadas a partir de então, a fim de induzir mudanças curriculares e formação de profissionais que pudessem atuar nas melhorias na oferta da atenção em saúde. Desde a criação da Secretaria de Gestão do Trabalho e da Educação na Saúde (SGTES), em 2004, o Ministério da Saúde assumiu a responsabilidade pela formação, regulação e gestão dos profissionais de saúde no Brasil (Haddad et al., 2010).

Nossa busca bibliográfica revelou que um grande número de iniciativas têm ocorrido nas últimas décadas, no que concerne a indução de transformações na formação o profissional em saúde por meio de políticas públicas.

Existe uma trajetória marcada pelas iniciativas em prol da reorientação profissional em saúde, reconhecida como uma necessidade desde a concepção do SUS.

Em 1981, o Programa de Integração Docente Assistencial (IDA), promovia a inserção de estudantes em unidades de atenção primária, estimulando a integração ensino-serviço como estratégia de reestruturação da formação. O Projeto UNI, em 1991, buscou redimensionar questões relativas ao Programa IDA. As ações orientavam a formação na perspectiva da multiprofissionalidade. Reforçava que os processos de mudança deveriam ocorrer na comunidade, como forma de superar a dissociação entre proposições acadêmicas e sua aplicabilidade prática. Essas, além de outras ações, com mobilizações da Rede Unida e outras entidades, como a já citada CINAEM (Garcia, 2007), desde o Movimento da Reforma Sanitária, apesar de apresentarem limitações de alcance, contribuíram para a reinserção da 
temática recursos humanos na construção das políticas de saúde (Dias, 2013).

Vale destacar que a implementação das DCN, iniciada em 2001, para os cursos de graduação da área de saúde classificados pelo Conselho Nacional de Saúde como cursos profissionais de saúde foi um relevante marco desse processo (Brasil, 2010). As DCN tiveram caráter inovador uma vez que buscaram promover a inclusão precoce e gradativa dos estudantes de graduação no ambiente do SUS para que os mesmos tivessem a oportunidade de estabelecer contato com a comunidade local o mais cedo possível e a partir disso adquirirem conhecimento associado à vivência que lhes permitam atender as necessidades de saúde locais e nacionais (Haddad et al., 2010).

Políticas públicas indutoras vem sendo implementadas para induzir mudanças curriculares desde então. O Programa PROMED (Programa de Incentivo às Mudanças Curriculares nos Cursos de Medicina), foi implementado em 2002 (Brasil, 2002a). Seu objetivo era dar apoio financeiro para as escolas médicas desenvolverem e implementarem mudanças curriculares em conformidade com as DCN (Brasil, 2001) em três áreas principais: orientação teórica, cenários de prática e abordagem pedagógica (Souza et al., 2011). O Programa PROMED começou em 2003, após um processo de seleção que envolveu mais de 100 universidades, dentre as quais 19 escolas de medicina tiveram seus projetos aprovados e desenvolvidos ao longo de um período de três anos. Embora haja uma carência em termos de avaliação de resultados do PROMED, Souza et al (2008) destacou que alguns dos obstáculos enfrentados para promover as mudanças propostas foram os aspectos críticos da integração de membros do corpo docente com as redes de saúde e da comunidade. Houve indicações sobre a necessidade de se aprimorar a parceria entre as escolas médicas e os serviços de saúde. O autor ressaltou ainda que a resistência à incorporação de mudanças curriculares resulta do fato de se iniciar uma reforma antes da disponibilidade dos recursos humanos necessários para realizá-la. A 
maneira tradicional de ensino já existe há décadas e, portanto, a formação de novos professores para trabalhar em novas propostas curriculares ainda deve ser mais claramente estabelecida.

Os desafios enfrentados, como resultado das ações sugeridas, levaram a novas iniciativas governamentais. Havia a necessidade de se oportunizar uma aproximação entre os cursos de graduação em saúde e as realidades vivenciadas nos serviços de saúde. O estabelecimento da Política de Educação e Desenvolvimento para o SUS, em 2003, visava assistir nesta abordagem. A Política Nacional de Educação Permanente em Saúde foi, então, estabelecida em 2004 (Brasil, 2004a). Educação Permanente é um conceito adotado no Brasil, baseado na proposta de incorporação do ensino e aprendizagem ao processo de trabalho em saúde, em que as questões relacionadas à prestação de cuidados de saúde enfrentados no ambiente de trabalho são utilizadas como base para o aprendizado com foco na discussão, análise e reflexão. Além de atender à demanda de uma das competências gerais contidas no artigo $4^{\circ}$. das DCN (Brasil, 2001a; Brasil, 2001b; Brasil, 2002; Brasil, 2014), que é a própria educação permanente. Espera-se como resultado, ao se lançar mão dessa forma de abordagem, que o conhecimento adquirido torne o futuro profissional mais habilitado para desenvolver soluções para os problemas detectados (Moreira 2010), pelo fortalecimento da competência capacidade de tomada de decisões (Brasil, 2001a; Brasil, 2001b; Brasil, 2002).

A criação dos Polos de Educação Permanente foi uma estratégia utilizada para permitir que os serviços públicos de saúde se tornassem um lócus de ensino-aprendizagem através do trabalho. Esses Polos eram compostos por gestores de saúde, universidades (professores e estudantes), profissionais de saúde, conselhos de saúde e movimentos sociais ligados à educação popular em saúde (Brasil, 2012). Ele trabalhou como um lugar de diálogo, negociação e acordos envolvendo todas as partes interessadas e com papéis no 
planejamento de ações para o desenvolvimento e formação profissional para o SUS. Em um curto período de menos de dois anos, os Polos reuniram 1.122 diferentes organizações regionais, colocando em prática o artigo 14 da Lei Orgânica da Saúde (Brasil, 1990), o qual afirma que devem existir comissões permanentes de integração entre os serviços de saúde e universidades, com o objetivo de dar prioridade às estratégias de oferta de educação profissional em saúde aos profissionais que atuam no SUS (Ceccim, 2005).

Em 2007, a Política Nacional de Educação Permanente em Saúde foi revista e algumas modificações foram instituídas pelo Ministério da Saúde, pelo Decreto ${ }^{\circ}{ }^{\circ}$. 1.996 (Brasil, 2007b), a fim de seguir as orientações do Pacto pela Saúde, implementado partir de 2006 (Brasil, 2006). Entre os avanços houve a criação da Comissão de Integração EnsinoServiço (CIES), em substituição aos Polos. O objetivo era avançar dois princípios do SUS: descentralização e regionalização (Moreira, 2010). A CIES visa subsidiar na consolidação da Educação Permanente em Saúde, bem como sobre a sua incorporação na agenda de gestão da saúde como eixo de integração entre educação e trabalho (Haddad, 2011).

Outros projetos haviam sido lançados anteriormente com enfoque nessas demandas. Os projetos APRENDER SUS e VER-SUS (Projeto de Vivências e Estágios na Realidade do SUS) foram ambos lançados em 2004, objetivando atingir mudanças no âmbito do ensino de graduação dos cursos da saúde, a fim de atender as necessidades da população brasileira (Brasil, 2004b). O VER-SUS foi uma estratégia utilizada para o estabelecimento de um contato mais próximo entre os gestores de saúde e as universidades, criando oportunidades para que os estudantes aprendessem por meio de atividades externas à universidade e em contato com a realidade de saúde da população (Oliveira et al., 2008). Apesar do cuidado em saúde ser muitas vezes direcionado e impulsionado pela disponibilidade de novas tecnologias e terapias, e ocorrer centrado no procedimento e na doença, entende-se que isso poderia ser modificado. Projetos educacionais formulados como políticas públicas de 
formação de profissionais de saúde, devem promover uma visão mais integral do profissional, de modo que o mesmo tenha a capacidade de considerar o paciente ou usuário de serviços como o centro dos cuidados de saúde, e passem a inserir como processo de trabalho a referência de equipe, que possa gerar uma cadeia de cuidados em saúde de forma progressiva e integral, com uma matriz apropriada de conhecimento (Brasil, 2004b).

Inspirado pelo PROMED e cobrindo uma ampla gama de cursos de graduação em saúde, o Programa Nacional de Reorientação dos Profissionais de Saúde (Pró-Saúde) foi implementado em 2005 (Brasil, 2005a). Seu principal objetivo é promover a integração entre o ensino e os serviços de saúde para alcançar a transformação desejada para os cursos de graduação na área de saúde. O Programa visa ofertar uma abordagem abrangente sobre o processo saúde-doença com ênfase na atenção primária, a fim de promover transformações no processo de ensino-aprendizagem e, conseqüentemente, mudanças na qualidade dos serviços ofertados (Brasil, 2005a ) .

O Programa de Educação pelo trabalho em Saúde (PET-Saúde) foi regulamentado pela Portaria Interministerial no. 1.507, em 2007 (Brasil, 2007a). É composto por grupos tutorais liderados por professores universitários (tutores), e composto por profissionais de saúde que atuam na rede de saúde (preceptores) e estudantes de graduação de cursos da área da saúde. Este programa promove a formação de grupos de aprendizagem tutorial para o trabalho em saúde em áreas temáticas estratégicas do Sistema Único de Saúde. Possui como princípio a educação para o trabalho e funciona como dispositivo para fortalecer o Programa Pró-Saúde. Portanto, apenas os cursos que recebem os subsídios do Pró-Saúde são elegíveis para se candidatar a este programa. O incentivo é oferecido a diversas categorias do programa. O PET Saúde/Saúde da Família é composto por um tutor acadêmico, seis preceptores e trinta acadêmicos, dentre os quais doze serão monitores bolsistas. No PETSaúde/Vigilância em Saúde cada grupo possui um tutor acadêmico, oito estudantes e dois 
preceptores. Em 2011, o PET-Saúde/Saúde Mental iniciou suas atividades, com a aprovação de 69 projetos (Brasil, 2011).

Em 2011, ocorreu uma chamada para apresentação de propostas sobre a última versão do Programa de Saúde PET, denominado PET Saúde/Saúde da Rede (Brasil, 2011), o qual objetiva promover um estreitamento entre as universidades e os serviços de saúde, dentro dessa lógica de organização de redes de cooperação e colaboração. Um dos critérios de elegibilidade dos projetos é que o mesmo deve ser uma proposta conjunta, envolvendo os serviços de saúde e qualquer curso de graduação de saúde de Instituições de Ensino Superior públicas ou privadas. A ideia principal é estabelecer parceria para o desenvolvimento de ações na área da saúde em harmonia com as estratégias pedagógicas dos cursos acadêmicos. Bolsas de estudo para tutores, preceptores e estudantes de graduação são oferecidas, de forma similar aos demais programas PET anteriormente em andamento. Neste momento, para ser elegível para ser um tutor, o educador deve ser envolvido em assuntos relacionados com a integração de serviços em ensino, e os preceptores (profissionais de saúde) devem ser envolvidos em atividades de ensino nos centros de saúde em que trabalham. Considerando que a organização de redes de saúde deve ter o cuidado primário como ordenador e como centro da atenção em saúde, as propostas devem descrever ações que possam ser desenvolvidas com foco no atendimento integral e permanente em algumas das áreas prioritárias, tais como necessidades especiais; condições crônicas; maternidade; urgências; área psicossocial com prioridade para as drogas e uso de álcool e a saúde indígena.

O desenvolvimento de habilidades e visão necessárias para que efetivamente ocorra uma oferta de atenção à saúde de forma integral, conforme previsto nas DCN, pressupõe o desenvolvimento da capacidade de se trabalhar em coletividade, de modo a fortalecer o trabalho em equipe; a capacidade de assumir lideranças para conduzir essas equipes, sempre que necessário, com o entendimento de que a liderança que possa ser capaz de agregar 
requer comprometimento, a habilidade de ouvir, de dialogar, de motivar.

Dessa necessidade de se ampliar e melhorar a qualificação, surge também uma política que visa ofertar qualificação para o profissional de saúde em larga escala - a UNASUS (Universidade Aberta do SUS), estabelecida desde 2008. Esta iniciativa do Ministério da Saúde, em parceria com a Organização Pan-Americana da Saúde (OPAS ) e outras instituições, oferece cursos de formação e qualificação a distância para profissionais de saúde que atuam no SUS, por meio de uma rede de Instituições de Ensino Superior credenciadas. A rede formada pelo UNA-SUS agrega ações de universidades e outras instituições acadêmicas, constituindo uma rede nacional de educação continuada na área da saúde. A proposta destina-se a receber a contribuição de cada instituição de acordo com o seu potencial, e está estruturada em produção de conhecimento, cooperação em tecnologias educacionais, apoio no local e certificação escolar (Brasil, 2010). O objetivo é criar um arquivo público colaborativo de materiais educacionais para o setor de saúde. A UNA-SUS promove a introdução de novas tecnologias de informação e comunicação nos processos de educação em saúde (Brasil, 2011). As decisões sobre a formação e qualificação dos profissionais são realizadas considerando-se as políticas nacionais de saúde. Atualmente, existem 14 instituições credenciadas que oferecem cursos em áreas relevantes, como saúde da família, vigilância em saúde ambiental, saúde materna e infantil, saúde mental, gestão da assistência farmacêutica e capacitação de gestores do SUS . A formação educacional e experiência de trabalho de cada profissional são registrados na Plataforma Arouca, que é o Sistema de Informação dos profissionais de saúde do Brasil. As ofertas de cursos e módulos de ensino são disponibilizados nesta plataforma para o público. Pretende-se alcançar com a UNA-SUS melhoria da qualidade e expansão das ações de educação em saúde (Brasil, 2010).

Para atender às demandas de qualificação dos trabalhadores da saúde de nível 
secundário, foi criado em 2009 o Programa Nacional para Formação de Profissionais de Nível Médio para a Saúde (PROFAPS). Buscou-se com isso qualificar trabalhadores técnicos de saúde. Este projeto foi inspirado em uma experiência semelhante, lançado em 2000, denominado Projeto de Profissionalização dos Profissionais da área de Enfermagem (PROFAE), o qual incidiu sobre a qualificação dos profissionais de enfermagem. Este foi inicialmente programado para duração de quatro anos, mas se estendeu até 2007 (Brasil, 2000a). A implementação do PROFAE teve importante significado no que se referia às propostas dos cursos oferecidos pelo Projeto, os quais tiveram como parâmetro a inserção de metodologias de ensino e aprendizagem que privilegiavam a problematização (Ferreira et al., 2007; Schaurich et al., 2007).

No PROFAPS o objetivo é mais amplo e inclui diversas áreas da saúde, a fim de proporcionar o acesso à educação para os trabalhadores ou potenciais trabalhadores do SUS. A necessidade desta iniciativa baseia-se na escassez de profissionais de saúde qualificados de nível secundário, principalmente nas regiões Norte e Nordeste do país. O programa inclui uma grande diversidade de cursos para cobrir as áreas de saúde, como cuidadores de idosos, radiologia, patologia, hemoterapia, saúde bucal, enfermagem, diálise, vigilância ambiental, epidemiológica e sanitária e atenção domiciliar. Para alcançar este objetivo, é essencial reforçar a parceria e articulação entre as escolas técnicas, universidades, conselhos profissionais, serviços de saúde e gestores de saúde. O apoio técnico e pedagógico é fornecido pelos envolvidos no processo de educação para a saúde, como faculdades e universidades (Brasil, 2009).

Existem grandes disparidades na distribuição de profissionais de saúde qualificados pelo Brasil, agravados pelo fato das carreiras de trabalho não serem atraentes e os salários diferirem de região para região (Victora et al., 2011). Essas questões refletem sobre a desigualdade da oferta de serviços de saúde em todo o país. O Programa de Valorização dos 
Profissionais de Saúde na Atenção Básica (PROVAB ) foi lançado em 2012 com o objetivo de incentivar os médicos a iniciar suas carreiras em áreas remotas, onde a população tem dificuldade de acesso aos serviços de saúde. Os profissionais selecionados para o programa devem fazer um curso de pós- graduação de um ano em Saúde da Família, oferecido pela UNA- SUS. As atividades profissionais são supervisionadas por uma instituição acadêmica. O programa está em sua segunda edição e atualmente conta com o suporte de cinquenta e quatro instituições acadêmicas (Brasil, 2013). Os supervisores das instituições possuem como atribuições instruir, planejar as atividades , monitorar e avaliar o profissional sob sua responsabilidade em base individual, em seus locais de trabalho. Esta iniciativa promove a qualificação dos médicos de acordo com a necessidade da população, e oferece serviços de saúde em áreas mais carentes. De acordo com dados do Ministério da Saúde, em 2013, o programa pretende alocar em torno de 4.000 médicos para 1.407 cidades brasileiras (Brasil, 2013). No que se refere à qualificação do profissional de saúde em nível de pós-graduação, o projeto denominado Pró-Ensino na Saúde foi lançado em 2010, através de uma parceria entre a Coordenação de Aperfeiçoamento de Pessoal de Nível Superior (CAPES) do Ministério da Educação e Secretaria de Gestão do Trabalho e da Educação na Saúde (SGTES), do Ministério da Saúde. O objetivo deste projeto é implementar uma rede de cooperação acadêmica na área de ensino na saúde, como o intuito de fortalecer e consolidar esta área no Brasil. Os principais objetivos da implementação do Pró-Ensino na Saúde incluem estimular a pesquisa científica e tecnológica na área e a formação de mestres, doutores e pós- doutores na área ensino na saúde, a qual tem sido considerada como estratégica para a consolidação do Sistema Único de Saúde. Outro aspecto relevante é o fortalecimento dos programas de pós-graduação stricto sensu em que o projeto foi inserido, além de oportunizar a inclusão do Ensino na Saúde a outros programas de pós-graduação com áreas de concentração ou linhas de pesquisa relacionadas com a temática. A intenção é 
ampliar a criação de áreas ou a inserção de linhas de pesquisa relacionadas ao Ensino na Saúde em programas de pós-graduação já existentes para que ocorra a interação entre grupos de pesquisa que possam desenvolver tecnologia, inovação e publicação de trabalhos científicos nesta área. Além disso, visa apoiar a formação de recursos humanos, capacitando-os para disseminar o conhecimento adquirido para os alunos de graduação e pós-graduação, promover a troca de conhecimentos, motivar o estabelecimento de parcerias entre instituições acadêmicas, serviços de saúde pública, centros de pesquisa, por meio de redes de pesquisa e articulações com o objetivo de desenvolver a pesquisa em saúde, tecnologias e inovações para a área de ensino na saúde, para reduzir as diferenças entre as regiões no que se refere a programas de pós-graduação em saúde, especialmente no Nordeste, no Norte (incluindo a bacia do Amazonas) e Centro-Oeste. A Universidade de Brasília (UnB) está entre as instituições acadêmicas que estão desenvolvendo projeto do Pró- Ensino na Saúde, o qual encontra-se em andamento desde 2011, quando um total de vinte alunos foram selecionados dentre os setenta candidatos que manifestaram interesse em ingressar no curso (quarenta para mestrado e trinta para doutorado). Essa demanda demonstra o crescente interesse nesta área do Ensino na saúde. Dias et al (2013) destacou o crescimento gradativo da institucionalidade e da aproximação entre os Ministérios da Educação e Saúde na participação e na elaboração de políticas de reorientação da formação, com continuidade e permanência dos eixos norteadores inicialmente preconizados.

As políticas indutoras aqui apresentadas possuem como base a concepção de educação interprofissional (EI), pautada na colaboração e na cooperação. A complexidade desta temática envolve, dentre outros desafios, a necessidade de mudanças culturais. Existem discussões em torno dessas questões há décadas em alguns países. Como exemplo, estudo canadense afirma a necessidade de se formar "o profissional de saúde correto, para atuar no local correto, oferecendo o serviço correto" para que o sistema de saúde local possa 
se sustentar (Herbert, 2005). O autor ainda ressalta que apesar da integração entre diferentes áreas da saúde ocorrer no processo de formação na graduação, e do fato de diferentes profissionais de saúde dividirem o mesmo espaço de trabalho, ainda não observa-se avanços no sentido de modificar a cultura do cuidado em saúde baseada no isolamento profissional, para um sistema de cooperação que venha contribuir para uma visão comum em saúde. É necessário dentro da proposta atual da educação e prática interprofissional focar na necessidade de mudança cultural.

Cada profissional da saúde carrega diferentes valores, crenças, atitudes e comportamentos, os quais se desenvolveram de formas distintas nas diferentes áreas à medida que as profissões evoluíram, sob influências de fatores históricos e sociais. A crescente demanda pela especialização foi colocando à deriva interesses comuns a todos, e para que esse resgate ocorra, qualquer iniciativa dentro da EI deve considerar a necessidade de enfrentamento dessas barreiras (Hall, 2005).

As tendências na EI em saúde foram relatadas em recente revisão sistemática (AbuRish et al., 2012), destacando-se alguns tópicos para abordagem, incluindo bases conceituais e desenvolvimento de competências como comunicação, cuidado centrado no paciente e respeito mútuo. Há a necessidade do fortalecimento de pesquisas que demonstrem a efetividade do trabalho em equipe na educação interprofissional. Outro ponto ressaltado é a relevância de se desenvolver modelos robustos para implementação da EI nos currículos e práticas clínicas dos profissionais de saúde. Alguns estudos acerca da implementação da EI em cursos de graduação têm sido relatados. Hind et al. (2003) relataram atitudes positivas de estudantes de graduação em saúde no Reino Unido em relação à inclusão de aprendizagem sobre EI em estágios iniciais da formação. Um estudo australiano demonstrou o valor de uma experiência de aprendizagem na comunidade envolvendo estudantes de diferentes cursos de graduação (McNair et al., 2005). Curran et al. (2007) 
estudaram no Canadá a associação entre perfis de estudantes e atitudes em relação a EI. No Brasil, estudo recente (Aguilar-da-Silva et al., 2011) aponta que estudantes de graduação de cursos da saúde demonstraram abertura para a aprendizagem compartilhada. A implementação de mudanças desse porte devem prever enfrentamentos, que assim como relatado por Alves et al (2013), envolvem uma diversidade e complexidade de obstáculos. Os autores destacaram desafios que vão desde resistência de docentes, relações interpressoais e aspectos inerentes à estrutura dos cenários de práticas. Além dos fatores dificultadores relacionados à esfera educacional existem outras categorias de obstáculos, como administrativos, financeiros e políticos, que associados potencializam-se.

Fica evidente a importância de políticas que induzam mudanças, pois se durante a formação não houver formação que tome como referência a interdisciplinaridade e a interprofissionalidade, o desafio de formar profissionais que saibam trabalhar de forma multi e interprofissional permanecerá ainda como um enfrentamento a ser suplantando para o avanço dos sistemas de saúde, incluindo o SUS.

A Figura 1A apresenta uma representação da linha do tempo das políticas indutoras de transformação do ensino em saúde no Brasil.
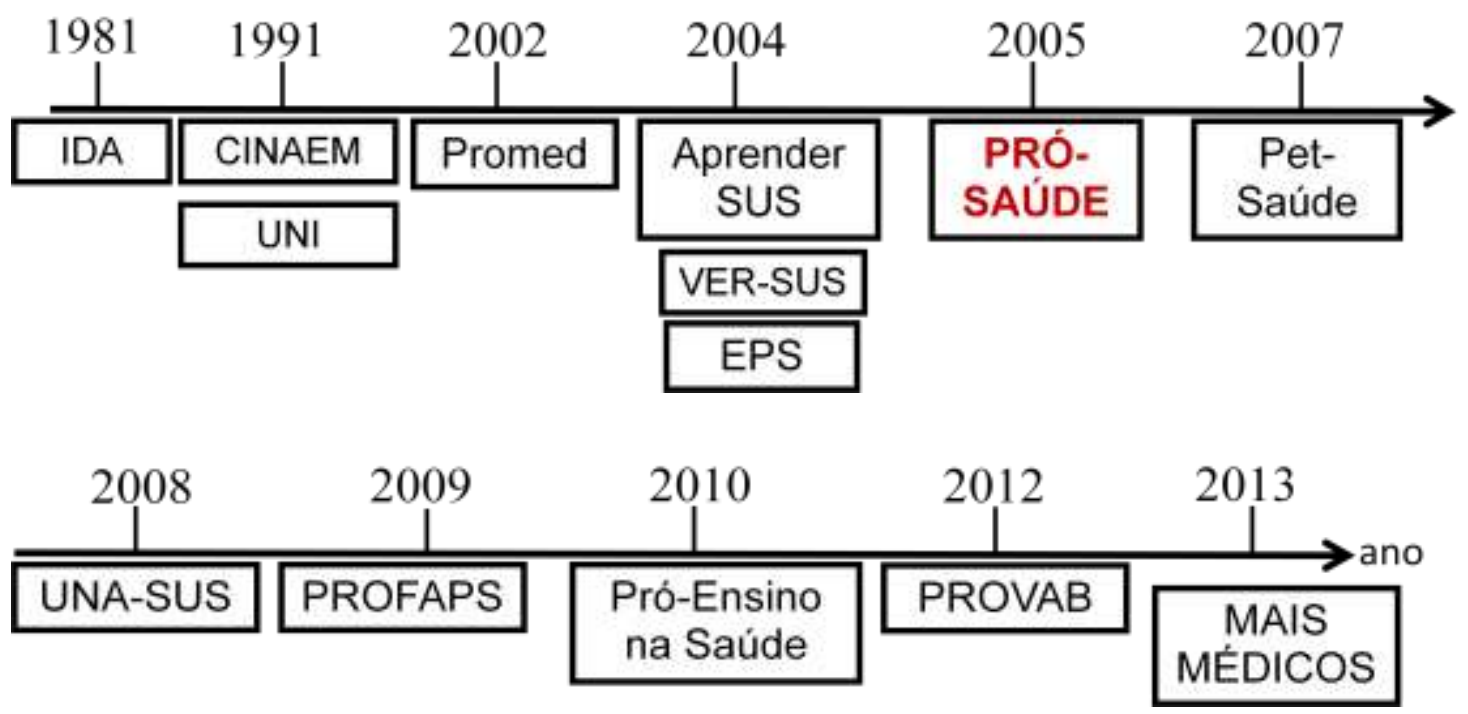
Figura 1A. Linha do tempo das políticas indutoras de transformação na formação em saúde.

\subsection{PROGRAMA NACIONAL DE REORIENTAÇÃO PROFISSIONAL EM SAÚDE - PRÓ-SAÚDE}

Dentre as propostas de indução de mudanças na formação do profissional de saúde apresentadas na seção anterior, o Programa Nacional de Reorientação da Formação Profissional (Pró-Saúde), lançado em 2005, será a seguir descrito mais detalhadamente, uma vez que o elegemos como objeto do presente estudo.

Ao propor transformações na formação profissional em saúde, tomando por base as propostas das DCN para os cursos da área de saúde, o Programa Pró-Saúde almeja alcançar um deslocamento do eixo da formação, centrado na assistência individual prestada em unidades especializadas, para uma formação sintonizada, além da dimensão técnica, com as necessidades sociais, culturais e econômicas da população (Brasil, 2005a). Espera-se que a formação em saúde resulte em um profissional com habilidades e competências que atendam às necessidades da sociedade brasileira.

Em sentido amplo, a proposta do Programa Pró-Saúde tem como imagem-objetivo mudanças na formação do profissional e para tal se ancora nas DCN para os cursos de saúde.

Ao comparar-se o Pró-Saúde com o Promed, é sabido que em ambos os Programas, a proposta foi semelhante, de reorientar a formação dos profissionais de saúde, para uma adequada atuação na atenção básica. Um dos principais diferenciais do Pró-Saúde em relação ao Promed, além da composição multiprofissional do primeiro, foi a consolidação da parceria entre as Instituições de Ensino Superior e os Serviços de Saúde, especialmente os vinculados ao SUS. Ferreira et al. (2007) destacam que o Pró-Saúde trouxe uma importante inovação no que se refere à distribuição dos recursos na tentativa de facilitar a parceria intersetorial. 
O Pró-Saúde vem ao encontro de uma das funções prioritárias do Ministério da Saúde, que é a reordenação da formação de recursos humanos para a saúde. É inegável a deficiência presente no que se refere à disponibilidade de profissionais com formação generalista, com visão humanística e preparada para prestar cuidados contínuos e resolutivos à comunidade. Atualmente, muitos dos profissionais em atuação na ESF foram formados pelo modelo flexneriano, cujo foco é hospitalocentrico e não na perspectiva do SUS, o qual propõe a atenção primária como porta de entrada do sistema, com perspectiva de resolutividade para a maioria das necessidades de saúde das pessoas (Haddad e Morita, 2006).

O Programa Pró-Saúde foi instituído pela Portaria Interministerial 2.101 de 3 de novembro de 2005 e elaborado pelo Ministério da Saúde, com o suporte das Secretarias de Gestão do Trabalho, da Educação na Saúde (SGTES) e de Educação Superior (SESu), além da participação do Instituto Nacional de Estudos e Pesquisas Educacionais Anísio Teixeira (INEP) do Ministério da Educação (Brasil, 2005). O Programa é amparado pelo o Artigo 200 da Constituição Federal de 1988, Lei Orgânica da Saúde de 1990 e ações normativas como a NOB-RH-SUS de 2003 (Brasil, 2003) e a Portaria 399/GM de 2006 (Brasil, 2006). A NOB-RH-SUS de 2003 trata da política de desenvolvimento do trabalhador para o SUS, com o seguinte texto:

Estabelecer mecanismos de negociação intersetorial - saúdeleducação - com os respectivos gestores da educação ou dirigentes de escolas, para um progressivo entendimento, com vistas a uma ação integrada e cooperativa que busque ajustar, qualitativa e quantitativamente, a instituição formadora às demandas e necessidades do SUS em âmbito dos sistemas municipais, estaduais e federal de saúde, com o estabelecimento e definição de responsabilidades conjuntas. 
A Portaria 399/GM de 2006 estabelece três dimensões para o SUS: Pacto pela Vida, Pacto em Defesa do SUS e Pacto de Gestão. Além dessas diretrizes, coloca a Educação na Saúde como responsabilidade da União no texto que segue: "Articular e cooperar com a construção e implementação de iniciativas políticas e práticas para a mudança na graduação das profissões de saúde, de acordo com as diretrizes do SUS” (Brasil, 2006).

Como o Pró-Saúde visa subsidiar modificações do ensino em saúde atualmente desenvolvido nas universidades brasileiras, o programa é baseado na integração dos cursos com a prestação de serviços em saúde. Pretende-se com isso, contribuir com a formação e capacitação de recursos humanos para a geração de conhecimento e voltados também para o atendimento ao público pela Rede SUS, e tendo como ênfase a atenção básica desde a sua formação (Brasil, 2007).

Tendo em vista a proposta do SUS, de implantação de um sistema de saúde universal e equânime para os brasileiros, os processos formativos devem considerar o equilíbrio entre excelência técnica e relevância social por ocasião do repasse do conhecimento aos futuros profissionais da área de saúde, de modo a torná-los aptos a atuarem em um sistema de saúde de forma qualificada e integrada.

O Programa Pró-Saúde contempla três eixos de atuação: orientação teórica, cenários de prática e orientação pedagógica. A orientação teórica visa priorizar os determinantes de saúde e os biológicos e sociais das doenças, a pesquisa clínico-epidemiológica baseada em evidências para uma avaliação crítica do processo de Atenção Básica, orientação sobre melhores práticas gerenciais que facilitem o relacionamento e atenção especial à educação permanente, não restrita à pós-graduação especializada. Os cenários de prática é o eixo que busca incentivar a utilização de processos de aprendizado ativo (nos moldes da educação de adultos), o aprender fazendo e com sentido crítico na análise da prática clínica, sendo que o 
eixo do aprendizado deve ser a própria atividade dos serviços, a ênfase no aprendizado baseado na solução de problemas e a avaliação formativa e somativa. A orientação pedagógica trabalha com a diversificação, incluindo vários ambientes e níveis de atenção, dando maior ênfase ao nível básico com possibilidade de referência e contra-referência, dando importância à excelência técnica e relevância social e à ampla cobertura da patologia prevalente, assim como a interação com a comunidade e estudantes, assumindo responsabilidade crescente mediante a evolução do aprendizado e importância do trabalho conjunto das equipes multiprofissionais (Brasil, 2007).

Cada um dos eixos descritos possui três vetores, totalizando nove vetores, e cada vetor apresenta três estágios que representam o momento que cada curso vivencia dentro de cada vetor, sendo denominados estágio 1, 2 ou 3, conforme exposto na Figura 2:

\begin{tabular}{|c|c|c|}
\hline \multicolumn{3}{|c|}{ PROPOSTA PARA REORIENTAÇÃO DA FORMAÇÃO PROFISSIONAL - PRÓ-SAÚDE } \\
\hline EIXO & VETORES & ESTÁGIOS \\
\hline \multirow[t]{2}{*}{ A. orientação } & $\begin{array}{l}\text { 1. Determinantes de saúde e } \\
\text { doença }\end{array}$ & $\begin{array}{l}\text { Estágio } 1 \text { - A escola prioriza a consideração de determinantes } \\
\text { biológicos da doença, enfatizando uma abordagem de caráter } \\
\text { curativo orientado ao indivíduo. } \\
\text { Estágio } 2 \text { - A escola considera os determinantes biológicos e } \\
\text { sociais da doença, sem destacar adequadamente os aspectos } \\
\text { relativos à normalidade em nível individual e coletivo. } \\
\text { Estágio } 3 \text { - A escola dedica importância equivalente aos } \\
\text { determinantes da saúde e da doença, procurando, tanto na } \\
\text { abordagem do conhecimento teórico, como em sua aplicação } \\
\text { assistencial manter uma adequada articulação biológico- } \\
\text { social. }\end{array}$ \\
\hline & $\begin{array}{l}\text { 2. Produção de conhecimentos } \\
\text { segundo as necessidades da }\end{array}$ & $\begin{array}{l}\text { Estágio 1- escolas que não tenham produção sistemática de } \\
\text { investigação em atenção básica ou que apenas tenham } \\
\text { produção na área da atenção hospitalar e de alta tecnologia. }\end{array}$ \\
\hline
\end{tabular}




\begin{tabular}{|c|c|c|}
\hline & $\begin{array}{l}\text { população brasileira e a } \\
\text { operacionalização do SUS }\end{array}$ & $\begin{array}{l}\text { Estágio } 2 \text { - escolas que tenham uma baixa produção de } \\
\text { investigações relacionadas com a atenção básica ou com a } \\
\text { gestão do SUS. }\end{array}$ \\
\hline & & $\begin{array}{l}\text { Estágio } 3 \text { - escolas com alta produção de investigações } \\
\text { orientadas às necessidades da atenção básica, sem prejuízo da } \\
\text { investigação pura e tecnológica, e que tenham uma forte } \\
\text { interação com os serviços públicos de saúde na área de } \\
\text { produção e avaliação de protocolos clínicos, inovações da } \\
\text { gestão, análises de custo-benefício e outras assemelhadas. }\end{array}$ \\
\hline & 3. Pós-graduação e educação & Estágio 1 - oferta exclusiva de especialidades. \\
\hline & permanente & $\begin{array}{l}\text { Estágio } 2 \text { - conformação intermediária, em que há esforços } \\
\text { para a oferta de educação permanente relacionada à nosologia } \\
\text { prevalente, mas não há questionamentos do perfil de oferta de } \\
\text { residências, mestrados e doutorados que não atendem às } \\
\text { necessidades da população. }\end{array}$ \\
\hline & & $\begin{array}{l}\text { Estágio } 3 \text { - oportunidades educacionais em articulação com } \\
\text { gestores do SUS. }\end{array}$ \\
\hline & 4. Integração docente assistencial & $\begin{array}{l}\text { Estágio } 1 \text { - curso mantém rígida separação entre programação } \\
\text { teórica e prática assistencial. }\end{array}$ \\
\hline & & $\begin{array}{l}\text { Estágio } 2 \text { - alguma articulação da teórica com a prática } \\
\text { assistencial, porém predomina atenção de caráter individual e } \\
\text { curativo. }\end{array}$ \\
\hline $\begin{array}{l}\text { B. cenários } \\
\text { de prática }\end{array}$ & & $\begin{array}{l}\text { Estágio } 3 \text { - os cursos integram durante o processo de ensino- } \\
\text { aprendizagem orientação teórica com prática assistencial } \\
\text { individual e coletiva. }\end{array}$ \\
\hline & 5. Diversificação de cenários do & $\begin{array}{l}\text { Estágio 1- primeiros } 2 \text { anos: apenas laboratórios da área } \\
\text { básica; ciclo clínico em instalações da instituição. }\end{array}$ \\
\hline
\end{tabular}




\begin{tabular}{|c|c|c|}
\hline & processo de ensino & $\begin{array}{l}\text { Estágio } 2 \text { - atividades extramurais isoladas de acadêmicos em } \\
\text { unidades do SUS, durante os primeiros anos do curso, com a } \\
\text { participação exclusiva ou predominante de professores da área } \\
\text { de Saúde Coletiva, correspondendo a um pequeno percentual } \\
\text { da carga horária semanal do aluno. Ciclo clínico mais baseado } \\
\text { em atividades assistenciais em instalações da universidade não } \\
\text { funcionalmente vinculadas ao SUS. }\end{array}$ \\
\hline & & $\begin{array}{l}\text { Estágio } 3 \text { - atividade extra-muro e atividades clínicas em } \\
\text { unidades do SUS, escolas; ao longo do curso com graus } \\
\text { crescentes de complexidade; estágios com totalidade na rede } \\
\text { SUS. }\end{array}$ \\
\hline & $\begin{array}{l}\text { 6. Articulação dos serviços } \\
\text { assistenciais com o SUS }\end{array}$ & $\begin{array}{l}\text { Estágio 1- serviços próprios, isolados da rede SUS, com } \\
\text { clientela cativa. }\end{array}$ \\
\hline & & $\begin{array}{l}\text { Estágio } 2 \text { - serviços parcialmente abertos ao SUS, porém com } \\
\text { autonomia na definição de seus pacientes. }\end{array}$ \\
\hline & & $\begin{array}{l}\text { Estágio } 3 \text { - serviços integrados ao SUS (desenvolvimento dos } \\
\text { mecanismos de ref. e contra ref. com a rede do }\end{array}$ \\
\hline & & SUS). \\
\hline \multirow{5}{*}{$\begin{array}{l}\text { C. orientação } \\
\text { pedagógica }\end{array}$} & \multirow[t]{3}{*}{ 7. Análise crítica da atenção básica } & $\begin{array}{l}\text { Estágio } 1 \text { - abordagem acrítica das necessidades do serviço de } \\
\text { saúde. }\end{array}$ \\
\hline & & $\begin{array}{l}\text { Estágio } 2 \text { - em algumas disciplinas clínicas há uma análise } \\
\text { clínica da organização dos serviços. }\end{array}$ \\
\hline & & $\begin{array}{l}\text { Estágio } 3 \text { - ensino-aprendizagem na parte clínica tem como } \\
\text { eixo a análise crítica da totalidade da experiência assistencial } \\
\text { com ênfase no componente da atenção básica. }\end{array}$ \\
\hline & \multirow[t]{2}{*}{$\begin{array}{l}\text { 8. Integração ciclo básico } \\
\text { profissional }\end{array}$} & $\begin{array}{l}\text { Estágio } 1 \text { - clínico/básico, completamente separados; } \\
\text { disciplinas fragmentadas. }\end{array}$ \\
\hline & & $\begin{array}{l}\text { Estágio } 2 \text { - há disciplinas ou atividades integradoras ao longo } \\
\text { dos primeiros anos do curso. }\end{array}$ \\
\hline
\end{tabular}




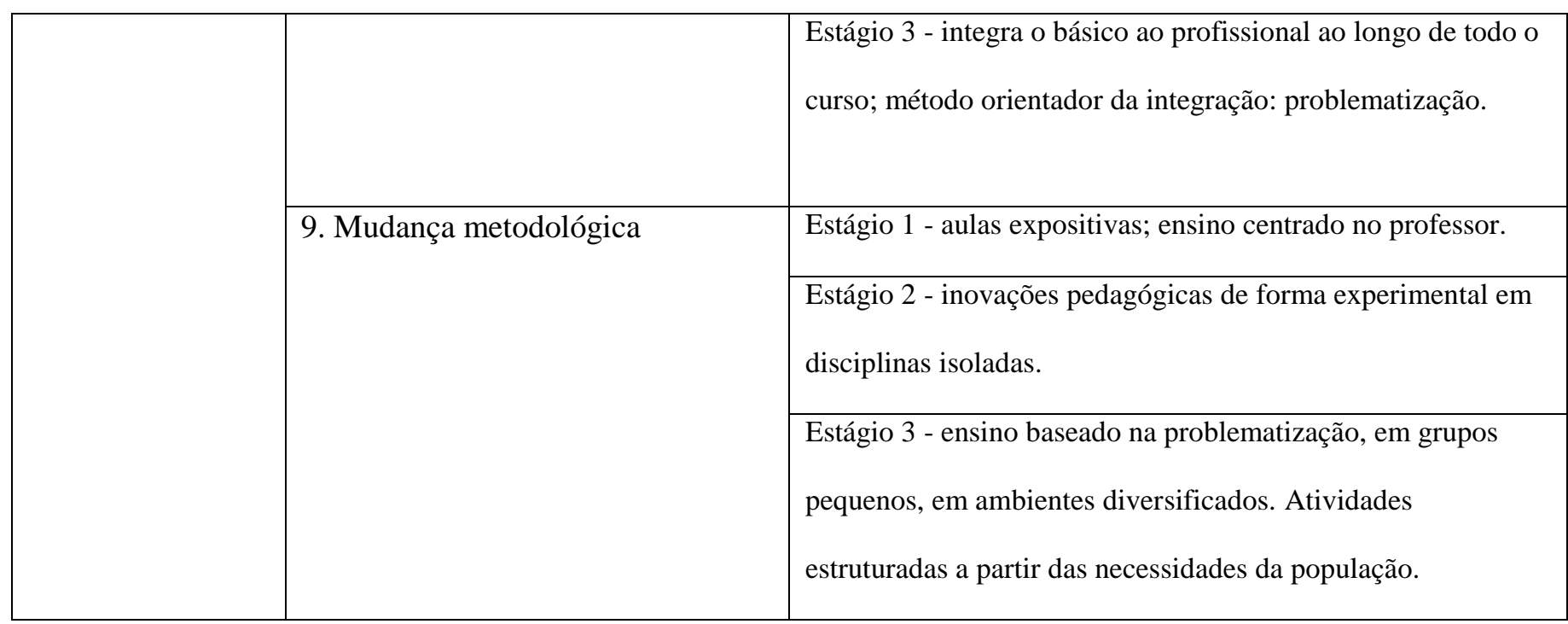

Figura 2. Eixos, vetores e estágios propostos pelo Programa Nacional de Reorientação da Formação Profissional (Pró-Saúde).

A participação das Instituições de Ensino Superior no Pró-Saúde se deu até o momento através de três editais de fomento lançados desde 2005. A equipe da ESF era inicialmente composta por profissionais de Medicina, Enfermagem e Odontologia. Sob esta perspectiva, no primeiro Edital do Pró-Saúde apenas estes três cursos foram elegíveis para submissão de projetos. Dos 185 projetos submetidos, 90 deles foram aprovados por serem considerados com potencial para promover a transformação do modelo de formação (Veloso, 2008). Esses projetos incluíram a participação de um total de 57 universidades contempladas, com projetos aprovados na Enfermagem, Medicina e Odontologia (Brasil, 2005a). Essas informações encontram-se descritas nas Figuras 3 e 4.

\begin{tabular}{|c|c|c|c|}
\hline INSTITUIÇÃO & Enfermagem & Medicina & Odontologia \\
\hline Univ. Federal de Alagoas & $\mathrm{X}$ & $\mathrm{X}$ & \\
\hline Univ. Federal da Bahia & & $\mathrm{X}$ & \\
\hline Univ. Federal do Ceará & $\mathrm{X}$ & $\mathrm{X}$ & \\
\hline Univ. Federal do Espírito Santo & $\mathrm{X}$ & & $\mathrm{X}$ \\
\hline Univ. Federal de Goiás & $\mathrm{X}$ & $\mathrm{X}$ & $\mathrm{X}$ \\
\hline Univ. Federal de Juiz de Fora & $\mathrm{X}$ & $\mathrm{X}$ & $\mathrm{X}$ \\
\hline Univ. Federal do Maranhão & & $\mathrm{X}$ & \\
\hline Univ. Federal de Mato Grosso do Sul & $\mathrm{X}$ & & \\
\hline Univ. Federal. de Minas Gerais & $X$ & $\mathrm{X}$ & $\mathrm{X}$ \\
\hline Univ. Federal do Pará & $\mathrm{X}$ & & \\
\hline $\begin{array}{l}\text { Univ. Federal da Paraíba (João } \\
\text { Pessoa) }\end{array}$ & $X$ & $\mathrm{X}$ & $X$ \\
\hline Univ. Federal de Pernambuco & & $\mathrm{X}$ & \\
\hline Univ. Federal do Piauí & & & $\mathrm{X}$ \\
\hline
\end{tabular}




\begin{tabular}{|c|c|c|c|}
\hline Univ. Federal do Rio de Janeiro & & & $\mathrm{X}$ \\
\hline Fund. Univ. Federal do Rio Grande & & $\mathrm{X}$ & \\
\hline Univ. Federal do Rio Grande do Norte & $\mathrm{X}$ & $\mathrm{X}$ & \\
\hline Univ. Federal do Rio Grande do Sul & & $\mathrm{X}$ & $\mathrm{X}$ \\
\hline Univ. Federal de Santa Catarina & $\mathrm{X}$ & $\mathrm{X}$ & $\mathrm{X}$ \\
\hline Univ. Federal de São Paulo & $\mathrm{X}$ & $\mathrm{X}$ & \\
\hline Univ. Federal. do Triângulo Mineiro & & $\mathrm{X}$ & \\
\hline Univ. Federal de Uberlândia & & $\mathrm{X}$ & $\mathrm{X}$ \\
\hline $\begin{array}{l}\text { Univ. Federal Vales } \\
\text { Jeauitinhonha/Mucuri }\end{array}$ & $\mathrm{X}$ & & \\
\hline Univ. Estadual de Campinas & $\mathrm{X}$ & $\mathrm{X}$ & $\mathrm{X}$ \\
\hline Univ. Estadual de Londrina & & $\mathrm{X}$ & $\mathrm{X}$ \\
\hline Univ. Estadual de Maringá & & $\mathrm{X}$ & $\mathrm{X}$ \\
\hline Univ. Estadual de Montes Claros & & $\mathrm{X}$ & $\mathrm{X}$ \\
\hline Univ. Estadual Paulista (Botucatu) & & $\mathrm{X}$ & \\
\hline Univ. Estadual do Pará & & $\mathrm{X}$ & \\
\hline Univ. Estadual do Rio de Janeiro & $\mathrm{X}$ & $\mathrm{X}$ & $\mathrm{X}$ \\
\hline Univ. de Pernambuco & $\mathrm{X}$ & $\mathrm{X}$ & \\
\hline Univ. de São Paulo (São Paulo, capital) & $\mathrm{X}$ & $\mathrm{X}$ & $\mathrm{X}$ \\
\hline Univ. de São Paulo (Ribeirão Preto) & $\mathrm{X}$ & & $\mathrm{X}$ \\
\hline $\begin{array}{l}\text { Univ. Estadual do Vale do Acaraú } \\
\text { (Sobral) }\end{array}$ & $\mathrm{X}$ & & \\
\hline $\begin{array}{l}\text { Univ. Estadual do Rio Grande do } \\
\text { Norte }\end{array}$ & $\mathrm{X}$ & & \\
\hline Pont. Univ. Católica de Campinas & & $\mathrm{X}$ & \\
\hline Pont. Univ. Católica de Minas Gerais & $X$ & & $\mathrm{X}$ \\
\hline Pont. Univ. Católica do Paraná & & & $\mathrm{X}$ \\
\hline $\begin{array}{l}\text { Pont. Univ. Católica S. Paulo } \\
\text { (Sorocaba) }\end{array}$ & & $\mathrm{X}$ & \\
\hline $\begin{array}{l}\text { Pont. Univ. Católica Rio Grande do } \\
\text { Sul }\end{array}$ & $\mathrm{X}$ & & \\
\hline Fac. Evangélica do Paraná & & $\mathrm{X}$ & \\
\hline Univ. de Caxias do Sul & & $\mathrm{X}$ & \\
\hline Univ. de Passo Fundo & & $\mathrm{X}$ & \\
\hline Univ. Comunitária Reg. de Chapecó & $\mathrm{X}$ & & \\
\hline Univ. José do Rosário Vellano & & $\mathrm{X}$ & \\
\hline $\begin{array}{l}\text { Univ. Grande Rio "Pr. José Souza } \\
\text { Herdy" }\end{array}$ & & & $\mathrm{X}$ \\
\hline Univ. Severino Sombra & $\mathrm{X}$ & & $\mathrm{X}$ \\
\hline Univ. Santa Cruz do Sul & & & $\mathrm{X}$ \\
\hline Univ. do Vale do Itajaí & & $\mathrm{X}$ & $\mathrm{X}$ \\
\hline Centro Univ. de Barra Mansa & $\mathrm{X}$ & & \\
\hline Fac. C. Méd. Santa Casa de São Paulo & & $\mathrm{X}$ & \\
\hline Fac. Med. do ABC & & $\mathrm{X}$ & \\
\hline Fac. Medicina de Marília & $\mathrm{X}$ & $\mathrm{X}$ & \\
\hline Fac. Medicina de Petrópolis & & $\mathrm{X}$ & \\
\hline Fac. Unificadas de Serra dos Órgãos & $\mathrm{X}$ & $\mathrm{X}$ & $\mathrm{X}$ \\
\hline Fac. Med. de S. José do Rio Preto & & $\mathrm{X}$ & \\
\hline Fac. de Odontologia de Caruaru & & & $\mathrm{X}$ \\
\hline
\end{tabular}

Figura 3. Instituições integrantes do Pró-Saúde I 


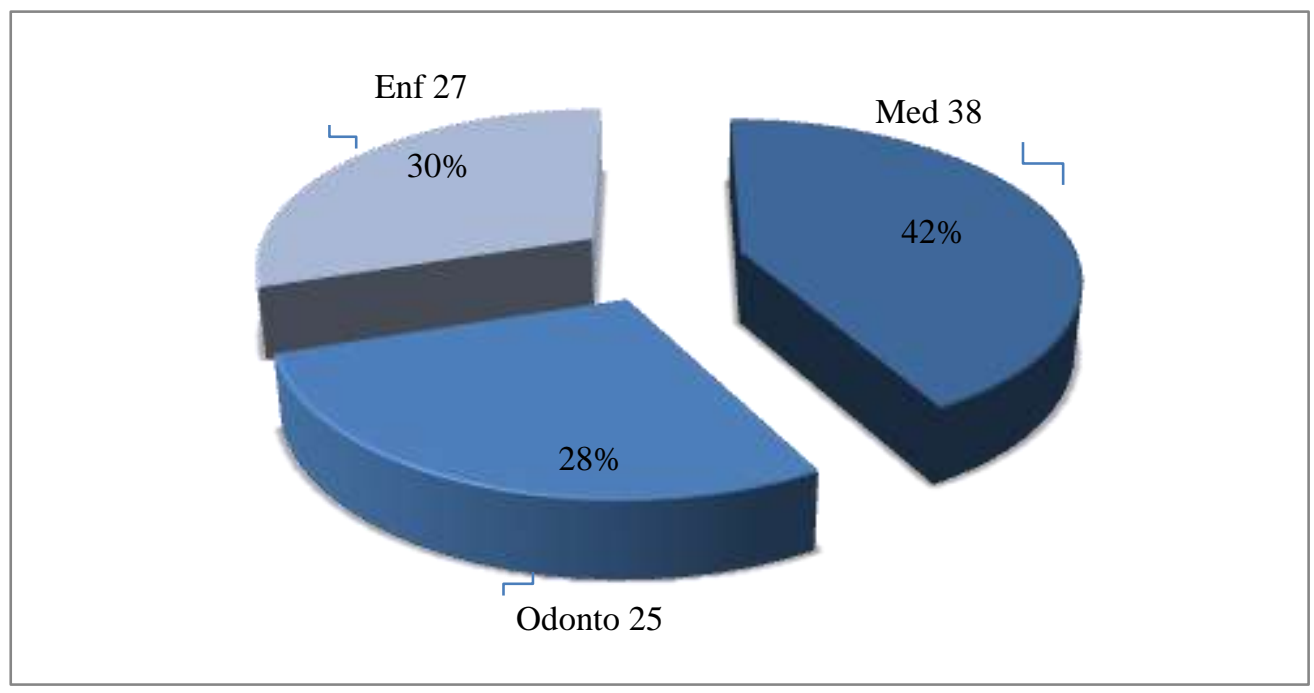

Fonte: Brasil, 2005a

Figura 4. Valores absolutos e percentuais dos cursos de Enfermagem, Medicina e Odontologia.

Tanto Instituições de Ensino Superior públicas quanto privadas participaram e obtiveram aprovação de projetos, conforme demonstrado na Figura 5.

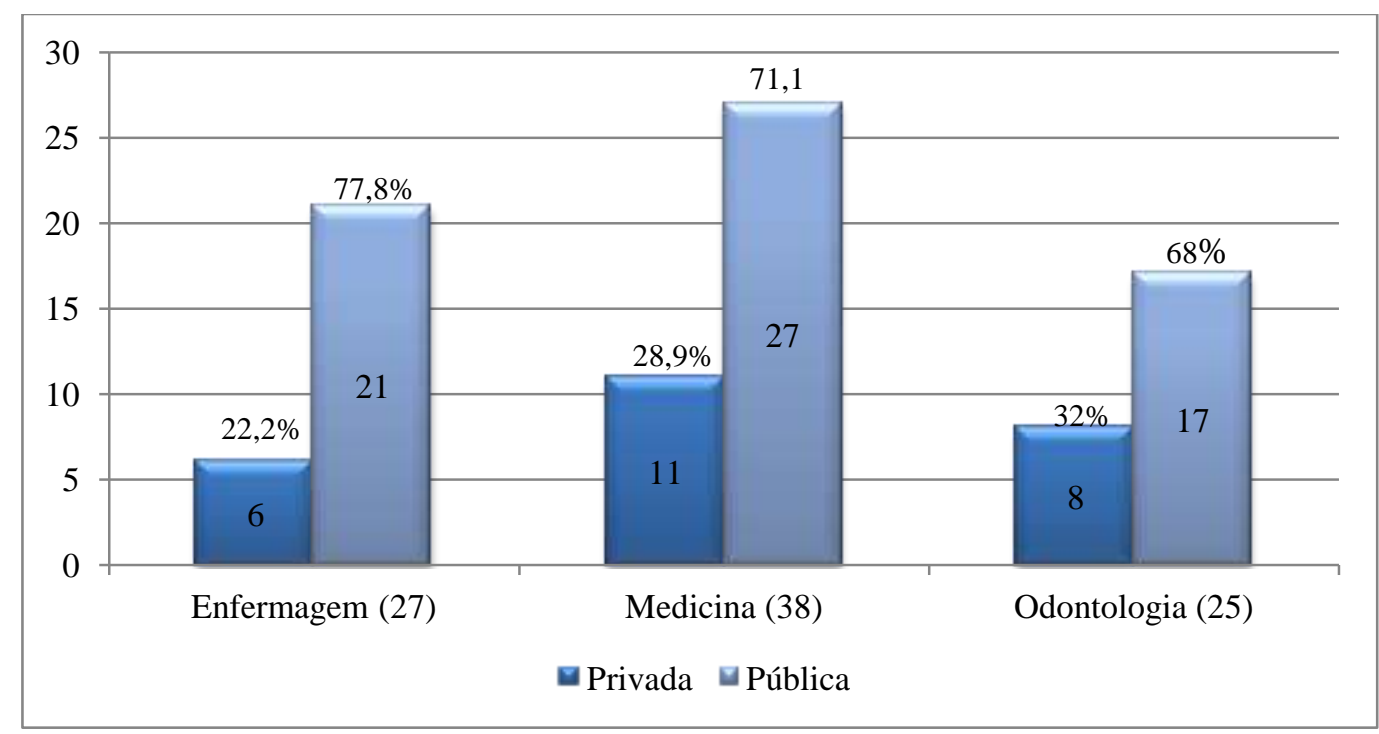

Fonte: Deges/SGTS/MS, 2005a

Figura 5. Valores absolutos e percentuais por Unidade Administrava dos cursos de Enfermagem, Medicina e Odontologia.

A segunda edição deste Programa abrangeu as catorze áreas de saúde e resultou na aprovação de 68 projetos em 2007 (Brasil, 2007). Cada projeto pôde envolver mais de um 
curso da mesma instituição acadêmica, ao contrário do edital anterior, em que a submissão ocorreu por curso. O Programa Pró-Saúde está atualmente em sua terceira edição, com 119 projetos, resultantes de um edital conjunto Pró-Saúde e Pet-Saúde, ocorrido em final de 2011, com início de vigência em 2012.

Os editais do Pró-Saúde até 2011 contemplaram 379 cursos de graduação. Atualmente, a partir do edital em que houve a integração dos Programas Pró-Saúde/Pet Saúde, um total de 709 cursos de graduação da área de saúde passaram a desenvolver atividades nos Programas (Figura 6).

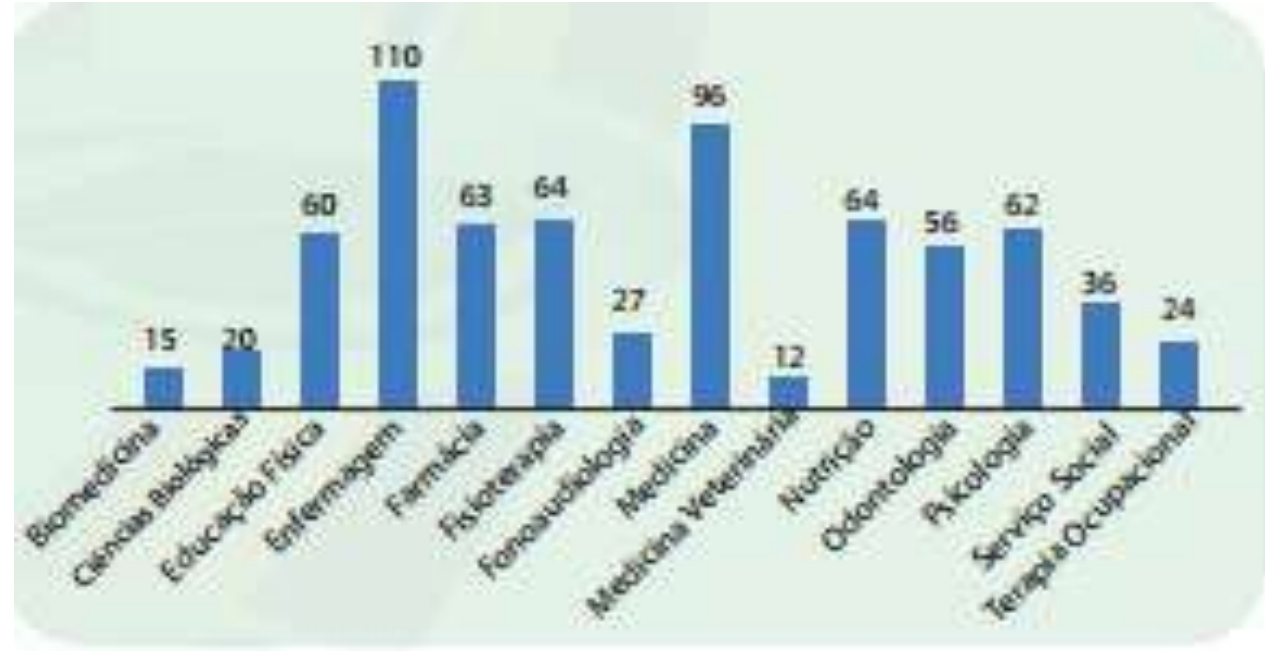

Fonte: MS, 2014

Figura 6. Cursos de graduação participantes do Pró-Saúde/ PET-Saúde 2013.

As Figuras 7, 8, e 9 apresentam respectivamente, para os cursos de Enfermagem, Medicina e Odontologia, a partir dos resultados obtidos no primeiro edital do Pró-Saúde, a continuidade de participação dessas IES nos editais posteriores.

\begin{tabular}{|l|c|c|c|}
\hline \multicolumn{1}{|c|}{ Instituição } & Pró-Saúde I & Pró-Saúde II & Pró-Saúde III \\
\hline \multicolumn{3}{|c|}{ CENTRO-OESTE } \\
\hline Univ. Fed. de Mato Grosso do Sul & $\mathrm{X}$ & & \\
\hline Univ. Fed. de Goiás & $\mathrm{X}$ & $\mathrm{X}$ & $\mathrm{X}$ \\
\hline \multicolumn{4}{|c|}{ NORTE } \\
\hline Univ. Fed. do Pará & $\mathrm{X}$ & & $\mathrm{X}$ \\
\hline
\end{tabular}




\begin{tabular}{|c|c|c|c|}
\hline \multicolumn{4}{|c|}{ NORDESTE } \\
\hline Univ. Fed. de Alagoas & $\mathrm{X}$ & $\mathrm{X}$ & $\mathrm{X}$ \\
\hline Univ. Fed. do Ceará & $\mathrm{X}$ & $\mathrm{X}$ & $\mathrm{X}$ \\
\hline Univ. Fed. da Paraíba (João Pessoa) & $\mathrm{X}$ & $\mathrm{X}$ & $\mathrm{X}$ \\
\hline Univ. Fed. do Rio Grande do Norte & $\mathrm{X}$ & $\mathrm{X}$ & $\mathrm{X}$ \\
\hline Univ. de Pernambuco & $\mathrm{X}$ & & $\mathrm{X}$ \\
\hline Univ. Est. do Vale do Acaraú (Sobral) & $\mathrm{X}$ & & \\
\hline Univ. Est. do Rio Grande do Norte & $\mathrm{X}$ & & $\mathrm{X}$ \\
\hline \multicolumn{4}{|c|}{ SUDESTE } \\
\hline Univ. Fed. do Espírito Santo & $\mathrm{X}$ & & \\
\hline Univ. Fed. de Juiz de Fora & $\mathrm{X}$ & & $\mathrm{X}$ \\
\hline Univ. Fed. de Minas Gerais & $\mathrm{X}$ & $\mathrm{X}$ & \\
\hline Univ. Fed. de São Paulo & $\mathrm{X}$ & $\mathrm{X}$ & $\mathrm{X}$ \\
\hline Univ. Fed. Vales Jequitinhonha/Mucuri & $\mathrm{X}$ & $\mathrm{X}$ & $\mathrm{X}$ \\
\hline Univ. Est. de Campinas & $\mathrm{X}$ & $\mathrm{X}$ & $\mathrm{X}$ \\
\hline Univ. Est. do Rio de Janeiro & $\mathrm{X}$ & $\mathrm{X}$ & $\mathrm{X}$ \\
\hline Univ. de São Paulo (São Paulo, capital) & $\mathrm{X}$ & & $\mathrm{X}$ \\
\hline Univ. de São Paulo (Ribeirão Preto) & $\mathrm{X}$ & $\mathrm{X}$ & $\mathrm{X}$ \\
\hline Pont. Univ. Católica de Minas Gerais & $\mathrm{X}$ & $\mathrm{X}$ & $\mathrm{X}$ \\
\hline Univ. Severino Sombra (RJ) & $\mathrm{X}$ & & \\
\hline Centro Univ. de Barra Mansa (RJ) & $\mathrm{X}$ & & $\mathrm{X}$ \\
\hline Fac. Med. de Marília & $\mathrm{X}$ & & $\mathrm{X}$ \\
\hline Fac. Unificadas de Serra dos Órgãos (RJ) & $\mathrm{X}$ & & \\
\hline \multicolumn{4}{|c|}{ SUL } \\
\hline Univ. Fed. de Santa Catarina & $\mathrm{X}$ & $\mathrm{X}$ & $\mathrm{X}$ \\
\hline Pont. Univ. Católica Rio Grande do Sul & $\mathrm{X}$ & $\mathrm{X}$ & $\mathrm{X}$ \\
\hline Univ. Comunitária Reg. de Chapecó (SC) & $\mathrm{X}$ & $\mathrm{X}$ & $\mathrm{X}$ \\
\hline
\end{tabular}

Figura 7. Cursos de Enfermagem contemplados pelo Pró-Saúde I, e suas permanências nos Editais II e III por região do país.

\begin{tabular}{|l|c|c|c|}
\hline \multicolumn{1}{|c|}{ Instituição } & Pró-Saúde I & Pró-Saúde II & Pró-Saúde III \\
\hline \multicolumn{3}{|c|}{ CENTRO-OESTE } \\
\hline Univ. Fed. de Goiás & $\mathrm{X}$ & $\mathrm{X}$ & $\mathrm{X}$ \\
\hline \multicolumn{3}{|c|}{ NORDESTE } \\
\hline Univ. Fed. de Alagoas & $\mathrm{X}$ & $\mathrm{X}$ & $\mathrm{X}$ \\
\hline Univ. Fed. da Bahia & $\mathrm{X}$ & $\mathrm{X}$ & $\mathrm{X}$ \\
\hline Univ. Fed. do Ceará & $\mathrm{X}$ & $\mathrm{X}$ & $\mathrm{X}$ \\
\hline Univ. Fed. do Maranhão & $\mathrm{X}$ & & $\mathrm{X}$ \\
\hline Univ. Fed. do Rio Grande do Norte & $\mathrm{X}$ & $\mathrm{X}$ & $\mathrm{X}$ \\
\hline Univ. Fed. da Paraíba (João Pessoa) & $\mathrm{X}$ & $\mathrm{X}$ & $\mathrm{X}$ \\
\hline Univ. Fed. de Pernambuco & $\mathrm{X}$ & $\mathrm{X}$ & $\mathrm{X}$ \\
\hline Univ. de Pernambuco & $\mathrm{X}$ & & $\mathrm{X}$ \\
\hline Univ. Est. do Rio Grande do Norte & $\mathrm{X}$ & & $\mathrm{X}$ \\
\hline
\end{tabular}




\begin{tabular}{|c|c|c|c|}
\hline \multicolumn{4}{|c|}{ NORTE } \\
\hline Univ. Est. do Pará & $\mathrm{X}$ & & $\mathrm{X}$ \\
\hline \multicolumn{4}{|c|}{ SUDESTE } \\
\hline Univ. Fed. de Juiz de Fora & $\mathrm{X}$ & & $\mathrm{X}$ \\
\hline Univ. Fed. de Minas Gerais & $\mathrm{X}$ & $\mathrm{X}$ & \\
\hline Univ. Fed. de São Paulo & $\mathrm{X}$ & $\mathrm{X}$ & $\mathrm{X}$ \\
\hline Univ. Fed. do Triângulo Mineiro & $\mathrm{X}$ & $\mathrm{X}$ & $\mathrm{X}$ \\
\hline Univ. Fed. de Uberlândia & $\mathrm{X}$ & $\mathrm{X}$ & $\mathrm{X}$ \\
\hline Univ. Est. de Campinas & $\mathrm{X}$ & $\mathrm{X}$ & $\mathrm{X}$ \\
\hline Univ. Est. de Montes Claros & $\mathrm{X}$ & $\mathrm{X}$ & $\mathrm{X}$ \\
\hline Univ. Est. Paulista (Botucatu) & $\mathrm{X}$ & & $\mathrm{X}$ \\
\hline Univ. Est. do Rio de Janeiro & $\mathrm{X}$ & $\mathrm{X}$ & $\mathrm{X}$ \\
\hline Univ. de São Paulo (São Paulo, capital) & $\mathrm{X}$ & & $\mathrm{X}$ \\
\hline Univ. José do Rosário Vellano & $\mathrm{X}$ & & $\mathrm{X}$ \\
\hline Pont. Univ. Católica de Campinas & $\mathrm{X}$ & & \\
\hline Pont. Univ. Católica S. Paulo (Sorocaba) & $\mathrm{X}$ & $\mathrm{X}$ & $\mathrm{X}$ \\
\hline Fac. Unificadas de Serra dos Órgãos (RJ) & $\mathrm{X}$ & & \\
\hline Fac. C. Méd. Santa Casa de São Paulo & $\mathrm{X}$ & $\mathrm{X}$ & \\
\hline Fac. Med. de Marília & $\mathrm{X}$ & & $\mathrm{X}$ \\
\hline Fac. Med. de Petrópolis & $\mathrm{X}$ & & $\mathrm{X}$ \\
\hline Fac. Med. de S. José do Rio Preto & $\mathrm{X}$ & $\mathrm{X}$ & $\mathrm{X}$ \\
\hline Fac. Med. do ABC & $\mathrm{X}$ & $\mathrm{X}$ & $\mathrm{X}$ \\
\hline \multicolumn{4}{|c|}{ SUL } \\
\hline Univ. Fed. de Santa Catarina & $\mathrm{X}$ & $\mathrm{X}$ & $\mathrm{X}$ \\
\hline Univ. Fed. do Rio Grande do Sul & $\mathrm{X}$ & $\mathrm{X}$ & $\mathrm{X}$ \\
\hline Univ. Est. de Londrina & $\mathrm{X}$ & $\mathrm{X}$ & $\mathrm{X}$ \\
\hline Univ. Est. de Maringá & $\mathrm{X}$ & $\mathrm{X}$ & $\mathrm{X}$ \\
\hline Univ. de Caxias do Sul & $\mathrm{X}$ & & $\mathrm{X}$ \\
\hline Univ. de Passo Fundo & $\mathrm{X}$ & $\mathrm{X}$ & $\mathrm{X}$ \\
\hline Univ. do Vale do Itajaí & $\mathrm{X}$ & $\mathrm{X}$ & $\mathrm{X}$ \\
\hline Fac. Evangélica do Paraná & $\mathrm{X}$ & & \\
\hline Fund. Univ. Fed. do Rio Grande & $\mathrm{X}$ & & $\mathrm{X}$ \\
\hline
\end{tabular}

Figura 8. Cursos de Medicina contemplados pelo Pró-Saúde I, e suas permanências nos Editais II e III por região do país.

\begin{tabular}{|c|c|c|c|}
\hline Instituição & Pró-Saúde I & Pró-Saúde II & Pró-Saúde III \\
\hline \multicolumn{4}{|c|}{ CENTRO-OESTE } \\
\hline UFG & $\mathrm{X}$ & $\mathrm{X}$ & $\mathrm{X}$ \\
\hline \multicolumn{4}{|c|}{ NORDESTE } \\
\hline UF Paraíba & $\mathrm{X}$ & $\mathrm{X}$ & $\mathrm{X}$ \\
\hline UF Piauí & $\mathrm{X}$ & & $\mathrm{X}$ \\
\hline Faculdade de Caruaru & $\mathrm{X}$ & & \\
\hline \multicolumn{4}{|c|}{ SUDESTE } \\
\hline
\end{tabular}




\begin{tabular}{|l|c|c|c|}
\hline UF Espírito Santo & $\mathrm{X}$ & & $\mathrm{X}$ \\
\hline UF Juiz de Fora & $\mathrm{X}$ & & $\mathrm{X}$ \\
\hline UF MG & $\mathrm{X}$ & $\mathrm{X}$ & $\mathrm{X}$ \\
\hline UF Uberlândia & $\mathrm{X}$ & $\mathrm{X}$ & $\mathrm{X}$ \\
\hline Univ. Estadual de Montes Claros & $\mathrm{X}$ & $\mathrm{X}$ & $\mathrm{X}$ \\
\hline PUC MG & $\mathrm{X}$ & $\mathrm{X}$ & $\mathrm{X}$ \\
\hline UFRJ & $\mathrm{X}$ & $\mathrm{X}$ & $\mathrm{X}$ \\
\hline Univ. do Estado do Rio de Janeiro & $\mathrm{X}$ & $\mathrm{X}$ & $\mathrm{X}$ \\
\hline Univ. do Grande Rio & $\mathrm{X}$ & $\mathrm{X}$ & \\
\hline Univ. Severino Sombra & $\mathrm{X}$ & & \\
\hline Faculdades Unificadas Serra dos Órgãos & $\mathrm{X}$ & & $\mathrm{X}$ \\
\hline USP São Paulo & $\mathrm{X}$ & & $\mathrm{X}$ \\
\hline USP Ribeirão Preto & $\mathrm{X}$ & $\mathrm{X}$ & $\mathrm{X}$ \\
\hline UNICAMP & $\mathrm{X}$ & $\mathrm{X}$ & $\mathrm{X}$ \\
\hline & & $\mathrm{X}$ & \\
\hline UEL & $\mathrm{X}$ & $\mathrm{X}$ & $\mathrm{X}$ \\
\hline UEM & $\mathrm{X}$ & $\mathrm{X}$ & $\mathrm{X}$ \\
\hline PUC PR & $\mathrm{X}$ & & \\
\hline UFSC & $\mathrm{X}$ & $\mathrm{X}$ & $\mathrm{X}$ \\
\hline Univ. do Vale do Itajaí & $\mathrm{X}$ & $\mathrm{X}$ & $\mathrm{X}$ \\
\hline UFRGS & $\mathrm{X}$ & $\mathrm{X}$ & $\mathrm{X}$ \\
\hline Univ. de Santa Cruz do Sul & $\mathrm{X}$ & $\mathrm{X}$ \\
\hline
\end{tabular}

Figura 9. Cursos de Odontologia contemplados pelo Pró-Saúde I, e suas permanências nos Editais II e III por região do país.

O Programa Pró-Saúde envolve três anos de apoio financeiro a projetos que apresentem o potencial de transformação do modelo de formação de profissionais da área de saúde. Os projetos aprovados são monitorados por uma comissão gestora local, constituída por representantes dos professores, gestores municipais de saúde, discentes e membros de conselhos locais, além do Ministério da Saúde (MS) por meio de um grupo de assessores compostos por técnicos do MS, da Organização Panamericana de Saúde (OPAS) e de entidades externas com experiência em formação nas áreas envolvidas (Brasil, 2007). De acordo com o monitoramento anual do Pró-Saúde e Seminário de Avaliação, ocorrido em 2008 (Brasil, 2008), as experiências de aprendizagem de serviços que estão sendo mostrados para resultados da aprendizagem incluem comunicação e habilidades interpessoais, 
desenvolvimento da capacidade de trabalhar em equipe, desenvolvimento de liderança, a melhor compreensão das questões de política de saúde, a definição mais ampla de saúde. É também relevante o potencial de proporcionar ganhos para a comunidade e para o sistema de saúde, pois pode fornecer profissionais melhor preparados para integrar as equipes de saúde.

No entanto, reconhece-se que um dos grandes obstáculos ao se propor mudanças na educação profissional na área da saúde é cultural. Embora a aprendizagem baseada em serviço possa ser uma ferramenta poderosa para melhorar a qualidade do ensino, essa estratégia ainda é pouco explorada como uma tarefa pedagógica a ser implementada. Este assunto carece de mais discussão entre os diversos atores envolvidos neste processo de transformação (Brasil, 2008).

Atividades práticas na atenção primária tem sido identificadas como uma experiência desafiadora, uma vez que envolve professores, estudantes, profissionais de saúde, gestores e comunidade.

Todos eles têm valores singulares, conhecimento e experiências que são esperados para ser compartilhado com base na interdisciplinaridade e abrangência da abordagem pedagógica proposta (Arrais et al., 2012). Como o Pró-Saúde busca oferecer como produto recursos humanos mais capacitados para lidar com as demandas contemporâneas em saúde no Brasil, espera-se que todos os envolvidos estejam em processo de crescimento profissional sob a lógica desta proposta. Nesse sentido, fica já constatado o nível de complexidade que norteia a implementação do Programa e os percalços que deverão ser superados. O fato da forma de inserção ao Programa ocorrer por meio de edital desencadeia um componente de competitividade, que dentro da essência da proposta do Programa, pode ser interpretado como uma limitação. 


\section{CAPÍTULO 3 \\ METODOLOGIA}

\subsection{TIPO DE ESTUDO}

Trata-se de um estudo de natureza qualitativa, do tipo método misto. Optou-se neste estudo por uma abordagem mista a fim de se buscar, por diferentes meios, obter uma compreensão sobre os desafios que permeiam uma proposta que requer mudanças de paradigma e até mesmo cultural, e que pode requerer longos períodos para se consolidar.

O tipo de método misto eleito foi a estratégia explanatória sequencial, que envolveu a abordagem qualitativa, seguida da quantitativa, retorno à qualitativa e por fim a interpretação de toda a análise. A análise comparativa foi realizada por convergência, caracterizada pela coleta e análise separada dos dados quantitativos e qualitativos sobre um objeto de estudo, com interpretação geral dos dados obtidos (Creswell, 2007).

No primeiro momento, a abordagem qualitativa envolveu análise documental, seguida da construção, de um instrumento. Este foi desenvolvido especificamente para aplicação nos cursos de Enfermagem, Medicina e Odontologia incluídos neste estudo. A seleção desses cursos se deu devido ao histórico de inserção dos três, desde a primeira edição do Pró-Saúde. Pretendeu-se construir uma escala de atitudes que permitisse identificar as tendências atitudinais dos sujeitos da pesquisa frente ao objeto deste estudo, o Programa Pró-Saúde, pautado em seus eixos e vetores. Após isso, ocorreu a aplicação e validação do instrumento, que consistiu em uma abordagem quantitativa e depois, com a conversão dos resultados obtidos para conceitos e também através de entrevistas, retomou-se a abordagem qualitativa. 


\subsection{CENÁRIO DO ESTUDO}

Este estudo foi desenvolvido na Universidade de Brasília (UnB), com a participação de três cursos de graduação da área de saúde. Os cursos de Enfermagem e Odontologia pertencem à Faculdade de Ciências da Saúde e o curso de Medicina à Faculdade de Medicina. Todos estão localizados no Campus Darcy Ribeiro. O curso de Medicina foi implantando em 1965 e reconhecido em 1972; o curso de Enfermagem teve início em 1975 e reconhecido 1980 e o curso de Odontologia foi criado em 1980 e reconhecido em 1985 . À época os três cursos pertenciam à Faculdade de Ciências da Saúde.

Na sua concepção, o curso de Medicina era caracterizado pela estrutura de blocos de ensino concentrado, com ênfase na integração interdisciplinar e na orientação comunitária centrada na Unidade Integrada de Saúde de Sobradinho. Esse período antecedeu o Programa de Integração Docente Assistencial (IDA), mencionado anteriormente. O projeto UNI, desenvolvido a partir dos anos 1990, teve participação da UnB, convidada a participar por conta de sua experiência prévia de contato com o cenário real do serviço e com a comunidade. As propostas, as quais incluíam cenários que não fossem hospitais ou clínicas, foi um elemento importante na ruptura que culminou na separação do curso de Medicina, a qual passou a integrar a Faculdade de Medicina. Esta possuía uma posição mais conservadora em relação à formação de seus futuros profissionais (Bem-te-vi, 2015). O curso de Enfermagem passou ao longo desses anos por reestruturação curricular em três momentos (1979, 1981 e 1988) até a reforma atual, vigente desde 2009. O curso de Odontologia passou por uma reestruturação em 1988 e a atual, também vigente desde 2009. O curso de Medicina, passou por uma reestruturação em 1988 e a atual reformulação em processo de implementação em 2015. 


\subsection{PARTICIPANTES}

A população do estudo foi constituída por estudantes e professores dos cursos participantes da pesquisa. Essa população vivencia um cenário contemplado em dois dos três Editais do Programa Pró-Saúde desenvolvidos no âmbito dos três cursos.

Pretende-se obter um equilíbrio de opiniões sob diferentes perspectivas, e para isso os sujeitos convidados a participar do estudo serão estudantes e professores dos três cursos.

Optou-se pela realização de censo, ou seja, inclusão de todos aqueles que aceitassem participar da pesquisa, com a justificativa de tratar-se de populações de pequeno porte. No curso de Odontologia a população de estudantes de graduação incluiu um total de 233 matriculados no curso no segundo semestre de 2013 e de 45 professores efetivos. No curso de Enfermagem o número de matriculados no primeiro segundo semestre de 2014 foi de 278 estudantes. O corpo docente é composto por 27 professores efetivos. No curso de Medicina o total de matriculados na graduação no segundo semestre de 2014 foi de 485 estudantes e um total de 93 professores.

\subsection{DESCRIÇÃO DAS ETAPAS E PROCEDIMENTOS DE COLETA DE DADOS}

Na primeira etapa do projeto, foi realizada análise documental. Para isso foram selecionados documentos de domínio público do Ministério da Saúde que abordam os temas de interesse para esta pesquisa. A maioria do material necessário foi obtido da web page do Programa Pró-Saúde (www.prosaude.gov.br), o qual inclui documentos de implementação, atas, relatórios e resumos. Planejou-se que, se em algum momento houvesse a necessidade de quaisquer documentos adicionais, buscaríamos autorização de acesso diretamente na Coordenação do Programa Pró-Saúde. 
Pretendeu-se com a análise dos documentos, compreender de forma mais detalhada a implementação do Programa Pró-Saúde, assim como obter informações inerentes à proposta, ao seu funcionamento e sobre sua implementação nas Instituições de Ensino Superior contempladas. A coleta de dados forneceu informações para subsidiar a elaboração do instrumento a ser utilizado na fase seguinte do estudo. De acordo com May (2004) os documentos devem ser interpretados e suas informações sintetizadas, para que se possa determinar tendências, ressaltando ainda que documentos não existem isoladamente, e portanto precisam ser situados em uma estrutura teórica para que o seu conteúdo seja entendido.

Na segunda etapa do projeto, realizou-se a construção do instrumento. Optou-se pela construção de uma escala de atitudes do tipo Likert, composto por assertivas com atitudes positivas e negativas relacionadas ao objeto de estudo.

Em relação ao construto "atitude", este possui uma multiplicidade conceitual, as quais convergem para a complexidade envolvida em questões inseridas no contexto de relações sociais. Existem algumas definições clássicas, como a de Guildford (1954), que define atitude como "uma disposição pessoal comum aos indivíduos, mas provida em graus diferentes, a qual os impele a reagir a objetos, situações ou proposições em moldes que podem ser considerados favoráveis ou desfavoráveis". Lambert \& Lambert (1972), conceituam atitude como "uma maneira organizada e coerente de pensar, sentir e reagir em relação a pessoas, grupos, questões sociais ou, mais genericamente, a qualquer acontecimento ocorrido no meio circulante”. Mais recentemente, Bohner \& Dickel (2011) conceituaram atitude como uma predisposição para responder de determinada forma frente a um objeto ou sujeito, de forma mais sólida que uma opinião ou razão de momento, considerando avaliações e comportamentos construídos de acordo com a informação atualmente acessível ao sujeito. As atitudes são consideradas construtos hipotéticos, 
utilizados como elementos importantes na explicação do comportamento humano. Assim, determinam como os indivíduos tomam posições frente aos outros e aos acontecimentos, e é em função das atitudes que se avaliam comportamentos e escolhas (Collares et al, 2002).

As escalas psicométricas são utilizadas para viabilizar a quantificação de construtos denominados "hipotéticos", como é o caso das atitudes (Pasquali, 1996). Escala de atitudes é definida por Miguel (1983) como "um instrumento de auto-avaliação, que mede até que ponto um indivíduo tem sentimentos favoráveis ou desfavoráveis para com uma pessoa, grupo ou instituição sócia”. A associação dos conceitos de Guildford (1954) e Miguel (1983) foram adotados nessa pesquisa.

Nesse sentido, tornou-se coerente a construção de um instrumento que nos permitisse obter um panorama geral sobre a atitude de atores envolvidos no dia-a-dia da implementação do Pró-Saúde dos três cursos. O processo de construção do instrumento envolveu quatro fases.

Na primeira fase de construção da escala de atitudes foram selecionados os temas centrais, aqui denominados dimensões, os quais direcionaram a construção dos itens da escala. Nesta fase, os pesquisadores envolvidos diretamente no projeto (doutoranda e orientadora) participaram da elaboração dos itens, gerando, após sucessivas revisões, a evolução de doze versões do instrumento. Os itens foram construídos baseados nos eixos descritos no documento do Pró-Saúde (Figura 2), além da análise documental e revisão da literatura pertinente.

O instrumento foi dividido em duas seções. A Seção 1 foi composta por itens relacionados a dados sociodemográficos e profissionais nos instrumentos dirigidos aos professores, e dados sociodemográficos e acadêmicos nos instrumentos dirigidos aos estudantes. A Seção 2 foi organizada por quatro blocos de itens, separados por incluírem diferentes dimensões. O Bloco 1 incluiu afirmações na temática dimensão teórica; no Bloco 
2, as afirmativas relacionavam-se à dimensão cenários de práticas; o Bloco 3 à dimensão reorientação da formação, que representa a vivência e a percepção da mudança, e o Bloco 4, dimensão pedagógica.

$\mathrm{Na}$ sequência ocorreu a segunda fase, que foi denominada de pré-teste, a qual consistiu em apresentar a versão atualizada do instrumento a seis profissionais convidados, sendo estes professores da área de saúde, com experiência em aspectos referentes ao assunto investigado, para que fizessem uma análise criteriosa dos itens, sob diferentes perspectivas, tais como conteúdo, semântica, aprimoramento visual e textual, necessidade de inclusão ou exclusão de itens. Nesta fase, foram sugeridas e realizadas modificações de redação de itens por questões de semântica (41), modificações de redação de itens por questões gramaticais (8), inclusão de alternativas em itens de múltipla escolha (7), transferência de item para outra seção (1), inclusão de item (4), exclusão de item (1), alteração na legenda (1).

Na sequência, atribuiu-se para cada item uma pontuação, determinada de acordo com o nível de concordância do respondente, e baseado no fato da assertiva ser relacionada a uma atitude positiva ou negativa em relação ao objeto de estudo. Essas pontuações foram posteriormente utilizadas para fins de análise dos resultados obtidos. Dessa forma, os itens obtiveram suas pontuações, conforme descrito na Figura 10. 


\begin{tabular}{|l|c|c|c|}
\hline $\begin{array}{c}\text { Nível de } \\
\text { concordância }\end{array}$ & Abreviatura & $\begin{array}{c}\text { Valor atribuído } \\
\text { ao item categorizado } \\
\text { como atitude positiva }\end{array}$ & $\begin{array}{c}\text { Valor atribuído ao } \\
\text { item categorizado } \\
\text { como atitude negativa }\end{array}$ \\
\hline Discordo totalmente & DT & -2 & +2 \\
\hline Discordo & D & -1 & +1 \\
\hline $\begin{array}{l}\text { Não concordo nem } \\
\text { discordo }\end{array}$ & NCND & 0 & -1 \\
\hline Concordo & C & +1 & -2 \\
\hline Concordo totalmente & CT & +2 & 9 \\
\hline Não sei & NS & 9 & 0 \\
\hline
\end{tabular}

Figura 10. Valor atribuído a cada item do instrumento de acordo com o nível de concordância do respondente.

Para a dimensão teórica (Bloco 1) foram selecionados 10 itens, dentre os quais, cinco itens incluem assertivas positivas e cinco são negativas. Para esta dimensão, os aspectos analisados relacionam-se à produção de conhecimento, direcionamento da teoria em nível de graduação e pós-graduação. A Figura 11 descreve os itens e apresenta os valores atribuídos a cada um.

\begin{tabular}{|l|c|c|c|c|c|c|}
\hline \multicolumn{1}{|c|}{ BLOCO 1 } & DT & D & $\begin{array}{c}\text { NC } \\
\text { ND }\end{array}$ & C & CT & NS \\
\hline $\begin{array}{l}\text { 1- Os conteúdos teóricos ministrados na } \\
\text { graduação abordam aspectos biológicos do } \\
\text { processo saúde-doença. }\end{array}$ & +2 & +1 & 0 & -1 & -2 & 9 \\
\hline $\begin{array}{l}\text { 2- Os conteúdos teóricos ministrados na } \\
\text { graduação abordam aspectos sociais do } \\
\text { processo saúde-doença. }\end{array}$ & -2 & -1 & 0 & +1 & +2 & 9 \\
\hline $\begin{array}{l}\text { 3- Há interação entre as abordagens teóricas } \\
\text { das disciplinas das áreas básicas, clínicas e } \\
\text { sociais da graduação. }\end{array}$ & -2 & -1 & 0 & +1 & +2 & 9 \\
\hline $\begin{array}{l}\text { 4- A produção de conhecimento, no que se } \\
\text { refere à pesquisa, está articulada com as } \\
\text { demandas do serviço e da comunidade da } \\
\text { Regional de Saúde do Paranoá/Itapoã. }\end{array}$ & -2 & -1 & 0 & +1 & +2 & 9 \\
\hline $\begin{array}{l}\text { 5- A produção científica é focada em } \\
\text { investigações sobre aspectos biomédicos ou } \\
\text { tecnológicos da atenção à saúde. }\end{array}$ & +2 & +1 & 0 & -1 & -2 & 9 \\
\hline
\end{tabular}




\begin{tabular}{|l|c|c|c|c|c|c|}
\hline $\begin{array}{l}\text { 6- A produção de conhecimento, no que se } \\
\text { refere à extensão, está articulada com as } \\
\text { demandas do serviço da comunidade da } \\
\text { Regional de Saúde do Paranoá/Itapoã. }\end{array}$ & -2 & -1 & 0 & +1 & +2 & 9 \\
\hline $\begin{array}{l}\text { 7- A oferta de cursos de pós-graduação é } \\
\text { voltada para os profissionais do SUS. }\end{array}$ & -2 & -1 & 0 & +1 & +2 & 9 \\
\hline $\begin{array}{l}\text { 8- Os cursos de pós-graduação possuem } \\
\text { como público-alvo os profissionais que } \\
\text { atuam na rede privada. }\end{array}$ & +2 & +1 & 0 & -1 & -2 & 9 \\
\hline $\begin{array}{l}\text { 9- Os cursos de pós-graduação são } \\
\text { oferecidos de acordo com interesses ou } \\
\text { necessidades do curso. }\end{array}$ & +2 & +1 & 0 & -1 & -2 & 9 \\
\hline $\begin{array}{l}\text { 10- As disciplinas teóricas de conteúdos } \\
\text { relacionados às áreas básicas, clínicas e } \\
\text { sociais são ministradas em blocos } \\
\text { separados, sem articulação entre elas. }\end{array}$ & +2 & +1 & 0 & -1 & -2 & 9 \\
\hline
\end{tabular}

Figura 11. Valores atribuídos a cada item da dimensão teórica.

A dimensão cenário de práticas, incluída no Bloco 2, foi composta por 13 itens, sendo 10 itens referentes a atitudes positivas e três itens de atitudes negativas. Foram abordadas nesta dimensão questões relacionadas às atividades práticas desenvolvidas pelos cursos; à integração da universidade com o serviço e entre diferentes cursos; à relevância do envolvimento da universidade nos serviços de saúde, sob a perspectiva de infraestrutura, formação dos envolvidos no processo, organização dos serviços. A Figura 12 apresenta os 13 itens e suas respectivas pontuações.

\begin{tabular}{|l|c|c|c|c|c|c|}
\hline BLOCO 2 & DT & D & $\begin{array}{c}\text { NC } \\
\text { ND }\end{array}$ & C & CT & NS \\
\hline $\begin{array}{l}\text { 1- A integração da universidade com o } \\
\text { serviço de saúde traz benefícios para a } \\
\text { comunidade. }\end{array}$ & -2 & -1 & 0 & +1 & +2 & 9 \\
\hline $\begin{array}{l}\text { 2- A integração da universidade com o } \\
\text { serviço de saúde traz benefícios para o } \\
\text { serviço. }\end{array}$ & -2 & -1 & 0 & +1 & +2 & 9 \\
\hline $\begin{array}{l}\text { 3- A integração da universidade com o } \\
\text { serviço de saúde traz benefícios para a } \\
\text { universidade. }\end{array}$ & -2 & -1 & 0 & +1 & +2 & 9 \\
\hline $\begin{array}{l}\text { 4- Meu curso de graduação contribui para a } \\
\text { organização dos serviços da Regional de } \\
\text { Saúde do Paranoá/Itapoã. }\end{array}$ & -2 & -1 & 0 & +1 & +2 & 9 \\
\hline
\end{tabular}




\begin{tabular}{|l|c|c|c|c|c|c|}
\hline $\begin{array}{l}\text { 5- A infraestrutura das unidades de saúde } \\
\text { nas quais são realizadas atividades das } \\
\text { disciplinas e/ou ações do Pró-Saúde são } \\
\text { adequadas ao processo de ensino e } \\
\text { aprendizagem dos estudantes. }\end{array}$ & -2 & -1 & 0 & +1 & +2 & 9 \\
\hline $\begin{array}{l}\text { 6- As atividades práticas das disciplinas } \\
\text { clínicas são realizadas nas instalações } \\
\text { assistenciais universitárias, a exemplo das } \\
\text { clínicas e hospital universitário. }\end{array}$ & +2 & +1 & 0 & -1 & -2 & 9 \\
\hline $\begin{array}{l}\text { 7- Meu curso de graduação está voltado para } \\
\text { a formação especializada do dentista. }\end{array}$ & +2 & +1 & 0 & -1 & -2 & 9 \\
\hline $\begin{array}{l}\text { 8- As atividades desenvolvidas nos cenários } \\
\text { de práticas do Paranoá-Itapoã são } \\
\text { importantes para a formação do dentista. }\end{array}$ & -2 & -1 & 0 & +1 & +2 & 9 \\
\hline $\begin{array}{l}\text { 9- O Pró-Saúde contribuiu para a integração } \\
\text { do curso com a Rede de Serviço de Saúde } \\
\text { do Paranoá-Itapoã. }\end{array}$ & -2 & -1 & 0 & +1 & +2 & 9 \\
\hline $\begin{array}{l}\text { 10- Meu curso de graduação se volta para a } \\
\text { formação generalista do dentista. }\end{array}$ & -2 & -1 & 0 & +1 & +2 & 9 \\
\hline $\begin{array}{l}\text { 11- O Pró-Saúde contribuiu para a } \\
\text { integração do meu curso de graduação com } \\
\text { os demais cursos da área da saúde. }\end{array}$ & -2 & -1 & 0 & +1 & +2 & 9 \\
\hline $\begin{array}{l}\text { 12- As atividades práticas dos primeiros } \\
\text { anos do curso ocorrem em laboratórios da } \\
\text { área básica. }\end{array}$ & +2 & +1 & 0 & -1 & -2 & 9 \\
\hline $\begin{array}{l}\text { 13- A inserção dos estudantes do meu curso } \\
\text { de graduação com atividades práticas na } \\
\text { comunidade ou nos serviços de saúde ocorre } \\
\text { desde os primeiros dois anos do curso. }\end{array}$ & -2 & -1 & 0 & +1 & +2 & 9 \\
\hline
\end{tabular}

Figura 12. Valores atribuídos a cada item da dimensão cenário de práticas.

O Bloco 3 foi composto por nove itens relacionados à dimensão reorientação da formação. Destes, um item aborda o tópico negativamente, e as demais são assertivas positivas. Nesta dimensão foi realizada uma abordagem mais direta no que se refere ao objeto deste estudo, o Programa Pró-Saúde. Houve um enfoque em aspectos, como objetivos, contribuição e relevância do Programa para a formação do futuro profissional. A Figura 13 apresenta os itens com suas respectivas pontuações. 


\begin{tabular}{|l|c|c|c|c|c|c|}
\hline \multicolumn{1}{|c|}{ BLOCO 3 } & DT & D & $\begin{array}{c}\text { NC } \\
\text { ND }\end{array}$ & C & CT & NS \\
\hline $\begin{array}{l}\text { 1- Eu conheço os objetivos do Programa } \\
\text { Pró-Saúde. }\end{array}$ & -2 & -1 & 0 & +1 & +2 & 9 \\
\hline $\begin{array}{l}\text { 2- O Pró-Saúde contribuiu com o processo } \\
\text { de reforma curricular do curso de } \\
\text { Odontologia. }\end{array}$ & -2 & -1 & 0 & +1 & +2 & 9 \\
\hline $\begin{array}{l}\text { 3- A participação do estudante no Pró-Saúde } \\
\text { contribui para a sua maior preparação para } \\
\text { atuação profissional na rede pública. }\end{array}$ & -2 & -1 & 0 & +1 & +2 & 9 \\
\hline $\begin{array}{l}\text { 4- A participação do estudante no Pró-Saúde } \\
\text { contribui para a sua maior preparação para } \\
\text { atuação profissional na rede privada. }\end{array}$ & +2 & +1 & 0 & -1 & -2 & 9 \\
\hline $\begin{array}{l}\text { 5- As atividades desenvolvidas no contexto } \\
\text { do Pró-Saúde nas unidades de saúde não } \\
\text { alteram as rotinas de trabalho nem as } \\
\text { práticas dos profissionais no serviço. }\end{array}$ & +2 & +1 & 0 & -1 & -2 & 9 \\
\hline $\begin{array}{l}\text { 6- O Pró-Saúde possibilita a interação entre } \\
\text { os profissionais da área de saúde. }\end{array}$ & -2 & -1 & 0 & +1 & +2 & 9 \\
\hline $\begin{array}{l}\text { 7- As atividades desenvolvidas pelos } \\
\text { estudantes de Odontologia no contexto do } \\
\text { Pró-Saúde influenciam na qualidade de sua } \\
\text { formação. }\end{array}$ & -2 & -1 & 0 & +1 & +2 & 9 \\
\hline $\begin{array}{l}\text { 8- As atividades desenvolvidas no âmbito } \\
\text { do Pró-Saúde contribuem para a } \\
\text { qualificação da prática dos profissionais que } \\
\text { atuam na rede pública de atenção à saúde do } \\
\text { Paranoá-Itapoã. }\end{array}$ & -2 & -1 & 0 & +1 & +2 & 9 \\
\hline $\begin{array}{l}\text { 9- O Pró-Saúde contribui para o trabalho em } \\
\text { equipe. }\end{array}$ & -2 & -1 & 0 & +1 & +2 & 9 \\
\hline
\end{tabular}

Figura 13. Valores atribuídos a cada item da dimensão reorientação da formação.

A dimensão pedagógica, inserida no Bloco 4 do instrumento, foi formada por dez itens, sendo 6 itens de atitudes positivas e 4 itens de atitudes negativas. Os itens abordados nesta dimensão relacionam-se ao processo de ensino aprendizagem, com enfoque em metodologias, estratégias de abordagem, tipo de integração. A Figura 14 apresenta os itens e respectivas pontuações desta dimensão incluída no estudo. 


\begin{tabular}{|l|c|c|c|c|c|c|}
\hline \multicolumn{1}{|c|}{ BLOCO 4 } & DT & D & $\begin{array}{c}\text { NC } \\
\text { ND }\end{array}$ & C & CT & NS \\
\hline $\begin{array}{l}\text { 1- As atividades desenvolvidas nas } \\
\text { disciplinas básicas e clínicas são integradas. }\end{array}$ & -2 & -1 & 0 & +1 & +2 & 9 \\
\hline $\begin{array}{l}\text { 2- A estrutura curricular do curso inclui } \\
\text { primeiro o aprendizado da teoria e na } \\
\text { sequência a aplicação da teoria na prática. }\end{array}$ & +2 & +1 & 0 & -1 & -2 & 9 \\
\hline $\begin{array}{l}\text { 3- O curso de Odontologia está estruturado } \\
\text { em ciclo básico e ciclo clínico. }\end{array}$ & +2 & +1 & 0 & -1 & -2 & 9 \\
\hline $\begin{array}{l}\text { 4- A maior parte dos conteúdos teóricos } \\
\text { da(s) disciplina(s) da graduação que } \\
\text { ministro é apresentada na forma de aula } \\
\text { expositiva. }\end{array}$ & +2 & +1 & 0 & -1 & -2 & 9 \\
\hline $\begin{array}{l}\text { 5- As estratégias de ensino utilizadas são } \\
\text { variadas, a exemplo de seminários, } \\
\text { discussões em grupos tutoriais, estudos de } \\
\text { casos, etc. }\end{array}$ & -2 & -1 & 0 & +1 & +2 & 9 \\
\hline $\begin{array}{l}\text { 6- O processo de ensino-aprendizagem } \\
\text { envolve atividades interdisciplinares. }\end{array}$ & -2 & -1 & 0 & +1 & +2 & 9 \\
\hline $\begin{array}{l}\text { 7- Existe interação entre a teoria ministrada } \\
\text { e a prática. }\end{array}$ & -2 & -1 & 0 & +1 & +2 & 9 \\
\hline $\begin{array}{l}\text { 8- A interação entre a equipe de } \\
\text { profissionais de saúde, estudantes, } \\
\text { professores e comunidade facilita o processo } \\
\text { de ensino e aprendizagem. }\end{array}$ & -2 & -1 & 0 & +1 & +2 & 9 \\
\hline $\begin{array}{l}\text { 9- Atividades práticas envolvendo } \\
\text { profissionais das equipes de saúde são } \\
\text { estratégias que pouco acrescentam à } \\
\text { formação do dentista, dado as } \\
\text { especificidades do curso. }\end{array}$ & +2 & +1 & 0 & -1 & -2 & 9 \\
\hline $\begin{array}{l}\text { 10- As estratégias de ensino-aprendizagem } \\
\text { que ocorrem no ambiente do SUS são } \\
\text { avaliadas conjuntamente pelos profissionais } \\
\text { da Rede e docentes. }\end{array}$ & -2 & -1 & 0 & +1 & +2 & 9 \\
\hline
\end{tabular}

Figura 14. Valores atribuídos a cada item da dimensão pedagógica.

$\mathrm{Na}$ terceira fase, os instrumentos foram submetidos à fase de teste. Os mesmos foram aplicados a seis professores e dezessete acadêmicos, todos vinculados a cursos de graduação da área de saúde que não fariam parte da população do estudo. Nesta etapa, os respondentes tiveram a oportunidade de preencher sugestões sobre os itens respondidos no instrumento, utilizando um espaço disponibilizado ao final do mesmo. Os principais 
comentários foram referentes à legenda e semântica. Nesta fase o tempo médio utilizado para preenchimento do instrumento foi verificada, e foi estimado em quinze minutos.

A quarta fase deste processo envolveu a aplicação e validação do instrumento, após as alterações necessárias, em um dos cursos incluídos na população do estudo, o curso de Odontologia. Estudantes e professores da graduação foram convidados a participar, e aqueles que aceitaram participaram da aplicação do instrumento. Um total de 191 estudantes e 18 professores de Odontologia participaram desse processo de validação.

\subsubsection{Análise de validade do instrumento}

\subsubsection{Agrupamento dos itens do instrumento}

Para fins de análise, os itens de cada bloco foram agrupados de acordo com sua caracterização na dimensão inserida, de modo que os mesmos foram classificados em itens confirmatórios (pareamento de dois itens que se contrapõem e portanto se anulam); itens complementares (quando os itens estão relacionados às dimensões, mas não se contrapõem a outros itens) e itens para transferência (quando o item estiver localizado em um bloco, mas deva ser deslocado para o bloco de outra dimensão e reclassificado como confirmatório ou complementar).

Com isso, foi definida a pontuação mínima e máxima possível para cada item de todas as dimensões avaliadas neste estudo.

Para a identificação dos itens, os mesmos foram codificados de acordo com suas inserções em cada bloco. Assim, cada item foi identificado com dois números, sendo o primeiro referente ao bloco inserido, ou seja, Blocos 1, 23 e 4, foram codificados respectivamente como $1,2,3$ e 4 . A seguir o número identificador refere-se à ordem de localização do item dentro do bloco em que está inserido. 
Na dimensão teórica (Bloco 1 do instrumento), foram identificados um total de oito itens confirmatórios e dois itens complementares, conforme apresentado na Figura 15.

\begin{tabular}{|l|l|}
\hline \multicolumn{1}{|c|}{ Identificação do item } & Classificação \\
\hline Item 1.1 (negativo) e item 1.2 (positivo) & Confirmatórios \\
\hline Item 1.3 (positivo) e item 1.10 (negativo) & Confirmatórios \\
\hline Item 1.4 (positivo) e item 1.5 (negativo) & Confirmatórios \\
\hline Item 1.7 (positivo) e item 1.8 (negativo) & Confirmatórios \\
\hline Item 1.6 (positivo) & Complementar \\
\hline Item 1.9 (negativo) & Complementar \\
\hline
\end{tabular}

Figura 15. Classificação e pontuação atribuídas a cada item da dimensão teórica (Bloco 1).

$\mathrm{Na}$ dimensão cenário de práticas (inserida no Bloco 2 do instrumento) foram identificados dois itens confirmatórios, sete itens complementares e quatro itens para transferência. Os itens indicados para transferência foram inseridos no Bloco 3. Após esses ajustes, para fins de análise e pontuação, o Bloco 2 passou a incluir nove itens (Figura 16)

\begin{tabular}{|l|c|}
\hline \multicolumn{1}{|c|}{ Identificação do item } & Classificação \\
\hline Item 2.1 (positivo) & Complementar \\
\hline Item 2.2 (positivo) & Complementar \\
\hline Item 2.3 (positivo) & Complementar \\
\hline Item 2.4 (positivo) & Complementar \\
\hline Item 2.5 (positivo) & Complementar \\
\hline Item 2.6 (negativo) & Complementar \\
\hline Item 2.7 (negativo) e item 2.10 (positivo) & $\begin{array}{c}\text { Transferência do Bloco } \\
\end{array}$ \\
& 2 para o Bloco 3: \\
& Reclassificar \\
\hline Item 2.8 (positivo) & Complementar \\
\hline Item 2.9 (positivo) & Transferência do Bloco \\
& 2 para o Bloco 3: \\
& Reclassificar \\
\hline Item 2.11 (positivo) & Transferência do Bloco \\
& 2 para o Bloco 3: \\
& Reclassificar \\
\hline Item 2.12 (negativo) e item 2.13 (positivo) & Confirmatórios \\
\hline
\end{tabular}

Figura 16. Classificação e pontuação atribuídas a cada item da dimensão cenário de práticas (Bloco 2). 
Na dimensão reorientação da formação foram identificados seis itens confirmatórios e três complementares. Após a reclassificação dos itens transferidos do Bloco 2 para o Bloco 3, para fins de análise e pontuação, o Bloco 3 passou a ser composto por oito itens confirmatórios e cinco itens complementares, totalizando 13 itens. A Figura 17 apresenta as informações sobre a classificação e pontuação do Bloco 3.

\begin{tabular}{|l|c|}
\hline \multicolumn{1}{|c|}{ Identificação do item } & Classificação \\
\hline Item 3.1 (positivo) & Complementar \\
\hline Item 3.2 (positivo) & Complementar \\
\hline Item 3.3 (positivo) e item 3.4 (negativo) & Confirmatório \\
\hline Item 3.5 (negativo) e item 3.8 (positivo) & Confirmatório \\
\hline Item 3.6 (positivo) e item 3.9 (positivo) & Confirmatório \\
\hline Item 3.7 (positivo) & Complementar \\
\hline Item 2.7 (negativo) e item 2.10 (positivo) & $\begin{array}{c}\text { Reclassificação: } \\
\text { Confirmatório }\end{array}$ \\
\hline Item 2.9 (positivo) & $\begin{array}{c}\text { Reclassificação: } \\
\text { Complementar }\end{array}$ \\
\hline Item 2.11 (positivo) & $\begin{array}{c}\text { Reclassificação: } \\
\text { Complementar }\end{array}$ \\
\hline
\end{tabular}

Figura 17. Classificação e pontuação atribuídas a cada item da dimensão reorientação da formação (Bloco 3).

A dimensão pedagógica foi composta por oito itens confirmatórios e dois itens complementares (Figura 18).

\begin{tabular}{|l|l|}
\hline \multicolumn{1}{|c|}{ Identificação do item } & Classificação \\
\hline Item 4.1 (positivo) e item 4.3 (negativo) & Confirmatório \\
\hline Item 4.2 (negativo) e item 4.7 (positivo) & Confirmatório \\
\hline Item 4.4 (negativo) e item 4.5 (positivo) & Confirmatório \\
\hline Item 4.6 (positivo) & Complementar \\
\hline Item 4.8 (positivo) e item 4.9 (negativo) & Confirmatório \\
\hline Item 4.10 (positivo) & Complementar \\
\hline
\end{tabular}

Figura 18. Classificação e pontuação atribuídas a cada item da dimensão pedagógica (Bloco 4). 


\subsubsection{Verificação da confiabilidade do instrumento}

O teste estatístico empregado para avaliação de consistência interna do instrumento foi o alfa de Cronbach, cujos valores de interpretação variam de 0 a 1 . O resultado zero indica a ausência total de consistência interna dos itens e o valor 1 alcance de $100 \%$. de consistência. Considera-se que existe um satisfatório nível de confiabilidade para valores iguais ou maiores que 0,80 .

O resultado obtido para o total de itens dessa escala foi de 0,87 (Tabela 1)

\section{Tabela 1}

Consistência interna para a escala de atitudes

\begin{tabular}{c|c}
\hline Sumário Estatístico & Escala de atitudes \\
\hline Número de itens & 42 \\
\hline Média (pontos) & 124,52 \\
\hline Desvio-padrão (pontos) & 24,275 \\
\hline Alfa de Cronbach & 0,866 \\
\hline n válidos & 185 \\
\hline
\end{tabular}

A Tabela 2 apresenta todos os itens da escala, destacando aqueles cuja remoção levaria à redução do valor do coeficiente de alfa. Portanto, do total de 42 itens da escala, 30 não devem ser removidos. Comparando o valor de alfa obtido de 0,866 para a escala com os valores de alfa dos outros 12 itens da escala, verificou-se que a remoção de cada um destes itens específicos não representaria um aumento significativo na consistência interna da escala. O máximo de elevação que se obteria seria com a remoção do item B1Q1, B4Q1, B4Q4 e B4Q9, os quais se removidos, individualmente elevariam o alfa para 0,869. Optouse pela manutenção dos 42 itens. 


\section{Tabela 2}

Coeficiente alfa de Cronbach da escala de atitude construída nesta pesquisa

\begin{tabular}{|c|c|c|c|c|c|}
\hline & $\begin{array}{l}\text { Média de } \\
\text { escala se o } \\
\text { item for } \\
\text { excluído }\end{array}$ & $\begin{array}{l}\text { Variância de } \\
\text { escala se o item } \\
\text { for excluído }\end{array}$ & $\begin{array}{l}\text { Correlação de } \\
\text { item total } \\
\text { corrigida }\end{array}$ & $\begin{array}{l}\text { Correlação } \\
\text { múltipla ao } \\
\text { quadrado }\end{array}$ & $\begin{array}{c}\text { Alfa de Cronbach } \\
\text { se o item for } \\
\text { excluído }\end{array}$ \\
\hline $\mathrm{B} 1 \mathrm{Q} 2$ & 120,46 & 582,381 &, 152 & ,492 & 866 \\
\hline B1Q1 & 120,19 & 581,016 & 229 & ,403 &, 865 \\
\hline B1Q3 & 120,74 & 587,457 & ,024 & ,412 & ,867 \\
\hline B1Q10 & 121,81 & 588,839 &,- 018 & ,425 & ,869 \\
\hline B1Q4 & 121,62 & 580,128 & ,099 & ,394 & ,868 \\
\hline B1Q5 & 121,57 & 565,909 & ,266 & ,333 &, 865 \\
\hline B1Q7 & 122,94 & 562,104 & ,325 & ,392 & ,863 \\
\hline B1Q8 & 122,73 & 573,198 & , 170 & ,509 & ,867 \\
\hline B1Q6 & 121,62 & 562,780 & ,338 & ,431 & ,863 \\
\hline B1Q9 & 122,68 & 565,936 & ,249 & ,414 & ,865 \\
\hline B2Q1 & 119,99 & 577,571 & ,314 & ,795 & ,864 \\
\hline B2Q2 & 120,25 & 570,647 &, 349 & 680 &, 863 \\
\hline B2Q3 & 120,21 & 575,947 & ,253 & ,704 & ,865 \\
\hline B2Q4 & 121,00 & 572,946 & ,217 & ,403 & ,865 \\
\hline B2Q5 & 122,63 & 569,996 & ,246 & ,306 &, 865 \\
\hline B2Q6 & 120,61 & 573,816 &, 241 & ,404 & ,865 \\
\hline B2Q8 & 120,43 & 576,540 & ,231 & ,548 & ,865 \\
\hline B2Q13 & 120,72 & 576,777 & , 165 & ,373 & ,866 \\
\hline B2Q12 & 121,37 & 572,571 & ,218 & ,395 & ,865 \\
\hline B3Q1 & 122,72 & 542,636 & ,558 & ,676 & ,858 \\
\hline B3Q2 & 122,59 & 525,722 & ,643 & ,727 & ,855 \\
\hline B3Q3 & 122,09 & 525,758 & ,633 & ,824 & ,855 \\
\hline B3Q4 & 122,88 & 536,192 & ,630 & ,738 & ,856 \\
\hline B3Q8 & 122,37 & 521,082 & 697 & ,802 &, 854 \\
\hline B3Q5 & 123,43 & 548,182 & 651 & ,656 & ,858 \\
\hline B3Q6 & 122,22 & 518,616 & ,725 & 877 & ,853 \\
\hline B3Q9 & 122,11 & 517,434 & ,700 & ,865 & ,853 \\
\hline B3Q7 & 122,09 & 516,062 & ,736 & 901 & ,852 \\
\hline B2Q10 & 120,81 & 579,310 & , 166 & ,427 & ,866 \\
\hline B2Q7 & 121,66 & 580,171 & , 128 & ,426 & ,867 \\
\hline B2Q9 & 122,17 & 523,622 & ,661 & ,671 & ,855 \\
\hline B2Q11 & 122,55 & 521,879 & ,720 & ,743 & ,853 \\
\hline B4Q1 & 121,38 & 587,923 &,- 001 & ,506 & ,869 \\
\hline B4Q3 & 121,52 & 577,729 &, 127 & ,345 & ,867 \\
\hline B4Q7 & 120,57 & 576,432 &, 253 & ,455 & ,865 \\
\hline B4Q2 & 121,02 & 579,864 &, 142 & ,485 & ,866 \\
\hline B4Q5 & 120,71 & 578,175 &, 211 & ,411 & ,865 \\
\hline B4Q4 & 121,14 & 584,861 & ,028 & ,383 & ,869 \\
\hline
\end{tabular}




\begin{tabular}{c|c|c|c|c|c} 
B4Q6 & 120,89 & 580,988 &, 150 &, 414 &, 866 \\
B4Q8 & 120,44 & 577,879 &, 235 &, 569 &, 865 \\
B4Q9 & 122,24 & 589,522 &,- 030 &, 362 &, 869 \\
B4Q10 & 122,31 & 555,008 &, 352 &, 399 &, 863 \\
\hline
\end{tabular}

Os coeficientes obtidos ao se realizar a análise de cada dimensão encontram-se apresentados na Tabela 3. Dentre as quatro dimensões do instrumento, a dimensão reorientação da formação obteve o melhor resultado do coeficiente de alfa, com um valor de 0,932 .

\section{Tabela 3}

Consistência interna para cada dimensão da escala de atitudes

\begin{tabular}{l|c|l|c|c|c}
\hline \multicolumn{1}{c|}{ Dimensão } & $\begin{array}{l}\text { número } \\
\text { de itens }\end{array}$ & $\begin{array}{l}\text { Alfa de } \\
\text { Cronbach }\end{array}$ & \multicolumn{2}{|c|}{ Média } & \multicolumn{2}{c|}{ Dontos } & Desvio-Padrão & válidos \\
\hline Teórica & 10 & $\mathbf{0 , 5 6 3}$ & 29,24 & 6,168 & 211 \\
& & & & & \\
\hline Cenário de Práticas & 9 & $\mathbf{0 , 6 3 2}$ & 33,60 & 5,408 & 210 \\
\hline Reorientação da formação & 13 & $\mathbf{0 , 9 3 2}$ & 29,79 & 17,596 & 203 \\
\hline Pedagógica & & & & & \\
\hline
\end{tabular}

$\mathrm{n}=$ número de respondentes

O coeficiente alfa de Cronbach e as correlações dos itens que compõem cada dimensão da escala de atitudes podem ser observadas nas Tabelas 4, 5, 6 e 7. 


\section{Tabela 4}

Coeficiente alfa de Cronbach na dimensão teórica da escala de atitude.

\begin{tabular}{|c|c|c|c|c|c|c|c|}
\hline & $\begin{array}{l}\text { Média } \\
\text { do } \\
\text { item }\end{array}$ & $\begin{array}{l}\text { Desvio } \\
\text { Padrão }\end{array}$ & $\begin{array}{l}\text { Média de } \\
\text { escala se o } \\
\text { item for } \\
\text { excluído }\end{array}$ & $\begin{array}{c}\text { Variância de } \\
\text { escala se o } \\
\text { item for } \\
\text { excluído }\end{array}$ & $\begin{array}{l}\text { Correlação de } \\
\text { item total } \\
\text { corrigida }\end{array}$ & $\begin{array}{c}\text { Correlação } \\
\text { múltipla ao } \\
\text { quadrado }\end{array}$ & $\begin{array}{c}\text { Alfa de } \\
\text { Cronbach } \\
\text { se o item for } \\
\text { excluído }\end{array}$ \\
\hline B1Q2 & 4,04 & 858 & 25,20 & 35,684 & ,158 & 343 & ,556 \\
\hline B1Q1 & 4,34 & 695 & 24,90 & 36,014 & 185 & 286 & ,554 \\
\hline B1Q3 & 3,78 & 885 & 25,46 & 38,050 &,- 073 & 222 & ,593 \\
\hline B1Q10 & 2,72 & 1,225 & 26,53 & 36,498 & ,003 & 131 & ,593, \\
\hline B1Q4 & 2,95 & 1,440 & 26,29 & 32,730 & ,196 & 229 & ,551 \\
\hline B1Q5 & 3,03 & 1,603 & 26,21 & 29,254 & ,358 & ,159 & ,502 \\
\hline B1Q7 & 1,68 & 1,613 & 27,56 & 28,095 & ,430 & 293 & ,477 \\
\hline B1Q8 & 1,89 & 1,667 & 27,36 & 28,735 & ,365 & ,343 & ,499 \\
\hline B1Q6 & 2,92 & 1,504 & 26,32 & 29,865 & ,360 & 233 &, 503 \\
\hline B1Q9 & 1,90 & 1,729 & 27,35 & 28,180 & ,374 & 301 & ,495 \\
\hline
\end{tabular}

Tabela 5

Coeficiente alfa de Cronbach na dimensão cenário de práticas da escala de atitude.

\begin{tabular}{c|c|c|c|c|c|c|c}
\hline & $\begin{array}{c}\text { Média } \\
\text { do item }\end{array}$ & $\begin{array}{c}\text { Desvio } \\
\text { Padrão }\end{array}$ & $\begin{array}{c}\text { Média de } \\
\text { escala se o } \\
\text { item for } \\
\text { excluído }\end{array}$ & $\begin{array}{c}\text { Variância de } \\
\text { escala se o } \\
\text { item for } \\
\text { excluído }\end{array}$ & $\begin{array}{c}\text { Correlação de } \\
\text { item total } \\
\text { corrigida }\end{array}$ & $\begin{array}{c}\text { Correlação } \\
\text { múltipla ao } \\
\text { quadrado }\end{array}$ & $\begin{array}{c}\text { Alfa de Cronbach } \\
\text { se o item for } \\
\text { excluído }\end{array}$ \\
\hline B2Q1 & 4,54 &, 713 & 29,06 & 24,446 &, 609 &, 612 &, 568 \\
B2Q2 & 4,28 & 1,045 & 29,32 & 23,089 &, 504 &, 501 &, 563 \\
B2Q3 & 4,33 & 0,974 & 29,27 & 23,778 &, 476 &, 480 &, 573 \\
B2Q4 & 3,49 & 1,395 & 30,11 & 22,969 &, 324 &, 222 &, 602 \\
B2Q5 & 1,90 & 1,435 & 31,70 & 25,955 &, 084 &, 036 &, 670 \\
B2Q6 & 3,98 & 1,159 & 29,62 & 25,126 &, 239 &, 160 &, 622 \\
B2Q8 & 4,06 & 1,047 & 29,54 & 23,790 &, 427 &, 300 &, 580 \\
\hline B2Q12 & 3,80 & 1,366 & 29,80 & 23,966 &, 255 &, 148 &, 621 \\
\hline
\end{tabular}




\section{Tabela 6}

Coeficiente alfa de Cronbach na dimensão reorientação da formação da escala de atitude.

\begin{tabular}{c|c|c|c|c|c|c|c}
\hline & Média & $\begin{array}{c}\text { Desvio } \\
\text { Padrão }\end{array}$ & $\begin{array}{c}\text { Média de escala se } \\
\text { o item for excluído }\end{array}$ & $\begin{array}{c}\text { Variância de escala } \\
\text { se o item for } \\
\text { excluído }\end{array}$ & $\begin{array}{c}\text { Correlação } \\
\text { de item } \\
\text { total } \\
\text { corrigida }\end{array}$ & $\begin{array}{c}\text { Alfa de } \\
\text { Correlação } \\
\text { múltipla ao } \\
\text { quadrado }\end{array}$ & $\begin{array}{c}\text { Cronbach se o } \\
\text { item for } \\
\text { excluído }\end{array}$ \\
\hline B3Q1 & 1,88 & 1,691 & 27,91 & 267,170 &, 716 &, 570 &, 927 \\
B3Q2 & 1,99 & 2,022 & 27,80 & 256,518 &, 756 &, 652 &, 925 \\
\hline B3Q3 & 2,48 & 2,028 & 27,31 & 253,918 &, 798 &, 737 &, 923 \\
B3Q4 & 1,69 & 1,711 & 28,09 & 264,343 &, 761 &, 681 &, 925 \\
B3Q8 & 2,22 & 2,003 & 27,57 & 253,771 &, 812 &, 700 &, 923 \\
B3Q5 & 1,14 & 1,309 & 28,65 & 276,040 &, 732 &, 580 &, 927 \\
\hline B3Q6 & 2,39 & 2,025 & 27,39 & 248,567 &, 892 &, 852 &, 920 \\
\hline B3Q9 & 2,47 & 2,100 & 27,32 & 249,247 &, 844 &, 800 &, 921 \\
\hline B3Q7 & 2,51 & 2,059 & 27,28 & 247,250 &, 897 &, 870 &, 919 \\
\hline B2Q10 & 3,70 & 1,101 & 26,09 & 307,269 &, 029 &, 043 &, 942 \\
B2Q7 & 2,91 & 1,233 & 26,88 & 307,709 &, 009 &, 075 &, 943 \\
\hline B2Q9 & 2,38 & 2,027 & 27,41 & 259,154 &, 710 &, 595 &, 927 \\
\hline B2Q11 & 2,03 & 1,952 & 27,76 & 257,798 &, 766 &, 674 &, 925 \\
\hline
\end{tabular}

\section{Tabela 7}

Coeficiente alfa de Cronbach na dimensão pedagógica da escala de atitude.

\begin{tabular}{|c|c|c|c|c|c|c|c|}
\hline & Média & $\begin{array}{l}\text { Desvio } \\
\text { Padrão } \\
\end{array}$ & $\begin{array}{c}\text { Média de escala se o } \\
\text { item for excluído }\end{array}$ & $\begin{array}{c}\text { Variância de } \\
\begin{array}{c}\text { escala se o item for } \\
\text { excluído }\end{array}\end{array}$ & $\begin{array}{l}\text { Correlação } \\
\text { de item } \\
\text { total } \\
\text { corrigida } \\
\end{array}$ & $\begin{array}{l}\text { Correlação } \\
\text { múltipla ao } \\
\text { quadrado }\end{array}$ & $\begin{array}{c}\text { Alfa de } \\
\text { Cronbach se o } \\
\text { item for excluído }\end{array}$ \\
\hline B4Q1 & 3,11 & 1,205 & 29,99 & 23,449 & ,275 &, 169 &, 431 \\
\hline B4Q3 & 3,08 & 1,484 & 30,02 & 24,125 & , 122 & , 179 & ,486 \\
\hline B4Q7 & 3,98 & ,965 & 29,13 & 23,511 & ,392 & 231 & ,408 \\
\hline B4Q2 & 3,51 & 1,163 & 29,59 & 25,885 & ,074 & 243 & ,492 \\
\hline B4Q5 & 3,81 & 1,022 & 29,29 & 24,730 & ,230 & , 174 & , 449 \\
\hline B4Q4 & 3,40 & 1,501 & 29,70 & 23,014 & ,198 & ,142 & ,457 \\
\hline B4Q6 & 3,64 & 1,030 & 29,46 & 25,080 & 191 & , 180 & ,459 \\
\hline B4Q8 & 4,10 & ,909 & 29,00 & 24,589 & ,299 & ,245 & ,435 \\
\hline B4Q9 & 2,26 & 1,205 & 30,84 & 26,534 & ,010 & , 170 & ,512 \\
\hline B4Q10 & 2,20 & 1,828 & 30,90 & 19,879 & ,300 & ,171 & ,414 \\
\hline
\end{tabular}


A versão final dos instrumentos para estudantes e professores desenvolvido neste estudo encontram-se nos Anexos C e D. A Figura 19 resume o processo de construção e validação do mesmo.

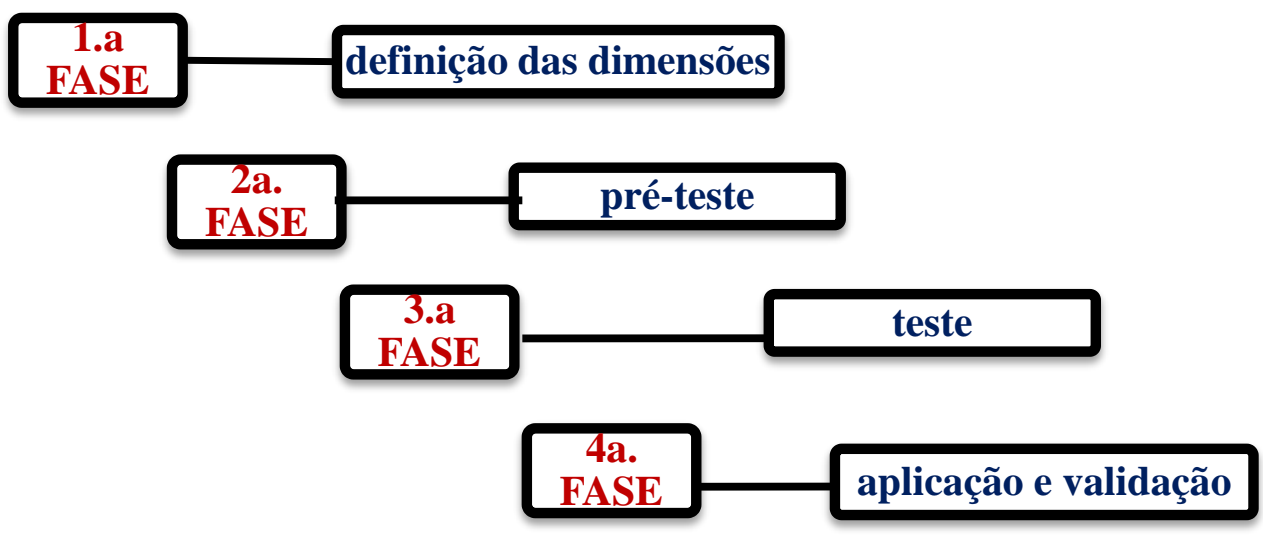

Figura 19. Fases do processo de construção e validação do instrumento

A terceira etapa do projeto refere-se à aplicação do instrumento a todos aqueles que atenderam ao critério de inclusão no estudo: ser acadêmico ou professor dos cursos de graduação de Odontologia, Enfermagem e Medicina da IES onde a pesquisa está sendo desenvolvida. Da aplicação deste instrumento obteve-se uma caracterização inicial dos cursos, em relação às tendências atitudinais de professores e estudantes, com enfoque para o Programa Pró-Saúde.

Na quarta etapa, realizou-se um aprofundamento da análise das experiências com a implementação do Pró-Saúde, de forma qualitativa com participantes que representem os três cursos avaliados neste estudo. O procedimento selecionado para a coleta de dados nesta etapa foi a entrevista. A escolha de entrevistas como recurso metodológico, especialmente a entrevista aberta ou semi-estruturada, deve-se ao fato das mesmas possuírem um papel privilegiado na construção de conhecimentos, sendo caracterizado por Madureira e Branco (2001) como um momento que consiste de um espaço dialógico, perpassado pelos 
significados construídos pelos participantes, ou seja, pelo entrevistado e pesquisador. A entrevista em profundidade explora a percepção e os sentidos elaborados pelos sujeitos (Souza e Oliveira, 2008). É útil para a compreensão dos pontos de vista particulares dos entrevistados e grupos sociais (Gaskell e Bauer, 2002). Yin (2001) ressalta que as entrevistas são uma das mais importantes fontes de informação para estudo de caso.

Dentre as propostas de entrevistas descritas por Flick et al (2009), optamos pela entrevista centrada no problema, sugerida por Witzel (2000) e descrita por Flick et al (2009), por considerá-la a mais apropriada para aproximação à nossa questão de pesquisa. Nela, busca-se traçar biografias profissionais em relação a determinado problema, tendo como pano de fundo teórico o interesse nos pontos de vista subjetivos. Entretanto é necessário estar atento às limitações apontadas pelo autor. Toda entrevista tende a ser centrada em um problema específico; porém na entrevista centrada no problema há uma promessa implícita de que esta seja mais centrada que as demais formas de entrevista. Embora sejam fornecidas instruções prévias ao entrevistador, estas não previnem os dilemas entre profundidade e espectro. As entrevistas foram realizadas pessoalmente e gravadas. O local das mesmas foi acordado de modo a facilitar a participação dos sujeitos. Os tópicos norteadores elaborados para os roteiros das entrevistas são apresentados no Anexo E. A seleção dos entrevistados se deu por meio da busca ativa de sujeitos que pudessem propiciar um aprofundamento e análise do objeto de estudo. O número de entrevistados foi definido pelo critério de saturação. De acordo com Minayo (2008), o número adequado de entrevistas deve ser entendido como aquele capaz de refletir a totalidade nas suas dimensões. A Figura 20 resume as etapas de procedimento de coleta de dados desta pesquisa, assim como sinaliza os produtos já obtidos dos resultados de algumas das etapas. 


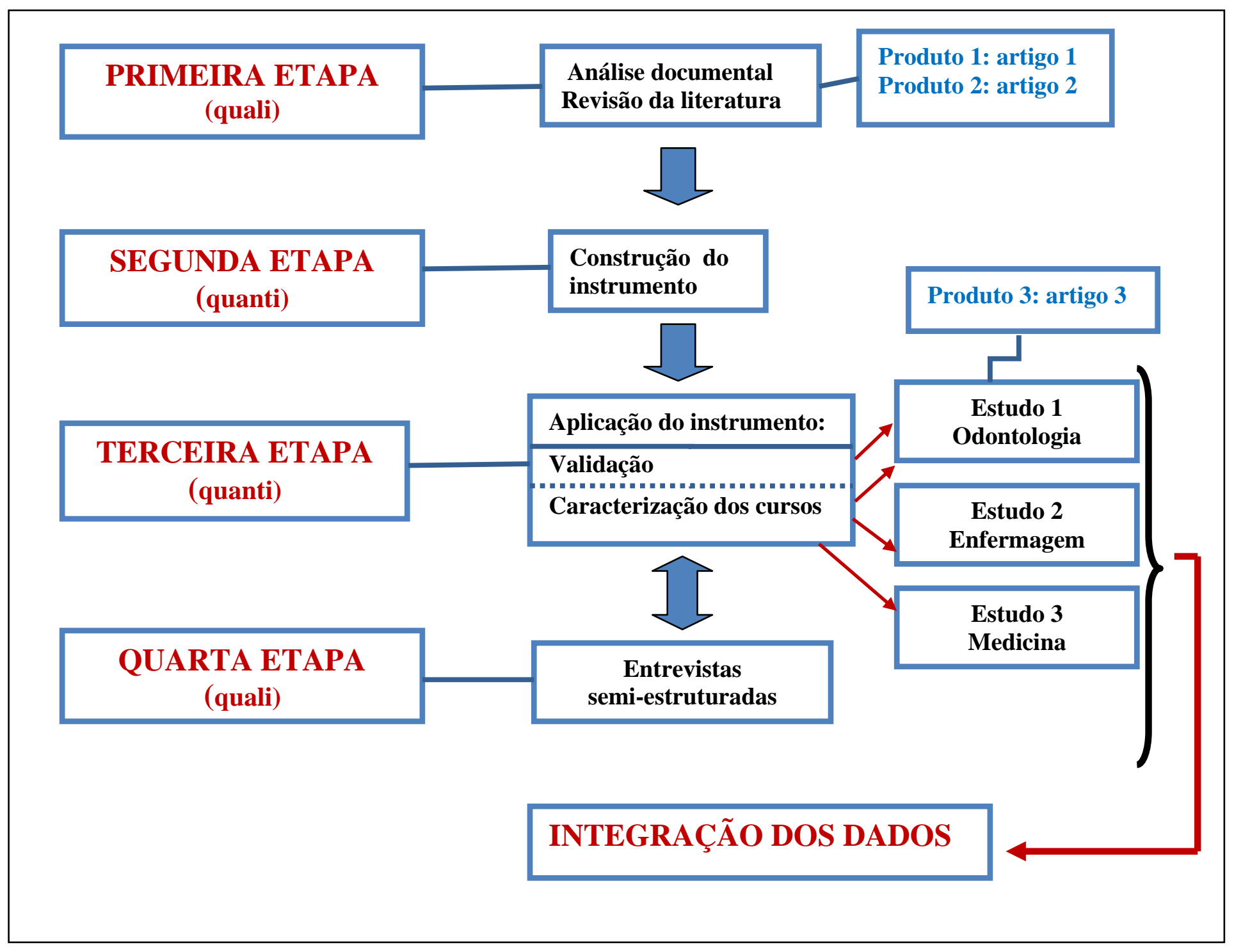

Figura 20. Esquema das etapas de procedimentos de coletas de dados

\subsection{PROCEDIMENTOS PARA ANÁLISE DOS DADOS}

A primeira etapa da análise dos dados foi a análise de validade do instrumento, realizada a partir da aplicação da escala de Likert. O primeiro passo, o qual precedeu a aplicação de testes estatísticos, foi a reorganização dos itens após aplicação do instrumento, de modo que os mesmos fosse reagrupados de acordo com sua aproximação em uma das quatro dimensões. A partir disso, o procedimento de validação do instrumento incluiu a análise da confiabilidade do mesmo utilizando o coeficiente alfa de Cronbach, que mede a 
homogeneidade dos componentes da escala, ou seja, a consistência interna de seus itens (Bisquerra et al, 2004). Esse processo de validação do instrumento foi desenvolvido a partir dos dados coletados com a população, do primeiro curso, incluída no estudo - o curso de graduação de Odontologia. Na sequência, os dados foram analisados e apresentados separadamente, para cada um dos três cursos incluídos no estudo, e para tal os identificamos como Estudo 1 (Odontologia), Estudo 2 (Enfermagem) e Estudo 3 (Medicina). Os resultados em cada estudo foram apresentados da seguinte forma:

1- Análise descritiva dos dados obtidos na seção 1 (para estudantes e professores) e na seção 2 do instrumento (para estudantes e professores)

2- Pontuação dos itens dos quatro blocos da Seção 2, para acadêmicos e professores.

3- Comparação entre os resultados obtidos por acadêmicos e professores, com a aplicação do teste estatístico Kruskall-Wallis.

Os dados coletados foram tabulados no programa Excel 7.0 e para a análise estatística foi empregado o programa SPSS (Statistical Package for the Social Sciences).

Na segunda etapa foi utilizado o procedimento da análise de conteúdo, para a análise do corpus constituído pela transcrição integral das entrevistas. O corpus, no presente estudo, utilizou a conceituação adotada por Bauer e Gaskell (2011), que o considera, como uma coleção finita de materiais definida de antemão pelo pesquisador.

Após a organização do corpus, foi realizada uma leitura flutuante dos textos, para permitir uma familiarização do pesquisador com os dados obtidos (Bardin, 2009). Para a definição das categorias, foi empregado o procedimentos de caixas, definido por Bardin (2009) como um sistema em que as categorias são pré-definidas, baseadas em hipóteses 
teóricas. Neste estudo, as categorias temáticas definidas foram as dimensões definidas no instrumento utilizado na etapa quantitativa. A partir da definição destas categorias, realizou-se um aprofundamento no corpus para a determinação de subcategorias e unidades de registro. Esta etapa foi também realizada e apresentada dentro de cada estudo.

Por último, realizou-se uma análise comparativa entre os resultados obtidos de acadêmicos e professores entre os três cursos, com a aplicação dos testes estatísticos de análise de correlação de Pearson e ANOVA para comparação dos resultados obtidos dos instrumentos, além da comparação entre as análises de conteúdo obtidas para cada curso, a qual foi do tipo triangulação por convergência. $O$ modelo de convergência consiste na coleta e análise separada dos dados quantitativos e qualitativos sobre um mesmo fenômeno. Os resultados obtidos são analisados separadamente, mas interpretados de maneira global pelo pesquisador, a fim de obter conclusões válidas e bem fundamentadas.

\subsection{QUESTÕES ÉTICAS}

Este projeto de pesquisa foi aprovado pelo Comitê de Ética em Pesquisa da Faculdade de Ciências da Saúde da Universidade de Brasília (Parecer no. 62/2012 - Anexo $1)$.

Sendo de natureza educacional, a pesquisa não prevê riscos à saúde dos participantes. Entretanto, considerando o possível desconforto decorrente das falas das pessoas, da apresentação pública das informações coletadas e dos resultados da pesquisa, alguns 
cuidados foram tomados. Todo o sigilo e anonimato foram garantidos aos participantes, por meio do Termo de Consentimento Livre e Esclarecido (TCLE), apresentado no Anexo 2.

O direito à participação voluntária e a desistência em qualquer momento, ou seja, o respeito à autonomia dos participantes, foi assegurada e respeitada.

Os dados coletados serão mantidos sob a guarda exclusiva da pesquisadora e usados segundo os preceitos éticos, apenas para os fins previstos neste estudo. Julgando ser esta pesquisa socialmente relevante, assume-se o compromisso em divulgar e publicar quaisquer que sejam os resultados encontrados, resguardando, no entanto, os interesses dos sujeitos envolvidos.

\section{CAPÍtULO 4}

\section{RESULTADOS}

Os resultados obtidos no presente estudo serão apresentados de forma sintética representando cada uma das etapas do estudo e seus objetivos.

O estudo 1 (Odontologia), o estudo 2 (Enfermagem) e o estudo 3 (Medicina) estão descritos na íntegra na forma de anexos (Apêndices A, B e C). 
As produções desse estudo que já foram publicadas estão apresentadas nessa seção na forma de artigos.

A partir do objetivo 1 do estudo, em que se propôs descrever e analisar o cenário atual da implantação da política indutora Pró-Saúde e a sua contribuição para a reorientação da formação foram obtidas as seguintes produções científicas:

4.1 Artigo 1: Re-orientation of human resources for health: a great challenge for the Brazilian National Health System.

4.2 Artigo 2: Reflexões sobre as bases conceituais das Diretrizes Curriculares Nacionais em cursos de graduação de saúde. 


\title{
AATICLE IN PAESS
}

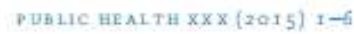

\section{Original Research}

\section{Re-orientation of human resources for health: a great challenge for the Brazilian National Health System}

\author{
D.L.C. Furlanetto", D.L.M. Pinho, C.M.S.F. Parreira \\ University of Brasitia, Brazil
}

\section{A RTICLE IN FO}

Article history:

Received 5 June 2014

Received in revised form

11 January 2015

Accepted 6 July 2015

Available ontine $\mathrm{xxx}$

\section{Keywords:}

Health professional education

Human resources

Brazilian National Health System

\begin{abstract}
A BST R A C T
Objectives: To present the data available and discuss the progress, current advances and challenges of the initiatives, current policies and guidance implemented by the Health and Education Ministries in Brazil to target transfomation of health teaching in order to improve the health care offered by the Brazilian National Health System.

Study design: Literature review.

Methods: Docimentary analysis and review of articles identified in a search of electronic databases, along with reports and documents acquired from the Health and Education Ministries between 1988 and 2013

Results: This study identifed some important initiatives, including the Programme for the Encouragement of Curnicular Changes in Medical Courses (PROMED), implemented in 2002 for medical eourses alone. inspired by PROMID and eovering a wider range of graduate courses, the National Programme for Re-onentation of Health Professionals was implemented in 2005. This initiative launched its third edition in 2012, covering 14 health professional areas, Another relevant innovation was the National Policy of Permanent Health Education, implemented in 2007 , with the goal of transforming public health services into a locus of teaching-learning through working. The Unified Health System Open University was also implemented

Conclusions: There is general concern and ongoing actions involving different sectors in Brazil in an attempt to improve the health of the Brazilin population in the future. However, the changes pursued involve deep transformations and may take considerable time.

D 2015 The Royal Society for Pub tic Health. Published by Elsevier Itd. All rights reserved.
\end{abstract}

\footnotetext{
- Corresponding authar. Colina Bbco J, apt. 301, Campus Universitáno Darcy Ribeiro, Asa Norte, Brasilia, Distrito Pederal 70904-110, Brazil. Tel: $+556135421200,+556182074404$.

E-mail address: dlefurtaohotmail com (D.L.C. Furlanetto)

http//dicdoi.org 10.1016/).puhe, 2015.07.003

0033-3506/0 2015 The Royal Society for Public Health. Published by Elsevier Ltd. All rights reserved.
} 


2 ARTICLE PN PRESS

\section{Introduction}

The World Health organization (WHO) plays a leading role in supporting countries in the challenge of achieving universal health coverage, which is an aspiration and part of the agenda across the world. However, the global shortage of all types of health workers is of concern. As such, human resources for health is an important strategy for WHO and other organizations. ${ }^{1}$

The Brazilian National Health System [Sistema Único de Saúde (SUS)] was established in the Brazilian Constitution in 1988. Comprehensiveness, equality and universa lity are some of its principles in order to guide the provision of health care for the Brazilian population. SUS is a lso responsible for managing the training of health professionals.

The Flexner report ${ }^{2}$ has strongly influenced medical education throughout the world, including Brazil. As a result, the Brazilian health educational system produces professionals with a narrow view of care, with their focus on the in dividual and not the population; on the disease and cure, rather than care and health. As a consequence, in Brazil, there has been considerable growth in medical and other health-related schools and health professionals, but this has not been reflected in the health conditions of the Brazilian population.

The epidemiological transition resulting from aging and the increase in life expectancy means an increase in chronic conditions. As a consequence, most health care systems, which are fragmented systems attuned to the care of acute conditions and characterized by a hierarchical structure without communication flow between the different levels of health care, are facing a crisis in the face of increasing prevalence of chronic conditions. The Brazilian health care profile is now presenting a triple burden of diseases due to the concomitant presence of infectious diseases, external causes and chronic diseases. The current system of health care practice needs to adapt, and one approach could be the implementation of health care networks to achieve comprehensive care for patients. ${ }^{3}$

In order to deal with changes in health and to have a positive ef fect on the quality of health systems and the health outcomes of individuals and populations, educational institutions have to be designed to generate an optimum instructional process.

Investments have been made in this area in recent decades in an attempt to improve the provision of health care for the Brazilian population. The Brazilian national curriculum guidelines for health care courses, published from 2001, anticipated the need for health education plans to incorporate competencies that could correspond with SUS principles. It was also established that it was necessary to introduce innovative teaching-leaming methodologies with a focus on the development of practical activities involving community services, rather than having medical schools as the main learning environment.

Nevertheless, in Brazil, the Dawson report ${ }^{6}$ has been accepted to have a strong influence on the frame of health care networks in terms of the a doption of territorial division in health, need for articulation between public health and individual health care, and association between organization model and management services. ${ }^{7}$ Regarding the influence of the Dawson report on the organization of health systems in Brazil, Carvalho and Ceccim "emphasized its relevance for the management and planning of health systems, and for public health as a whole. They considered that the emphasis of the Dawson report lies in the incorporation of practices in primary care rather than in specialized care, but mainly based on the regular network services as the core, rather than based on college hospitals. The Dawson report places the state as the manager and regulator of public health policies.

One of the greatest challenges in Brazil, and therefore considered to be one of the key issues in the agenda of health policies, is the lack of health professionals prepared to deal with the requirements of SUS. These issues are being addressed through government interventions to incorporate emphasis of the competencies that meet the principles of the Brazilian health system into the health educational plan.

\section{Objective}

The aim of this study is to present the data available, and to discuss the progress, current advances and challenges of some initiatives, current policies and guidance implemented by the Health and Education Ministries in Brazil to target transformation of health education to improve health care offered by SUS.

\section{Methods}

Documentary analysis and a review of the scien tific literature were mnducted via an electronic search of Scielo, Bireme and Lilacs. In addition, the websites of the Health and Education Ministries, and those of other official bodies were searched for relevant reports and documents released between 1988 and 2013.

The keywords used in the searches were: "health professional', 'health education', 'health formation', 'health teaching' and 'health programmes'.

\section{Results}

The searches revealed that important initiatives have been undertaken by the Brazilian Government in recent decades.

\section{Curriculum guidelines}

The implementation of 14 undergraduate programmes, clas sified by the National Health Council as health professional courses, was a starting point initiated in 2001 . $^{5}$ The courses included were: biomedicine, dentistry, life scien ces, medicine, nursing, nutrition, occupational therapy, pharmacy, physical education, physical therapy, psychology, social work, speech and language therapy, and veterinary medicine. This important advance took place following decades of discussions and collective planning, underway since the Brazilian Sanitary Reform in the 1980 s that called for changes in health professional education in order to incorporate the theoretical framework of SUS." It was anticipated that health 
professionals would develop comprehensive social vision and technical ability to provide continuous care for the community, with the aim of addressing the real problems within the Brazilian population. ${ }^{5}$ The curriculum guidelines are innovative as they promote early and progressive inclusion of students in the SUS environment to enable them to have contact with the local community as early as possible, and to gain knowledge that can lead to commitment to addressing local and national health needs.'

\section{Programme for the encouragement of curriculum changes in} medical courses (PROMED)

PROMED was implemented in $20022^{10}$ Its purpose was to provide financial support for medical schools to develop and implement curricular changes in compliance with the national curriculum guidelines ${ }^{5}$ in three key areas: theoretical orientation, practice scenarios and pedagogical approach. The approved projects were developed over a period of three years.

The challenges faced as a result of the proposed actions led to further government initia tives. There was a need to define the manner by which health professional schools and the realities faced when delivering health services could be drawn closer together. Development of the Policy of Education and Development for SUS in 2003 assisted in this approach. The National Policy of Permanent Education in Health was established in 2004. ${ }^{11}$ Permanent education is a concept adopted in Brazil based on the teaching and learning incorporated into the health working process, whereby the issues of health care delivery faced within a job are used as the basis for learning with a focus on discussion, analysis and reflection.

\section{Partnership between Ministries of Health and Education}

Partnership between the Ministries of Health and Education was formalised through Interministerial Decree №, 2.118 in $2005 .{ }^{12}$ Important activities and programmes were already underway, and new initiatives were launched subsequently in order to induce curricular and professional changes that may lead to improvements in health care provision. Since the introduction of a Secretariat of Health Workforce and Education in 2004, the Health Ministry has taken responsibility for formation, regulation and management of health professionals in Brazil.

National programme for re-orientation of health professionals (Pró-Saúde)

Inspired by PROMED and covering a wider range of graduate courses, Pró-Saúde was implemented in 2005. ${ }^{\text {ts }}$ Its main objective was integration between learning and health services to reach the desired changes in health professional training. It aimed to ensure a comprehensive approach to the health-disease process, focusing on primary care in order to promote changes in the teaching-learning process and consequently changes in the quality of services offered to the Brazilian population. ${ }^{14}$ The key areas considered in the project's proposal were inspired by those of PROMED: theoretical orientation, practice scenarios and pedagogical approach Theoretical orientation aims to give priority to the determinants and social aspects of health, clinical epidemiology, evidence-based practice, critical evaluation of primary care, and orientation to the best practices that can allow a permanent education approach, instead of focusing solely on postgraduation and specialities. Practice scen arios aim to use the active process of learning with development of practical activities within the services, working with problem-based learning and also with formative and summative evaluation. The pedagogical approach works with diversity including different environments and levels of attention in health, focusing mainly on primary care, emphasizing the importance of not only technical ability but also the social aspects involved in health care. As a result, there tends to be better in tegration between students and the community, teamwork training and comprehensive provision of health care. ${ }^{14}$

There was emphasis on the need for improvement in primary care, represented in Brazil by the Family Health Programme, initially composed of professionals from medicine, nursing and dentistry. As a result, in the first round of ProSaúde, only these threecourses were eligible to apply with their projects. From the 185 applications, 89 projects that had potential for promoting transformation in the model of training were considered, and received three years of finan cial support for their implementation. ${ }^{13}$ Pró-Saúde is currently in its third edition, and 119 projects covering the 14 health undergraduate programmes were approved in 2012 The Educational Programme for Health Work (PET) was regulated by Interministe. rial Decree No. 1.507 in $2007,{ }^{15}$ offering scholarships for tutors (educators from universities), preceptors (health professionals from the health services) and students from health-related undergraduate degree courses. This programme promotes the formation of tutorial learning groups in strategic areas for SUS, and has, as its principle, education for work. It works as a device to strengthen Pro-Saúde Therefore, only the courses that receive grants from Pro-Saúde are eligible to apply for PET

\section{Unified Health System Open University (UNA-SUS)}

In order to provide large-scale training, UNA-SUS was established in 2008 as an initiative of the Ministry of Health, in partnership with the Pan American Health Organization and other institutions offering training courses and qualifications to health professionals from SUS through a network of accredited educational institutions. The network formed in UNA-SUS links actions of universities and other academic institutions, such as public health schools, health care services and SUS management, in order to meet the proposed objectives, constituting a nationwide network for continuous education in health care. The system aims to receive the contribution from each institution according to its poten tial, and is structured in knowledge production, cooperation in educational technologies, on-site support and educational certification. ${ }^{16}$ The purpose is to create a collaborative, public archive of educational materials for the health sector. It promotes the introduction of new communication and information technologies into health education processes. Decisions about training and qua lification of professiona ls are madeconsidering thenational health policies.

The Programme of Valorization of Health Professionals in Primary Care (PROVAB) ${ }^{17}$ was launched in 2012 to motivate doctors to start their careers in remote areas, where the 
population have difficulties accessing health services. It is compulsory for professionals selected to participatein PROVAB to take a 1-year postgraduate course in family health of fered by UNA-SUS. The professionals activities are supervised by an academic institution. ${ }^{17}$ The supervisors from the institutions are expected to instruct, plan the activities, monitor, and evaluate the professional in their workplace. This initiative promotes the qualification of doctors according to the needs of the population, and provides health services in poorer areas.

\section{Discussion}

Undoubtedly, one of the key points to target for the consolidation of SUS is the public health workforce The Brazilian health system focuses on universal coverage and primary health care, and therefore there is high demand for professionals able to deal with this reality. Worldwide, the importance of engaging in developments that emphasize population health interventions, particularly structural and environmental interventions, has been highlighted. ${ }^{1}$

This study found that various in novative initiatives are underway in order to change the provision of health care in Brazil. Various issues of relevance are addressed below.

\section{Importance of education to population health}

Given that the network health care organization is supposed to have primary care as the cordinator and the centreof care, educational proposals must include actions that focus on comprehensive and permanent care in some of the priority areas such as special needs, chronic conditions, maternity, urgencies, psychosocial areas with priority for drugs and use of alcohol, and indigenous health.

The Family Health Programme, created in Brazil in 1994, has focused on primary care for re-orientation of the health care system. It aims to change the focus from service provision by demand to wider coverage and provision of health actions with more social commitment, and meet the needs and demands of a defined population. Now called the 'Family Health Strategy', it consists of approximately 32,000 teams distributed throughout Brazil. ${ }^{18}$ Since its creation, the Family Health Strategy has become an important job market for health professionals. However, the great expansion of the programme brought the challen ges of dealing with an insufficient number of professionals, and deficiencies in training professionals to work in primary care. These issues have limited consolidation of the strategy, and desirable changes in organization of the Brazilian Healthcare System.

The dearth of health professionals with the necessary competencies to attend to the needs of primary care is due to the focus of academic institutions on the formation of specialists rather than general practitioners. The 2010 Report emphasizes that clinical specialists working in isolation would not strengthen the basic system substantially.

\section{Failure of curriculum reform to respond to population needs}

There is a crisis emerging in the incompatibility of professional competencies to deal with patient and population needs and priorities due to fragmented, outdated and static curricula. In most countries, the education of health professionals $\mathrm{h}$ as failed to overcome dysfunctional and inequitable health systems because of rigid curricula, professional silos, static pedagogy, insufficient adaptation to bcal contexts, and commercialism in the professions. ${ }^{4}$

The curriculum guidelines in Brazil propose the promotion of reflection among those involved in building a new model for health professional qualification. The aim is to enable health professionals to develop the capacity to respond to the health needs of the Brazilian population from both social and technical viewpoints. ${ }^{19}$ However, that is not an easy task as, behind the institutional matter, there are real people for whom the meaning of educational transformation assumes different positions; some become more positive while others are more resistant, according to perceptions. ${ }^{\text {OO }}$ Over the past years, there has been discussion on the challenge of dealing with cultural changes. For years, health professionals have been educated in a culture of health care silos, focusing on the disease and individuals. $^{21}$

\section{Obstacles to implementation of initiatives}

Regarding PROMED, ${ }^{10}$ which was launched just after implementation of the curriculum guidelines, ${ }^{5}$ although its results have not been evaluated, reported obstacles for promotion of the changes proposed by the programme included critical aspects of integration of faculty mem bers with those from the health care network and community. As such, there is a need to improve partmership between medical schools and teaching services. Resistance to changes in the curriculum may be the result of initiating reform prior to having the necessary human resources. The traditional way of teaching has existed for decades, and the training of new lecturers to work within the new curriculum still needs to be established more clearly..$^{22}$

The direction of health care is often driven by the availability of new technologies and therapies, and is often procedure-centred and medicalized. However, this can be countered by educational projects formulated as public policy to train health professionals appropriately to consider the patient or user of services to be at the centre of health care, and to use a progressive health care team with an appropriate matrix of expertise.

\section{Focus on organization and structure}

Implementation of the areas of permanent education in health gathered in a short period of less than two years, more than one thousand different regional centres (Polos), putting into practice the article 14 of the Organic Health Law, which stated that there should be Permanent Commissions of integration between health services and universities, with the goal of giving priority to strategies for the provision of health professional education for the human resources of SUS.

It was expected that using the knowledge gained by this initiative would result in learners being able to develop solutions to the problems detected. ${ }^{22}$ However, what can be realised is that the advancements are more focused on its 
organization and structure, as it happened with the establishment of the Teaching-Service Integration Commission (Comissaa de Integraçäo de Ensino-Serviço - CIES), which replaced the existing local centres. The CIES is assisting with the consolidation of permanent education, as well as its incorporation into the health management agenda as the axis integrating education and work. ${ }^{23}$ Moreira stated that the purpose was to advance two principles of sus: decentralization and regionalization.

There is a belief worldwide that moving more control to local authorities, or decentralization, is one approach to expanding the reach of primary care. However, aritics argue that it may increase fragmentation and disparities, and provide opportunities for local economic and political gains that do not improve population health.?

Failure of the reforms to tackle the distribution of health professionals

The continental dimension of Brazil is also a barrier for qualification provision to health care teams throughout the country. Disparities in the distribution of qualified health professionals are a major challenge. Careers are not a ttractive and wages differ between regions, ${ }^{2 x}$ and these issues are re flected in the inequality of health provision throughout the country. Considering the broader concept of health that recognizes the relevance of social determinants for health conditions, programmes such as UNA-SUS and PROVAB shoul focus on investments that can reach further than the provision of health services. Education and health promotion should be priority actions to deal with health inequalities in deprived areas.

As stated previously (inverse care law), ${ }^{20}$ the availability of good medical care tends to vary inversely with the needs of the population served.

\section{Promising initiatives}

The quality of health professionals degrees was the main concern when Pro-Saude was established. According to the Pró-Saúde Annual Monitoring and Evaluation Seminar in $2008,{ }^{30}$ the service leaming experiences are being shown to deliver key learning outcomes: communication and interpersonal skills; development of the ability to work in a team; leadership development; better understanding of health policy issues; and a broader definition of health. It is beneficial to the community and the health system, as it can provid better-prepared professionals to integrate the health teams. However, it is recognized that one of the major barriers to changing health educa tion is cultural. Although service-based learning can be a powerful tool to improve quality in health education, this strategy is still underestimated as a pedagogic task. This subject needs to be discussed further. ${ }^{x}$

Practical activities in primary care have been identified as challenging experience as they involve lecturers, students health professionals, administrators and the comm unity. Al have singular values, knowledge and experiences that are expected to be shared based on the interdisciplin ary naure and comprehensiveness of the proposed pedagogical approach. $^{3}$
Conclusion

It is undeniable that there is general concern about human resources for health in Brazil Many ongoing actions have demonstrated the progress of investments being directed not only at qualified health professionals already working in public services, through permanent or continuing education, but also at health undergraduate students and those responsible for the education of health students. This scenario has led to proposals at professional, undergraduate and postgraduate levels. Considering that all those involved in the provision of health care play an important role in the quality of a health system, all efforts should be made to prepare present and future health professionals to address the needs of the Brazilian population. However, despite all the attempts presented here, changes will involve deep transformations and may take considerable time.

\section{Author statements}

\section{Acknowledgement}

This research is part of an ongoing PhD project in the Teachin Health Programme, in wh ich the research project will focus on analysis of the Brazilian National Programme for Reorientation of Health Professionals (Pro-Saúde) in dentistry, nursing and medicine degree courses. This paper was presented at the Critical Perspectives on Professional Learning Sixth Annual Conference, Leeds Institute of Medical Education, Leeds, UK.

\section{Ethical approval}

This study did not involve hum an participants and therefore does not require ethical approval. However, as this is part of a $\mathrm{PhD}$ project, ethical approval for the development of other steps of the project was obtained from the Ethical Committee of Health Faculty at University of Brasilia (Protocol No. 62) 2012).

\section{Funding}

PhD Scholarship Coordination for the Improvement of Higher Education Personnel (Coordenaçâo de Aperfeiçoamento de Pessoalde Nivel Superior - CAPES), Education Ministry, Brazil.

Approved project from the National Council of Technobgical and Scientific Development (CNPq), Public Call MCT) CNPq/MS/SCTIE-Decit no. 8/2013.

\section{Competing interests}

None declared

\section{REFEREN CES}

1. Lin V. Universal coverage and the public health workforce. Perspect Publ Fealth 2014,134:245-7. 
2. Fexner A. Mecical edication in the United Stutes and Canuda: a report to the Carnegie Foundation for the Advancement of Teaching. New York: The Camegie Foundation for the Advancernent of Teaching; 1910 ,

3. Arrais PSD, Aguiar ASW, Solma MAN, Machado MMT, Mota MV, Alves R.5, et al. Comprehensivenesss a pedapagical challenge for the Educational Program for Health Work. Rev Brae Edue Méd 2012;36:56-61.

4. Frenk J, Chen L, Bhutta ZA, Cohen J. Crisp N, Evans T, et al. Health professionals for a new century transforming education to strengthen health systems in an interdependent world. Lanat 2010;376:1923-58.

5. Ministério da Educaçāo. Resolução CNE/CES 3/2001. Dürío Oficial da Uniāo, 9 Novembro de 2001 . Seçâo 1. Brasflia: Ministério da Educação 37. Retrieved May 10 2014, from, hitp//portal,mec.gov.br/cne/arquivos/pdf/CESO3,pdf; 200 .

6. Socialist Health Association, Dawson rquart - intes im repart ar the future provision of medical and al Hed senvios. London: Socialist Health Association; 1920.

7. Kuschnir $\mathrm{r}$, Chomy AH. Redes de atenção à saúde: contextualizando o debate. Ciênc Saúd Colet 2010,15:2307-16.

8. Carvalho YM, Cecim RB. Formaça e educacio em sanide: aprendizados com a saúde coletiva. In: Gastīo WS. Mirayo MCS, Akerman M, Drumond finior M, Carvalho MM, editors. Tratado de saúde coleriva. Rio de Faneiro; Hucitec Fibcruz; 2006. p. 149-80.

9. Haddad AE, Morita MC, Pierantoni CR, Brenelli SI, Passarella T, Campos FE, Undergraduate programs for health professionals in Brazil, Reur Salude Plablien 2010,44:383-93.

10. Ministerío da Saúde e Ministério da Educaçäo. Proyrama de Incentivo a Mudarcas Carricularee nos Cursas de Meficina. PROMFD: uma nova Erola Medica para a rem novo Sistema de Saúle. Brasflia: Ministério da Saúde e Ministério da Educaçīo; 2000.

11. Ministerio da Saúde. Politica Nadianal de Educapäo Permanente em 5alide. Portaria no. 198. Diário of cial da Uniāo, 24 fevereiro 2004, Seçào 1 Brasflia; 2004.

12. Ministério da Saúde. Diário oficial Uniâo. Seçâo 1. Portaria Inteministerial $n^{\prime} 2118$ de 03 de novembro de 2005, institui parceria entreo Ministéno da Educaçāo e o Ministerio da Savide para cooperaçäo técrica na formapaio e desenvolvimento de recursas hummos na area di salide, vol. 112. Brasilia: Ministerio da Educação e Ministéno ds Saúde. Retrieved May 30 2014, from, http//download inep.gov.br/download/superior/2005/ avalincao institicional/portaria interninisterial 2118.pdf 2005 .

13. Ministerio da Saude; Ministerio da Educaçăo. Portaria 2.101/ 2005. Pró-Saúde: programa nadianal de reorientaçōo da formaçāo profissianal em saúde. Diaria ofrial da União. Ministerio da Educação e Ministéno ds Saude. Retrieved May 282014 , from. hitp//www.prosaude,org'lepisheao/1-Portaria consellho consultivo parte_1. paf; 2005

14. Ministério da Saúde; Ministerio da Educação. Programa Nacianal de Reorientaçio da Formagũo Profissianal en Savide - PróSaúde objetivos, implementaçāo e desenwohimento potendal. Brasilia: Ministério da Educapào e Ministerio da Saúde. Retrieved May 28 2014, from, http://www. prosaude.org/ publicacoes/pro saude1.pdf; 2007.
15. Ministérí da Saude. Partaria $n^{\prime} 1.507$. Institui a Programa de Educaçōo pebo Trabal ho para a Savide - PET - Savide. Diáño Oficial da Uniâa. Brasitia: Ministério da Safude. Retrieved May 302014 , from, http://bvsms.saude,gov.br/bve/saudelegis/gm/2007/ prit507 $2206 \quad 2007 . h+m l ; 2007$.

16. Ministério da Saude. Relatärib de Gestào 2008-2010 da Universidade Aberta do Sistema Unico de Saude. Brasflia: Secretaria de Cestão do Trabalho e da Educação na Sabde Retrieved May 302014 from, http://wuw unasus gov.br/sites/ default/files/relatorio se unasus.pdf; 2010.

17. Ministerio da Saude. Programa de Valorizaço do Profissional de Atencia Busion - PFOVA.B. Brasilia: Secretaria de Gestao do Trabalho e da Educaçāo na Saúde. Retrieved May 302014 from, http://provab. saude gov.br/; 2013.

18. Ministénio da Saude Giossario temátion: gestajo do trabalho e da edicaçao ma saúde Brasflia: Secretaria de Gestão do Traba tho e da Educaçato na Saude. Retrieved May 302014 from, http.// busms saude.gov. bu/bus/publicacoes/glossario sgtes.pdf; 2012.

19. Souza TY, Branco A, Lopes de Olivein MCS. Pesquisa qualitativa e desenvolvimento humano: aspectos históricos e tendencias atuais. Fractal Rev Peiol 2008,20:357-76.

20. Alves CRL, Belisario AS, Lemos MMC, Abreu DMX, DÁvila LS, Coulart LMHF. Mudanças curriculares: principais difículdades na implementaça do do PROMED, Rev Bras Fitue Med 2013;37:157-66,

21. Hebert CP. Changing the calture: interprofessional education for collaborative patient-centred practice in Canadn, 1 Interprof Care 2005; 1(Suppl) :1-4.

22. Souza PA, Zeferino AMB, Da Ros MA. Changes in medicine course curricula in Brazil encouraged by the Program for the Promotion of Medical School Curricula (PROMID). Bio Med Cent Med Educ 2008,8:5.4.

23. Brasil Lei Orgấica da Salíe. 8080. Brasfia: Gabinete da presidencia da Republica. Retrieved May 302014 from, http:// www.planalto. gov.br/ecivil 03/leie/so80 htm; 1990.

24. Ceccim RB. nducaçáo Pemanente em Saude. descentralizaçâo e disseminaçāo de capacidade pedagógica na saiside. Cienc Savide Colet 2005,10:975-85.

25. Haddad AE. Nursing and the National Policy of Education for Health Care Professionals for the Brazilian National Health System. Fey da Foc de Erfermagem da Universidode de sio Pauls 2011,45(2): 1799-605.

26. Moreira MC. Educaciōo Pemanente em Salk: revisàa sistemírica da literatura cientifion. (Manografia ie Especial iz açäo). Porto Alegre: Universidade Federal do Rio Grande do Sul, 2010.

27. Guanais FC, Madinko J. The health effects of decentmliting primary care in Bnazil Health Aff 2009,28:1127-35.

28. Victora CG, Barreto MI, Leal MC, Monteiro CA, 5chift MI, Paim I, et al. Health conditions and health-policy innovations in Brazil: the way forward. Ianct 2011;377:2012-53.

29. Hard JT. The inverse care law, Lanat $1971,1,405-12$.

30. Ministerio da Saude. II Seminário Nacional do Programa de Reorientaçio da famaçao profissional em savide - PRD-SALIDE. Brasftia: Secretaria de Gestáo do Trabalho e da Educaçáo na Sabde Retrieved May 202014 from, http://www prossude. orgipublicacoes/SegundoSemNacProsaude 1/ RelatoriaSeminarioNacionalProsaude-30ulhozo0s.pd; 2008. 


\section{Reflexōes sobre as bases conceituais das Diretrizes Curriculares Nacionais em cursos de graduaçäo em saúde}

Reflections on the conceptual basis of the National Curriculum Guidelinas for the heaith degree courses

Trenise de Lima Costa Furlasente Mifa Milhoveem thosto Jetro Willumis Silvalutio Dans Locia Moun Finho

Thamano de Psicologa/Facultade de Cailandis da Dhiversitade de Bratla- Unik Hrosilia-Dé

Cotrespondencia Denise de Lima Conpa Furlinet: Univenidade de finsilla - Campas Universi

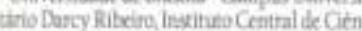

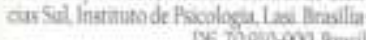
DE, 709.0-900, Bnini dlduhathomaitcan

Rectoidoen $14 /$ julhorzot Aprovadoem L/oututros/2014

\section{RESUMO}

A necessidade de mudanças na formaça profissional em saude term mobilizado as profissoes da área de maneira expressiva. As discussoles ocorrem em torno da necessidade de se implementar as trans formacoes sugeridas nas Diretrizes Curriculares Nacionais para os cursos graduaçlo na área da saude. A grande majoria dos cursos tiveram suas diretrizes publicadas entre 2001 e 2004 . Para a gra duaça em Medicina ha uma recente publicaçao, ocorrida em 2014 Este artigo busca promover uma reflexalo no que se refere ds bases conceituais norteadoras das competências e habilidades gerais pro postas neste documento, com ênfase nos cursos de Enfermagem Medicina e Odontologia. Destacamos a formacio do profissional generalista, a integralidade da atenço e o trabalho em equipe, res. saltando os desafios a serem superados.

Palavnas-chave. Ensino na saúde, Diretrises curriculares; Formaclo profissional 
Furlanemo Dt.ce al

\section{ABSTRACT}

The issues related to the required changes in health professional education have been addressed by the health professions in a crpressive way. The discussions are around the need to reach the transformations proposed by the Curricular Guidelines for under: graduate health courses. The majority of the courses had the referred document published between 2004 and 2004 . There is a recent publication for the undergraduate degree courses in Medicine. $\alpha$ curred in 2014 . This article aims to bring a reflection about the cotceptual basis of the general competencies and abilities proposed on the current guidelines, emphasizing the degrees of Nursing Medrcine and Dentistry. We addressed mainly the role of the geneeal practirioner professional, the comprehensiveness and team work. highlighting the challenged still to be faced and to be overcome

Keywords: Health teaching, Curricular guidelines, Health profes: stional education.

\section{INTRODUÇÄO}

E consenso of ato de que a formaça de recursos humanos é um dos nós criticos para a consolidaçao do Sistema Único de Sande Por muitos anos. oque tem se reproduzidoé uma visalo com enflascem procedimentose cura de doenças, emi detrimento do pensalr saùde. A conceppaso medicalizadora ocupou, e segue ocupando un espaço hierarquicamente superior na cultura académica e na conceppcto do trabalho em saudel. O eixo da medicalizaçalo necessita ser deslocado para uma aruacito interdisciplinar, com base na coletividade, e que oferęa atençao integral, respeitando os principios do Sistema Cnico de Saúde. E ponto-chave para este alcance a mudança do perfil dos profissionais que atuam $e$ passam ser protagonistas de urna nova concepça do processo de trabalho em saùde. Operfil dos egressos de formação superior ma área da saude passou, e ainda passa por ampla discussto dentro do cenairio brasileiro

\section{A Construçâo das Diretrizes Curriculares Nacionais (DCN) para cursos da saúde}

As discussoes que culminaram nas propostas das DCN dos cursos de graduiçito ocorreram em momento privilegiado da nossa sociedade.
Fram pautadas $\mathrm{cm}$ torno da necessidate \& mudancas e envolveram a contribuicla de de versos atores sociais para a elaboractio das DCS em todo o pais. Tal iniciativa foi um avases importante a ter lugar após décadas de discas: soes e plancjamento coletivo em andarmen:s desde a Reforma Sanitaria Brasileira, na decalb de 1980, que exigia mudanças na edacaclo pre fissional em saude que pudessem incorporaz s: referencial teórico proposto pos principios do SUS?

Este de hate mobilizou as diversas prof ivedes 1 r area de maneina expressiva, as quais otara: em concordancia quanto a necessidade de ra? tura ao modelo de curriculo minimo obnesens rio para as carreiras $O$ s movimentos de $=$ ? dança na graduaçào propunham que a aocka de diretrizes indicasse como possibilidade a de sejivel perspectiva transformadora da forma caio de prof issionais de saûde?. Ressalta-se ex cada profissao teve suas diretrizes publicadie separadamente, sendo que para a maicra das cursos, foram homologadas entre 2004 e aOc4

Afirma-seque as DCN foram resultantesdacar relaçâo de forças entre diferentes idecioge: Elas buscavaum dar um direcionamento para 
construçato de um perfil academico e prof tissional cotn competénciass habilidades e conteatdos de acordo com as necessidades atuais das populaçóes! Em seus conteudos foram antecipadasa necessidade de planos de eductecto em saúde que correspondessem a uma formaça academica em consondancia com os principios doSUS. Apontou-se a nocessidade da introdu. ço de metodologias de ensino-aprendizagem inovadoras com laca no deservolvimento de atividades práticas conjuntas coin os serviços de sande. A ideia é a supetacilo do espaco das Instituiçóes de Ensino Superior como o centírio principal ou único de aprendizagem durante a formaçato academica nos cursos de satude?

Conforme consta no artigo $3^{\circ}$ das Resoluçoes que instituem as $\mathrm{DCN}$ publicadas no inicio da decada de 2000 pura os cursos de Fnfermagem. Medicina e Odontologia"t existe uma simila- ridade em relacalo ao perfil geral do formando egresso/profissional que se pretende obter nas areas supracitadas. Os recém-graduados enfermeiros médicos e cirurgioes-dentistas, devem sair com uma formaçlo generalista, humanistica, critica e reflexiva Observa-se comocaracteristica necessiria ao egresso desses cursos, a capucidade de promover a situde integral do ser humano, provocando transformaçese atuando em diferentes niveis de atençio al saude, em prol dar sociedude

$\mathrm{O}$ antigo 4." das referidas $\mathrm{DCN}^{-4}$ estabeleceus que as formar o profissional objeriva-se dota-lo dos conhecimentos requeridos para o exercicio das competéncias e habilidades relacionadas à atencio a saude, á tomada de decisces, a comu: nicaçào à lidenança, a udininistraçao e gerenciamento c educaço permanente (Figura 1)

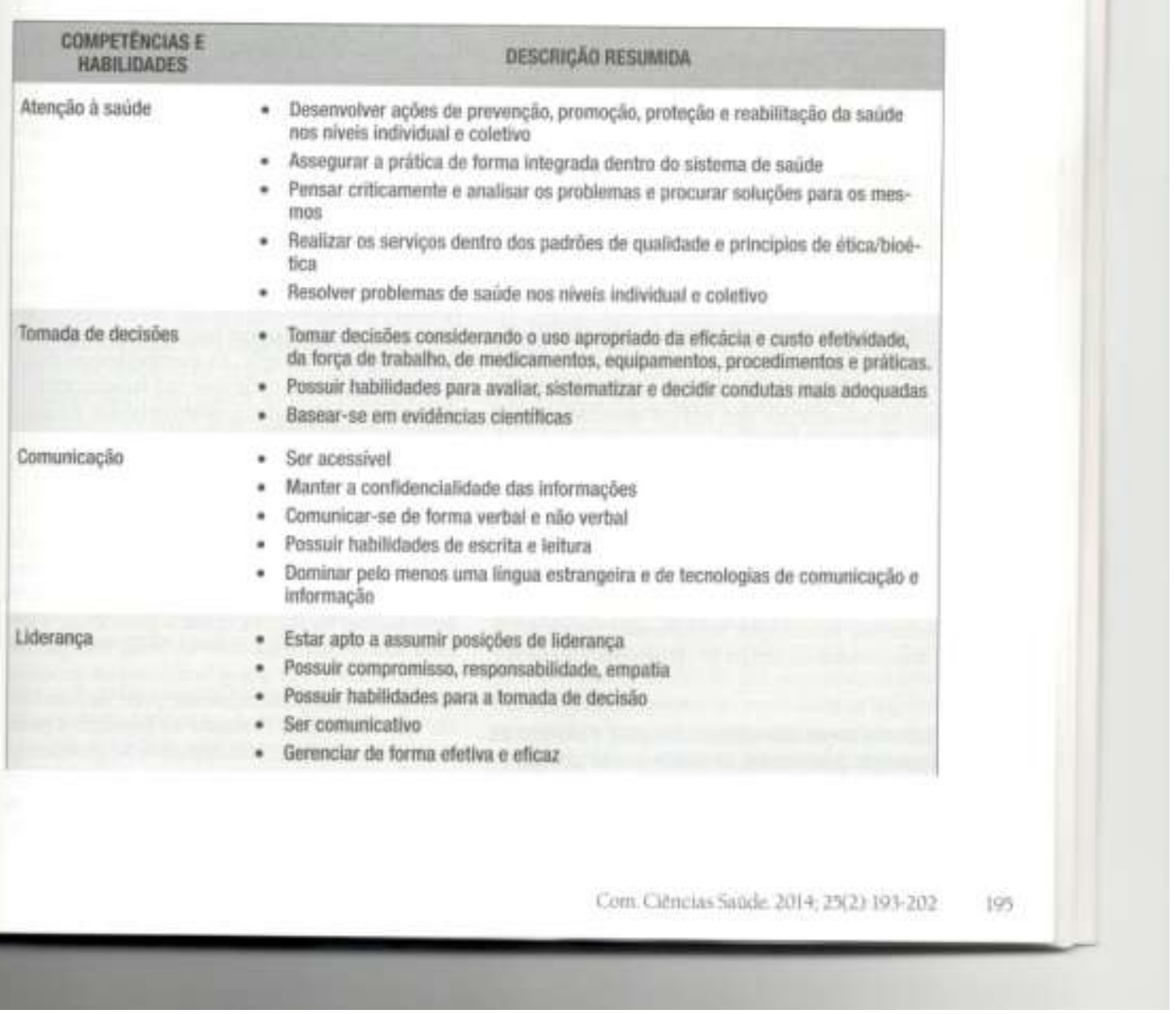


Furlanetho DeCetal.

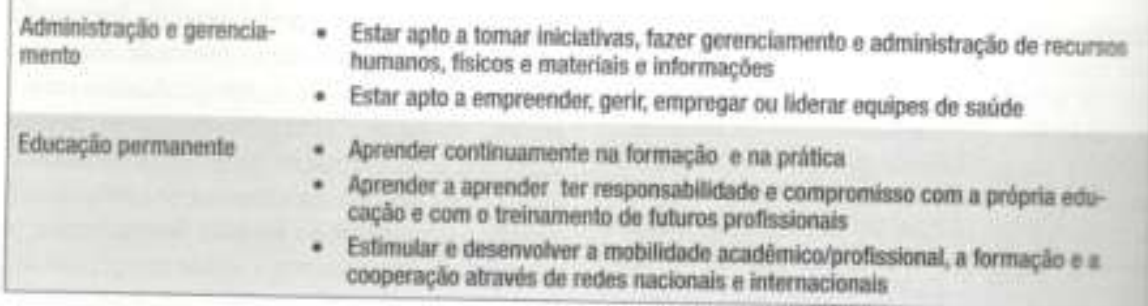

Figura 1.

Resumo das competências e habilidades gerais requeridas aos profissionais, constantes no artigo 4.' das Diretrians Curriculares Nacionals dos cursos de Enfermagem (2001); Medicina (2001) e Odontologia (2002)

Com a recente publicaçalo das DCN para o curso de Medicina, ocorrida em junho de 2014\%; a publicaçato de 2001 para este curso foi revogada Algumas mudanças ocorreram no componente curricular da atual publicasio, como a inclusâo do SUS como cenario de práticas obrigatório, atnavẽs do estagio curricular, com enfase na Atenęlo Basica e no Serviço de Urgéncia e Ernergéncia Além disso, os estudantes serto avaliados a cada dois anos durante o proces. so de formaçto na graduaça As avaliacoes ocotridas serito incorporadas como parte do processo de classificaça para os exames dos programas de residéncia médica. Para o alcance do perfil profissional esperado do graduado em Medicina, o atual documento propoc areas de competencias norteadoras da formacto, incluindo os eixos atençalo em saude, gestao em satude e educaça em saude. Estas estao cm consonancia com as corrupeténcias e habilidades publicadas anteriormente, conforme observado na Figura $L$. O atual documento ressalta que as adequaçóes dos cursos deverào ocorrer ate ofinal de 2018 .

As implementaços propostas nas atuais DCN para a Medicina?, assim como nas DCN anteriores, para Enfermagem, Medicina e Odontolo giat ${ }^{t}$, reforcam a busca pelo perfil gemal deses profissionais, com base em uma formacia generalista, humanista, critico, reflexivo e ético como consta no artigo $3^{\circ}$ desses documentos

Que mudanças são necessárias para o alcance da formaçỉo profissional de saúde que se atmeja?

Neste momento cabe uma reflexalo no que tan$\mathrm{ge}$ as bases conceituais que fundamentam o perfil geral proposto pelas DCN para o prolis sional que se pretende desenvolver durante processo de formaça superior em saude.

Ao se requerer um profissional com formapla generalista, humanista, que oferte savide de forma integral, o que cferivamente se espera dese profissional em relaçao ao prof issional de sasde que atua hoje no pais? Sto transi ormacós que visem subtrair, substiruir aquilo que antesta o fat existente ou buscam-se modificagoes ese possain agregar, acrescentar, adaptar e tomare profissional inais "completo" em sua formacas"

\section{Perfil generalista - que profissional è esse?}

O perfil generalista pressupoe que of porkan nal seja capaz de ir além do ato técricos par que o mesmo desenvolva as compethacien rais que possam suprir lacunas existestes a formaçao em saude ${ }^{10}$. As competencian escr cificas inerentes a cada ärea sto fundamenta devem ser respeitadas e desenvolvidas d o processo de formacalo de maneira assocal as habilidades gerais requeridas pata $=$ formaçat. Enfatiza-se que o generalioea dese ser capaz de conhecer o individuo on nas a tegralidade, de entender o todo como a tar do atendimento das necessidades de mascar pessous. A formactotradicional, con entasea profissional tecnicista, tende a pasiciocar e neralista de maneina inferiorizath incroes a ser resolutivo. Por outro lado, com as ceresen da especializacao, aruaimiente pode se camarar rar que uma visto limitada ao especifice pase acarretat ao nalo reconhecimento de proble maiores, is vezes tanto quanto ou mabs = tantes que o objeto da atenclo especiali = um determinado cuso"l. 
É necessário que o profissional esteja apto a litdar com a subjetividade dos sujeitose com a obktividade de suas condiçoes socioeconomicas e culturais. Fernandes et al. ${ }^{\prime \prime}$ afirmam que ac se produzir um prof issional com perfil generalista, o mesmo estara instrumentalizado para atum nos mais diversos contextos, em oposicica a especializacao precoce, que pode induzir a visoes parciais da realidade.

\section{Em busca da integralidade $\mathrm{e}$ atençẫo à saúde}

No que tange a atença a saúde, descrita como uma das competèncias nas $\mathrm{DCN}$ dos três cursos aqui analisados, afirma-se que o profissional deve estar apto a desenvolver aços de preven. caa promocáo protecace reabilitaçáo da saúde. o que nos remete ao conceito de integralidade. E relevante ressaltar a diversidade de sentidos e terminologias utilizadas para definir essa di retriz do SUS, que inclusive, conforme destaca Mattos nao e a expressado utilizada no artigo 198 da Constituicalo Federal de $1988^{14}$, ao prever "atendimento integral, com prioridade pana as atividades preventivas, sem prejuizo dos servicos assistenciais". Dentre outros, ressaltamos aqui o conceito de integralidade como "um conjunto articulado e continuo das acoes e servicos preventivos e curativos, individuaise coletivos. exigidos para cada caso em todos os niveis de complexidade do sistena" 71 . Nesta perspectiva, a inserçao da nocalo de integralidade busca uma contraposiço ì dissociecalo existente entre as praticas assistenciais, fomentadas pela distinçao entre serviços de saude publica e servicos assistenciais ${ }^{13}$. Na prática, a integralidadeé descrita, cotmo a capacidade dos profissionais para responder ao sofrimento manifesto, que gerou determinada demanda espontanea, de forma articulada a oferta de açoes de prevença e de promocalo de saũde. lsso significa incluir no cotidiano de trabalho rotinas ou processos de busca sistemárica daquelas necessidades mais silenciosas, que antecedem a experiencia individual de sofrimento ${ }^{13}$.

Ao se discutir integralidade $e$ sua inserçito no processo de formaça é gerada uma zona de tensoes a medida que se pressupoe equivocadamente que ao se dur ênfase a Átençıo Básica e a Fstrategia Sadede da Familia durante a formaça profissional propotese uma modelo de formacto com carater substitutivo, que busca excluir os demais locus de ensino e aprendizagem. Entretanto a ideia é expandir para alem do que hoje é oferecido, e que tem demonstrado ser incompleto e ineficaz para a formacio Assim, os hospitais escola tornam-se um do locus, porém nào o ûnico, assim como os cenários incluidos no campo de atuação da Atençac Primària.

A integrafidade das açoes de saude nao devem desconsiderar as avancos da tecnologia na saúde Entretanto, estes devem ser utilizados de forma criteriosa e complementar e nao prioritaria, com sta indicaçao bern fundamentada na atençao à saude, e bascada na melhor evidencia cientifica. A tomada de decisoes, incluida dentre as competéncias descritas nas DCN ${ }^{\circ-4}$, exerce relevante papel neste contexto O desenvol. vitnento da habilidade de avaliar, sistematizar. optar pela conduta mais apropriada, requer do sujeito uma formaçao critica e reflexiva

A formacio profissional, entendida de um modo geral como o preparo técnico para o exercicio de determinadas atividades privilegia o conhecimento aplicado $c$ informaçoes atualf. zadas. Entretanto, uma formaçao básica deve trabalhar conceitos e principios que regem o núcleo fundamental do saber em determinada area. Neste caso privilegia também um conjunto de conhecimentos essenciafs a existencia na dinamica do mundo moderno, ao exercicio da cidadania $e$ a vida profissional. Torna-se entao imprescindivel o desenvolvimento dn capacidade de pensar, de acompanhar os avanços e transformaçoes na sociedade" ${ }^{16}$. O autor alerta pari o possivel equivoco de se crer que a inclusalo de disciplinas vistas como detento: ras de determinadas esteras do conhecimento possam de forma isolada e desconectada com as demais, caracterizar um curso como gerador de uma formacia critica. Defende que os cursose curticulos devem constituir-se em espacos privilegiados da produça do saber, do exerécio da reflexao, do debate e da critica, nos quais ocorram mais dúvidas do que respostasea livre busca seja uma exigencia. Lssocoloca os sujeitos envolvidos, tais como professores e estudantes como condutores de um processo de construcalo, o qual emerge do repensar, do recriar de ideias e do fazer. Exige desses atores superacilo 
de limites cumpliaçato e realizaçato de possibilidades

Ao desenvolver a capacidade de criar, criticar, tomar iniciativas $e$ decisoes. o profissional se torna preparado pura adaptar-see agir de acordo com as situacoes que lhe saio impostas e coth is mudanzas que ocorrem na sociedade. Considera-se que a valorizaça profissional ocorre na medida de sua habilidade para estabelecer relaçoes e assumir liderancas. Uima questao relevante no contexto da sociedade atual apontada por Silvae Cunha "e que osaber ca comunicacto passam a ocupar a maiorta das atividades humanas Os novos profissionais devem set capazes de operacionaltat seu contiecimento de forma integrada as suas aptidoes e vivencias culturais

Ao incluir at educaça permanente como uma das competencias zerais para os profissionais de saude, entende-se a importancia de preparar of futuro profissional para ter condiçóes de arualizar seus conhecimentos de forma conti nuada, respondendo aos desaf los que o mundo soxial $e$ do trabalho the impuserem.

A Pottaria 198/GM de 2004 " explicita seu entendimento de educacao permanente oome uprendizazem no trabalho, onde o aprender e o ensinar se incorporam no cotidiano das organizaçoes $e$ ao trabalho". A implementaça da Politica Nacional de Educicalo Permanente demonstrou o esfarço de tornar a rede pública de sitúde uma rede de ensino-aprendizagem no exercicio do trabalho"s. Fsse conceito foi adotado com o objetivo de dimensionar essa tarefa na ampla intimidade entre formaçalo gestabo atencalo e participacao mediante as interves sóes promovidas pela educacio na saude, com a oferta de suas tecnologias construtivistas e de ensino-aprendizagem 20 . O sujecito que obteve uma formaça básica solida adquire autonomia para buscar informaçoes, transferir apren dizagem de uma area para outra, fazer getreralizacoes, estabelecer relaçoes, tirar conclusoes e encontrar soluçoes para problemas com os quais se deparari"

No item Vidoartigo 4 ' das DCN de 2001 e 2002 anteriormente apresentadas" "e no item 1 do ar tigo $7^{\mathrm{N}}$, da recente publicapao das DCN pura a Medicina", os quais discorrem sobre educacaio permanente. e ressaltada a necessidade de o profissional de saúde ser capaz de aprender 3 aprender. Esta afirmaço faz parte de un dos quatro pilares da Educaça estabelecidos em um relatório elaborado pela Comissào Interna cional sobre a Educacaro para o século XXI, da UNESCO, em 1998, denominado Relatórjo De Ion $^{21}$ em que se propós um novo tipo de edu cacto com enfoque em aprender a conheser aprender a fazer, aprender a viver junto e tam bèm uprender a ser

O pilar ajuender a conhecer supoe a necessidade de se exercitar a atençâ, a memória e o pensamento Envolve o aprender a pensar, a bascar a informaçao, partindo do pressuposto de que o processo de aprendizagem nảo se esgota durante a formaçio profissional e, portanta e necessirio que se obtenha autonomia para buscar o conticeimento durante toda a yida profis. sional.

O aprender a fazer esta ligado al questao de como ensinar o estudante a colocar em priti ca seu conhecimenta A formacio nas deve reduzida apenas a transmissao de praticas to tineiras. Deve implicar no desenvolvimento de competenclas pessoais que extrapolem $=$ obtençao aperas da qualificacto profissional. em seu sentido mais estrito. Envolve adquirir qualidades como ocomportamento social, a ap tidao pana o trabalho em equipe, a capacidade de iniciativa g gosto pelo risea. Delors destace que o aprender a conhecere o aprender a fuzet são indissociaveis, uma vez que aproximam. teoria e a prítica.

O aprender a viver junto representa um dos grandes desafios da educaça, uma vez que envolve o enfrentamento do individualismo e competirividade do mundo atualt:- Trata-se de desenvolver a atitude de empatia, o que podera auxiliar nos comportamentos sociais ao longo da vida. Trata-se de aprender a viver conjuintamente. desenvolvendo o contiecimento dos outros, de sua história, de suas tradiçóes e de sua espiritualidade. A ponta-se que o aprender a construir coletivamente é csencial a me dida que o conhecimento na area de saúde e multiprol tssional $e$ transdisciplinar ${ }^{10}$. Ao se propor a formaça do prof issional generalista pressupoe-s, dentre outras habilidades, a ca pacidade de atuaçlo em equipe. Isso envolve a 
articulaça entre os profissionais de saúde, sendo considerada como uma das estratézias de reorganizaça das praticas de saude. Pieduzzi ${ }^{2}$ conceitua 'trabalho em equipe' multiprof isstonal como uma modalidade de trabalho colerivo que è construido por meio da relaça reciproca. de dupla mato, entre as multiplas intervencoes técrvicas e a interaçalo dos profi issionais de diferentes áreas, configurando, através da comunicacto, a articulacio das açdes $e$ a cooperacao. A autora ressalta que a ideia do trabalho em equipe em saûde aparece respaldada pela nociso de atença integral, pautada pela coletividade. Costa et al. "destacam os desafios para se organizar essa forma de organizacalo do tratualho de modo a contemplar a complexidade de saberes. a responsabilidade coletiva $e$ a efetiva interaça dos recursos humanos de diferentes areas profissionais. Incluem enf retamentos comosuperaçao de atuacoes fragmentadas, isolamento c manutençào de relaçoes de poder entre prol is: sionais e destes com os usuarios, dificultando a produça de uma atençao a saude mais integral e resolutiva. A descoberta do outro e a participaça ein projetos comunts sto apontados como caminhos que podem evitar ou resolver conflitos latentes ${ }^{11}$. Passando a descoberta do outro. necessariamente, passa-se pela descoberta de si mestrio.

O pilar aprender a ser refere-se ao desenvolvimento total do individuo. Um Relatorio denominado "Aprender a ser", publicado em 1972 pela Comissao Internacional sobre o Desenvolvimento da Educaçao't, fi exprimia preocupa. coes com a desumanizaça do mundo relacionado à evoluçào técnica. Assim, assumiusese o postulado do referido relatôrio para descrever esse pilar da educacaa: "o desenvolvimento tem por objeto a realizaçdo comipleta do homem, en toda a sua riqueza e na complexidade das suas expressecs $e$ dos seus compromissos individus membro de uma familia e de uma coletividade, cidadao e produtor, inventor de tánicas e cria. dor de sonhos til Enfatiza-se tambèn que esse desenvolvimento do ser humano $c$ um processo dialetico que se inicia pelo processo de conhecimento de si mesmo para em seguida se abri! para a relaçao com o outro. O perfil humanista que se espera do profissional de saúde, conforme apontado mas DCN requer um retorno a identidade humana, num mundo imerso em novas tecnologiats Moysés ${ }^{7}$ afirma que huma- nisticho assume uma alusao a fítea de humanidades no sentido de posicionar o homem como objeto central de reflexalo. Ao entender que a atença a saude nalo se encerra no ato técnico,e simn, na resoluçato do problema de saúde, tanto em nivel individual quanto coletivo o processo de transformaçato pode avançar com vistas a humanizaças

Para o desenvolvimento do profissional, a educaça atua como utmu ferramenta que é ao mesmo tempo um processo individualizado e também uma construçato social interativa. 0 pilar aprender a ser integra os demais e cria condiçoes para o deserivolvimento integral da pessala, com sensibilidade, sentido etico, responsabilidade pessoal, pensamento autónomo e critico, criatividade, iniciativa e rigor cientifico' ${ }^{12}$

Os quarro pilares da educaço anteriormente descritos nalo se a poiam, exclusivamente, numa fase da vida ou num ánico lugar. Os tempos e as áreas da educaça devem ser repensados. completar-se e interpenetrar-se de maneira que cada individuo ao longo de stua vida, possa titar o melhot partido de um ambiente educativo em constante ampliaçato. Moysés" destaca que esses pilares sao aspectos fundamentais da aprendizagem significativa, e se contrapoem is propostas educacionals de cunho mercadológico Busca-se dessa forma, uma educacio solidäria, com aprendizagens inter-relacionadas $e$ uma educaço integral do ser humano.

\section{CONSIDERACOESS FINAIS}

A intencionalidade inicial na proposiçato das DCN foi a de promover a reflexas para que os sujcitos envolvidos no processo de formaça construam um novo olhar. Espera-se que os profissionais de saude desenvolvarn com isso a capacidade de visao social e técnica dos problemas reais existentes na populaça brasilei-

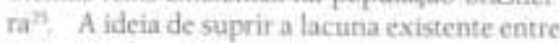
o modelo de saúde vigente e a formaçalo profissional daqueles que nele atuam e vital para o consolidaça de um sistema de saúde que ainda encontra-se em construçio. Por trás da raciona. lidade institucional, existem pessous reais, para as quais os significados de mudanças cducacionats assumem diferentes posicionamentos. 
e por esta rasto elas se tornam favoráveis on resistentes de acordo com suas percepcỏes".

A pesar dos avanços jat obtidos em relaçao a inserça das propostas das DCN nos curriculos dos cursos da saúde, hà um longo caminho a set percorrido para que sejam alcancadas transfor macoes prof undas, que se reproduzam em meThoria a saùde do cidadao brastileino

\section{REFERÉNCIAS}

1. Ceccim RB Inovacio na prepancica de pro fissionais de saude e a novidade da gradua ço em saúde coletiva. Boletim da Sauide. 2002; 16:1):-38

2. Morita MC, Haddad AF, Araùio ME Perfil atual e tendencias do cirurgialo-dentista brasileiro, Maringt Dental Press, 2001

3. Ceceim RB, Feuerwerker LCM O quadrilatero da formaçio para a area da saúde ensino, gestáo, atençao e controle social. Ptyysis 2004:1441) $41-65$

4. Lampert I Rossoni E. Formacalo de profis sionais para o Sistema Unico de Saude e as diretrises curriculares. Boletim da Saúde $2004,18(1) 87-98$

5. Gonzalez AD Almeida MI Movimentos de mudança na formaçáo em saúde da medicina comunitiria as diretrizes curriculares. Physis 2010, 20(2): 551-70

6 Brasil Ministério da Educaçà. Conselho Nacional de Educaçao, Camara de Educacalo Supetior. Diretrizes Curriculares Nat cionais do Curso de Gradiucacio em Enfermagem Diario Oficial da Uniao, Brasilia, 9 de novembro de 200t. Secalo 1. p37. Brasilia, 2001

7. Brasil Ministério da Educaçào Conselho Nacional de Educacalo, Clmara de Fduca. calo Superior. Diretrizes Curriculares Nacionats do Curso de Graduacio em Medicina Diärio Oficial da Uniào, Brasillia, 9 de novernbro de 2001 . Seçato L. p.38 Brasilia, 2001

8 Brasil. Ministerrio da Fducacala. Conseltho Nacional de Fducaçao, Camara de Educacato Superior. Diretrizes Curriculares $\mathrm{Na}$ - cionais do Curso de Graduaça etn Odontologia Diário Oficial da Uniào, Brastia 4 de março de 2002 Seçáo 1. p.10 Brasilaa. 2002

9. Brasil Ministério da Educaçala Conselho Nacional de Fducacasa Camara de Educacao Superior. Diretrizes Curriculares $\mathrm{Na}$ cionais do Curso de Graduaço em Medicina. Diário Oficial da Uniâo, Brasilia, 23 de junhode 2014. Seçao L, p8-1L. Brasilia, 2014

10. Kriger L. Moysés SI. Moysés ST. Humanis mo e formacio prof issional. Gaderno da Aboprev, 20055 Rio de Janeiro.

11. Brasil. Ministério da Saudde/Ministerrio do Educacto Programa Nacional de Reorientacto da Formacto Profissional em Saude Pró-Saùde: objetivos, implementaçao e de senvolvimento potencial. Brasilia-DF: 86n 2097

12. Fernandes ID, Xavier IM, Ceribelli MIPF Bianco MHC Maeda D, Rodrigues MVC Ditetrizes curriculares e estratégias para implantaçào de uma nova proposta peda gógica. Revista da Escola de Enfermagem da USP, $2005.39(4)+443-9$

13. Mattos RA. A integralidade na prática (ou sobre a prática da integralidade). Instituro de Medicina Social, Universidade do Estado do Rio de Janeiro, 2004. Rio de Janeito Brasil. 1412-1416

14. Brasil Constituicto da República Federa tiva do Brasil. Brasilia, DF Senado Federal. 1988

15. Machado MFAS, Monteiro EMLM, Queiroz DT. Vieira NFC. Barroso MGT. Integralida- 
Reflexoes sobre as bases conceinais das Dretrises Curriculares Nacionais

de, formaça de saúde, educaça em saúde e as propostas do SUS - uma revisto conceitual. Universidade de Fortaleza-UFP. 2005 336-342

16. Coelho IM. Diretrizes curriculares e ensino de graduaçao Revista du Associaçào Brasileira de Mantenedoras de Ensino Superior $1998.10 \times 22) 7-20$

17. Silva EL, Cunha MV, A formaçao profissional no século XXI desafiose dilemas Giencia da Informaçáa, 200z, 31(3)77-82 de 13 de fevereiro de 2004. Institui a PollSaúde como estratégia do Sistema Único de Saude para a formaçao e o desenvolvimen. to de trabalhadores para o setor e dat outras providencias Diario Oficial die Uniao, 14 fev 2004: Secialo 1

19. Ceccim RB Educaçato Permunente em Saúde: deccentralizaçào e disseminaçao de capacidade pedagógica na saode. Ciencia e Saúde Coletiva 2005 5 10(4),975-986.

20. Ceccim RB, Ferla AA. Educaça e saúde ensino e cidadania cotho travessia de fronteiras. Trabalho, Educaçào e 5audde. 2009 . $6(3), 443-456$

21. Delors J. Al-Mufti 1, Amagi 1, Garneiro R, Chumg F, Germek B, et al Educaçao,

de Educaçlo Medica 2013, 37/2):157-166
18 Brasil. Ministério da Saúde. Portaria no 198 tica Nacional de Educaçao Permanente em

um tesouro a descobrir. Relatónio para a UNESCO da Comistio Internacional sobre Educaçào para o século XXI, 1998 . Unesco-Brasil Brasilia-DF

22. Peduzzi M. Multiprofessional heathcare tearn concept and typology. Revista de Saúde Pública. 2001; 3501 103-109.

23. Costa RKS, Enders BC, Menezes RMP. Trabalho em equipe de saúde uma anallse contextual. Ciència, cuidado $\mathrm{e}$ saúde 2008, $7(4) 530-536$

24. Faure E, Herrera F, Kaddoura AR, Lopes H, Petrovsky AV, Rabnema M, et al. Learning to be - the world of education today and tomorrow. Relatório para a Comissio Internacional para desenvolvimento da Educaçao Paris UNESCO, 1972.

25 Moysés S7. A humanizaçato da educaçao em odontologia. Pro-posiçoes $2003,14(40) 87$ 106

26. Souza TY, Branco A, Lopes de Oliveina MCS Pesquisa qualitativa e desenvolvimento humano aspectos históricos e tendencias atuais Fractal: Revista de Psicologia. 2008 $203357-376$

27. Alves CRL, Belisärio AS, Lemos JMC, Abreu DMX, D'Avila LS, Goulart LMHF. Mudancas curriculares principais dificuldades na implementaçlodoPROMED Revista Brasileira

Este trabalho faz parte do projeto de tese de doutorado em andamento na Universidade de Braslia. intirulado "Analise da implementaça do Programa Nacional de Reorientaçao da Formaçıło Profissional em Saude (Pró-Saude) em cursos de Enfermagem, Medicina e Odontologia".

Recursos financeiros Capes - Bolsa de doutorado e Cnpq - Projeto aprovado no Edital MCTI/ CNFq/MS - SCTIE - Decit N0 08/2013 - Pesquisa em educacalo permanente patra SUS e dimensio: namento da força de trabalho em saude/ Concessao de duas bolsas de apoio técrico. Processo
$401437 / 2013-2$ 
Do objetivo 2 do estudo, em que se propôs construir e validar uma escala sobre tendências atitudinais com aspectos relacionados ao Programa Pró-Saúde para estudantes e professores; e do objetivo 3, que pretendeu mensurar as tendências atitudinais de estudantes e professores dos cursos de Enfermagem, Odontologia e Medicina, obteve-se a seguinte publicação:

4.3 Artigo 3: Atitudes de estudantes e professores de odontologia sobre a reorientação na formação profissional.

O instrumento, construído e validade neste estudo, foi adaptado e aplicado em outro contexto, o que resultou na seguinte publicação:

4.4 Artigo 4: Avaliação dos estudantes do Pró-Pet-Saúde sobre as contribuições do Programa Pró-Saúde nos cursos de saúde Campus Darcy Ribeiro - Universidade de Brasília. 
68

ARTIGO ORIGINAL

\section{Atitudes de estudantes e professores de odontologia sobre a reorientação na formação profissional \\ Attitudes of dental students and professors about the reorientation of health professional}

Denise de Lima Costa Furlanetto ${ }^{1}$, Jetro Williams Silva Junior ${ }^{2}$, Mábia Milhomem Bastos ${ }^{2}$, Adriano de Almeida de Lima ${ }^{3}$, Diana Lúcia Moura Pinho ${ }^{4}$

${ }^{1}$ Doutoranda em Ensino na Saúde-Instituto de Psicologia da Faculdade de Ceilândia-UnB

${ }^{2}$ Graduação em Saúde Coletiva, Universidade de Brasilia

${ }^{3}$ Doutor; professor efetivo da Faculdade de Ciências da Saúde, Departamento de Odontologia, Universidade de Brasilia - Campus Universitário Darcy Ribeiro, Brasilia, DF.

${ }^{4}$ Doutora; professora efetiva da Faculdade de Ceilândia e Instituto de Psicologia-UnB; orientadora do projeto de doutorado em andamento.

Resumo:

Introdução: A formação profissional na área de saúde é de extrema importância para a construção, manutenção e consolidação de modelos de saúde. Algumas iniciativas governamentais têm ocorrido no Brasil em prol de modificações na lógica que rege a formação em saúde, a partir das Diretrizes Curriculares Nacionais, desde 2001. O Programa Nacional de Reorientação da Formação Profissional em Saúde (Pró-Saúde), implantado desde 2005, é uma ação conjunta entre Ministérios da Saúde e da Educação, o qual visa incentivar a colocação em prática das propostas das diretrizes. Objetivo: Analisar as atitudes de estudantes e professores de Odontologia, no que se refere às contribuições do Pró-Saúde para a reorientação na formação em um curso de graduação em Odontologia. Casuística e Métodos: A amostra foi composta por 191 estudantes e 28 professores de Odontologia de uma Instituição de Ensino Superior. Cada participante respondeu a um instrumento do tipo escala de Likert, construido e validado especificamente para este estudo, com base nos eixos temáticos propostos no Programa Pró-Saúde. Resultados: Os resultados apontam para posicionamentos favoráveis em direção a mudanças que possam fortalecer uma formação generalista crítica e que consiga atender às demandas do sistema de saúde vigente no país. Conclusão: Apesar dos avanços, fícou demonstrado que há muito a ser trabalhado para que transformações significativas sejam alcançadas.

Descritores: Educação superior; Odontologia.

Abstract:

Introduction: The professional qualification in the health area is of extreme importance for the consolidation of health systems. Some governmental initiatives have been taken in Brazil in order to achieve the expected changes for the health qualification in higher degrees. The starting point was the implementation of the National Curriculum Guidelines, since 2001, for the health undergraduate courses. The Reorientation National Program in Health Professional Formation (PRÓ-SAÚDE), implemented since 2005, was a result of the partnership between the Ministries of Health and Education. The aim of the program is to motivate actions in consonance with the guidelines proposals. Objective: The aim of the present study is to analyse the perception of dental students and professors regarding the contributions of the Pró-Saúde Program to dental undergraduate courses. Patients and Methods: The study was composed by 191 students and 28 professors of a dental undergraduate course. Each participant responded to an instrument specially designed for this study on the basis of the Pró-Saúde axis. Results: The results indicated favourable views regarding the direction that can lead to a good qualification of a dental general practitioner, with critical and reflexive view and that are able to respond to the needs of the Brazilian Unified Health System. Conclusion: Despite the advances, it can be seen that there are many issues to be addressed in order to reach significant transformations.

Descriptors: Higher Education; Dentistry. 
Introdução

A formação profissional na área de saúde e as questões que a envolvem, encontram-se em destaque na agenda de politicas públicas no Brasil. Estão pautadas na necessidade de se alcançar uma qualificação profissional que possa oferecer condições de atender as demandas de um sistema de saúde carente da superação da influência do paradigma flexneriano, ainda hoje considerado o grande responsável pela mais importante reforma das escolas médicas em todo o mundo. A ênfase no modelo biomédico (ou flexneriano), caracterizado por ser centrado na doença e no hospital, conduziu os programa educacionais nos diversos cursos da área de saúde a uma visão reducionista e marcado pela desumanização do atendimento Relaciona-se também à fragmentação do conhecimento e ao consequente comprometimento em relação à responsabilidade sobre o paciente por parte dos profissionais especialistas ${ }^{(1)}$

O modelo hegemônico nos cursos de Odontologia, no mundo ocidental, segue as propostas contidas no Relatório Gies, de 1926, concebido em consonância com o Relatório Flexner, de 1910. Dentro da mesma lógica de proposição de reformas no ensino, o Relatório Gies abordou especificamente o ensino da Odontologia. Caracterizou-se pela migração de um modelo pouco sistematizado à época, para um modelo ancorado na cientificidade para a reorganização da prática odontológica, que passou desde então a orientar-se pelo biologicismo, mecanicismo e curativismo(2). As propostas de ambos os relatórios, Flexner e Gies, expandiram-se mundialmente e aind seguem influenciando a formação dos profissionais da saúde, tanto em paises desenvolvidos quanto em paises em desenvolvimento ${ }^{(3)}$.

Atualmente, busca-se um modelo educacional capaz de lidar com as novas demandas em saúde, e que possa orientar-se na construção do paradigma da integralidade e ter como imagemobjetivo uma formação mais contextualizada, que associe dimensões sociais, econômicas e culturais da vida da população, em contraposição ao paradigma flexneriano/ giesiano(2).

Muitos problemas dos sistemas de serviços de saúde, como a iniquidade ao acesso a serviços, o descuido com a saúde coletiva, a fragmentação do cuidado e difículdades na gestão, estão relacionados aos recursos humanos que neles atuam. Sem mudanças nas ações e na formação dos profissionais de saúde, qualquer tentativa de reforma não produz efeitos, ou ate mesmo, pode produzir efeitos contrários ${ }^{(+)}$. Assim, para que o novo paradigma sanitário se efetive em ações e práticas profissionais, é necessário investir na readequação da formação, por meio da reestruturação dos currículos e das metodologias dos cursos de graduação e pós-graduação em saúde, assim como no desenvolvimento dos profissionais que já estão atuando nos serviços ${ }^{(4)}$.

É necessário reconhecer que as mudanças que se espera nos cursos da área da saúde, exijam transformações na lógica do sistema formador. Os movimentos e discussões em prol de mudanças na formação em saúde culminaram em propostas de Diretrizes Curriculares Nacionais (DCN) para os cursos de saúde ocorridas a partir de $2001^{(5)}$. Essas podem ser consideradas um marco, dentro de um cenário refletido por um modelo de formação ultrapassado e que clama por mudanças ${ }^{(\sigma)}$. A construção das DCN vislumbrou, além do estimulo ao debate, a possibilidade de mobilizar os setores da saúde para que passassem a influenciar, de forma organizada, o perfil profissional mais adequado às necessidades da população ${ }^{(7)}$.

Para que as ações se concretizem, são imprescindiveis propostas articuladas que facilitem e motivem a implementação das DCN, representando com isso um avanço dos proje-tos pedagógicos e não uma acomodação de situações existentes. A necessidade de articulação entre Educação e Saúde tem se refletido na forma de implantação de politicas públicas que visam estimular mudança de paradigma na formação superior dos profissionais de saúde ${ }^{(8)}$

Dentre as propostas de indução de mudanças na formação do profissional de saúde, o Programa Nacional de Reorientação da Formação Profíssional (Pró-Saúde), vigente desde 2005, é uma estratégia que visa promover a integração entre o ensino e os serviços de saúde, de modo a alcançar a transformação desejada para os cursos de graduação na área de saúde ${ }^{(9)}$. O Programa Pró-Saúde, ao propor transformações na formação profissional, tomando por base as propostas das DCN para os cursos da área de saúde, almeja alcançar um deslocamento do eixo da formação, centrado na assistência individual prestada em unidades especializadas, para uma formação sintonizada, além da dimensão técnica, com as necessidades sociais, culturais e econômicas da população ${ }^{(10)}$. O Pró-Saúde propõe que os processos de reorientação da formação contemplem simultaneamente três eixos distintos: orientação teórica, cenários de prática e orientação pedagógica. Espera-se com isso, que a formação em saúde obtenha como resultado um profissional com habilidades e competências que possam melhor atender às necessidades da sociedade brasileira ${ }^{(9)}$.

Este estudo tem por objetivo analisar as contribuições do PróSaúde para a reorientação na formação em um curso de graduação em Odontologia.

\section{Casuística e métodos}

Trata-se de uma pesquisa quantitativa, transversal e de caráter descritivo. A abordagem quantitativa se materializa pela construção, validação e aplicação de um instrumento desenvolvido especificamente para a análise da reorientação da formação em cursos de graduação da área da saúde. Com o objetivo de identificar as tendências atitudinais dos participantes da pesquisa, construiu-se uma escala de atitudes. A "atitude" pode ser definida de diversas formas. Seguindo uma conceituação clássica ${ }^{(11)}$, pode-se explicar o termo, como sendo "uma disposição pessoal comum aos indivíduos, mas provida em graus diferentes, a qual os impele a reagir a objetos, situações ou proposições em moldes que podem ser considerados favoráveis ou desfavoráveis".

Os sujeitos incluídos na pesquisa foram estudantes regularmente matriculados no segundo semestre de 2013 e professores do curso de Odontologia de uma Instituição de Ensino Superior (IES), contemplada pelos Editais do Pró-Saúde de 2007 e 2012. Foram excluídos os estudantes que não efetivaram a matricula

Arq. Ciênc. Saúde. 2014out-dez; 21(4) 68-77 
70

em 2013/2 ou que não concordaram em participar, e professores em férias ou licença no período da coleta de dados ou que não aceitaram participar. Esta pesquisa foi aprovada pelo Comitê de Ética em Pesquisa da Faculdade de Ciências da Saúde da Universidade de Brasilia (Protocolo no. CAAE 01660012.6.3001.5078). Todo o sigilo e anonimato foram garantidos aos participantes por meio do Termo de Consentimento Livre e Esclarecido (TCLE). O direito à desistência em qualquer momento e o respeito à autonomia foi sempre assegurado e respeitado, de acordo com as normas vigentes em pesquisas envolvendo seres humanos.

$O$ instrumento empregado na coleta de dados foi construído em etapas e para mensuração das atitudes foi utilizada a escala de Likert. Na primeira etapa, foram definidas as dimensões que orientariam a construção dos itens da escala, tomando como referência o documento do Pró-Saúde e a literatura referente ao tema. A segunda, denominada de pré-teste, referiu-se à análise crítica do instrumento por profissionais com experiência na temática, no intuito de identificar pontos a serem aperfeiçoados. $\mathrm{Na}$ avaliação de fidedignidade da escala, realizou-se o teste de alfa de Cronbach e observou-se o valor de 0,86 na correlação entre os itens.

Para facilidade de preenchimento, o instrumento foi dividido em duas seções. A primeira seção, denominada seção 1 , foi composta pelos dados sociodemográficos, acadêmicos para os estudantes e profissionais para os professores. Nessa seção, algumas informações se diferenciaram, de acordo com os participantes. Já a seção 2, foi dividida em quatro blocos de itens, sendo três deles correspondentes aos eixos descritos no documento do Pró-Saúde (blocos 1, 2 e 4). O bloco 1, incluiu itens da dimensão teórica; no bloco 2 , as afirmativas relacionavam-se à dimensão "cenários de práticas"; o bloco 3 , à dimensão "reorientação da formação" e o bloco 4, à dimensão "pedagógica".

A cada item atribuiu-se uma pontuação, de acordo com o nivel de concordância dos participantes. As assertivas estavam relacionadas a uma atitude positiva ou negativa, em relação à dimensão do bloco. Considerando os niveis de concordância da escala: discordo totalmente (DT); discordo (D); não concordo e nem discordo (NCND); concordo (C); concordo totalmente (CT) e não sei (NS), atribuiu-se - $2,-1,0,+1,+2$ e 9 , respectivamente, ao item categorizado como atitude positiva. Para o item categorizado como atitude negativa, atribuiu-se +2 , $+1,0,-1,-2$ e 9 , respectivamente.

A análise de dados foi conduzida de forma descritiva para os dados sociodemográficos. Para a análise das dimensões, além da análise descritiva, verificou-se a pontuação atribuída aos itens pelos participantes, baseado na atitude positiva ou negativa, definida para cada item em relação às propostas do Pró-Saúde. Foram realizadas análises de interpretação das tendências atitudinais dos resultados obtidos para cada dimensão. Cada item recebeu uma pontuação total, e considerando o total de estudantes $(n=191)$, o valor mínimo e máximo da soma para cada item variou entre -382 pontos (se todos os respondentes pontuassem -2) e +382 pontos (se todos pontuassem +2 ) em cada item. Para os professores $(n=28)$ o valor mínimo da soma variou de -56 (se todos os respondentes pontuassem -2 ) $a+56$ (se todos pontuassem +2 ). Foi realizada uma média geral (M) dos escores obtidos em cada item da escala para possibilitar a comparação entre estudantes e professores, uma vez que dado o fato desses grupos de sujeitos possuírem valores de " $n$ " diferentes, a comparação entre eles pela soma, se tornaria inviável. A partir dos valores de $\mathrm{M}$ obtidos, foi realizada uma conversão para conceito.

Compararam-se os resultados obtidos para acadêmicos e professores, com a aplicação do teste estatístico Kruskal-Wallis Os dados coletados foram tabulados no programa Microsoft Excel $^{\$} 7.0$ e para a análise estatistica foi empregado o programa SPSS (Statistical Package for the Social Sciences), versão 22.

\section{Resultados}

Do total de 223 estudantes de graduação do curso de Odontologia da IES participante do estudo, matriculados no segundo semestre de 2013, um total de $191(85,7 \%)$ aceitaram participar da pesquisa. Quanto aos professores, $28(62 \%)$ aceitaram participar.

Quanto ao perfil sociodemográfico dos estudantes, observouse a predominância da faixa etária entre 21 e 25 anos $(49,2 \%)$ do sexo feminino $(75,9 \%)$. Em relação a questões acadêmicas, com ênfase no Pró-Saúde, mais da metade (56\%) relatou não conhecer o Programa, e apenas $8,9 \%$ afirmaram participar de projetos relacionados ao programa.

Em relação ao perfil sociodemográfico e profissional dos professores, aproximadamente $53 \%$ são do sexo feminino. Em relação à faixa etária, constatou-se que maioria (75\%) está compreendida entre de 30 e 49 anos. A maioria possui 10 anos ou mais de formados e grau de doutorado. Dentre os respondentes, a maioria ministra aulas de disciplinas da área clinica $(60,5 \%)$. Quanto à orientação em projetos, há um predomínio de orientação a projetos de extensão, sendo que apenas $9,6 \%$ dos professores orientam projetos oriundos do Pró-Saúde/Pet-Saúde. Quanto ao tempo de participação em disciplinas inseridas na proposta do Pró-Saúde, verificou-se que em torno de $22 \%$ dos professores participam há mais de três anos nessas disciplinas, seguido por $18,5 \%$ com tempo de participação superior a quatro anos. Um percentual expressivo de aproximadamente $25 \%$, respondeu "não sei" a essa assertiva. Dos entrevistados, $18 \%$ atuam como tutores do Pró-Saúde, e destes, a maioria é voluntário.

Tendência atitudinal dos estudantes e professores frente às quatro dimensões: análise descritiva

$\mathrm{Na}$ dimensão teórica, ao considerar-se conjuntamente as respostas "concordo" e "concordo totalmente", como atitude positiva em relação a um item, verificou-se que em termos de conteúdos ministrados, itens 1 e 2, que avaliaram abordagem de aspectos biológicos e aspectos sociais do processo saúdedoença, respectivamente, a maioria dos acadêmicos respondeu positivamente a ambos os itens, com $95,8 \%$ para o item $1 \mathrm{e}$ $84,9 \%$ para o item 2 . Já os professores, foram unânimes ao se posicionarem positivamente sobre a abordagem de aspectos biológicos nos conteúdos teóricos das disciplinas, com a opção 
"concordo" e "concordo totalmente", totalizando $100 \%$ das escolhas. Em relação à abordagem de aspectos sociais do processo saúde-doença, apesar de não ter ocorrido unanimidade, a maioria $(82,2 \%)$ se posicionou positivamente Em relação ao enfoque da produção de conhecimento, a produção voltada às demandas da sociedade (item 4) e a produção focada em aspectos biomédicos ou tecnológicos da atenção à saúde (item 5 ), foram avaliadas positivamente pelos estudantes com frequências de $49 \%$ e $52,4 \%$, respectivamente. Em ambos os itens, $20 \%$ dos respondentes optaram pela resposta "não concordo nem discordo". Quanto ao desenvolvimento de pesquisa articulada com demandas da sociedade, em torno de $36 \%$ dos professores demonstraram atitudes positivas ao "concordarem ou concordarem totalmente" com o item que abordou essa questão, enquanto aproximadamente $32 \%$ apresentaram atitudes negativas. Um total de $68 \%$ entende que a produção cientifica é focada em aspectos biomédicos. Quanto à ênfase da pós-graduação, maioria dos docentes não acredita que seja voltada para profissionais do SUS, com um total de $53,5 \%$ (representando somatória de "discordo" e "discordo totalmente"). Sobre mesmo tópico, 39,3\% se mostraram neutros ao optarem por "não concordo nem discordo", quanto à oferta dos cursos serem voltadas para a rede privada, seguido de $29,5 \%$ que se manifestaram positivamente ("concordo" e "concordo totalmente"). Nos itens referentes à pós-graduação, a maioria dos estudantes optou pela resposta "não sei".

$\mathrm{Na}$ dimensão cenário de práticas, ao responderem o item relacionado à integração entre universidade e serviços de saúde, estudantes e professores, respectivamente, demonstraram atitudes positivas ("concordo" e "concordo totalmente"), en relação aos beneficios para a comunidade $(97,9 \%$ e $92,8 \%$,), beneficios para o serviço $(89 \%$ e $85,7 \%$ ) e para a própria IES participante $(91,5 \%$ e $92,8 \%)$. Além disso, $67 \%$ dos estudante e $60 \%$ dos professores demonstraram acreditar que o curso de Odontologia contribui para a reorganização dos serviços. Já em relação à infraestrutura das unidades utilizadas como cenário de práticas, $37,1 \%$ dos estudantes e $57 \%$ dos professores as consideraram inadequadas para o processo de ensino e aprendizagem, enquanto $25,9 \%$ (estudantes) e $21,4 \%$ (professores) não souberam opinar sobre essa questão. Os estudantes, na sua maioria $(63,4 \%)$, concordaram que as atividades práticas nos primeiros anos do curso ocorrem em laboratórios. Já entre os professores, as opiniões em relação a este item, se distribuiram entre aqueles que manifestaram concordância em relação ao desenvolvimento das práticas em laboratórios (28,6\%), seguido por $25 \%$ que escolheram a opção "não sei".

Quanto à assertiva da possibilidade das práticas clinicas ocorrerem no ambiente universitário, ambos os grupos demonstraram atitudes de concordância, $87,4 \%$ (estudantes) e $75 \%$ (professores). Entretanto, em relação à afirmação da possibilidade da inserção dos estudantes, desde os primeiros anos do curso no cenário das práticas da atenção básica e serviços de saúde, a maioria (78,5\%), em ambos os grupos, concordaram com a afirmação.

As atitudes dos participantes quanto à dimensão reorientação da formação foi variável, considerando a totalidade das assertivas. Os estudantes apresentaram uma tendência à atitude "não sei", como resposta em 11 itens. Entretanto, quanto às assertivas relacionadas às contribuições do Pró-Saúde, na formação para atuação na rede pública, para a interação entre profissionais da saúde, para a qualidade da formação e para o trabalho em equipe, ao se realizar a somatória das atitudes "concordo" e "concordo totalmente", a maioria dos estudantes demonstrou atitude positiva, seguida pela opção de resposta "não sei".

Em relação ao perfil do profissional formado, o item 10 mostrou que ocorre com ênfase na formação especializada e o item 12 na formação generalista. Nessas assertivas, conforme apresentado na Tabela 1, apesar de ambos os grupos apresentarem atitude de discordância quanto à ênfase na formação focada na especialização e aproximadamente metade de ambos os grupos demonstrarem atitude de concordância quanto à formação generalista, os valores apresentados para tal atitude não se mostraram expressivos.

Tabela 1. Atitude dos estudantes e professores em relação à dimensão "reorientação da formação" (generalista ou especializada).

\begin{tabular}{|c|c|c|c|c|c|c|c|}
\hline $\begin{array}{l}\text { Reorientação da formação } \\
\text { Bloco } 3\end{array}$ & & & & $\begin{array}{l}\text { Nível de C } \\
\text { escala de }\end{array}$ & $\begin{array}{l}\text { rdãn } \\
\text { ert }(\%\end{array}$ & & \\
\hline Item & Grupo & DT & $\mathrm{D}$ & NCND & $\mathrm{C}$ & $\mathrm{CT}$ & NS * \\
\hline $\begin{array}{l}\text { 10- O curso de Odontologia está voltado para a } \\
\text { formação especializada do dentista. }\end{array}$ & estudantes & 6,8 & 34,2 & 19,5 & 25,8 & 11,1 & 2,6 \\
\hline & professores & 10,7 & 42,9 & 21,4 & 17,9 & 7,1 & 0 \\
\hline 12- O curso de Odontologia se volta para a & estudantes & 1,6 & 10,1 & 15,3 & 45,5 & 25,4 & 2,1 \\
\hline formação generalista do dentista. & professores & 0 & 17,9 & 21,4 & 50 & 10,7 & 0 \\
\hline
\end{tabular}

*DT (discordo totalmente); D (discordo); NDNC (não concordo nem discordo); C (concordo); CT (concordo totalmente); NS (não sei)

Arq. Ciênc. Saúde. 2014out-dez; 21(4) 68-77 
72

Os professores demonstraram atitudes favoráveis para a maioria das assertivas incluidas no bloco 3 . Quanto à atitude sobre as contribuições do Pró-Saúde para a integração entre os cursos da área da saúde (item 13), verificou-se uma divisão de opiniões, com um total de $28,6 \%$ dos professores optando pela resposta "não concordo nem discordo", enquanto $25 \%$ responderam "não sei" ao referido item. Em relação à contribuição do Pró-Saúde

Tabela 2: Frequências de respostas obtidas dos estudantes em cada item da dimensão "reorientação da formação".

\begin{tabular}{|c|c|c|c|c|c|c|}
\hline BLOCO 3-REORIENTAÇÃO DAFORMAÇÃO & $\begin{array}{l}\text { Discordo } \\
\text { total- } \\
\text { mente }\end{array}$ & $\begin{array}{l}\text { Discor- } \\
\text { do }\end{array}$ & $\begin{array}{l}\text { Não } \\
\text { concordo } \\
\text { Nem } \\
\text { discordo }\end{array}$ & $\begin{array}{l}\text { Concor- } \\
\text { do }\end{array}$ & $\begin{array}{l}\text { Concordo } \\
\text { total- } \\
\text { mente }\end{array}$ & $\begin{array}{l}\text { Não } \\
\text { sei }\end{array}$ \\
\hline 1- Eu conheço os objetivos do Programa Pró-Saúde. & $9,0 \%$ & $21,2 \%$ & $12,2 \%$ & $14,8 \%$ & $3,7 \%$ & $39,2 \%$ \\
\hline $\begin{array}{l}\text { 2- O Pró-Saúde contribuiu com o processo de reforma } \\
\text { curricular do curso de Odontologia. }\end{array}$ & $1,1 \%$ & $1,6 \%$ & $10,5 \%$ & $26,8 \%$ & $7,4 \%$ & $52,6 \%$ \\
\hline $\begin{array}{l}\text { 3- A participação do estudante no Pró-Saúde contribui para a } \\
\text { sua maior preparação para atuação profissional na rede } \\
\text { pública. }\end{array}$ & $0,5 \%$ & $2,1 \%$ & $8,5 \%$ & $34,9 \%$ & $12,2 \%$ & $41,8 \%$ \\
\hline $\begin{array}{l}\text { 4- A participação do estudante no Pró-Saúde contribui para a } \\
\text { sua maior preparação para atuação profissional na rede } \\
\text { privada. }\end{array}$ & $2,6 \%$ & $12,7 \%$ & $18,0 \%$ & $14,3 \%$ & $3,2 \%$ & $49,2 \%$ \\
\hline $\begin{array}{l}\text { 5- As atividades desenvolvidas no contexto do Pró-Saúde } \\
\text { nas unidades de saúde não alteram as rotinas de trabalho e } \\
\text { nem as práticas dos profíssionais de saúde no serviço. }\end{array}$ & $5,9 \%$ & $23,9 \%$ & $9,6 \%$ & $4,8 \%$ & $1,1 \%$ & $54,7 \%$ \\
\hline $\begin{array}{l}\text { 6- O Pró-Saúde possibilita a interação entre os profissionais } \\
\text { da área de saúde. }\end{array}$ & $0,0 \%$ & $1,6 \%$ & $9,5 \%$ & $35,4 \%$ & $9,5 \%$ & $43,9 \%$ \\
\hline $\begin{array}{l}\text { 7- As atividades desenvolvidas pelos estudantes de } \\
\text { Odontologia no contexto do Pró-Saúde influenciam na } \\
\text { qualidade de sua formação. }\end{array}$ & $0,5 \%$ & $1,1 \%$ & $5,3 \%$ & $38,8 \%$ & $11,2 \%$ & $43,1 \%$ \\
\hline $\begin{array}{l}\text { 8- As atividades desenvolvidas no âmbito do Pró-Saúde } \\
\text { contribuem para a qualificação da prática dos profissionais } \\
\text { que atuam na rede pública de atenção à saúde. }\end{array}$ & $0,5 \%$ & $2,6 \%$ & $7,9 \%$ & $38,9 \%$ & $5,3 \%$ & $44,7 \%$ \\
\hline 9- O Pró-Saúde contribui para o trabalho em equipe. & $1,1 \%$ & $1,1 \%$ & $6,3 \%$ & $33,3 \%$ & $15,3 \%$ & $42,9 \%$ \\
\hline $\begin{array}{l}\text { 10- O curso de Odontologia está voltado para a formação } \\
\text { especializada do dentista. }\end{array}$ & $6,8 \%$ & $34,2 \%$ & $19,5 \%$ & $25,8 \%$ & $11,1 \%$ & $2,6 \%$ \\
\hline $\begin{array}{l}\text { 11- O Pró-Saúde contribuiu para a integração do curso com a } \\
\text { Rede de Serviço de Saúde. }\end{array}$ & $0,5 \%$ & $3,1 \%$ & $11,1 \%$ & $31,1 \%$ & $12,6 \%$ & $41,6 \%$ \\
\hline $\begin{array}{l}\text { 12- O curso de Odontologia se volta para a formação } \\
\text { generalista do dentista. }\end{array}$ & $1,6 \%$ & $10,1 \%$ & $15,3 \%$ & $45,5 \%$ & $25,4 \%$ & $2,1 \%$ \\
\hline $\begin{array}{l}\text { 13- O Pró-Saúde contribuiu para a integração da Odontologia } \\
\text { com os demais cursos da área da saúde. }\end{array}$ & $2,1 \%$ & $7,9 \%$ & $9,5 \%$ & $26,8 \%$ & $9,5 \%$ & $44,2 \%$ \\
\hline
\end{tabular}

$\mathrm{Na}$ dimensão pedagógica, os estudantes demonstraram atitudes positivas em relação à maioria dos itens, com a frequência da somatória dos itens "concordo" e "concordo totalmente", prevalecendo em nove dos dez itens desse bloco. Nesses itens, os estudantes demonstraram acreditar que há integração das atividades envolvendo disciplinas básicas e clinicas $(45,2 \%)$ e que ocorrem atividades interdisciplinares no processo de ensino e aprendizagem (67,7\%). Os estudantes se mostraram positivos no que se refere à interação entre profissionais de saúde, estudantes e comunidade para o processo de ensino e aprendizagem, com um percentual de $86,8 \%$. Quando o item considerou a ocorrência de atividades práticas, envolvendo para a qualificação dos profissionais do serviço de saúde, $39 \%$ demonstraram atitude positiva, apesar de $28 \%$ optarem pelo "não sei".

As frequências obtidas na escala de Likert para a dimensão "reorientação da formação", tanto para estudantes como para professores, estão apresentadas, respectivamente, nas tabelas 2 e 3 .

profissionais das equipes da saúde uma estratégia de pouca relevância para a formação do profissional, os respondentes demonstraram estar desfavoráveis, com a somatória da opção "discordo" e "discordo totalmente", correspondendo a $68,3 \%$ Quanto às estratégias utilizadas, os estudantes consideraram aula expositiva o formato mais empregado para a apresentação de conteúdo teórico $(74,2 \%)$, apesar de também concordarem que existe variação nas estratégias de ensino utilizadas (74,7\%). Já os professores, apresentaram opiniões divididas em diversos itens. Apesar de $35,7 \%$ não considerarem as atividades entre disciplinas clinicas e básicas integradas, $32 \%$ se pronunciaram 
Tabela 3: Frequências de respostas obtidas dos professores em cada item da dimensão "reorientação da formação".

\begin{tabular}{|c|c|c|c|c|c|c|}
\hline BLOCO 3-REORIENTAÇÃO DAFORMAÇÃO & $\begin{array}{l}\text { Discordo } \\
\text { total- } \\
\text { mente }\end{array}$ & $\begin{array}{l}\text { Discor- } \\
\text { do }\end{array}$ & $\begin{array}{l}\text { Não } \\
\text { concordo } \\
\text { Nem } \\
\text { discordo }\end{array}$ & $\begin{array}{l}\text { Concor- } \\
\text { do }\end{array}$ & $\begin{array}{l}\text { Concordo } \\
\text { total- } \\
\text { mente }\end{array}$ & $\begin{array}{l}\text { Não } \\
\text { sei }\end{array}$ \\
\hline 1- Eu conheço os objetivos do Programa Pró-Saúde. & $3,6 \%$ & $0,0 \%$ & $17,9 \%$ & $50,0 \%$ & $179 \%$ & $10,6 \%$ \\
\hline $\begin{array}{l}\text { 2- O Pró-Saúde contribuiu com o processo de reforma } \\
\text { curricular do curso de Odontologia. }\end{array}$ & $0,0 \%$ & $7,1 \%$ & $7,1 \%$ & $39,3 \%$ & $32,1 \%$ & $14,4 \%$ \\
\hline $\begin{array}{l}\text { 3- A participação do estudante no Pró-Saúde contribui para a } \\
\text { sua maior preparação para atuação profissional na rede } \\
\text { pública. }\end{array}$ & $3,6 \%$ & $3,6 \%$ & $10,7 \%$ & $46,4 \%$ & $28,6 \%$ & $7,1 \%$ \\
\hline $\begin{array}{l}\text { 4- A participação do estudante no Pró-Saúde contribui para a } \\
\text { sua maior preparação para atuação profissional na rede } \\
\text { privada. }\end{array}$ & $7,1 \%$ & $17,9 \%$ & $21,4 \%$ & $32,1 \%$ & $7,1 \%$ & $14,4 \%$ \\
\hline $\begin{array}{l}\text { 5- As atividades desenvolvidas no contexto do Pró-Saúde } \\
\text { nas unidades de saúde não alteram as rotinas de trabalho e } \\
\text { nem as práticas dos profissionais de saúde no serviço. }\end{array}$ & $14,3 \%$ & $50,0 \%$ & $14,3 \%$ & $0,0 \%$ & $0,0 \%$ & $21,4 \%$ \\
\hline $\begin{array}{l}\text { 6- O Pró-Saúde possibilita a interação entre os profissionais } \\
\text { da área de saúde. }\end{array}$ & $0,0 \%$ & $3,6 \%$ & $10,7 \%$ & $46,4 \%$ & $25,0 \%$ & $14,3 \%$ \\
\hline $\begin{array}{l}\text { 7- As atividades desenvolvidas pelos estudantes de } \\
\text { Odontologia no contexto do Pró-Saúde influenciam na } \\
\text { qualidade de sua formação. }\end{array}$ & $0,0 \%$ & $0,0 \%$ & $7,1 \%$ & $50,0 \%$ & $32,1 \%$ & $10,8 \%$ \\
\hline $\begin{array}{l}\text { 8- As atividades desenvolvidas no âmbito do Pró-Saúde } \\
\text { contribuem para a qualificação da prática dos profissionais } \\
\text { que atuam na rede pública de atenção à saúde. }\end{array}$ & $3,6 \%$ & $0,0 \%$ & $7,1 \%$ & $39,3 \%$ & $21,4 \%$ & $28,6 \%$ \\
\hline 9- O Pró-Saúde contribui para o trabalho em equipe. & $3,6 \%$ & $0,0 \%$ & $7,1 \%$ & $46,4 \%$ & $32,1 \%$ & $10,8 \%$ \\
\hline $\begin{array}{l}\text { 10- O curso de Odontologia está voltado para a formação } \\
\text { especializada do dentista. }\end{array}$ & $10,7 \%$ & $42,9 \%$ & $21,4 \%$ & $17,9 \%$ & $7,1 \%$ & $0,0 \%$ \\
\hline $\begin{array}{l}\text { 11- O Pró-Saúde contribuiu para a integração do curso com a } \\
\text { Rede de Serviço de Saúde. }\end{array}$ & $3,6 \%$ & $3,6 \%$ & $7,1 \%$ & $42,9 \%$ & $25,0 \%$ & $17,8 \%$ \\
\hline $\begin{array}{l}\text { 12- O curso de Odontologia se volta para a formação } \\
\text { generalista do dentista. }\end{array}$ & $0,0 \%$ & $17,9 \%$ & $21,4 \%$ & $50,0 \%$ & $10,7 \%$ & $0,0 \%$ \\
\hline $\begin{array}{l}\text { 13- O Pró-Saúde contribuiu para a integração da Odontologia } \\
\text { com os demais cursos da área da saúde. }\end{array}$ & $3,6 \%$ & $7,1 \%$ & $28,6 \%$ & $25,0 \%$ & $10,7 \%$ & $25,0 \%$ \\
\hline
\end{tabular}

de forma oposta. Um total de $25 \%$ se manteve neutro sobre essa questão. Metade dos respondentes (50\%) demonstrou tendência a discordar que o curso está estruturado em ciclo básico e clínico. Com relação às metodologias de ensino houve um equilibrio de opiniões sobre o item que se referiu à utilização de aula expositiva, com $46,5 \%$ da somatória de "concordo" e "concordo totalmente", enquanto $42,9 \%$ optaram pelo extremo oposto (soma de "discordo" e "discordo totalmente"). Sobre o uso de metodologias de ensino diversificadas, $82,2 \%$ se posicionou favoravelmente. Os professores demonstraram reconhecer a relevância do emprego de estratégias de ensino que envolva profissionais das equipes de saúde, conforme se observou nos itens que abordaram essa questão.

As tendências atitudinais de professores e estudantes em relação às dimensões

Para a dimensão teórica, observou-se que tanto professores quanto estudantes apresentaram os valores das médias próximos de zero, sendo seus posicionamentos em polos. De um lado, os valores apontaram a tendência negativa para professores $(M=$

$-0,06)$ e do outro lado, a tendência positiva para estudantes ( $M$ $=+0,07$ ).

Os resultados para a dimensão com itens referentes a cenário de práticas, apresentou pequena diferença no valor das médias entre os grupos, sem significância estatística. Ambos, professores e estudantes, apresentaram uma tendência atitudinal positiva em relação ao bloco, de modo que ao se realizar a conversão para o conceito, os dois grupos demonstraram predominantemente concordar com as assertivas. A média obtida dos itens para os estudantes no bloco de reorientação da formação foi de 0,64 e dos professores 0,95. Apesar de ambos os grupos apresentarem o conceito $\mathrm{C}$ (concordo) ao se realizar a conversão, demonstrando uma tendência atitudinal positiva em relação a essa dimensão, a diferença apresentada nas médias dos grupos foi estatisticamente significante. Em todos os itens considerados negativos em relação ao objeto de estudo, tanto professores quanto estudantes, após as conversões das médias, apresentaram os conceitos "discordo" ou "discordo totalmente", ou no mínimo neutro (NCND), reforçando a

Arq. Ciênc. Saúde. 2014out-dez; 21(4) 68-77 
74

tendência positiva em relação a essa dimensão

$\mathrm{Na}$ dimensão pedagógica, os resultados diferiram entre professores e estudantes. Os professores demonstraram uma tendência atitudinal mais positiva que os estudantes em relação a essa dimensão. Entretanto, com exceção do item que afirmava que as atividades práticas envolvendo profissionais das equipes de saúde são estratégias que pouco acrescentam à formação do dentista, dado as especificidades do curso, em que na média os professores obtiveram o conceito "discordo totalmente" e os estudantes "discordo", em todos os demais itens negativos, os estudantes apresentaram uma tendência favorável aos mesmos e, portanto, negativa em relação ao objeto norteador da análise. Os professores apresentaram uma posição neutra ("não concordo nem discordo") em relação a esses iten negativos e, em geral, a média do bloco para os professores fo favorável, com conceito "concordo". Para os acadêmicos, a tendência no bloco foi neutra. Essas diferenças foram estatisticamente significantes. A Tabela 4 apresenta comparação da tendência da atitude, em relação às quatro dimensões entre professores e estudantes.

Tabela 4. Comparação das tendências entre professores e estudantes para as quatro dimensões estudadas

\begin{tabular}{|c|c|c|c|c|c|c|c|c|}
\hline \multirow[b]{2}{*}{ Grupo } & \multicolumn{2}{|c|}{$\begin{array}{l}\text { Bloco } 1 \\
\text { dimensão teórica }\end{array}$} & \multicolumn{2}{|c|}{$\begin{array}{l}\text { Bloco } 2 \\
\text { cenário de práticas }\end{array}$} & \multicolumn{2}{|c|}{$\begin{array}{l}\text { Bloco } 3 \\
\text { reorientação da formação }\end{array}$} & \multicolumn{2}{|c|}{$\begin{array}{l}\text { Bloco } 4 \\
\text { dimensão pedagógica }\end{array}$} \\
\hline & $\begin{array}{l}\text { Média } \\
\text { dos escores }\end{array}$ & Conceito & $\begin{array}{l}\text { Média } \\
\text { dos escores }\end{array}$ & Conceito & $\begin{array}{l}\text { Média } \\
\text { dos escores }\end{array}$ & Conceito & $\begin{array}{l}\text { Média } \\
\text { dos escores }\end{array}$ & Conceito \\
\hline Estudantes & 0,07 & $\begin{array}{l}\text { Não concordo } \\
\text { nem discordo }\end{array}$ & 0,59 & concordo & 0,64 & concordo & 0,28 & $\begin{array}{l}\text { Não concordo } \\
\text { nem discordo }\end{array}$ \\
\hline Professores & $-0,06$ & $\begin{array}{l}\text { não concordo } \\
\text { nem discordo }\end{array}$ & 0,55 & concordo & 0,95 & concordo & 0,55 & concordo \\
\hline $\begin{array}{l}\text { Teste de } \\
\text { Kruskal-Wallis }\end{array}$ & $\mathrm{H}(1)=3,863$ & & $\mathrm{H}(1)=0,045$ & & $H(1)=12,763$ & & $\mathrm{H}(1)=6,043$ & \\
\hline Valor de $\mathrm{p}$ & $\mathrm{p}=0,049$ & & $\mathrm{p}=0,381$ & & $\mathrm{p}=0,005$ & & $\mathrm{p}=0,014$ & \\
\hline
\end{tabular}

Discussão

Frente ao crescente entendimento do papel essencial que os profissionais podem exercer para o fortalecimento e consolidação de modelos de saúde, fica em evidência a necessidade de ações conjuntas entre diferentes setores que vislumbrem transformações na forma de pensar e na forma de atuar em saúde. Tal demanda se refere ao campo das práticas e também à formação daqueles que eventualmente poderão conduzi-las. O que se tem observado nos últimos anos, é que a maioria dos cursos formam profissionais distantes das necessidades de saúde da população e da organização do sistema de saúde do pais ${ }^{(12)}$

Neste estudo foram analisadas as contribuições da implantação da politica intersetorial entre Ministérios da Saúde e Educação, o Programa Nacional de Reorientação da Formação Profissional em Saúde (Pró-Saúde) ${ }^{(10)}$, que possui papel indutor na reorientação da formação do ensino superior em saúde. Apesar de fazer parte de uma pesquisa que envolve mais de um curso, neste estudo foi dada ênfase ao curso de Odontologia. Os dados obtidos se restringem à realidade do curso analisado $\mathrm{e}$, portanto, dadas as particularidades de cada curso e de cada Instituição de Ensino Superior, não seria conveniente extrapolar os resultados aqui apresentados. A partir da análise das dimensões norteadas pelas propostas do Pró-Saúde, este estudo revelou importantes pontos alcançados e questões a serem ainda equacionadas. Entretanto, vale ressaltar que, dada a impossibilidade de aprofundamento de análise no contexto do presente estudo, pretendeu-se obter neste momento, um panorama geral sobre tendências atitudinais, e a partir disso, em estudo seguinte realizar uma abordagem mais detalhada sobre cada dimensão. Este é um aspecto de limitação do presente estudo.

Os resultados relevaram que para a maioria dos estudantes e professores, os conteúdos teóricos ministrados envolvem a abordagem tanto de aspectos biológicos quanto de aspectos sociais do processo saúde-doença. Isto pode indicar que a abordagem em questões que extrapolam o enfoque no especifico e no microambiente provavelmente tem ocorrido Tradicionalmente, a abordagem de aspectos sociais em cursos de Odontologia restringe-se a disciplinas que formalmente possuem como escopo esse enfoque. Entretanto, é imprescindivel que haja o entendimento de que abordagens de cunho social e humanístico, assim como outras competências apontadas pelas DCN para os cursos de Odontologia ${ }^{(13)}$, não deveriam ser interpretadas como atribuições de disciplinas especificas do curso. Isto porque estas abordagens deveriam fazer parte da rotina dentro do processo de ensino-aprendizagem independente da área em questão, uma vez que todo profissional é formado para lidar com pessoas, e para tal deverá estar apto a considerar os diferentes contextos e realidades em que estas estão inseridas. Lampert ${ }^{(14)}$ ressalta o predomínio e a ênfase ao estudo e à pesquisa nas ciências básicas e especializadas, com aprimoramento do conhecimento biomédico de modo aprofundado, porém, fragmentado e dissociado do contexto social. A ênfase em um modelo construído historicamente, 
apoiado no reparo e na cura, em detrimento do cuidado e da promoção de saúde, relegou aos fatores sociais, culturais e econômicos um papel secundário. Isto se mostrou refletido neste estudo, em relação à percepção dos participantes quanto à ênfase dada à pesquisa desenvolvida no local, que para a maioria ainda focada em aspectos biomédicos. Os contornos de um estrutura político- administrativa que separa formalmente ensino da pesquisa, deixa exposto o desafio pela busca por reformulações e reflexões sobre o papel da pesquisa na formação em Odontologia ${ }^{(15)}$

A integração entre universidade e serviços de saúde, abordada na dimensão cenário de práticas, apesar de reconhecida pela grande maioria como positiva para todos os envolvidos, também trouxe à tona suas fragilidades. A infraestrutura das unidades de saúde que recebem os estudantes foi reconhecida como inadequada, o que pode se tornar um fator limitador no processo de integração ensino-serviço. O enfrentamento da falta de estrutura fisica das Unidades Básicas de Saúde foi ressaltado por outras instituições que incorporaram iniciativas de diversificação de cenários de práticas durante a formação. A falta de espaço fisico para abrigar professores, estudantes profissionais; a falta de profissionais para compor as equipes; a inexistência de atividades multidisciplinares foram pontos críticos relatados pelos autores ${ }^{(16-18)}$

É inegável a necessidade de investimento massivo no desenvolvimento de habilidades técnicas para a formação completa e de excelência do cirurgião-dentista. A falta de estrutura dos serviços para incorporar a universidade dentro desse processo, talvez explique a percepção dos participante deste estudo, sobre os espaços de atividades práticas desde os primeiros anos de curso. As atividades práticas clínicas ocorrem dentro do ambiente universitário e nos primeiros ano as aulas práticas ocorrem em laboratórios, de acordo com os resultados encontrados neste estudo. Há um consenso de que para o estudante se tornar um profissional qualificado, se treinamento deve ocorrer nas melhores condições possiveis, certamente as adversidades encontradas no contexto do real entram em choque com essa cultura já estabelecida na área. E inquestionável a importância do domínio de aspectos biológicos e clínicos na formação dos profissionais da saúde, mas também é imprescindivel aliar a isso o desenvolvimento de competências éticas, politicas, econômicas, culturais e sociais ${ }^{(19)}$. Para que isso ocorra, o estudante necessariamente deve assumir um postura ativa de contato com a comunidade, desde o inicio de sua formação. No curso analisado, há um processo de sensibilização sobre essa questão, percebido na forma como estudantes e professores, na sua grande maioria, reconheceram a importância das atividades desenvolvidas nos cenários de práticas dos serviços de saúde para a formação do cirurgiãodentista.

O Programa Pró-Saúde possui como imagem-objetivo reorientar a formação, e para tal, dentre as diversas propostas dos cursos participantes, inclui-se a oportunidade de participação em projetos em que participam estudantes como bolsistas ou voluntários e professores tutores, também nas duas categorias Pelos resultados obtidos neste estudo, no bloco em que houve uma análise mais direcionada em relação ao Programa, observouse que há uma falta de aproximação, principalmente por parte dos estudantes. Uma possivel razão disso poderia ser o fato de que esta pesquisa abrangeu os sujeitos em geral, e demonstraram familiaridade com o Pró-Saúde, apenas aqueles que estão diretamente envolvidos em projetos ligados ao programa, e que de acordo com os resultados, trata-se de uma minoria.

Outro aspecto analisado e que corroborou a detecção da incipiente aproximação dos estudantes com o Pró-Saúde, envolve o fato de o programa ter dentre seus eixos a interdisciplinaridade, de modo a alcançar o "construir coletivamente". Esta pesquisa apresentou respostas, demonstrando que pouco mais da metade dos estudantes entendem haver integração entre disciplinas, reconhecem a relevância de atividades práticas com equipes multiprofissionais e acreditam ocorrer atividades interdisciplinares no curso. Entretanto, o fato de os participantes relatarem que não conhecem o programa, que não sabem opinar se o mesmo tem contribuido para a integração do curso com a rede de serviços e com os demais cursos da saúde, e que não sabem opinar se ele contribui para o trabalho em equipe, demonstra que ainda que o Pró-Saúde seja um indutor dessas ações, elas ainda são pouco abrangentes no curso e não estão sendo entendidas como contribuições do mesmo. Percebe-se que há uma lacuna que não permite uma aproximação entre áreas que, embora possuam objetivos comuns (ou deveriam possuir), mantêm-se focadas nos aspectos relacionados às suas especificidades. A proposta do Pró-Saúde visa uma reorientação da formação. Nesse sentido, mesmo que a participação direta junto ao programa seja de uma minoria, espera-se um alcance abrangente nas transformações na formação propostas. As respostas positivas aos itens deste estudo que contemplavam o escopo do programa demonstram que determinados beneficios já têm sido vivenciados no curso. A implantação das DCN, em 2002 ${ }^{(13)}$, assim como a reforma curricular do curso participante desta pesquisa, em discussão e implantação de algumas mudanças desde 2009 , possivelmente tem produzido seus reflexos na formação.

Ao se posicionarem quanto à formação, generalista ou com ênfase na formação especializada, as opiniões entre professores e estudantes se mostraram divididas, sem destaque em nenhum dos grupos. Se ambos os grupos não tem uma clareza de definição sobre a formação ser generalista ou especializada, ao trazerem divergências de percepções sobre essa questão, fica a demonstrada a inquietação e possibilidade de ampliação e amadurecimento de discussões sobre a temática.

O ensino da Odontologia é marcado por um sistema que forma o profissional para o mercado de trabalho, caracterizado pelo tecnicismo, especialização, e alienação em relação a questões sociais $^{(19)}$. Um estudo qualitativo relatou que a imagem-objetivo de estudantes de Odontologia, em relação à profissão, relevou a predominância de uma visão de mercado liberal, de profissão especializada e de uma prática profissional elitista, afastada da sociedade ${ }^{(20)}$. A abordagem dessas questões é complexa e requer muito mais do que consensos obtidos no que se refere

Arq. Ciênc. Saúde. 2014out-dez; 21(4) 68-77 
76

ao certo e errado, ou beneficios e perdas. Requer mudanças profundas no modo de pensar e agir, de todos os envolvidos. Esse tradicionalismo tem trazido reflexos à profíssão, que durante anos tem tido sua inserção nos sistemas de atenção à saúde de forma paralela e afastada do processo de organização dos serviços de saúde no Brasil(21). A inclusão de equipes de saúde bucal à Estratégia Saúde da Familia (ESF) teve como prioridade, incluir a oferta de serviços que possam melhorar a saúde bucal no âmbito da atenção primária à saúde. Entretanto, é ressaltado que tal proposta se defrontou com a precária disponibilidade de profissionais com visão humanística e que estejam preparados para prestar cuidados contínuos e resolutivos à comunidade ${ }^{(22)}$. Considerando que dentre as caracteristicas do modelo proposto para atuação nas equipes da ESF, inclui-se um maior vínculo e humanização na atenção básica, tal cenário se confronta com as deficiências existentes na formação do cirurgião-dentista, tradicionalmente marcada pela pouca valorização da formação humanistica, cultural e politica ${ }^{(23)}$

Conclusão

O estudo revelou que o Programa Pró-Saúde contribuiu para movimentações em direção a mudanças na formação do cirurgião-dentista, que produziram reflexos na atitude de professores e estudantes em relação às dimensões que estruturam os eixos do Programa. A valorização do cenário de práticas no contexto real do sistema de saúde, a abordagem de aspectos sociais no processo saúde-doença e a formação generalista são algumas dessas respostas. Entretanto, é imprescindivel destacar que os resultados obtidos, diante dos limites do próprio estudo, pelo tipo de instrumento utilizado nessa fase, tornariam precoce considerar o Pró-Saúde como o mentor ou responsável pelas ações ou atitudes favoráveis às transformações desejáveis à formação do cirurgião-dentista, apesar de possivelmente o Programa ter trazido contribuições e fomentado a reflexão dos atores do processo de formação, universidade e serviços de saúde. Além disso, fica evidente a necessidade de se criar estratégias e mais investimentos que possam inserir o Programa no cotidiano de todos os participantes da formação nas IES e no sistema de saúde, para que se concretize a reorientação da formação dos profissionais voltada às necessidades do Sistema Único de Saúde.

\section{Referências}

1-Aguiar RAT. A construção internacional do conceito de atenção primária à saúde (APS) e sua influência na emergência e consolidação do sistema único de saúde no Brasil [dissertação]. Belo Horizonte: Universidade Federal de Minas Gerais; 2003.

2-Cordón JA. Sobre a construção histórica do conceito de Odontologia em saúde coletiva. Ação Coletiva. 1998;1(1):7-26. 3-Baltazar MMM, Moysés SJ, Bastos CCBC. Profissão, docente de odontologia: o desafio da pós-graduação na formação de professores. Trab Educ Saúde. 2010;8(2)285-303

4-Frenk J, Chen L, Bhutta ZA, Cohen J, Crisp N, Evans T, et al. Health professionals for a new century: transforming education to strengthen health systems in an interdependent world.
Lancet. 2010; 376(9756):1923-58 doi: $10.1016 / \mathrm{S} 0140$ 6736(10)61854-5

5-Ministério da Educação. Resolução $\mathrm{CNE} / \mathrm{CES} \mathrm{n}{ }^{\circ} 4$, aprovada em 07 de novembro de 2001. Institui Diretrizes Curriculares Nacionais do Curso de Graduação em Medicina. Diário Oficial da República Federativa do Brasil, Brasilia (DF); 2001; Seção 1, p. 38 .

6-Carvalho YM, Ceccim RB. Formação e educação em saúde aprendizados com a saúde coletiva. In: Gastão WS, Minayo MCS, Akerman M, Drumond Júnior M, Carvalho YM. Tratado de saúde coletiva. Rio de Janeiro: Hucitec Fiocruz; 2006, p.14982.

7-Gonzalez AD, Almeida MJ. Movimentos de mudança na formação em saúde: da medicina comunitária às diretrizes curriculares. Physis. 2010;20(2):551-70

8-Morita MC, Kriger L. Mudanças nos cursos de odontologia e a interação com o SUS. Rev Abeno. 2004;4(1):17-21

9-Ministério da Saúde. Ministério da Educação. Portaria 2.101 2005. Pró-Saúde: Programa Nacional de Reorientação da Formação Profissional em Saúde. Brasilia (DF); 2005.

10-Ministério da Saúde. Ministério da Educação. Programa Nacional de Reorientação da Formação Profissional em Saúde - Pró-Saúde: objetivos, implementação e desenvolvimento potencial. Brasilia (DF); 2007

11-Guilford JP. Psychometric methods. New York: McGraw-Hill; 1954.

12-Ezequiel MCDG, Noel BK, Lemos PP, Paiva AC, Borges LP, Ferreira GM, et al. Estudantes e usuários avaliam ferramenta de educação permanente em saúde - Sieps. Rev Bras Educ Med. 2012;36(1 Supl 2):112-30.

13-Ministério da Educação. Conselho Nacional de Educação, Câmara de Educação Superior. Diretrizes Curriculares Nacionais do Curso de Graduação em Odontologia. Diário Oficial da União, Brasilia (DF), 4 de março de 2002. Seção 1, p.10

14-Lampert JB. Paradigmas da Educação Médica in tendências de mudanças na formação médica no Brasil. São Paulo: Hucitec - Associação Brasileira de Educação Médica; 2009.

15-Maltagliati LA, Goldenberg P. O lugar da pesquisa na reorganização curricular em odontologia: desafios de origem para um debate atual. Saúde Soc. 2011;20(2):436-47.

16-Almeida MM, Morais RP, Guimarães DF, Machado MFAS, Diniz RCM, Nuto SAS. Da teoria à prática da interdisciplinaridade: a experiência do Pró-Saúde Unifor e seus nove cursos de graduação. Rev Bras Educ Med. 2012;36(1 Supl):119-26.

17-Pizzinato A, Gustavo AS, Santos BRL, Ojeda BS, Ferreira E, Thiesen FV, et al. A integração ensino-serviço como estratégia na formação profissional para o SUS. Rev Bras Educ Med 2012;36(1Supl 2):170-7

18-Zeferino AMB, Zanolli MLA, Monteiro MARG Experiência da atenção integral à saúde individual e familiar com enfoque na responsabilização, vínculo médico-paciente, ética e profissionalismo no currículo médico integrado. Rev Bras Educ Med. 2012;36(1 Supl 2):141-6.

19-Moysés SJ. A humanização da educação em odontologia Pro-Posições UNICAMP.. 2003;14(1):40-74. 
20-Lazzarin HC, Nakama L, Cordoni Júnior L. O papel do professor na percepção dos alunos de Odontologia. Saúde Soc. 2007;16(1):90-101

21-Ministério da Saúde. Secretaria de Atenção à Saúde Cadernos de Atenção Básica n. 17. Brasilia (DF): Departamento de Atenção Básica, Saúde Bucal; 2006.

22-Kriger L, Moysés SJ, Moysés ST. Humanismo e formação profissional. Rev Aboprev. 2005;3(1):1-8.

23-Finkler M, Caetano JC, Ramos FRS. A dimensão ética da formação profíssional em saúde: estudo de caso com cursos de graduação em odontologia. Ciênc Saúde Coletiva 2011;16(11):4481-92.

Apoio Financeiro: Coordenação de Aperfeiçoamento de Pessoal de Nivel Superior (CAPES) e Conselho Nacional de Desenvolvimento Científico e Tecnológico $(C N P q)$.

Endereço para correspondência: Universidade de Brasilia Campus Universitário Darcy RibeiroColina, Bloco J, apt. 301 Brasilia, DF, CEP: 70904-110E-mail:dlcfurla@hotmail.com

Arq. Ciênc. Saúde. 2014out-dez; 21(4) 68-77 
$11 / /$

\title{
Avaliação dos estudantes do Pró-PET - Saúde sobre as contribuições do Programa Pró-Saúde nos cursos de saúde Campus Darcy Ribeiro - Universidade de Brasília.
}

\author{
Evaluation of students Pro-PET-Health on the \\ contributions of the Pro-Health Program in health \\ courses Campus Darcy Ribeiro - University of \\ Brasilia.
}
La evaluación de los estudiantes Pro-PET-Salud sobre las contribuciones de la Pro-Salud Programa en cursos de salud Campus Darcy Ribeiro - Universidad de Brasilia.

\author{
Denise Lima Costa FURLANETTO \\ Adriano de Almeida de LIMA ${ }^{2}$ \\ Jetro Williams SILVA JÚNIOR \\ Mábia Milhomem BASTOS \\ Diana Lúcia Moura PINHO
}

\begin{abstract}
RESUMO: A Universidade de Brasilia (UnB) e a Secretaria de Estado de Saúde do Distrito Federal (SES-DF) participam do Programa Pró-Saúde, desde 2007, que é um programa de indução da formação de profissionais de saúde que visa ofertar uma abordagem abrangente sobre o processo saúde-doença com ênfase na atenção primária, a fim de promover transformações no processo de ensino-aprendizagem e, consequentemente, mudanças na qualidade dos serviços. Os efeitos 1 Possui graduação em Odontologia pela Universidade Estadual Paulista Júlio de Mesquita Filho; Especialização em Odontopediatria pela Universidade Estadual Paulista Júlio de Mesquita Filho; Mestrado em Dental Public Health University of Dundee UK.

2 Possui graduação em Odontologia na Faculdade de Odontologia de Piracicaba da Universidade Estadual de Campinas; Mestrado em Materiais Dentários pela Universidade Estadual de Campinas e Doutorado em Clínica Odontológica Área de concentração em Dentística pela Universidade Estadual de Campinas (2001). Atualmente é Professor Adjunto da Universidade de Brasilia - UnB, no departamento de Odontologia.

3 Possui graduação em Gestão de Saúde Coletiva pela Universidade de Brasilia.

4 Graduada em Saúde Coletiva pela Universidade de Brasilia (UnB), foi estudante bolsista de Apoio Técnico e aluna do Programa de Iniciação Cientifica da UnB. Atualmente é estudante de mestrado do Programa de Pós-Graduação em Medicina Tropical - UnB.

5 Graduada em Enfermagem pela Universidade Católica do Salvador (1976), mestre em Educação pela Universidade de Brasilia (1994) e doutora em Psicologia pela Universidade de Brasilia (2002), na área de Ergonomia. Professora Adjunta da Universidade de Brasilia, atua na graduação em enfermagem e na pós graduação nos Programas de Pós Graduação em Enfermagem da Faculdade de Ciencias da Saúde/PPGENF e no Programa de Pós Graduação em Ciências e Tecnologia em Saúde/PPGCTS do Campus UnB Ceilândia, da Universidade de Brasilia.
\end{abstract}


na mudança da formação e incorporação dessa visão precisam ser constantemente avaliados. $\mathrm{O}$ objetivo deste estudo foi analisar a percepção de estudantes bolsistas sobre os alcances doPróSaúde sobre os cursos da área de saúde do Campus Darcy Ribeiro da UnB. O estudo foi uma pesquisa quantitativa, transversal e de caràterdescritivo. Foi aplicado um instrumento para a análise da reorientação daformação em cursos da área da saúde, dividido em duas seções: dados sociodemogrảicos e percepção sobre componentes do Pró-Saúde (dimensão teórica; cenários de práticas; reorientação da formação; dimensão pedagógica). Os 50 estudantes bolsistas ( $62,5 \%$ dos bolsistas) apresentaram os seguintes resultados: faixa etária entre 21 e 25 anos (68\%); sexo feminino ( $72 \%$ ); graduando em Enfermagem (32\%), Medicina (26\%), Odontologia (12\%) e de outros (30\%); no programa há mais de 12 meses $(69,4 \%$; frequência mensal de reuniōes de equipe (44\%); $90 \%$ disseram que poucas ou nenhuma disciplina oportuniza vivência semelhante à do Pró-Saúde; na dimensão teórica, observou-se valores com pequena tendência neutra $(0,04)$; em cenário de práticas observou-se tendência positiva $(0,6)$; assim como a reorientação da formação $(0,82)$; na dimensão pedagógica, tendência neutra $(0,19)$. O Pró-Saúde demonstrou ter trazido suas contribuições aos participantes mais envolvidos no Programa.

Palavras-chave: Educação superior, Educação Profissional em Saúde Pública; Politica de Educação Superior

ABSTRACT: The University of Brasilia (UnB) and SES / DF participate in the Pró-Saúde Programme since 2007, which is an induction training of health workers program to offer a comprehensive approach to the health-disease with emphasis on primary care in order to promote changes in process of teaching and learning and, consequently, changes in the quality of services. The effects in changing the formation and incorporation of this vision need to be constantly evaluated. The objective of this study was to analyze the perception of scholarship students on the Pró-Saúde reaches on healthcare courses of Darcy Ribeiro Campus of UnB. The study was a quantitative, transversal and descriptive research. A tool for the analysis of the reorientation of training in healthcare courses was applied, divided into two sections: demographic data and perception of components of the Pró-Saúde (theoretical dimension, practical scenarios; reorientation training; pedagogical dimension). The 50 scholarship students ( $62.5 \%$ of the stock) showed the following results: age between 21 and 25 years ( $68 \%$ ); female $(72 \%)$; graduating in Nursing $(32 \%)$, medicine (26\%), Dentistry (12\%) and others (30\%); in the program for over 12 months (69.4\%); monthly frequency of team meetings (44\%); $90 \%$ said that few or no discipline nurture experience similar to Pró-Saúde; the theoretical dimension was observed values with small neutral trend $(0.04)$; in practical scenario there was a positive trend $(0.6)$; as well as the reorientation of training $(0.82)$; the pedagogical dimension, neutral trend $(0.19)$. The Pro-Saude showed contributions to the most involved participants in the program.

Key words: Education, Higher, Education, Public Health Professional; Higher Education Policy

RESUMIEN: UNB y SES/ DF participan en el Pró-Saúde desde 2007, que es un programa de inducción de laformación de los profesionales de la saludque tiene como objetivo o frecerun 
enfoque integral de la salud-enfermedad, con énfasis en la atención primariacon el fin depromover cambioselprocesode enseñanza-aprendizajey, en consecuencia, los cambios en lacalidad de los servicios. Los efectosenel cambio dela formacióny la incorporacióndeesta visióndeben ser evaluados constantemente. El objetivo de este estudio fue analizar la percepción de los estudiantes becados acerca de los alcances del programa Pró-Saúde de los cursos de la salud de la UnB/Darcy Ribeiro. El estudio fue cuantitativo, transversal y la investigación descriptiva. Se aplicó un instrumento para el análisis de la reorientación de la formación en cursos de salud, dividido en dos secciones: datos demográficos y de percepción de los componentes del Pró-Saúde (dimensión teórica, escenarios prácticos de capacitación; reorientación; dimensión pedagógica). Los 50 estudiantes ( $62,5 \%$ de las acciones) mostró los siguientes resultados: edad entre 21 y 25 años ( $68 \%)$; hembra $(72 \%)$; con especialización en Enfermeria (32\%), medicina ( $26 \%$ ), Odontologia (12\%) y otros (30\%); en el programa de más de 12 meses $(69,4 \%)$; Frecuencia mensual de las reuniones de equipo $(44 \%) ; 90 \%$ dijo que pocas o ninguna experiencia en la disciplina crianza similar del Pró-Saúde; la dimensión teórica se observó valores con pequeña tendencia neutral $(0,04)$; en escenario de práctica hubo una tendencia positiva $(0,6)$; asi como la reorientación de la formación $(0,82)$; en la dimensión pedagógica, tendencia neutra (0.19). El Pró-Saúde mostró contribuciones alos participantes más involucradosenel programa.

Palabras clave: Educación Superior; Educaciónen Salud Pública Profesional; Politica de Educación Superior

\section{INTRODUÇÃo}

A qualificação e o comprometimento dos profissionais de saúde tornam-se mais do que simples necessidades à medida que passam a ser aspectos cruciais para a real consolidação do Sistema Único de Saúde (SUS) ${ }^{1}$. Ao propor transformações na formação profissional em saúde, tomando por base as propostas das Diretrizes Curriculares Nacionais (DCN) para os cursos da àrea de saúde, o Programa Pró-Saúde almeja alcançar um deslocamento do eixo da formação, centrado na assistência individual prestada em unidades especializadas, para uma formação sintonizada, além da dimensão técnica, com as necessidades sociais, culturas e econômicas da população ${ }^{2}$.

Dessa forma, o Programa Pró-Saúde visa ofertar uma abordagem abrangente sobre o processo saúde-doença com ênfase na atenção primária, a fim de promover transformações no processo de ensino-aprendizagem e, consequentemente, mudanças na qualidade dos serviços ofertados ${ }^{2}$.

O Programa de Educação pelo trabalho em Saúde (PET-Saúde) possui como principio a educação para o trabalho e funciona como dispositivo para fortalecer o Pró-Saúde ${ }^{3}$. O PET-Saúde é composto por grupos tutorais liderados por professores universitários (tutores), e composto por profissionais de saúde que atuam na rede de saúde (preceptores) e estudantes de graduação de cursos da área da saúde. Este programa promove a formação de grupos de aprendizagem tutorial para o trabalho em saúde em áreas temáticas estratégicas do SUS. 
Como o Pró-Saúde busca oferecer como produto recursos humanos mais capacitados para lidar com as demandas contemporâneas em saúde no Brasil, espera-se que todos os envolvidos estejam em processo de crescimento profissional sob a lógica desta proposta.

Nesse contexto, a Universidade de Brasilia (UnB) em parceria com a Secretaria de Estado de Saúde do Distrito Federal (SES-DF) aderiu ao Pró-Saúde desde o segundo edital (Pró-Saúde II), e em 2011, ao Pró-Saúde III articulado ao PET-Saúde. A estratégia de educação pelo trabalho que vem sendo desenvolvida pela UnB e a SES-DF para a consolidação da integração ensino-serviçocomunidade se fundamenta na implementação do Sistema Saúde-Escola (SSE).Este Sistema propõe a reorientação da formação profissional por meio de abordagem integral do processo saúdedoença e de transformações nos processos de geração de conhecimento, ensino-aprendizagem e de prestação de serviços de saúde à população.

Assim, o objetivo deste estudo foianalisar a percepção de bolsistas do Programa Pró-Saúde sobre os alcances obtidos desde a implementação do mesmo em cursos de graduação da área de saúde do Campus Darcy Ribeiro da UnB.

\section{METODOLOGIA}

Trata-se de uma pesquisa quantitativa, transversal e de caráterdescritivo.Os participantes da pesquisa foram estudantes bolsistas do Programa Pró-Saúde do Campus Darcy Ribeiro, da Universidade de Brasilia. Os estudantes pertencem aos cursos de graduaçãode Enfermagem, Farmácia, Gestão em Saúde Coletiva, Medicina, Nutrição e Odontologia.

A abordagem quantitativa se materializoupela construção, validação e aplicação de um instrumento desenvolvido especificamente para a análise da reorientação da formação em cursos de graduação da área da saúde.Com o objetivo de identificar as tendências atitudinais dos participantes da pesquisa, construiu-se uma escala de atitudes. $O$ instrumento empregado na coleta de dados foi construido em etapas e para mensuração das atitudes foi utilizada a escala de Likert. A validação do instrumento está descrito em Furlanettoet al, 2014

Para facilidade de preenchimento, $o$ instrumento foi dividido em duas seções.A primeira seção, denominada seção 1 , foi composta pelos dados sociodemográficos dos participantes. Já a seção 2 , foi dividida em quatro blocos de itens, sendo três deles correspondentes aos eixos descritos no documento do Pró-Saúde (blocos 1, 2 e 4). O bloco lincluiu itens da dimensão teórica; no bloco 2 , as afirmativas relacionavam-se à dimensão "cenários de práticas"; o bloco 3 , à dimensão "reorientação da formação", com itens mais diretos sobre o Programa e o bloco 4 , à dimensão "pecagógica".

A cada item atribuiu-se uma pontuação, de acordo com o nivel de concordância dos participantes. As assertivas estavam relacionadas a uma atitude positiva ou negativa, em relação à dimensão do bloco. Considerando os niveis de concordância da escala: discordo totalmente (DT); discordo (D); 


\section{$15 / /$}

não concordo e nem discordo (NCND); concordo (C); concordo totalmente (CT) e não sei (NS), atribuiu-se $-2,-1,0,+1,+2$ e 9 , respectivamente, ao item categorizado como atitude positiva. Para o item categorizado como atitude negativa, atribuiu-se $+2,+1,0,-1,-2$ e 9 , respectivamente $4^{4}$.

$O$ instrumento foi aplicado por ocasião da realização de uma oficina de 1 dia, oferecida aos bolsistas, pela Coordenação do Programa Pró-Saúde. Todos os presentes foram convidados a participar da pesquisa. O tempo médio de aplicação do instrumento foi 15 minutos.

A anàlise de dados foi conduzida de forma descritivapara os dados sociodemográficos. Para a análise das dimensões, além da anảlise descritiva, verificou-se a pontuação atribuida aos itens pelos participantes, baseado na atitude positiva ou negativa, definida para cada item em relação às propostas do Pró-Saúde. Foram realizadas análises de interpretação das tendências atitudinais dos resultados obtidos para cada dimensão.Cada item recebeu uma pontuação total, e considerando o total de estudantes $(\mathrm{n}=50)$, o valor mínimo e máximo da soma para cada item variou entre -100 pontos (se todos os respondentes pontuassem -2 ) $\mathrm{e}+100$ pontos (se todos pontuassem +2 ) em cada item.

Os dados coletados foram tabulados no programa Microsoft $\mathrm{Excel}^{\$} 7.0$ e para a análise estatística foi empregado o programa SPSS (StatisticalPackage for the Social Sciences), versão 22.

\section{RESULTADOS}

Participaram do estudo 50 estudantes bolsistas do Programa Pró-Saúde do Campus Darcy Ribeiro, da UnB, o que representa um percentual de $62,5 \%$ do total de bolsistas que atualmente participam do Programa Pró-PET-Saúde.

Quanto ao perfil sociodemográfico dos bolsistas, observou-se a predominância da faixa etária entre 21 e 25 anos (68\%) e do sexo feminino (72\%).Dos participantes, $88 \%$ relataram não possuir graduação em outras áreas.A maioria dos incluídos no estudo são graduandos do curso de Enfermagem (32\%), seguidos de $26 \%$ do curso de Medicina e $12 \%$ do curso de Odontologia.

Ao serem indagados quanto às atividades acadêmicas que atualmente participam na universidade, além doPrograma Pró-Saúde, projeto de extensão foi a atividade que obteve o maior percentual de estudantes participantes, representando $16 \%$. Em relação a projetos de iniciação cientifica, $15 \%$ dos estudantes relataram participar, seguidos de $12,9 \%$ que fazem parte de projeto de monitoria. $\dot{E}$ importante ressaltar que os alunos entrevistados podiam eleger mais de uma opção nesta questão, uma vez que a participação em projetos não énecessariamente exclusiva.

Quanto às atividades práticas oferecidas em ambientes externos à Universidade, seja em rotina ou de forma esporádica, nas disciplinas regulares ou optativas, os resultados demonstraram que na percepção da maioria, tais atividades ocorrem a partir do $7^{\circ}$. semestredo curso. Apenas $8 \%$ entendem que atividades externas ocorrem desde os primeiros três semestres de seus cursos.

ISSN $1982-8829$

Tempus, actas de saúde colet, Brasilia, 9(1), 11-24 mar, 2015 
Em questões mais diretamente relacionadas ao Pró-Saúde, quando perguntados se conheciam o Programa, 2 bolsistas responderam "não", muito provavelmente pelo fato de se reconhecerem como bolsista do PET, e não do Pró-Saúde.Quanto ao tempo de participação, $69,4 \%$ desenvolvem atividades há mais de 12 meses. Em relação à frequência de reuniões com tutores, um total de 28 bolsistas $(56 \%)$ relatou que tais encontros ocorrem mensalmente. Quanto à frequência de reuniões com a participação do estudante, tutor e preceptor, $44 \%$ relatou que ocorrem mensalmente, seguidos de $36 \%$ que elegeram a opção "outros" e a descreveram como semanalmente ( $n=14$ ), quinzenalmente ( $n=11)$, pela internet $(n=1)$, não ocorrem $(n=1)$ e apenas 2 vezes $(n=1)$. Um dos itens do instrumento questionou se alguma disciplina do curso oportunizavivência semelhante à da participação no Pró-Saúde. A grande maioria dos participantes do estudo (72\%) optaram pela resposta "poucas", seguido de $28 \%$ que selecionaram a opção "nenhuma".

Tendência atitudinal dos bolsistas frente às quatro dimensões do instrumento: análise descritiva

Para a análise dos resultados obtidos, considerou-se conjuntamente as respostas "concordo" e "concordo totalmente", como atitude positiva em relação a um item, e "discordo" e "discordo totalmente" como atitude negativa.

Para a dimensão teórica, verificou-se que em termos de conteúdos ministrados nas disciplinas dos cursos, os itens 1 e 2, os quais avaliaram abordagem de aspectos biológicos e aspectos sociais do processo saúde-doença, respectivamente, a maioria dos bolsistas $(88 \%)$ respondeu positivamente ao item 1 . Em relação à abordagem de aspectos sociais do processo saúde-doença, apesar da maioria $(60 \%)$ se posicionar positivamente, houve uma divisão de opiniões, uma vez que $20 \%$ assumiram uma postura neutra e $20 \%$ discordaram que tais abordagens ocorrem. Quanto ao desenvolvimento da pesquisa estar articulada com demandas da sociedade (item 4), em torno de $42 \%$ demonstraram atitudes positivas ao "concordarem ou concordarem totalmente" com o item que abordou essa questão, enquanto aproximadamente $26 \%$ assumiram uma postura neutra e $24 \%$ apresentaram atitudes negativas. Um total de $62 \%$ entende que a produção cientifica é focada em aspectos biomédicos (item 5). A maioria ( $48 \%$ ) entende que as disciplinas teóricas de conteuidos relacionados ás áreas básicas, clínicas e sociais são ministradas em blocos separados, sem articulação entre elas.

Na dimensão cenário de práticas, ao responderem o item relacionado à relevância da integração entre universidade e serviços de saúde, os estudantes e demonstraram atitudes positivas ("concordo" e "concordo totalmente") em relação aos beneficios para a comunidade $(98 \%)$, benefícios para o serviço ( $96 \%$ ) e para a própria Instituição de Ensino Superior (IES) participante (98\%). Além disso, $56 \%$ dos estudantes demonstraram acreditar que seus cursos contribuem para a reorganização dos serviços. Já em relação ả infraestrutura das unidades utilizadas como cenảrio de práticas, $32 \%$ as consideraram inadequadas para o processo de ensino e aprendizagem, enquanto $32 \%$ consideraram adequadas e $34 \%$ se mostraram neutros sobre essa questão. A maioria ( $54 \%$ ) concordou que as 
$17 / /$

atividades práticas nos primeiros anos do curso ocorrem em laboratórios.Quanto à assertiva sobre as práticas clínicas ocorrerem no ambiente universitário, $88 \%$ dos participantes demonstraram atitudes de concordância.

As atitudes dos participantes quanto à dimensão reorientação da formaçãosemostraram favoráveis para a maioria das assertivas incluídas no bloco 3. Os bolsistas responderam positivamente ao concordarem com as contribuições do Pró-Saúde no processo de reforma curricular, para o trabalho em equipe, para a integração entre os cursos epara a integração dos cursos com a rede de serviços. Em relação ao perfil do profissional formado, conforme demonstrado no item 10, que afirma que a formação ocorre com ênfase nas especialidades e o item 12 na formação generalista, apesar de $70 \%$ dos estudantes apresentarem atitude de concordância quanto à ênfase na formação generalista, há divisão de opiniões.As frequências obtidas na escala de Likert para a dimensão "reorientação da formação" estão apresentadas na Tabela 1.

Tabela 1. Frequências de respostas obtidas dos estudantes em cada item da dimensão reorientação da formação (continua).

\begin{tabular}{|c|c|c|c|c|c|c|}
\hline $\begin{array}{l}\text { BLOCO } 3- \\
\text { REORIENTAC̣ÃO DA } \\
\text { FORMAC̣ÃO }\end{array}$ & $\begin{array}{c}\text { discordo } \\
\text { totalmente }\end{array}$ & discordo & $\begin{array}{l}\text { nào concordo } \\
\text { nem discordo }\end{array}$ & concordo & concordototalmente & não sei \\
\hline $\begin{array}{l}\text { 1- Eu conheço os } \\
\text { objetivos do Programa } \\
\text { Pró-Saúde. }\end{array}$ & $0 \%$ & $8 \%$ & $18 \%$ & $56 \%$ & $12 \%$ & $4 \%$ \\
\hline $\begin{array}{l}\text { 2-OPró-Saúde contribuiu } \\
\text { com o processo de } \\
\text { reforma curncular do meu } \\
\text { curso de graduação. }\end{array}$ & $0 \%$ & $4 \%$ & $14 \%$ & $52 \%$ & $8 \%$ & $20 \%$ \\
\hline $\begin{array}{l}\text { 3-A participação do } \\
\text { estudante no Pró-Saúde } \\
\text { contribui para a sua } \\
\text { maior preparação para } \\
\text { atuação profissional na } \\
\text { rede pública. }\end{array}$ & $0 \%$ & $0 \%$ & $6 \%$ & $52 \%$ & $42 \%$ & $0 \%$ \\
\hline $\begin{array}{l}\text { 4-A participação do } \\
\text { estudante no Pró-Saúde } \\
\text { contribui para a sua } \\
\text { maior preparação para } \\
\text { atuação profissional na } \\
\text { rede privada. }\end{array}$ & $2 \%$ & $18 \%$ & $24 \%$ & $34 \%$ & $14 \%$ & $8 \%$ \\
\hline
\end{tabular}




\begin{tabular}{|c|c|c|c|c|c|c|}
\hline $\begin{array}{l}\text { 5- As atividades } \\
\text { desenvolvidas no } \\
\text { contexto do Pró-Saúde } \\
\text { nasunidades de saúde } \\
\text { não alteram as rotinas de } \\
\text { trabalho e nem as práticas } \\
\text { dos profissionais de saúde } \\
\text { no serviço. }\end{array}$ & $10 \%$ & $50 \%$ & $18 \%$ & $10 \%$ & $4 \%$ & $8 \%$ \\
\hline $\begin{array}{l}\text { 6- O Pró-Saúde } \\
\text { possibilita a interação } \\
\text { entre os profissionais da } \\
\text { área de saúde. }\end{array}$ & $0 \%$ & $2 \%$ & $4 \%$ & $66 \%$ & $24 \%$ & $2 \%$ \\
\hline $\begin{array}{l}\text { 7- As atividades } \\
\text { desenvolvidas pelos } \\
\text { estudantes do meu curso } \\
\text { no contexto do Pró-Saúde } \\
\text { influenciam na qualidade } \\
\text { de sua formação. }\end{array}$ & $0 \%$ & $0 \%$ & $8 \%$ & $60 \%$ & $32 \%$ & $0 \%$ \\
\hline $\begin{array}{l}\text { 8- As atividades } \\
\text { desenvolvidas no âmbito } \\
\text { do Pró-Saúde contribuem } \\
\text { para a qualificação da } \\
\text { prática dos profissionais } \\
\text { que atuam na rede } \\
\text { pública de atenção à } \\
\text { saúde. }\end{array}$ & $0 \%$ & $4 \%$ & $10 \%$ & $50 \%$ & $26 \%$ & $10 \%$ \\
\hline $\begin{array}{l}\text { 9. O Pró-Saude contribui } \\
\text { para o trabalho em } \\
\text { equipe. }\end{array}$ & $0 \%$ & $0 \%$ & $8 \%$ & $56 \%$ & $36 \%$ & $0 \%$ \\
\hline $\begin{array}{l}\text { 10- O meu curso de } \\
\text { graduação está voltado } \\
\text { para a formação } \\
\text { especializada. }\end{array}$ & $4 \%$ & $24 \%$ & $22 \%$ & $40 \%$ & $6 \%$ & $0 \%$ \\
\hline $\begin{array}{l}\text { 11- O Pró-Saúde } \\
\text { contribuiu para a } \\
\text { integração do curso com } \\
\text { a Rede de Serviço de } \\
\text { Saúde. }\end{array}$ & $0 \%$ & $0 \%$ & $6 \%$ & $48 \%$ & $32 \%$ & $12 \%$ \\
\hline $\begin{array}{l}\text { 12- O meu curso de } \\
\text { graduaçào se volta para a } \\
\text { formaçào generalista. }\end{array}$ & $2 \%$ & $10 \%$ & $14 \%$ & $44 \%$ & $26 \%$ & $0 \%$ \\
\hline $\begin{array}{l}\text { 13- O Pró-Saúde } \\
\text { contribuiu para a } \\
\text { integração do meu curso } \\
\text { com os demais cursos da } \\
\text { área da saúde. }\end{array}$ & $0 \%$ & $8 \%$ & $16 \%$ & $52 \%$ & $24 \%$ & $0 \%$ \\
\hline
\end{tabular}

Na dimensão pedagógica, os bolsistas manifestaram atitudes positivas em relação à maioria dos itens, com a frequência da somatória dos itens "concordo" e "concordo totalmente", prevalecendo em $80 \%$ das assertivas desse bloco. Em algumas, entretanto, os participantes apresentaram opiniões divididas. Um total de $30 \%$ tem a percepção de que as atividades entre disciplinas clínicas e básicas não são integradas, enquanto $32 \%$ acreditam que são. Um total de $24 \%$ se manteve neutro sobre essa questão.Ao opinarem se as estratégias de ensino-aprendizagem que ocorrem no ambiente do Tempus, actas de saúde colet, Brasilia, 9(1), 11-24, mar, 2015.

ISSN 1982-8829 
SUS são avaliadas conjuntamente pelos profissionais da rede de serviços de saúde e docentes, $34 \%$ dos bolsistas demonstraram tendência a concordar, enquanto $22 \%$ assumiram uma postura neutra e $16 \%$ entendem que tais avaliações não ocorrem. A grande maioria ( $92 \%$ ) manifestou reconhecer a relevância do emprego de estratégias de ensino que envolvam profissionais das equipes de saúde, conforme observou-se nos itens que abordaram essa questão.

\section{Comparativo das tendências atitudinais nas diferentes dimensões}

Para a dimensão teórica, observou-se que os bolsistas do Pró-Saúde apresentaram os valores das médias próximos de zero, com tendência positiva $(M=0,04)$, o que caracteriza uma postura neutra. Em relação à dimensão cenário de práticas, a média obtida indicou uma tendência atitudinal positiva em relação ao bloco. O mesmo ocorreu com o bloco reorientação da formação, em que a média obtida dos itens para os estudantes no bloco foi de 0,82 . Em ambas as dimensões, ao se realizar a conversão para o conceito, obteve-se concordância com as assertivas. Na dimensão pedagógica,os resultadosdemonstraram que a tendência no bloco foi neutra.Os resultados demonstraram que os participantes encontraram maior facilidade em opinar nos itens que refletem a aplicação das propostas (bloco 2 e bloco 3), do que nos itens relacionados aos blocos 1 e 4 .A Tabela 2 apresenta a comparação da tendência da atitude em relação às quatro dimensões incluídas no estudo.

Tabela 2. Comparação das tendências entre as quatro dimensões estudadas

\begin{tabular}{|c|c|c|c|c|c|c|c|c|}
\hline \multirow[b]{2}{*}{ Grupo } & \multicolumn{2}{|c|}{$\begin{array}{c}\text { Bloco } 1 \\
\text { dimensão teórica }\end{array}$} & \multicolumn{2}{|c|}{$\begin{array}{c}\text { Bloco } 2 \\
\text { cenário de práticas }\end{array}$} & \multicolumn{2}{|c|}{$\begin{array}{c}\text { Bloco } 3 \\
\text { reorientação da } \\
\text { formação }\end{array}$} & \multicolumn{2}{|c|}{$\begin{array}{c}\text { Bloco } 4 \\
\text { dimensào pedagógica }\end{array}$} \\
\hline & $\begin{array}{l}\text { Média } \\
\text { dos } \\
\text { escores }\end{array}$ & conceito & $\begin{array}{l}\text { Média } \\
\text { dos } \\
\text { escores }\end{array}$ & conceito & $\begin{array}{c}\text { Média } \\
\text { dos escores }\end{array}$ & conceito & $\begin{array}{c}\text { Média } \\
\text { dos escores }\end{array}$ & conceito \\
\hline $\begin{array}{l}\text { Estudantes } \\
\text { Bolsistas }\end{array}$ & 0,04 & $\begin{array}{l}\text { nào } \\
\text { concordo } \\
\text { nem } \\
\text { discordo }\end{array}$ & 0,60 & concordo & 0,82 & concordo & 0,19 & $\begin{array}{l}\text { não concordo } \\
\text { nem discordo }\end{array}$ \\
\hline
\end{tabular}

\section{DISCUSSÃO}

A concepção medicalizadora da saúde ocupou, e segue ocupando um espaço hierarquicamente superior na cultura acadêmica e na concepção do trabalho em saúde ${ }^{5}$. O perfil dos egressos da formação superior na área da saúde passou, e ainda passa por ampla discussão dentro do cenário brasileiro. A iniciativa de construção das DCN foi um avanço importante após décadas de discussões e planejamento coletivo, em andamento desde a Reforma Sanitária Brasileira, na década de 1980, que exigia mudanças na educação profissional em saúde que pudessem incorporar o referencial teórico proposto nos principios do $\mathrm{SUS}^{6}$. A implementação das DCN para os cursos de graduação classificados pelo Conselho Nacional de Saúde como cursos profissionais de saúde foi um relevante ponto de partida iniciado em $2001^{1}$. As DCN tiveram caráter inovador uma vez que buscaram promover a inclusão precoce e gradativa dos estudantes de graduação no ambiente do SUS para que os mesmos tivessem a oportunidade de estabelecer contato com a comunidade local o mais cedo 
possivel e a partir disso adquirirem conhecimento associado à vivência que thes permitam atender as necessidades de saúde locais e nacionais ${ }^{6}$.

O Pró-Saúde, visando atender a essas demandas, contempla três eixos de atuação: orientação teórica, cenários de prática e orientação pedagógica.A orientação teórica visa priorizar os determinantes de saúde e os biológicos e sociais das doenças, a pesquisa clínico-epidemiológica baseada em evidências para uma avaliação crítica do processo de Atenção Básica, orientação sobre melhores práticas gerenciais que facilitem o relacionamento $e$ atenção especial à educação permanente, não restrita à pós-građuação especializada. Os cenários de prática é o eixo que busca incentivar a utilização de processos de aprendizado ativo, o aprender fazendo e com sentido crítico na análise da prática clínica, sendo que o eixo do aprendizado deve ser a própria atividade dos serviços, a ênfase no aprendizado baseado na solução de problemas. A orientação pedagógica trabalha com a diversificação, incluindo vários ambientes e niveis de atenção, dando maior ênfase ao nivel básico com possibilidade de referência e contra-referência, dando importância a excelência técnica e relevância social e à ampla cobertura da patologia prevalente, assim como a interação com a comunidade e estudantes, assumindo responsabilidade crescente mediante a evolução do aprendizado e importância do trabalho conjunto das equipes multiprofissionais ${ }^{s}$.

Neste estudo, ficam demonstradas as dificuldades de adesão às propostas do eixo teórico do Pró-Saúde, uma vez que os participantes tem a percepção deque há necessidade de maior inserção de aspectos sociaisnas abordagens teóricas das disciplinas, além da carência de articulação entre as àreas.

Quanto aos cenários de práticas, percebe-se que ainda hả um predominio das atividades dentro do ambiente universitário. São necessárias reflexões sobre possiveis razões para esse posicionamento, apesar das propostas curriculares e do Pró-Saúde. Vale ressaltar que as atividades práticas na atenção primária tem sido identificadas como uma experiência desafiadora, uma vez que envolve professores, estudantes, profissionais de saúde, gestores e comunidade.Cada um possui valores singulares, conhecimento e experiências que são esperados para ser compartilhado com base na interdisciplinaridade e abrangência da abordagem pedagógica proposta ${ }^{9}$.Ao concordarem que as atividades práticas nos primeiros anos do curso ocorrem em laboratórios, verifica-se a necessidade de se buscar estratégias que visem a inserção dos estudantes em atividades práticas desde os primeiros semestres com o intuito de se aproximarem da realidade da comunidade desde o início da formação.

Diante das respostas positivas dos estudantes acerca dos benefícios da integração entre a comunidade, o serviço e a universidade, é notório que os bolsistas visualizam possibilidades de ensino-aprendizagem extramuros. Isso se torna muito mais evidente, do ponto de vista prático, quando os alunos podem vivenciar esses beneficios através da realidade do Pró-Saúde, pois acabam esbarrando na proposta do próprio Programa de promover a integração entre essas três 


\section{$21 / /$}

áreas. Aspectos positivos relacionados à vivência de estudantes de graduação de cursos da área de saúde em novos espaços de formação foram relatados em estudo recente ${ }^{10}$. Estudantes participantes do PET-Saúde e do Estágio de Vivências do SUS destacaram a importância da aproximação da realidade do SUS para a compreensão do seu lugar profissional e do trabalho interdisciplinar. Além disso, a vivência nos serviços de saúde promove a oportunidade de uma aprendizagem significativa e reflexiva.

Os produtos positivos advindos dessa integração podem se traduzir na formação de um profissional capacitado para lidar com a realidade, enfrentando desafios e buscando soluções mais adequadas para atender as necessidades da comunidade. Dessa forma, o serviço de saúde passa a responder suas demandas em consonância com os principios e diretrizes do SUS.

Pretende-se com isso, contribuir com a formação e capacitação de recursos humanos para a geração de conhecimento e voltados também para o atendimento ao público pela Rede SUS, e tendo como ênfase a atenção primária desde a sua formação $0^{8}$. A intenção é formar um profissional que consiga assumir uma responsabilidade longitudinal pelo paciente em uma relação contínua de cuidado que transcorre ao longo da vida independente da presença ou ausência de doença. A integralidade almejada diz respeito à identificaçào das necessidades dos individuos no âmbito orgânico, social e psíquico dentro da possibilidade de atuação do profissional da saúde. A capacidade crítico-reflexiva que se busca desenvolver nos profissionais durante sua formação é importante para a coordenação de ações e serviços inerentes à solução de demandas menos frequentes e mais complexas ${ }^{11}$.

O Pró-Saúde, na realidade, constitui um mecanismo facilitador da parceria ensino-serviço para a real implementaçãode todas estas propostas, as quais estão inseridas nas $\mathrm{DCN}^{12}$. No presente estudo, os resultados revelaram que na percepção da maioria dos bolsistas do Pró-Saúde, as atividades externas da grade curricular de seus cursos ocorrem somente a partir da metade do curso.É importante o entendimento de que o grande desafio para que ocorra a integração ensinoserviço-comunidade é o reconhecimento de que esse movimento requer a construção de uma nova formade ensinar, de aprender e de fazer.Além disso, qualquer proposta que almeje tal alcance deve ser efetiva para todos os sujeitos envolvidos no processo: professores, estudantes, gestores das instituições de ensino superior (IES) e do SUS, profissionais da saúde e população ${ }^{13}$. Fatores como,por exemplo,agenda e deslocamento podem ser fatores dificultadores para uma maior aproximação entre as partes envolvidas.Ainda assim, esforços podem ser verificados nos dados obtidos, considerando que a maioria das frequências de encontros das equipes relatada foi mensalmente, semanalmente e quinzenalmente. Percebeu-se a relevância dessas iniciativas diante da percepção da grande maioria dos bolsistas, os quais manifestaram reconhecer a importância do emprego de estratégias de ensino que envolvam profissionais das equipes de saúde. $O$ serviço de saúde precisa estar comprometido juntamente com a IES para a formação de novos profissionais.

Ao propor transformações na formação profissional em saúde, tomando por base as propostas 
das DCN para os cursos da área de saúde, o Pró-Saúde almeja alcançar um deslocamento do eixo da formação, centrado na assistência individual prestada em unidades especializadas, para uma formação sintonizada, além da dimensão técnica, com as necessidades sociais, culturas eeconômicas da população ${ }^{2}$.Houve uma divisão de opiniões nos resultados obtidos sobre o perfil percebido do profissional atualmente formado nos cursos dos participantes, o que demonstra que ainda enfrentase uma falta de clareza em relação à formação, ou seja, se tendem à formação de umperfil generalista ou especializado.Fica, portanto, sugerida a necessidade de inclusão dessa questão na agenda de discussões sobre a temática. O Pró-Saúde tem o potencial de ampliar oportunidades para isso.É inegável a deficiência presente no mercado, no que se refere à disponibilidade de profissionais com formação generalista, com visão humanística e preparada para prestar cuidados contínuos e resolutivos à comunidade. Atualmentemuitos profissionais que atuam na Estratégia Saúde da Familia (ESF) têm formação pelo modelo hospitalocêntrico, o que não atende ao perfil adequado para atuar no modelo proposto para SUS. Neste, a atenção primária deve ser a porta de entrada do sistema, com perspectiva de resolutividade para a maioria das necessidades de saúde das pessoas ${ }^{14}$.

Os bolsistas demonstraram reconhecer ascontribuições do Programa para a interação entre profissionais da saúde, para a integração entre os cursos e para o trabalho em equipe.Isto sugere que a formação acadêmica desses estudantes tem sido beneficiada pelo Programa.Entretanto,ao responderem que poucas, ou nenhuma disciplina de seus cursos oportunizam vivência semelhante à da participação no Pró-Saúde, fica ressaltada a limitação de alcance dos efeitos da proposta.

\section{CONCLUSÒES}

Este estudo revelou a importância de políticas indutoras que possam promovermovimentos em direção a mudanças na formação profissional. O Pró-Saúde demonstrou ter trazido suas contribuiçôes aos participantes mais diretamente envolvidos no Programa.Considerando toda a complexidade e desafios envolvidos na reorientação de um modelo de formação profissional,fica evidente a necessidade de estratégias que possam ampliar o alcance do Programa no cotidiano detodos os participantes da formação nas IES e no sistema de saúde. Além disso, a fim de motivar aqueles que acreditam na possobilidade de vivenciarmos no futuro uma formação que possa atender às demandas em saúde de nosso pais, esta proposta pode ser entendida como o inicio de uma longa trajetória a ser percorrida.

\section{REFERÊNCLAS BIBLIOGRÁFICAS}

1.Ceccim RB. Inovação na preparação de profissionais de saúde e a novidade da graduação em saúde coletiva. Boletim da saúde. Porto Alegre. 2002;16(1):9-38.

2. Brasil. Ministério da Saúde, Brasil. Ministério da Educação. Portaria n ${ }^{\circ} 2.101$ denovembro de 2005. Institui o Pró-Saúde: Programa Nacional de Reorientação daFormação Profissional em 
Saúde. Brasilia. Diärio Oficial [da] República Federativado Brasil. 2005 nov. 16; Seção 3. p. 62.

3. Brasil. Ministério da Saúde. Portaria conjunta $n^{\circ} 10$ de 14 de dezembro de 2010. Homologa o resultado do processo de seleção dos Projetos que se candidataram aoPrograma de Educação pelo Trabalho para a Saúde. Brasilia. Diário Oficial [da]República Federativa do Brasil. 2011 dez. 1; Seção 1. p. 98.

4. Furlanetto DLC, Silva Junior JW, Bastos MM, Lima AA, Pinho DLM. Atitudes de Estudantes e Professores de Odontologia sobre a Reorientação na Formação Profissional. Arquivos de Ciências da Saúde (FAMERP) .2014;21:68-77.

5. Ceccim RB, Bilibio LFS. In: Br MS. Observatório de recursos humanos em saúde noBrasil: estudos e análises. Observação da educação dos profissionais da saúdeevidèncias à articulação entre gestores, formadores e estudantes. 2002. p. 343-372.

6. Haddad AE, Morita MC, Pierantoni CR, Brenelli SL, Passarella T, Campos FE. Undergraduate programs for health professionals in Brazil. Revista de Saude Pública.2010;44(3):383-393.

7. Brasil. Relatório de Gestão 2008-2010 da Universidade Aberta do Sistema Único de Saúde. Brasilia, DF, Secretaria de Gestão do Trabalho e da Educação na Saúde, Ministério da Saúde. 2010.

8. Brasil. Ministério da Saúde. Portaria no 1.507 de 22 de junho de 2007. Institui oPrograma de Educação pelo Traballho para a Saúde. Brasilia. Diärio Oficial [da]República Federativa do Brasil. 2008 jan. 14; Seção 1. p. 37.

9. Arrais PSD, Aguiar ASW, Souza MAN, Machado MMT, Mota MV, Alves RS, Araújo MFM. Comprehensiveness: a pedagogical challenge for the Educational Program forHealth Work. Revista Brasileira de Educação Médica. 2012;36(1-2):56-61.

10.Leal JAL, Melo CMM, Veloso RBP, Juliano IA.Novos espaços de reorientação para formação em saúde: vivências de estudantes. Interface.2015;19(53):361-371.

11. Starfield B. Atenção Primária: Equilibrio entre necessidades de saúde, serviços e tecnologia. 2002. Brasilia, UNESCO: Ministério da Saúde.

12. Ferreira JR, Cury GC, Campos FE, Haddad AE, Gusso GDF. A Construção deParcerias como Estratégia para o Sucesso do Pró-Saúde. Cademos ABEM. 2007. 3(1).

13. Almeida FCM, Maciel APP, Bastos AR, Barros FC, Ibiapina JR, Souza SMF Araújo DP. Avaliação da inserção do estudante na Unidade Básica de Saúde: visão do usuário. Revista Brasileira 


\section{$24 / /$}

deEducação emMedicina. 2012;36(1):33-39.

14. Haddad AE, Morita MC. In: Carvalho ACP, Kriger L. Educação odontológica. O ensino da odontologia e as politicas de saúde e de educação. Artes Médicas. SãoPaulo. 2006.

Artigo apresentado em: 21/05/2015

Artigo aprovado em: 11/07/2015

Artigo publicado no sistema em: 15/07/2015 


\section{CAPÍtulO 5}

\section{DISCUSSÃO E CONCLUSÕES}

\subsection{ANÁLISE COMPARATIVA ENTRE OS ESTUDOS 1, 2 e 3}

A reorientação da formação em saúde é um processo que vivencia há décadas discussões e construção de políticas que visam alcançar mudanças no Ensino na Saúde e no perfil do profissional, de modo que se obtenham melhorias na atenção dada à população brasileira. Os estudos realizados no presente trabalho, em que cursos de graduação em Enfermagem, Odontologia e Medicina foram incluídos, focaram na análise dessa temática, sob a perspectiva da inserção dos referidos cursos no Programa Pró-Saúde.

O Programa Pró-Saúde possui eixos que norteiam seus objetivos. Considerando que os instrumentos de avaliação utilizados nos presentes estudos mantiveram como pano de fundo esses eixos, as comparações aqui realizadas também seguirão essa lógica. Um total de seis grupos, professores e estudantes dos três cursos, foram objetos de análise.

A dimensão teórica foi um componente que apresentou poucas divergências entre os grupos estudados. Tanto professores quanto estudantes dos três cursos demonstraram convergência de opiniões na maioria dos itens.

As principais diferenças ocorreram no item 4 (articulação da pesquisa de acordo com demandas do serviço e comunidade), o qual representa uma afirmação favorável à proposta do Pró-Saúde e no item 10 (disciplinas ministradas de forma isolada e sem articulação entre elas), o qual representa uma afirmação que desfavorece as propostas de reformulação da formação.

Em ambos os itens, professores e estudantes dentro de cada curso apresentou o mesmo padrão de opinião, o que demonstra uma consistência dos resultados dentro de cada curso. Entretanto, ao compararmos os cursos, as realidades se mostraram divergentes. Os 
resultados do curso de Medicina diferiram da Enfermagem e Odontologia. Naquele, os participantes demonstraram acreditar que as pesquisas não estão articuladas com as demandas da sociedade, ao apresentarem uma postura de discordância em relação ao item 4. Já em relação ao item 10, o qual apresenta uma afirmativa daquilo que não é o que se almeja, e por esta razão, seria uma demonstração a favor do Pró-Saúde considerar o item como negativo/desfavorável, tanto professores quanto estudantes da Medicina, concordaram com o mesmo (Tabela 8).

\section{Tabela 8}

Comparação entre resultados obtidos nos itens 4 e 10 nos três cursos

\begin{tabular}{|l|c|c|c|c|c|c|}
\hline & $\begin{array}{l}\text { Professores } \\
\text { Medicina }\end{array}$ & $\begin{array}{l}\text { Estudantes } \\
\text { Medicina }\end{array}$ & $\begin{array}{l}\text { Professores } \\
\text { Enfermagem }\end{array}$ & $\begin{array}{l}\text { Estudantes } \\
\text { Enfermagem }\end{array}$ & $\begin{array}{l}\text { Professores } \\
\text { Odontologia }\end{array}$ & $\begin{array}{l}\text { Estudantes } \\
\text { Odontologia }\end{array}$ \\
\hline $\begin{array}{l}\text { Item 4 } \\
\text { (favorável ao } \\
\text { Programa) }\end{array}$ & $\mathrm{X}$ & $\mathrm{X}$ & $\checkmark$ & $\checkmark$ & $\checkmark$ & $\checkmark$ \\
\hline $\begin{array}{l}\text { Item 10 } \\
\text { (desfavorável } \\
\text { ao Programa) }\end{array}$ & $\checkmark$ & $\checkmark$ & $\mathrm{X}$ & $\mathrm{X}$ & $\mathrm{X}$ & $\mathrm{X}$ \\
\hline
\end{tabular}

$\checkmark=$ concordância ao item $\quad \mathrm{x}=$ discordância ao item

Além de outros, alguns aspectos relacionados aos itens mencionados foram aprofundados nas entrevistas realizadas. Nas subcategorias "integração entre disciplinas do curso" e "fragmentação", pertencentes à categoria currículo e na subcategoria "integração entre teoria e prática", incluída na categoria processo de ensino e aprendizagem, apesar da diversidade de manifestações, pôde-se observar que existem posicionamentos otimistas dos participantes dos cursos de Odontologia e Enfermagem, apesar de alguns mais críticos, porém que indicam um movimento, o que possivelmente pode ser resultante do processo da implementação do currículo reformulado, em andamento em ambos os cursos. 
"esse negócio de teoria-prática está interagindo, mas tem matérias que faltam ainda"

"é muito bom quando a teoria é casada com a prática" "dependendo da matéria tem o paralelo da teoria com a prática"

Estudantes de Odontologia (EO)

"há a intenção"

"a integração está engatinhando ainda" "na nossa disciplina a gente tem tentando"

Professores de Odontologia (PO)

"nós temos as vivências integradoras, e elas buscam integrar todas as matérias do semestre na prática dessa disciplina" "as disciplinas, querendo ou não se comunicam, a gente sente essa complementação na maioria das disciplinas" "algumas matérias tiveram integração de todos os professores do semestre, então foi bem enriquecedor, e reflete positivamente"

Estudantes de Enfermagem (EE)

"percebo nas reuniões que é uma preocupação dos docentes" "em algumas áreas a integração acontece a contento" "vejo que essas barreiras aos poucos vão se rompendo" "precisa melhorar bastante. Existe uma aproximação mínima" Professores de Enfermagem (PE)

O Projeto Político Pedagógico (PPC) do curso de Medicina vigente no momento da coleta dos dados dessa pesquisa era aquele vigente desde o ano 2000. A reformulação curricular foi aprovada em março de 2015, com previsão de implementação imediata. Esta singularidade do curso deve ser considerada. O posicionamento dos entrevistados do referido curso nesse estudo justifica-se pela atual realidade vivenciada pelos envolvidos no processo de formação, e explicam as diferenças encontradas na comparação entre os três cursos.

"não acontece, a gente sempre vê o mais profundo de cada área" "não existe integração, mas está sendo muito discutido" "são totalmente separadas" "falta às vezes essa integração entre teórico-prática, que seria importante esse elo" Estudantes de Medicina (EM)

"as áreas do curso não se conversam, acho que não" "eu acho que hoje é muito fragmentado, tanto entre o ciclo básico e ciclo clínico" "acho que talvez esse seja o ponto mais crítico"

Professores de Medicina (PM) 
Assim como já afirmava De Paola (2008) e pode-se verificar nos resultados aqui obtidos, ainda perdura na formação em saúde o exemplo de um modelo ancorado no estudo e pesquisa que prioriza as ciências básicas e especializadas, com ênfase no conhecimento biomédico e ensino fragmentado, dissociado do contexto social. A força das propostas desde Flexner ainda segue influenciando a formação dos profissionais das diversas áreas da saúde (Baltazar, 2010). Este componente histórico deve ser considerado e apreciado sempre para que não se subestime as dificuldades que qualquer proposta de reformulação encontrará ao confrontar um modelo consolidado desde o século passado.

Outros componentes analisados na dimensão teórica obtiveram algumas similaridades e diferenças entre os grupos, explicadas possivelmente por alguma limitação do instrumento ao abordar algum item em que o participante não se sentisse habilitado a opinar, ou pelo componente de subjetividade existente em escalas com a Likert, ou pela própria construção do mesmo, como no caso de itens relacionados à ênfase dada pelo os cursos de pós-graduação, em que os estudantes dos três cursos foram unânimes em optar por "não sei”. Entre professores, as diferenças ocorridas nesse tópico provavelmente devem-se às experiências singulares nesse quesito.

Na dimensão cenário de práticas houve uma convergência nas respostas aos itens, com todos, professores e estudantes, optando pelos mesmos níveis de concordância, dentro de cada curso. Ao se comparar os resultados entre os cursos, o único item em que não houve similaridade foi o item 5, o qual afirmava haver adequação da infraestrutura das unidades de saúde onde são desenvolvidas atividades das disciplinas. O item caracteriza o cenário ideal que seria a imagem-objetivo dentro das propostas do Pró-Saúde. Entretanto, não necessariamente as assertivas contidas no instrumento reproduzem a realidade presente no dia-a-dia de cada curso. Nessa questão, a Enfermagem diferiu da Odontologia e Medicina. 
Naquela, professores e estudantes, na sua maioria responderam "não sei" ao item. Todos os demais participantes dos outros dois cursos foram unânimes em discordar do item, indicando que todos entendem que a infraestrutura do serviço não atende as necessidades para desenvolvimento de atividades de parceria ensino-serviço. Os resultados obtidos da Enfermagem sugerem algumas possibilidades que possam explicar o posicionamento dos participantes do estudo: no caso dos professores participantes da pesquisa, uma possível falta de envolvimento em atividades em serviços de saúde, o que leva ao desconhecimento de sua estrutura. No caso dos estudantes, o estágio do curso em que se encontram poderia ser uma possível justificativa. Entretanto, ao checar a participação por semestre, observa-se que a distribuição foi equilibrada. Comparado aos outros dois cursos, o curso de Enfermagem tem os serviços de saúde como cenário de práticas em maior escala e há mais tempo, fato que pode explicar essa diferença. Entretanto, estudos demonstram que há dificuldades no estabelecimento de papéis melhor definidos de modo a potencializar o trabalho conjunto entre as diferentes áreas da saúde (Fewster-Thuente, 2011).

Nas entrevistas, ficou evidente o reconhecimento da importância da ampliação do cenário de práticas como mecanismo enriquecedor da formação do profissional de saúde.

"a teoria tá mostrando a importância e a gente tá indo e vendo realmente como é"(EO) "é somatório na formação do aluno"(PO) "a gente vê que a gente pode fazer alguma coisa pra mudar a comunidade"(EE) "as atividades dos alunos nesse novo modelo de currículo em que o aluno está lá no campo de estágio executando contribui também para a força de trabalho" (PE) "eu vejo isso como uma oportunidade de crescimento muito grande e não consolidada totalmente" $(E M)$

"essa vivência da gente viver o cotidiano lá, no serviço, ela é muito rica" (PM)

Entretanto, em nenhum momento os entrevistados perderam a oportunidade trazer à tona suas percepções em relação às dificuldades enfrentadas para que de fato essa integração ocorra, de modo a proporcionar uma diversidade de cenários de práticas 
vivenciadas na formação profissional. As barreiras percebidas passam por questões relacionadas à falta de infraestrutura e espaço físico, porém não se esgotam nelas.

"parece que alguns pensam que é uma coisa secundária" (EO)

"a unidade não recebe bem o aluno"(EO)

"não está havendo um processo de comunicação estabelecido" (PO)

"trabalhar a cabeça das pessoas é uma coisa muito complicada" (PO)

"eles não dão preferência pra gente; a gente sempre fica com o que sobra"(EE)

"a gente foi lá só prá visitar, e já era pra estarmos estagiando"(EE)

"eu acho que precisa aproximar mais as pessoas" (PE)

"os papéis não estão bem definidos" (PE)

"pensando no que tive até agora, acho que todas foram extremamente sem sentido" (EM) "não tem um eixo que comece no primeiro semestre e siga ao longo do curso que faça criar um vínculo" (EM)

"a rede também tem que estar preparada para isso, não só da estrutura física, mas dos profissionais também. Acho que ainda estamos engatinhando nisso" (PM) "essa sensação de ser um intruso é muito forte pra mim. Eu não consigo compreender o porquê" (PM)

Já era de se esperar que a proposição de qualquer tipo de ação que envolvam frentes distintas e que requeiram uma atuação inter e multiprofissional (docentes, discentes, profissionais de saúde, gestores e comunidade), ou seja, composta por sujeitos com diferentes bagagens, anseios, expectativas e interesses, será carregada de enfrentamentos a serem suplantados. Requer revisão de valores, conduta e postura por parte de todos que de alguma forma participam desse processo. Tem sido muito discutido o quanto é precária a disponibilidade de profissionais de saúde providos de visão humanística e estejam preparados para prestar cuidados contínuos e resolutivos à comunidade (Kriger e Morita, 2004). Conforme sinalizou Silva e Cunha (2002), os novos profissionais devem ser capazes de operacionalizar seu conhecimento de forma integrada às suas aptidões e vivências culturais.

À medida que nos deparamos com questões tomadas pela complexidade envolvidas em mudanças mais profundas, de crenças e de culturas diversificadas, tais fatores devem estar, se não incluídos, no mínimo reconhecidos, nas propostas em que formação em saúde esteja em pauta. Herbert (2005) destacou que ainda não se alcançou êxito em se modificar a 
cultura do cuidado em saúde baseado, que tem por base o isolamento profissional, na buca de um sistema de cooperação que possa contribuir para uma visão comum em saúde.

As comparações dos resultados na dimensão pedagógica demonstraram haver também poucas divergências nas opiniões dos participantes. Na comparação dentro de cada curso, professores e estudantes de Medicina apresentaram convergência em seus posicionamentos em todos os itens. Isso sugere que a realidade existente, mesmo que não seja desejável, está bem estabelecida na percepção da maioria daqueles que vivenciam as questões relacionadas a esta dimensão.

$\mathrm{Na}$ Enfermagem, houve divergência de opiniões em alguns itens. A maioria dos estudantes entende que a estrutura curricular inclui primeiro aprendizado da teoria e depois a aplicação da mesma na prática (item 2). Já a maioria dos professores se dividiram entre a neutralidade de opinião ("não concordo nem discordo") ou na escolha da opção discordando que ocorre essa separação no aprendizado, em opinião oposta à dos estudantes. O mesmo ocorreu em relação à predominância da forma de ministrar os conteúdos teóricos no formato de aulas expositivas (item 4). A maioria dos estudantes concorda que essa é a forma como as aulas teóricas são ministradas e a maioria dos professores discordam. Nessas duas assertivas percebe-se a necessidade de reflexões sobre em que medida determinados aspectos propostos na reforma curricular já vigente tem se reproduzido em prática. Ou ainda, rever em que medida, determinadas ações implementadas possam estar alcançando seus objetivos. Nas entrevistas ocorreram manifestações de inquietações e reconhecimentos de que no momento existe um processo em andamento, o qual necessita de constantes discussões e revisões.

"percebo nas reuniões que é uma preocupação dos docentes, eles estão preocupados com a inserção dos professores das disciplinas básicas" (PE2) 
“com o currículo reformulado, a gente está em processo de adaptação, reestruturação em questão de rever alguns pontos" (PE4)

"já foi discutido em oficinas pedagógicas, mas a gente não fez uma avaliação ainda do nosso currículo" (PE5)

"não ocorrem na velocidade que a gente gostaria, mas as coisas vão se encaminhando"

"o nosso currículo atual vem com uma metodologia integrada, uma metodologia que já parte para uma metodologia ativa e isso já começou a ser uma discussão" (PE7) "estamos ainda em um momento de reconhecimento dessa tecnologia" (PE7)

"eu acho que é uma movimentação inicial, acho que o caminho é bem longo, porque o olhar é uma cultura que a gente estabelece" (PE7) "estamos em um processo interno de adequação curricular" (PE7) "falta diálogo" (PE8)

No curso de Odontologia os resultados indicam que assim como no curso de Enfermagem, algumas divergências percebidas entre professores e estudantes devem ser consideradas, como a verificada em relação ao item que se referiu à integração entre disciplinas básicas e clínicas (item 1) e no item que afirmou que o formato da estrutura curricular do curso ocorre em ciclo básico e clínico (item 3). O fato dos professores discordarem do item 3, o qual afirma que o curso está estruturado em ciclo básico e clínico era esperado, uma vez que este foi um dos aspectos abordados na reforma curricular, vigente desde 2010, e que propõe uma integração na estrutura. Entretanto, o posicionamento dos estudantes demonstra que na percepção dos mesmos as mudanças ocorridas ainda não produziram efeitos.

Por outro lado, ao discordarem do item 1, os professores reconhecem que as atividades desenvolvidas nas disciplinas básicas e clínicas ainda não são integradas. Pelo conteúdo das entrevistas, pode-se perceber que essas questões têm gerado mobilização no curso no sentido de avaliar as adequações necessárias ao atual currículo. Um exemplo disso 
foi o relato quanto à atuação do Núcleo Docente Estruturante (NDE) no curso de Odontologia. O NDE possui dentre suas atribuições contribuir para a consolidação do perfil profissional do egresso do curso; zelar pela integração curricular interdisciplinar; zelar pelo cumprimento das Diretrizes Curriculares Nacionais para os cursos de graduação; realizar as atividades necessárias para a reformulação curricular.

"foi montado um núcleo docente estruturante pra discutir sobre os problemas dos conteúdos do ensino" (PO2)

"existe um núcleo docente estruturante, que é um grupo dentro do departamento, aonde se trabalha essa problemática de buscar as soluções e buscar entender onde estão os nós do curso e buscar diminuir esses problemas" (PO4)

"tem o esforço do NDE, a gente vai tentar. A gente tem duas situações: apagar incêndios, ou seja, minimizar esse prejuízo da formação e outro é uma tentativa estrutural do próprio curso

$\mathrm{Na}$ comparação entre os cursos, os estudantes de Enfermagem e Odontologia apresentaram posicionamentos semelhantes em todos os itens. Comparando ambos com os resultados obtidos na Medicina, este diferiu dos demais, à medida que os respondentes discordaram dos itens que abordaram ocorrer a integração entre as disciplinas e o desenvolvimento de atividades interdisciplinares. De alguma maneira, mesmo que ainda exista um caminho a percorrer, nos cursos em que reformas curriculares já aconteceram, observa-se algum alcance no que tange a atividades abordadas nesses itens. No curso de Medicina, em que a estrutura curricular no momento da coleta de dados permanecia a tradicional, os estudantes se posicionaram diferentemente dos outros dois cursos. Além disso, é importante ressaltar, assim como relatado por Herbert (2007), as questões relacionadas ao histórico dos sujeitos refletindo nas escolhas profissionais, os esteriótipos e culturas inerentes a cada profissão. 
Os professores dos três cursos se manifestaram diferentemente em diversos itens, o que demonstra a complexidade nas questões que envolvem mais diretamente aspectos pedagógicos do processo de ensino e aprendizagem.

Existe um esforço em prol da consolidação da rede pública de saúde como elemento central no processo de ensino-aprendizagem (Ceccim (2005). Entretanto, enquanto os papéis de todos não estiverem bem definidos e aceitos, corre-se o risco desta aproximação tornar-se frustrante e até desmotivadora para todos. Conforme verificado no caso da Universidade de Brasília, em relação aos cursos objeto do presente estudo, que as dificuldades começam ainda no espaço da universidade, quando se verifica que a integração de disciplinas e dos cursos ainda é um aspecto a ser trabalhado. Em muitos momentos, pôdese perceber que apesar de haver um árduo esforço, enfrenta-se muita resistência de adesão a propostas interdisciplinares e multiprofissionais. Por outro lado, no serviço, o trabalho em equipe é também um desafio e requer esforços para que se consolide, ou ainda, em alguns casos, se inicie. Essas carências têm sido apontadas na literatura (Nogueira, 2009; Finkler, 2011).

Existe uma demanda de ações para que os pilares da educação (Delors, 1998), como o " aprender a fazer", o "aprender a viver junto" e o "aprender a aprender" sejam incorporados na formação em saúde. Assim como afirmou Kriger et al. (2005), o aprender a construir coletivamente é essencial à medida que o conhecimento na área de saúde é multiprofissional e transdisciplinar.

Conforme já mencionado anteriormente em Relatório do Pró-Saúde (Brasil, 2008), e que corrobora os resultados encontrados nessa pesquisa, um dos grandes obstáculos para as mudanças na educação profissional na área da saúde é cultural. Nas entrevistas realizadas emergiram subcategorias relacionadas a questões culturais. Embora a aprendizagem integrada aos serviços possa ser uma ferramenta poderosa para melhorar a qualidade do 
ensino, essa estratégia ainda é subestimada como uma tarefa pedagógica. Os estudos aqui desenvolvidos demonstraram a existência de barreiras e resistências, e com isso a necessidade de amadurecimento neste processo de transformação. Estudo na mesma temática, com ênfase no Promed (Veloso, 2008) indicou a resistência de parte do corpo docente como um dos enfrentamentos para o processo de transformação na formação médica. O processo de reestruturação do projeto político pedagógico dos cursos deveria considerar a possibilidade de inserção de ações do Pró-Saúde no contexto das disciplinas obrigatórias vigentes ou a serem criadas, o que permitiria a implementação do Programa como proposta estruturante dos projetos pegagógicos dos cursos. . No momento, enfrenta-se uma distorção, na qual se caracteriza o Pró-Saúde como projeto, e portanto, com início, meio e fim, além de potencializar a possibilidade de adesão ou não. É preciso considerar a implantação de estratégias que possibilitem avanços e um percurso a ser seguido, o qual iniciou-se de uma demanda real, e portanto, torna-se um caminho sem retorno. Inclui-se nessa questão a necessidade de decisões políticas, que no caso da integração ensino-serviço precisam ser melhor delineadas e apropriadas tanto pelas instituições de ensino quanto pelos serviços de saúde. As mudanças ainda não ocorreram como parte de uma política institucional.

A dimensão reorientação da formação foi a que mais apresentou divergência entre os três cursos estudados. Ao confrontarmos os dados dentro de cada curso, comparando professores e seus estudantes, o curso de Medicina foi o único que apresentou $100 \%$ de convergência interna nas respostas aos itens. Hall (2005) enfatizou que no caso no estabelecimento da identidade profissional estão inseridos valores compartilhados, linguagem técnica própria, campos de prática comuns, o que leva a modos de pensar que se assemelham, e se distinguem de outras perspectivas profissionais. Essas questões, 
associadas ao corporativismo que permeia o profissional da área médica, poderiam explicar essa convergência de resultados.

Nos cursos de Enfermagem e Odontologia, os estudantes discordaram de seus professores em mais da metade dos itens. Em ambos os cursos, as divergências se deram nos mesmos itens para os dois cursos. Dentre esses, o item 1 afirmava que o respondente conhecia os objetivos do Programa Pró-Saúde. A maioria dos graduandos da Enfermagem discordou e os da Odontologia optaram por "não sei". Em outros itens $(2,4,5$ e 8$)$ relacionados às contribuições do Programa para o processo da reforma curricular, para a formação, para a qualificação do profissional da rede, todos demonstraram não saber. Por não conhecer a que o Programa se propõe, é de se esperar que haja um desconhecimento sobre como o mesmo pode trazer contribuições. Esses resultados podem sugerir a necessidade de formulação de estratégias que possibilitem uma maior aproximação do corpo discente no desenvolvimento das ações no sentido de aumentar a capilaridade das iniciativas induzidas pelo Pró-Saúde no contexto da formação. Para reforçar, esses pontos também ficaram explicitados na verificação de subcategorias advindas dos dados qualitativos.

$$
\begin{array}{r}
\text { "ainda não vi e não vejo divulgação, não vejo muita gente falando" (EE6) } \\
\text { "acho que não conseguiu alcançar todo mundo. Não vejo ele chegar até mim" (EE5) } \\
\text { "falta vivência deles (professores) na comunidade” (EO1) } \\
\text { "trouxe vivência apenas para aqueles que participaram"(EO8) } \\
\text { "se você não consegue sensibilizar, as pessoas não vão mudar" (EO7) }
\end{array}
$$

$\mathrm{Na}$ comparação entre os cursos, os três grupos de professores apresentaram convergência de opiniões em todos os itens, demonstrando uma postura positiva e otimista no potencial do Programa em subsidiar o processo de formação profissional. Puccini et al (2010) apontaram as contribuições que os projetos do Pró-Saúde podem exercer na identificação de fragilidades e necessidades de mudanças na formação, ressaltando o quanto tais transformações podem ser complexas. Mas ressaltam que avanços ocorrem à medida 
que se implementam ações, as quais devem ser contínuas e pactuadas, uma vez que inúmeros caminhos podem ser seguidos.

Já na comparação entre os estudantes, Odontologia e Enfermagem, conforme ocorrido na dimensão pedagógica e já exposto na comparação entre professores e estudantes para essa dimensão, apresentaram convergência em relação aos itens, com ambos apresentando algumas divergências em relação à Medicina. Nesse curso os estudantes demonstraram percepção positiva em relação aos objetivos do Programa e sua contribuição para a reforma curricular. Uma possível explicação pode ser devido ao momento vivenciado pelo curso da Medicina no que tange à reestruturação do currículo, o que torna essas temáticas mais em pauta e presente entre todos os envolvidos.

Os graduandos dos três cursos se posicionaram positivamente sobre itens que abordavam as possibilidades do Pró-Saúde em proporcionar benefícios durante o processo de formação para atuação na rede pública e na melhoria da qualidade da formação. Também demonstraram reconhecer o potencial do Programa em possibilitar avanços em relação à interação entre os profissionais da saúde e ao trabalho em equipe. Alguns trechos das entrevistas corroboram essa percepção.

“interessante a perspectiva multiprofissional que tem no Pró-Saúde” (EM4)

"é a primeira vez que as pessoas tomam contato com alguma coisa que não é hospital" (EM6) "o Pró-Saúde está envolvido nesse contexto da atenção multiprofissional, está muito envolvido com isso, está certo, é isso mesmo" (EM7) "a gente trabalha com equipe multidisciplinar. A gente não vê isso acontecendo no hospital, mesmo que tenha que acontecer. E no Pró-Saúde nós vemos isso" (EE2) "a gente tem o contato com pessoas, essa vivência de conhecer pessoas que você vai ter que trabalhar depois, lugares" (EE3) "a partir do momento que você coloca em contato, mesmo que mínimo, é significativo" (EE4) "no nosso curso não teve muita participação" (EO7) "trouxe vivência apenas para aqueles que participaram”(EO8) 
Comparado aos demais cursos, na Odontologia os estudantes não demonstraram o mesmo teor de percepção em suas falas, talvez por um contato uma realidade ainda mais superficial em relação a essas questões. O caráter mais individualista e de isolamento dentro da profissão, na sua essência, talvez imponha um desafio maior do que para os demais cursos aqui comparados.

Na Odontologia, aqueles que exercem o papel na formação tiveram sua formação pautada nessa perspectiva, e isso pode se reproduzir em ações dentro do processo de formação, ainda que políticas indutoras estejam presentes para subsidiar mudanças. Xavier (2013) constatou em estudo recente que analisou currículos de cursos de graduação de Odontologia, que apesar da presença de disciplinas sociais, existe o "currículo oculto", em que ainda direciona para a formação privatista; que a ênfase de conteúdos humanísticos estão direcionados a disciplinas sociais; que existe uma clara dissociação entre disciplinas básicas e clínicas, sem integração entre as mesmas. O autor destaca que o componente flexneriano parece estar enraizado no currículo.

Costa et al ${ }^{23}$ destacam os enfrentamentos, tais como superação de atuações fragmentadas, isolamento e manutenção de relações de poder entre profissionais e destes com os usuários, dificultando a produção de uma atenção à saúde mais integral e resolutiva, baseada na atuação de equipes multiprofissionais. Politicamente, é importante ressaltar os enfrentamentos. Enquanto a Medicina e Enfermagem compõem a equipe básica da Estratégia Saúde da Família (ESF) desde a criação do Programa em 1994, a inserção das equipes de saúde bucal passou a ocorrer apenas a partir de 2001, e até hoje não são automaticamente incorporadas às equipes de ESF. A concepção da proposta gera um isolamento e compromete a aproximação da Odontologia com a Atenção Primária, o que dificulta o estabelecimento e consolidação de equipes de forma efetiva. A divisão parcelar do trabalho entre profissionais de saúde especializados e dependentes do trabalho de outros, 
gera uma a atuação de equipes fragmentadas, em que profissionais executam suas partes no processo sem envolvimento no resultado geral (Silva et al, 2010). Fica ressaltada a necessidade de aprofundamento dentro da complexidade desse tema, que envolve relações interpessoais (Martins et al, 2010).

Resgatando os objetivos dessa pesquisa, pôde-se constatar que:

1- Ao longo de décadas a temática formação em saúde encontra-se na pauta de políticas indutoras, e tem se reproduzido em investimentos ao longo do tempo. Entretanto, ainda existe um longo caminho a ser percorrido para que mudanças sólidas ocorram. O Programa Pró-Saúde tem sido um importante indutor dessas transformações, e portanto, deveria possuir um caráter de continuidade para que se possa vivenciar o reflexo das ações provenientes dessa proposta.

2- O instrumento construído e aplicado nessa pesquisa incluiu, conforme previsto, itens que abordaram aspectos dos eixos teórico, cenário de práticas e pedagógico.

3- Os resultados quantitativos desse estudo demonstraram, que em linhas gerais, respeitado o momento de estruturação curricular que cada curso vivencia no momento, existe, tanto por parte de professores quanto de estudantes dos três cursos analisados, o reconhecimento de que mudanças estão ocorrendo, ainda que de forma tímida em algumas vertentes, e de que o Pró-Saúde tem o potencial de ser uma referencial de apoio importante nessa missão. 
4- Da análise qualitativa, pode-se extrair que, apesar desse reconhecimento, os nós críticos ainda possuem força que se manifesta na forma de barreiras, dificuldades, resistência e equívocos, os quais devem ser considerados para a elaboração de ações de enfrentamento ao cenário.

5- É preciso o reconhecimento de que as mudanças que se almeja requer mudanças culturais profundas por parte da maioria dos envolvidos. Isso enseja um processo de conquista, e o momento que a Universidade vivencia pode ser favorável a essa abordagem. Na comparação entre os três cursos analisados, as diferenças foram apresentadas e são pertinentes ao momento de cada curso dentro do processo de reestruturação. O que vale ressaltar são as similaridades apresentadas entre eles. A abertura ao diálogo, as discussões presentes e as inquietações manifestadas, demonstram um importante momento de abertura para que se busque uma aproximação, a qual é essencial para que de fato essa jornada se torne um novo panorama na história da formação em saúde na Universidade de Brasília.

Fazendo um cotejamento entre políticas indutoras e a reorientação da formação, no caso do presente estudo, com o Programa Pró-Saúde, identificou-se uma diversidade de variáveis envolvidas em toda complexidade desse processo, as quais foram discorridas ao longo deste estudo e são apresentadas no modelo descritivo da Figura 21. 


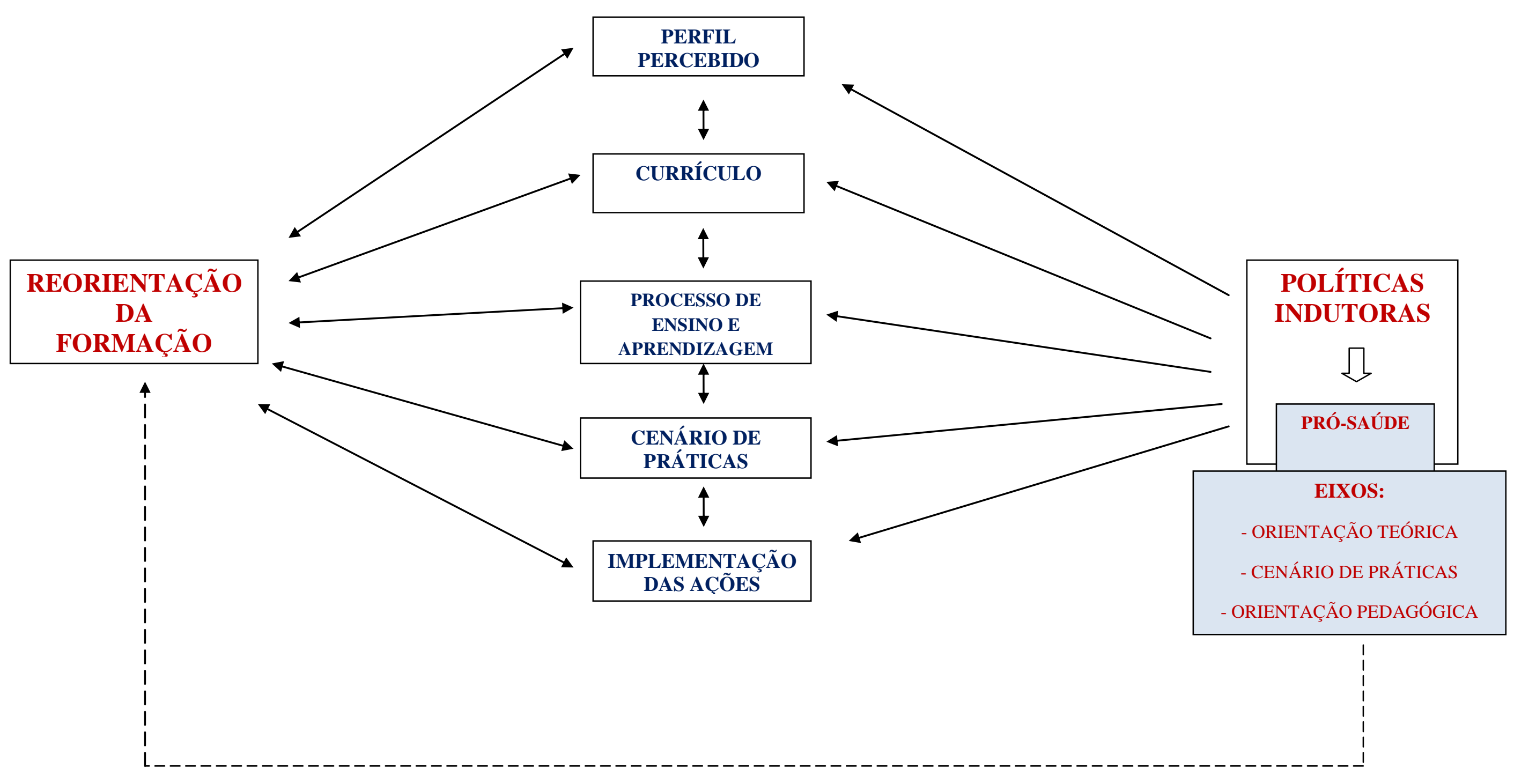

Figura 21 - Modelo descritivo do processo de reorientação da formação - Pró-Saúde, com as categorias obtidas da análise de conteúdo das entrevistas dos estudantes e professores 


\subsection{CONSIDERAÇÕES FINAIS}

É imprescindível ressaltar que o objetivo maior da reorientação na formação profissional em saúde é promover a melhoria da atenção à saúde da população brasileira, e se para tal, é necessário aprimorar a formação de modo a atender as necessidades do SUS, isso justifica o enfoque de reestruturação proposto pelo Programa Pró-Saúde. Não se buscam mudanças com caráter substitutivo. Nenhuma área da saúde pode abrir mão de suas competências e habilidades técnicas e específicas. Entretanto, estas encontram-se suficientemente bem estabelecidas, o que gera ênfase naqueles aspectos que ainda apresentam suas fragilidades, que são as competências comuns indicadas pelas DCN para os cursos de graduação em saúde.

As políticas indutoras estão presentes no movimento para a reorientação da formação há algumas décadas, e no caso específico do Pró-Saúde, desde 2005, sendo no caso da Universidade de Brasília, desde 2007. Vale ressaltar que essa Instituição de Ensino Superior carrega um histórico de participação em movimentos em prol de mudanças na formação, a exemplo do Programa UNI. Essa característica pode ter trazido repercussões e refletido nos importantes avanços que vêm ocorrendo, como a reestruturação dos currículos, apesar de se dar em passos diferenciados entre os três cursos analisados. Pode-se afirmar que o Pró-Saúde possibilitou sustentação a iniciativas já presentes, e favoreceu a inserção de novas propostas. Entretanto, outras frentes, como a integração entre áreas, entre cursos e entre universidade e serviço, assim como mudança de perfil profissional ainda requerem construção de outras estratégias para o seu fortalecimento, pois ambas requerem transformações que extrapolam a implementação do que é formalmente instituído. 
Para finalizar, é importante apontar alguns aspectos que podem ser considerados como limitações do estudo. A pesquisa se deu em uma Universidade, oferecendo a visão de uma IES que sempre esteve na vanguarda de transformação do ensino. É importante se ter a clareza de que esse fato pode inserir componentes que poderiam gerar diferentes resultados, caso o estudo fosse replicado em outra IES, que podem apresentar diferenças nesse sentido.

Em estudos futuros, sugere-se políticas de monitoramento, por eixos e dimensões, e com a criação de modelos preditivos em relação às dimensões em questão. É relevante também que estudos que abordem a influência das políticas indutoras na educação interprofissional. 


\section{REFERÊNCIAS}

Abu-Rish, E., Kim, S., Choe, L., Varpio, L., Malik, E., White, A. A., Craddick, K., Blondon, K., Robins, L., Nagasawa, P., Thigpen, A., Chen, L., Rich, J., \& Zierler, B. (2012). Current trends in interprofessional education of health sciences students: a literature review. Journal of Interprofessional Care, 26, 444-451.

Aguiar, R. A. T. (2003). A construção internacional do conceito de atenção primária à saúde (APS) e sua influência na emergência e consolidação do sistema único de saúde no Brasil. (Dissertação). Belo Horizonte: Universidade Federal de Minas Gerais.

Aguilar-da-Silva, R. H. A., Scapin, L. T. R., \& Batista, N. A. (2011). Avaliação da formação interprofissional no ensino superior em saúde: aspectos da colaboração e do trabalho em equipe. Avaliação, 16(1), 167-184.

Almeida, M. M., Morais, R. P., Guimarães, D. F., Machado, M. F. A. S., Diniz, R. C. M., \& Nuto, S. A. S. (2012). Da teoria à prática da interdisciplinaridade: a experiência do Pró-Saúde Unifor e seus nove cursos de graduação. Revista brasileira de educação médica, 36(1 suppl), 119-126.

Alves, C. R. L. Belisario, S. A, Lemos, J. M.C, Abreu, D.M.X, D’Ávila, L.S, Goulart, L.M.H.F. (2013). Mudanças curriculares: principais dificuldades na implementação do PROMED. Revista Brasileira de Educação Médica, 37(2), 157-166.

Araújo, M. E. (2006). Palavras e silêncio na educação superior em odontologia. Ciência e Saúde Coletiva, 11(1), 179-182.

Arrais, P. S. D., Aguiar, A. S. W., Souza, M. A. N., Machado, M. M. T., Mota, M. V., Alves, R. S., \& Araújo, M. F. M. (2012). Comprehensiveness: a pedagogical challenge for the Educational Program for Health Work. Revista Brasileira de Educação Médica, 36(1-2), 56-61.

Baltazar, M. M. M., Moysés, S. J., \& Bastos, C. C. B. C. (2010). Profissão, docente de odontologia: o desafio da pós-graduação na formação de professores. Trabalho, Educação e Saúde, 8(2), 285-303.

Bardin, L. (2009). Análise de conteúdo. Lisboa: Edições 70.

Batista, N. A. (1998). O ensino médico e sua trajetória no cenário nacional. O professor de medicina. São Paulo: Loyola, 19-44.

Bauer, M. W., \& Gaskell, G. (2011). Pesquisa qualitativa com texto, imagem e som. Petrópolis: Vozes. Escola Superior de Tecnologia e Gestão de Viseu. (2012). Biblioteca. Recuperado em 01 outubro, 2012 de http://www.estv.ipv.pt/biblioteca/ 
Bem-te-vi. Informativo mensal do Sistema Saúde-Escola das Faculdades de Ciências da Saúde e Medicina da Universidade de Brasília. (2015). Recuperado em maio de 2015 de http://fs.unb.br/?portfolio=bem-te-vi-traz-edicao-especial-comretrospectiva-do-sistema-saude-escola-das-fs-e-fmunb

Bisquerra, R., Sarreira, J.C., Martinez, F. (2004). Introdução à Estatística: Enfoque Informático com o Pacote Estatístico SPSS. Porto Alegre: Artmed, v.1. p.256.

Bohner, G., \& Dickel, N. (2011). Attitudes and Attitude Change. Annual Review of Psychology. 62, 391-417.

Brasil (1988). Constituição da República Federativa do Brasil de 1988. Brasília, DF.

Brasil (1990). Lei $n^{\circ} 8080$ - 19 de setembro de 1990. Dispõe sobre as condições para a promoção, proteção e recuperação da saúde, a organização e o funcionamento dos serviços correspondentes, e dá outras providências. Brasília, DF.

Brasil, Ministério da Saúde. (2000). Portaria $n^{\circ} 1444$ de 28 de dezembro de 2000. Dispõe sobre a reorganização das ações de saúde bucal na atenção básica portaria de incentivos financeiros. Brasília, seção-1, p. 85.

Brasil, Ministério da Saúde. (2000a). Referências conceituais para a organização do sistema de certificação de competências/PROFAE. Brasília, DF: MS.

Brasil, Ministério da Educação. (2001). Secretaria de Educação Superior. Diretrizes Curriculares para os Cursos de Graduação. Resolução CNE/ CES $\mathrm{n}^{\circ} 3$. Recuperado em 7 novembro, 2012, de http://www.mec.gov.br/sesu/diretriz.htm.

Brasil, Ministério da Educação. (2001a). Resolução CNE/CES n ${ }^{\circ} 3$, aprovada em 07 de novembro de 2001. Institui Diretrizes Curriculares Nacionais do Curso de Graduação em Enfermagem. Diário Oficial da União, Brasília, seção-1, p. 37.

Brasil, Ministério da Educação. (2001b). Resolução CNE/CES n 4, aprovada em 07 de novembro de 2001. Institui Diretrizes Curriculares Nacionais do Curso de Graduação em Medicina. Diário Oficial da União, Brasília, seção-1, p. 38.

Brasil, Ministério da Educação. (2002). Conselho Nacional de Educação, Câmara de Educação Superior. Diretrizes Curriculares Nacionais do Curso de Graduação em Odontologia. Diário Oficial da União, Brasília, seção-1, p.10.

Brasil, Ministério da Saúde., Brasil, Ministério da Educação., \& Organização Panamericana de Saúde. (2002a). Relatório das Oficinas Regionais do Promed. Brasil.

Brasil, Ministério da Saúde. (2003). Princípios e Diretrizes para NOB/RH-SUS. Conselho Nacional de Saúde. 2. ed., rev. e atual., $2^{\text {a }}$ reimpressão - Brasília.

Brasil, (2004). Ministério da Saúde. Secretaria de Atenção à Saúde. Departamento de Atenção Básica. Coordenação Nacional de Saúde Bucal. Diretrizes da Política 
Nacional de Saúde Bucal. Brasília, DF, Recuperado em 23 Março de 2012, de http://dtr2004.saude.gov.br/dab/saudebucal/publica-coes.php

Brasil, Ministério da Saúde. (2004a). Portaria no. 198, de 13 de fevereiro de 2004. Institui a Política Nacional de Educação Permanente em Saúde como estratégia do Sistema Único de Saúde para a formação e o desenvolvimento de trabalhadores para o setor e dá outras providências. Brasília.

Brasil, (2004b). Aprender SUS: O SUS e os Cursos de Graduação da Área da Saúde. Brasília: Departamento de Gestão da Educação na Saúde, Secretaria de Gestão do Trabalho e da Educação na Saúde, Ministério da Saúde. Recuperado em 03 Março, 2013, de http://portal.saude.gov.br/portal/arquivos/pdf/aprendersus.pdf

Brasil, Ministério da Saúde. (2005). Portaria Interministerial n²118 de 03 de novembro de 2005. Institui parceria entre o Ministério da Educação e o Ministério da Saúde para cooperação técnica na formação e desenvolvimento de recursos humanos na área da saúde. Brasília.

Brasil, Ministério da Saúde., Brasil, Ministério da Educação. (2005a). Portaria $n^{o} 2.101$ de novembro de 2005. Institui o Pró-Saúde: Programa Nacional de Reorientação da Formação Profissional em Saúde. Brasília.

Brasil, Ministério da Saúde. (2006). Portaria $n^{o} 399$ de 22 de fevereiro de 2006. Divulga o Pacto pela Saúde 2006 - Consolidação do SUS e aprova as Diretrizes Operacionais do Referido Pacto. Brasília.

Brasil, Ministério da Saúde (2006a). Cadernos de Atenção Básica n.17. Série A. Normas e Manuais Técnicos. Brasília: Departamento de Atenção Básica, Saúde Bucal.

Brasil, Ministério da Saúde \& Ministério da Educação (2007). Programa Nacional de Reorientação da Formação Profissional em Saúde - Pró-Saúde: objetivos, implementação e desenvolvimento potencial. Brasília-DF: 86p. Recuperado em 18, dezembro, 2012, de http://prosaude.org/noticias/2012edital/edital-24prosaude-petsaude.

Brasil, Ministério da Saúde (2007a). Portaria $n^{o} 1.507$ de 22 de junho de 2007. Institui o Programa de Educação pelo Trabalho para a Saúde. Brasília.

Brasil, (2007b). Portaria $n^{o} 1.996$ de 20 de agosto de 2007. Dispõe sobre as diretrizes para a implementação da Política Nacional de Educação em Saúde. Brasília, DF.

Brasil, Ministério da Saúde (2008). Relatório Final do II Seminário Nacional de Reorientação da Formação Profissional em Saúde - Pró-saúde (Relatório de Pesquisa/2008), Brasília, DF, Secretaria de Gestão do Trabalho e da Educação na Saúde, Departamento de Gestão da Educação na Saúde. 
Brasil, (2009). Portaria $n^{\circ} 3.189$, de 18 de dezembro de 2009. Dispõe sobre as diretrizes para implementação do Programa de Formação de Profissionais de Nível Médio para a Saúde (PROFAPS). Brasília, DF.

Brasil (2010). Relatório de Gestão 2008-2010 da Universidade Aberta do Sistema Único de Saúde. Brasília, DF, Secretaria de Gestão do Trabalho e da Educação na Saúde, Ministério da Saúde.

Brasil, Ministério da Saúde. (2011). Portaria conjunta $n^{o} 10$ de 14 de dezembro de 2010. Homologa o resultado do processo de seleção dos Projetos que se candidataram ao Programa de Educação pelo Trabalho para a Saúde. Brasília.

Brasil (2012). Glossário temático: gestão do trabalho e da educação na saúde (2a ed.). Brasília: Secretaria de Gestão do Trabalho e da Educação na Saúde, SecretariaExecutiva, Ministério da Saúde.

Brasil, Ministério da Saúde. (2013). Portaria $n^{\circ} 55$ de 2 de dezembro de 2013. Divulga a relação dos médicos com conceito satisfatório na primeira avaliação somativa do Programa de Valorização do Profissional da Atenção Básica referente ao ano de 2013. Brasília.

Brasil. Ministério da Educação. Conselho Nacional de Educação, Câmara de Educação Superior. Diretrizes Curriculares Nacionais do Curso de Graduação em Medicina. Diário Oficial da União, Brasília, 23 de junho de 2014. Seção 1, p.811. Brasília, 2014.

Campos, F. E., Ferreira, J. R., \& Feuerwerker, L. (2001). Caminhos para Aproximar a Formação de profissionais de Saúde das necessidades da Atenção Básica. Revista Brasileira de Educação Médica, 25(2), 53-59.

Carvalho, Y. M., \& Ceccim, R. B. (2006). Formação e educação em saúde: aprendizados com a saúde coletiva. In Gastão, W. S., Minayo, M. C. S., Akerman, M., Drumond Júnior, M., \& Carvalho, Y. M. Tratado de saúde coletiva. Rio de Janeiro, Hucitec. Fiocruz, 149-182.

Ceccim, R. B., \& Bilibio, L. F. S. (2002). Observação da educação dos profissionais da saúde: evidências à articulação entre gestores, formadores e estudantes. In: $\mathrm{Br}$ MS. Observatório de recursos humanos em saúde no Brasil: estudos e análises. 343-372.

Ceccim, R. B. (2002). Inovação na preparação de profissionais de saúde e a novidade da graduação em saúde coletiva. Boletim da saúde, Porto Alegre, 16(1), 9-38.

Ceccim, R. B., \& Feuerwerker, L. C. M. (2004). Mudança na graduação das profissões de saúde sob o eixo da integralidade. Cad. Saúde Pública, 20(5), 1400-1410.

Ceccim, R. B. (2005). Educação Permanente em Saúde: descentralização e disseminação de capacidade pedagógica na saúde. Ciência e Saúde Coletiva, 10(4), 975-986. 
Ceccim, R. B., \& Ferla A. A. (2009). Educação e saúde: ensino e cidadania como travessia de fronteiras. Trabalho, Educação e Saúde, 6(3), 443-456.

Coelho, I. M. (1998). Diretrizes curriculares e ensino de graduação. Revista da Associação Brasileira de Mantenedoras de Ensino Superior, 16(22):7-20.

Cordón, J. A. (1998). Sobre a construção histórica do conceito de Odontologia em saúde coletiva. Ação Coletiva, 1(1), 7-26.

Costa, R. K. S., Enders, B. C., \& Menezes, R. M. P. (2008). Trabalho em equipe de saúde: uma análise contextual. Ciência, cuidado e saúde, 7(4), 530-536.

Curran, V. R., Sharpe, D., \& Forristall, J. (2007). Attitudes of health sciences faculty members towards interprofessional teamwork and education. Journal of interprofessional care, 41, 892-896.

Colares, M. F. A., Troncon, L. E. A., Figueiredo, J. F. C., Cianflone, A. R. L., Rodrigues, M. L. V., Piccinato, C. E., Peres, L. C., \& Coleta, J. A. D. (2002). Construção de um instrumento para avaliação das atitudes de estudantes de Medicina frente a aspectos relevantes da prática médica. Revista brasileira de educação médica. 26(3), 194-203.

Creswell, J.W. (2007). Procedimentos de métodos mistos. In: Projeto de Pesquisa: método qualitativo, quantitativo e misto. Porto Alegre: Artmed, v.1. p.211-224.

Cruz, K. T. (2004). A formação médica no discurso da CINAEM. (Dissertação). Campinas: Universidade Estadual de Campinas.

De Paola, D. O., \& Slavkin, H.C. (2004). Reforming dental health professions education: a white paper. J. Dent. Educ. Whashington, 68(11):1139-1150.

De Paola, D. P. (2008). The Revitalization of U.S. Dental Education. Journal of Dental education, 72(2):28-42.

Delors, J., Al-Mufti, I., Amagi, I., Carneiro, R., Chumg, F., Germek, B., \& Gorham, W. (1998). Educação, um tesouro a descobrir (Relatório para a UNESCO da Comissão Internacional sobre Educação para o século XXI). Unesco-Brasil. Brasília-DF.

Dias, H., Lima, L. e Teixeira, M. (2013). A trajetória da política nacional de reorientação da formação profissional em saúde no SUS. Ciência e Saúde Coletiva, 18 (6), 1613-1624.

Ezequiel, M. C. D. G., Noel, B. K., Lemos, P. P., Paiva A. C., Borges, L. P., \& Ferreira, G. M. (2012). Estudantes e usuários avaliam ferramenta de educação permanente em saúde - Sieps. Revista brasileira de educação médica, 36(1suppl 2), 112-130.

Faure, E., Herrera, F., Kaddoura, A. R., Lopes, H., Petrovsky, A. V., Rahnema, M., \& Ward, F. C. (1972). Learning to be: the world of education today and tomorrow. 
Relatório para a Comissão Internacional para desenvolvimento da Educação. Paris, UNESCO.

Fernandes, J. D., Xavier, I. M., Ceribelli, M. I. P. F., Bianco, M. H. C., Maeda, D., \& Rodrigues M. V. C. (2005). Diretrizes curriculares e estratégias para implantação de uma nova proposta pedagógica. Revista da Escola de Enfermagem da USP, 39(4), 443-9.

Feuerwerker, L. (1998). Mudanças na educação médica e residência médica no Brasil. Interface: comunicação, saúde, educação, 2(3), 51-71.

Ferreira, J. R., Cury, G. C., Campos, F. E., Haddad, A. E., \& Gusso, G. D. F. (2007). A Construção de Parcerias como Estratégia para o Sucesso do Pró-Saúde. Cadernos ABEM, 3(1).

Ferreira, M. A., Oliveira, B. G. R., Porto, I. S., Anhorn, C. G., \& Castro, J. B. A. (2007). O significado do profae segundo os alunos: contribuição para a construção de uma política pública de formação profissional em saúde. Texto contexto - enfermagem.16(3). 445-452.

Fewster-Thuente, L.L. (2011). Working together toward a common goal: a grounded theory of Nurse-Physician Collaboration. PhD Thesis, Loylola University, Chicago, United States.

Fiehn, N. (2002). Perspectives on dental education in the Nordic countries. Journal of Dental Education, 66(12):1374-80.

Finkler, M., Caetano, J. C., \& Ramos, F. R. S., (2011). A dimensão ética da formação profissional em saúde: estudo de caso com cursos de graduação em odontologia. Ciência \& Saúde Coletiva, 16(11), 4481-4492.

Flexner, A. (1910). Medical education in the United States and Canada. New York, Carnegie Foundation for the Advancement of Science.

Flick, U. (2009). Uma Introdução à Pesquisa Qualitativa (3a ed.). Porto Alegre: Artmed.

Frenk, J., Chen, L., Bhutta, Z. A., Cohen, J., Crisp, N., \& Evans, T., et al. (2010). Health professionals for a new century: transforming education to strengthen health systems in an interdependent world. Lancet, 376, 1923-58.

Galleguillos, T. G. B., \& Oliveira, M. A. D. C. (2001). A gênese e o desenvolvimento histórico do ensino de enfermagem no Brasil. Revista da Escola de Enfermagem.

Garcia, M. A. A. (2007). A interdisciplinaridade necessária à educação médica. Revista Brasileira de Educação Médica, 31(2), 147-155.

Gaskell, G., \& Bauer, M. W. (2002). Para uma prestação de contas pública: além da amostra, da fidedignidade e da validade. In: Pesquisa qualitativa com texto, imagem e som: um manual prático. Petrópolis, Rio de Janeiro: Vozes. 
Germano, R. M. (2003). O ensino de enfermagem em tempos de mudança. Revista Brasileira de Enfermagem, 56(4), 365-8.

Gonzalez A. D., Almeida M. J. (2010). Movimentos de mudança na formação em saúde: da medicina comunitária às diretrizes curriculares. Physis, 20(2): 551-70.

Guilford J. P. (1954). Psychometric methods. New York: Mc Graw-Hill.

Haddad, A. E., \& Morita, M. C., (2006). O ensino da odontologia e as políticas de saúde e de educação. In: Carvalho, A. C. P., \& Kriger, L. Educação odontológica. São Paulo: Artes Médicas.

Haddad, A. E., Morita, M. C., Pierantoni, C. R., Brenelli, S. L., Passarella, T., \& Campos, F. E. (2010). Undergraduate programs for health professionals in Brazil. Revista de Saúde Pública, 44(3), 383-393.

Haddad, A. E. (2011). Nursing and the National Policy of Education for Health Care Professionals for the Brazilian National Health System. Revista da Escola de Enfermagem da Universidade de São Paulo, 45(2),1799-805.

Hall, P. (2005). Interprofessional teamwork: Professional cultures as barriers. Journal of interprofessional care, CN. 1(supp), $188-196$.

Hebert, C. P. (2005). Changing the culture: Interprofessional education for collaborative patient-centred practice in Canada. Journal of interprofessional care. 1 (supp), 1 -4 .

Herbert, C.P., Bainbridge L., Bickford J., Baptiste S., Brajtman S., Dryden T., et al. (2007). Factors that influence engagement in collaborative practice: how 8 health professionals became advocates. Canadian Family Physician, 53(8), 13181325.

Hind, M., Norman, I., Cooper, S., Gill, E., Hilton, R., Judd, P., \& Jones, S. C. (2003). Interprofessional perceptions of health care students. Journal of interprofessional care, 17(1).

Huang, C., Bian, Z., Tai, B., Fan, M., \& Chiu-Yin, K. (2007). Dental Education in Wuhan, China: challenges and changes. Journal of Dental Education, 71(2), 304311.

Hubner, L. C. M., \& Franco, T. B. (2007). O programa médico de família de Niterói como estratégia de implementação de um modelo de atenção que contemple os princípios e diretrizes do SUS. Physis 17(1),173-191.

Ito, E. E., Peres, A. M., Takahashi, R. T., \& Leite, M. M. J. (2006). O ensino de enfermagem e as diretrizes curriculares nacionais: utopia $\mathrm{x}$ realidade. Revista Escola de Enfermagem USP, 40(4), 570-5. 
Kriger, L., \& Morita, M. C. (2004). Mudanças nos cursos de Odontologia e a interação com o SUS. Revista da Abeno, 4(1),17-21.

Kriger, L., Moysés, S. J., \& Moysés, S. T. (2005). Humanismo e formação profissional. Carderno ABOPREV. Rio de Janeiro.

Kuschnir, R., \& Chorny, A. H. (2010). Redes de atenção à saúde: contextualizando o debate. Ciência e Saúde Coletiva, 15(5), 2307-2316. In Mendes, E. V (2010). Redes de atenção em saúde. Ciência e Saúde Coletiva, 15(5), 2297-2305.

Lambert, W. W., \& Lambert W. E. (1972). Psicologia social. Rio de Janeiro: Zahar.

Lampert, J. B. (1998). O curso de medicina de Santa Maria no contexto histórico da medicina e do ensino médico no Brasil. In Lampert, J. B. 40 anos de curso de medicina em Santa Maria, 1954-1994: depoimentos históricos (2a ed.). Santa Maria: CDU.

Lampert, J. B. (2009). Paradigmas da Educação Médica in Tendências de mudanças na formação médica no Brasil. São Paulo: Hucitec - Associação Brasileira de Educação Médica.

Lazzarin, H. C., Nakama, L., \& Cordoni Júnior, L. (2007). O papel do professor na percepção dos alunos de Odontologia. Saúde e sociedade, 16(1), 90-101.

Machado, M. F. A. S., Monteiro, E. M. L. M., Queiroz, D. T., Vieira, N. F. C., \& Barroso, M. G. T., (2005). Integralidade, formação de saúde, educação em saúde e as propostas do SUS - uma revisão conceitual. Universidade de Fortaleza-UFP, 336-342.

Mack, T. (2010). Desafios à educação médica contemporânea: uma conversa com Thomas Mack. Interface, 14 (35), 957-966.

Madureira, A. F. A., \& Branco, A. U. (2001). A pesquisa qualitativa em psicologia do desenvolvimento: questões epistemológicas e implicações metodológicas. Temas em Psicologia da SBP, 9(1), p. 63-75. Ribeirão Preto, São Paulo.

Maltagliati, L. A., \& Goldenberg, P. (2011). O lugar da pesquisa na reorganização curricular em odontologia: desafios de origem para um debate atual. Saúde e sociedade, 20(2), 436-447.

Marins, J. J. N. (2004). Os cenários de aprendizagem e o processo do cuidado em saúde. In: Marins, J. J. N., Rego, S., Lampert, J. B., \& Araújo, J. G. C. (Orgs).

Educação médica em transformação - instrumentos para a construção de novas realidades. São Paulo: ABEM Ed. Hucitec, 97-108.

Marsiglia, R. M. G. (1998). Perspectivas para o ensino das ciências sociais na graduação odontológica. In C. Botazzo \& S. F. T. de Freitas (Orgs.). Ciências sociais e saúde bucal: questões e perspectivas. São Paulo - Bauru: UNESP EDUSC. 
Martins, A.R., Pereira, D.B., Nogueira, M.L.S., Pereira, C.S., Schrader, G., Thoferhn, M.B. (2012). Relações interpessoais, equipe de trabalho e seus reflexos na atenção básica. Revista Brasileira de Educação Médica, 36(1), 6-12.

Mattos, D. (2006). As novas diretrizes curriculares e a integralidade em saúde: uma análise das possíveis contribuições da odontologia para o trabalho em equipe. Dissertação de mestrado, Universidade do Estado do Rio de Janeiro, Rio de Janeiro, RJ, Brasil.

May, T. (2004). Pesquisa social: questões, métodos e processo. Porto Alegre: Artmed.

McNair, R., Stone, N., Sims, J., \& Curtis, C. (2005). Australian evidence for interprofessional education contributing to effective teamwork preparation and interest in rural practice. Journal of interprofessional care, 19(6), 579-594.

Mendes, E. V. (1985). A evolução histórica da prática médica, suas implicações no ensino, na pesquisa e na tecnologia médica. Belo Horizonte: PUC/FINEP.

Mendes, E. V. (1996). Um novo paradigma sanitário: a produção social da saúde. In: Uma agenda para a saúde. São Paulo: Hucitec, p. 233-300.

Mendes, E. V. (2010). Redes de atenção em saúde. Ciência e Saúde Coletiva, 15(5), 2297-2305.

Merhy, E. E., Feuerwerker, L. C. M., \& Ceccim, R. B. (2006). Educación Permanente en Salud: una estrategia para intervenir en la micropolítica del trabajo en salud. Salud Colectiva, Buenos Aires, 2(2), 147-160.

Miguel, G. B. (1983). Testes psicométricos e projetivos — medidas psico-educacionais. São Paulo: Loyola.

Minayo M. C. S. (2008). Desafio do conhecimento: pesquisa qualitativa em saúde. São Paulo: Hucitec.

Moreira, M. C. (2010). Educação Permanente em Saúde: revisão sistemática da literatura científica. Monografia de Especialização. Universidade Federal do Rio Grande do Sul, Porto Alegre, Brasil.

Morita, M. C., Kriger, L., (2007). Mudanças nos cursos de odontologia e a interação com o SUS. Revista da Abeno, 4(1),17-21.

Morita, MC., Haddad, A. E., \& Araújo, M. E. (2010). Perfil atual e tendências do cirurgião - dentista brasileiro. Maringá: Dental Press.

Moysés, S. J. (2003). A humanização da educação em odontologia. Pro-posições, 14(40), 87-106.

Nogueira, M.I. (2009). As mudanças na educação médica brasileira em perspectiva: reflexões sobre a emergência de um novo estilo de pensamento. Revista Brasileira de Educação Médica.33(2), 262-270. 
Nunes, E. D. (2010). Cem anos do relatório Flexner. Ciência e Saúde Coletiva, 15(suppl.1), 956-956.

Oliveira, N. A., Meirelles, R. M. S., Cury, G. C., \& Alves, L. A. (2008). Mudanças curriculares no ensino médico brasileiro: um debate crucial no contexto do Promed. Revista Brasileira de Educação Médica, 32(3), 333-346.

Peduzzi, M. (2001). Multiprofessional heathcare team: concept and typology. Revista de Saúde Pública, 35(1), 103-109.

Pagliosa, F. L., \& Da Ros, M. A. (2008). O relatório Flexner: para o bem e para o mal. Revista Brasileira de Educação Médica, 32(4), 492-499.

Pasquali, L. (1996). Teoria e métodos de medida em ciências do comportamento. Brasília: Instituto Nacional de Estudos e Pesquisas Educacionais, Secretaria de Avaliação e Informação Educacional.

Pinhel, I., \& Kurcgant, P. (2007). Reflexões sobre competência docente no ensino de Enfermagem. Revista da Escola de Enfermagem USP, 41(4), 711-6.

Pizzinato, A., Gustavo, A. S., Santos, B. R. L., Ojeda, B. S., Ferreira, E., \& Thiesen, F. V. (2012) A integração ensino-serviço como estratégia na formação profissional para o SUS. Revista brasileira de educação médica, 36(1suppl 2),170-177.

Puccini, R. F., Ventura, R. N., Gabrielloni. M.C., Ávila, C. R. B., Figueiredo, E. N., Andreazza, R., (2012). O Pró-Saúde da Universidade Federal de São Paulo: contribuições para institucionalização e integração Universidade/Serviços de Saúde. Revista Brasileira de Educação Médica, 36, (1 suppl 2), 80-88.

Rizzotto, M. L. F. (1999). História da enfermagem e sua relação com a saúde pública. AB Editora.

Rossoni, E., \& Lampert, J. (2004). Formação de profissionais para o Sistema Único de Saúde e as diretrizes curriculares. In: Boletim da Saúde. Porto Alegre, 18(1), 8798.

Schaurich, D., Cabral, F. B., \& Almeida, M. A. (2007). Metodologia da problematização no ensino em Enfermagem: uma reflexão do vivido no Profae. Escola Anna Nery R. Enfermagem, 11(2), 318-24.

Scott, J. (2003). Dental education in Europe: the challenges of variety. Journal of Dental Education, 67(1), 69-78.

Silva, E. L., \& Cunha, M. V. (2002). A formação profissional no século XXI: desafios e dilemas. 31(3), 77-82.

Silva, T. N., Borges, M. N. T. F., Santana, M. M., et al. (2012). A equipe na estratégia de saúde da família: uma experiência do PET-Saúde. Revista Brasileira de Educação Médica, 36(1), 50-55. 
Silva Junior, A. G. (1998). Modelos tecnoassistenciais em saúde: o debate no campo da saúde coletiva. São Paulo: Hucitec.

Souza, T. Y., Branco, A., \& Lopes de Oliveira, M. C. S. (2008). Pesquisa qualitativa e desenvolvimento humano: aspectos históricos e tendências atuais. Fractal: Revista de Psicologia, 20, 357-376.

Souza, P. A., Zeferino, A. M. B., \& Da Ros, M. A. (2011). Health conditions and health-policy innovations. Integrated medical curriculum: from discourse to practice. Revista Brasileira de Educação Médica, 35(1), 20-25.

Souza, U. (2005). País tem 12.227 vagas em medicina. Revista da APM, 558, 6-13

Veloso, T. C. M. A. (2008). Programa nacional de incentivo a mudanças curriculares no curso de medicina: a experiência da UFG. Tese de doutorado, Universidade Federal de Goiás, Goiânia, Brasil.

Victora, C. G., Barreto, M. L., Leal, M. C., Monteiro, C. A., Schidt, M. I., \& Paim J., (2011). Health conditions and health-policy innovations in Brazil: the way forward. Lancet, 377(9782), 2042-2053.

Xavier, G.M. (2013). A formação do cirurgião-dentista no contexto do Sistema Único de Saúde: uma avaliação do ensino de Odontologia. (Dissertação). Brasília: Universidade de Brasília.

Yin, R. K. (2001). Estudo de caso: planejamento e métodos (3a ed.). Porto Alegre: Bookman.

Zeferino, A. M. B., Zanolli, M. L. A., \& Monteiro, M. A. R. G. (2012). Experiência da atenção integral à saúde individual e familiar com enfoque na responsabilização, vínculo médico-paciente, ética e profissionalismo no currículo médico integrado. Revista Brasileira de Educação Médica, 36(1 suppl2),141-146. 
ANEXOS

\section{Anexo A - Aprovação do projeto pelo Comitê de Ética em Pesquisa}

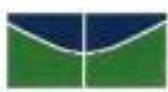

Universidade de Brasilia

Faculdade de Ciências da Saúde

Comitê de Ética em Pesquisa - CEP/FS

\section{PROCESSO DE ANÁLISE DE PROJETO DE PESOUISA}

Registro do Projeto no CEP: 062/12

Título do Projeto: “Avaliação do impacto do programa nacional de reorientação da formação profissional em saúde (pró-saúde) em cursos de odontologia"

Pesquisador Responsável: Denise de Lima Costa Furlanetto

Data de Entrada: 05/05/12

Com base na Resolução 196/96, do CNS/MS, que regulamenta a ética em pesquisa com seres humanos, o Comitê de Ética em Pesquisa com Seres Humanos da Faculdade de Ciências da Saúde da Universidade de Brasília, após análise dos aspectos éticos e do contexto técnico-cientifico, resolveu APROVAR o projeto 062/12 com o titulo: Avaliaçâo do impacto do programa nacional de reorientação da formação profissional em saúde (pró-saúde) em cursos de odontologia", analisado na $5^{a}$ Reunião Ordinảria, realizada no dia 12 de junho de 2012.

A pesquisadora responsável fica, desde jà, notificada da obrigatoriedade da apresentação de um relatório semestral e relatório final sucinto e objetivo sobre o desenvolvimento do Projeto, no prazo de 1 (um) ano a contar da presente data (item VII.13 da Resoluçăo 196/96).

Brasilia, 14 de janeiro de 2013.

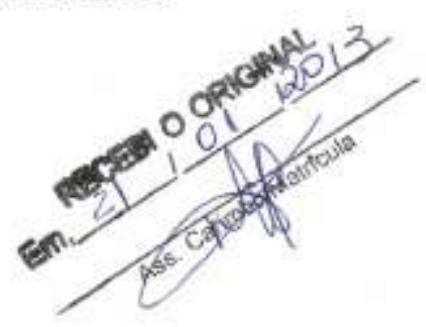

Prof. Nflun Monsores Coordenador do CEP-FS/UnB

Comité de Etica em Pesquisa com Seres Humanos - Faculdade de Ciéncias da Saúce Universidade de Brasilia - Campus Universitário Darcy Ribeiro - CEP: 70.910-900

Telefone: (61)-3107-1947 Email: cepfsegunt br 


\title{
Anexo B - Termo de Consentimento Livre e Esclarecido
}

\section{TERMO DE CONSENTIMENTO LIVRE E ESCLARECIDO}

\section{Dados de identificação}

\author{
Título do Projeto: Análise da implementação do Programa Nacional de Reorientação \\ da Formação Profissional em Saúde (Pró-Saúde) em cursos da saúde. \\ Pesquisador Responsável: Denise de Lima Costa Furlanetto \\ Orientadora: Dra. Diana Lúcia Moura Pinho \\ Instituição a que pertence o Pesquisador Responsável: Universidade de Brasília
}

Você está sendo convidado (a) a participar, como voluntário, deste projeto de pesquisa. O objetivo deste estudo é analisar os resultados e progressos obtidos, assim como os desafios enfrentados para o alcance dos objetivos propostos na implementação do Programa Nacional de Reorientação da Formação Profissional em Saúde (Pró-Saúde) em cursos de Enfermagem, Medicina e Odontologia. A realização da mesma justifica-se dada a relevância de se apontar os avanços desde a implantação do Programa, assim como propor mudanças e ajustes, se necessário, a serem efetuados, visando a formação do cirurgião-dentista que possa atender às necessidades do SUS.

Para tal serão convidados a participar estudantes e professores dos cursos mencionados, os quais tem sido apoiados pelo Pró-Saúde. Serão utilizados como instrumentos da pesquisa questionários desenvolvidos a partir de análise documental, além de entrevistas com envolvidos diretos ou indiretos no Programa.

Vale ressaltar que caso sua participação seja na forma de entrevista, as mesmas serão gravadas para posterior transcrição e análise. Em relação ao questionário, caso você considere que alguma das questões lhe ocasione algum constrangimento, de alguma natureza, você tem o direito de recusar-se a responder tais questões. Caso você queira desistir de sua participação, mesmo após o aceite do termo de consentimento, preenchimento dos questionários ou entrevista, seus direitos serão preservados. Para isso, solicite a retirada de suas respostas através do e-mail do pesquisador: dlcfurla@hotmail.com

Todas as informações obtidas serão consideradas confidenciais. Serão analisadas em conjunto com outros participantes da pesquisa, não sendo divulgada a identificação de nenhum participante. Os dados coletados serão utilizados exclusivamente para a realização dessa pesquisa. Os resultados da mesma serão disponibilizados após o término da análise dos dados na forma de publicações científicas.

Esclarecemos que não há benefício pecuniário para o participante da pesquisa. Entretanto, esperamos, ao final do estudo, obter respostas que sejam de benefício coletivo, para a sociedade, para as profissões da saúde e para os cursos de graduação estudados.

Caso você queira obter quaisquer esclarecimentos antes ou durante o curso da pesquisa, entre em contato com a pesquisadora responsável pelos telefones (61) 82074404 ou (61) 35421200 . Se você tiver alguma dúvida ou consideração sobre a ética da pesquisa, entre em contato com o Comitê de Ética em Pesquisa da Faculdade de Ciências da Saúde - UnB - Contatos: cepfs@unb.br/ 3107-1947/www.unb.br/fs/cep

Eu, abaixo assinado, declaro ter sido informado e esclarecido sobre a proposta desta pesquisa e os procedimentos envolvidos, e concordo em participar do estudo como sujeito.

Brasília, de de 


\section{Anexo C - Versão final do instrumento aplicado aos estudantes}

\section{INSTRUMENTO PARA ANÁLISE DO PRÓ-SAÚDE EM CURSOS DE ODONTOLOGIA}

Prezado (a) acadêmico (a):

Estas questões fazem parte de um estudo sobre a formação do cirurgião-dentista, realizado em cursos de Odontologia contemplados pelo Programa Pró-Saúde. Neste sentido conto com a

sua colaboração para o desenvolvimento do mesmo.

\section{INSTRUÇÕES PARA O PREENCHIMENTO DO INSTRUMENTO:}

1-Todas as afirmações estão relacionadas ao curso de Odontologia desta Instituição de Ensino Superior.

2- Não existem respostas "certas" ou "erradas", uma vez que este instrumento tem por objetivo analisar tendências atitudinais.

3- Ao fazer a leitura do instrumento, circule todo item que the causar dúvida ou que por qualquer motivo você gostaria de fazer algum comentário. Ao final, lembre-se de acrescentar suas observações sobre os itens que você circulou, utilizando o espaço reservado após o término da Seção 2.

\section{SEÇÃO 1: Dados sociodemográficos e acadêmicos}

1-Sexo: ( ) masculino ( ) feminino

2- Faixa etária: ( ) 16 a 20 anos ( ) 21 a 25 anos ( ) 26 a 30 anos ( ) 31anos ou mais

3- Já sou graduado em outro curso na área de:

( ) ciências da saúde ( ) ciências exatas e da terra ( ) ciências biológicas ( ) engenharias

( ) ciências agrárias ( ) ciências sociais aplicadas ( ) ciências humanas ( ) multidisciplinar

( ) linguística, letras e artes ( ) outra área não mencionada ( ) não se aplica

4-Período da graduação de Odontologia que estou cursando:

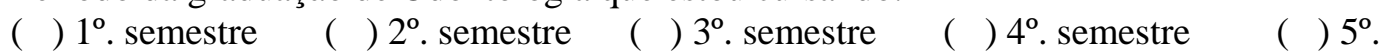
semestre

( ) $6^{\circ}$. semestre $\quad\left(\right.$ ) $7^{\circ}$. semestre $\quad\left(\right.$ ) $8^{\circ}$. semestre $\quad\left(\right.$ ) $9^{\circ}$. semestre $\quad$ ( ) $10^{\circ}$. semestre

5- As atividades práticas oferecidas em ambientes externos à Universidade (seja em rotina ou de forma

esporádica), nas (s) disciplina(s) regulares ou optativas que cursei ou estou cursando ocorrem no:

*é possível assinalar mais de uma opção

*desconsidere atividades de estágios, extensão, monitorias.

( ) $1^{\circ}$. semestre ( ) $2^{\circ}$. semestre ( ) $3^{\circ}$. semestre ( ) $4^{\circ}$. semestre ( ) $5^{\circ}$. semestre

( ) $6^{\circ}$. semestre ( ) $7^{\circ}$. semestre ( ) $8^{\circ}$. semestre ( ) $9^{\circ}$. semestre ( ) $10^{\circ}$. semestre

( ) nenhuma disciplina que estou cursando ou cursei até o momento oferece atividades práticas

externas 
6- Atualmente participo:

*é possível assinalar mais de uma opção

( ) de projeto de iniciação científica

( ) de projeto de extensão

( ) de projeto do Pró-Saúde/Pet-Saúde

( ) de projeto de monitoria

( ) outros - especificar

( ) atualmente não participo de nenhum projeto

7- Você conhece o Programa Pró-Saúde?
( ) $\operatorname{sim}$
( ) não

8- Sou/fui bolsista do Pró-Saúde/Pet-Saúde
( ) $\operatorname{sim}$
( ) não

9- Se você respondeu sim na questão 8, qual o seu tempo de participação?

( ) menos de 3 meses ( ) 3 a 6 meses ( ) 6 a 12 meses ( ) acima de 12 meses ( ) não se aplica

\section{SEÇÃO 2: Parte específica}

\section{INSTRUÇÕES PARA O PREENCHIMENTO DA SEÇÃO 2:}

- Leia cada afirmação a seguir e assinale com um X a opção que você julgar mais apropriada.

- Assinale apenas uma opção por questão.

- Lembre-se de que todas as afirmações referem-se ao curso de Odontologia desta Universidade.

\begin{tabular}{|c|c|c|c|c|c|c|}
\hline BLOCO 1 & $\begin{array}{c}\text { discordo } \\
\text { totalmente }\end{array}$ & discordo & $\begin{array}{c}\text { não } \\
\text { concordo } \\
\text { nem } \\
\text { discordo }\end{array}$ & concordo & $\begin{array}{c}\text { concordo } \\
\text { totalmente }\end{array}$ & não sei \\
\hline $\begin{array}{l}\text { 1- Os conteúdos teóricos ministrados na graduação abordam } \\
\text { aspectos biológicos do processo saúde-doença. }\end{array}$ & & & & & & \\
\hline $\begin{array}{l}\text { 2- Os conteúdos teóricos ministrados na graduação abordam } \\
\text { aspectos sociais do processo saúde-doença. }\end{array}$ & & & & & & \\
\hline $\begin{array}{l}\text { 3- Há interação entre as abordagens teóricas das disciplinas das } \\
\text { áreas básicas, clínicas e sociais da graduação. }\end{array}$ & & & & & & \\
\hline $\begin{array}{l}\text { 4- A produção de conhecimento, no que se refere à pesquisa, } \\
\text { está articulada com as demandas do serviço e da comunidade da } \\
\text { Regional de Saúde do Paranoá/Itapoã. }\end{array}$ & & & & & & \\
\hline $\begin{array}{l}\text { 5- A produção científica é focada em investigações sobre } \\
\text { aspectos biomédicos ou tecnológicos da atenção à saúde. }\end{array}$ & & & & & & \\
\hline $\begin{array}{l}\text { 6- A produção de conhecimento, no que se refere à extensão, } \\
\text { está articulada com as demandas do serviço e da comunidade da } \\
\text { Regional de Saúde do Paranoá/Itapoã. }\end{array}$ & & & & & & \\
\hline $\begin{array}{l}\text { 7- A oferta de cursos de pós-graduação é voltada para os } \\
\text { profissionais do SUS. }\end{array}$ & & & & & & \\
\hline $\begin{array}{l}\text { 8- Os cursos de pós-graduação possuem como público-alvo os } \\
\text { profissionais que atuam na rede privada. }\end{array}$ & & & & & & \\
\hline $\begin{array}{l}\text { 9- Os cursos de pós-graduação são oferecidos de acordo com } \\
\text { interesses ou necessidades do curso. }\end{array}$ & & & & & & \\
\hline
\end{tabular}


10- As disciplinas teóricas de conteúdos relacionados às áreas básicas, clínicas e sociais são ministradas em blocos separados, sem articulação entre elas.

BLOCO 2

\begin{tabular}{|l|l|l|l|l|l|}
\hline $\begin{array}{c}\text { discordo } \\
\text { totalmente }\end{array}$ & discordo & $\begin{array}{c}\text { não } \\
\text { concordo } \\
\text { nem } \\
\text { discordo }\end{array}$ & concordo & $\begin{array}{l}\text { concordo } \\
\text { totalmente }\end{array}$ & não sei \\
\hline & & & & & \\
\hline \\
\hline
\end{tabular}

1- A integração da universidade com o serviço de saúde traz benefícios para a comunidade.

2- A integração da universidade com o serviço de saúde traz benefícios para o serviço.

3- A integração da universidade com o serviço de saúde traz benefícios para a universidade.

4- O curso de Odontologia contribui para a organização dos serviços da Regional de Saúde do Paranoá/Itapoã.

5- A infraestrutura das unidades de saúde nas quais são realizadas atividades das disciplinas e/ou ações do Pró-Saúde são adequadas ao processo de ensino e aprendizagem dos estudantes.

6- As atividades práticas das disciplinas clínicas são realizadas nas instalações assistenciais universitárias, a exemplo das clínicas e hospital universitário.

7- O curso de Odontologia está voltado para a formação especializada do dentista.

8- As atividades desenvolvidas nos cenários de práticas do Paranoá-Itapoã são importantes para a formação do dentista.

9- O Pró-Saúde contribuiu para a integração do curso com a Rede de Serviço de Saúde do Paranoá-Itapoã.

10- O curso de Odontologia se volta para a formação generalista do dentista.

11- O Pró-Saúde contribuiu para a integração da Odontologia com os demais cursos da área da saúde.

12- As atividades práticas dos primeiros anos do curso ocorrem em laboratórios da área básica.

13- A inserção dos estudantes de Odontologia com atividades práticas na comunidade ou nos serviços de saúde ocorre desde os primeiros dois anos do curso.

\begin{tabular}{|c|c|c|c|c|c|c|}
\hline BLOCO 3 & $\begin{array}{l}\text { discordo } \\
\text { totalmente }\end{array}$ & discordo & $\begin{array}{c}\text { não } \\
\text { concordo } \\
\text { nem } \\
\text { discordo }\end{array}$ & concordo & $\begin{array}{l}\text { concordo } \\
\text { totalmente }\end{array}$ & não sei \\
\hline \multicolumn{7}{|l|}{$\begin{array}{l}\text { 2- O Pró-Saúde contribuiu com o processo de reforma curricular } \\
\text { do curso de Odontologia. }\end{array}$} \\
\hline \multicolumn{7}{|l|}{$\begin{array}{l}\text { 4- A participação do estudante no Pró-Saúde contribui para a } \\
\text { sua maior preparação para atuação profissional na rede privada. }\end{array}$} \\
\hline \multicolumn{7}{|l|}{$\begin{array}{l}\text { 5- As atividades desenvolvidas no contexto do Pró-Saúde nas } \\
\text { unidades de saúde não alteram as rotinas de trabalho e nem as } \\
\text { práticas dos profissionais de saúde no serviço. }\end{array}$} \\
\hline
\end{tabular}


8- As atividades desenvolvidas no âmbito do Pró-Saúde contribuem para a qualificação da prática dos profissionais que atuam na rede pública de atenção à saúde do Paranoá-Itapoã. 9- O Pró-Saúde contribui para o trabalho em equipe.

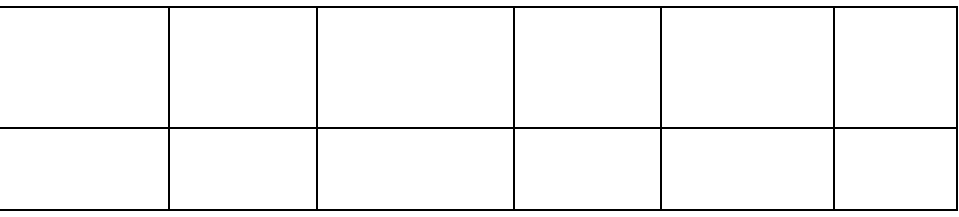

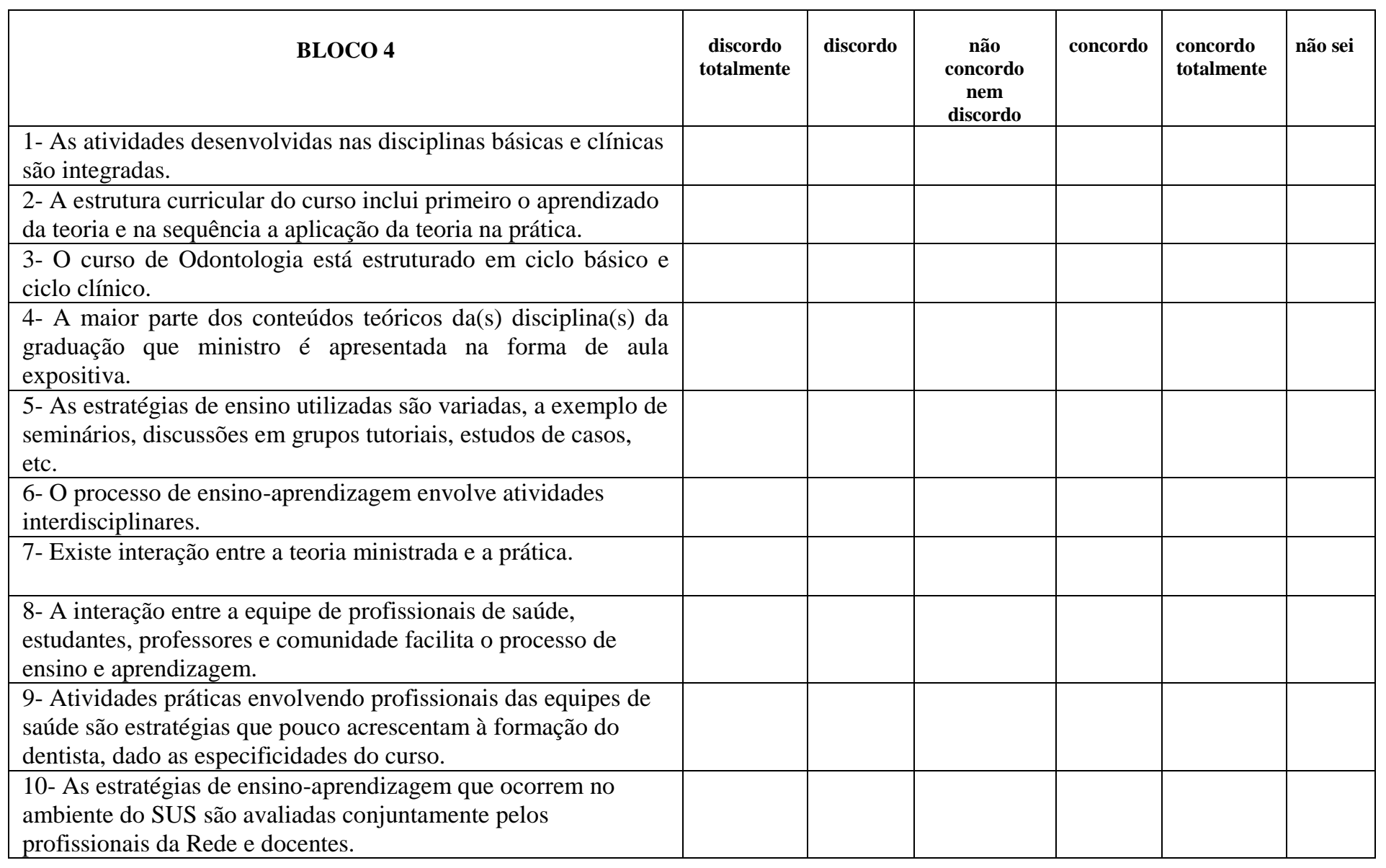

\section{Comentários/sugestões sobre os itens respondidos}

Obrigada por sua colaboração! 


\section{Anexo D - Versão final do instrumento aplicado aos professores \\ INSTRUMENTO PARA ANÁLISE DO PRÓ-SAÚDE EM CURSOS DE ODONTOLOGIA}

Prezado (a) colega,

Estas questões fazem parte de um estudo sobre a formação do cirurgião-dentista, realizado em cursos de Odontologia contemplados pelo Programa Pró-Saúde. Neste sentido conto com a sua colaboração para o desenvolvimento do mesmo.

\section{INSTRUÇÕES PARA O PREENCHIMENTO DO INSTRUMENTO:}

1-Todas as afirmações estão relacionadas ao curso de Odontologia desta Instituição de Ensino Superior.

2- Considere como referência a disciplina em que estiver inserido (a).

3- Não existem respostas "certas" ou "erradas", uma vez que este instrumento tem por objetivo analisar tendências atitudinais.

4- Ao fazer a leitura do instrumento, circule todo item que lhe causar dúvida ou que por qualquer motivo você gostaria de fazer algum comentário. Ao final, lembre-se de acrescentar suas observações sobre os itens que você circulou, utilizando o espaço reservado após o término da Seção 2.

\section{SEÇÃO 1: Dados sociodemográficos e profissionais}

1-Sexo: ( ) masculino ( ) feminino

2- Faixa etária: ( ) 20 a 29 anos ( ) 30 a 49 anos ( ) 50 a 59 anos ( ) 60 anos ou mais

3- Sou graduado em:

( ) Odontologia

( ) outro curso da área de saúde - especificar

( ) outra área não mencionada - especificar

( ) não se aplica

4-Tempo de formado (a): ( ) menos de 2 anos ( ) 2 a 5 anos ( ) 6 a 9 anos ( ) 10 anos ou mais

5- Maior grau de formação:

( ) graduação ( ) especialização ( ) mestrado ( ) doutorado ( ) pós-doutorado

6- Sou docente de disciplina (s) da (s) área (s):

*é possível assinalar mais de uma opção
( ) básica
( ) clínica
( ) social
( ) outra - especificar

7- As atividades práticas ministradas em ambientes externos à Universidade (seja em rotina ou de forma esporádica), nas (s) disciplina(s) que ofereço ocorrem no:

*é possível assinalar mais de uma opção

( ) $1^{\circ}$. semestre ( ) $2^{\circ}$. semestre ( ) $3^{\circ}$. semestre ( ) $4^{\circ}$. semestre ( ) $5^{\circ}$. semestre

( ) $6^{\circ}$. semestre ( ) $7^{\circ}$. semestre ( ) $8^{\circ}$. semestre ( ) $9^{\circ}$. semestre ( ) $10^{\circ}$. semestre

( ) em minha(s) disciplina(s) atividades práticas externas não se aplicam

8- Atualmente oriento aluno de graduação: *é possível assinalar mais de uma opção

( ) em projeto de iniciação científica 
( ) em projeto de extensão

( ) em projeto do Pró-Saúde/Pet-Saúde

( ) em projeto de monitoria

( ) outros

9- Tempo de participação em disciplinas inseridas na proposta do Pró-Saúde:

( ) menos de 1 ano ( ) 1 ano ( ) $2 \operatorname{anos~(~)~} 3$ anos ( ) 4 anos ( ) 5 anos ou + ( ) não sei

10- Tutoria do Pró-Saúde/Pet-Saúde

( ) não ( ) sim, voluntário ( ) sim, bolsista

11- Se você respondeu sim na questão 10, qual o seu tempo de participação?

( ) menos de 3 meses ( ) 3 a 6 meses ( ) 6 a 12 meses ( ) acima de 12 meses ( ) não se aplica

12- Ministro disciplina em curso de pós-graduação lato sensu e o conteúdo que trabalho está relacionado aos conhecimentos de natureza:

( ) clínica ( ) social ( ) básica ( ) não oferto disciplinas na pós-graduação ( ) não se aplica

13- Ministro disciplina em curso de pós-graduação stricto sensu e o conteúdo que trabalho está relacionado aos conhecimentos de natureza:

( ) clínica ( ) social ( ) básica ( ) não oferto disciplinas na pós-graduação （ ） não se aplica

\section{SEÇÃO 2: Parte específica}

\section{INSTRUÇÕES PARA O PREENCHIMENTO DA SEÇÃO 2:}

- Leia cada afirmação a seguir e assinale com um X a opção que você julgar mais apropriada.

- Assinale apenas uma opção por questão.

- Lembre-se de que todas as afirmações referem-se ao curso de Odontologia desta Universidade.

\begin{tabular}{|c|c|c|c|c|c|c|}
\hline BLOCO 1 & $\begin{array}{c}\text { discordo } \\
\text { totalmente }\end{array}$ & discordo & $\begin{array}{c}\text { não } \\
\text { concordo } \\
\text { nem } \\
\text { discordo }\end{array}$ & concordo & $\begin{array}{c}\text { concordo } \\
\text { totalmente }\end{array}$ & não sei \\
\hline $\begin{array}{l}\text { 1- Os conteúdos teóricos ministrados na graduação abordam } \\
\text { aspectos biológicos do processo saúde-doença. }\end{array}$ & & & & & & \\
\hline $\begin{array}{l}\text { 2- Os conteúdos teóricos ministrados na graduação abordar } \\
\text { aspectos sociais do processo saúde-doença. }\end{array}$ & & & & & & \\
\hline $\begin{array}{l}\text { 3- Há interação entre as abordagens teóricas das disciplinas da } \\
\text { áreas básicas, clínicas e sociais da graduação. }\end{array}$ & & & & & & \\
\hline $\begin{array}{l}\text { 4- A produção de conhecimento, no que se refere à pesquisa, } \\
\text { está articulada com as demandas do serviço e da comunidade da } \\
\text { Regional de Saúde do Paranoá/Itapoã. }\end{array}$ & & & & & & \\
\hline $\begin{array}{l}\text { 5- A produção científica é focada em investigações sobre } \\
\text { aspectos biomédicos ou tecnológicos da atenção à saúde. }\end{array}$ & & & & & & \\
\hline $\begin{array}{l}\text { 6- A produção de conhecimento, no que se refere à extensão, } \\
\text { está articulada com as demandas do serviço e da comunidade da } \\
\text { Regional de Saúde do Paranoá/Itapoã. }\end{array}$ & & & & & & \\
\hline $\begin{array}{l}\text { 7- A oferta de cursos de pós-graduação é voltada para os } \\
\text { profissionais do SUS. }\end{array}$ & & & & & & \\
\hline $\begin{array}{l}\text { 8- Os cursos de pós-graduação possuem como público-alvo os } \\
\text { profissionais que atuam na rede privada. }\end{array}$ & & & & & & \\
\hline
\end{tabular}


9- Os cursos de pós-graduação são oferecidos de acordo com interesses ou necessidades do curso.

10- As disciplinas teóricas de conteúdos relacionados às áreas básicas, clínicas e sociais são ministradas em blocos separados, sem articulação entre elas.

\section{BLOCO 2}

1- A integração da universidade com o serviço de saúde traz benefícios para a comunidade.

2- A integração da universidade com o serviço de saúde traz benefícios para o serviço.

3- A integração da universidade com o serviço de saúde traz benefícios para a universidade.

4- O curso de Odontologia contribui para a organização dos serviços da Regional de Saúde do Paranoá/Itapoã.

5- A infraestrutura das unidades de saúde nas quais são realizadas atividades das disciplinas e/ou ações do Pró-Saúde são adequadas ao processo de ensino e aprendizagem dos estudantes.

6- As atividades práticas das disciplinas clínicas são realizadas nas instalações assistenciais universitárias, a exemplo das clínicas e hospital universitário.

7- O curso de Odontologia está voltado para a formação especializada do dentista.

8- As atividades desenvolvidas nos cenários de práticas do Paranoá-Itapoã são importantes para a formação do dentista. 9- O Pró-Saúde contribuiu para a integração do curso com a Rede de Serviço de Saúde do Paranoá-Itapoã.

10- O curso de Odontologia se volta para a formação generalista do dentista.

11- O Pró-Saúde contribuiu para a integração da Odontologia com os demais cursos da área da saúde.

12- As atividades práticas dos primeiros anos do curso ocorrem em laboratórios da área básica.

13- A inserção dos estudantes de Odontologia com atividades práticas na comunidade ou nos serviços de saúde ocorre desde m primeiros dois anos do curso.

\begin{tabular}{|c|c|c|c|c|c|c|}
\hline BLOCO 3 & $\begin{array}{l}\text { discordo } \\
\text { totalmente }\end{array}$ & discordo & $\begin{array}{c}\text { não } \\
\text { concordo } \\
\text { nem } \\
\text { discordo }\end{array}$ & concordo & $\begin{array}{l}\text { concordo } \\
\text { totalmente }\end{array}$ & não sei \\
\hline \multicolumn{7}{|l|}{$\begin{array}{l}\text { 2- O Pró-Saúde contribuiu com o processo de reforma curricular } \\
\text { do curso de Odontologia. }\end{array}$} \\
\hline \multicolumn{7}{|l|}{$\begin{array}{l}\text { 4- A participação do estudante no Pró-Saúde contribui para a } \\
\text { sua maior preparação para atuação profissional na rede privada. }\end{array}$} \\
\hline \multicolumn{7}{|l|}{$\begin{array}{l}\text { 5- As atividades desenvolvidas no contexto do Pró-Saúde nas } \\
\text { unidades de saúde não alteram as rotinas de trabalho e nem as } \\
\text { práticas dos profissionais de saúde no serviço. }\end{array}$} \\
\hline
\end{tabular}




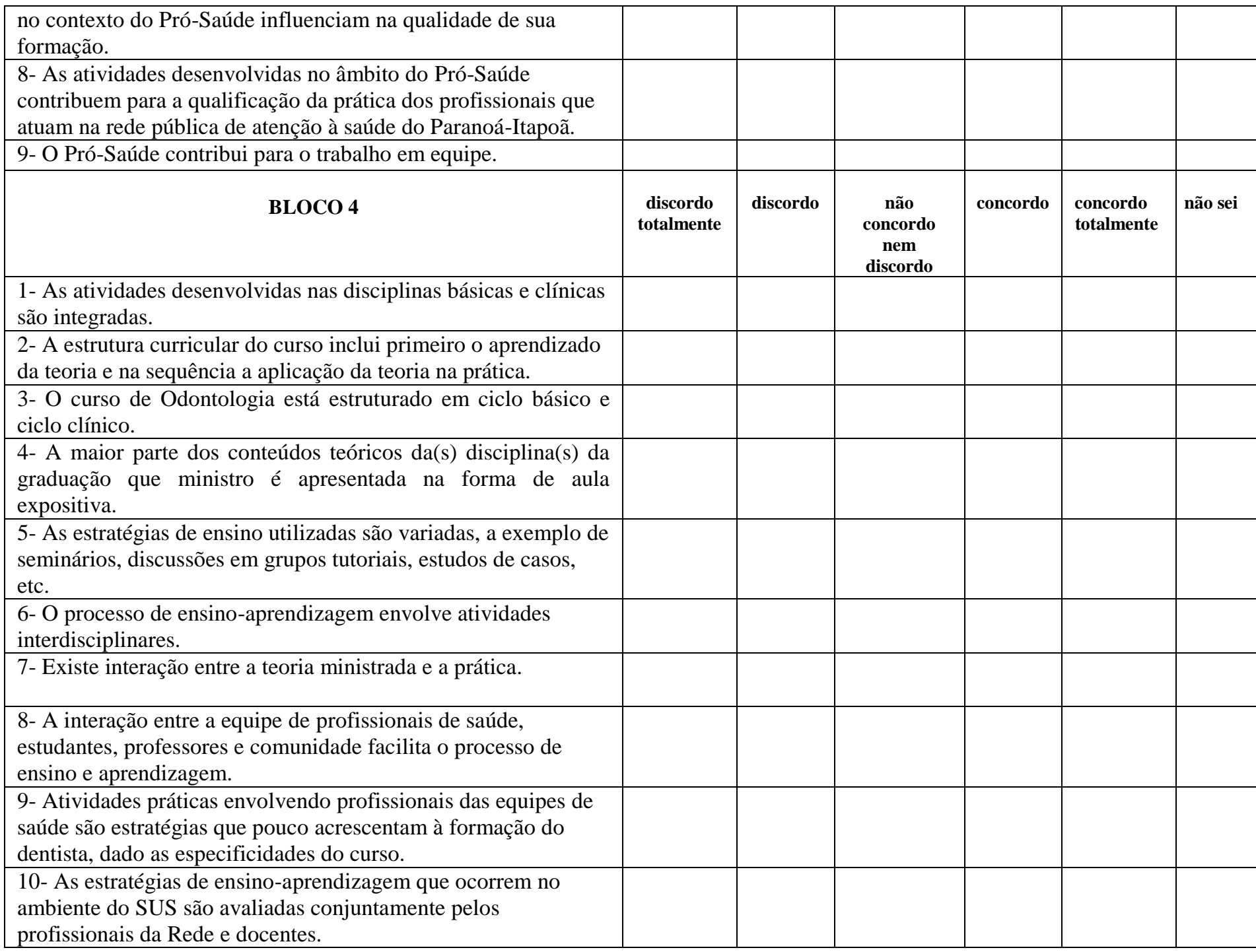

\section{Comentários/sugestões sobre os itens respondidos}




\section{Anexo E - Roteiro de entrevista}

1- O que você entende por formação generalista? De forma ampla, diga quais as competências que devem ser desenvolvidas no decorrer da formação? Como você acredita que as atividades do curso devem ocorrer para o alcance dessa formação? Isso é desenvolvido em seu curso? 2- Na sua compreensão as metodologias de ensino influenciam a formação? Como elas são desenvolvidas e qual a maior predominância em seu curso?

3- Fale sobre a integração entre as áreas do curso.

4- Como acontece a integração do curso com a rede de serviços de saúde? Como você avalia essa integração em termos de benefícios e entraves?

5- Na sua opinião, de que maneira as atividades práticas devem ocorrer e de que maneira ocorrem aqui?

6- Qual a sua percepção sobre o perfil profissional da sua área hoje?

7- Considerando as questões abordadas até agora e outras talvez não mencionadas, você acredita que o Programa Pró-Saúde tenha trazido alguma contribuição para a formação? Por quê?

8- Na sua opinião, quais são fatores dificultadores para a implementação e o desenvolvimento do Programa Pró-Saúde? 


\section{Apêndice A}

\section{ESTUDO 1 - ODONTOLOGIA}

\section{Análise descritiva dos dados coletados dos estudantes na Seção 1 - dados}

\section{sociodemográficos e acadêmicos}

Os dados coletados na Seção 1 do instrumento forneceram informações sobre aspectos sociodemográficos e acadêmicos de estudantes de Odontologia que aceitaram participar do estudo, após leitura do Termo de Consentimento Livre e Esclarecido (TCLE), cujo modelo encontra-se no Anexo 2.

Do total de 223 estudantes regularmente matriculados no segundo semestre de 2013 na graduação de Odontologia, cursando do $1^{\circ}$ ao $10^{\circ}$ semestre do curso, 191 acadêmicos aceitaram participar da pesquisa. Dentre os participantes, conforme ilustrado na Figura 22, 14,1\% estão cursando o primeiro semestre do curso, ocupando a primeira posição em número de estudantes que responderam ao questionário. $\mathrm{Na}$ segunda posição se encontram os acadêmicos do segundo semestre, representando $13,1 \%$, seguidos dos discentes do quarto semestre, com 11,5\%. Observou-se que apenas 5\% dos estudantes que participaram eram do terceiro semestre, sendo esse o período com menor número de estudantes participantes, seguido do décimo semestre. 


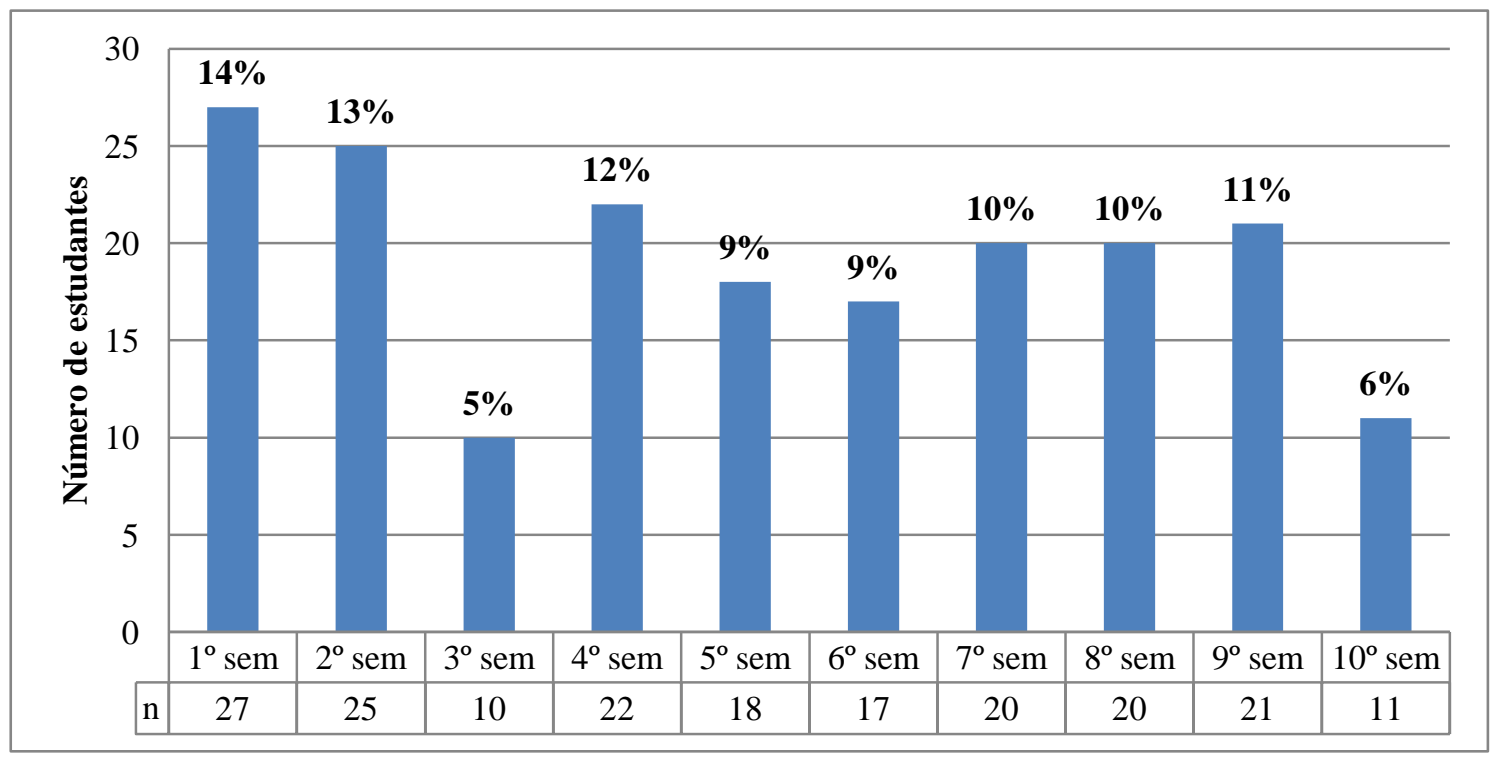

Figura 22. Distribuição percentual dos acadêmicos de Odontologia, por semestre, que responderam o instrumento.

As diferenças em percentuais de estudantes por semestre que compuseram a amostra estão relacionadas às variações no total de estudantes que cursavam cada semestre no momento da coleta de dados. O número de matriculados em cada semestre variou entre 10 acadêmicos (pertencentes ao $3^{\circ}$. semestre) e 31 acadêmicos (matriculados no $4^{\circ}$. semestre do curso). A turma com menor número de respondentes foi o quarto semestre, com 22 estudantes incluídos, de um total de 31 (71\%). O terceiro semestre, com um total de 10 acadêmicos matriculados e o oitavo semestre, com 20 matriculados, atingiram 100\% de participação. A Figura 23 ilustra a distribuição do total de discentes em cada semestre, e a proporção de participação dos mesmos neste estudo. 


\begin{tabular}{|c|c|c|c|}
\hline \multirow{2}{*}{$\begin{array}{c}\text { Semestre } \\
\text { do curso }\end{array}$} & $\begin{array}{c}\text { Total de } \\
\text { matriculados } \\
\text { por semestre }\end{array}$ & \multicolumn{2}{|c|}{$\begin{array}{c}\text { Total de participantes } \\
\text { na pesquisa }\end{array}$} \\
\cline { 2 - 4 } & $\mathbf{n}$ & $\mathbf{n}$ & $\%$ \\
\hline $1^{\circ}$. & 30 & 27 & $90 \%$ \\
\hline $2^{\circ}$. & 28 & 25 & $89,2 \%$ \\
\hline $3^{\circ}$. & 10 & 10 & $100 \%$ \\
\hline $4^{\circ}$. & 31 & 22 & $70,9 \%$ \\
\hline $5^{\circ}$. & 20 & 18 & $90 \%$ \\
\hline $6^{\circ}$. & 20 & 17 & $85 \%$ \\
\hline $7^{\circ}$. & 28 & 20 & $71,4 \%$ \\
\hline $8^{\circ}$. & 20 & 20 & $100 \%$ \\
\hline $9^{\circ}$. & 22 & 21 & $95,4 \%$ \\
\hline $10^{\circ}$. & 14 & 11 & $78,6 \%$ \\
\hline Total $^{\circ}$ & $\mathbf{2 2 3}$ & $\mathbf{1 9 1}$ & $\mathbf{8 5 , 7 \%}$ \\
\hline
\end{tabular}

Figura 23. Acadêmicos matriculados e participantes que compuseram a amostra segundo o semestre.

Considerando a distribuição segundo sexo dos incluídos no estudo, observou-se que o curso é formado majoritariamente por discentes do sexo feminino. Em relação à idade dos acadêmicos, observou-se que $49 \%$ dos mesmos encontram-se na faixa etária compreendida entre 21 e 25 anos e $43 \%$ dos alunos estão inclusos na faixa etária dos 16 aos 20 anos. Essas duas faixas etárias abarcam mais de $90 \%$ dos estudantes que responderam os questionários. Nota-se que apenas 3\% dos acadêmicos estão incluídos na faixa etária dos 31 anos ou mais. Os dados relacionados às variáveis sexo e faixa etária estão apresentados na Tabela 9. 


\section{Tabela 9}

Caracterização dos acadêmicos de Odontologia quanto aos dados sócio-demográficos sexo e faixa etária.

\begin{tabular}{|c|c|c|c|c|c|c|c|c|c|c|c|c|c|c|c|c|}
\hline \multirow[b]{3}{*}{ Semestre } & \multicolumn{4}{|c|}{ Sexo } & \multicolumn{12}{|c|}{ Faixa etária } \\
\hline & \multicolumn{2}{|c|}{ Feminino } & \multicolumn{2}{|c|}{ Masculino } & \multicolumn{2}{|c|}{ Total } & \multicolumn{2}{|c|}{16 a 20 anos } & \multicolumn{2}{|c|}{21 a 25 anos } & \multicolumn{2}{|c|}{26 a 30 anos } & \multicolumn{2}{|c|}{$\begin{array}{c}31 \text { anos ou } \\
\text { mais }\end{array}$} & \multicolumn{2}{|c|}{ Total } \\
\hline & $\mathbf{n}$ & $\%$ & $\mathbf{n}$ & $\%$ & $\mathbf{n}$ & $\%$ & $\mathbf{n}$ & $\%$ & $\mathbf{N}$ & $\%$ & $\mathbf{n}$ & $\%$ & $\mathbf{n}$ & $\%$ & $\mathbf{n}$ & $\%$ \\
\hline 1 & 18 & $66,7 \%$ & 9 & $33,3 \%$ & 27 & $100,0 \%$ & 21 & $77,8 \%$ & 6 & $22,2 \%$ & & $0,0 \%$ & & $0,0 \%$ & 27 & $100,0 \%$ \\
\hline 2 & 22 & $88,0 \%$ & 3 & $12,0 \%$ & 25 & $100,0 \%$ & 21 & $84,0 \%$ & 3 & $12,0 \%$ & & $0,0 \%$ & 1 & $4,0 \%$ & 25 & $100,0 \%$ \\
\hline 3 & 8 & $80,0 \%$ & 2 & $20,0 \%$ & 10 & $100,0 \%$ & 5 & $50,0 \%$ & 4 & $40,0 \%$ & 1 & $10,0 \%$ & & $0,0 \%$ & 10 & $100,0 \%$ \\
\hline 4 & 17 & $77,3 \%$ & 5 & $22,7 \%$ & 22 & $100,0 \%$ & 16 & $72,7 \%$ & 6 & $27,3 \%$ & & $0,0 \%$ & & $0,0 \%$ & 22 & $100,0 \%$ \\
\hline 5 & 11 & $61,1 \%$ & 7 & $38,9 \%$ & 18 & $100,0 \%$ & 7 & $38,9 \%$ & 10 & $55,6 \%$ & 1 & $5,6 \%$ & & $0,0 \%$ & 18 & $100,0 \%$ \\
\hline 6 & 14 & $82,4 \%$ & 3 & $17,6 \%$ & 17 & $100,0 \%$ & 8 & $47,1 \%$ & 8 & $47,1 \%$ & & $0,0 \%$ & 1 & $5,9 \%$ & 17 & $100,0 \%$ \\
\hline 7 & 12 & $60,0 \%$ & 8 & $40,0 \%$ & 20 & $100,0 \%$ & 1 & $5,0 \%$ & 16 & $80,0 \%$ & 2 & $10,0 \%$ & 1 & $5,0 \%$ & 20 & $100,0 \%$ \\
\hline 8 & 15 & $75,0 \%$ & 5 & $25,0 \%$ & 20 & $100,0 \%$ & 1 & $5,0 \%$ & 18 & $90,0 \%$ & 1 & $5,0 \%$ & & $0,0 \%$ & 20 & $100,0 \%$ \\
\hline 9 & 20 & $95,2 \%$ & 1 & $4,8 \%$ & 21 & $100,0 \%$ & 1 & $4,8 \%$ & 15 & $71,4 \%$ & 3 & $14,3 \%$ & 2 & $9,5 \%$ & 21 & $100,0 \%$ \\
\hline 10 & 8 & $72,7 \%$ & 3 & $27,3 \%$ & 11 & $100,0 \%$ & 1 & $9,1 \%$ & 8 & $72,7 \%$ & 1 & $9,1 \%$ & 1 & $9,1 \%$ & 11 & $100,0 \%$ \\
\hline Total & 145 & $75,9 \%$ & 46 & $24,1 \%$ & 191 & $100,0 \%$ & 82 & $42,9 \%$ & 94 & $49,2 \%$ & 9 & $4,7 \%$ & 6 & $3,1 \%$ & 191 & $100,0 \%$ \\
\hline
\end{tabular}


Na questão levantada aos acadêmicos em relação a possuírem ou não graduação em outras áreas, notou-se, conforme ilustrado na Figura 24, que apenas 4,7\% dos discentes já são graduados em outras áreas e 2,1\% desses, possuem graduação em Ciências da Saúde. As Ciências Exatas e da terra e as ciências biológicas são áreas que detém 0,5\% cada de estudantes graduados, totalizando $1 \%$, enquanto 1,6\% dos discentes possuem graduação em outra área não considerada nessa questão. A maioria expressiva dos estudantes, somando $95,3 \%$, não fez outra graduação antes de cursar a atual.

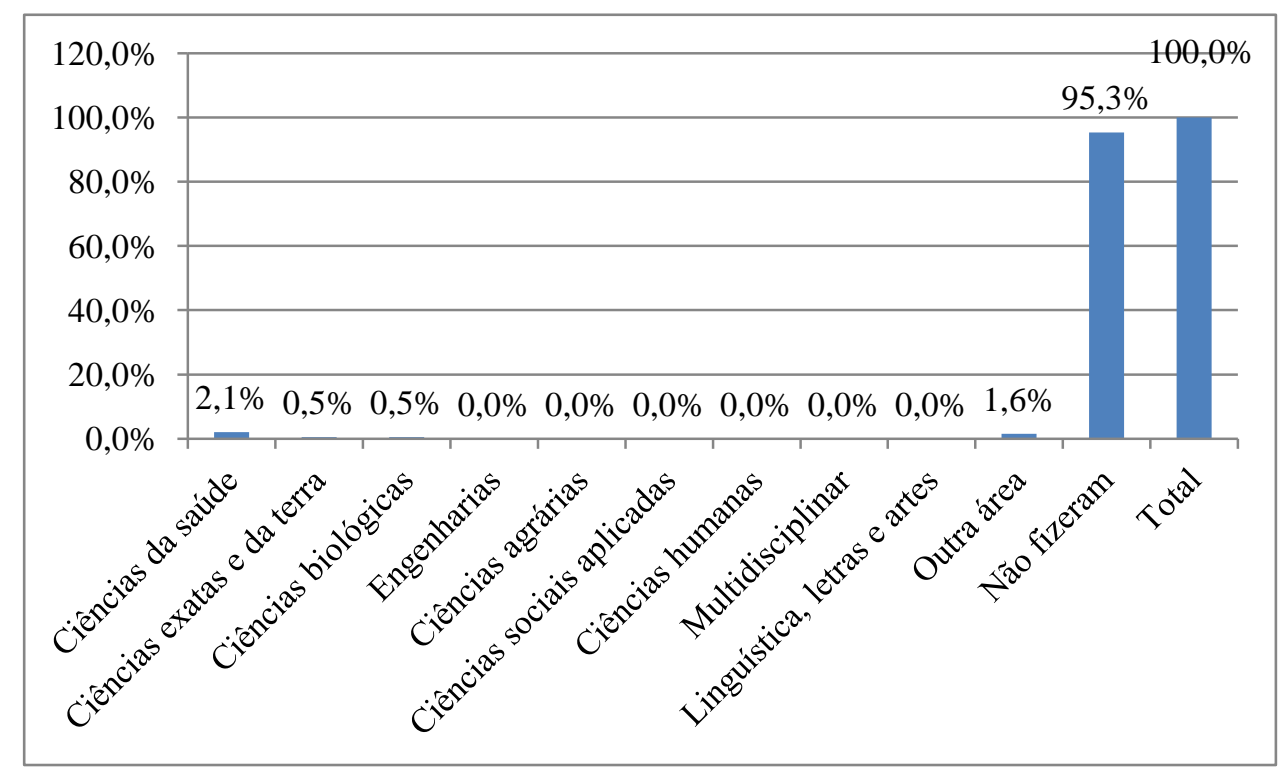

Figura 24. Distribuição percentual dos acadêmicos, segundo graduação concluída em outras áreas.

Ao serem indagados quanto às atividades acadêmicas que atualmente participam na universidade, o Programa Pró-Saúde foi a que obteve o menor número de relatos de acadêmicos participantes, representando $8,9 \%$ do total. Projeto de extensão foi a atividade que obteve o maior percentual de estudantes participantes, representando 47,1\%. Em relação a projeto de iniciação científica, 19,4\% dos estudantes estão inclusos no mesmo, seguidos de $16,8 \%$ que participam de projeto de monitoria. É importante ressaltar que os alunos 
entrevistados podiam escolher mais de uma opção na questão, não sendo a participação nos projetos necessariamente exclusiva.

Em relação à questão “Você conhece o Programa Pró-Saúde?” (item 7 da Seção 1 do instrumento), mais da metade dos discentes afirmaram que não conhecem o Programa, totalizando 56\% dos acadêmicos. Observou-se que 41,9\% dos estudantes conhecem o programa e $2,1 \%$ não opinaram na questão, deixando-a em branco.

Do total de acadêmicos incluídos no estudo, $89 \%$ deles não são ou não foram bolsistas do Programa Pró-Saúde, enquanto 10,5\% dos discentes afirmaram ser ou terem sido anteriormente bolsista do Programa. Uma parcela de $0,5 \%$ dos alunos não respondeu a essa pergunta. Esses dados estão representados na Figura 25.

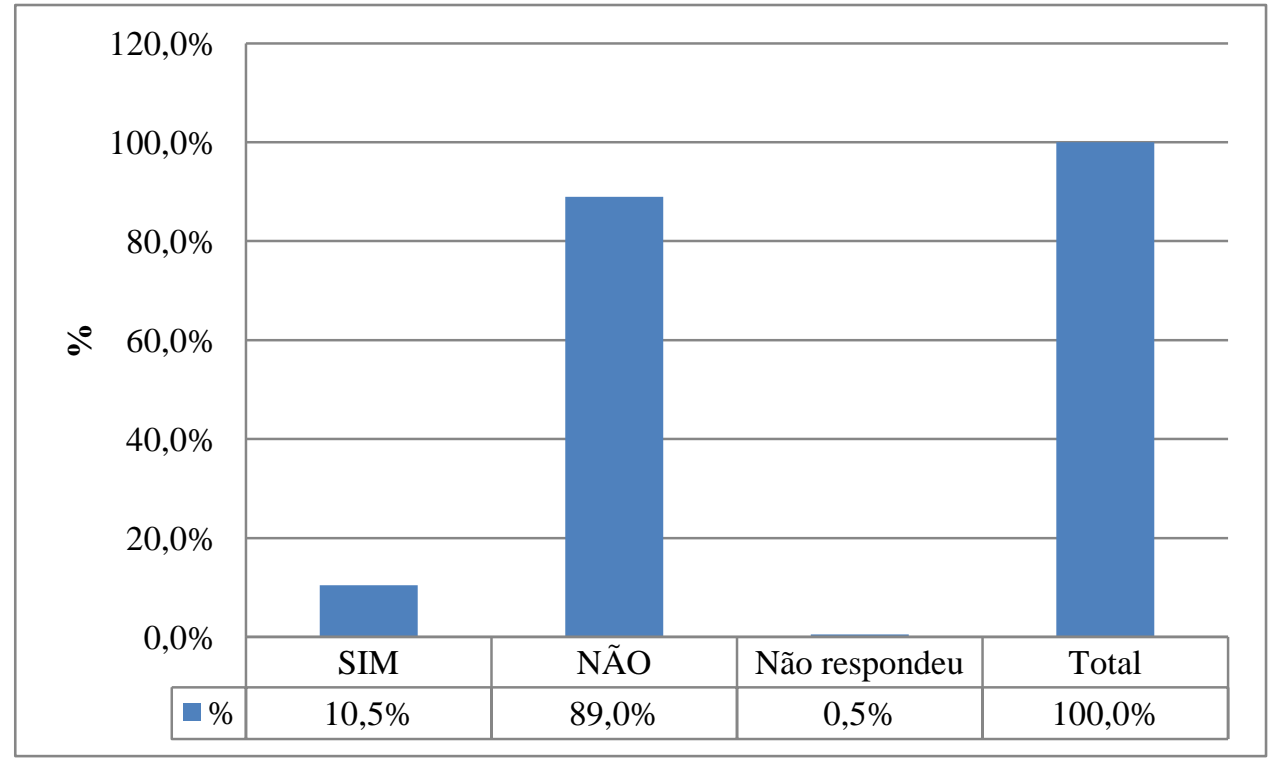

Figura 25. Distribuição percentual dos acadêmicos bolsistas pelo Pró-Saúde.

A partir das afirmações positivas dos estudantes em relação à participação no Programa Pró-Saúde como bolsista, os mesmos foram indagados sobre o tempo de participação no Programa. Observou-se que 4,2\% dos acadêmicos participantes do PróSaúde estão no mesmo há mais de 12 meses e 2,6\% estão incluídos no Programa de 6 a 12 meses, seguidos de 2,6\% de alunos que desenvolvem atividades no período de 3 a 6 meses. 
Apenas 1,6\% dos estudantes afirmam estarem no projeto há menos de 3 meses. Um número expressivo de acadêmicos, compondo um total de mais de $79 \%$, responderam que a pergunta não se aplica e 9,4\% dos entrevistados não responderam a questão. Os dados referentes a esta questão estão representados na Figura 26.

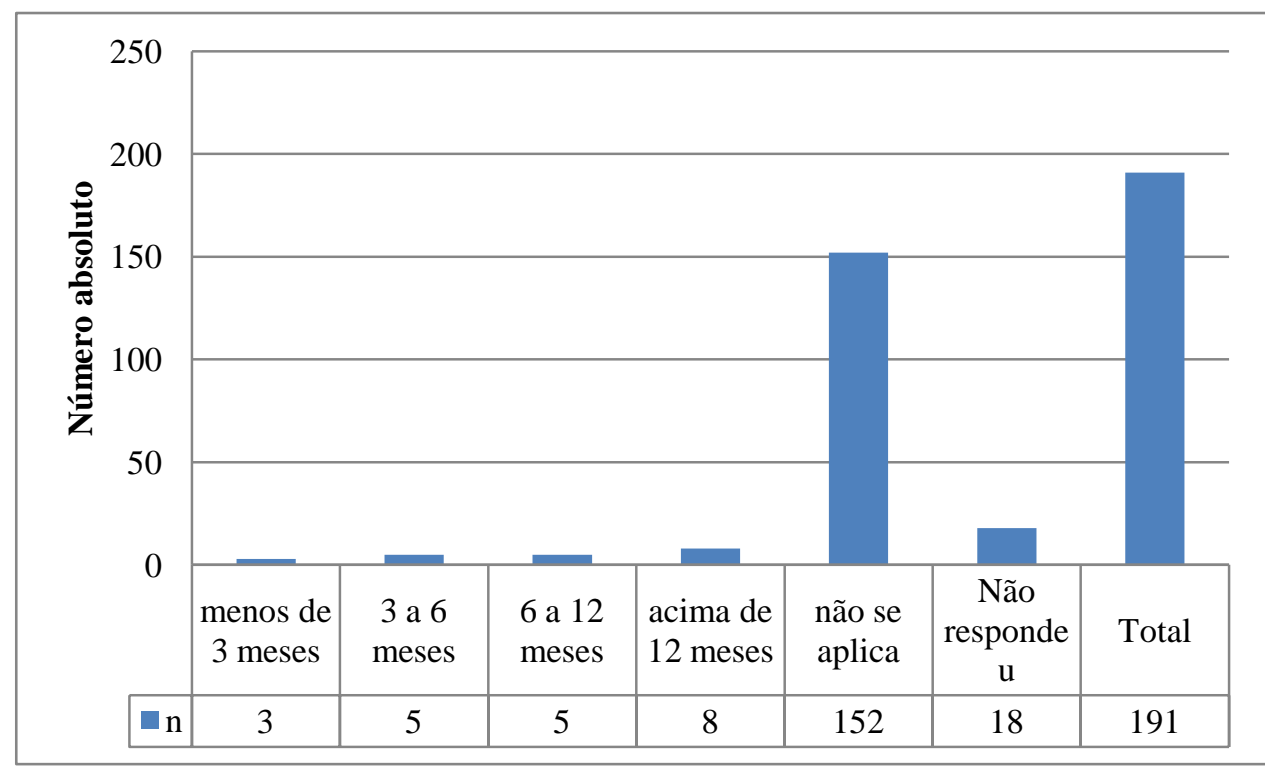

Figura 26. Distribuição dos acadêmicos em números absolutos em relação ao tempo de participação no Pró-Saúde

O resumo do perfil sociodemográfico e acadêmico dos estudantes participantes do estudo encontram-se apresentados na Tabela 10.

\section{Tabela 10}

Dados dos estudantes de Odontologia participantes do estudo.

\begin{tabular}{lcc}
\hline \multicolumn{1}{c}{ Variáveis } & N & \% \\
\hline Idade & 82 & 42,9 \\
De 16 a 20 anos & 94 & 49,2 \\
De 21 a 25 anos & 9 & 4,7 \\
De 26 a 30 anos & 6 & 3,1 \\
Mais de 30 anos & & \\
Sexo & 46 & 24,1 \\
Masculino & 145 & 75,9 \\
Feminino & &
\end{tabular}

\section{Graduação em outras áreas}




\begin{tabular}{lcc} 
Sim & 9 & 4,7 \\
Não & 182 & 95,3 \\
Participação em atividades acadêmicas & & \\
Projeto de iniciação científica & 37 & 19,4 \\
Projeto de extensão & 90 & 47,1 \\
Projeto do Pró-Saúde/Pet-Saúde & 17 & 8,9 \\
Monitoria & 32 & 16,8 \\
O & 7 & 3,7 \\
utros projetos & & \\
Nenhum projeto & 58 & 30,4 \\
Conhece o Pró-Saúde & & \\
Sim & 80 & 41,9 \\
Não & 107 & 56,0 \\
Não opinaram & 4 & 2,1 \\
Bolsista do Pró-Saúde/Pet-Saúde & & \\
Sim & 20 & 10,5 \\
Não & 170 & 89,0 \\
Não opinaram & 1 & 0,5 \\
\hline
\end{tabular}

2. Análise descritiva dos dados coletados dos professores na Seção 1 - dados sociodemográficos e profissionais

Considerando um universo populacional de 45 professores do curso de Odontologia, o total de $28(62,2 \%)$ aceitou participar da pesquisa e responderam o instrumento. Observou-se que mais da metade dos mesmos, aproximadamente 53\%, são do sexo feminino, conforme é apresentado na Tabela 11. Em relação à faixa etária em que se encontram os respondentes, constatou-se que maioria deles $(75 \%)$ está compreendida na faixa etária de 30 a 49 anos. Apenas 3,6\% dos educadores se encontram na faixa etária de 20 a 29 anos. 


\section{Tabela 11}

Caracterização dos professores do curso de Odontologia quanto aos dados sóciodemográficos sexo e faixa etária.

\begin{tabular}{lcc}
\hline Sexo & $\mathbf{N}$ & \% \\
\hline \hline Feminino & 15 & $53,6 \%$ \\
Masculino & 13 & $46,4 \%$ \\
\hline Total & 28 & $100,0 \%$ \\
\hline Faixa etária & $\mathbf{N}$ & $\%$ \\
\hline \hline 20 a 29 anos & 1 & $3,6 \%$ \\
30 a 49 anos & 21 & $75,0 \%$ \\
50 a 59 anos & 4 & $14,3 \%$ \\
60 anos ou mais & 2 & $7,1 \%$ \\
\hline Total & 28 & $100,0 \%$ \\
\hline
\end{tabular}

Em relação à formação, observou-se que a maioria expressiva, representada por 96,4\% dos participantes do estudo possui graduação em Odontologia. Os demais (3,6\% dos professores) não responderam esse item. Não houve respostas referentes à graduação em outros cursos ou em outras áreas.

Quanto ao tempo de formado observou-se que a grande maioria dos professores que participaram do estudo $(89,3 \%)$ possui 10 ou mais anos de formados, enquanto $7,1 \%$ dos mesmos têm de 6 a 9 anos de formados. Em relação ao grau de formação, a maioria $(78,6 \%)$ possui doutorado, seguidos de 10,7\% que possuem pós-doutorado.

No questionário foi perguntado aos professores participantes do estudo se ensinam disciplinas da área básica, clínica, social e/ou outra área. De acordo com a Figura 27, observa-se que $60,5 \%$ ministram aulas de disciplinas pertencentes à área clínica, enquanto apenas $36,9 \%$ dos mesmos atuam em disciplinas das áreas básica e social juntas. Outra área de ensino foi indicada por apenas $2,6 \%$ dos educadores. A questão levantada no instrumento 
de coleta não restringia a resposta dos participantes à apenas uma alternativa, sendo possível escolher mais de uma opção. Nota-se, entretanto, que a somatória dos percentuais de todas as áreas totalizam $100 \%$, indicando que os professores escolheram somente uma alternativa e, portanto, não ministram disciplinas de duas áreas concomitantemente.

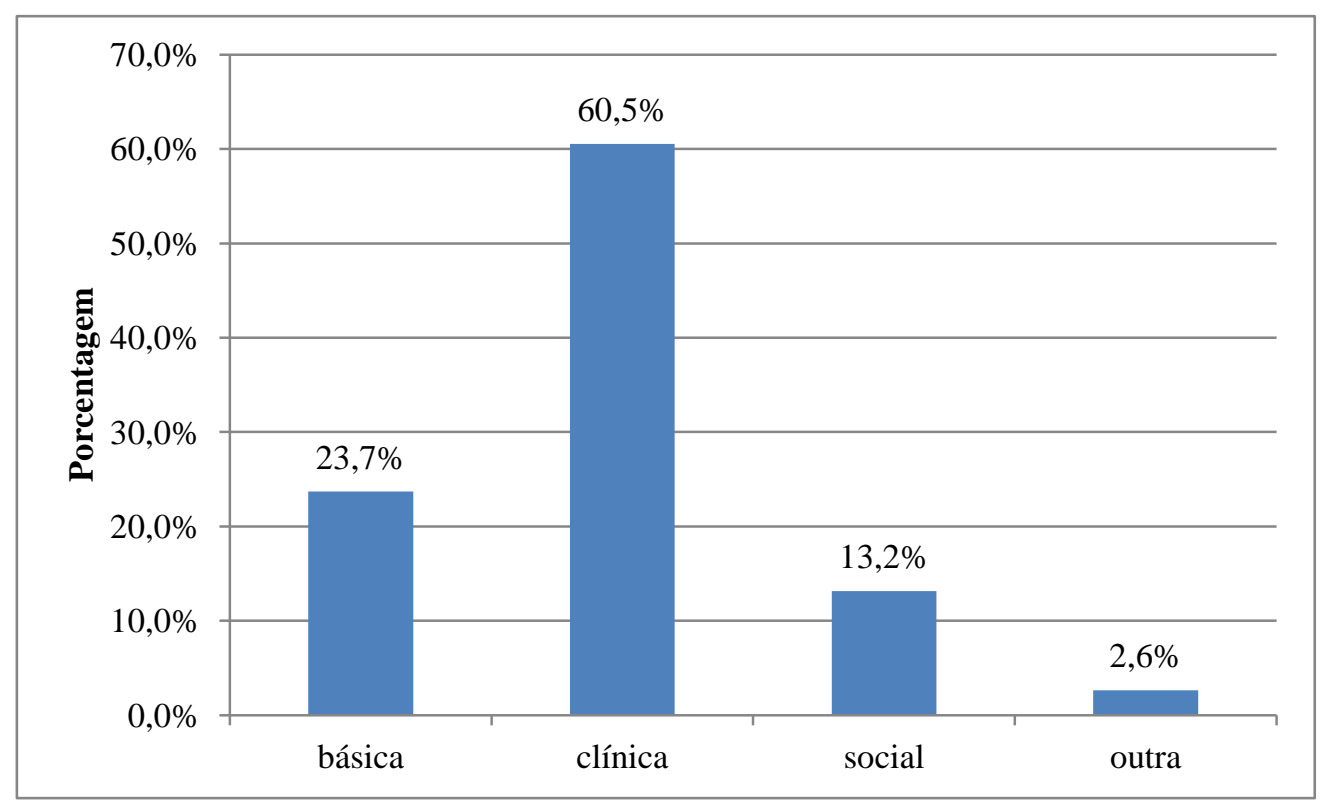

Figura 27. Distribuição percentual dos professores segundo as disciplinas das áreas que ensinam.

Indagou-se também aos educadores, que tipo de atividades os mesmos orientam na universidade. Os resultados indicaram que a maioria dos docentes (30,8\%), conforme mostra a Figura 28, são orientadores de projetos de extensão, enquanto a iniciação científica (IC) é a atividade com segundo maior percentual de orientação, contabilizando $21,2 \%$ do total de docentes. Para os projetos de monitoria, cerca de 19\% dos professores orientam esse tipo de atividade. Apenas 9,6\% dos educadores orientam projetos de Pró-Saúde/ Pet-Saúde e mais de $15 \%$ dos mesmos orientam outras atividades não mencionadas no questionário. Um percentual mínimo de 3,8\% dos docentes não orienta nenhum tipo de projeto. 


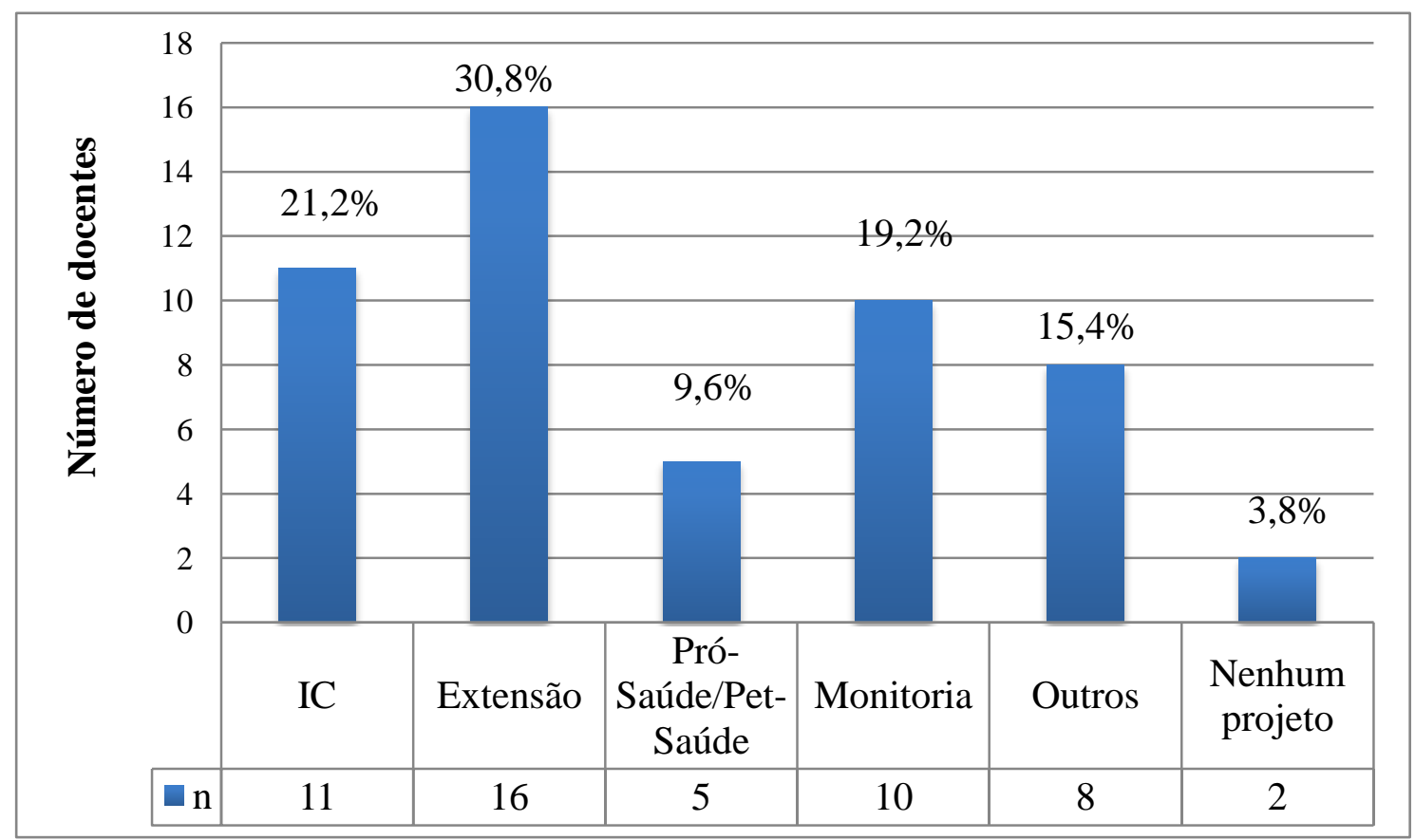

Figura 28. Distribuição percentual dos professores conforme as atividades em que orientam os estudantes.

No que se refere à distribuição percentual dos professores em relação ao tempo de participação em disciplinas inseridas na proposta do Pró-Saúde, ilustrada na Figura 29, verifica-se em torno de $22 \%$ dos professores participam há mais de três anos nessas disciplinas, seguido por com $18,5 \%$ com tempo de participação superior a quatro anos em disciplinas inseridas na proposta do Pró-Saúde. Um percentual expressivo de cerca de $25 \%$ dos educadores responderam "não sei” à questão levantada. 


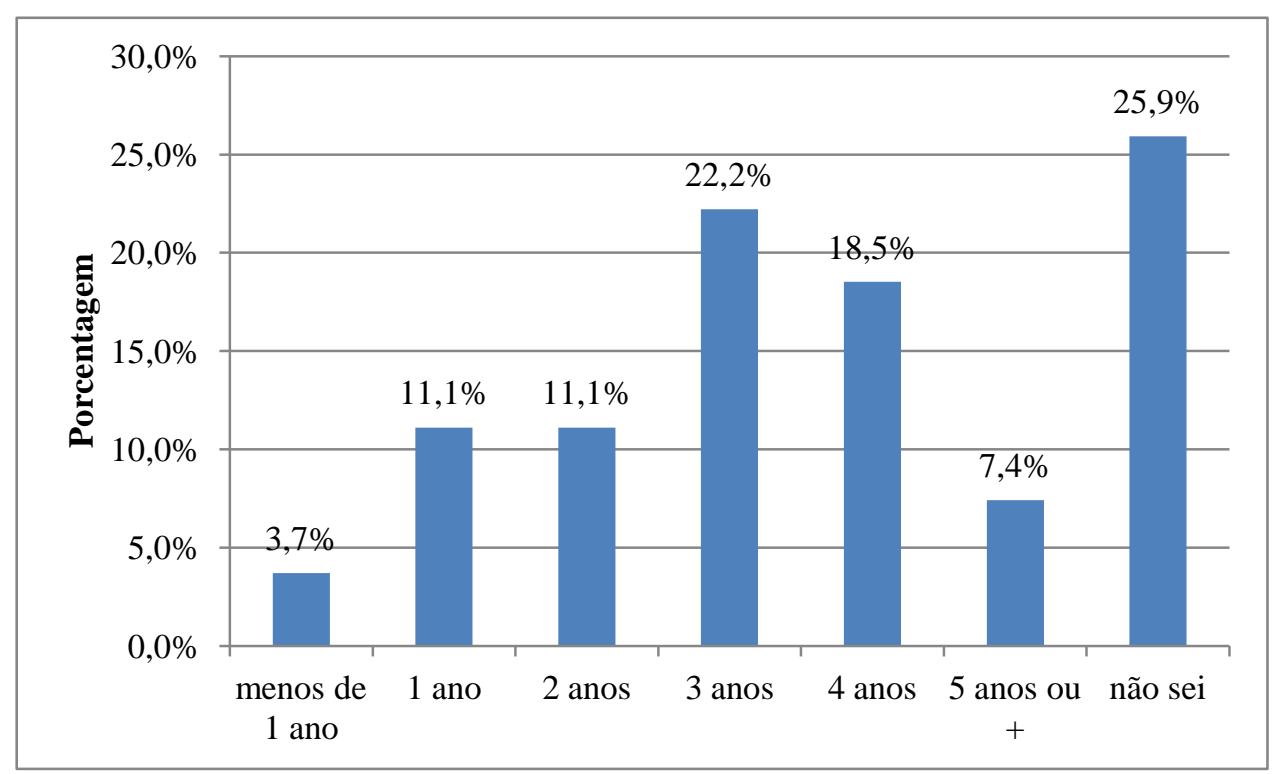

Figura 29. Distribuição percentual dos professores conforme o tempo de participação em disciplinas inseridas na proposta do Pró-Saúde.

Sobre a participação em tutoria do Pró-Saúde/Pet-Saúde, a grande maioria, representando um total de $82,1 \%$, responderam negativamente, enquanto $17,9 \%$ responderam afirmaram participar. Dentre aqueles que responderam "sim" ao item, 14,3\% participam da tutoria como voluntários e apenas 3,6\% como bolsistas (Figura 30). Aos que afirmaram fazer parte da tutoria do Pró/Pet Saúde, foi solicitado o tempo de participação na referida atividade. Considerando os $17,9 \%$ dos docentes que são tutores, $10,7 \%$ afirmaram participar há mais de um ano. A Figura 31 apresenta esses resultados. 


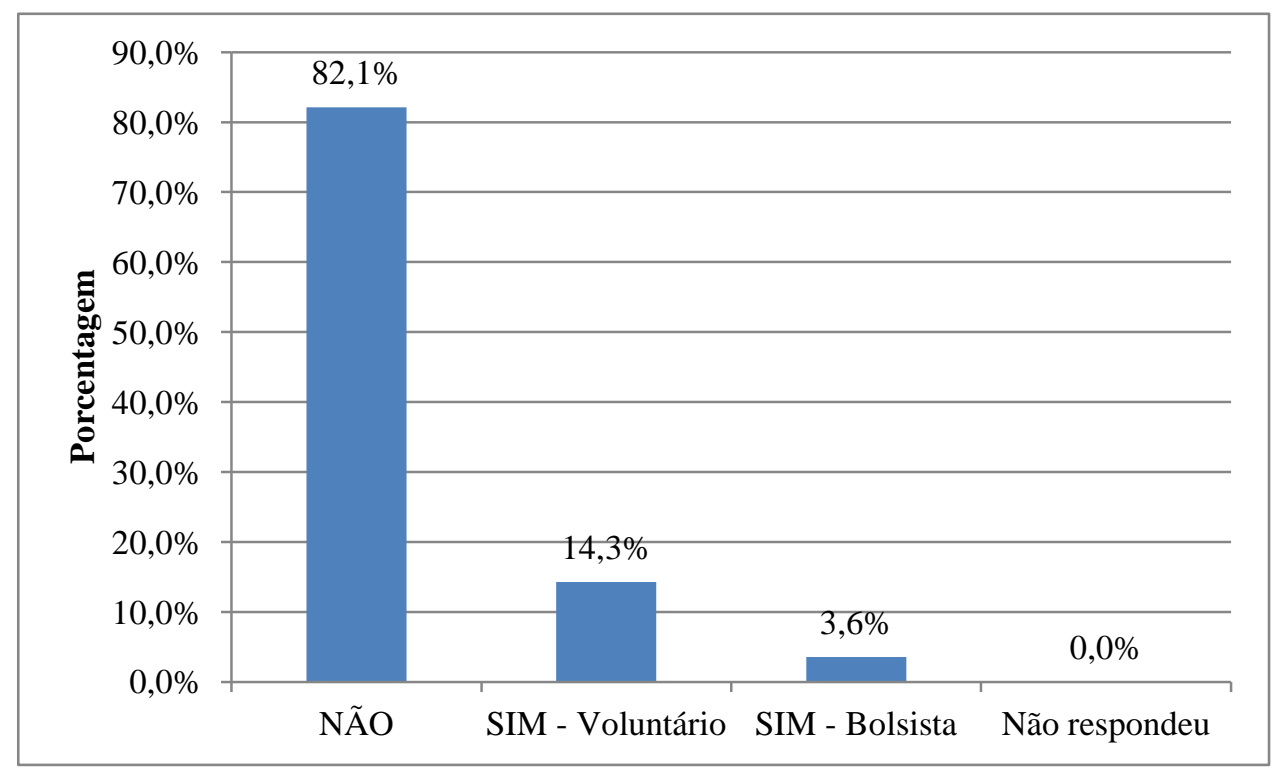

Figura 30. Distribuição percentual dos professores segundo participação em tutoria do Pró-Saúde/Pet-Saúde.

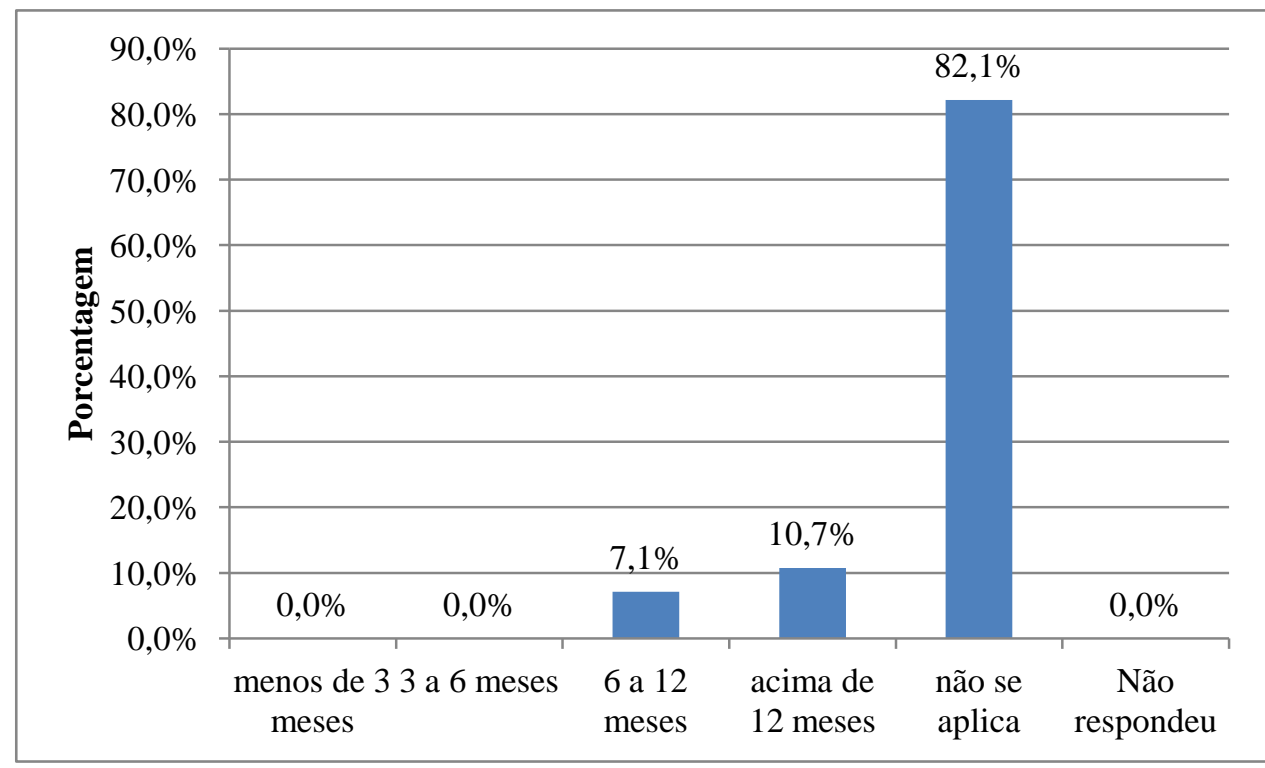

Figura 31. Distribuição percentual dos professores em relação ao tempo de participação em tutoria do Pró-Saúde/Pet-Saúde.

Sobre a inserção no ensino de pós-graduação lato sensu e a área do conteúdo ministrado, foi possível verificar, conforme ilustrado na Figura 32, que comparando as áreas clínica, social e básica, $30 \%$ dos docentes ministram aulas na primeira área citada. 
Entretanto, as áreas social e básica juntas detêm apenas 6,6\% do total, sendo 3,3\% a representação de docentes em cada uma dessas áreas.

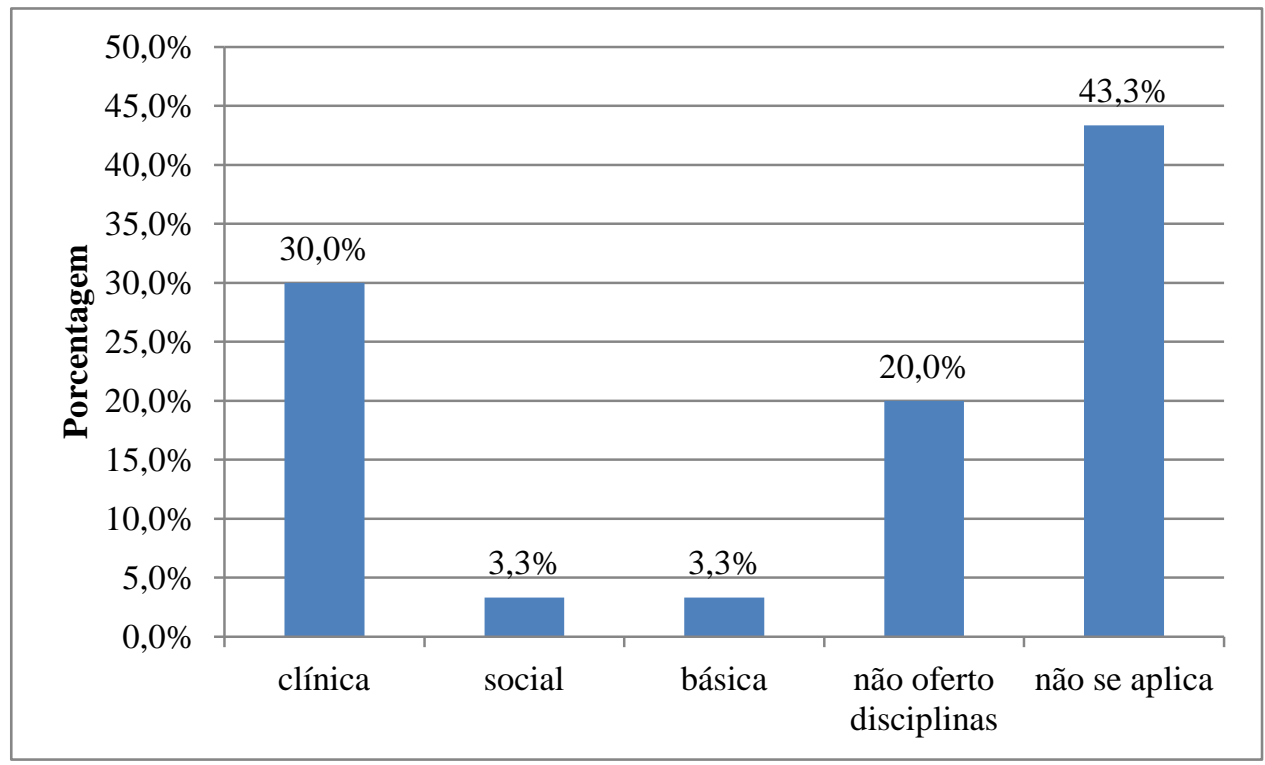

Figura 32 - Distribuição percentual dos professores em relação ao ensino na pós-graduação lato sensu e a área do conteúdo trabalhado.

Em relação à participação em disciplinas na pós-graduação stricto sensu e a área a que pertence o conteúdo trabalhado, do total de $71,8 \%$ dos respondentes afirmaram participar, sendo que mais da metade $(53,1 \%)$ ofertam disciplinas na área clínica, seguida da área básica com um total de $15,6 \%$ dos docentes, e a área social com apenas 3,1\% do total de docentes entrevistados (Figura 33). 


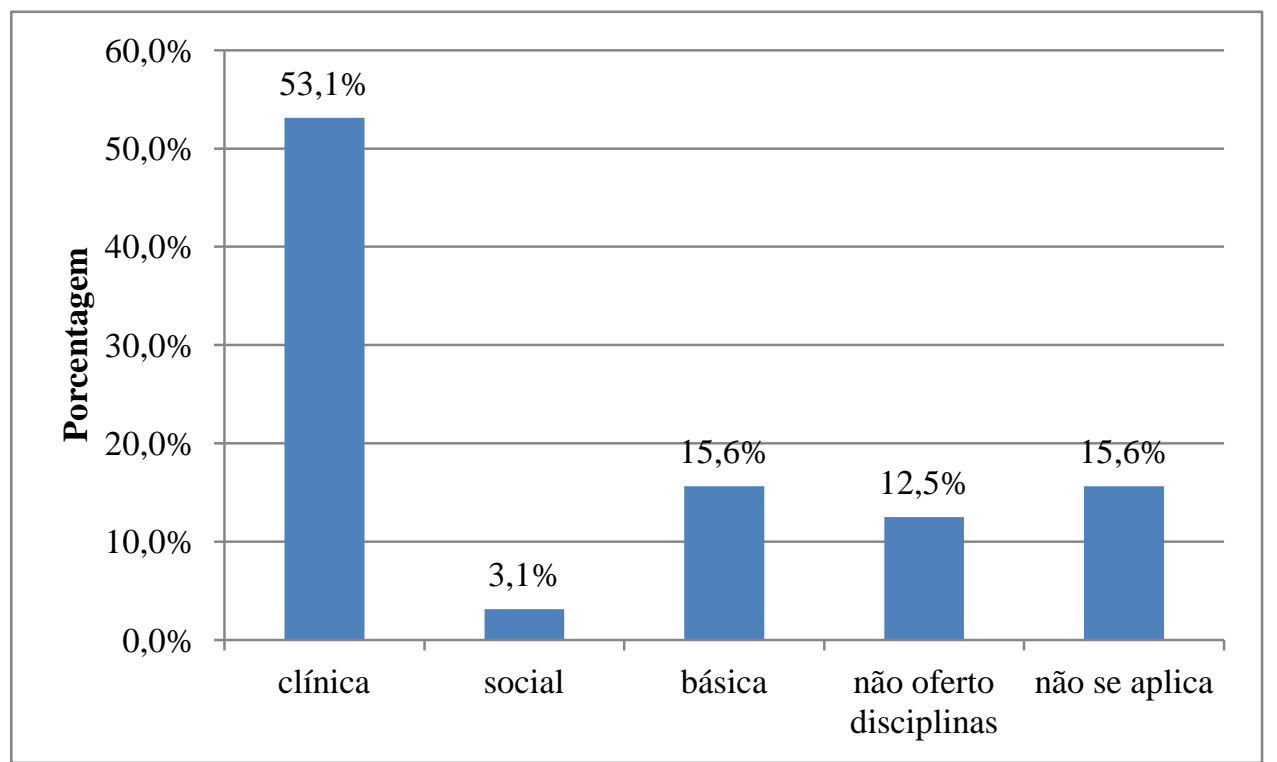

Figura 33 - Distribuição percentual dos professores em relação ao ensino na pósgraduação stricto sensu e a área do conteúdo trabalhado.

\section{Análise descritiva da Seção 2 - parte específica do instrumento}

\subsection{Dimensão teórica - estudantes}

Dos dados obtidos na dimensão teórica, inserida no Bloco 1 da Seção 2 do instrumento, considerando conjuntamente as respostas "concordo" e "concordo totalmente" como atitude positiva em relação a um item, verificou-se que em termos de conteúdos ministrados, incluídos nos itens 1 e 2, os quais avaliaram abordagem de aspectos biológicos e aspectos sociais do processo saúde-doença, respectivamente, a maioria dos acadêmicos respondeu positivamente em ambos os itens, com 95,8\% para o item 1 e $84,9 \%$ para o item 2. Os itens relacionados a questões de abordagem teórica em nível de pós-graduação (itens 7, 8 e 9) obtiveram dos acadêmicos na sua maioria a resposta "não sei". Em relação ao enfoque da produção de conhecimento, os itens 4 e 5 foram avaliados positivamente pelos respondentes, com frequências de $49 \%$ e 52,4\%, respectivamente. Em ambos os itens 20\% dos respondentes optaram pela resposta "não concordo nem discordo". A definição de cada item e as respectivas frequências obtidas para cada opção de seleção na escala de Likert aplicada está apresentada na Tabela 12. 


\section{Tabela 12}

Frequências de respostas obtidas dos estudantes em cada item da dimensão teórica.

\begin{tabular}{|c|c|c|c|c|c|c|}
\hline BLOCO 1 - DIMENSÃO TEÓRICA & $\begin{array}{l}\text { discordo } \\
\text { totalmente }\end{array}$ & discordo & $\begin{array}{l}\text { não } \\
\text { concordo } \\
\text { nem } \\
\text { discordo }\end{array}$ & concordo & $\begin{array}{l}\text { concordo } \\
\text { totalmente }\end{array}$ & não sei \\
\hline $\begin{array}{l}\text { 1- Os conteúdos teóricos ministrados na graduação abordam } \\
\text { aspectos biológicos do processo saúde-doença. }\end{array}$ & $0,0 \%$ & $0,5 \%$ & $2,6 \%$ & $58,6 \%$ & $37,2 \%$ & $1,1 \%$ \\
\hline $\begin{array}{l}\text { 2- Os conteúdos teóricos ministrados na graduação abordam } \\
\text { aspectos sociais do processo saúde-doença. }\end{array}$ & $1,0 \%$ & $3,7 \%$ & $9,9 \%$ & $59,2 \%$ & $25,7 \%$ & $0,5 \%$ \\
\hline $\begin{array}{l}\text { 3- Há interação entre as abordagens teóricas das disciplinas das } \\
\text { áreas básicas, clínicas e sociais da graduação. }\end{array}$ & $0,0 \%$ & $8,0 \%$ & $15,4 \%$ & $59,6 \%$ & $16,5 \%$ & $0,5 \%$ \\
\hline $\begin{array}{l}\text { 4- A produção de conhecimento, no que se refere à pesquisa, } \\
\text { está articulada com as demandas do serviço e da comunidade da } \\
\text { Regional de Saúde do Paranoá/Itapoã. }\end{array}$ & $2,1 \%$ & $17,4 \%$ & $20,5 \%$ & $41,1 \%$ & $7,9 \%$ & $11 \%$ \\
\hline $\begin{array}{l}\text { 5- A produção científica é focada em investigações sobre } \\
\text { aspectos biomédicos ou tecnológicos da atenção à saúde. }\end{array}$ & $0,5 \%$ & $7,4 \%$ & $20,6 \%$ & $42,3 \%$ & $10,2 \%$ & $19,0 \%$ \\
\hline $\begin{array}{l}\text { 6- A produção de conhecimento, no que se refere à extensão, } \\
\text { está articulada com as demandas do serviço e da comunidade da } \\
\text { Regional de Saúde do Paranoá/Itapoã. }\end{array}$ & $1,6 \%$ & $15,2 \%$ & $22,0 \%$ & $37,7 \%$ & $9,4 \%$ & $14,1 \%$ \\
\hline $\begin{array}{l}\text { 7- A oferta de cursos de pós-graduação é voltada para os } \\
\text { profissionais do SUS. }\end{array}$ & $1,6 \%$ & $22,0 \%$ & $15,7 \%$ & $13,1 \%$ & $3,7 \%$ & $43,9 \%$ \\
\hline $\begin{array}{l}\text { 8- Os cursos de pós-graduação possuem como público-alvo os } \\
\text { profissionais que atuam na rede privada. }\end{array}$ & $5,8 \%$ & $17,3 \%$ & $18,8 \%$ & $13,1 \%$ & $5,8 \%$ & $39,2 \%$ \\
\hline $\begin{array}{l}\text { 9- Os cursos de pós-graduação são oferecidos de acordo com } \\
\text { interesses ou necessidades do curso. }\end{array}$ & $1,6 \%$ & $9,4 \%$ & $19,4 \%$ & $21,5 \%$ & $3,7 \%$ & $44,4 \%$ \\
\hline $\begin{array}{l}\text { 10- As disciplinas teóricas de conteúdos relacionados às áreas } \\
\text { básicas, clínicas e sociais são ministradas em blocos separados, } \\
\text { sem articulação entre elas. }\end{array}$ & $9,9 \%$ & $43,5 \%$ & $14,7 \%$ & $20,4 \%$ & $8,9 \%$ & $2,6 \%$ \\
\hline
\end{tabular}

\subsection{Dimensão cenário de práticas - estudantes}

Na dimensão cenário de práticas, as frequências obtidas, no que se refere à integração da universidade com o serviço e os benefícios dessa aproximação para a comunidade, para o próprio serviço e para a universidade, os acadêmicos consideraram positiva (somatória das frequências "concordo" e "concordo totalmente") para as três frentes envolvidas. Além disso, $67 \%$ dos respondentes demonstraram acreditar que o curso de Odontologia contribui para a organização dos serviços. Já em relação à infraestrutura das unidades utilizadas como cenário de práticas, $37,1 \%$ consideraram as mesmas inadequadas para o processo de ensino e aprendizagem, enquanto $25,9 \%$ não souberam opinar sobre essa questão. Os acadêmicos, na sua maioria $(63,4 \%)$, concordaram que as atividades práticas dos primeiros anos do curso 
ocorrem em laboratórios, e que as atividades práticas clínicas ocorrem dentro do ambiente universitário $(87,4 \%)$.

O único item deste bloco que obteve "não sei” selecionado como opção de escolha pela maioria dos acadêmicos foi o item 11. Todas as frequências obtidas nos itens da dimensão denominada cenário de práticas estão apresentadas na Tabela 13.

Tabela 13

Frequências de respostas obtidas dos estudantes em cada item da dimensão cenário de práticas.

\begin{tabular}{|c|c|c|c|c|c|c|}
\hline $\begin{array}{l}\text { 2- A integração da universidade com o serviço de saúde traz } \\
\text { benefícios para o serviço. }\end{array}$ & $0,0 \%$ & $1,6 \%$ & $6,3 \%$ & $38,2 \%$ & $51,3 \%$ & $2,6 \%$ \\
\hline $\begin{array}{l}\text { 4- O curso de Odontologia contribui para a organização dos } \\
\text { serviços da Regional de Saúde do Paranoá/Itapoã. }\end{array}$ & $0,5 \%$ & $11,8 \%$ & $13,8 \%$ & $44,7 \%$ & $22,3 \%$ & $6,9 \%$ \\
\hline $\begin{array}{l}\text { 5- A infraestrutura das unidades de saúde nas quais são } \\
\text { realizadas atividades das disciplinas e/ou ações do Pró-Saúde } \\
\text { são adequadas ao processo de ensino e aprendizagem dos } \\
\text { estudantes. }\end{array}$ & $10,6 \%$ & $26,5 \%$ & $18,0 \%$ & $16,9 \%$ & $2,1 \%$ & $25,9 \%$ \\
\hline $\begin{array}{l}\text { 7- O curso de Odontologia está voltado para a formação } \\
\text { especializada do dentista. }\end{array}$ & $6,8 \%$ & $34,2 \%$ & $19,5 \%$ & $25,8 \%$ & $11,1 \%$ & $2,6 \%$ \\
\hline $\begin{array}{l}\text { 8- As atividades desenvolvidas nos cenários de práticas do } \\
\text { Paranoá-Itapoã são importantes para a formação do dentista. }\end{array}$ & $0,5 \%$ & $5,2 \%$ & $8,4 \%$ & $49,2 \%$ & $35,1 \%$ & $1,6 \%$ \\
\hline $\begin{array}{l}\text { 9- O Pró-Saúde contribuiu para a integração do curso com a } \\
\text { Rede de Serviço de Saúde do Paranoá-Itapoã. }\end{array}$ & $0,5 \%$ & $3,2 \%$ & $11,1 \%$ & $31,1 \%$ & $12,6 \%$ & $41,5 \%$ \\
\hline $\begin{array}{l}\text { 10- O curso de Odontologia se volta para a formação generalista } \\
\text { do dentista. }\end{array}$ & $1,6 \%$ & $10,1 \%$ & $15,3 \%$ & $45,5 \%$ & $25,4 \%$ & $2,1 \%$ \\
\hline $\begin{array}{l}\text { 11- O Pró-Saúde contribuiu para a integração da Odontologia } \\
\text { com os demais cursos da área da saúde. }\end{array}$ & $2,1 \%$ & $7,9 \%$ & $9,5 \%$ & $26,8 \%$ & $9,5 \%$ & $44,2 \%$ \\
\hline $\begin{array}{l}\text { 12- As atividades práticas dos primeiros anos do curso ocorrem } \\
\text { em laboratórios da área básica. }\end{array}$ & $1,0 \%$ & $16,2 \%$ & $12,6 \%$ & $50,3 \%$ & $13,1 \%$ & $6,8 \%$ \\
\hline
\end{tabular}




\subsection{Dimensão reorientação da formação - estudantes}

No Bloco 3, do total de nove itens incluídos, todos relacionados à reorientação da formação, com enfoque direto ao Programa Pró-Saúde, os acadêmicos optaram pela alternativa “não sei” como resposta em cinco deles (itens 1, 2, 4, 5 e 8). Nos demais itens, os quais abordaram aspectos relacionados a contribuições do Pró-Saúde para a formação para atuação na rede pública (item 3), para a interação entre profissionais da saúde (item 6), para a qualidade da formação (item 7) e para o trabalho em equipe (item 9), a maioria dos acadêmicos demonstraram atitude positiva (alternativas "concordo" e concordo totalmente"), seguidas pela opção de resposta "não sei”. As frequências obtidas nesta dimensão estão descritas na Tabela 14.

\section{Tabela 14}

Frequências de respostas obtidas dos estudantes em cada item da dimensão reorientação da formação.

\begin{tabular}{|c|c|c|c|c|c|c|}
\hline BLOCO 3 - REORIENTAÇÃO DA FORMAÇÃO & $\begin{array}{l}\text { discordo } \\
\text { totalmente }\end{array}$ & discordo & $\begin{array}{c}\text { não } \\
\text { concordo } \\
\text { nem } \\
\text { discordo }\end{array}$ & concordo & $\begin{array}{l}\text { concordo } \\
\text { totalmente }\end{array}$ & não sei \\
\hline 1- Eu conheço os objetivos do Programa Pró-Saúde. & $9,0 \%$ & $21,2 \%$ & $12,2 \%$ & $14,8 \%$ & $3,7 \%$ & $39,2 \%$ \\
\hline $\begin{array}{l}\text { 2- O Pró-Saúde contribuiu com o processo de reforma curricular } \\
\text { do curso de Odontologia. }\end{array}$ & $1,1 \%$ & $1,6 \%$ & $10,5 \%$ & $26,8 \%$ & $7,4 \%$ & $52,6 \%$ \\
\hline $\begin{array}{l}\text { 3- A participação do estudante no Pró-Saúde contribui para a } \\
\text { sua maior preparação para atuação profissional na rede pública. }\end{array}$ & $0,5 \%$ & $2,1 \%$ & $8,5 \%$ & $34,9 \%$ & $12,2 \%$ & $41,8 \%$ \\
\hline $\begin{array}{l}\text { 4- A participação do estudante no Pró-Saúde contribui para a } \\
\text { sua maior preparação para atuação profissional na rede privada. }\end{array}$ & $2,6 \%$ & $12,7 \%$ & $18,0 \%$ & $14,3 \%$ & $3,2 \%$ & $49,2 \%$ \\
\hline $\begin{array}{l}\text { 5- As atividades desenvolvidas no contexto do Pró-Saúde nas } \\
\text { unidades de saúde não alteram as rotinas de trabalho e nem as } \\
\text { práticas dos profissionais de saúde no serviço. }\end{array}$ & $5,9 \%$ & $23,9 \%$ & $9,6 \%$ & $4,8 \%$ & $1,1 \%$ & $\mathbf{5 4 , 7 \%}$ \\
\hline $\begin{array}{l}\text { 6- O Pró-Saúde possibilita a interação entre os profissionais da } \\
\text { área de saúde. }\end{array}$ & $0,0 \%$ & $1,6 \%$ & $9,5 \%$ & $35,4 \%$ & $9,5 \%$ & $43,9 \%$ \\
\hline $\begin{array}{l}\text { 7- As atividades desenvolvidas pelos estudantes de Odontologia } \\
\text { no contexto do Pró-Saúde influenciam na qualidade de sua } \\
\text { formação. }\end{array}$ & $0,5 \%$ & $1,1 \%$ & $5,3 \%$ & $38,8 \%$ & $11,2 \%$ & $43,1 \%$ \\
\hline $\begin{array}{l}\text { 8- As atividades desenvolvidas no âmbito do Pró-Saúde } \\
\text { contribuem para a qualificação da prática dos profissionais que } \\
\text { atuam na rede pública de atenção à saúde do Paranoá-Itapoã. }\end{array}$ & $0,5 \%$ & $2,6 \%$ & $7,9 \%$ & $38,9 \%$ & $5,3 \%$ & $44,7 \%$ \\
\hline 9- O Pró-Saúde contribui para o trabalho em equipe. & $1,1 \%$ & $1,1 \%$ & $6,3 \%$ & $33,3 \%$ & $15,3 \%$ & $42,9 \%$ \\
\hline
\end{tabular}




\subsection{Dimensão pedagógica - estudantes}

Em relação à dimensão pedagógica, analisada no Bloco 4 do instrumento, os respondentes se mostraram positivos em relação à grande maioria dos itens, com a frequência da somatória dos itens "concordo" e "concordo totalmente" prevalecendo em nove dos dez itens deste bloco. Nesses itens os acadêmicos demonstraram acreditar que há integração das atividades envolvendo disciplinas básicas e clínicas $(45,2 \%)$ e que ocorrem atividades interdisciplinares no processo de ensino e aprendizagem $(67,7 \%)$. Os mesmos se mostraram positivos no que se refere à interação entre profissionais de saúde, estudantes e comunidade para o processo de ensino e aprendizagem, com um percentual de $86,8 \%$. Os respondentes demonstraram estar desfavoráveis, com a somatória da opção "discordo" e "discordo totalmente" correspondendo a $68,3 \%$, quando o item considerou a ocorrência de atividades práticas envolvendo profissionais das equipes da saúde uma estratégia de pouca relevância para a formação do profissional. Quanto às estratégias utilizadas, os acadêmicos consideraram aula expositiva o formato mais empregado para a apresentação de conteúdo teórico $(74,2 \%)$, e também concordaram que existe variação nas estratégias de ensino utilizadas $(74,7 \%)$. Os dados percentuais dessa dimensão estão apresentados na Tabela 15.

\section{Tabela 15}

Frequências de respostas obtidas dos estudantes em cada item da dimensão pedagógica.

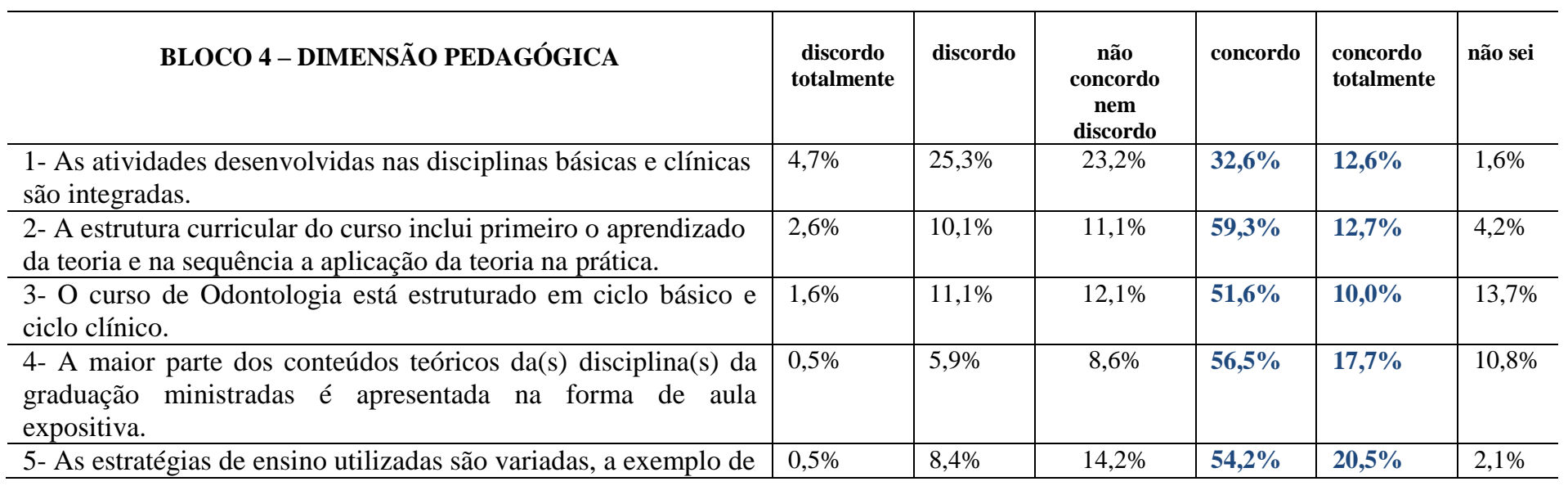




\begin{tabular}{|c|c|c|c|c|c|c|}
\hline $\begin{array}{l}\text { seminários, discussões em grupos tutoriais, estudos de casos, } \\
\text { etc. }\end{array}$ & & & & & & \\
\hline $\begin{array}{l}\text { 6- O processo de ensino-aprendizagem envolve atividades } \\
\text { interdisciplinares. }\end{array}$ & $1,6 \%$ & $10,6 \%$ & $18,0 \%$ & $53,4 \%$ & $14,3 \%$ & $2,1 \%$ \\
\hline $\begin{array}{l}\text { 8- A interação entre a equipe de profissionais de saúde, } \\
\text { estudantes, professores e comunidade facilita o processo de } \\
\text { ensino e aprendizagem. }\end{array}$ & $0,5 \%$ & $2,1 \%$ & $9,0 \%$ & $56,1 \%$ & $30,7 \%$ & $1,6 \%$ \\
\hline $\begin{array}{l}\text { 9- Atividades práticas envolvendo profissionais das equipes de } \\
\text { saúde são estratégias que pouco acrescentam à formação do } \\
\text { dentista, dado as especificidades do curso. }\end{array}$ & $26,5 \%$ & $41,8 \%$ & $7,4 \%$ & $16,9 \%$ & $6,3 \%$ & $1,1 \%$ \\
\hline $\begin{array}{l}\text { 10- As estratégias de ensino-aprendizagem que ocorrem no } \\
\text { ambiente do SUS são avaliadas conjuntamente pelos } \\
\text { profissionais da Rede e docentes. }\end{array}$ & $4,3 \%$ & $11,2 \%$ & $13,8 \%$ & $28,7 \%$ & $9,6 \%$ & $32,4 \%$ \\
\hline
\end{tabular}

\subsection{Dimensão teórica - professores}

Na dimensão teórica (Bloco 1), os docentes foram unânimes ao se posicionarem positivamente sobre a abordagem de aspectos biológico nos conteúdos teóricos das disciplinas, com a opção "concordo" e "concordo totalmente" totalizando $100 \%$ das escolhas. Já em relação à abordagem de aspectos sociais do processo saúde-doença as opiniões de dividiram.

Quanto ao desenvolvimento de pesquisa articulada com demandas da sociedade, em torno de $36 \%$ dos docentes se mostraram positivos ao concordarem ou concordarem totalmente com o item 4 , enquanto aproximadamente $32 \%$ se mostraram negativos. Um total de $68 \%$ entende que a produção científica é focada em aspectos biomédicos.

Quanto à ênfase da pós-graduação, a maioria não acredita que seja voltada para profissionais do SUS, com um total de 53,5\% (somatória de "discordo" e "discordo totalmente"). Sobre o mesmo tópico, a maioria de 39,3\% se mostrou neutra ao optarem por "não concordo nem discordo" quanto à oferta dos cursos serem voltadas para a rede privada, seguido de $29,5 \%$ se posicionando positivamente ("concordo" e "concordo totalmente"). Os dados percentuais referentes a todos os itens do Bloco 1 estão descritos na Tabela 16. 


\section{Tabela 16}

Frequências de respostas obtidas dos professores em cada item da dimensão teórica.

\begin{tabular}{|c|c|c|c|c|c|c|}
\hline $\begin{array}{l}\text { 2- Os conteúdos teóricos ministrados na graduação abordam } \\
\text { aspectos sociais do processo saúde-doença. }\end{array}$ & $0,0 \%$ & $7,1 \%$ & $3,6 \%$ & $42,9 \%$ & $39,3 \%$ & $7,1 \%$ \\
\hline $\begin{array}{l}\text { 4- A produção de conhecimento, no que se refere à pesquisa, } \\
\text { está articulada com as demandas do serviço e da comunidade da } \\
\text { Regional de Saúde do Paranoá/Itapoã. }\end{array}$ & $7,1 \%$ & $25,0 \%$ & $10,7 \%$ & $32,1 \%$ & $3,6 \%$ & $21,5 \%$ \\
\hline $\begin{array}{l}\text { 5- A produção científica é focada em investigações sobre } \\
\text { aspectos biomédicos ou tecnológicos da atenção à saúde. }\end{array}$ & $3,6 \%$ & $7,1 \%$ & $14,3 \%$ & $53,6 \%$ & $14,3 \%$ & $7,1 \%$ \\
\hline $\begin{array}{l}\text { 8- Os cursos de pós-graduação possuem como público-alvo os } \\
\text { profissionais que atuam na rede privada. }\end{array}$ & $3,6 \%$ & $14,3 \%$ & $39,3 \%$ & $21,4 \%$ & $7,1 \%$ & $14,3 \%$ \\
\hline $\begin{array}{l}\text { 9- Os cursos de pós-graduação são oferecidos de acordo com } \\
\text { interesses ou necessidades do curso. }\end{array}$ & $14,3 \%$ & $35,7 \%$ & $17,9 \%$ & $25,0 \%$ & $0,0 \%$ & $7,1 \%$ \\
\hline $\begin{array}{l}\text { 10- As disciplinas teóricas de conteúdos relacionados às áreas } \\
\text { básicas, clínicas e sociais são ministradas em blocos separados, } \\
\text { sem articulação entre elas. }\end{array}$ & $10,7 \%$ & $28,6 \%$ & $21,4 \%$ & $35,7 \%$ & $0,0 \%$ & $3,6 \%$ \\
\hline
\end{tabular}

\subsection{Dimensão cenário de práticas - professores}

Na dimensão cenário de práticas, do Bloco 2 do instrumento, os professores se

mostraram positivos em relação aos benefícios para a comunidade $(92,8 \%$ na somatória de "concordo" e "concordo totalmente"), para o serviço $(85,7 \%)$ e para a própria IES participante $(92,8 \%)$, ao ocorrer a integração entre universidade e serviço de saúde.

Em relação às atividades práticas nas comunidades ou serviços de saúde, a maioria dos docentes $(78,5 \%)$ se mostraram positivos ao concordarem que os estudantes desenvolvem tais atividades desde o início do curso. Por outro lado, $28 \%$ dos docentes concordaram que as atividades práticas dos primeiros anos do curso ocorrem em laboratórios, seguido por $25 \%$ que escolheram a opção "não sei". Um total de $75 \%$ 
(somatória de "concordo" e "concordo totalmente") disseram que as atividades práticas clínicas ocorrem dentro do ambiente universitário.

Sobre o item que afirma haver adequação da infraestrutura das unidades de saúde para o desenvolvimento das atividades, em torno de $57 \%$ se mostraram negativos, ao discordarem ou discordarem totalmente com o item. As frequências obtidas nos itens desse bloco estão apresentadas na Tabela 17.

\section{Tabela 17}

Frequências de respostas obtidas dos professores em cada item da dimensão cenário de práticas.

\begin{tabular}{|c|c|c|c|c|c|c|}
\hline $\begin{array}{l}\text { 2- A integração da universidade com o serviço de saúde traz } \\
\text { benefícios para o serviço. }\end{array}$ & $7,1 \%$ & $0,0 \%$ & $3,6 \%$ & $35,7 \%$ & $50,0 \%$ & $3,6 \%$ \\
\hline $\begin{array}{l}\text { 4- O curso de Odontologia contribui para a organização dos } \\
\text { serviços da Regional de Saúde do Paranoá/Itapoã. }\end{array}$ & $7,1 \%$ & $3,6 \%$ & $14,3 \%$ & $46,4 \%$ & $14,3 \%$ & $14,3 \%$ \\
\hline $\begin{array}{l}\text { 5- A infraestrutura das unidades de saúde nas quais são } \\
\text { realizadas atividades das disciplinas e/ou ações do Pró-Saúde } \\
\text { são adequadas ao processo de ensino e aprendizagem dos } \\
\text { estudantes. }\end{array}$ & $10,7 \%$ & $46,4 \%$ & $14,3 \%$ & $7,1 \%$ & $0,0 \%$ & $21,5 \%$ \\
\hline $\begin{array}{l}\text { 7- O curso de Odontologia está voltado para a formação } \\
\text { especializada do dentista. }\end{array}$ & $10,7 \%$ & $42,9 \%$ & $21,4 \%$ & $17,9 \%$ & $7,1 \%$ & $0,0 \%$ \\
\hline $\begin{array}{l}\text { 8- As atividades desenvolvidas nos cenários de práticas do } \\
\text { Paranoá-Itapoã são importantes para a formação do dentista. }\end{array}$ & $3,6 \%$ & $0,0 \%$ & $3,6 \%$ & $50,0 \%$ & $35,7 \%$ & $7,1 \%$ \\
\hline $\begin{array}{l}\text { 9- O Pró-Saúde contribuiu para a integração do curso com a } \\
\text { Rede de Serviço de Saúde do Paranoá-Itapoã. }\end{array}$ & $3,6 \%$ & $3,6 \%$ & $7,1 \%$ & $42,9 \%$ & $25,0 \%$ & $17,8 \%$ \\
\hline $\begin{array}{l}\text { 10- O curso de Odontologia se volta para a formação generalista } \\
\text { do dentista. }\end{array}$ & $0,0 \%$ & $17,9 \%$ & $21,4 \%$ & $\mathbf{5 0 , 0 \%}$ & $10,7 \%$ & $0,0 \%$ \\
\hline $\begin{array}{l}\text { 11- O Pró-Saúde contribuiu para a integração da Odontologia } \\
\text { com os demais cursos da área da saúde. }\end{array}$ & $3,6 \%$ & $7,1 \%$ & $28,6 \%$ & $25,0 \%$ & $10,7 \%$ & $25,0 \%$ \\
\hline $\begin{array}{l}\text { 12- As atividades práticas dos primeiros anos do curso ocorrem } \\
\text { em laboratórios da área básica. }\end{array}$ & $3,6 \%$ & $21,4 \%$ & $21,4 \%$ & $25,0 \%$ & $3,6 \%$ & $25,0 \%$ \\
\hline
\end{tabular}




\subsection{Dimensão reorientação da formação - professores}

Na dimensão reorientação da formação, que trata de itens relacionados ao

Programa Pró-Saúde, os docentes apresentaram tendências positivas em todos os itens incluídos no bloco. Um percentual de $67 \%$ disseram conhecer os objetivos Programa; mais 70\% acreditam que o Pró-Saúde contribuiu para a reforma curricular e 75\% se mostraram positivos quanto à contribuição do mesmo para o preparo na formação do acadêmico para atuação na rede pública. Ainda que com frequência menor, $39 \%$ dos docentes acreditam que auxilia também no preparo para atuação na rede privada, seguido de $21 \%$ que permaneceu neutro neste item. Os dados percentuais obtidos em cada item estão descritos na Tabela 18.

\section{Tabela 18}

Frequências de respostas obtidas dos professores em cada item da dimensão reorientação da formação.

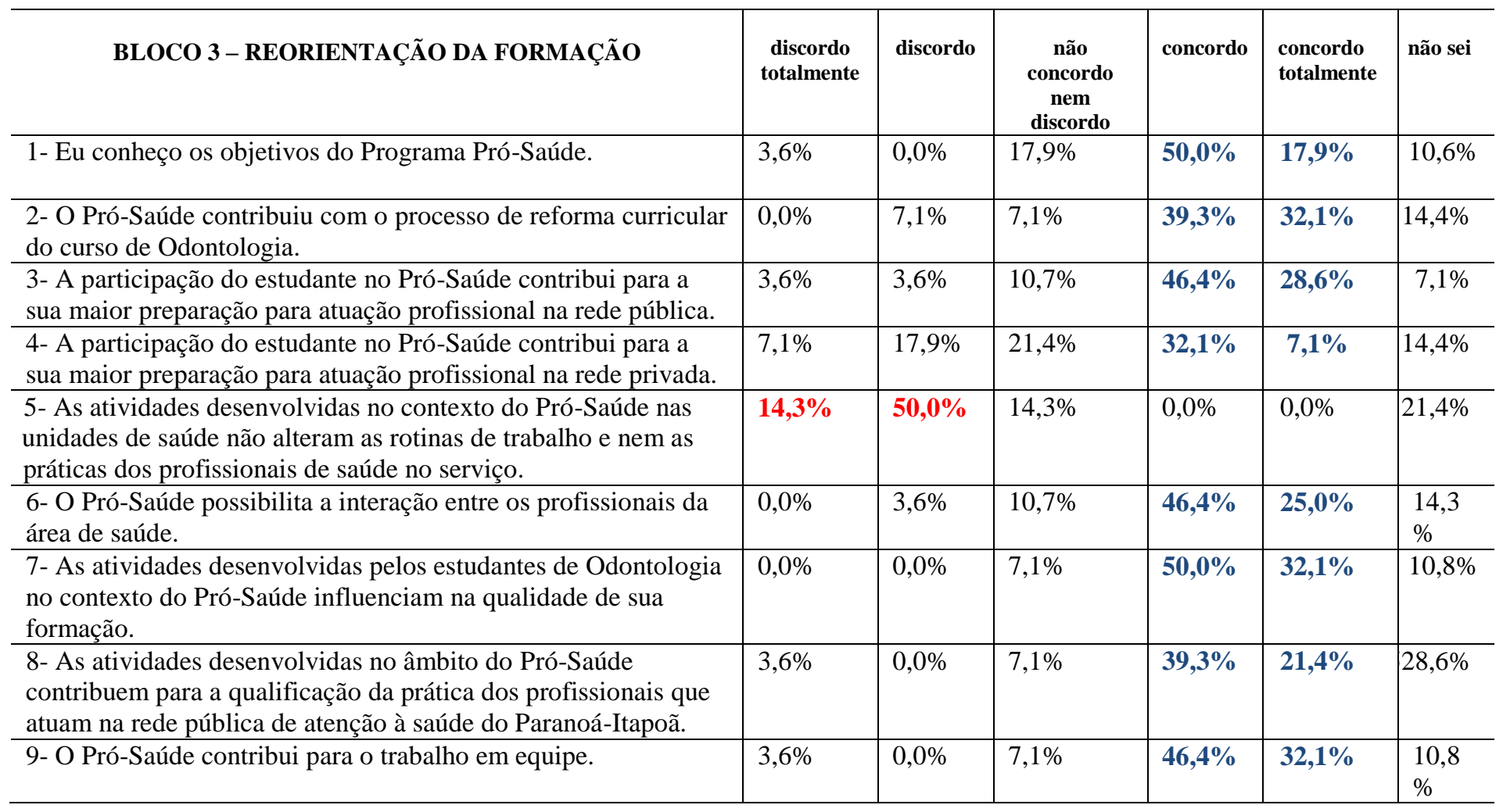




\subsection{Dimensão pedagógica - professores}

Na dimensão pedagógica, incluída no Bloco 4, os docentes apresentaram opiniões divididas em vários itens. Apesar de 35,7\% não considerarem as atividades entre disciplinas clínicas e básicas integradas, $32 \%$ se pronunciaram de forma oposta. Um total de $25 \%$ se manteve neutro sobre essa questão. Metade dos respondentes (50\%) demonstrou tendência a discordar que o curso está estruturado em ciclo básico e clínico.

Com relação às metodologias de ensino houve um equilíbrio de opiniões sobre o item que se referiu à utilização de aula expositiva, com 46,5\% da somatória de "concordo" e "concordo totalmente", enquanto $42,9 \%$ optaram pelo extremo oposto (soma de "discordo" e “discordo totalmente"). Sobre o uso de metodologias de ensino diversificadas, $82,2 \%$ se posicionou favoravelmente. Os docentes demonstraram reconhecer relevância do trabalho em equipe, conforme se observou nos itens 8 e 9. Os resultados obtidos nessa dimensão podem ser verificados na Tabela 19.

\section{Tabela 19}

Frequências de respostas obtidas dos professores em cada item da dimensão pedagógica.

\begin{tabular}{|c|c|c|c|c|c|c|}
\hline $\begin{array}{l}\text { 2- A estrutura curricular do curso inclui primeiro o aprendizado } \\
\text { da teoria e na sequência a aplicação da teoria na prática. }\end{array}$ & $3,6 \%$ & $21,4 \%$ & $28,6 \%$ & $39,3 \%$ & $7,1 \%$ & $0,0 \%$ \\
\hline $\begin{array}{l}\text { 4- A maior parte dos conteúdos teóricos da(s) disciplina(s) da } \\
\text { graduação que ministro é apresentada na forma de aula } \\
\text { expositiva. }\end{array}$ & $14,3 \%$ & $28,6 \%$ & $0,0 \%$ & $28,6 \%$ & $17,9 \%$ & $10,7 \%$ \\
\hline $\begin{array}{l}\text { 5- As estratégias de ensino utilizadas são variadas, a exemplo de } \\
\text { seminários, discussões em grupos tutoriais, estudos de casos, } \\
\text { etc. }\end{array}$ & $3,6 \%$ & $10,7 \%$ & $3,6 \%$ & $53,6 \%$ & $28,6 \%$ & $0,0 \%$ \\
\hline
\end{tabular}




\begin{tabular}{l|l|l|l|l|l|l}
\hline 7- Existe interação entre a teoria ministrada e a prática. & $0,0 \%$ & $7,1 \%$ & $17,9 \%$ & $\mathbf{1 7 , 9 \%}$ & $\mathbf{5 3 , 6 \%}$ & $3,6 \%$ \\
\hline $\begin{array}{l}\text { 8- A interação entre a equipe de profissionais de saúde, } \\
\text { estudantes, professores e comunidade facilita o processo de } \\
\text { ensino e aprendizagem. }\end{array}$ & $3,6 \%$ & $3,6 \%$ & $10,7 \%$ & $\mathbf{2 8 , 6 \%}$ & $\mathbf{5 3 , 6 \%}$ & $0,0 \%$ \\
\hline $\begin{array}{l}\text { 9- Atividades práticas envolvendo profissionais das equipes de } \\
\text { saúde são estratégias que pouco acrescentam à formação do } \\
\text { dentista, dado as especificidades do curso. }\end{array}$ & $\mathbf{3 9 , 3 \%}$ & $\mathbf{5 0 , 0 \%}$ & $3,6 \%$ & $3,6 \%$ & $3,6 \%$ & $0,0 \%$ \\
\hline $\begin{array}{l}\text { 10- As estratégias de ensino-aprendizagem que ocorrem no } \\
\text { ambiente do SUS são avaliadas conjuntamente pelos } \\
\text { profissionais da Rede e docentes. }\end{array}$ & $\mathbf{7 , 1 \%}$ & $\mathbf{3 5 , 7 \%}$ & $10,7 \%$ & $7,1 \%$ & $3,6 \%$ & $35,7 \%$ \\
\hline
\end{tabular}

\subsection{Comentários/sugestões de professores e acadêmicos sobre os itens}

\section{respondidos no instrumento}

Ao ser oferecida a oportunidade aos respondentes destes se manifestarem em relação ao instrumento, observou-se que majoritariamente os comentários retornados se referiram ao tema objeto do estudo mesmo e não sobre aspectos estruturais do instrumento. As

Figuras 34 e 35 apresentam essas colocações.

\begin{tabular}{|c|c|}
\hline $\mathbf{1}^{\circ}$ Semestre & Bloco 4 item 2: tanto a teoria quanto a prática são sempre integradas \\
\hline $2^{\circ}$ Semestre & Sem Comentários \\
\hline $3^{\circ}$ Semestre & Sem Comentários \\
\hline $4^{\circ}$ Semestre & Sem Comentários \\
\hline $5^{\circ}$ Semestre & Sem Comentários \\
\hline $6^{\circ}$ Semestre & Sem Comentários \\
\hline $7^{\circ}$ Semestre & $\begin{array}{l}\text { Disciplinas, de modo geral deviam ser mais bem organizadas. } \\
\text { Falta de material e infraestrutura afeta gravemente o aprendizado de toda } \\
\text { faculdade de saúde. } \\
\text { As atividades fora do Campus deveriam ser mais bem organizadas. Tem que } \\
\text { haver mais comunicação entre a universidade e as pessoas do posto de } \\
\text { saúdel escolas em que são ministrados os conteúdos. Nessas atividades os } \\
\text { estudantes só tem a ajudar, mas a impressão que fica é que estamos } \\
\text { atrapalhando toda a rotina e funcionamento destes lugares, principalmente } \\
\text { nas escolas (não temos nem uma ala adequada para realizar atendimentos } \\
\text { simples como ART). Tudo funciona na base do improviso e da boa vontade } \\
\text { dos professores do curso. } \\
\text { Frequentemente a falta de comunicação entre as áreas de especialidades e } \\
\text { disciplinas do curso prejudicaram e muito a organização e desempenho dos }\end{array}$ \\
\hline
\end{tabular}




\begin{tabular}{|c|c|}
\hline & alunos, algo que reflete na formação profissional. \\
\hline $8^{\circ}$ Semestre & Sem Comentários \\
\hline $9^{\circ}$ Semestre & $\begin{array}{l}\text { Bloco } 04 \text { item } 7 \text {-Depende dos professores } \\
\text { Bloco } 04 \text { item } 1 \text { - As disciplinas são muito dissociadas. Atendemos o } \\
\text { paciente só o que interessa para a matéria, por exemplo, se for clínica de } \\
\text { dentística, só fazemos dentística. Mesmo com o novo currículo que tenta } \\
\text { integrar as matérias não resolveu, pois acaba que você deixa de realizar } \\
\text { procedimentos com endo, porque seu paciente só tem dentística, e a clínica é } \\
\text { dentísticalendo. Além disso não são contabilizados os procedimentos } \\
\text { realizados para que assim o SUS repasse recursos financeiros para o HUB e } \\
\text { assim invista em materiais para melhorar o atendimentolaprendizado. } \\
\text { Bloco } 04 \text { item } 6 \text { - O processo de ensino - aprendizagem envolve atividades } \\
\text { interdisciplinares, apenas no último ano de curso, nas clínicas integradas. } \\
\text { Bloco } 02 \text { item } 8 \text { - A maneira como foi executada as atividades no referido } \\
\text { cenário não trouxe benefício significativo em minha formação, porém a } \\
\text { proposta possui potencial elevado se feito de forma organizada e realmente } \\
\text { articulada com as atividades de saúde coletiva. } \\
\text { Bloco } 03 \text { item } 11 \text { - no } 9^{o} \text { e } 10^{o} \text { semestre tem-se a clínica integrada. No } \\
\text { entanto é bastante compartimentalizadolespecializado, visto que o professor } \\
\text { geralmente te auxiliará só naquilo relacionado a especialidade dele. Ex: Se } \\
\text { não houver professor de prótese em determinado dia que você atende um } \\
\text { caso de prótese o indicado é transferir o paciente para um dia que o } \\
\text { professor respectivo esteja presente. } \\
\text { As atividades que envolvem profissionais da rede, apesar de eu perceber a } \\
\text { importância, não foi bem aproveitada, da forma que nos foi apresentada. }\end{array}$ \\
\hline $10^{\circ}$ Semestre & $\begin{array}{l}\text { Acredito que o Pró-Saúde precisa ser melhor explicado para o corpo } \\
\text { discente. Só ouvimos rumores sobre esse programa, sem a devida explicação } \\
\text { dos seus objetivos e de que forma os alunos podem participar e contribuir } \\
\text { para o mesmo. }\end{array}$ \\
\hline
\end{tabular}

Figura 34- Comentários /sugestões dos estudantes sobre os itens respondidos. 
Bloco 02 item 4 - Não contribuiu como deveria ou poderia.

Bloco 02 item 5 - Muitas vezes não estão. Depende do local.

Bloco 02 item 6 - Nem sempre. Mas na maioria das vezes sim.

Bloco 02 item 7 - O curso passa por uma crise de identidade séria. Quem formamos?

Bloco 02 item 10 - Idem à resposta anterior. Há um embate entre o que a legislação e as DCN esperam e o que os professores praticam/querem.

Bloco 02 item 12 - Não exclusivamente, mas também. A redação deixou a questão difícil de responder.

Bloco 04 item 6 - Algumas disciplinas têm essa prática. A maioria não.

Bloco 04 item 10 - Não são, mas precisam ser urgentemente. Muitas respostas "não sei" atribui por causa da falta de avaliação sistemática.

Bloco 04 item 10 - As estratégias de ensino-aprendizagem são avaliadas conjuntamente pelos professores que atuam diretamente na Rede, em separado do restante do Colegiado, e pelos profissionais da Rede. Aqui o processo de implementação do Pro-saúde e a reforma curricular ocorreram de forma, em minha opinião, acelerada e sem o devido planejamento e discussão. As áreas clínicas foram excessivamente tolhidas de carga horária. As práticas clínicas foram reduzidas e prejudicadas. As estruturas para atividades externas à UnB até hoje não existem. $O$ dentista generalista é aquele capaz de atender dignamente em todas as áreas de odontologia. Atualmente, o formado do novo currículo terá deficiências em sua capacidade generalista, pois teve pouco contato com áreas clínicas específicas que formam o generalista. A minha área é odontologia a qual não tem cobertura por nenhum tipo de plano público. Faço parte do projeto de extensão. Não tem quase nada de referências dos serviços que sejam pagos ou suportados financeiramente pelo governo ou serviço público a falta de incentivo é clara, portanto não vejo realmente uma relação prática entre a minha área e o serviço público. É um grande equívoco entender que a formação de um profissional de qualidade deva ser vinculada à um programa assistencial. Há a possibilidade de trabalho dessas vertentes de maneira isolada.

Bloco 01 item 6 - Só não está mais porque o SUS aqui é engessado. A atenção básica é muito atrasada e quase não há progresso na política de atenção básica. A falta de dinamismo da Secretaria de Saúde atrapalha muito.

Bloco 01 item 8 - A oferta de pós está centrada na pessoa e no projeto acadêmico dos professores da pós. Não há uma política de inclusão de professores e de expansão da pós como uma missão clara e deliberada. A instituição não é proativa (positivo). Nesse caso ela é reativa.

Bloco 02 item 6 - Isso não se refere as disciplinas da Saúde Coletiva, mas sim a maioria das disciplinas clínicas "tradicionais" do curso.

Bloco 02 item 9 - O impedimento em investimento em transporte no Pró-Saúde atrapalha o desenvolvimento dessa integração. Precisávamos não só levar alunos e professores, mas também trazer pacientes para o campus.

Figura 35. Comentários /sugestões dos professores sobre os itens respondidos. 


\section{Pontuação e codificação dos itens e blocos para interpretação das tendências}

\section{de atitudes}

Partindo do pressuposto de que cada item foi pontuado baseado na categorização do mesmo como uma atitude positiva ou negativa em relação ao objeto de estudo, conforme já ilustrado na Figura 10, e considerando que os itens foram agrupados de modo a serem classificados como confirmatórios (itens que se contrapõem) e complementares (relação única com a dimensão), foram realizadas análises de interpretação das tendências atitudinais dos resultados obtidos para cada dimensão.

Cada item recebeu uma pontuação total, e considerando o total de estudantes (n=191), o valor mínimo e máximo da soma para cada item variou entre -382 pontos (se todos os respondentes pontuassem -2) e +382 pontos (se todos pontuassem +2 ) em cada item. Para os professores $(\mathrm{n}=28)$ o valor mínimo da soma variou de -56 (se todos os respondentes pontuassem -2 ) a +56 (se todos pontuassem +2 ).

Foi realizada uma média geral $(\mathrm{M})$ dos escores obtidos em cada item da escala para possibilitar a comparação entre estudantes e professores, uma vez que dado o fato desses grupos de sujeitos possuírem valores de $\mathrm{n}$ diferentes, a comparação entre os mesmos pela soma se tornaria inviável. A partir dos valores de $\mathrm{M}$ obtidos, foi realizada uma conversão para conceito. Assim, para a conversão das médias dos itens em conceito, seguiu-se a interpretação descrita na Figura 36. 


\begin{tabular}{|c|c|c|c|}
\hline \multicolumn{2}{|c|}{ ITENS POSITIVOS } & \multicolumn{2}{c|}{ ITENS NEGATIVOS } \\
\hline Média (M) & Conceito & Média (M) & Conceito \\
\hline$-2<\mathrm{M} \leq-1,2$ & $\mathrm{DT}$ & $-2<\mathrm{M} \leq-1,2$ & $\mathrm{CT}$ \\
\hline$-1,2<\mathrm{M} \leq-0,4$ & $\mathrm{D}$ & $-1,2<\mathrm{M} \leq-0,4$ & $\mathrm{C}$ \\
\hline$-0,4<\mathrm{M} \leq+0,4$ & $\mathrm{NCND}$ & $-0,4<\mathrm{M} \leq+0,4$ & NDNC \\
\hline$+0,4<\mathrm{M} \leq+1,2$ & $\mathrm{C}$ & $+0,4<\mathrm{M} \leq+1,2$ & $\mathrm{D}$ \\
\hline$+1,2<\mathrm{M} \leq+2,0$ & $\mathrm{CT}$ & $+1,2<\mathrm{M} \leq+2,0$ & $\mathrm{DT}$ \\
\hline
\end{tabular}

Figura 36 - Conversão da pontuação dos itens e blocos para conceitos

Em relação à dimensão teórica, pode-se observar nas Tabelas 20 e 21, que tanto professores quanto estudantes apresentaram valores das Médias próximos de zero, e mesmo que professores tenham apresentado um valor negativo e estudantes um valor positivo, ambos demonstraram uma tendência atitudinal neutra.

Tabela 20

Pontuação dos itens do Bloco 1 em relação aos estudantes

\begin{tabular}{|c|c|c|c|c|c|c|c|c|c|c|}
\hline & B1Q2 & B1Q1 & B1Q3 & B1Q10 & B1Q4 & B1Q5 & B1Q7 & B1Q8 & B1Q6 & B1Q9 \\
\hline Sinal & + & - & + & - & + & - & + & - & + & - \\
\hline Soma & 200 & -253 & 159 & 48 & 67 & -102 & -9 & 8 & 73 & -31 \\
\hline Média (M) & 1,05 & $-1,34$ & 0,85 & 0,26 & 0,40 & $-0,67$ & $-0,08$ & 0,07 & 0,45 & $-0,29$ \\
\hline $\begin{array}{l}\text { Desvio } \\
\text { Padrão }\end{array}$ & 0,77 & 0,56 & 0,79 & 1,17 & 0,98 & 0,84 & 1,00 & 1,12 & 0,97 & 0,93 \\
\hline Moda & 1 & -1 & 1 & 1 & 1 & -1 & -1 & 0 & 1 & -1 \\
\hline Mediana & 1 & -1 & 1 & 1 & 1 & -1 & 0 & 0 & 1 & 0 \\
\hline Conceito & C & CT & C & ND/NC & ND/NC & C & ND/NC & ND/NC & C & ND/NC \\
\hline Confirmatório & \multicolumn{2}{|c|}{$-0,29$} & \multicolumn{2}{|c|}{1,11} & \multicolumn{2}{|c|}{$-0,27$} & \multicolumn{2}{|c|}{$-0,02$} & & \\
\hline Conceito & \multicolumn{2}{|c|}{ ND/NC } & \multicolumn{2}{|c|}{ C } & \multicolumn{2}{|c|}{ ND/NC } & \multicolumn{2}{|c|}{ ND/NC } & & \\
\hline Bloco & \multicolumn{4}{|l|}{0,07} & \multicolumn{4}{|c|}{ ND/NC } & & \\
\hline
\end{tabular}


Tabela 21

Pontuação dos itens do Bloco 1 em relação aos professores

\begin{tabular}{|c|c|c|c|c|c|c|c|c|c|c|}
\hline & B1Q2 & B1Q1 & B1Q3 & B1Q10 & B1Q4 & B1Q5 & B1Q7 & B1Q8 & B1Q6 & B1Q9 \\
\hline Sinal & + & - & + & - & + & - & + & - & + & - \\
\hline Soma & 32 & -45 & 10 & 4 & 0 & -19 & -9 & -4 & 2 & 11 \\
\hline Média (M) & 1,28 & $-1,61$ & 0,45 & 0,19 & 0,00 & $-0,86$ & $-0,43$ & $-0,31$ & 0,12 & 0,52 \\
\hline $\begin{array}{l}\text { Desvio } \\
\text { Padrão }\end{array}$ & 0,84 & 0,50 & 1,18 & 1,21 & 1,25 & 0,99 & 1,21 & 1,32 & 1,41 & 1,17 \\
\hline Moda & 1 & -2 & 1 & -1 & 1 & -1 & -1 & -1 & 1 & 1 \\
\hline Mediana & 1 & -2 & 1 & 1 & 1 & -1 & -1 & -1 & 1 & 1 \\
\hline Conceito & CT & CT & C & ND/NC & ND/NC & C & D & ND/NC & ND/NC & D \\
\hline Confirmatório & \multicolumn{2}{|c|}{$-0,33$} & \multicolumn{2}{|c|}{0,65} & \multicolumn{2}{|c|}{$-0,86$} & \multicolumn{2}{|c|}{$-0,74$} & & \\
\hline Conceito & \multicolumn{2}{|c|}{ ND/NC } & \multirow{2}{*}{\multicolumn{4}{|c|}{$\frac{D}{N D / N C}$}} & \multicolumn{2}{|c|}{ D } & & \\
\hline Bloco & \multicolumn{2}{|l|}{$-0,06$} & & & & & & ND/NC & & \\
\hline
\end{tabular}

Na dimensão cenário de práticas ambos os grupos (professores e estudantes) apresentaram uma tendência atitudinal positiva em relação ao bloco. Houve uma pequena diferença no valor de $\mathrm{M}$ ao compará-los, de modo que ao se realizar a conversão para o conceito, os dois grupos demonstraram predominantemente concordar com as assertivas.

Ao se analisar os itens de forma individualizada observou-se que nos itens classificados como negativos, houve uma tendência em se concordar com os mesmos, o que demonstra nesses casos uma tendência atitudinal negativa em relação ao construto analisado. Os resultados obtidos em relação aos estudantes e aos docentes, estão apresentados, respectivamente, nas Tabelas 22 e 23. 
Tabela 22

Pontuação dos itens do Bloco 2 em relação aos estudantes

\begin{tabular}{|c|c|c|c|c|c|c|c|c|c|}
\hline & B2Q1 & $\mathrm{B} 2 \mathrm{Q} 2$ & B2Q3 & B2Q4 & B2Q5 & B2Q6 & B2Q8 & B2Q13 & B2Q12 \\
\hline Sinal & + & + & + & + & + & - & + & + & - \\
\hline Soma & 302 & 266 & 261 & 144 & -50 & -217 & 216 & 186 & -111 \\
\hline Média & 1,60 & 1,43 & 1,40 & 0,82 & $-0,36$ & $-1,19$ & 1,15 & 1,04 & $-0,62$ \\
\hline $\begin{array}{l}\text { Desvio } \\
\text { Padrão }\end{array}$ & 0,54 & 0,69 & 0,78 & 0,96 & 1,07 & 0,79 & 0,83 & 1,01 & 0,97 \\
\hline Moda & 2 & 2 & 2 & 1 & -1 & -1 & 1 & 1 & -1 \\
\hline Mediana & 2 & 2 & 2 & 1 & -1 & -1 & 1 & 1 & -1 \\
\hline Conceito & CT & CT & CT & C & ND/NC & C & C & C & C \\
\hline Confirmatório & & & & & & & & \multicolumn{2}{|c|}{0,42} \\
\hline Conceito & & & & & & & & \multicolumn{2}{|c|}{ C } \\
\hline Bloco & 0,59 & & & & $\bar{C}$ & & & & \\
\hline
\end{tabular}

Tabela 23

Pontuação dos itens do Bloco 2 em relação aos professores

\begin{tabular}{l|c|c|c|c|c|c|c|cc}
\hline & B2Q1 & B2Q2 & B2Q3 & B2Q4 & B2Q5 & B2Q6 & B2Q8 & B2Q13 & B2Q12 \\
\hline Sinal & + & + & + & + & + & - & + & + & - \\
Soma & 38 & 34 & 38 & 16 & -17 & -29 & 32 & 26 & -1 \\
Média & 1,36 & 1,31 & 1,36 & 0,80 & $-0,94$ & $-1,26$ & 1,28 & 1,08 & $-0,07$ \\
Desvio & 1,06 & 1,09 & 1,06 & 1,15 & 0,80 & 0,86 & 0,84 & 0,78 & 1,22 \\
Padrão & 2 & 2 & 2 & 1 & -1 & -1 & 1 & 1 & -1 \\
Moda & 2 & 2 & 2 & 1 & -1 & -1 & 1 & 1 & -1 \\
Mediana & CT & CT & CT & C & D & CT & CT & C & ND/NC \\
Conceito & Confirmatório & \multicolumn{10}{|c}{ C C } \\
Conceito & \multicolumn{10}{|c|}{}
\end{tabular}

No Bloco 3, em que se analisou a dimensão reorientação da formação, a Média dos estudantes para o bloco foi de 0,64 e dos professores 0,95. Ambos os grupos apresentaram o conceito $\mathrm{C}$ (concordo) ao se realizar a conversão, demonstrando uma tendência atitudinal positiva em relação a essa dimensão.

Com isso, em todos os itens considerados negativos em relação ao objeto de estudo, tanto professores quanto estudantes, após as conversões das Médias, apresentaram os 
conceitos C (discordo) ou DT (discordo totalmente), ou no mínimo neutro (NCND), reforçando a tendência positiva em relação a essa dimensão.

Para os estudantes, a soma de alguns itens apresentou-se baixa devido ao elevado número de casos em que a opção de resposta ao item foi "não sei", e outros em que houve uma distribuição equilibrada entre as opções selecionadas pelos respondentes. O item B2Q7, o qual foi transferido do Bloco 2 para o 3, o resultado da somatória dos itens foi nula.

Os dados referentes a esse bloco encontram-se descritos nas Tabelas 24 e 25 .

Tabela 24

Pontuação dos itens do Bloco 3 em relação aos estudantes

\begin{tabular}{|c|c|c|c|c|c|c|c|c|c|c|c|c|c|}
\hline & B3Q1 & B3Q2 & B3Q3 & B3Q4 & B3Q8 & B3Q5 & B3Q6 & B3Q9 & B3Q7 & B2Q10 & B2Q7 & B2Q9 & B2Q11 \\
\hline Sinal & + & + & + & - & + & - & + & + & + & + & - & + & + \\
\hline Soma & -32 & 72 & 106 & -5 & 87 & 54 & 100 & 115 & 111 & 157 & 0 & 99 & 64 \\
\hline Média & $-0,28$ & 0,80 & 0,96 & $-0,05$ & 0,83 & 0,64 & 0,94 & 1,06 & 1,04 & 0,85 & 0,00 & 0,89 & 0,60 \\
\hline $\begin{array}{l}\text { Desvio } \\
\text { Padrão }\end{array}$ & 1,17 & 0,82 & 0,77 & 1,00 & 0,70 & 0,92 & 0,67 & 0,79 & 0,67 & 0,98 & 1,17 & 0,84 & 1,05 \\
\hline Moda & -1 & 1 & 1 & 0 & 1 & 1 & 1 & 1 & 1 & 1 & 1 & 1 & 1 \\
\hline Mediana & 0 & 1 & 1 & 0 & 1 & 1 & 1 & 1 & 1 & 1 & 0 & 1 & 1 \\
\hline Conceito & ND/NC & C & $\mathrm{C}$ & ND/NC & C & D & C & $\mathrm{C}$ & C & C & ND/NC & $\mathrm{C}$ & $\mathrm{C}$ \\
\hline Confirmatório & & & \multicolumn{2}{|c|}{0,91} & \multicolumn{2}{|c|}{1,46} & \multicolumn{2}{|c|}{2,00} & & \multicolumn{2}{|c|}{0,85} & & \\
\hline Conceito & & & \multicolumn{2}{|c|}{ C } & & & \multicolumn{2}{|c|}{ CT } & & \multicolumn{2}{|c|}{ C } & & \\
\hline Bloco & 0,64 & \multicolumn{12}{|c|}{ C } \\
\hline
\end{tabular}

Tabela 25

Pontuação dos itens do Bloco 3 em relação aos professores

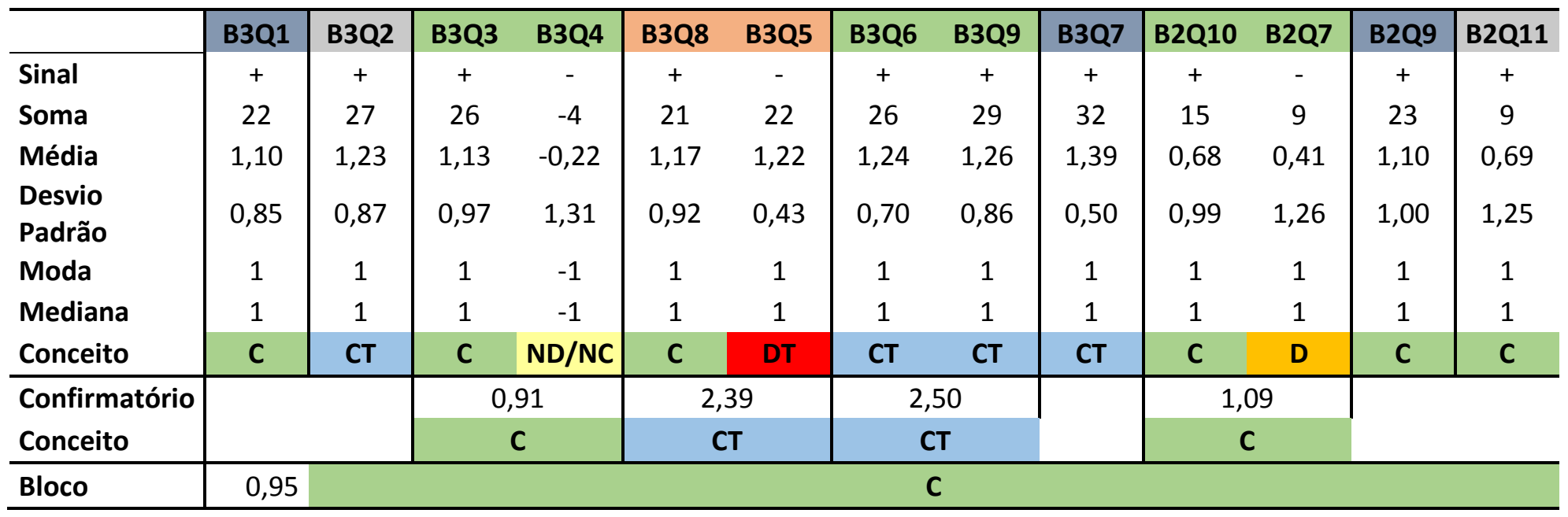


Na dimensão pedagógica os resultados diferiram entre professores e estudantes. Os professores demonstraram uma tendência atitudinal mais positiva que os estudantes em relação a esta dimensão. Entretanto, com exceção do item B4Q9, em que na média os professores obtiveram o conceito DT (discordo totalmente) e os estudantes D (discordo), em todos os demais itens negativos, os estudantes apresentaram uma tendência favorável aos mesmos, e portanto, negativa em relação ao objeto norteador da análise. Os professores apresentaram uma posição neutra (NCND) em relação a esses itens negativos, e em geral a média do bloco para estes foi favorável, com conceito C (concordo). Para os acadêmicos, a tendência no bloco foi neutra (NCND).

Os resultados de cada item deste bloco está descrito nas Tabelas 26 e 27.

\section{Tabela 26}

Pontuação dos itens do Bloco 4 em relação aos estudantes

\begin{tabular}{|c|c|c|c|c|c|c|c|c|c|c|}
\hline & B4Q1 & B4Q3 & B4Q7 & B4Q2 & B4Q5 & B4Q4 & B4Q6 & B4Q8 & B4Q9 & B4Q10 \\
\hline Sinal & + & - & + & - & + & - & + & + & - & + \\
\hline Soma & 44 & -109 & 195 & -131 & 163 & -158 & 129 & 216 & 123 & 53 \\
\hline Média & 0,24 & $-0,66$ & 1,05 & $-0,72$ & 0,88 & $-0,95$ & 0,70 & 1,16 & 0,66 & 0,42 \\
\hline $\begin{array}{l}\text { Desvio } \\
\text { Padrão }\end{array}$ & 1,12 & 0,91 & 0,75 & 0,92 & 0,86 & 0,78 & 0,91 & 0,72 & 1,22 & 1,12 \\
\hline Moda & 1 & -1 & 1 & -1 & 1 & -1 & 1 & 1 & 1 & 1 \\
\hline Mediana & 0 & -1 & 1 & -1 & 1 & -1 & 1 & 1 & 1 & 1 \\
\hline Conceito & ND/NC & C & C & C & C & C & C & C & D & C \\
\hline Confirmatório & \multicolumn{2}{|c|}{$-0,43$} & \multicolumn{2}{|c|}{0,32} & \multicolumn{2}{|c|}{$-0,08$} & & \multicolumn{2}{|c|}{1,82} & \\
\hline Conceito & \multicolumn{2}{|c|}{ D } & \multicolumn{2}{|c|}{ ND/NC } & \multicolumn{2}{|c|}{ ND/NC } & & \multicolumn{2}{|c|}{ CT } & \\
\hline Bloco & \multicolumn{4}{|l|}{0,28} & \multicolumn{3}{|c|}{ ND/NC } & & & \\
\hline
\end{tabular}


Tabela 27

Pontuação dos itens do Bloco 4 em relação aos professores

\begin{tabular}{|c|c|c|c|c|c|c|c|c|c|}
\hline & B4Q1 B4Q3 & B4Q7 & B4Q2 & B4Q5 & B4Q4 & B4Q6 & B4Q8 & B4Q9 & B4Q10 \\
\hline Sinal & + & + & - & + & - & + & + & - & + \\
\hline Soma & 8 & 33 & -7 & 26 & -2 & 27 & 35 & 33 & -10 \\
\hline Média & 0,36 & 1,50 & $-0,35$ & 0,96 & $-0,08$ & 1,17 & 1,40 & 1,22 & $-0,67$ \\
\hline $\begin{array}{l}\text { Desvio } \\
\text { Padrão }\end{array}$ & 1,09 & 0,91 & 1,18 & 1,06 & 1,47 & 0,83 & 1,00 & 0,93 & 1,11 \\
\hline Moda & -1 & 2 & -1 & 1 & 1 & 1 & 2 & 1 & -1 \\
\hline Mediana & -1 & 2 & -1 & 1 & -1 & 1 & 2 & 1 & -1 \\
\hline Conceito & ND/NC ND/NC & CT & ND/NC & & ND/NC & C & CT & DT & D \\
\hline Confirmatório & 0,36 & \multicolumn{2}{|c|}{1,15} & \multicolumn{2}{|c|}{0,88} & & \multicolumn{2}{|c|}{2,62} & \\
\hline Conceito & ND/NC & \multicolumn{2}{|c|}{$\mathrm{C}$} & \multicolumn{2}{|c|}{$\mathrm{C}$} & & \multicolumn{2}{|c|}{$\overline{C T}$} & \\
\hline Bloco & \multicolumn{3}{|l|}{0,55} & \multicolumn{3}{|c|}{ C } & & & \\
\hline
\end{tabular}

Para realizar a análise comparativa entre estudantes e professores por bloco, calculou-se a soma de cada indivíduo de cada grupo (estudantes e professores). Considerando que havia itens positivos (favoráveis ao Pró-saúde) e negativos (desfavoráveis ao Pró-saúde), a soma indica o quão favorável ao Pró-saúde cada indivíduo é, em cada bloco.

Como o estudo tem variáveis ordinais, o teste estatístico aplicado foi o Teste $\mathrm{H}$ de Kruskal-Wallis, o qual demonstra se há diferença entre as medianas ou na distribuição dos grupos. Uma análise visual da distribuição dos grupos mostrou que há semelhança na forma da distribuição e portanto, a análise foi realizada entre as medianas. Para rejeitar a hipótese de igualdade, foi considerado nível mínimo de significância de 5\%.

A Tabela 28 apresenta a comparação entre medianas dos dois grupos para os quatro blocos. 
Tabela 28

Comparação entre as medianas para estudantes e professores nos Blocos 1, 2, 3 e 4

\begin{tabular}{|c|c|c|c|c|c|}
\hline \multicolumn{2}{|c|}{ GRUPO } & BLOCO 1 & BLOCO 2 & BLOCO 3 & BLOCO 4 \\
\hline \multirow[t]{2}{*}{ Estudantes } & $\mathrm{N}$ & 191 & 191 & 191 & 191 \\
\hline & Mediana & 1,00 & 5,00 & 4,00 & 3,00 \\
\hline \multirow[t]{2}{*}{ Professores } & $\mathrm{N}$ & 28 & 28 & 28 & 28 \\
\hline & Mediana & $-1,00$ & 5,50 & 8,50 & 4,50 \\
\hline \multirow[t]{2}{*}{ Total } & $\mathrm{N}$ & 219 & 219 & 219 & 219 \\
\hline & Mediana & 1,00 & 5,00 & 4,00 & 3,00 \\
\hline
\end{tabular}

Nos Blocos 1, 3 e 4, o teste de Kruskal-Wallis indicou diferenças significativas entre professores e estudantes. Para o Bloco 2, cenários de práticas, a diferença entre os dois grupos não foi estatisticamente significante. A Tabela 29 apresenta o resultado comparativo entre professores e estudantes para as quatro dimensões estudadas, assim como os valores de p e do teste Kruskall Wallis.

\section{Tabela 29}

Comparação dos resultados entre professores e estudantes para as quatro dimensões estudadas.

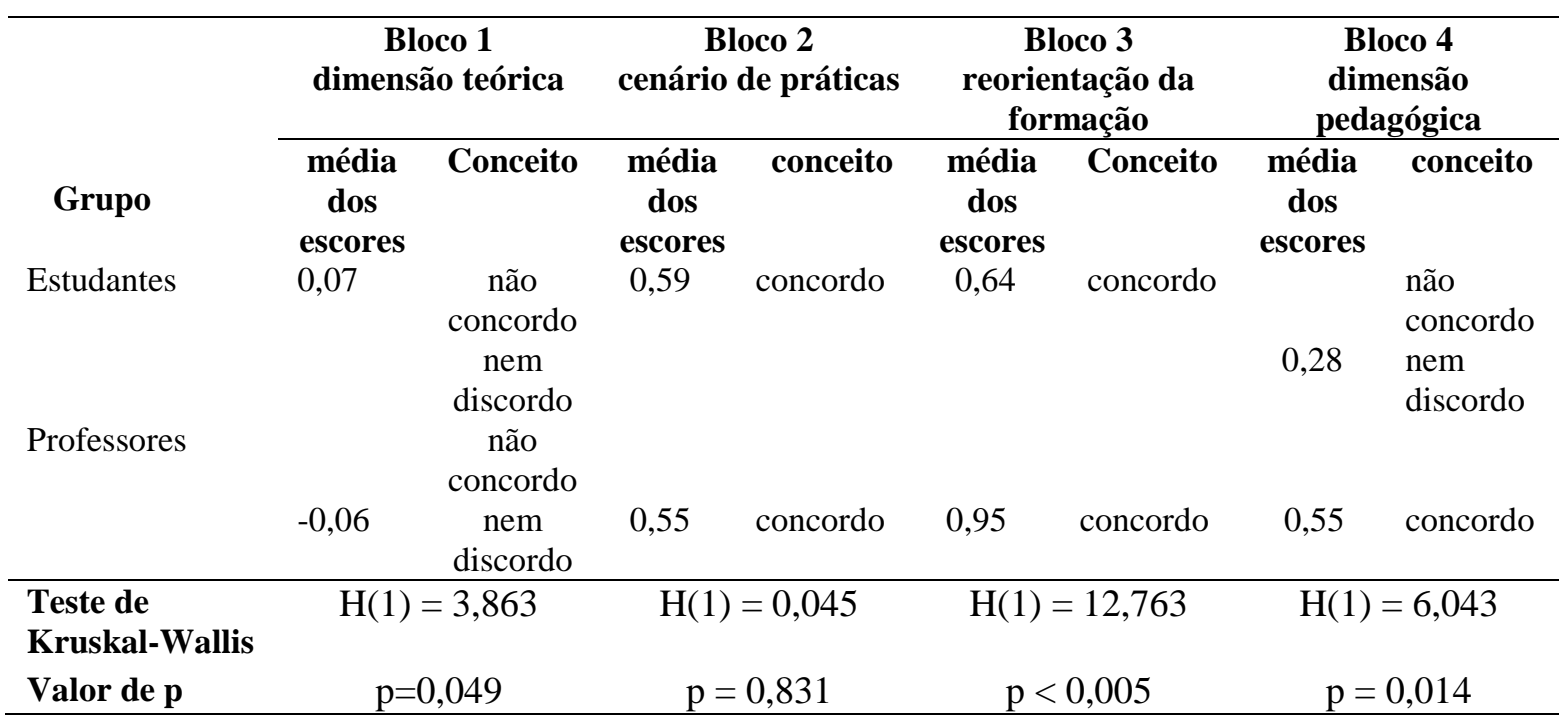




\section{Análise de conteúdo das entrevistas}

Um total de oito estudantes e oito professores do curso de graduação de Odontologia foram entrevistados. Norteadas pela temática reorientação da formação, e possuindo como elemento de análise o Pró-Saúde, as entrevistas geraram, pelo procedimento de caixa (Bardin, 2009) as seguintes categorias: perfil percebido; currículo; processo de ensino e aprendizagem; cenário de práticas e implementação das ações. A partir disso foi elaborado um modelo descritivo do processo de reorientação da formação, já apresentado na Figura 21.

A partir das categorias, foram estabelecidas subcategorias, e neste momento obtivemos algumas variações entre estudantes e professores. Unidades de registro de cada subcategoria estão representadas respectivamente, para estudantes e professores, nas Figuras 37 e 38. 


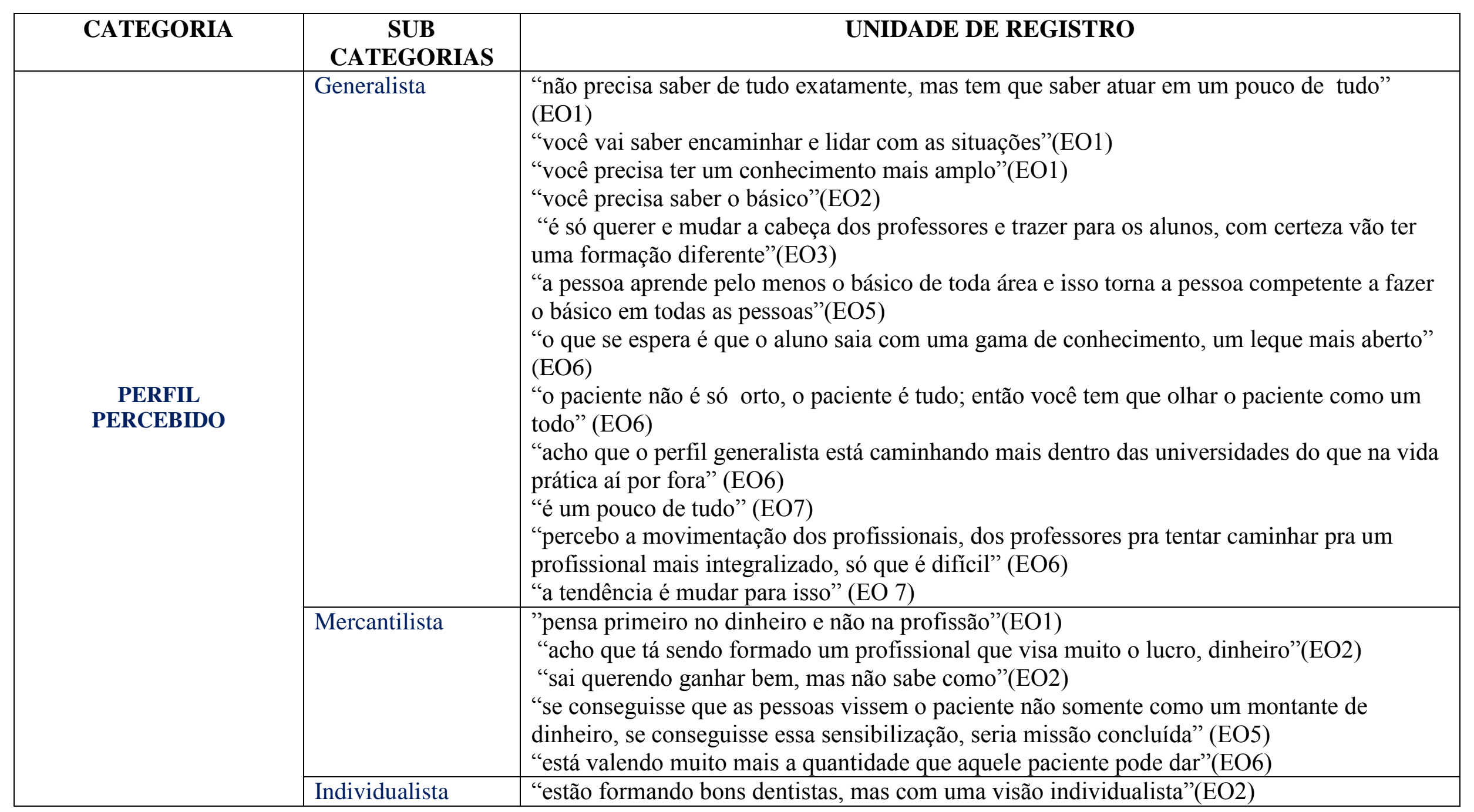




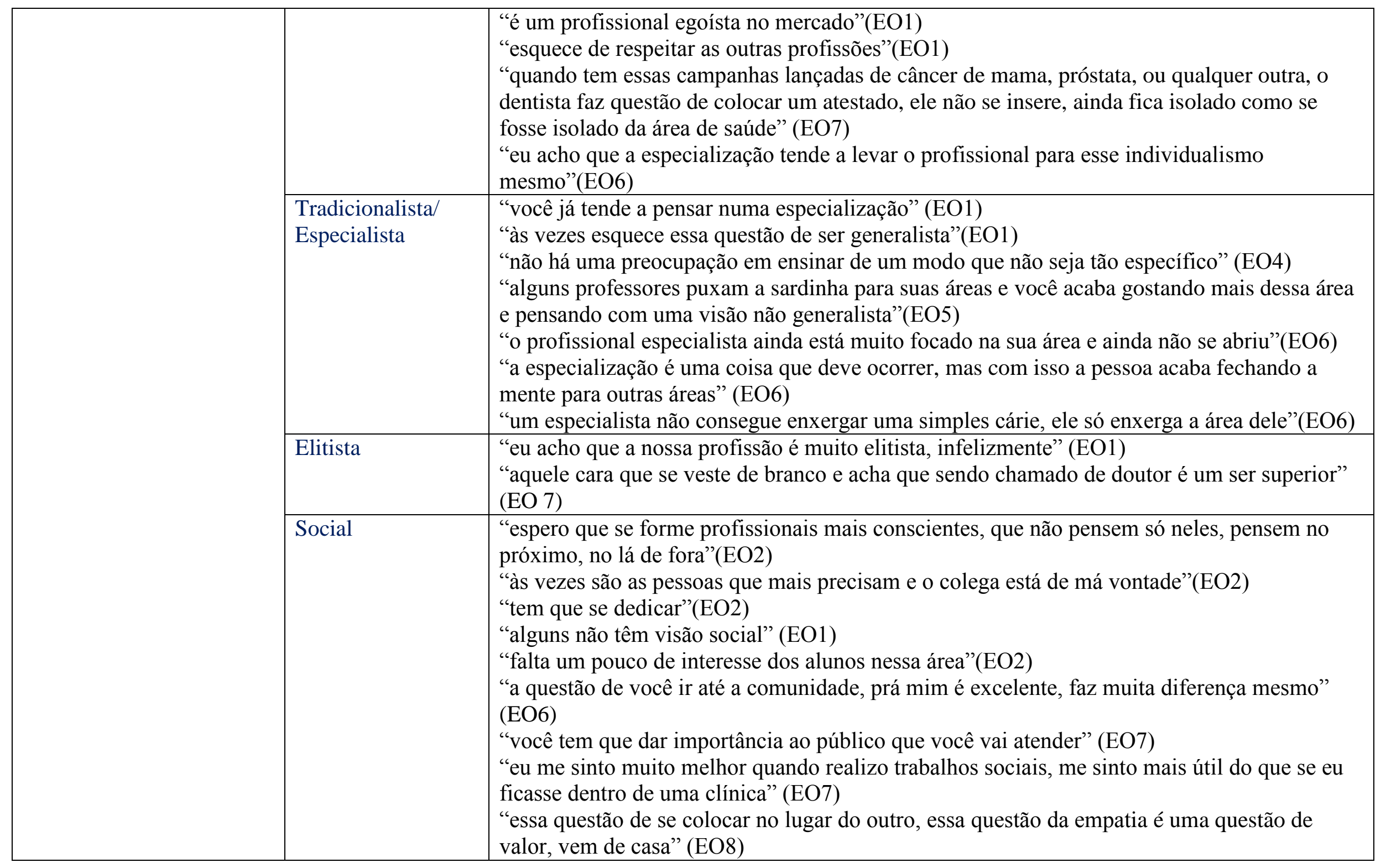




\begin{tabular}{|c|c|c|}
\hline \multirow{3}{*}{ CURRÍCULO } & Fragmentação & $\begin{array}{l}\text { "o geral é muito visto no começo e aí vai deixando de lado com o tempo"(EO2) } \\
\text { "nos semestres mais avançados você vai deixando as vertentes que adquiriu para trás"(EO1) } \\
\text { "você acaba se especializando no fim"(EO1) } \\
\text { "passam pra gente coisas fracionadas pra gente ter que montar depois"(EO6) } \\
\text { "ver a pessoa como um todo, eu só vi na saúde coletiva" (EO5) }\end{array}$ \\
\hline & $\begin{array}{l}\text { Integração entre } \\
\text { disciplinas do curso }\end{array}$ & $\begin{array}{l}\text { "acho que tinha que ter uma integração maior"(EO2) } \\
\text { "tem alguns professores que querem que a matéria seja muito independente, não tenha } \\
\text { relação com as outras" (EO1) } \\
\text { "eles não se conversam" (EO1) } \\
\text { "essa mudança de currículo tá favorecendo essa integração, mas eu ainda acho que tem coisa } \\
\text { que tá independente"(EO3) } \\
\text { "não houve uma aproximação maior entre as áreas" (EO1) } \\
\text { "a primeira coisa que nós alunos reclamamos muito é que muitos professores não sabem o } \\
\text { básico de cada área" (EO5) } \\
\text { "as áreas discutirem entre si, eu não vejo" (EO5) } \\
\text { "falta comunicação"(EO1) } \\
\text { "há um distanciamento"(EO6) } \\
\text { "professores não conversam, não falam a mesma língua"(EO4) } \\
\text { "os profissionais não estão se comunicando"(EO6) } \\
\text { "eu acho que há o propósito das disciplinas conversarem entre si, mas tá faltando" (EO 6) } \\
\text { "às vezes não há integração nem dentro da mesma disciplina”(EO4) } \\
\text { "eu não consigo fazer essa associação" (EO7) } \\
\text { "eu acho tem que trabalhar muito nessa questão da comunicação entre as disciplinas" (EO 6) } \\
\text { "acho que as matérias de saúde coletiva têm essa tendência, as nossas ideias ficam mais } \\
\text { coerentes com essa questão da integralização" (EO6) } \\
\text { "muitas vezes o professor não consegue integralizar a matéria dele com as outras"(EO6) } \\
\text { "eu não vejo muita integração entre as disciplinas da odontologia" (EO8) }\end{array}$ \\
\hline & $\begin{array}{l}\text { Integração entre } \\
\text { cursos }\end{array}$ & $\begin{array}{l}\text { "não houve uma aproximação maior" (EO1) } \\
\text { "eu não me sinto preparada para passar informações mais abrangentes, fora de minha } \\
\text { área"(EO2) } \\
\text { "no meu curso hoje vejo que não tem essa integração"(EO4) } \\
\text { "acho que todas as áreas da saúde são isoladas, não conversam"(EO6) }\end{array}$ \\
\hline
\end{tabular}




\begin{tabular}{|c|c|c|}
\hline & $\begin{array}{l}\text { Integração entre } \\
\text { curso e rede de } \\
\text { serviços }\end{array}$ & $\begin{array}{l}\text { "é uma coisa muito relevante"(EO8) } \\
\text { "muito gratificante"(EO2) } \\
\text { "poderia ter um pouco mais"(EO2) } \\
\text { "a unidade não aceita bem os alunos" (EO1) } \\
\text { "eles nos veem como um problema" (EO2) } \\
\text { "ali a gente está adquirindo conhecimento e auxiliando os dentistas que estão ali”(EO1) } \\
\text { "o professor tem que estar preparado com a equipe de saúde" (EO1) } \\
\text { "a integração com o Itapoã-Paranoá é muito fraca ainda, é muito pouco, e essa integração só } \\
\text { ocorre nas matérias de Saúde Coletiva. As outras matérias o campo é exclusivamente o } \\
\text { HUB" (EO5) } \\
\text { "aqui você vê coisas mais complexas, matérias que te levam prá conhecer e você faz } \\
\text { atendimento dá uma base do que é o SUS" (EO6) } \\
\text { "acontece muito mais em projetos do que em matérias" (EO6) } \\
\text { "do pouco contato que tive ajudou muito a questão da visão social" (EO5) }\end{array}$ \\
\hline \multirow[b]{3}{*}{$\begin{array}{c}\text { PROCESSO DE ENSINO } \\
\text { E APRENDIZAGEM }\end{array}$} & $\begin{array}{l}\text { Metodologias } \\
\text { tradicionais }\end{array}$ & $\begin{array}{l}\text { "na maioria slides"(EO2) } \\
\text { "há uma certa resistência por parte de alguns professores"(EO3) } \\
\text { "não com todos, mas para alguns você não tem o direito de errar, já ficam com aquela } \\
\text { cobrança" (EO7) } \\
\text { "continua sendo muito conservador" (EO8) } \\
\text { "alguns professores sabem muito, mas não conseguem passar aquilo"(EO4) } \\
\text { "eu acho muito conservadora" (EO7) } \\
\text { "o professor falando e você escutando" (EO6) } \\
\text { "predomina é aula expositiva, na teoria" (EO8) }\end{array}$ \\
\hline & $\begin{array}{l}\text { Metodologias } \\
\text { inovadoras }\end{array}$ & $\begin{array}{l}\text { "deveria ter a participação direta do aluno, não só do professor"(EO4) } \\
\text { "métodos diferenciados, que prendam mais a atenção do aluno, faz com que ele absorva mais } \\
\text { a informação" (EO6) } \\
\text { "talvez uma aula menos cansativa, falando menos e mostrando mais, a gente consiga } \\
\text { absorver mais" (EO4) }\end{array}$ \\
\hline & $\begin{array}{l}\text { Integração entre } \\
\text { teoria e prática }\end{array}$ & $\begin{array}{l}\text { "excesso de teoria" } \\
\text { "tem muita teoria no começo"(EO2) } \\
\text { "poderia ser mais uma mistura, um pouco teoria um pouco prática"(EO2) } \\
\text { "esse negócio de teoria-prática está interagindo, mas tem matérias que falta ainda"(EO4) }\end{array}$ \\
\hline
\end{tabular}




\begin{tabular}{|c|c|c|}
\hline & & $\begin{array}{l}\text { "atividade prática deveria vir depois da teoria na maioria delas"(EO5) } \\
\text { "a práticas às vezes foge um pouco da teoria"(EO1) } \\
\text { "é muito bom quando a teoria é casada com a prática"(EO4) } \\
\text { "dependendo da matéria, tem o paralelo da teoria com a prática, e nas outras tem essa } \\
\text { diferenciação de teoria e depois a prática"(EO5) } \\
\text { "ainda hoje predomina a teoria, a gente está muito na teoria ainda". (EO6) } \\
\text { "na teoria é lindo e na prática não é bem aquilo. Falta um pouco de integração teórico- } \\
\text { prática (EO8) }\end{array}$ \\
\hline & $\begin{array}{l}\text { Influência das } \\
\text { metodologias }\end{array}$ & $\begin{array}{l}\text { "as formas de ensinar influenciam bastante"(EO2) } \\
\text { "são de acordo com a formação que o professor teve" (EO4) } \\
\text { "se você tem um professor que tem uma metodologia cansativa, que parece que ao assunto é } \\
\text { desinteressante, você acaba também achando que é desinteressante" (EO7) }\end{array}$ \\
\hline \multirow[t]{3}{*}{ CENÁRIO DE PRÁTICAS } & Clínicas & $\begin{array}{l}\text { "falta professor"(EO2) } \\
\text { "o tempo é curto"(EO2) } \\
\text { "falta triar mais paciente"(EO3) } \\
\text { "a demanda é gigantesca, e às vezes não tem paciente"(EO3) } \\
\text { "eu vejo que a quantidade de professores, ou monitores, ou auxiliares não tem sido } \\
\text { suficientes"(EO7) } \\
\text { "a gente tá restringindo demais as pessoas que podem vir aqui. Agora essa questão de cada } \\
\text { universidade tem um local” (EO6) } \\
\text { "precisa aumentar as práticas e a quantidade de professores" (EO6) } \\
\text { "precisamos ter mais clínicas" (EO8) }\end{array}$ \\
\hline & Rede de serviços & $\begin{array}{l}\text { "deveriam ser um pouco mais organizadas" (EO2) } \\
\text { "muito desorganizado"(EO1) } \\
\text { "muitas falhas"(EO1) } \\
\text { "as saídas de campo são muito boas"(EO2) } \\
\text { "parece que alguns pensam que é uma área secundária"(EO2) } \\
\text { "a teoria tá mostrando a importância e a gente tá indo e vendo realmente como é" } \\
\text { "no começo a gente fica um pouco perdido, mas acho que esse contato é importante"(EO3) } \\
\text { "eu acho que se continuar dessa forma a tendência é melhorar" (EO7) }\end{array}$ \\
\hline & Divulgação & “já ouvi falar, mas não conheço"(EO2) \\
\hline
\end{tabular}




\begin{tabular}{|c|c|c|}
\hline \multirow{4}{*}{$\begin{array}{l}\text { IMPLEMENTAÇÃO } \\
\text { DAS AÇÕES }\end{array}$} & & $\begin{array}{l}\text { “acho que poderia ter uma divulgação maior”(EO2) } \\
\text { "os alunos não estão sabendo”(EO2) } \\
\text { "tem colega meu que nem sabe como funciona”(EO3) }\end{array}$ \\
\hline & Envolvimento & $\begin{array}{l}\text { "falta vivência deles (professores) na comunidade" (EO1) } \\
\text { "acho que muitas pessoas estão interessadas"(EO2) } \\
\text { "não só ele (Pró-Saúde) está tímido, mas acho que a aceitação dele..." (EO4) } \\
\text { "tem muita gente interessada" } \\
\text { "não tem muita gente"(EO2) } \\
\text { "no nosso curso não teve muita participação" (EO7) } \\
\text { "trouxe vivência apenas para aqueles que participaram"(EO8) }\end{array}$ \\
\hline & $\begin{array}{l}\text { Conflitos de } \\
\text { interesse }\end{array}$ & $\begin{array}{l}\text { "o professor só quer atuar na área dele" } \\
\text { "cortaram o projeto que eu estava porque não estava escrito no Pró-Saúde, eu fiquei } \\
\text { frustrado"(EO1) } \\
\text { "acho que peca na demanda, às vezes o que quero fazer não é o que a sociedade } \\
\text { precisa"(EO1) } \\
\text { "eu achei que a gente ia promover saúde como um todo"(EO1) } \\
\text { "acho que o Pró-Saúde pecou nisso, pois quando entrei pensei que fosse aprender outras } \\
\text { áreas e aplicar o que sei em outras coisas"(EO1) } \\
\text { "achei que pessoas do mesmo curso do tutor tinham mais privilégios do que nós"(EO1) } \\
\text { "acho que a maioria das pessoas está ali, não pelo conhecimento nem nada; estão meramente } \\
\text { pelo financeiro que o Pró-Saúde proporciona"(EO1) }\end{array}$ \\
\hline & Barreiras & $\begin{array}{l}\text { "eu fiquei meio na resistência, porque queria muito"(EO1) } \\
\text { "falhou no recurso que não veio" (EO1) } \\
\text { "colocar como uma coisa obrigatória geram pessoas que estão ali apenas porque } \\
\text { precisam"(EO2) } \\
\text { "por mais que se tenha ferramentas, se a pessoa não tiver vontade de mudar, ela não vai } \\
\text { mudar"(EO7) } \\
\text { "se você não consegue sensibilizar, as pessoas não vão mudar" (EO7) }\end{array}$ \\
\hline
\end{tabular}

Figura 37 - Unidades de registro das subcategorias obtidas na análise de conteúdo das entrevistas dos estudantes de Odontologia 


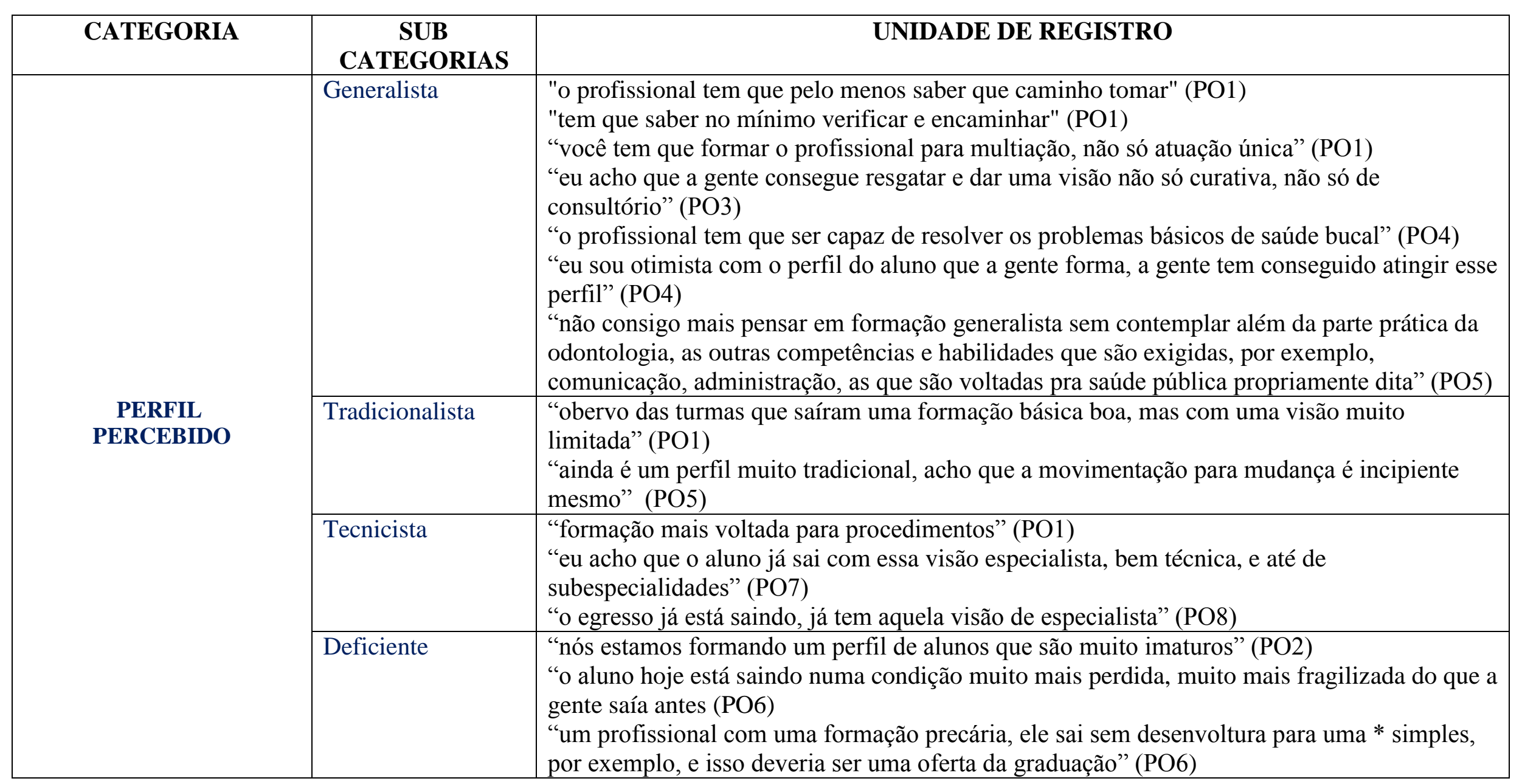




\begin{tabular}{|c|c|c|}
\hline & Privativista & $\begin{array}{l}\text { "acho que essa visão é muito forte para o aluno ainda" (PO3) } \\
\text { "a gente tem que formar o profissional para atuar nessas áreas, na iniciativa privada" (PO4) }\end{array}$ \\
\hline \multirow{3}{*}{ CURRÍCULO } & Transição & $\begin{array}{l}\text { "a gente vive um projeto pedagógico novo, precisa evoluir em cima das tentativas" (PO1) } \\
\text { "há uma inquietação geral" (PO1) } \\
\text { "o Pró-Saúde fez com que o curso corresse atrás dessa mudança, foi um dos estopins para } \\
\text { que houvesse mudança curricular" (PO1) } \\
\text { "os tempos mudaram e a gente precisa acompanhar isso; não adianta ser formador de uma } \\
\text { excelente restaurador de dente, mas péssimo profissional humanístico" (PO1) } \\
\text { "estamos numa fase de transição, onde estamos tentando consertar os buracos que foram } \\
\text { deixados" (PO1) } \\
\text { "a gente está passando por uma reforma curricular no curso, uma reestruturação (PO4) } \\
\text { "ele está sendo discutido, mas a reforma propriamente dita não se iniciou” (PO5) } \\
\text { "a gente tá saindo de um contexto que era modular, nucleado, pra um contexto mais integral. } \\
\text { Só que essa integralização não está acontecendo dentro de um modelo satisfatório" (PO6) }\end{array}$ \\
\hline & Resistência & $\begin{array}{l}\text { "muitas barreiras estão no corpo docente, algumas visões mais tradicionais, que são avessas a } \\
\text { mudanças" (PO1) } \\
\text { "é difícil sair da zona de conforto" (PO1) } \\
\text { 'acho que a gente tem uma grande vantagem, mas os professores de odontologia não } \\
\text { conseguem enxergar isso. A concepção desta universidade, quando Darcy Ribeiro criou, foi } \\
\text { com o princípio de atender as demandas da sociedade" (PO3) } \\
\text { "caminha com o esforço de um pequeno grupo de professores que entendem esse processo" } \\
\text { (PO3) } \\
\text { "a gente tem um corpo docente muito tradicional e imagino que essa realidade não é dó da } \\
\text { odontologia" (PO5) } \\
\text { "a gente ainda tem um corpo docente com uma percepção muito mais nucleada do que } \\
\text { integral" (PO6) }\end{array}$ \\
\hline & Grupo de discussão & $\begin{array}{l}\text { "foi montado um núcleo docente estruturante pra discutir sobre os problemas dos conteúdos } \\
\text { do ensino" (PO2) } \\
\text { "existe um núcleo docente estruturante, que é um grupo dentro do departamento, aonde se } \\
\text { trabalha essa problemática, de buscar as soluções e buscar entender onde estão os nós do } \\
\text { curso e buscar diminuir esses problemas" (PO4) }\end{array}$ \\
\hline
\end{tabular}




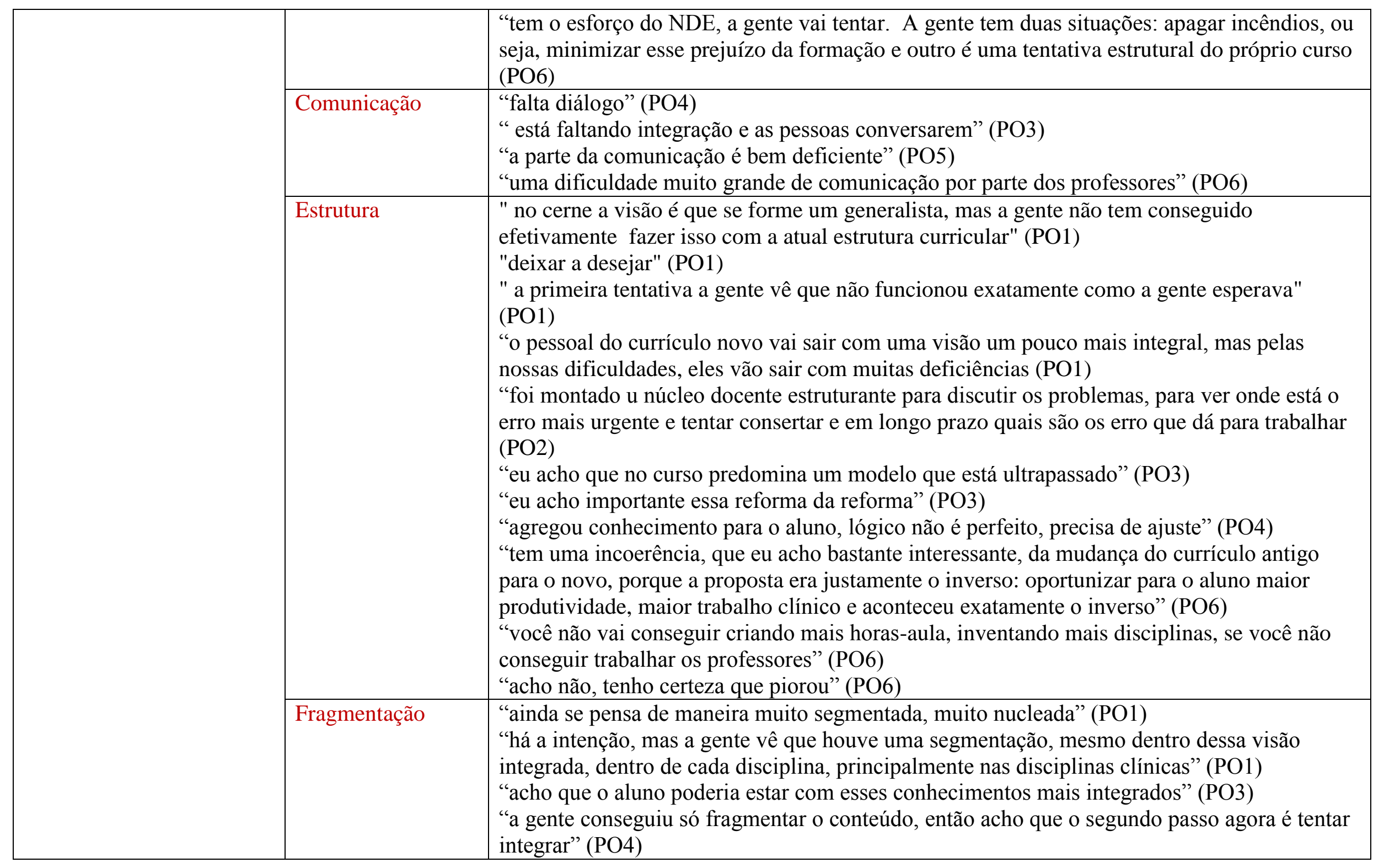




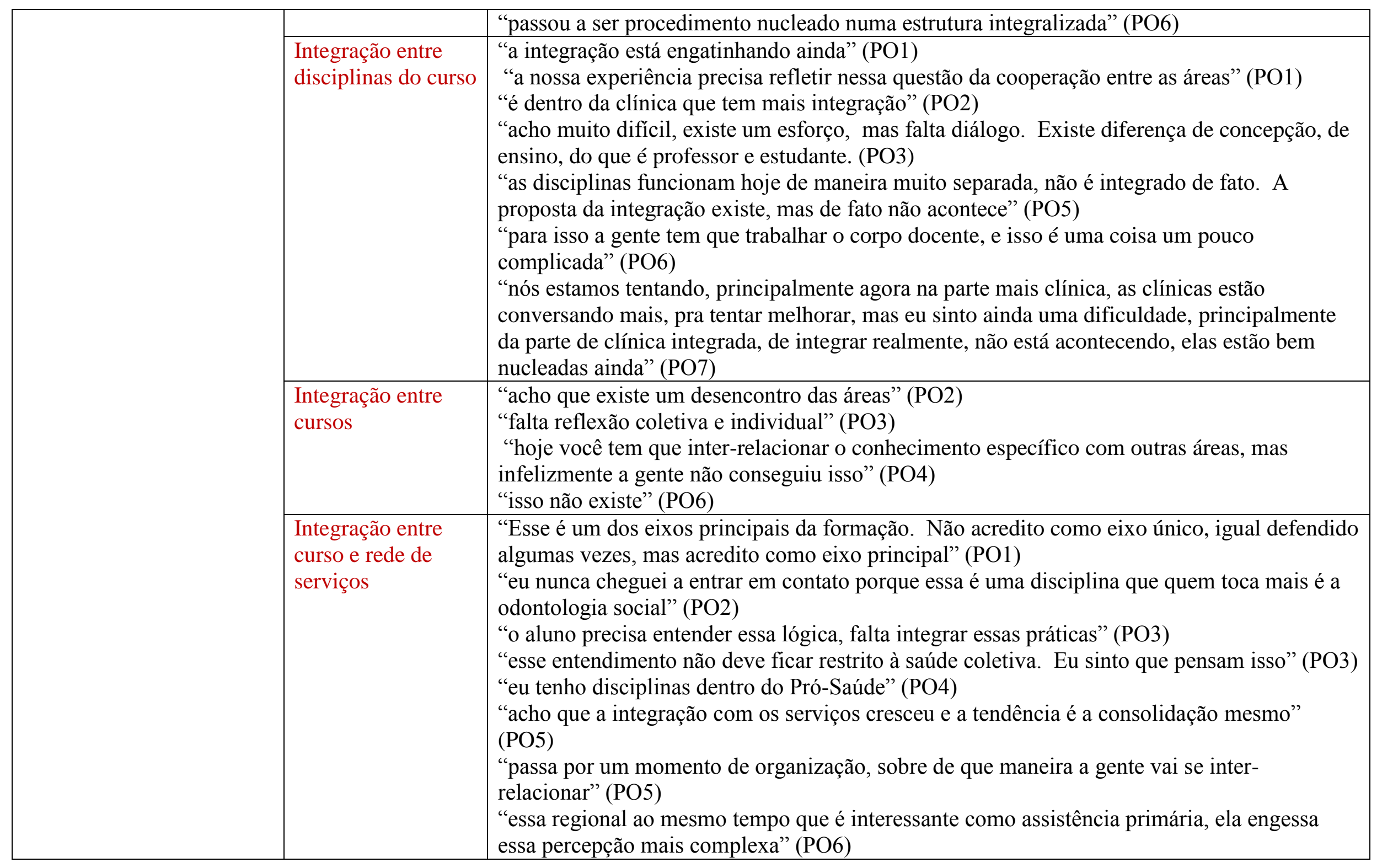




\begin{tabular}{|c|c|c|}
\hline \multirow{4}{*}{$\begin{array}{l}\text { PROCESSO DE ENSINO } \\
\text { E APRENDIZAGEM }\end{array}$} & $\begin{array}{l}\text { Lacuna de } \\
\text { formação }\end{array}$ & $\begin{array}{l}\text { "infelizmente a gente aprendeu mais na prática do que na nossa formação como professor" } \\
\text { (PO1) } \\
\text { "existe uma tentativa, mas em todas as áreas tem uma deficiência porque nós professores, na } \\
\text { maioria não tivemos essa formação" (PO1) } \\
\text { "essa integração é difícil porque nós professores formos formados no modelo antigo" (PO4) } \\
\text { "não é culpa dos professores, na verdade é questão de formação" (PO6) } \\
\text { "o professor foi formado dentro de um princípio modular e nucleado, e de repente é jogado } \\
\text { para você um processo de integralização sem que as condições de infra-estrutura estejam } \\
\text { voltadas pra isso, aí acontece um choque" (PO6) } \\
\text { "enquanto você não tiver professores que tenham uma formação e uma visão mais ampla, } \\
\text { esse modelo nunca vai funcionar" (PO6) } \\
\text { "a visão de especialistas está muito arraigada na formação, desde a nossa formação já era } \\
\text { cultural" (PO8) }\end{array}$ \\
\hline & Perfil do estudante & $\begin{array}{l}\text { "hoje o aluno é diferente, você manter a atenção do aluno, para manter entusiasmo, interesse, } \\
\text { hoje o público é diferente" (PO4) }\end{array}$ \\
\hline & $\begin{array}{l}\text { Integração entre } \\
\text { teoria e prática }\end{array}$ & $\begin{array}{l}\text { "eu vejo que a educação começa desde cedo, e a cabeça deles (alunos) na verdade nunca foi } \\
\text { moldada para integrar coisas" (PO2) } \\
\text { "na nossa disciplina a gente tem tentado através de atividades práticas, mistas com atividades } \\
\text { teóricas, diminuindo assim a duração da aula teórica" (PO4) }\end{array}$ \\
\hline & $\begin{array}{l}\text { Metodologias } \\
\text { inovadoras }\end{array}$ & $\begin{array}{l}\text { "a diversidade de metodologias, às vezes não ficar em uma única, você ganha quando você } \\
\text { faz uma mescla dessas metodologias" (PO1) } \\
\text { "a gente pode trabalhar determinadas disciplinas com a problematização" (PO1) } \\
\text { "tem que ter a visão crítica para mesclar essas metodologias" (PO1) } \\
\text { "o jeito de ser ministrado o conteúdo se tornou diferente" (PO2) } \\
\text { "a gente ainda está engatinhando, depois tem que discutir práticas pedagógicas, vai ser mais } \\
\text { difícil para discutir, é prá um segundo momento" (PO3) } \\
\text { "eu acho que buscar novas estratégias, novos métodos" (PO4) } \\
\text { "a gente tem buscado outra didática, por exemplo, o portfólio, vídeos de curta duração e que } \\
\text { sejam elucidativos para determinados temas" (PO4) } \\
\text { "a gente tem busca algumas ferramentas e tem observado que o aluno fica mais interessado, o } \\
\text { conteúdo fica mais consolidado" (PO4) } \\
\text { "eu vejo esforços pontuais de alguns professores que tentam se reinventar e trazer para a sala }\end{array}$ \\
\hline
\end{tabular}




\begin{tabular}{|c|c|c|}
\hline & & $\begin{array}{l}\text { de aula" (PO5) } \\
\text { "metodologias ativas são bem individuais mesmo. É uma iniciativa particular de alguns } \\
\text { professores" (PO5) } \\
\text { "acho que exige na verdade um início de uma discussão" (PO5) } \\
\text { "a gente até está tentando, como os alunos hoje tem uma agilidade de informação muito } \\
\text { rápida, a gente tenta um pouco diversificar" (PO7) }\end{array}$ \\
\hline & $\begin{array}{l}\text { Metodologias } \\
\text { tradicionais }\end{array}$ & $\begin{array}{l}\text { "acho que ainda predomina um pouco do ensino tradicional, do eu mostrei, demonstrei, então } \\
\text { você entendeu" (PO1) } \\
\text { "a aula nem é expositiva dialogada. É aula expositiva. Apresentam os slides, todos ficam ou } \\
\text { aceitando ou dormindo" (PO3) } \\
\text { "conversando com colegas ali, e dizendo - eu fiz uma aula linda, com } 400 \text { slides - que coisa } \\
\text { chata...você não ensinou nada, essa aula é linda mas não serviu prá nada" (PO3) } \\
\text { "se a gente continuar com aulas expositivas apenas, teóricas, de } 4 \text { horas, isso afasta o aluno" } \\
\text { (PO4) } \\
\text { "predomina aulas expositivas" (PO4) } \\
\text { "é exatamente expositiva. É o professor dando aula para o aluno: vocês fiquem quietos que } \\
\text { eu estou falando, ultra-tradicional mesmo" (PO5) } \\
\text { "predomina ainda a aula expositiva" (PO7) }\end{array}$ \\
\hline
\end{tabular}




\begin{tabular}{|c|c|c|}
\hline & Rede de serviços & $\begin{array}{l}\text { "é somatório na formação do aluno" (PO1) } \\
\text { "essa integração tem que ser ampliada, pois acaba que o paciente que ele atende aqui a } \\
\text { realidade é um pouco enviesada, você tem que ter ampliação para o alunos estar aqui, na } \\
\text { atenção primária, no Itapoã, na ESF, visitando casas" (PO3) } \\
\text { "é importante eles estarem lá e criar um sistema de referência e contra-referência, e tentar } \\
\text { organizar os fluxos. Não tem essa organização" (PO3) } \\
\text { "existe um interesse muito grande em todos os cenários que estivemos, mas ainda o espaço } \\
\text { físico é muito pequeno" (PO4) } \\
\text { "não está havendo um processo de comunicação estabelecido nessa relação de referência" } \\
\text { (PO6) } \\
\text { "é muito positivo a vivência do aluno com a vida real, porque por mais que eles vejam as } \\
\text { dificuldades dos pacientes com dificuldade financeira, lá é o dia-a-dia, é o que é verdade" } \\
\text { (PO7) }\end{array}$ \\
\hline $\begin{array}{l}\text { IMPLEMENTAÇÃO } \\
\text { DAS } \\
\text { AÇÕES }\end{array}$ & Divulgação & $\begin{array}{l}\text { "se o pró-saúde fosse tão abrangente, já teria me atingido.” (PO2) } \\
\text { "acho que entre os alunos foi até boa a disseminação, mas entre os professores, às vezes } \\
\text { pensam que o Pró-Saúde está entre essas entidades específicas" (PO3) } \\
\text { "falta comunicação, divulgação" (PO6) }\end{array}$ \\
\hline
\end{tabular}




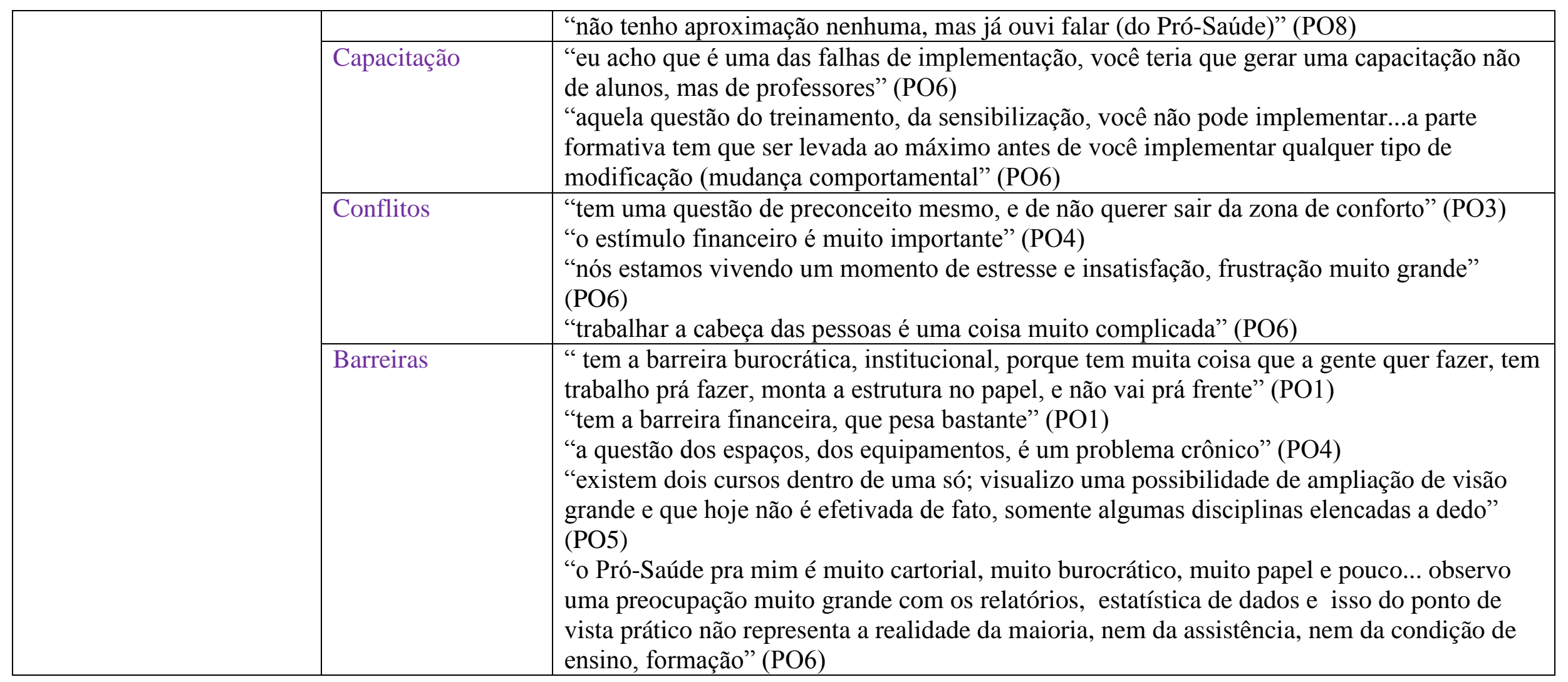

Figura 38 - Unidades de registro das subcategorias obtidas na análise de conteúdo das entrevistas dos professores de Odontologia 


\section{Apêndice B}

\section{ESTUDO 2 - ENFERMAGEM}

\section{Análise descritiva dos dados coletados dos estudantes na Seção 1 - dados sociodemográficos e acadêmicos}

Os aspectos sociodemográficos e acadêmicos dos estudantes do curso de Enfermagem incluídos neste estudo foram obtidos a partir das respostas dadas pelos participantes na Seção 1 do instrumento.

No primeiro semestre de 2014, período em que se realizou a coleta de dados, havia estudantes matriculados do primeiro ao nono período, devido ao momento de transição de proposta curricular do curso. Do total de 269 estudantes regularmente matriculados, 207 aceitaram fazer parte da pesquisa. A Figura 39 apresenta a distribuição por semestre dos participantes.

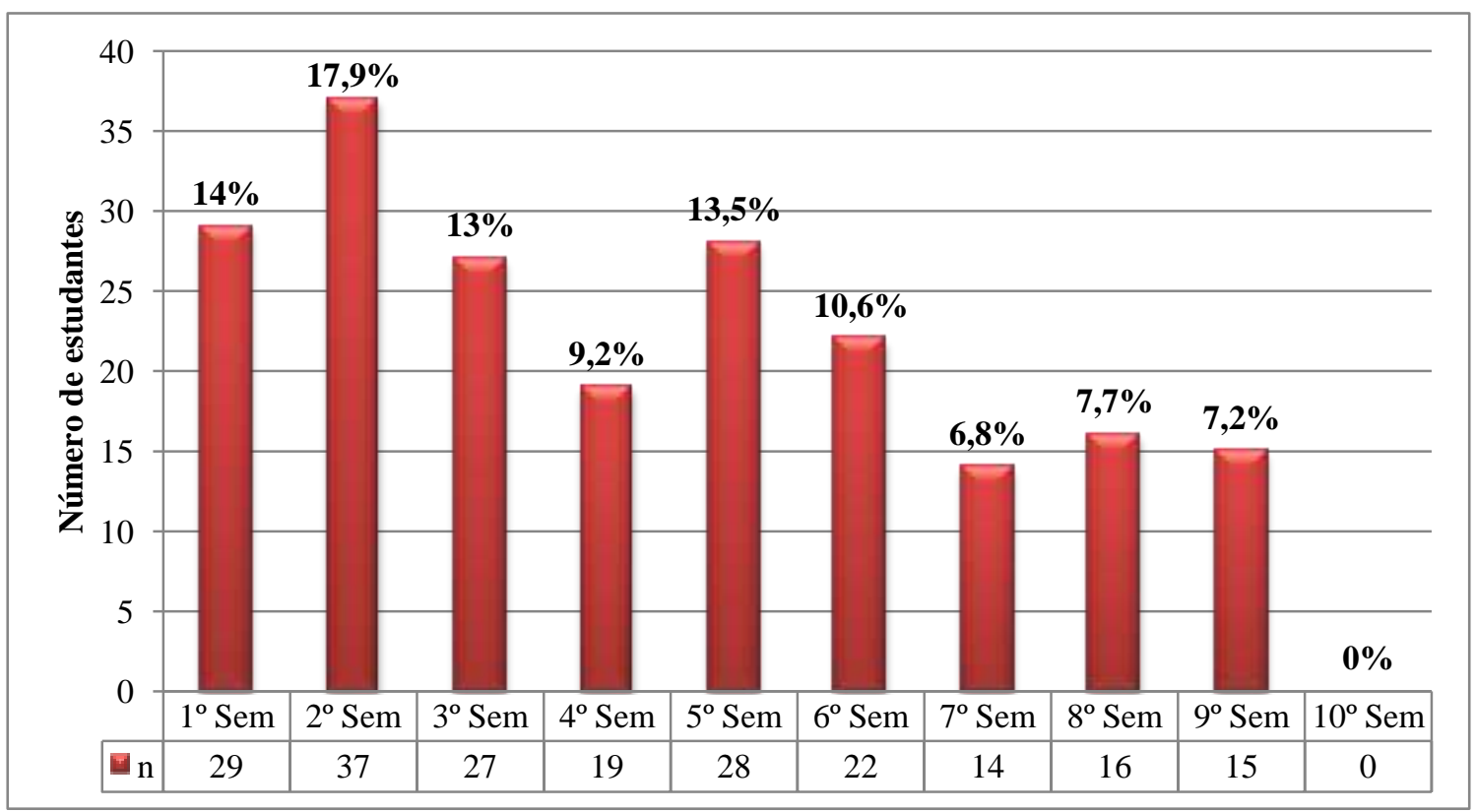

Figura 39. Distribuição percentual dos acadêmicos de Enfermagem, por semestre, que responderam o instrumento. 
A distribuição de acordo com sexo dos incluídos no estudo demonstrou que o curso é formado majoritariamente por discentes do sexo feminino (89\%). Em relação à faixa etária, observou-se que $46 \%$ dos mesmos encontram-se na faixa etária compreendida entre 21 e 25 anos, seguido de $43 \%$ dos estudantes na faixa etária dos 16 aos 20 anos. Os dados relacionados às variáveis sexo e faixa etária por período do curso estão apresentados na Tabela 30. 


\section{Tabela 30}

Caracterização dos acadêmicos de Enfermagem quanto aos dados sócio-demográficos sexo e faixa etária.

\begin{tabular}{|c|c|c|c|c|c|c|c|c|c|c|c|c|c|c|c|c|}
\hline \multirow[b]{3}{*}{ Período } & \multicolumn{4}{|c|}{ Sexo } & \multicolumn{12}{|c|}{ Faixa etária } \\
\hline & \multicolumn{2}{|c|}{ Feminino } & \multicolumn{2}{|c|}{ Masculino } & \multicolumn{2}{|c|}{ Total } & \multicolumn{2}{|c|}{16 a 20 anos } & \multicolumn{2}{|c|}{21 a 25 anos } & \multicolumn{2}{|c|}{26 a 30 anos } & \multicolumn{2}{|c|}{$\begin{array}{c}31 \text { anos ou } \\
\text { mais }\end{array}$} & \multicolumn{2}{|c|}{ Total } \\
\hline & $\mathbf{n}$ & $\%$ & $\mathbf{n}$ & $\%$ & $\mathbf{n}$ & $\%$ & $\mathbf{n}$ & $\%$ & $\mathbf{n}$ & $\%$ & $\mathbf{n}$ & $\%$ & $\mathbf{n}$ & $\%$ & $\mathbf{n}$ & $\%$ \\
\hline 1 & 22 & $75,86 \%$ & 6 & $20,68 \%$ & 28 & $100 \%$ & 21 & $72,41 \%$ & 8 & $27,58 \% \%$ & 0 & $0,0 \%$ & 0 & $0,0 \%$ & 29 & $100 \%$ \\
\hline 2 & 32 & $86,48 \%$ & 5 & $13,51 \%$ & 37 & $100 \%$ & 27 & $75,0 \%$ & 8 & $22,22 \%$ & 0 & $0,0 \%$ & 1 & $2,77 \%$ & 36 & $100 \%$ \\
\hline 3 & 25 & $92,59 \%$ & 2 & $7,4 \%$ & 27 & $100 \%$ & 15 & $57,69 \%$ & 9 & $34,61 \%$ & 2 & $7,69 \%$ & 0 & $0,0 \%$ & 26 & $100 \%$ \\
\hline 4 & 17 & $89,47 \%$ & 2 & $10,52 \%$ & 19 & $100 \%$ & 7 & $38,88 \%$ & 9 & $50,0 \%$ & 1 & $5,55 \%$ & 1 & $5,55 \%$ & 18 & $100 \%$ \\
\hline 5 & 26 & $92,85 \%$ & 2 & $7,14 \%$ & 28 & $100 \%$ & 9 & $32,14 \%$ & 16 & $57,14 \%$ & 3 & $10,71 \%$ & 0 & $0,0 \%$ & 28 & $100 \%$ \\
\hline 6 & 22 & $100 \%$ & 0 & $0,0 \%$ & 22 & $100 \%$ & 7 & $31,81 \%$ & 13 & $59,09 \%$ & 1 & $4,54 \%$ & 1 & $4,54 \%$ & 22 & $100 \%$ \\
\hline 7 & 14 & $100 \%$ & 0 & $0,0 \%$ & 14 & $100 \%$ & 2 & $14,28 \%$ & 9 & $64,28 \%$ & 1 & $7,14 \%$ & 2 & $14,28 \%$ & 14 & $100 \%$ \\
\hline 8 & 13 & $81,25 \%$ & 3 & $18,75 \%$ & 16 & $100 \%$ & 1 & $6,25 \%$ & 12 & $75,0 \%$ & 3 & $18,75 \%$ & 0 & $0,0 \%$ & 16 & $100 \%$ \\
\hline 9 & 14 & $93,33 \%$ & 1 & $6,66 \%$ & 15 & $100 \%$ & 0 & $0,0 \%$ & 10 & $66,66 \%$ & 2 & $13,33 \%$ & 3 & $20,0 \%$ & 15 & $100 \%$ \\
\hline Total & 185 & $89,37 \%$ & 21 & $10,14 \%$ & 206 & $100 \%$ & 89 & $43,62 \%$ & 94 & $46,07 \%$ & 13 & $6,37 \%$ & 8 & $3,92 \%$ & 204 & $100 \%$ \\
\hline
\end{tabular}


Em relação ao item sobre formação anterior, conforme ilustra a Figura 40, 4,8\% dos estudantes já são graduados em outras áreas, sendo que 1,9\% desses possuem graduação em Ciências da Saúde. A maioria dos estudantes, $(95,2 \%)$ não fez outra graduação antes da cursada atualmente.

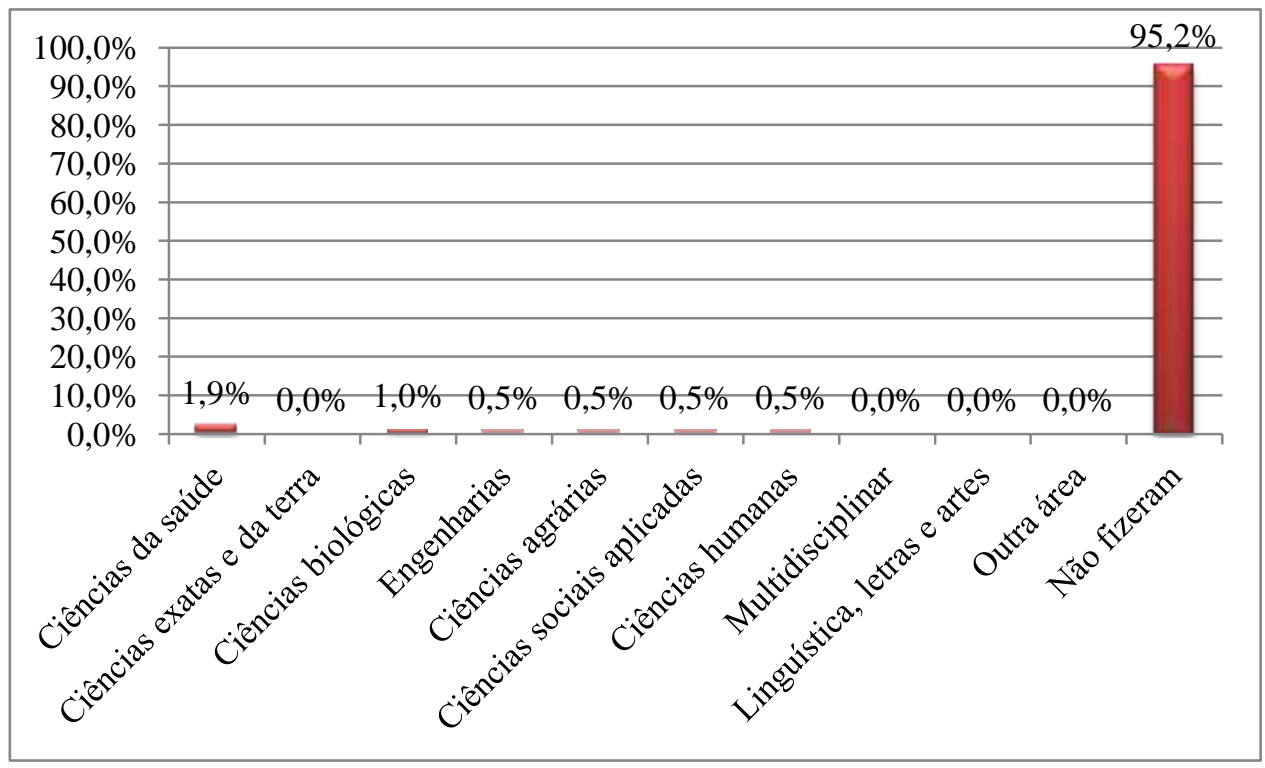

Figura 40. Distribuição percentual dos acadêmicos, segundo graduação concluída em outras áreas.

Em relação às atividades acadêmicas que atualmente participam na universidade, o Programa Pró-Saúde obteve um percentual de 11,6\% estudantes. Projeto de extensão foi a atividade que obteve o maior percentual de estudantes participantes, representando $32,9 \%$ do total. Em relação a projeto de iniciação científica, 18,8\% dos estudantes estão inclusos no mesmo, seguidos de $14 \%$ que participam de projeto de monitoria. É importante ressaltar que os alunos entrevistados podiam escolher mais de uma opção na questão, não sendo a participação nos projetos necessariamente exclusiva.

Em relação à questão "Você conhece o Programa Pró-Saúde?" (item 7 da Seção 1 do instrumento), opostamente ao resultado obtido no Estudo 1, mais da metade dos estudantes 
afirmaram que conhecer o Programa, totalizando 62,4\% dos acadêmicos. Apenas $1 \%$ dos participantes não responderam este item.

Do total de acadêmicos incluídos no estudo, $82,9 \%$ deles não são ou não foram bolsistas do Programa Pró-Saúde, enquanto 16,6\% afirmaram ser ou terem sido anteriormente bolsista do Programa. Esses dados estão representados na Figura 41.

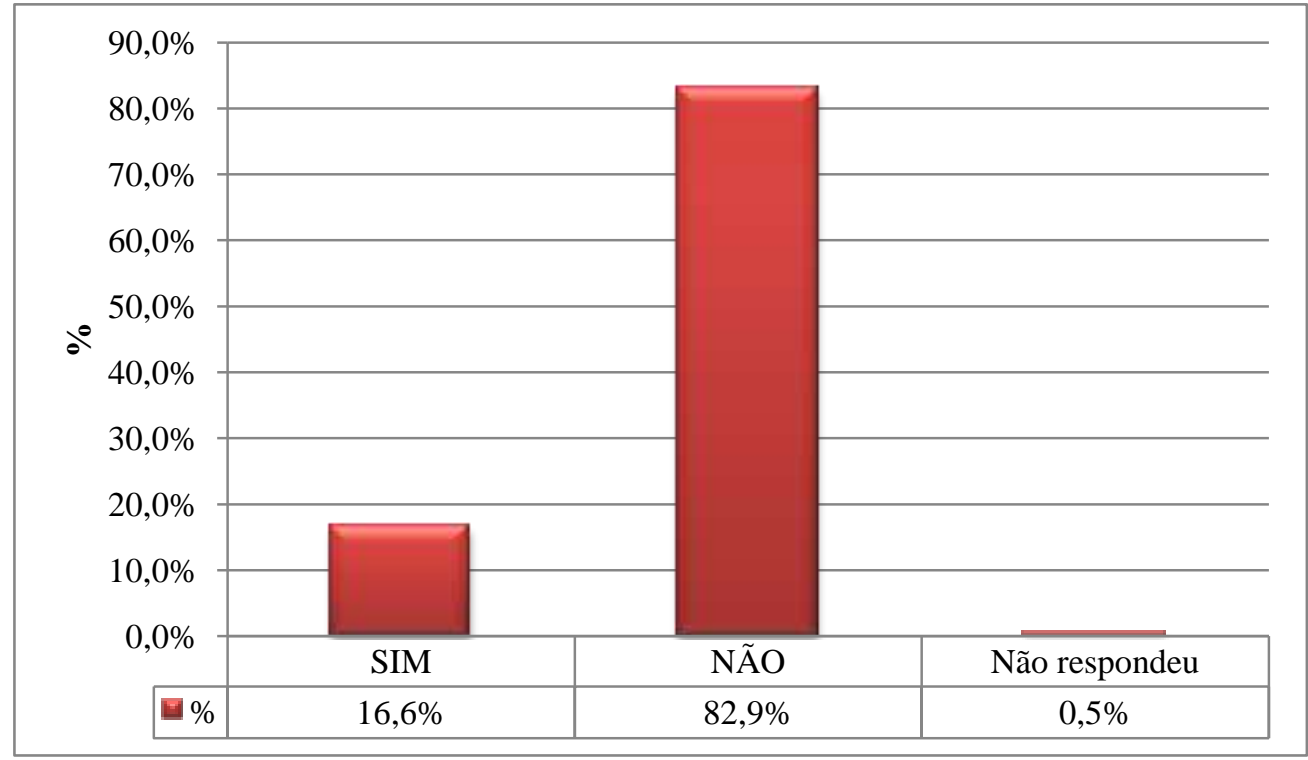

Figura 41. Distribuição percentual dos acadêmicos bolsistas pelo Pró-Saúde.

Dentre os participantes do Programa Pró-Saúde como bolsista, observou-se que a maioria participa do mesmo há mais de 12 meses. Os resultados obtidos neste item estão representados na Figura 42. 


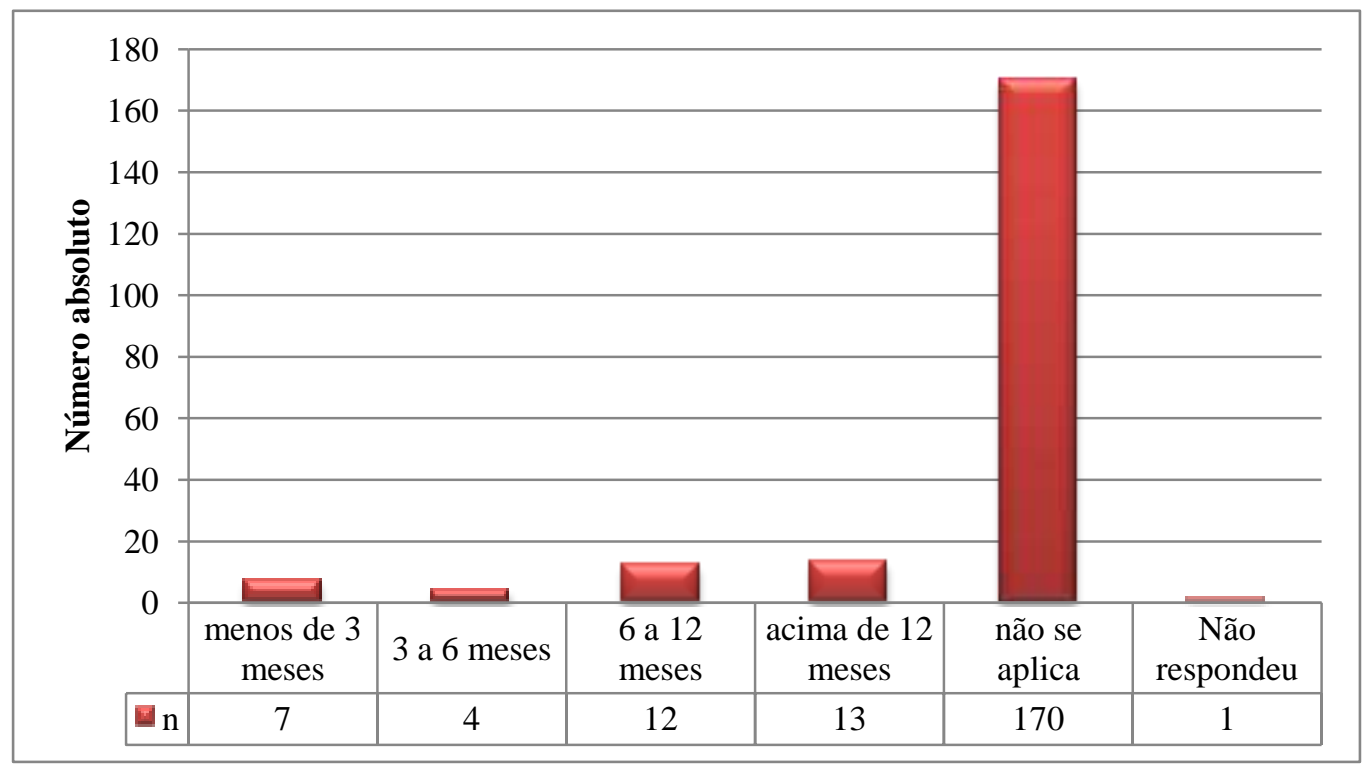

Figura 42. Distribuição dos acadêmicos em números absolutos em relação ao tempo de participação no Pró-Saúde

O resumo do perfil sociodemográfico e acadêmico dos estudantes de Enfermagem participantes do estudo encontram-se apresentados na Tabela 31.

\section{Tabela 31}

Perfil sociodemográfico e acadêmico dos estudantes de Enfermagem participantes do estudo.

\begin{tabular}{lccc}
\hline & Variáveis & $\mathbf{N}$ & $\%$ \\
\hline Idade & & \\
De 16 a 20 anos & 88 & $43,1 \%$ \\
De 21 a 25 anos & 94 & $46,1 \%$ \\
De 26 a 30 anos & 14 & $6,9 \%$ \\
Mais de 30 anos & 8 & $3,9 \%$
\end{tabular}

\section{Sexo}

Masculino

$21 \quad 10,2 \%$

Feminino

Graduação em outras áreas

Sim

$10 \quad 4,80 \%$

Não

Participação em atividades acadêmicas

Projeto de iniciação científica

Projeto de extensão

Projeto do Pró-Saúde/Pet-Saúde 
Monitoria

\section{Conhece o Pró-Saúde}

Sim

Não

Não opinaram

\section{Bolsista do Pró-Saúde/Pet-Saúde}

Sim

2. Análise descritiva dos dados coletados dos professores na Seção 1 - dados sociodemográficos e profissionais

Do total de 28 professores do curso, $18(64,2 \%)$ respondeu o instrumento. Observou-se que 94,4\% dos participantes são do sexo feminino, e a faixa etária predominante está compreendida entre 30 a 49 anos.

Em relação à formação, todos os participantes têm graduação em Enfermagem, e destes, um possui também formação em outro curso da área da saúde.

Quanto ao tempo de formado observou-se que a grande maioria dos professores (94\%) possui 10 ou mais anos de formados. Quanto ao grau de formação, 38,9\% possui doutorado, seguidos de $27,8 \%$ com mestrado e $22,2 \%$ com pós-doutorado.

No questionário foi perguntado aos professores se ensinam disciplinas da área básica, clínica, social e/ou outra área. De acordo com a Figura 43, observou-se que 37,5\% dos professores ministram aulas em disciplinas da área clínica, enquanto 16,7\% atuam em disciplinas da área básica e 12,5\% na social. Um total de 33\% indicou neste item a opção outra área de ensino, especificada pelos mesmos como Gestão, Epidemiologia, Saúde das Mulheres, Tecnologias da Educação em Saúde e Metodologia da Pesquisa em Saúde. 


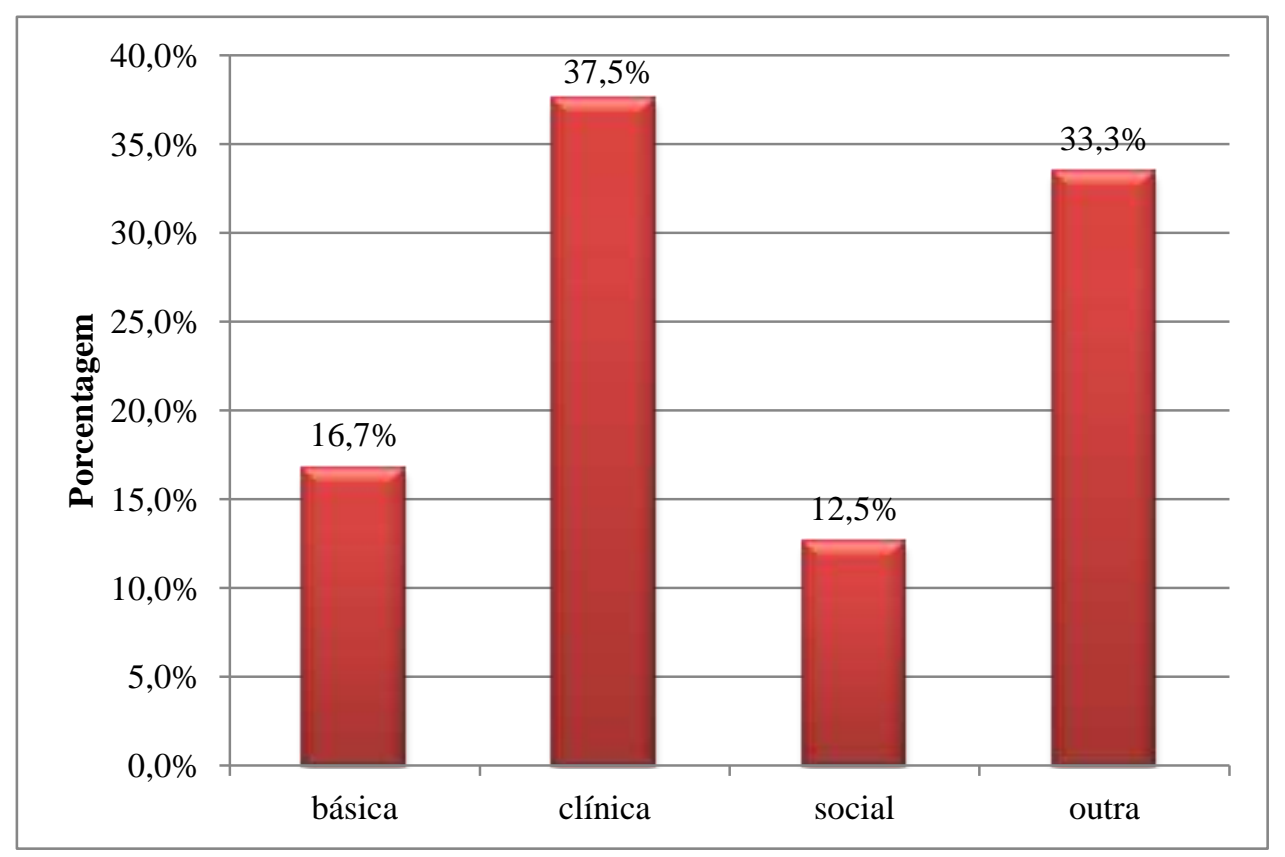

Figura 43. Distribuição percentual dos professores segundo as disciplinas das áreas que ensinam.

Ao serem perguntados quanto ao tipo de atividades que orientam na universidade, os resultados indicaram que a maioria dos docentes $(28,1 \%)$, conforme mostra a Figura 44, são orientadores de projetos de iniciação científica (IC). A orientação de projetos de extensão e projetos de monitoria contabilizaram cada, $15,6 \% \%$ do total de docentes. Um total de $21,6 \%$ orienta outras atividades não mencionadas no questionário. Dos participantes, 6,3\% não orienta nenhum tipo de projeto. 


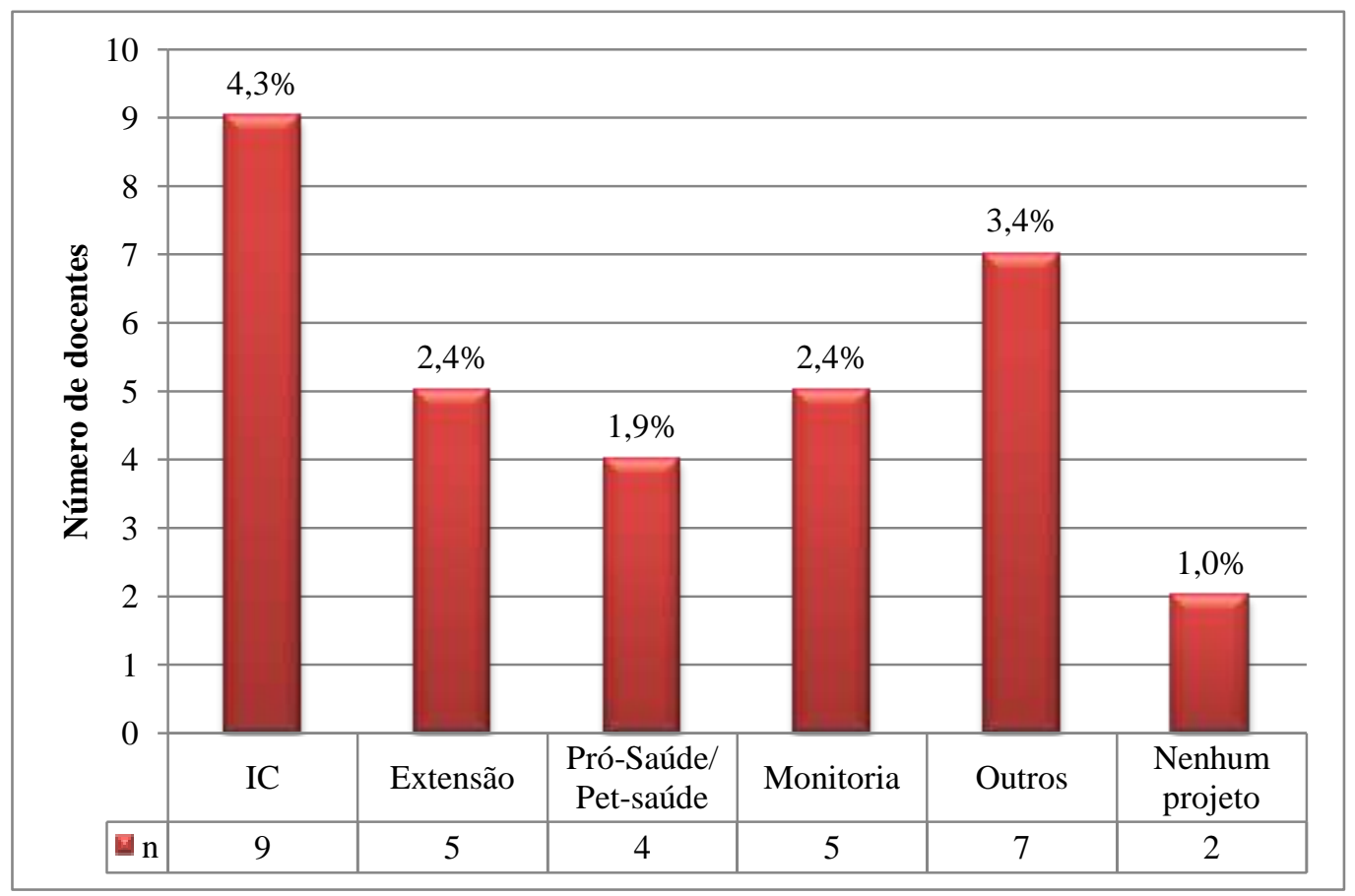

Figura 44. Distribuição percentual dos professores conforme as atividades em que orientam os estudantes.

No que se refere à distribuição percentual dos professores em relação ao tempo de participação em disciplinas inseridas na proposta do Pró-Saúde, ilustrada na Figura 45, verificou-se que $25 \%$ dos professores participam há menos de um ano nessas disciplinas. Um total de $16,7 \%$ possui tempo de participação superior a cinco anos, enquanto $25 \%$ dos educadores responderam "não sei” à questão levantada. 


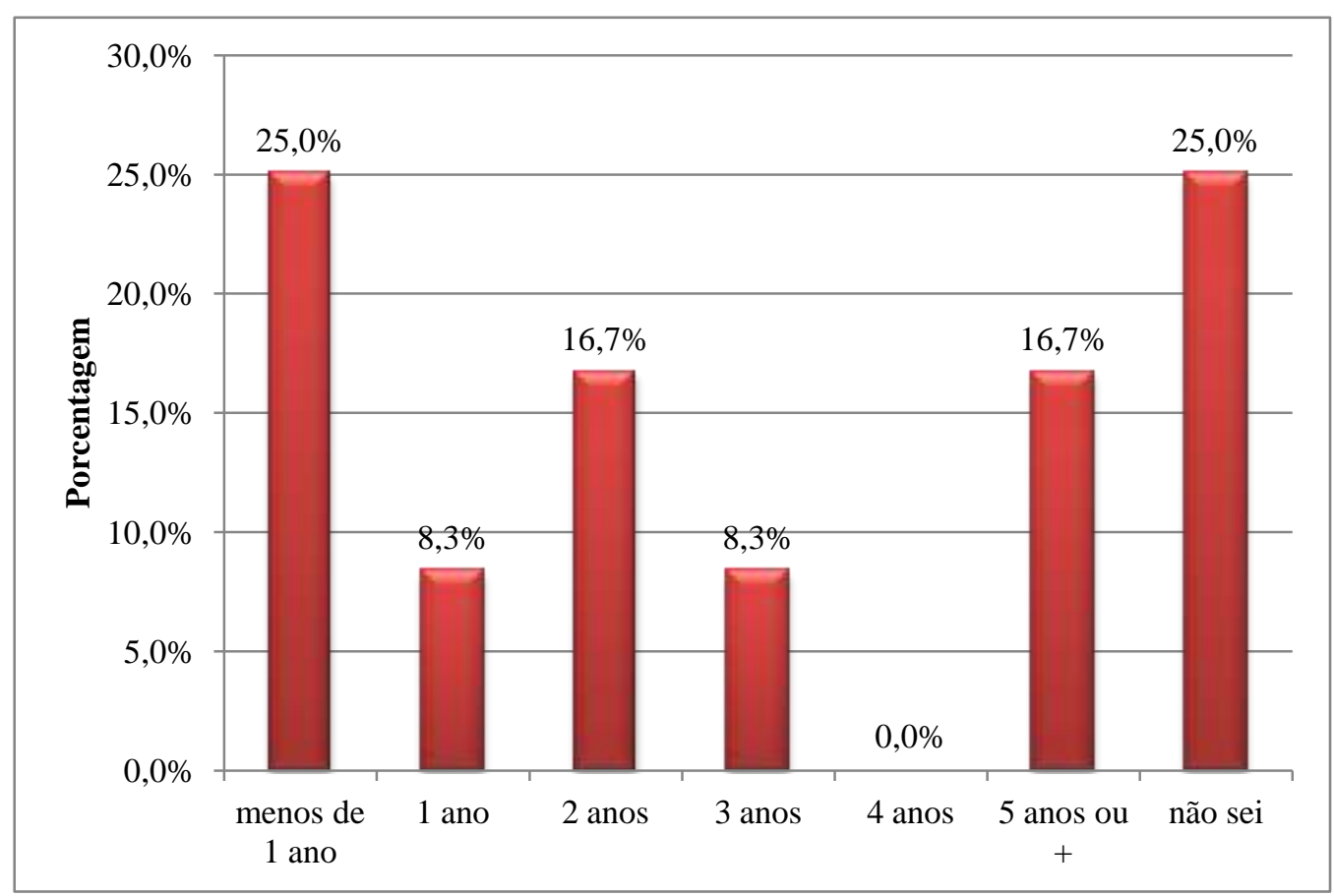

Figura 45. Distribuição percentual dos professores conforme o tempo de participação em disciplinas inseridas na proposta do Pró-Saúde.

Sobre a participação em tutoria do Pró-Saúde/Pet-Saúde, um total de 70,6\%, responderam negativamente, enquanto $29,4 \%$ responderam afirmaram participar. Dentre aqueles que responderam "sim" ao item, 11,8\% participam da tutoria como voluntários e apenas 17,6\% como bolsistas (Figura 46). O tempo de participação dos tutores variou entre entre 3 a 6 meses $(5,9 \%)$ e acima de doze meses (17,6\%). A Figura 47 apresenta esses resultados. 


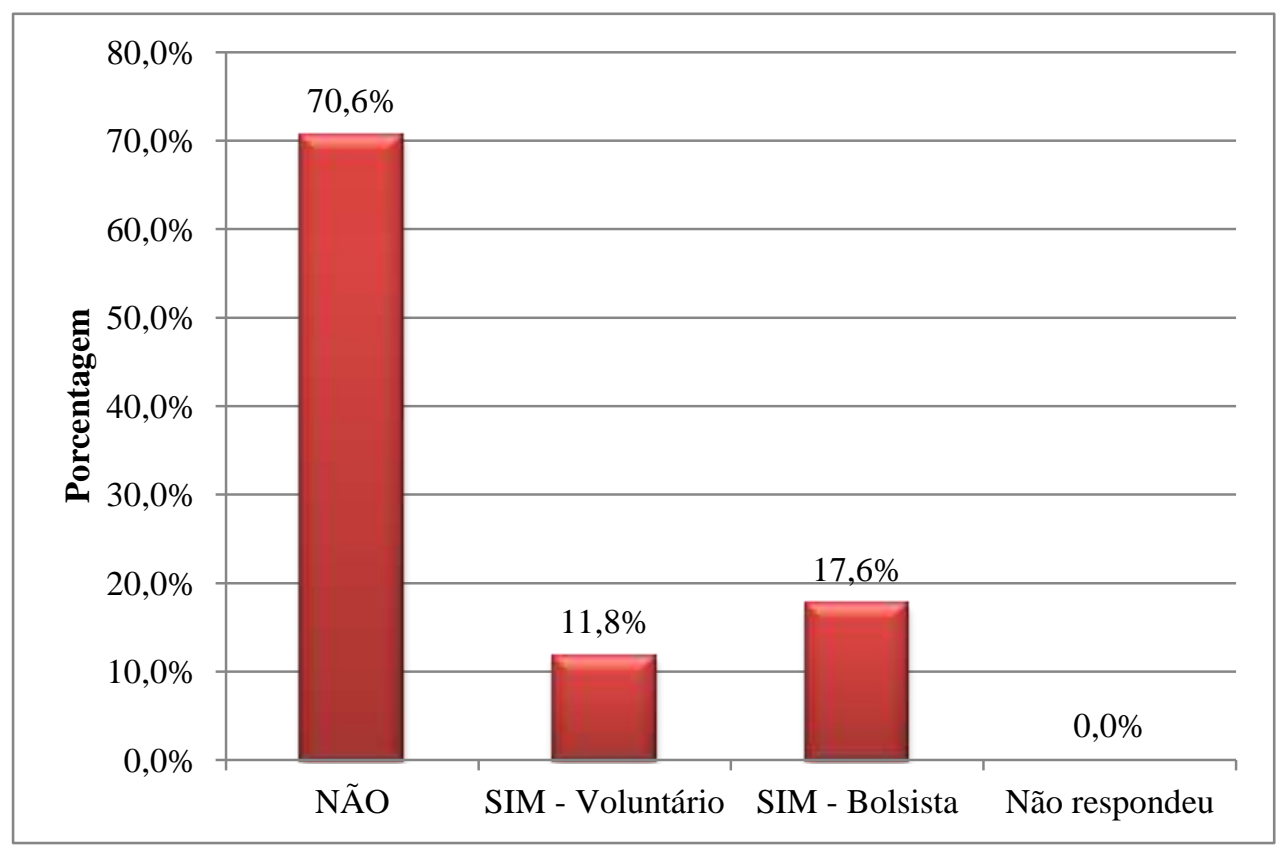

Figura 46. Distribuição percentual dos professores segundo participação em tutoria do Pró-Saúde/Pet-Saúde.

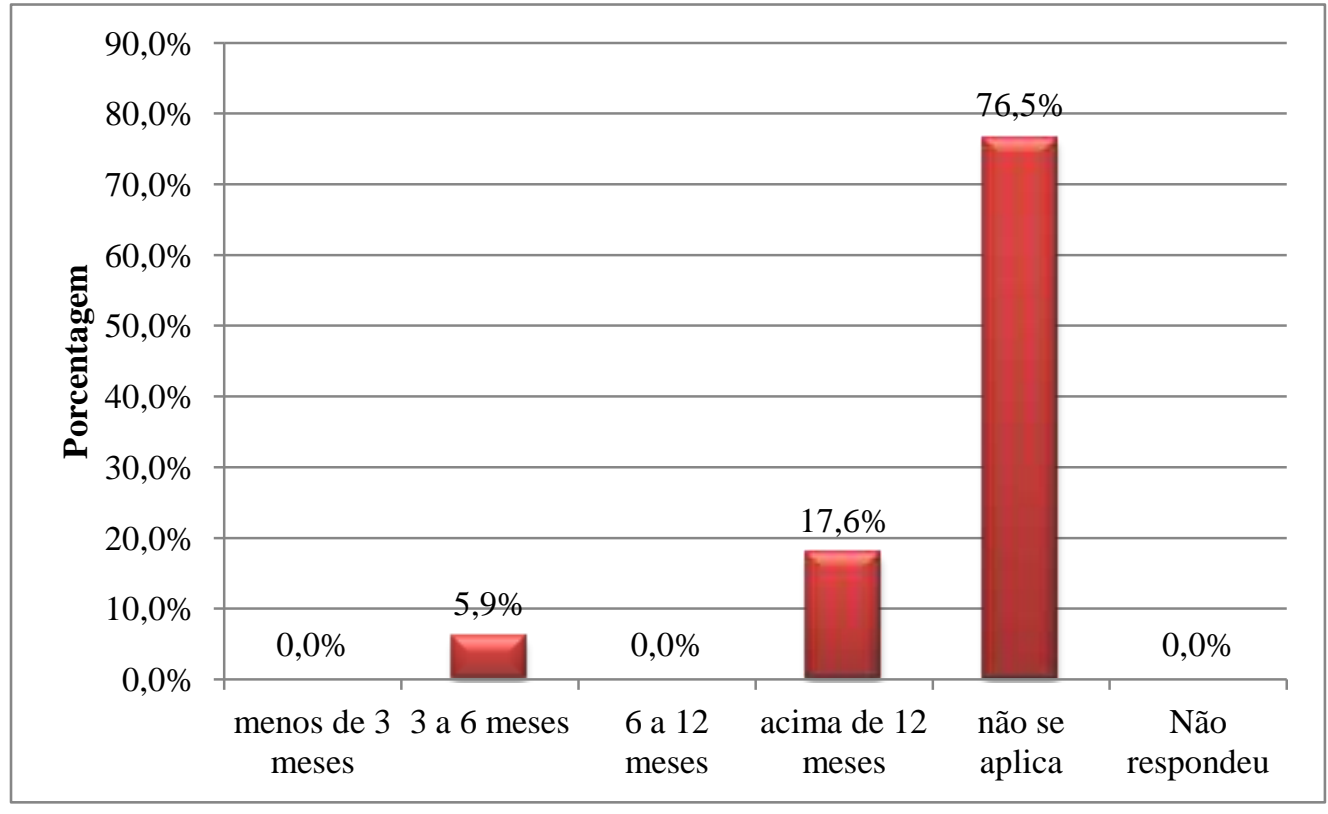

Figura 47. Distribuição percentual dos professores em relação ao tempo de participação em tutoria do Pró-Saúde/Pet-Saúde. 
Sobre a inserção no ensino de pós-graduação lato sensu e a área do conteúdo ministrado, foi possível verificar, conforme ilustrado na Figura 48, que 16,7\% dos docentes oferecem disciplinas nas áreas clínica; $11 \%$ na área social e 5,6\% em áreas básicas.

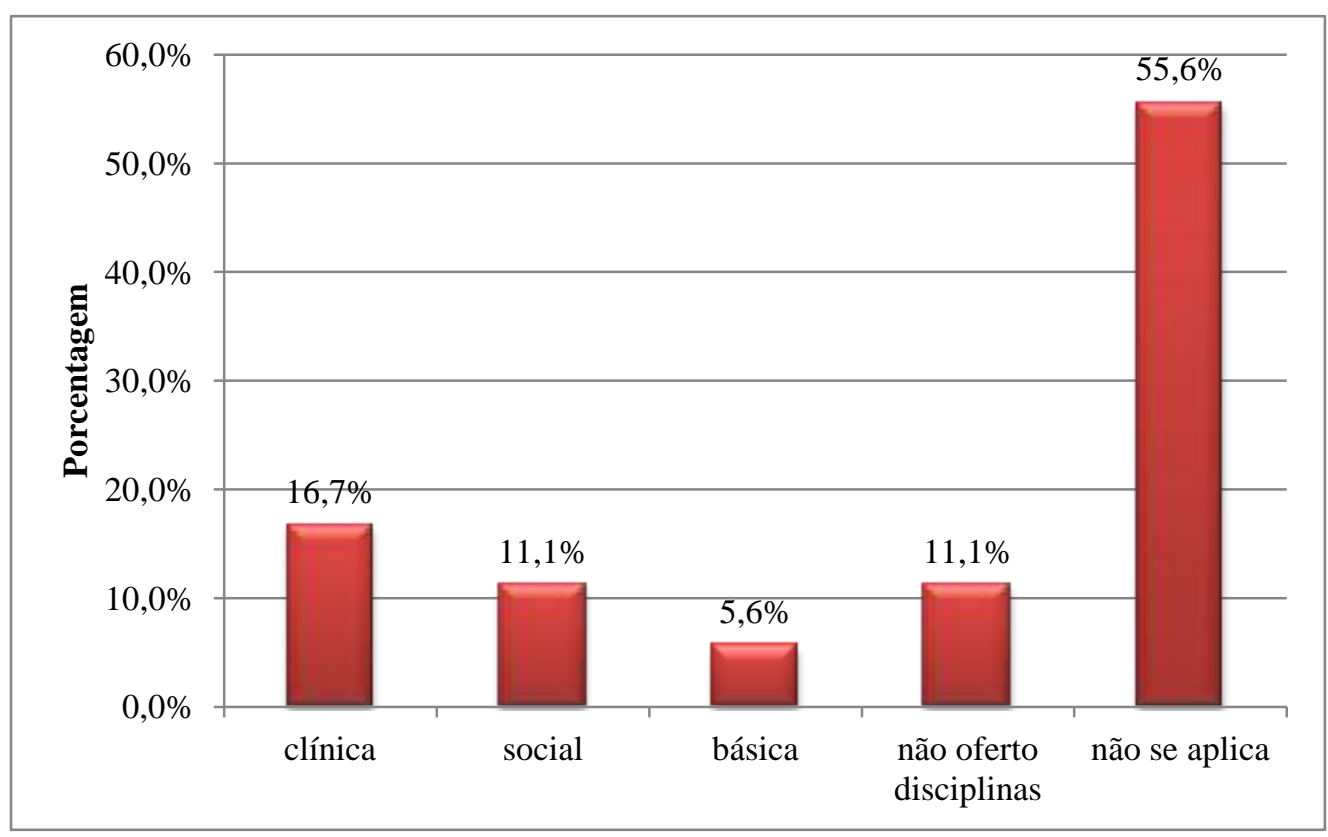

Figura 48 - Distribuição percentual dos professores em relação ao ensino na pós-graduação lato sensu e a área do conteúdo trabalhado.

Em relação à participação em disciplinas na pós-graduação stricto sensu e a área trabalhada, 27,8\% dos professores ofertam disciplinas na área clínica, seguida da área social com um total de $11 \%$ (Figura 49). 


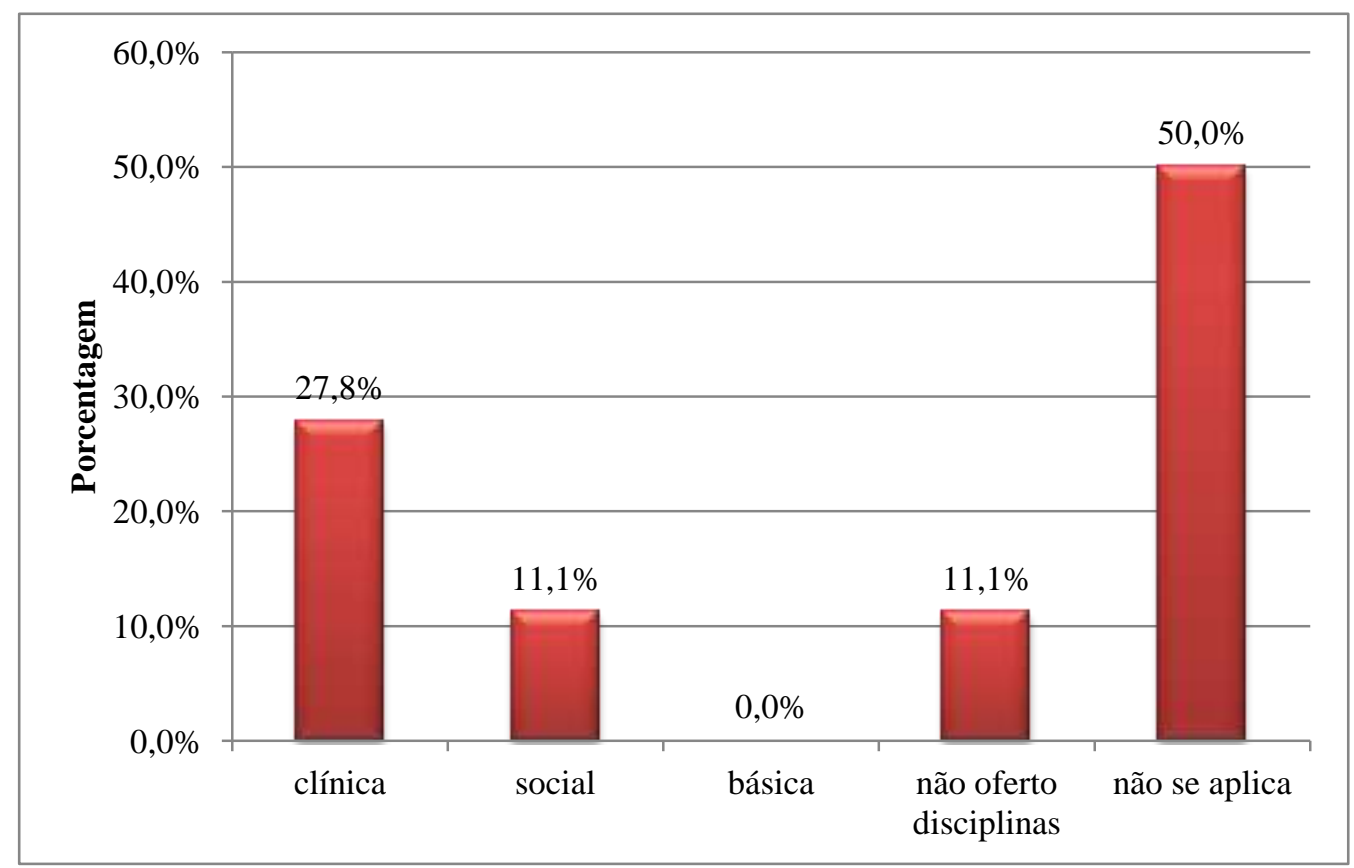

Figura 49 - Distribuição percentual dos professores em relação ao ensino na pósgraduação stricto sensu e a área do conteúdo trabalhado.

Para finalizar este tópico, apresentamos a Tabela 32, com um resumo do perfil sociodemográfico e profissional dos professores de Enfermagem participantes do presente estudo. 


\section{Tabela 32}

Perfil sociodemográfico e profissional dos professores de Enfermagem participantes do estudo.

\begin{tabular}{|c|c|c|}
\hline Variáveis & $\mathbf{N}$ & $\%$ \\
\hline \multicolumn{3}{|l|}{ Idade } \\
\hline 20 a 29 anos & 1 & $5,6 \%$ \\
\hline 30 a 49 anos & 10 & $55,6 \%$ \\
\hline 50 a 59 anos & 6 & $33,3 \%$ \\
\hline 60 anos ou mais & 1 & $5,6 \%$ \\
\hline \multicolumn{3}{|l|}{ Sexo } \\
\hline Masculino & 1 & $5,6 \%$ \\
\hline Feminino & 17 & $94,4 \%$ \\
\hline \multicolumn{3}{|l|}{ Graduação em outras áreas } \\
\hline Não & 18 & $90,0 \%$ \\
\hline Sim & 1 & $5,00 \%$ \\
\hline \multicolumn{3}{|c|}{ Orientação em atividades acadêmicas } \\
\hline Projeto de iniciação científica & 9 & $4,3 \%$ \\
\hline Projeto de extensão & 5 & $2,4 \%$ \\
\hline Projeto do Pró-Saúde/Pet-Saúde & 4 & $1,9 \%$ \\
\hline Monitoria & 5 & $2,4 \%$ \\
\hline Outros projetos & 7 & $3,4 \%$ \\
\hline Nenhum projeto & 2 & $1,0 \%$ \\
\hline \multicolumn{3}{|l|}{ Tutoria no Pró-Saúde } \\
\hline Não & 12 & $70,6 \%$ \\
\hline Sim - voluntário & 2 & $11,8 \%$ \\
\hline Sim - bolsista & 3 & $17,6 \%$ \\
\hline
\end{tabular}

3. Análise descritiva da Seção 2 - parte específica do instrumento

\subsection{Dimensão teórica - estudantes}

Na dimensão teórica, inserida no bloco 1 da Seção 2 do instrumento, considerando conjuntamente as respostas "concordo" e "concordo totalmente" como atitude positiva em relação a um item, verificou-se nos itens 1 e 2 que, quanto à abordagem de aspectos 
biológicos e aspectos sociais do processo saúde-doença, respectivamente, a maioria dos acadêmicos respondeu positivamente em ambos os itens, com 91,8\% para o item 1 e $88 \%$ para o item 2. Sobre o enfoque da produção de conhecimento estar voltada para as demandas dos serviços de saúde (item 4) ou voltada para aspectos biomédicos ou tecnológicos (item 5), ambos os itens foram avaliados positivamente pelos respondentes. A resposta "não sei" foi predominante para os itens relacionados a questões de abordagem teórica em nível de pós-graduação (itens 7,8 e 9). A descrição de cada item e as respectivas frequências obtidas para cada opção de seleção na escala de Likert aplicada está apresentada na Tabela 33 .

\section{Tabela 33}

Frequências de respostas obtidas dos estudantes em cada item da dimensão teórica.

\begin{tabular}{|c|c|c|c|c|c|c|}
\hline BLOCO 1 - DIMENSÃO TEÓRICA & $\begin{array}{l}\text { discordo } \\
\text { totalmente }\end{array}$ & discordo & $\begin{array}{l}\text { não } \\
\text { concordo } \\
\text { nem } \\
\text { discordo }\end{array}$ & concordo & $\begin{array}{l}\text { concordo } \\
\text { totalmente }\end{array}$ & não sei \\
\hline $\begin{array}{l}\text { 1- Os conteúdos teóricos ministrados na graduação abordam } \\
\text { aspectos biológicos do processo saúde-doença. }\end{array}$ & $0,5 \%$ & $1,9 \%$ & $4,3 \%$ & $57 \%$ & $34,8 \%$ & $1,0 \%$ \\
\hline $\begin{array}{l}\text { 2- Os conteúdos teóricos ministrados na graduação abordam } \\
\text { aspectos sociais do processo saúde-doença. }\end{array}$ & $0,0 \%$ & $5,3 \%$ & $5,8 \%$ & $64,3 \%$ & 23,7 & $0,5 \%$ \\
\hline $\begin{array}{l}\text { 3- Há interação entre as abordagens teóricas das disciplinas das } \\
\text { áreas básicas, clínicas e sociais da graduação. }\end{array}$ & $1,9 \%$ & $5,3 \%$ & $16,4 \%$ & $58,9 \%$ & $12,6 \%$ & $3,4 \%$ \\
\hline $\begin{array}{l}\text { 4- A produção de conhecimento, no que se refere à pesquisa, } \\
\text { está articulada com as demandas do serviço e da comunidade da } \\
\text { Regional de Saúde do Paranoá/Itapoã. }\end{array}$ & $1,4 \%$ & $10,6 \%$ & $25,1 \%$ & $30,0 \%$ & $8,2 \%$ & $24,2 \%$ \\
\hline $\begin{array}{l}\text { 5- A produção científica é focada em investigações sobre } \\
\text { aspectos biomédicos ou tecnológicos da atenção à saúde. }\end{array}$ & $0,0 \%$ & $9,7 \%$ & $14,5 \%$ & $44,0 \%$ & $8,2 \%$ & $22,7 \%$ \\
\hline $\begin{array}{l}\text { 6- A produção de conhecimento, no que se refere à extensão, } \\
\text { está articulada com as demandas do serviço e da comunidade da } \\
\text { Regional de Saúde do Paranoá/Itapoã. }\end{array}$ & $1,4 \%$ & $13,0 \%$ & $19,3 \%$ & $31,9 \%$ & $8,7 \%$ & $25,1 \%$ \\
\hline $\begin{array}{l}\text { 7- A oferta de cursos de pós-graduação é voltada para os } \\
\text { profissionais do SUS. }\end{array}$ & $3,9 \%$ & $11,1 \%$ & $19,3 \%$ & $13,5 \%$ & $2,4 \%$ & $49,3 \%$ \\
\hline $\begin{array}{l}\text { 8- Os cursos de pós-graduação possuem como público-alvo os } \\
\text { profissionais que atuam na rede privada. }\end{array}$ & $6,3 \%$ & $27,5 \%$ & $17,4 \%$ & $4,8 \%$ & $0,5 \%$ & $43,0 \%$ \\
\hline $\begin{array}{l}\text { 9- Os cursos de pós-graduação são oferecidos de acordo com } \\
\text { interesses ou necessidades do curso. }\end{array}$ & $0,5 \%$ & $9,2 \%$ & $14,5 \%$ & $29,5 \%$ & $2,9 \%$ & $41,1 \%$ \\
\hline $\begin{array}{l}\text { 10- As disciplinas teóricas de conteúdos relacionados às áreas } \\
\text { básicas, clínicas e sociais são ministradas em blocos separados, } \\
\text { sem articulação entre elas. }\end{array}$ & $10,6 \%$ & $42,9 \%$ & $15,9 \%$ & $16,4 \%$ & $5,8 \%$ & $8,7 \%$ \\
\hline
\end{tabular}




\subsection{Dimensão cenário de práticas - estudantes}

Os resultados obtidos nessa dimensão, em relação aos benefícios decorrentes da integração da universidade com o serviço, para a comunidade, para o próprio serviço e para a universidade, os estudantes consideraram positiva (somatória das frequências "concordo" e "concordo totalmente") para as três frentes envolvidas. Um total de 57,5\% dos respondentes entendem que o curso de Enfermagem contribui para a organização dos serviços. Em relação à infraestrutura das unidades utilizadas como cenário de práticas serem ou não adequadas, a maioria respondeu "não sei". Os acadêmicos, na sua maioria $(61,8 \%)$, concordaram que as atividades práticas dos primeiros anos do curso ocorrem em laboratórios, e que as atividades práticas clínicas ocorrem dentro do ambiente universitário $(77,8 \%)$.

Os resultados obtidos nos itens da dimensão denominada cenário de práticas estão apresentados na Tabela 34 .

\section{Tabela 34}

Frequências de respostas obtidas dos estudantes em cada item da dimensão cenário de práticas.

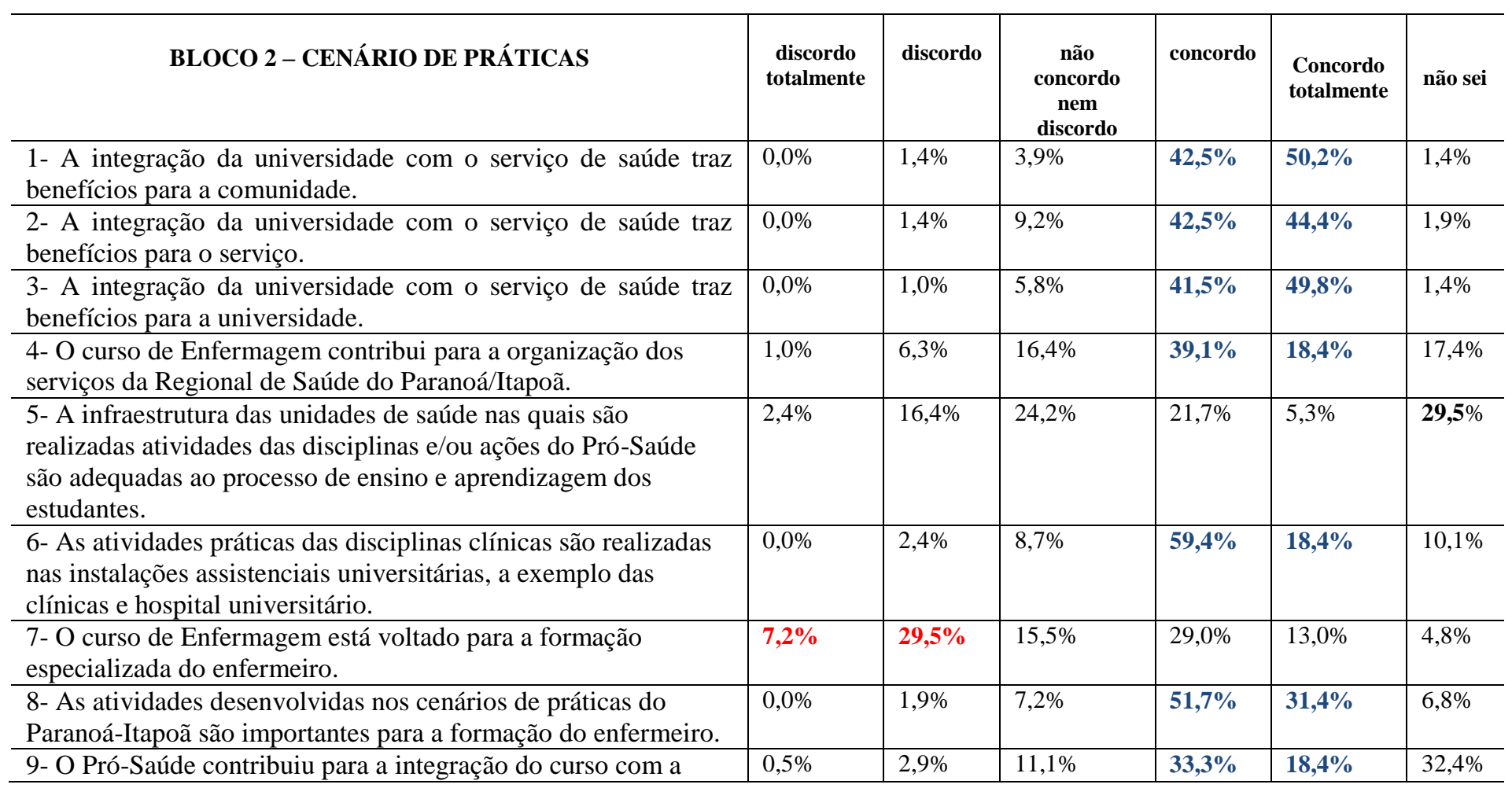




\begin{tabular}{l|l|l|l|l|l|l}
\hline Rede de Serviço de Saúde do Paranoá-Itapoã. & & & & & & \\
\hline $\begin{array}{l}\text { 10- O curso de Enfermagem se volta para a formação } \\
\text { generalista do enfermeiro. }\end{array}$ & $1,9 \%$ & $4,8 \%$ & $13,0 \%$ & $\mathbf{4 5 , 9 \%}$ & $\mathbf{2 6 , 6 \%}$ & $7,2 \%$ \\
\hline $\begin{array}{l}\text { 11- O Pró-Saúde contribuiu para a integração da Enfermagem } \\
\text { com os demais cursos da área da saúde. }\end{array}$ & $2,4 \%$ & $9,7 \%$ & $15,5 \%$ & $29,0 \%$ & $11,1 \%$ & $\mathbf{3 0 , 9} \%$ \\
\hline $\begin{array}{l}\text { 12- As atividades práticas dos primeiros anos do curso ocorrem } \\
\text { em laboratórios da área básica. }\end{array}$ & $1,0 \%$ & $13,0 \%$ & $11,6 \%$ & $\mathbf{5 0 , 2 \%}$ & $\mathbf{1 1 , 6 \%}$ & $10,6 \%$ \\
\hline $\begin{array}{l}\text { 13- A inserção dos estudantes de Enfermagem com atividades } \\
\text { práticas na comunidade ou nos serviços de saúde ocorre desde } \\
\text { os primeiros dois anos do curso. }\end{array}$ & $1,9 \%$ & $7,7 \%$ & $7,2 \%$ & $\mathbf{5 1 , 7 \%}$ & $\mathbf{2 1 , 7 \%}$ & $8,7 \%$ \\
\hline
\end{tabular}

\subsection{Dimensão reorientação da formação - estudantes}

Neste bloco, do total de nove itens incluídos, todos relacionados à reorientação da formação, com enfoque direto ao Programa Pró-Saúde, os acadêmicos optaram pela alternativa “não sei” como resposta em três deles (itens 2, 4 e 5). Nos demais itens, os quais abordaram aspectos relacionados a contribuições do Pró-Saúde para a formação para atuação na rede pública (item 3), para a interação entre profissionais da saúde (item 6), para a qualidade da formação (item 7), para a qualificação dos profissionais da rede (item 8) e para o trabalho em equipe (item 9), a maioria dos acadêmicos demonstraram atitude positiva (alternativas “concordo" e concordo totalmente"), seguidas pela opção de resposta "não sei”. O único item com o qual os estudantes discordaram foi aquele que afirmava que o respondente do instrumento conhece os objetivos do Pró-Saúde. Entretanto, as opiniões neste item foram bastante divididas. As frequências obtidas nesta dimensão estão descritas na Tabela 35.

\section{Tabela 35}

Frequências de respostas obtidas dos estudantes em cada item da dimensão reorientação da formação.

\begin{tabular}{|c|c|c|c|c|c|c|}
\hline BLOCO 3 - REORIENTAÇÃO DA FORMAÇÃO & $\begin{array}{l}\text { discordo } \\
\text { totalmente }\end{array}$ & discordo & $\begin{array}{c}\text { não } \\
\text { concordo } \\
\text { nem } \\
\text { discordo } \\
\end{array}$ & concordo & $\begin{array}{l}\text { Concordo } \\
\text { totalmente }\end{array}$ & não sei \\
\hline 1- Eu conheço os objetivos do Programa Pró-Saúde. & $12,6 \%$ & $21,7 \%$ & $11,6 \%$ & $29,0 \%$ & $3,9 \%$ & $20,8 \%$ \\
\hline $\begin{array}{l}\text { 2- O Pró-Saúde contribuiu com o processo de reforma curricular } \\
\text { do curso de Enfermagem. }\end{array}$ & $1,0 \%$ & $3,9 \%$ & $13,5 \%$ & $32,4 \%$ & $5,3 \%$ & $43,5 \%$ \\
\hline $\begin{array}{l}\text { 3- A participação do estudante no Pró-Saúde contribui para a } \\
\text { sua maior preparação para atuação profissional na rede pública. }\end{array}$ & $0,5 \%$ & $1,4 \%$ & $9,7 \%$ & $44,4 \%$ & $13,5 \%$ & $30,4 \%$ \\
\hline 4- A participação do estudante no Pró-Saúde contribui para a & $1,9 \%$ & $14,0 \%$ & $20,8 \%$ & $22,7 \%$ & $2,9 \%$ & $36,2 \%$ \\
\hline
\end{tabular}




\begin{tabular}{|c|c|c|c|c|c|c|}
\hline sua maior preparação para atuação profissional na rede privada. & & & & & & \\
\hline $\begin{array}{l}\text { 5- As atividades desenvolvidas no contexto do Pró-Saúde nas } \\
\text { unidades de saúde não alteram as rotinas de trabalho e nem as } \\
\text { práticas dos profissionais de saúde no serviço. }\end{array}$ & $3,4 \%$ & $27,1 \%$ & $16,4 \%$ & $12,6 \%$ & $1,9 \%$ & $38,2 \%$ \\
\hline $\begin{array}{l}\text { 6- O Pró-Saúde possibilita a interação entre os profissionais da } \\
\text { área de saúde. }\end{array}$ & $1,0 \%$ & $4,8 \%$ & $8,7 \%$ & $43,5 \%$ & $13,0 \%$ & $28,0 \%$ \\
\hline $\begin{array}{l}\text { 7- As atividades desenvolvidas pelos estudantes de Enfermagem } \\
\text { no contexto do Pró-Saúde influenciam na qualidade de sua } \\
\text { formação. }\end{array}$ & $0,5 \%$ & $1,0 \%$ & $9,7 \%$ & $44,4 \%$ & $19,3 \%$ & $24,6 \%$ \\
\hline $\begin{array}{l}\text { 8- As atividades desenvolvidas no âmbito do Pró-Saúde } \\
\text { contribuem para a qualificação da prática dos profissionais que } \\
\text { atuam na rede pública de atenção à saúde do Paranoá-Itapoã. }\end{array}$ & $0,5 \%$ & $0,5 \%$ & $15,9 \%$ & $35,7 \%$ & $11,1 \%$ & $35,3 \%$ \\
\hline 9- O Pró-Saúde contribui para o trabalho em equipe. & $0,5 \%$ & $1,4 \%$ & $8,7 \%$ & $42,5 \%$ & $19,3 \%$ & $27,1 \%$ \\
\hline
\end{tabular}

\subsection{Dimensão pedagógica - estudantes}

Neste bloco, os participantes responderam positivamente em todos os itens, exceto no item 9, em que se afirmava que atividades práticas com profissionais das equipes de saúde são estratégias que pouco acrescentam à formação. Os acadêmicos demonstraram acreditar que há integração das atividades envolvendo disciplinas básicas e clínicas $(52,1 \%)$ e que ocorrem atividades interdisciplinares no processo de ensino e aprendizagem $(67,1 \%)$. Quanto às estratégias utilizadas, os acadêmicos consideraram aula expositiva o formato mais empregado para a apresentação de conteúdo teórico (80,7\%). Os dados percentuais dessa dimensão estão apresentados na Tabela 36.

\section{Tabela 36}

Frequências de respostas obtidas dos estudantes em cada item da dimensão pedagógica.

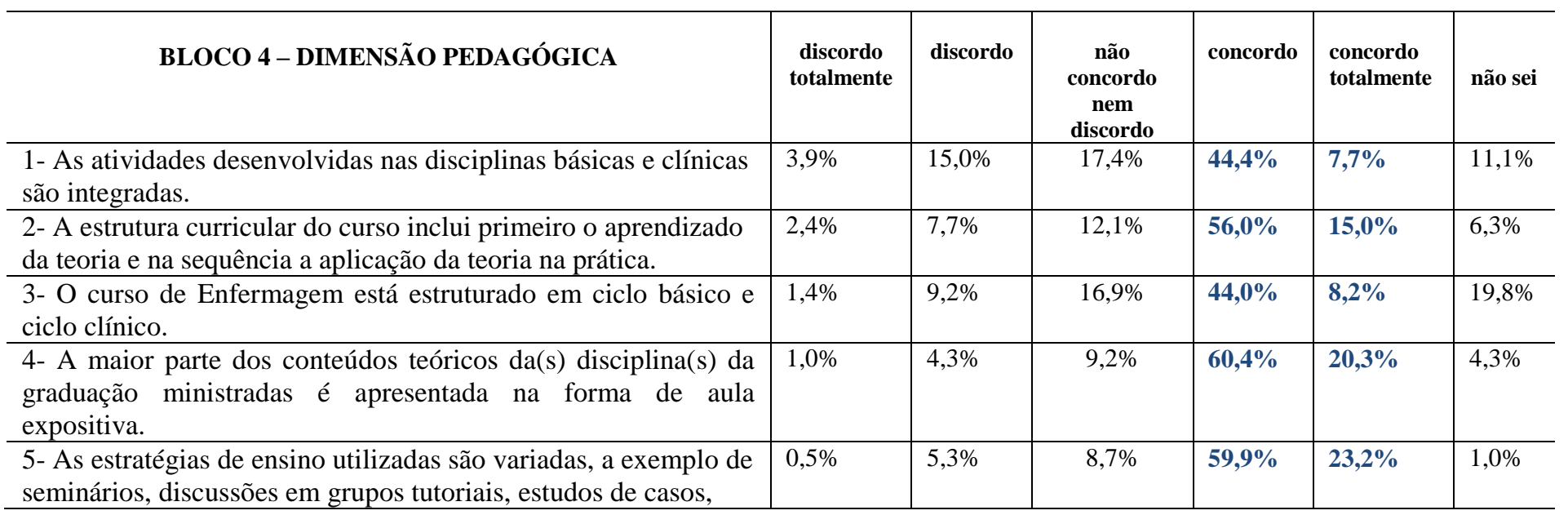




\begin{tabular}{|c|c|c|c|c|c|c|}
\hline etc. & & & & & & \\
\hline $\begin{array}{l}\text { 6- O processo de ensino-aprendizagem envolve atividades } \\
\text { interdisciplinares. }\end{array}$ & $0,0 \%$ & $13,5 \%$ & $15,0 \%$ & $50,2 \%$ & $16,9 \%$ & $3,9 \%$ \\
\hline 7- Existe interação entre a teoria ministrada e a prática. & $1,0 \%$ & $6,3 \%$ & $12,1 \%$ & $55,6 \%$ & $22,2 \%$ & $2,4 \%$ \\
\hline $\begin{array}{l}\text { 8- A interação entre a equipe de profissionais de saúde, } \\
\text { estudantes, professores e comunidade facilita o processo de } \\
\text { ensino e aprendizagem. }\end{array}$ & $1,0 \%$ & $3,4 \%$ & $6,8 \%$ & $53,1 \%$ & $32,9 \%$ & $2,4 \%$ \\
\hline $\begin{array}{l}\text { 10- As estratégias de ensino-aprendizagem que ocorrem no } \\
\text { ambiente do SUS são avaliadas conjuntamente pelos } \\
\text { profissionais da Rede e docentes. }\end{array}$ & $4,3 \%$ & $10,6 \%$ & $11,1 \%$ & $31,9 \%$ & $4,8 \%$ & $36,2 \%$ \\
\hline
\end{tabular}

\subsection{Dimensão teórica - professores}

A maioria dos professores concordou que ocorre a abordagem de aspectos biológicos nos conteúdos teóricos das disciplinas, com a opção "concordo" e "concordo totalmente" totalizando $88,9 \%$, assim como em relação à abordagem de aspectos sociais do processo saúde-doença, que obteve o mesmo percentual de concordância.

Um total de 44,4\% dos docentes entende que o desenvolvimento da pesquisa está articulado com demandas da sociedade, enquanto $50 \%$ considera que a produção científica é focada em aspectos biomédicos ou tecnológicos da atenção à saúde.

Em relação à pós-graduação, a maioria não acredita que seja voltada para profissionais do SUS, com um total de 53,5\% (somatória de "discordo" e "discordo totalmente"). Sobre o mesmo tópico, a maioria de 39,3\% se mostrou neutra ao optarem por "não concordo nem discordo" quanto à oferta dos cursos serem voltadas para a rede privada, seguido de $29,5 \%$ se posicionando positivamente ("concordo" e "concordo totalmente"). Os dados percentuais referentes a todos os itens do bloco 1 estão descritos na Tabela 37. 


\section{Tabela 37}

Frequências de respostas obtidas dos professores em cada item da dimensão teórica.

\begin{tabular}{|c|c|c|c|c|c|c|}
\hline BLOCO 1 - DIMENSÃO TEÓRICA & $\begin{array}{l}\text { discordo } \\
\text { totalmente }\end{array}$ & discordo & $\begin{array}{l}\text { não } \\
\text { concordo } \\
\text { nem } \\
\text { discordo }\end{array}$ & concordo & $\begin{array}{l}\text { concordo } \\
\text { totalmente }\end{array}$ & não sei \\
\hline $\begin{array}{l}\text { 1- Os conteúdos teóricos ministrados na graduação abordam } \\
\text { aspectos biológicos do processo saúde-doença. }\end{array}$ & $0,0 \%$ & $5,6 \%$ & $0,0 \%$ & $22,2 \%$ & $66,7 \%$ & $5,6 \%$ \\
\hline $\begin{array}{l}\text { 2- Os conteúdos teóricos ministrados na graduação abordam } \\
\text { aspectos sociais do processo saúde-doença. }\end{array}$ & $0,0 \%$ & $0,0 \%$ & $5,6 \%$ & $33,3 \%$ & $55,6 \%$ & $5,6 \%$ \\
\hline $\begin{array}{l}\text { 3- Há interação entre as abordagens teóricas das disciplinas das } \\
\text { áreas básicas, clínicas e sociais da graduação. }\end{array}$ & $11,1 \%$ & $0,0 \%$ & $16,7 \%$ & $38,9 \%$ & $22,2 \%$ & $11,1 \%$ \\
\hline $\begin{array}{l}\text { 4- A produção de conhecimento, no que se refere à pesquisa, } \\
\text { está articulada com as demandas do serviço e da comunidade da } \\
\text { Regional de Saúde do Paranoá/Itapoã. }\end{array}$ & $0,0 \%$ & $16,7 \%$ & $11,1 \%$ & $22,2 \%$ & $22,2 \%$ & $27,8 \%$ \\
\hline $\begin{array}{l}\text { 5- A produção científica é focada em investigações sobre } \\
\text { aspectos biomédicos ou tecnológicos da atenção à saúde. }\end{array}$ & $0,0 \%$ & $5,6 \%$ & $22,2 \%$ & $38,9 \%$ & $11,1 \%$ & $22,2 \%$ \\
\hline $\begin{array}{l}\text { 6- A produção de conhecimento, no que se refere à extensão, } \\
\text { está articulada com as demandas do serviço e da comunidade da } \\
\text { Regional de Saúde do Paranoá/Itapoã. }\end{array}$ & $0,0 \%$ & $5,6 \%$ & $11,1 \%$ & $38,9 \%$ & $5,6 \%$ & $33,3 \%$ \\
\hline $\begin{array}{l}\text { 7- A oferta de cursos de pós-graduação é voltada para os } \\
\text { profissionais do SUS. }\end{array}$ & $5,6 \%$ & $16,7 \%$ & $11,1 \%$ & $22,2 \%$ & $22,2 \%$ & $22,2 \%$ \\
\hline $\begin{array}{l}\text { 8- Os cursos de pós-graduação possuem como público-alvo os } \\
\text { profissionais que atuam na rede privada. }\end{array}$ & $16,7 \%$ & $33,3 \%$ & $5,6 \%$ & $0,0 \%$ & $11,1 \%$ & $27,8 \%$ \\
\hline $\begin{array}{l}\text { 9- Os cursos de pós-graduação são oferecidos de acordo com } \\
\text { interesses ou necessidades do curso. }\end{array}$ & $0,0 \%$ & $11,1 \%$ & $16,7 \%$ & $22,2 \%$ & $16,7 \%$ & $33,3 \%$ \\
\hline $\begin{array}{l}\text { 10- As disciplinas teóricas de conteúdos relacionados às áreas } \\
\text { básicas, clínicas e sociais são ministradas em blocos separados, } \\
\text { sem articulação entre elas. }\end{array}$ & $5,6 \%$ & $38,9 \%$ & $11,1 \%$ & $27,8 \%$ & $11,1 \%$ & $5,6 \%$ \\
\hline
\end{tabular}

\subsection{Dimensão cenário de práticas - professores}

Os professores demonstraram atitude positiva ao concordarem $(27,8 \%)$ e concordarem plenamente $(72,2 \%)$ que a integração entre universidade e serviço de saúde beneficia a comunidade, o serviço e a própria IES participante.

Em relação às atividades práticas nas comunidades ou serviços de saúde, a maioria dos docentes $(72,2 \%)$ se mostraram positivos ao concordarem que os estudantes desenvolvem tais atividades desde o início do curso. Metade dos docentes considerou que as atividades práticas dos primeiros anos do curso ocorrem em laboratórios. O total de $66,6 \%$ (somatória de "concordo" e "concordo totalmente") concordou que as atividades práticas clínicas ocorrem dentro do ambiente universitário. 
Sobre o item que afirma haver adequação da infraestrutura das unidades de saúde para o desenvolvimento das atividades, as opiniões se dividiram, com $50 \%$ optando por "não sei". As frequências obtidas nos itens desse bloco estão apresentadas na Tabela 38.

\section{Tabela 38}

Frequências de respostas obtidas dos professores em cada item da dimensão cenário de práticas.

\begin{tabular}{|c|c|c|c|c|c|c|}
\hline BLOCO 2 - CENÁRIO DE PRÁTICAS & $\begin{array}{l}\text { discordo } \\
\text { totalmente }\end{array}$ & discordo & $\begin{array}{c}\text { não } \\
\text { concordo } \\
\text { nem } \\
\text { discordo }\end{array}$ & concordo & $\begin{array}{l}\text { concordo } \\
\text { otalmente }\end{array}$ & não sei \\
\hline $\begin{array}{l}\text { 1- A integração da universidade com o serviço de saúde traz } \\
\text { benefícios para a comunidade. }\end{array}$ & $0,0 \%$ & $0,0 \%$ & $0,0 \%$ & $27,8 \%$ & $72,2 \%$ & $0,0 \%$ \\
\hline $\begin{array}{l}\text { 2- A integração da universidade com o serviço de saúde traz } \\
\text { benefícios para o serviço. }\end{array}$ & $0,0 \%$ & $0,0 \%$ & $0,0 \%$ & $27,8 \%$ & $72,2 \%$ & $0,0 \%$ \\
\hline $\begin{array}{l}\text { 3- A integração da universidade com o serviço de saúde traz } \\
\text { benefícios para a universidade. }\end{array}$ & $0,0 \%$ & $0,0 \%$ & $0,0 \%$ & $27,8 \%$ & $72,2 \%$ & $0,0 \%$ \\
\hline $\begin{array}{l}\text { 4- O curso de Enfermagem contribui para a organização dos } \\
\text { serviços da Regional de Saúde do Paranoá/Itapoã. }\end{array}$ & $0,0 \%$ & $11,1 \%$ & $11,1 \%$ & $22,2 \%$ & $44,4 \%$ & $11,1 \%$ \\
\hline $\begin{array}{l}\text { 5- A infraestrutura das unidades de saúde nas quais são } \\
\text { realizadas atividades das disciplinas e/ou ações do Pró-Saúde } \\
\text { são adequadas ao processo de ensino e aprendizagem dos } \\
\text { estudantes. }\end{array}$ & $11,1 \%$ & $11,1 \%$ & $5,6 \%$ & $16,7 \%$ & $5,6 \%$ & $50,0 \%$ \\
\hline $\begin{array}{l}\text { 6- As atividades práticas das disciplinas clínicas são realizadas } \\
\text { nas instalações assistenciais universitárias, a exemplo das } \\
\text { clínicas e hospital universitário. }\end{array}$ & $0,0 \%$ & $11,1 \%$ & $5,6 \%$ & $44,4 \%$ & $22,2 \%$ & $16,7 \%$ \\
\hline $\begin{array}{l}\text { 7- O curso de Enfermagem está voltado para a formação } \\
\text { especializada do enfermeiro. }\end{array}$ & $5,6 \%$ & $55,6 \%$ & $11,1 \%$ & $16,7 \%$ & $11,1 \%$ & $0,0 \%$ \\
\hline $\begin{array}{l}\text { 8- As atividades desenvolvidas nos cenários de práticas do } \\
\text { Paranoá-Itapoã são importantes para a formação do enfermeiro. }\end{array}$ & $0,0 \%$ & $0,0 \%$ & $0,0 \%$ & $55,6 \%$ & $27,8 \%$ & $16,7 \%$ \\
\hline $\begin{array}{l}\text { 9- O Pró-Saúde contribuiu para a integração do curso com a } \\
\text { Rede de Serviço de Saúde do Paranoá-Itapoã. }\end{array}$ & $0,0 \%$ & $5,6 \%$ & $11,1 \%$ & $16,7 \%$ & $33,3 \%$ & $27,8 \%$ \\
\hline $\begin{array}{l}\text { 10- O curso de Enfermagem se volta para a formação } \\
\text { generalista do enfermeiro. }\end{array}$ & $0,0 \%$ & $0,0 \%$ & $5,6 \%$ & $50,0 \%$ & $44,4 \%$ & $0,0 \%$ \\
\hline $\begin{array}{l}\text { 11- O Pró-Saúde contribuiu para a integração da Enfermagem } \\
\text { com os demais cursos da área da saúde. }\end{array}$ & $0,0 \%$ & $5,6 \%$ & $5,6 \%$ & $38,9 \%$ & $11,1 \%$ & $33,3 \%$ \\
\hline $\begin{array}{l}\text { 12- As atividades práticas dos primeiros anos do curso ocorrem } \\
\text { em laboratórios da área básica. }\end{array}$ & $0,0 \%$ & $5,6 \%$ & $27,8 \%$ & $38,9 \%$ & $11,1 \%$ & $16,7 \%$ \\
\hline $\begin{array}{l}\text { 13- A inserção dos estudantes de Enfermagem com atividades } \\
\text { práticas na comunidade ou nos serviços de saúde ocorre desde } \\
\text { os primeiros dois anos do curso. }\end{array}$ & $0,0 \%$ & $0,0 \%$ & $11,1 \%$ & $44,4 \%$ & $27,8 \%$ & $16,7 \%$ \\
\hline
\end{tabular}




\subsection{Dimensão reorientação da formação - professores}

Na dimensão reorientação da formação, que trata de itens relacionados ao Programa

Pró-Saúde, os professores se mostraram positivos em todos os itens, com exceção do item

5, sobre a alteração das rotinas nas unidades de saúde quando atividades universitárias são

desenvolvidas. Os dados percentuais obtidos em cada item estão descritos na Tabela 39.

\section{Tabela 39}

Frequências de respostas obtidas dos professores em cada item da dimensão reorientação da formação.

\begin{tabular}{|c|c|c|c|c|c|c|}
\hline BLOCO 3 - REORIENTAÇÃO DA FORMAÇÃO & $\begin{array}{l}\text { discordo } \\
\text { totalmente }\end{array}$ & discordo & $\begin{array}{l}\text { não } \\
\text { concordo } \\
\text { nem } \\
\text { discordo }\end{array}$ & $\begin{array}{l}\text { Concord } \\
\quad \mathbf{o}\end{array}$ & $\begin{array}{l}\text { Concordo } \\
\text { totalmente }\end{array}$ & não sei \\
\hline 1- Eu conheço os objetivos do Programa Pró-Saúde. & $5,6 \%$ & $5,6 \%$ & $5,6 \%$ & $44,4 \%$ & $22,2 \%$ & $16,7 \%$ \\
\hline $\begin{array}{l}\text { 2- O Pró-Saúde contribuiu com o processo de reforma curricular } \\
\text { do curso de Enfermagem. }\end{array}$ & $5,6 \%$ & $11,1 \%$ & $5,6 \%$ & $27,8 \%$ & $22,2 \%$ & $22,2 \%$ \\
\hline $\begin{array}{l}\text { 3- A participação do estudante no Pró-Saúde contribui para a } \\
\text { sua maior preparação para atuação profissional na rede pública. }\end{array}$ & $0,0 \%$ & $0,0 \%$ & $22,2 \%$ & $16,7 \%$ & $33,3 \%$ & $22,2 \%$ \\
\hline $\begin{array}{l}\text { 4- A participação do estudante no Pró-Saúde contribui para a } \\
\text { sua maior preparação para atuação profissional na rede privada. }\end{array}$ & $5,6 \%$ & $5,6 \%$ & $33,3 \%$ & $22,2 \%$ & $0,0 \%$ & $27,8 \%$ \\
\hline $\begin{array}{l}\text { 5- As atividades desenvolvidas no contexto do Pró-Saúde nas } \\
\text { unidades de saúde não alteram as rotinas de trabalho e nem as } \\
\text { práticas dos profissionais de saúde no serviço. }\end{array}$ & $27,8 \%$ & $16,7 \%$ & $11,1 \%$ & $16,7 \%$ & $0,0 \%$ & $22,2 \%$ \\
\hline $\begin{array}{l}\text { 6- O Pró-Saúde possibilita a interação entre os profissionais da } \\
\text { área de saúde. }\end{array}$ & $0,0 \%$ & $0,0 \%$ & $11,1 \%$ & $44,4 \%$ & $16,7 \%$ & $22,2 \%$ \\
\hline $\begin{array}{l}\text { 7- As atividades desenvolvidas pelos estudantes de Enfermagem } \\
\text { no contexto do Pró-Saúde influenciam na qualidade de sua } \\
\text { formação. }\end{array}$ & $0,0 \%$ & $0,0 \%$ & $11,1 \%$ & $33,3 \%$ & $22,2 \%$ & $27,8 \%$ \\
\hline $\begin{array}{l}\text { 8- As atividades desenvolvidas no âmbito do Pró-Saúde } \\
\text { contribuem para a qualificação da prática dos profissionais que } \\
\text { atuam na rede pública de atenção à saúde do Paranoá-Itapoã. }\end{array}$ & $0,0 \%$ & $0,0 \%$ & $11,1 \%$ & $33,3 \%$ & $22,2 \%$ & $27,8 \%$ \\
\hline 9- O Pró-Saúde contribui para o trabalho em equipe. & $0,0 \%$ & $5,6 \%$ & $16,7 \%$ & $16,7 \%$ & $33,3 \%$ & $22,2 \%$ \\
\hline
\end{tabular}

\subsection{Dimensão pedagógica - professores}

Neste bloco, os professores apresentaram posicionamento favorável em relação ao curso estar estruturado em ciclo básico e clínico (item 3); diversificação nas estratégias de ensino (item 5); atividades interdisciplinares (item 6) e interação entre teoria e prática (item 7). Em relação à utilização de aula expositiva para ministrar conteúdos teóricos, 55,6\% demonstraram tendência negativa (somatória de "discordo" e "discordo totalmente", 
enquanto 33,3\% optou pelo extremo oposto (soma de "discordo" e "discordo totalmente").

Em relação ao desenvolvimento das disciplinas básicas e clínicas serem integradas as opiniões de dividiram, com predominância da opção neutra ("não concordo nem discordo").

Os resultados obtidos nessa dimensão podem ser verificados na Tabela 40.

Tabela 40

Frequências de respostas obtidas dos professores em cada item da dimensão pedagógica.

\begin{tabular}{|c|c|c|c|c|c|c|}
\hline BLOCO 4 - DIMENSÃO PEDAGÓGICA & $\begin{array}{l}\text { discordo } \\
\text { totalmente }\end{array}$ & discordo & $\begin{array}{l}\text { não } \\
\text { concordo } \\
\text { nem } \\
\text { discordo }\end{array}$ & concordo & $\begin{array}{l}\text { concordo } \\
\text { totalmente }\end{array}$ & não sei \\
\hline $\begin{array}{l}\text { 1- As atividades desenvolvidas nas disciplinas básicas e clínicas } \\
\text { são integradas. }\end{array}$ & $5,6 \%$ & $27,8 \%$ & $38,9 \%$ & $27,8 \%$ & $0,0 \%$ & $0,0 \%$ \\
\hline $\begin{array}{l}\text { 2- A estrutura curricular do curso inclui primeiro o aprendizado } \\
\text { da teoria e na sequência a aplicação da teoria na prática. }\end{array}$ & $5,6 \%$ & $27,, 8 \%$ & $33,3 \%$ & $27,8 \%$ & $0,0 \%$ & $5,6 \%$ \\
\hline $\begin{array}{l}\text { 3- O curso de Enfermagem está estruturado em ciclo básico e } \\
\text { ciclo clínico. }\end{array}$ & $0,0 \%$ & $27,8 \%$ & $16,7 \%$ & $33,3 \%$ & $5,6 \%$ & $5,6 \%$ \\
\hline $\begin{array}{l}\text { 4- A maior parte dos conteúdos teóricos da(s) disciplina(s) da } \\
\text { graduação que ministro é apresentada na forma de aula } \\
\text { expositiva. }\end{array}$ & $27,8 \%$ & $27,8 \%$ & $11,1 \%$ & $22,2 \%$ & $11,1 \%$ & $0,0 \%$ \\
\hline $\begin{array}{l}\text { 5- As estratégias de ensino utilizadas são variadas, a exemplo de } \\
\text { seminários, discussões em grupos tutoriais, estudos de casos, } \\
\text { etc. }\end{array}$ & $0,0 \%$ & $0,0 \%$ & $0,0 \%$ & $38,9 \%$ & $61,1 \%$ & $0,0 \%$ \\
\hline $\begin{array}{l}\text { 6- O processo de ensino-aprendizagem envolve atividades } \\
\text { interdisciplinares. }\end{array}$ & $0,0 \%$ & $0,0 \%$ & $0,0 \%$ & $61,1 \%$ & $38,9 \%$ & $0,0 \%$ \\
\hline 7- Existe interação entre a teoria ministrada e a prática. & $0,0 \%$ & $0,0 \%$ & $16,7 \%$ & $38,9 \%$ & $44,4 \%$ & $0,0 \%$ \\
\hline $\begin{array}{l}\text { 8- A interação entre a equipe de profissionais de saúde, } \\
\text { estudantes, professores e comunidade facilita o processo de } \\
\text { ensino e aprendizagem. }\end{array}$ & $0,0 \%$ & $0,0 \%$ & $16,7 \%$ & $22,2 \%$ & $55,6 \%$ & $0,0 \%$ \\
\hline $\begin{array}{l}\text { 9- Atividades práticas envolvendo profissionais das equipes de } \\
\text { saúde são estratégias que pouco acrescentam à formação do } \\
\text { enfermeiro, dado as especificidades do curso. }\end{array}$ & $33,3 \%$ & $50,0 \%$ & $0,0 \%$ & $5,6 \%$ & $5,6 \%$ & $5,6 \%$ \\
\hline $\begin{array}{l}\text { 10- As estratégias de ensino-aprendizagem que ocorrem no } \\
\text { ambiente do SUS são avaliadas conjuntamente pelos } \\
\text { profissionais da Rede e docentes. }\end{array}$ & $5,6 \%$ & $11,1 \%$ & $11,1 \%$ & $16,7 \%$ & $5,6 \%$ & $44,4 \%$ \\
\hline
\end{tabular}

\subsection{Comentários/sugestões de professores e acadêmicos sobre os itens}

\section{respondidos no instrumento}

Ao ser oferecida a oportunidade aos respondentes destes se manifestarem em relação ao instrumento, observou-se que majoritariamente os comentários retornados se referiram 
ao tema objeto do estudo mesmo e não sobre aspectos estruturais do instrumento. As

Figuras 50 e 51 apresentam essas colocações.

\begin{tabular}{|c|c|}
\hline $\mathbf{1}^{\circ}$ Semestre & $\begin{array}{l}\text { a princípio esse semestre da Enfermagem tem abordado o ideal de realização } \\
\text { de trabalho e pesquisa fora do ambiente universitário" }\end{array}$ \\
\hline $2^{\circ}$ Semestre & $\begin{array}{l}\text { Não conheço o Pró-Saúde. Seria interessante um parágrafo no início do } \\
\text { questionário explicando o que é e como funciona } \\
\text { O que falta na UnB são práticas hospitalares desde o primeiro ano, como } \\
\text { pode-se observar em faculdades como a ESCS } \\
\text { Colocar o projeto em regiões mais próximas. Paranoá e Itapoã: acesso difícil. } \\
\text { Não conheço as propostas do Pró-Saúde, ainda. }\end{array}$ \\
\hline $3^{\circ}$ Semestre & $\begin{array}{l}\text { Nossa formação é generalista e não há especialização ou ênfase em alguma } \\
\text { área. } \\
\text { Item } 10 \text { bloco } 4 \text { - não há como avaliar âmbito do SUS com prática em apenas } \\
\text { em } 1 \text { hospital }\end{array}$ \\
\hline $4^{\circ}$ Semestre & $\begin{array}{l}\text { Temos atividades práticas externas desde o primeiro semestre no curso de } \\
\text { Enfermagem } \\
\text { Seria válido explicar o projeto Pró-Saúde para aqueles que não conhecem }\end{array}$ \\
\hline $5^{\circ}$ Semestre & $\begin{array}{l}\text { Bloco } 2-7 \text { e 8: embora o curso aborde o conhecimento do sujeito como um } \\
\text { todo, as disciplinas estão dividias por especialidade. Além disso, as ligas } \\
\text { acadêmicas são outro processo para iniciar o ensino especializado, } \\
\text { fragmentado. } \\
\text { Desde o segundo semestre do curso de Enfermagem temos Vivências Práticas } \\
\text { no Hospital Universitário de Brasília, porém somente no } 2^{o} \text {. e } 6^{o} \text {. Semestre } \\
\text { tivemos contato com estágio externo à Universidade (Centro de Saúde } \\
\text { Paranoá e Caps II Taguatinga). }\end{array}$ \\
\hline $6^{\circ}$ Semestre & $\begin{array}{l}\text { Peguei o curso em transição e consequentemente houve disparidades } \\
\text { Bloco } 1 \text { item } 2 \text { - a saúde é uma área totalmente social do ponto de vista } \\
\text { político e pouco se aborda sobre as formas sociais de organização e de classe. } \\
\text { Bloco } 2 \text { item } 6 \text { - são realizadas, porém pouco estimuladas fora da disciplina } \\
\text { que se utiliza do espaço. } \\
\text { Bloco } 3 \text { item } 3 \text { - a maior preparação se dá principalmente nos princípios e } \\
\text { valores do curso. } \\
\text { Bloco } 3 \text { item } 7 \text { - influenciam, porém ainda é insuficiente para fortalecer o SUS } \\
\text { Bloco } 3 \text { item } 9 \text { - teoricamente deve ser um trabalho em equipe, mas na prática } \\
\text { não ocorre dessa maneira, } \\
\text { Eu acredito que o Pró-Saúde seja tudo de bom que o bloco } 3 \text { propõe, mas } \\
\text { como não conheço respondi "não sei" }\end{array}$ \\
\hline $7^{\circ}$ Semestre & $\begin{array}{l}\text { Penso que perdemos muito tempo no curso com situações que não } \\
\text { acrescentam muito à nossa formação.Deveriam ser oferecidas mais } \\
\text { disciplinas optativas da área da Enfermagem. São poucas as opções, nos }\end{array}$ \\
\hline
\end{tabular}




\begin{tabular}{|c|l|}
\hline & $\begin{array}{l}\text { levando a fazer disciplinas que nada acrescentam à nossa formação. } \\
\text { Seria interessante que se pergunte antes ao entrevistado se conhece o Pró- } \\
\text { Saúde ou explicar a amplitude do mesmo. }\end{array}$ \\
\hline $\mathbf{8}^{\mathbf{0}}$ Semestre & \multicolumn{1}{|c|}{ Sem comentários } \\
\hline $\mathbf{9}^{\mathbf{0}}$ Semestre & $\begin{array}{l}\text { Seção } 1 \text { item } 5-\text { a universidade oferece diversas optativas que possuem } \\
\text { experiência prática; contudo o currículo vigente não proporciona grande } \\
\text { mobilidade na grade horária para tal. A maioria das atividades práticas está } \\
\text { em estágios/vivências em matérias oferecidas pelo próprio currículo do curso. }\end{array}$ \\
$\begin{array}{l}\text { Vejo que os alunos que participam do Pró-Saúde possuem habilidades } \\
\text { diferenciadas. O curso de Enfermagem, observo algumas deficiências no } \\
\text { campo de práticas; poderia interagir melhor na regional do Paranoá em } \\
\text { relação às vivências ofertadas no projeto político pedagógico. }\end{array}$ \\
\hline
\end{tabular}

Figura 50- Comentários /sugestões dos estudantes sobre os itens respondidos.

Não atuo no Pró-Saúde

Bloco 2 item 5 - CAPS Taguatinga sim

Bloco 2 item 6 - sim, mas não apenas. Além do HUB, os alunos utilizam serviços da Secretaria de Saúde do DF

Bloco 4 item 3 - na concepção não, mas na prática sim

Bloco 3 - não respondi esse bloco pelo seguinte: eu poderia responder com base no meu conhecimento sobre o tema, mas não posso responder porque como funciona efetivamente entre UnB-Serviço tenho apenas indícios

Sou professora vinda de outra universidade, estou aqui há pouco tempo e aqui não estou envolvida com o Pró-Saúde, mas lá estava

Bloco 2 - há unidades com modelo tradicional, que não favorecem a ousada proposta de atender integralmente às necessidades das pessoas, famílias, comunidades (item 5). Há parceria entre ações od HUB e unidades básicas de saúde em várias Vivências (item 6). Predominantemente especializada (item 7). Há um caráter mais hospitalocêntrico do que de âmbito mais socialmente aplicável, no curso (item 10).

Tenho pouca certeza quanto a outras disciplinas serem inseridas preferencialmente na comunidade; sei que há bastante inserção em laboratórios.

Bloco 3 - incitam discutir, refletir, compartilharem juntos as práticas (como ocorrem e como poderiam ocorrer),

Bloco 4 - nem sempre é possível garantir a aplicação da teoria na prática; a interação ideal no âmbito social só tem ocorrido no currículo novo com o estágio; do contrário, é visto o paciente fora do seu contexto e de forma superficial no HUB.

Figura 51. Comentários /sugestões dos professores sobre os itens respondidos 


\section{Pontuação e codificação dos itens e blocos para interpretação das tendências}

\section{atitudinais}

Assim como no Estudo 1, cada item foi pontuado baseado na categorização do mesmo como uma atitude positiva ou negativa em relação ao objeto de estudo, conforme já ilustrado na Figura 10. Para a conversão das médias obtidas nos itens em conceitos, seguiuse a interpretação já descrita na Figura 36.

Em relação à dimensão teórica (bloco 1), pode-se observar nas Tabelas 41 e 42, que tanto professores quanto estudantes apresentaram valores das Médias similares, com ambos os grupos demonstrando tendência de atitudes neutra.

\section{Tabela 41}

Pontuação dos itens do bloco 1 em relação aos estudantes

\begin{tabular}{|c|c|c|c|c|c|c|c|c|c|c|}
\hline & B1Q2 & B1Q1 & B1Q3 & B1Q10 & B1Q4 & B1Q5 & B1Q7 & B1Q8 & B1Q6 & B1Q9 \\
\hline Sinal & + & - & + & - & + & - & + & - & + & - \\
\hline Soma & 220 & -252 & 155 & 160 & 68 & -85 & -1 & 128 & 69 & -33 \\
\hline Média & 1,07 & $-1,24$ & 0,79 & 0,85 & 0,44 & $-0,54$ & $-0,01$ & 1,09 & 0,45 & $-0,28$ \\
\hline $\begin{array}{l}\text { Desvio } \\
\text { Padrão }\end{array}$ & 0,71 & 0,75 & 0,82 & 1,43 & 0,93 & 1,11 & 1,00 & 1,15 & 0,98 & 1,16 \\
\hline Moda & 1 & -1 & 1 & 2 & 1 & -1 & 0 & 2 & 1 & -1 \\
\hline Mediana & 1 & -1 & 1 & 2 & 1 & -1 & 0 & 2 & 1 & -1 \\
\hline Conceito & C & CT & C & D & C & C & ND/NC & D & C & ND/NC \\
\hline Confirmatório & \multicolumn{2}{|c|}{$-0,16$} & \multicolumn{2}{|c|}{1,64} & \multicolumn{2}{|c|}{$-0,10$} & \multicolumn{2}{|c|}{1,08} & & \\
\hline Conceito & \multicolumn{2}{|c|}{ ND/NC } & \multicolumn{2}{|c|}{ CT } & \multicolumn{2}{|c|}{ ND/NC } & \multicolumn{2}{|c|}{ C } & & \\
\hline Bloco & \multicolumn{4}{|l|}{0,26} & \multicolumn{4}{|c|}{ ND/NC } & & \\
\hline
\end{tabular}


Tabela 42

Pontuação dos itens do bloco 1 em relação aos professores

\begin{tabular}{|c|c|c|c|c|c|c|c|c|c|c|}
\hline & B1Q2 & B1Q1 & B1Q3 & B1Q10 & B1Q4 & B1Q5 & B1Q7 & B1Q8 & B1Q6 & B1Q9 \\
\hline Sinal & + & - & + & - & + & - & + & - & + & - \\
\hline Soma & 26 & -27 & 11 & 0 & 9 & -10 & 7 & 8 & 8 & -8 \\
\hline Média & 1,53 & $-1,59$ & 0,69 & 0,00 & 0,69 & $-0,71$ & 0,50 & 0,67 & 0,73 & $-0,67$ \\
\hline $\begin{array}{l}\text { Desvio } \\
\text { Padrão }\end{array}$ & 0,62 & 0,80 & 1,25 & 1,22 & 1,18 & 0,83 & 1,34 & 1,37 & 0,79 & 1,07 \\
\hline Moda & 2 & -2 & 1 & 1 & 2 & -1 & 1 & 1 & 1 & -1 \\
\hline Mediana & 2 & -2 & 1 & 0 & 1 & -1 & 1 & 1 & 1 & -1 \\
\hline Conceito & CT & CT & C & ND/NC & C & C & C & D & C & C \\
\hline Confirmatório & \multicolumn{2}{|c|}{$-0,06$} & \multicolumn{2}{|c|}{0,69} & \multicolumn{2}{|c|}{$-0,02$} & \multicolumn{2}{|c|}{1,17} & & \\
\hline Conceito & \multicolumn{2}{|c|}{ ND/NC } & \multicolumn{2}{|c|}{ C } & \multicolumn{2}{|c|}{ ND/NC } & \multicolumn{2}{|c|}{ C } & & \\
\hline Bloco & \multicolumn{4}{|c|}{0,18} & \multicolumn{4}{|c|}{ ND/NC } & & \\
\hline
\end{tabular}

$\mathrm{Na}$ dimensão cenário de práticas, professores e estudantes demonstraram tendência atitudinal positiva em relação ao bloco. Houve uma pequena diferença no valor de M ao compará-los, de modo que ao se realizar a conversão para o conceito, os dois grupos obtiveram o conceito "concordo". Ao se realizar uma comparação entre os grupos, em cada item, assim como no Estudo 1, observou-se que nos itens classificados como negativos, houve uma tendência em se concordar com os mesmos, o que demonstra nesses casos uma tendência atitudinal negativa em relação ao construto analisado. Os dados obtidos estão descritos nas Tabelas 43 e 44.

Tabela 43

Pontuação dos itens do bloco 2 em relação aos estudantes

\begin{tabular}{|c|c|c|c|c|c|c|c|c|c|}
\hline & B2Q1 & B2Q2 & B2Q3 & B2Q4 & B2Q5 & B2Q6 & $\mathrm{B} 2 \mathrm{Q} 8$ & B2Q13 & B2Q12 \\
\hline Sinal & + & + & + & + & + & - & + & + & - \\
\hline Soma & 293 & 269 & 290 & 140 & 23 & -189 & 233 & 173 & -94 \\
\hline Média & 1,44 & 1,33 & 1,43 & 0,83 & 0,16 & $-1,03$ & 1,22 & 0,93 & $-0,52$ \\
\hline $\begin{array}{l}\text { Desvio } \\
\text { Padrão }\end{array}$ & 0,65 & 0,71 & 0,65 & 0,91 & 0,98 & 0,74 & 0,68 & 0,92 & 1,22 \\
\hline Moda & 2 & 2 & 2 & 1 & 0 & -1 & 1 & 1 & -1 \\
\hline Mediana & 2 & 1 & 2 & 1 & 0 & -1 & 1 & 1 & -1 \\
\hline Conceito & CT & CT & CT & C & ND/NC & C & CT & C & C \\
\hline Confirmatório & & & & & & & & \multicolumn{2}{|c|}{0,41} \\
\hline Conceito & & & & & & & & \multicolumn{2}{|c|}{ C } \\
\hline Bloco & 0,64 & & & & C & & & & \\
\hline
\end{tabular}


Tabela 44

Pontuação dos itens do bloco 2 em relação aos professores

\begin{tabular}{|c|c|c|c|c|c|c|c|c|c|}
\hline & B2Q1 & B2Q2 & B2Q3 & B2Q4 & B2Q5 & B2Q6 & B2Q8 & B2Q13 & B2Q12 \\
\hline Sinal & + & + & + & + & + & - & + & + & - \\
\hline Soma & 31 & 31 & 31 & 18 & -1 & -14 & 20 & 18 & -10 \\
\hline Média & 1,72 & 1,72 & 1,72 & 1,13 & $-0,11$ & $-0,93$ & 1,33 & 1,20 & $-0,67$ \\
\hline $\begin{array}{l}\text { Desvio } \\
\text { Padrão }\end{array}$ & 0,46 & 0,46 & 0,46 & 1,09 & 1,45 & 0,96 & 0,49 & 0,68 & 0,82 \\
\hline Moda & 2 & 2 & 2 & 2 & 1 & -1 & 1 & 1 & -1 \\
\hline Mediana & 2 & 2 & 2 & 2 & 0 & -1 & 1 & 1 & -1 \\
\hline Conceito & CT & CT & CT & C & ND/NC & C & CT & C & C \\
\hline Confirmatório & & & & & & & & \multicolumn{2}{|c|}{0,53} \\
\hline Conceito & & & & & & & & \multicolumn{2}{|c|}{ C } \\
\hline Bloco & 0,79 & & & & c & & & & \\
\hline
\end{tabular}

No bloco 3, da dimensão reorientação da formação, estudantes e professores apresentaram tendência atitudinal positiva, com o conceito $\mathrm{C}$ (concordo) ocorrendo em ambos os grupos ao se realizar a conversão das Médias. Os dados referentes a esse bloco encontram-se descritos nas Tabelas 45 e 46.

Tabela 45

Pontuação dos itens do bloco 3 em relação aos estudantes

\begin{tabular}{|c|c|c|c|c|c|c|c|c|c|c|c|c|c|}
\hline & B3Q1 & B3Q2 & B3Q3 & B3Q4 & B3Q8 & B3Q5 & B3Q6 & B3Q9 & B3Q7 & B2Q10 & B2Q7 & B2Q9 & B2Q11 \\
\hline Sinal & + & + & + & - & + & - & + & + & + & + & - & + & + \\
\hline Soma & -21 & 77 & 142 & 7 & 117 & 92 & 130 & 163 & 168 & 187 & 38 & 137 & 76 \\
\hline Média & $-0,13$ & 0,66 & 0,99 & 0,05 & 0,89 & 0,72 & 0,88 & 1,09 & 1,08 & 0,98 & 0,19 & 1,00 & 0,54 \\
\hline $\begin{array}{l}\text { Desvio } \\
\text { Padrão }\end{array}$ & 1,21 & 0,81 & 0,70 & 1,26 & 0,72 & 1,34 & 0,83 & 0,72 & 0,70 & 0,91 & 1,55 & 0,83 & 1,04 \\
\hline Moda & 1 & 1 & 1 & -1 & 1 & 2 & 1 & 1 & 1 & 1 & 2 & 1 & 1 \\
\hline Mediana & 0 & 1 & 1 & 0 & 1 & 0 & 1 & 1 & 1 & 1 & 0 & 1 & 1 \\
\hline Conceito & ND/NC & C & C & ND/NC & C & D & C & C & C & C & ND/NC & C & C \\
\hline Confirmatório & & & \multicolumn{2}{|c|}{1,05} & \multicolumn{2}{|c|}{1,61} & \multicolumn{2}{|c|}{1,97} & & \multicolumn{2}{|c|}{1,17} & & \\
\hline Conceito & & & \multicolumn{2}{|c|}{ C } & & & \multicolumn{2}{|c|}{ CT } & & \multicolumn{2}{|c|}{ C } & & \\
\hline Bloco & 0,69 & \multicolumn{12}{|c|}{ C } \\
\hline
\end{tabular}




\section{Tabela 46}

Pontuação dos itens do bloco 3 em relação aos professores

\begin{tabular}{|c|c|c|c|c|c|c|c|c|c|c|c|c|c|}
\hline & B3Q1 & B3Q2 & B3Q3 & B3Q4 & B3Q8 & B3Q5 & B3Q6 & B3Q9 & B3Q7 & B2Q10 & B2Q7 & B2Q9 & B2Q11 \\
\hline Sinal & + & + & + & - & + & - & + & + & + & + & - & + & + \\
\hline Soma & 13 & 9 & 15 & -1 & 14 & 10 & 14 & 14 & 14 & 25 & 5 & 14 & 10 \\
\hline Média & 0,87 & 0,69 & 1,15 & $-0,08$ & 1,17 & 0,77 & 1,08 & 1,08 & 1,17 & 1,39 & 0,28 & 1,17 & 0,91 \\
\hline $\begin{array}{l}\text { Desvio } \\
\text { Padrão }\end{array}$ & 1,13 & 1,32 & 0,90 & 0,90 & 0,72 & 1,24 & 0,64 & 1,04 & 0,72 & 0,61 & 1,18 & 1,03 & 0,83 \\
\hline Moda & 1 & 1 & 2 & 0 & 1 & 2 & 1 & 2 & 1 & 1 & 1 & 2 & 1 \\
\hline Mediana & 1 & 1 & 1 & 0 & 1 & 1 & 1 & 1 & 1 & 1 & 1 & 2 & 1 \\
\hline Conceito & C & C & C & ND/NC & C & D & C & C & C & CT & ND/NC & C & C \\
\hline Confirmatório & & & \multicolumn{2}{|c|}{1,07} & \multicolumn{2}{|c|}{1,94} & \multicolumn{2}{|c|}{2,15} & & \multicolumn{2}{|c|}{1,67} & & \\
\hline Conceito & & & \multicolumn{2}{|c|}{ C } & & & \multicolumn{2}{|c|}{ CT } & & \multicolumn{2}{|c|}{ CT } & & \\
\hline Bloco & 0,89 & \multicolumn{12}{|c|}{ C } \\
\hline
\end{tabular}

Na dimensão pedagógica os professores demonstraram uma tendência atitudinal mais positiva que os estudantes. Apresentaram uma média do bloco para favorável, com conceito C (concordo). Para os acadêmicos, a tendência no bloco foi neutra (NCND). Os resultados para cada item estão descrito nas Tabelas 47 e 48 .

\section{Tabela 47}

Pontuação dos itens do bloco 4 em relação aos estudantes

\begin{tabular}{|c|c|c|c|c|c|c|c|c|c|c|}
\hline & B4Q1 & B4Q3 & B4Q7 & B4Q2 & B4Q5 & B4Q4 & B4Q6 & B4Q8 & B4Q9 & B4Q10 \\
\hline Sinal & + & - & + & - & + & - & + & + & - & + \\
\hline Soma & 77 & -81 & 190 & -136 & 207 & -187 & 146 & 235 & 257 & 46 \\
\hline Média & 0,42 & $-0,49$ & 0,95 & $-0,70$ & 1,02 & $-0,95$ & 0,74 & 1,17 & 1,27 & 0,35 \\
\hline $\begin{array}{l}\text { Desvio } \\
\text { Padrão }\end{array}$ & 1,01 & 1,12 & 0,84 & 1,09 & 0,77 & 0,90 & 0,91 & 0,78 & 1,31 & 1,07 \\
\hline Moda & 1 & -1 & 1 & -1 & 1 & -1 & 1 & 1 & 2 & 1 \\
\hline Mediana & 1 & -1 & 1 & -1 & 1 & -1 & 1 & 1 & 2 & 1 \\
\hline Conceito & C & C & C & C & C & C & C & C & DT & ND/NC \\
\hline Confirmatório & \multicolumn{2}{|c|}{$-0,07$} & \multicolumn{2}{|c|}{0,24} & \multicolumn{2}{|c|}{0,08} & & \multicolumn{2}{|c|}{2,44} & \\
\hline Conceito & \multicolumn{2}{|c|}{ ND/NC } & \multicolumn{2}{|c|}{ ND/NC } & \multicolumn{2}{|c|}{ ND/NC } & & \multicolumn{2}{|c|}{ CT } & \\
\hline Bloco & \multicolumn{4}{|c|}{0,38} & \multicolumn{3}{|c|}{ ND/NC } & & & \\
\hline
\end{tabular}




\section{Tabela 48}

Pontuação dos itens do bloco 4 em relação aos professores

\begin{tabular}{|c|c|c|c|c|c|c|c|c|c|c|}
\hline & B4Q1 & B4Q3 & B4Q7 & B4Q2 & B4Q5 & B4Q4 & B4Q6 & B4Q8 & B4Q9 & B4Q10 \\
\hline Sinal & + & - & + & - & + & - & + & + & - & + \\
\hline Soma & -2 & -3 & 23 & 2 & 29 & 7 & 25 & 24 & 18 & 1 \\
\hline Média & $-0,11$ & $-0,20$ & 1,28 & 0,12 & 1,61 & 0,39 & 1,39 & 1,41 & 1,06 & 0,11 \\
\hline $\begin{array}{l}\text { Desvio } \\
\text { Padrão }\end{array}$ & 0,90 & 1,01 & 0,75 & 0,93 & 0,50 & 1,42 & 0,50 & 0,80 & 1,09 & 1,27 \\
\hline Moda & 0 & -1 & 2 & 0 & 2 & 1 & 1 & 2 & 1 & 1 \\
\hline Mediana & 0 & 0 & 1 & 0 & 2 & 1 & 1 & 2 & 1 & 0 \\
\hline Conceito & ND/NC & ND/NC & CT & ND/NC & CT & ND/NC & CT & CT & D & ND/NC \\
\hline Confirmatório & \multicolumn{2}{|c|}{$-0,31$} & \multicolumn{2}{|c|}{1,40} & \multicolumn{2}{|c|}{2,00} & & \multicolumn{2}{|c|}{2,47} & \\
\hline Conceito & \multicolumn{2}{|c|}{ ND/NC } & & $\mathrm{T}$ & \multicolumn{2}{|c|}{ CT } & & \multicolumn{2}{|c|}{ CT } & \\
\hline Bloco & 0,71 & & & & & C & & & & \\
\hline
\end{tabular}

Para a análise comparativa entre estudantes e professores por bloco, calculou-se a soma de cada indivíduo de cada grupo (estudantes e professores). Considerando que havia itens positivos (favoráveis ao Pró-saúde) e negativos (desfavoráveis ao Pró-saúde), a soma indica o quão favorável ao Pró-saúde cada indivíduo é em cada bloco. Na sequência, aplicou-se o Teste H de Kruskal-Wallis, para verificação das diferenças entre as medianas dos grupos. Para rejeitar a hipótese de igualdade, foi considerado nível mínimo de significância de 5\%. A comparação entre Medianas para os dois grupos para os quatro blocos estão apresentadas na Tabela 49. 
Tabela 49

Comparação entre as medianas para estudantes e professores nos blocos 1, 2, 3 e 4 .

\begin{tabular}{lc|c|c|c|c}
\hline \multicolumn{2}{c|}{ GRUPO } & BLOCO 1 & BLOCO 2 & BLOCO 3 & BLOCO 4 \\
\hline Estudantes & $\mathrm{N}$ & 207 & 207 & 207 & 207 \\
& Mediana & 2,00 & 5,00 & 6,00 & 4,00 \\
\hline Professores & $\mathrm{N}$ & 18 & 18 & 18 & 18 \\
& Mediana & 2,00 & 6,50 & 6,50 & 5,50 \\
\hline \multirow{2}{*}{ Total } & $\mathrm{N}$ & 225 & 225 & 225 & 225 \\
& $\mathrm{Mediana}$ & 2,00 & 6,00 & 6,00 & 4,00 \\
\hline
\end{tabular}

Nos blocos 1, 2 e 3 o teste de Kruskal-Wallis não indicou diferenças significativas entre professores e estudantes. Para o bloco 4, a diferença entre os dois grupos foi estatisticamente significante. A Tabela 50 apresenta o resultado comparativo entre professores e estudantes para as quatro dimensões estudadas, assim como os valores de $p$ e do teste Kruskall Wallis.

\section{Tabela 50}

Comparação dos resultados entre professores e estudantes para as quatro dimensões estudadas.

\begin{tabular}{|c|c|c|c|c|c|c|c|c|}
\hline \multirow[t]{2}{*}{ Grupo } & \multicolumn{2}{|c|}{$\begin{array}{c}\text { Bloco } 1 \\
\text { dimensão teórica }\end{array}$} & \multicolumn{2}{|c|}{$\begin{array}{c}\text { Bloco } 2 \\
\text { cenário de práticas }\end{array}$} & \multicolumn{2}{|c|}{$\begin{array}{c}\text { Bloco } 3 \\
\text { reorientação da } \\
\text { formação } \\
\end{array}$} & \multicolumn{2}{|c|}{$\begin{array}{c}\text { Bloco } 4 \\
\text { dimensão } \\
\text { pedagógica }\end{array}$} \\
\hline & $\begin{array}{c}\text { média } \\
\text { dos } \\
\text { escores }\end{array}$ & Conceito & $\begin{array}{c}\text { média } \\
\text { dos } \\
\text { escores }\end{array}$ & conceito & $\begin{array}{c}\text { média } \\
\text { dos } \\
\text { escores }\end{array}$ & Conceito & $\begin{array}{l}\text { média } \\
\text { dos } \\
\text { escores }\end{array}$ & conceito \\
\hline Estudantes & 0,26 & $\begin{array}{c}\text { não } \\
\text { concordo } \\
\text { nem } \\
\text { discordo }\end{array}$ & 0,64 & concordo & 0,69 & concordo & 0,38 & $\begin{array}{l}\text { não } \\
\text { concordo } \\
\text { nem } \\
\text { discordo }\end{array}$ \\
\hline Professores & 0,18 & $\begin{array}{c}\text { não } \\
\text { concordo } \\
\text { nem } \\
\text { discordo }\end{array}$ & 0,79 & concordo & 0,89 & concordo & 0,71 & concordo \\
\hline $\begin{array}{l}\text { Teste de } \\
\text { Kruskal-Wallis }\end{array}$ & \multicolumn{2}{|c|}{$\mathrm{H}(1)=0,109$} & \multicolumn{2}{|c|}{$\mathrm{H}(1)=3,611$} & \multicolumn{2}{|c|}{$\mathrm{H}(1)=1,287$} & \multicolumn{2}{|c|}{$\mathrm{H}(1)=6,771$} \\
\hline Valor de p & \multicolumn{2}{|c|}{$\mathrm{p}=0,741$} & \multicolumn{2}{|c|}{$p=0,057$} & \multicolumn{2}{|c|}{$P=0,257$} & \multicolumn{2}{|c|}{$p=0,009$} \\
\hline
\end{tabular}




\section{Análise de conteúdo das entrevistas}

Nesta etapa do estudo, sete estudantes e oito professores foram entrevistados. Norteadas pela temática reorientação da formação, e possuindo como elemento de análise o Pró-Saúde, as entrevistas geraram, pelo procedimento de caixas (Bardin, 2009) as seguintes categorias: perfil percebido; currículo; processo de ensino e aprendizagem; cenário de práticas e implementação das ações. Na Figura 21 foi apresentado o modelo descritivo utilizado de forma similar nos estudos dos três cursos propostos para análise.

A partir das categorias, foram estabelecidas subcategorias, e neste momento obtivemos algumas variações entre estudantes e professores, além das variações entre os cursos. Unidades de registro de cada subcategoria estão representadas respectivamente, para estudantes e professores, nas Figuras 52 e 53. 


\begin{tabular}{|c|c|c|}
\hline CATEGORIA & $\begin{array}{c}\text { SUB } \\
\text { CATEGORIAS }\end{array}$ & UNIDADE DE REGISTRO \\
\hline \multirow{5}{*}{$\begin{array}{l}\text { PERFIL } \\
\text { PERCEBIDO }\end{array}$} & Generalista & $\begin{array}{l}\text { "eu acho que o modelo da enfermagem no caso da UnB, ele é bem generalista" (EE1) } \\
\text { "uma formação mais ampla" (EE1) } \\
\text { "trocar experiências com profissionais de outras áreas e ter liberdade para poder fazer isso" (EE3) } \\
\text { "é complicado falar sobre generalista porque a gente vai fazer de tudo um pouco, mas no fundo a gente } \\
\text { não chega a ver esse de tudo um pouco" (EE2) } \\
\text { "estamos conseguindo as vivências agora no curso da Enfermagem, pelo menos uma vez na vida a gente } \\
\text { vai passar uma sonda..." (EE2) } \\
\text { "seria trabalhar numa equipe multiprofissional" (EE3) } \\
\text { "eu acho que a formação generalista da UnB deixa um pouco a desejar, mas no geral acho que vou sair } \\
\text { capacitada em qualquer área que eu cair" (EE5) } \\
\text { "esse profissional deve saber de tudo um pouco, um pouco de cada área" (EE6) } \\
\text { "acho que a gente vê muito uma visão bem ampla" (EE7) }\end{array}$ \\
\hline & Especialista & $\begin{array}{l}\text { "o enfermeiro que a gente está lançando é generalista, mas ele busca de alguma forma uma } \\
\text { especialização" (EE1) }\end{array}$ \\
\hline & $\begin{array}{l}\text { Responsabilidade } \\
\text { profissional }\end{array}$ & $\begin{array}{l}\text { "a gente está aprendendo a ter autonomia" (EE2) } \\
\text { "às vezes acontece algum erro e a gente não quer ser esse profissional que vai errar porque vamos estar } \\
\text { lidando com vidas (EE3) } \\
\text { "um enfermeiro que sabe o seu papel na sociedade" (EE4) }\end{array}$ \\
\hline & Crítico & $\begin{array}{l}\text { "o enfermeiro que estamos lançando não é mais aquele enfermeiro que, se o médico mandou ele fazer } \\
\text { alguma coisa ele vai lá e faz" (EE2) } \\
\text { "a gente sempre quer saber mais, você quer aprender tudo o que você tem que saber" ((EE3) } \\
\text { "um enfermeiro extremamente crítico" (EE4) } \\
\text { "acho que a gente tem um senso crítico que as outras universidades não têm" (EE5) } \\
\text { "enfermeiro com o pensamento crítico" (EE7) }\end{array}$ \\
\hline & Teórico & $\begin{array}{l}\text { "um enfermeiro mais teórico um enfermeiro que sabe a teoria, mas na prática vai ter muita dificuldade" } \\
\text { (EE6) }\end{array}$ \\
\hline
\end{tabular}




\begin{tabular}{|c|c|c|}
\hline \multirow[t]{3}{*}{ CURRÍCULO } & $\begin{array}{l}\text { Oferta de } \\
\text { atividades práticas }\end{array}$ & $\begin{array}{l}\text { "a gente tem certo problemas por poucas aulas e poucas práticas" (EE1) } \\
\text { "eu acho que as práticas, elas podiam ser mais inseridas dentro do serviço" (EE1) } \\
\text { "a gente precisa de mais tempo de prática" (EE2) } \\
\text { "tem bastante pra melhorar, mas estamos conseguindo. Pelo menos uma vez na vida a gente vai passar } \\
\text { uma sonda" (EE2) } \\
\text { "não sei se é porque é currículo novo, às vezes o professor tem um pouco de receio de deixar a gente tão } \\
\text { solto" (EE5) } \\
\text { "a gente é inserido, mas é inserido muito na vivência, mas é muito observação" (EE5) } \\
\text { "as práticas deveriam ter mais uma atenção pra ela do professor, pra acompanhar o aluno mesmo, } \\
\text { acompanhar se ele está fazendo o procedimento correto" (EE6) } \\
\text { "eu acho que a prática deveria ser mais longa, acho que é muito pouca hora" (EE6) } \\
\text { "peca um pouco em relação à prática" (EE7) } \\
\text { "eu acho sempre pouco. A gente vai sair da faculdade ainda não preparados pra atuar" (EE7) } \\
\text { "como a turma é grande tem grupos, e nem todos fazíamos o procedimento" (EE7) } \\
\text { "maior carga horária em relação a aulas práticas" (EE7) }\end{array}$ \\
\hline & Fragmentação & $\begin{array}{l}\text { "a gente vê uma boa distinção do ciclo básico para o restante do curso" (EE2) } \\
\text { "a gente vê algumas coisas e se pergunta - pra que eu vou usar isso? Depois a gente vai vendo que tudo é } \\
\text { importante" (EE2) } \\
\text { "o curso daqui prega muito a teoria, fala que você tem que ter a teoria porque sem a teoria você não tem a } \\
\text { prática" (EE6) } \\
\text { "eu acho que ter o mesmo nível na balança, tanto na teoria quanto na prática e aqui tem mais teoria, pelo } \\
\text { menos até agora onde estou" (EE6) } \\
\text { "a gente vê muito no primeiro e segundo semestre a parte da teoria e a prática só foram dois dias na } \\
\text { atenção básica nunca mais" (EE7) }\end{array}$ \\
\hline & $\begin{array}{l}\text { Integração entre } \\
\text { áreas do curso }\end{array}$ & $\begin{array}{l}\text { "acho que não existe essa integração" (EE1) } \\
\text { "um problema que a gente tem é que as áreas não se conversam. Os professores estão muito dentro de } \\
\text { suas linhas de pesquisa" (EE1) } \\
\text { "a partir do quarto ou quinto semestre a gente começa a ver a prática, a gente começa a integrar o que } \\
\text { vimos em sala de aula com o que a gente faz no hospital" (EE2) } \\
\text { "eu tenho dificuldade de falar do curso. Eu tenho facilidade de falar dos semestres que estou envolvida" } \\
\text { (PE3) } \\
\text { "nós temos as vivências integradoras, e elas buscam integrar todas as matérias do semestre na prática }\end{array}$ \\
\hline
\end{tabular}




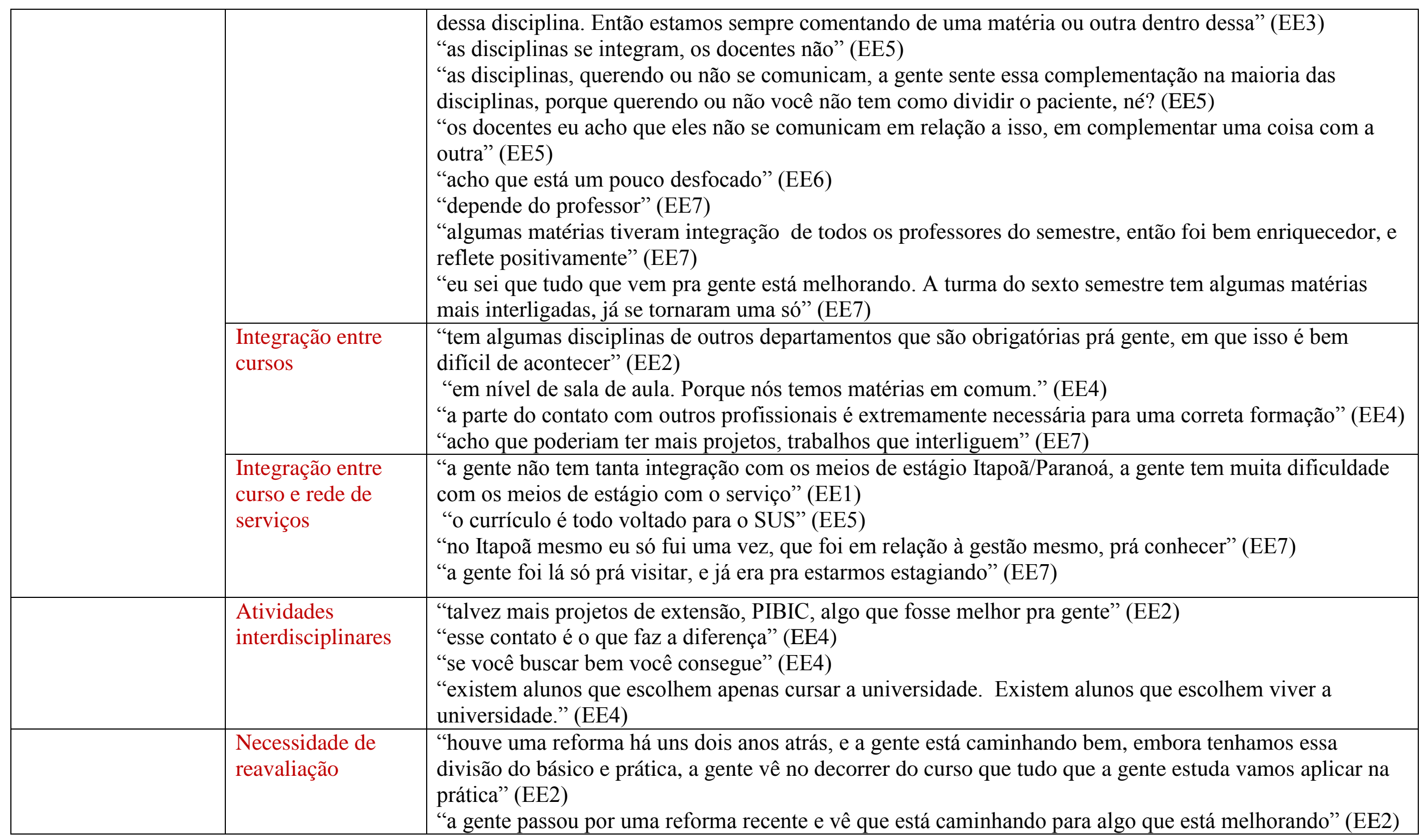




\begin{tabular}{|c|c|c|}
\hline & & $\begin{array}{l}\text { "a gente está em um currículo novo que já está em defasagem, já tem que ser reformulado" (EE5) } \\
\text { "a gente vê muitas falhas no processo... muitas perdas em relação ao outro currículo, ganhos que eles } \\
\text { ainda não sabem lidar, que seria a questão da prática: eu acho que eles não sabem lidar com essas horas- } \\
\text { aula que a gente ganhou da prática" (EE5) } \\
\text { "é um processo que eles não prepararam, foi jogado, lançado e agora que está acontecendo, eles estão } \\
\text { tentando reestruturar, não houve planejamento... é a impressão que passa...” (EE5) }\end{array}$ \\
\hline \multirow{4}{*}{$\begin{array}{c}\text { PROCESSO DE } \\
\text { ENSINO E } \\
\text { APRENDIZAGEM }\end{array}$} & $\begin{array}{l}\text { Metodologias } \\
\text { tradicionais }\end{array}$ & $\begin{array}{l}\text { "alguns professores continuam naquela de aula mais expositiva, falar a técnica" (EE1) } \\
\text { "no ciclo básico a gente assiste muita aula expositiva, mais teoria" (EE2) } \\
\text { "nos primeiros semestres são matérias gerais, não é tão empolgante" (EE3) } \\
\text { "nós temos o modelo clássico, né, do fala, fala, fala, joga informação, só que temos o incentivo da busca. } \\
\text { "predominante é a tradicional" (EE5) } \\
\text { "mais aula expositiva" (EE5) } \\
\text { "ah, slide... os professores não vivem sem slide. E se não tiver slide não tem aula" (EE6) } \\
\text { "mais metodologias tradicionais mesmo; passam a teoria, apresentação expositiva, tem algumas que são a } \\
\text { aula e exercícios em sala" (EE7) }\end{array}$ \\
\hline & $\begin{array}{l}\text { Metodologias } \\
\text { inovadoras }\end{array}$ & $\begin{array}{l}\text { "tem um certo dinamismo, alguns professoras utilizam dinâmicas" (EE1) } \\
\text { "tem professor que não tem como inovar muito, então os que vejo que tem como, eles se esforçam para } \\
\text { mostrar isso pra gente" (EE3) } \\
\text { "o professor passa a bibliografia e fala que não é só isso não, tem um canal no you tube, tem artigos assim } \\
\text { interessantes" (EE4) } \\
\text { "tem professores que tiram de sala mesmo ... como no exemplo do Pró-Saúde, com anatomia no semestre } \\
\text { passado. Estávamos terminando o módulo e disseram: agora vocês vão ter que trabalhar com crianças" } \\
\text { (EE4) } \\
\text { "mais do que do professor, depende de recursos" (EE4) } \\
\text { "mais pro final, nos estágios finais que a gente está com a metodologia, como se fala?...mais ativa? (EE5) }\end{array}$ \\
\hline & $\begin{array}{l}\text { Integração entre } \\
\text { teoria e prática }\end{array}$ & $\begin{array}{l}\text { "a gente às vezes vê picado, teoria, não fazemos a prática" (EE2) } \\
\text { "normalmente quando o primeiro grupo vai, ele não vê teoria" (EE7) } \\
\text { "acho que deveriam impedir: não vão para a vivencia, todos vão ver primeiro a teoria, depois vão" (EE7) }\end{array}$ \\
\hline & $\begin{array}{l}\text { Influência das } \\
\text { metodologias }\end{array}$ & $\begin{array}{l}\text { "os alunos acaba se apegando porque acaba estudando só pelos slides" (EE6) } \\
\text { "às vezes se o professor esquece o slide em casa, a aula é muito superficial" (EE6) }\end{array}$ \\
\hline
\end{tabular}




\begin{tabular}{|c|c|c|}
\hline \multirow{3}{*}{$\begin{array}{l}\text { CENÁRIO DE } \\
\text { PRÁTICAS }\end{array}$} & Hospital & $\begin{array}{l}\text { "de um semestre pra outro você passa de } 2 \text { para } 6 \text { créditos no hospital, aí você tem que se virar, fazer um } \\
\text { monte de coisa que eles acham que você já viu. Deveria ser maior desde o início" (EE6) } \\
\text { "acho que poderia ser melhor aproveitada essa questão do campo de estágio, porque a gente tem o hospital } \\
\text { universitário pra ser aproveitado" (EE5) } \\
\text { "a gente vai à medida que as matérias vão passando, acho que é muito pouco aproveitado" (EE5) }\end{array}$ \\
\hline & Rede de serviços & $\begin{array}{l}\text { "as faculdades particulares tem mais acesso do que nós nos campos de estágio" (EE1) } \\
\text { "os professores tentam, tem uma tentativa, mas tem essa barreira política que impede a gente de ser } \\
\text { inserido na totalidade no serviço" (EE1) } \\
\text { "a gente vê que a gente pode fazer alguma coisa pra mudar a comunidade" (EE2) } \\
\text { "na matéria de anatomia, que é no primeiro semestre tem o pró-saúde, que no meu caso a gente foi pra um } \\
\text { posto de saúde, fizemos entrevista pra saber o que as pessoas tinham curiosidade em saber, sobre quais } \\
\text { sistemas, depois voltamos prá cá, preparamos uma breve apresentação e fomos lá expor isso algumas } \\
\text { semanas depois" (EE3) } \\
\text { "acho que vamos começar com as vivências" (EE4) } \\
\text { "só com o Pró-Saúde, com a turma toda com a disciplina de Anatomia" (EE4) } \\
\text { "a gente tem o centro de saúde que é mais pro final, eu acho que s gente aproveita bem" (EE5) } \\
\text { "a gente não tem muita abertura na prática em estágio" (EE5) } \\
\text { "eles nunca dão preferência pra gente" (EE5) } \\
\text { "a gente sempre fica com o que sobra" (EE5) } \\
\text { "em vivências } 1 \text { a gente só vai visitar o posto de saúde, ver como funciona o SUS, e parece que a } 2 \text { é a } \\
\text { mesma coisa" (EE6) } \\
\text { "a gente não teve ainda autorização... não sei... para a prática no hospital do Paranoá" (EE7) }\end{array}$ \\
\hline & Divulgação & $\begin{array}{l}\text { "já ouvi falar muito inclusive, mas não sei o que é” (EE1) } \\
\text { "muita gente não sabe, não tem conhecimento, a gente não vê divulgação" (EE1) } \\
\text { "mas a gente só participação porque no início era obrigatório. Se não fosse eu não saberia. Se talvez } \\
\text { tivessem mais projeto integrados com as disciplinas, talvez as pessoas tomassem gosto para prosseguir" } \\
\text { (EE3) } \\
\text { "nunca foi falado pra gente" (EE5) } \\
\text { "ainda não vi e não vejo divulgação, não vejo muita gente falando" (EE6) } \\
\text { "quando entrei, antes foi muito difícil em relação à publicação. Faltou publicação da faculdade para os } \\
\text { alunos em sala de aula" (EE7) }\end{array}$ \\
\hline
\end{tabular}




\begin{tabular}{|c|c|c|}
\hline \multirow[t]{4}{*}{$\begin{array}{l}\text { IMPLEMENTAÇÃO } \\
\text { DAS AÇÕES } \\
\text { DO PRÓ-SAÚDE }\end{array}$} & Motivação & $\begin{array}{l}\text { "falta mais comunicação com o aluno" (EE1) } \\
\text { "teve um momento que era obrigatória a disciplina, depois alguns alunos optaram por prosseguir" (EE3) } \\
\text { "mas a gente só participa porque no início era obrigatório. Se não fosse eu não saberia" } \\
\text { "eu garanto que se no primeiro semestre se a gente tivesse levado a minha turma pelo menos duas ou três } \\
\text { vezes a um hospital, posto de saúde, a um centro comunitário, os colegas que desistiram não teriam } \\
\text { tomado essa decisão " (EE4) } \\
\text { "incentivar mais os alunos" (EE6) } \\
\text { "muito não conhecem ou não querem conhecer. Não tem interesse" (EE7) } \\
\text { "proposta muito boa na teoria, mas acho que não conseguiu alcançar todo mundo. Não vejo ele chegar até } \\
\text { mim" (EE5) }\end{array}$ \\
\hline & $\begin{array}{l}\text { Conflitos de } \\
\text { interesse }\end{array}$ & $\begin{array}{l}\text { 'acho que um pouco a visão dos professores, que estão naquilo há tanto tempo e não querem mudar” } \\
\text { (EE2) } \\
\text { "acho que falta dizer pra todo mundo que isso é uma equipe" (EE4) }\end{array}$ \\
\hline & Barreiras & $\begin{array}{l}\text { "toda essa burocracia atrapalha demais, criam normas demais" (EE4) } \\
\text { "no segundo semestre eu estava correndo atrás de qualquer tipo de projeto e é muito difícil" (EE7) }\end{array}$ \\
\hline & Contribuições & $\begin{array}{l}\text { “o que a gente escuta é que o Pró-Saúde é mais um projeto com essa parte diferenciada, de mais } \\
\text { aproximação da atenção mesmo, do serviço" (EE1) } \\
\text { "tem muita gente do Pró-Saúde, não só da Enfermagem que começa a ver com outros olhos } \\
\text { principalmente a Atenção Básica" (EE2) } \\
\text { "a gente trabalha com equipe multidisciplinar. A gente não vê isso acontecendo no hospital, mesmo que } \\
\text { tenha que acontecer. E no Pró-Saúde nós vemos isso" (EE2) } \\
\text { "a gente está aprendendo que tem como fazer. Não é o ideal, mas tem como, você vai resolver. Você não } \\
\text { vai deixar a pessoa sem o atendimento que ela precisa" (EE3) } \\
\text { "a gente tem o contato com pessoas, essa vivência de conhecer pessoas que você vai ter que trabalhar } \\
\text { depois, lugares" (EE3) } \\
\text { "a partir do momento que você coloca em contato, mesmo que mínimo, é significativo" (EE4) }\end{array}$ \\
\hline
\end{tabular}

Figura 52 - Unidades de registro das subcategorias obtidas da análise de conteúdo das entrevistas dos estudantes de Enfermagem. 


\begin{tabular}{|c|c|c|}
\hline CATEGORIA & $\begin{array}{c}\text { SUB } \\
\text { CATEGORIAS }\end{array}$ & UNIDADE DE REGISTRO \\
\hline \multirow[t]{4}{*}{$\begin{array}{c}\text { PERFIL } \\
\text { PERCEBIDO }\end{array}$} & Generalista & $\begin{array}{l}\text { "eu penso que esse profissional é realmente um generalista, não tem como sair disso aí, e eu } \\
\text { penso que não é da competência da graduação formar um especialista" (PE4) } \\
\text { "a ideia é para o cuidado humano do paciente" (PE2) } \\
\text { "estamos formando profissionais na perspectiva do SUS e nessa perspectiva temos que formar } \\
\text { profissionais que sejam competentes dentro de um cuidado integral” (PE3) } \\
\text { "uma das competências que ganha relevância é o saber ser... saber considerar a necessidade, a } \\
\text { especificidade do contexto e olhar pro outro de uma forma mais especial " (PE4) } \\
\text { "num primeiro momento, porque com o tempo o profissional vai se especializar" (PE6) } \\
\text { "ter estabelecido as principais metas de comunicação, de relacionamento interpessoal, você } \\
\text { aprende a exercitar um pouco a capacidade de troca com a equipe interdisciplinar, } \\
\text { multiprofissional" (PE7) } \\
\text { "observar a singularidade das pessoas, das suas inserções, e tornar o cuidado sempre em } \\
\text { equipe... está se tentando construir, embora um diálogo mais de perto com os campos é uma } \\
\text { coisa que pode se estreitar" (PE8) }\end{array}$ \\
\hline & Tradicionalista & $\begin{array}{l}\text { "ainda há uma predominância do perfil biomédico, tecnicista" (PE4) } \\
\text { "alunos preparados do ponto de vista teórico-prático, mas nessa parte de saber conversar, ter } \\
\text { postura, olhar nos olhos, penso que nesse sentido, um pouco mais com dificuldade" (PE7) } \\
\text { "eu acho que não é exatamente um enfermeiro que vai sair tão preparado para atuar na atenção } \\
\text { primária; mais na parte hospitalar mesmo, é a característica do curso" (PE8) }\end{array}$ \\
\hline & $\begin{array}{l}\text { Preparado para } \\
\text { mercado }\end{array}$ & $\begin{array}{l}\text { "o enfermeiro pode trabalhar tanto no hospital, quanto em unidade de saúde" (PE1) } \\
\text { "estou percebendo que estão com uma mente muito aberta para o novo" (PE2) } \\
\text { "tem muitos alunos nossos que foram formados por nós, e que estão em cargos de liderança; } \\
\text { eles estão tendo assim facilidade de inserção" (PE3) } \\
\text { "ele está saindo com possibilidades de abertura de aprendizagem pro novo, e é bastante } \\
\text { positivo" (PE4) }\end{array}$ \\
\hline & Comprometimento & $\begin{array}{l}\text { "o que eu vejo é que os alunos estão saindo sem toda a formação que deveriam, não só por } \\
\text { limitação de condução do curso, mas também por falta de compromisso por parte dos alunos } \\
\text { mesmo, porque a maioria deles quer cumprir a atividade prá ter nota" (PE1) } \\
\text { Eles estão entrando muito novos, então saem sem muita maturidade" (PE1) } \\
\text { "eles são responsáveis, compromissados, muito raramente a gente vê um mais sem }\end{array}$ \\
\hline
\end{tabular}




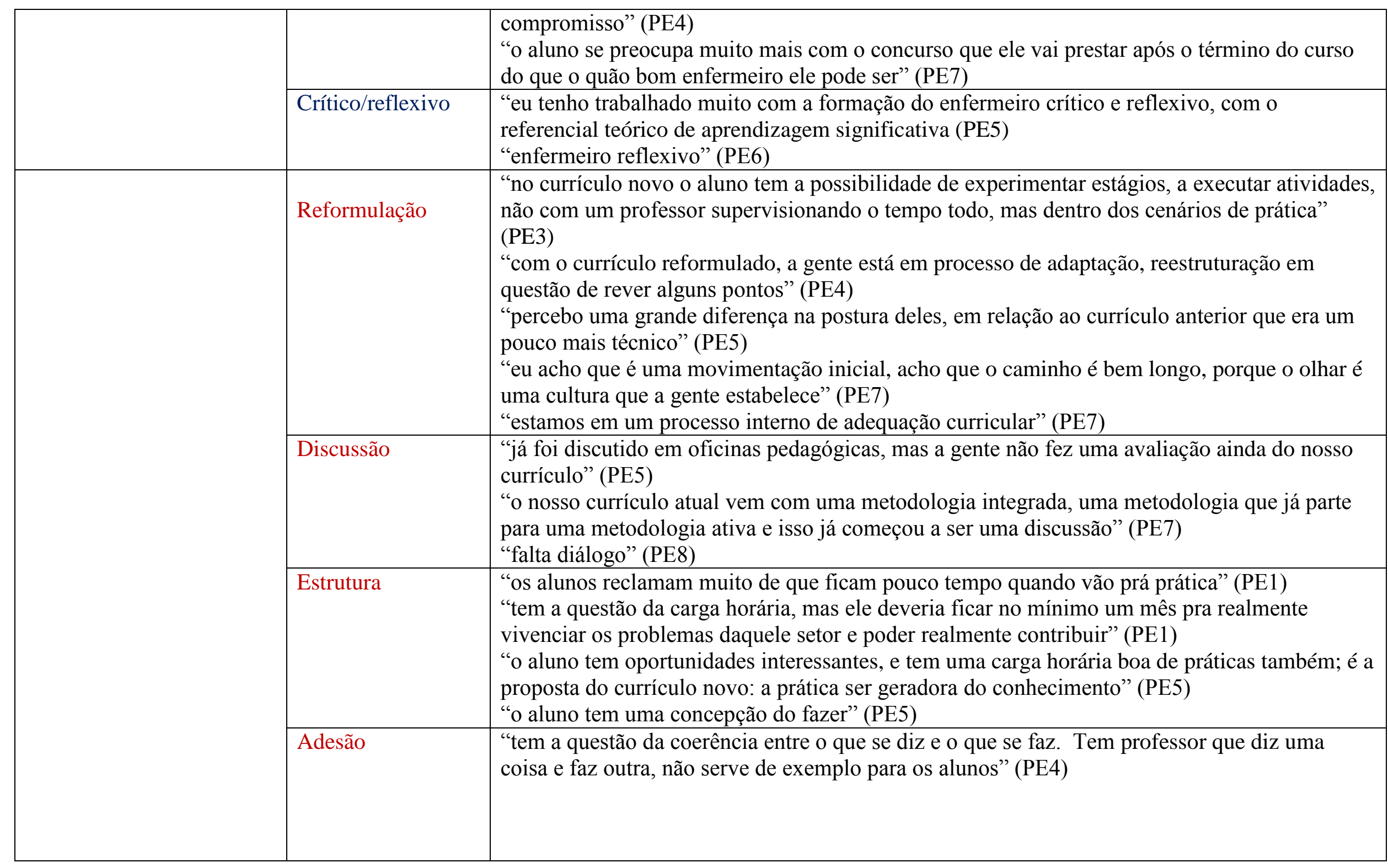




\begin{tabular}{|c|c|c|}
\hline \multirow[t]{2}{*}{ CURRÍCULO } & $\begin{array}{l}\text { Integração entre } \\
\text { disciplinas do curso }\end{array}$ & $\begin{array}{l}\text { "vejo que a integração é um problema de formação profissional. Para o profissional ser } \\
\text { integrado, ele tem que ter a vivência não só da disciplina, mas o que aquela disciplina pode } \\
\text { contribuir para a formação daquele profissional” (PE1) } \\
\text { "percebo nas reuniões que é uma preocupação dos docentes, eles estão preocupados com a } \\
\text { inserção dos professores das disciplinas básicas" (PE2) } \\
\text { "para o aluno enriquece. Ele sozinho não consegue fazer esse link" (PE1) } \\
\text { "em algumas áreas a integração acontece a contento. No meu semestre e na minha área está } \\
\text { tudo integrado, mas pelos comentários" (PE4) } \\
\text { "ainda tem algumas ações muito dispersas ainda, em que cada um faz do seu jeito, de sua } \\
\text { maneira, alguns fogem, talvez por essa falta de preparo, por essa falta de capacitação" (PE4) } \\
\text { "existem conteúdos que são transversais" (PE5) } \\
\text { "a gente faz a comunicação pensando nos eixos de integração vertical, mas não há um } \\
\text { planejamento conjunto das disciplinas" (PE5) } \\
\text { "vejo que essas barreiras aos poucos vão se rompendo" (PE6) } \\
\text { "eles tem que avançar para outros campos, como outras disciplinas avançam para o campo em } \\
\text { que estou" (PE6) } \\
\text { "precisa melhorar bastante. Existe uma aproximação mínima, mas eu acredito que precisa } \\
\text { melhorar..." (PE7) }\end{array}$ \\
\hline & $\begin{array}{l}\text { Integração entre } \\
\text { curso e rede de } \\
\text { serviços }\end{array}$ & $\begin{array}{l}\text { "é válido, porque querendo ou não, alguns profissionais que estão ali, alguns estão } \\
\text { acomodados e outros têm uma sobrecarga de trabalho muito grande e que já não tem aquele } \\
\text { olhar diferenciado para falar com um idoso" (PE1) } \\
\text { "não vou falar pelo curso, vou falar por mim: não tenho queixa absolutamente nenhuma, eles } \\
\text { são super abertos" (PE3) } \\
\text { "a crítica é mais burocrática, é a assinatura do papel, é o pedido, é o transporte que se pede, é } \\
\text { muito desgastante" (PE4) }\end{array}$ \\
\hline
\end{tabular}




\begin{tabular}{|c|c|c|}
\hline & & $\begin{array}{l}\text { "tem um componente burocrático" (PE6) } \\
\text { "toda a parte burocrática que é necessária é muito desgastante, pra gestão é desanimadora" } \\
\text { (PE7) } \\
\text { "tem muito a ser melhorado e a ser incentivada a melhora daqueles que já estão bons, porque a } \\
\text { gente não pode generalizar de jeito nenhum" (PE7) }\end{array}$ \\
\hline \multirow[b]{3}{*}{$\begin{array}{l}\text { PROCESSO DE ENSINO } \\
\text { E APRENDIZAGEM }\end{array}$} & Transição & $\begin{array}{l}\text { "é muito complicado porque a gente parte daquela parte tradicional e a gente tem que avançar } \\
\text { pra outras metodologias ativas e participativas" (PE7) }\end{array}$ \\
\hline & Perfil do estudante & $\begin{array}{l}\text { "ele vem com pouca autonomia na condução do processo de ensino, com insegurança e } \\
\text { esperando o professor" (PE5) }\end{array}$ \\
\hline & $\begin{array}{l}\text { Metodologias } \\
\text { inovadoras }\end{array}$ & $\begin{array}{l}\text { "percebo que quando trabalho com a metodologia ativa num determinado conteúdo, aproximo } \\
\text { o aluno mais da realidade" (PE1) } \\
\text { "o que eu percebo é que eles vão vivenciando a disciplina. Você pode cursar uma disciplina e } \\
\text { você pode viver a disciplina. Parece que eles participam do processo de construção da } \\
\text { disciplina" (PE2) } \\
\text { "a necessidade de inovação é uma tendência mundial" (PE5) } \\
\text { "vejo que eles vêm com pouca experiência em relação a essa metodologia mais ativa" (PE5) } \\
\text { "no começo eles ficam meio incomodados, mas no final avaliam como uma experiência } \\
\text { positiva e que ajudou realmente a aprender" (PE5) } \\
\text { "estamos ainda em um momento de reconhecimento dessa tecnologia" (PE7) } \\
\text { "tem professores que tentam inovar, que tenta fazer o aluno pensar, raciocinar desde o início } \\
\text { (PE8) }\end{array}$ \\
\hline
\end{tabular}




\begin{tabular}{|c|c|c|}
\hline & $\begin{array}{l}\text { Metodologias } \\
\text { tradicionais }\end{array}$ & $\begin{array}{l}\text { "eu sinto falta de um curso, inclusive de metodologias criativas, de outras metodologias, de } \\
\text { outras formas de fazer... então o que acontece... eu saio buscando" (PE4) } \\
\text { "acho que cada docente tem sua forma, estratégia de repassar o conhecimento e acho que a } \\
\text { partir dessas diferenças, distintas formas é que o aluno vai tendo sua formação" (PE6) } \\
\text { "predominância no curso, penso que é o padrão, ministração de aulas, ou seja, os alunos ficam } \\
\text { recebendo o conhecimento repassado pelo professor em aula" (PE6) }\end{array}$ \\
\hline & Hospital & $\begin{array}{l}\text { "ainda penso que a gente tem que priorizar nosso hospital universitário, pela comodidade, está } \\
\text { mais próximo e também pela convicção de que a gente precisa ter um hospital forte, isso é } \\
\text { fundamental" (PE4) } \\
\text { "nas vivências atuo no ambulatório interdisciplinar, e lá os alunos fazem consultas integradas" } \\
\text { (PE5) } \\
\text { "eu acho que o HUB termina sendo o lócus de maior prática na Enfermagem" (PE8) }\end{array}$ \\
\hline
\end{tabular}




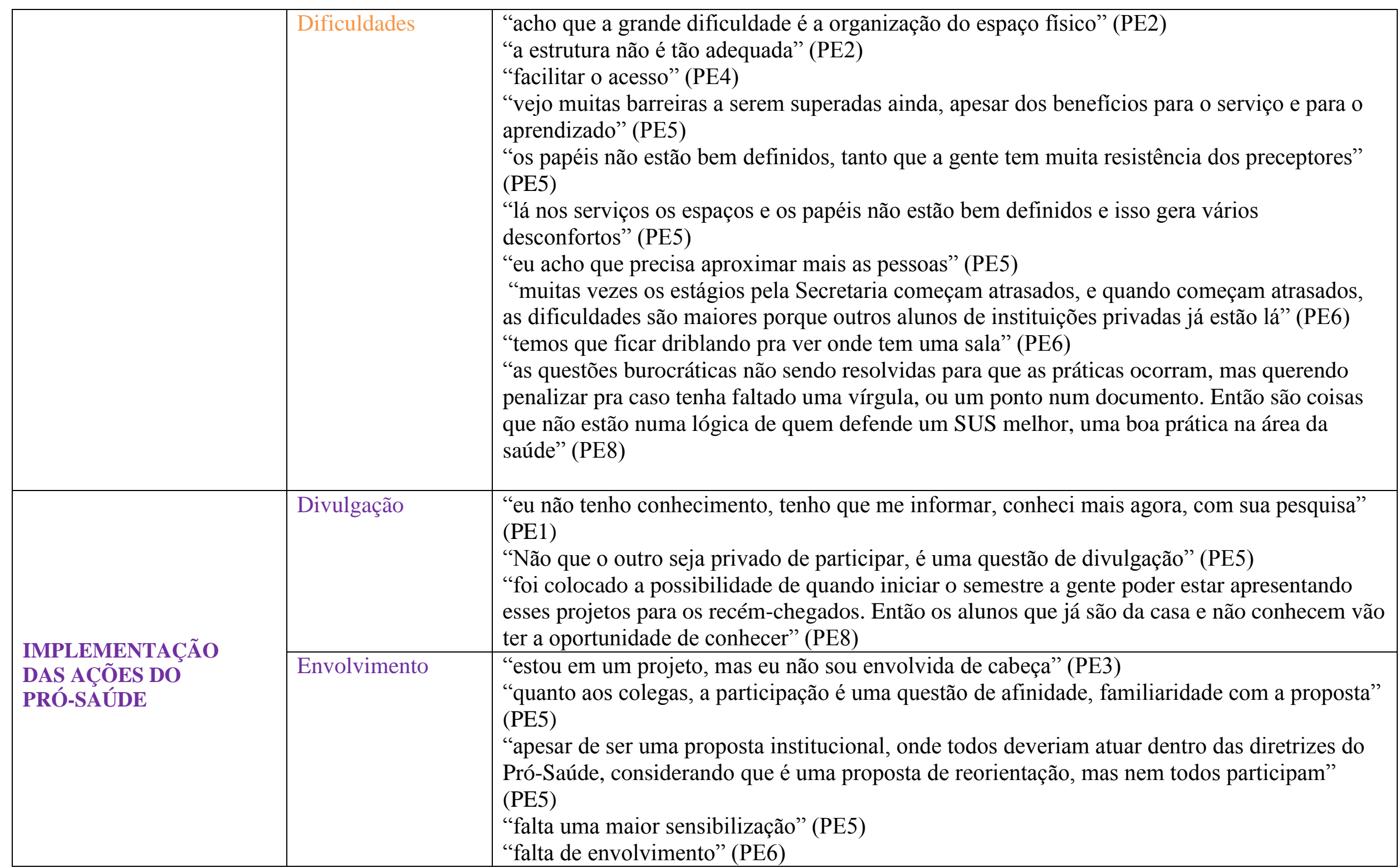




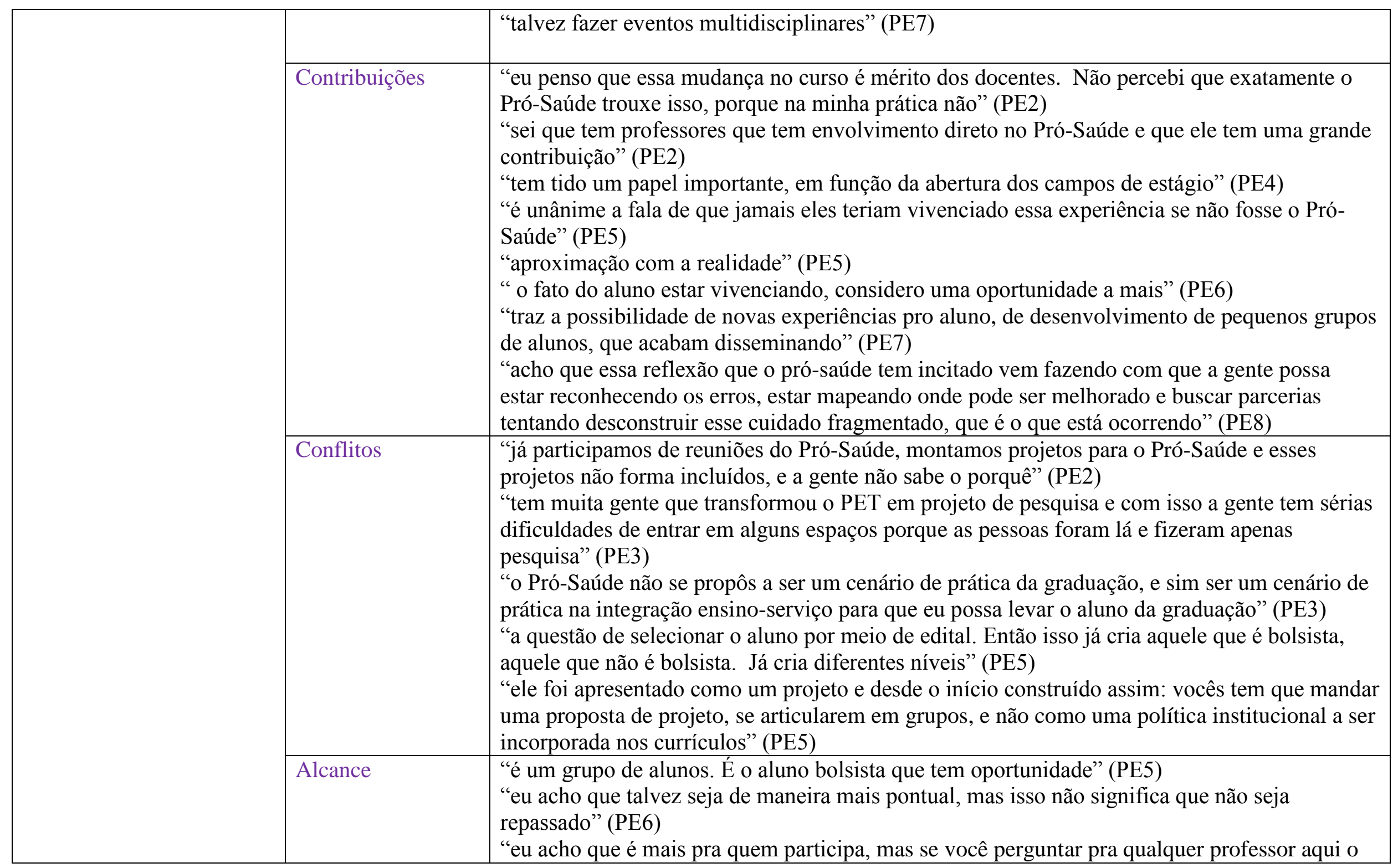




\begin{tabular}{|l|l|}
\hline & $\begin{array}{l}\text { que é o pró-saúde ele vai saber te responder" (PE6) } \\
\text { "na minha visão é mais pra quem participa" (PE7) } \\
\text { "o aluno que não entrou no Pró-Saúde não percebe nem o que é, isso ficou bem claro nos } \\
\text { nossos debates atuais" (PE8) }\end{array}$ \\
\cline { 2 - 3 } & $\begin{array}{l}\text { "as pessoas não entenderam muita essa dinâmica" (PE3) } \\
\text { "a universidade tem que ser reestruturada, a gente não faz coisa nova em molde velho" (PE3) } \\
\text { "'mudar a cabeça do professor" (PE3) } \\
\text { "há um descompasso, o desencontro entre aluno e profissional" (PE6) } \\
\text { "têm questões internas que precisam ser trabalhadas" (PE6) } \\
\text { "são muitos locais envolvidos e dispersos" (PE7) }\end{array}$ \\
\hline
\end{tabular}

Figura 53 - Unidades de registro das subcategorias obtidas na análise de conteúdo das entrevistas dos professores de Enfermagem. 


\section{Apêndice C}

\section{ESTUDO 3 - MEDICINA}

\section{Análise descritiva dos dados coletados dos estudantes na Seção 1 - dados}

\section{sociodemográficos e acadêmicos}

Os aspectos sociodemográficos e acadêmicos dos estudantes do curso de Medicina incluídos neste estudo foram obtidos a partir das respostas dadas pelos participantes na Seção 1 do instrumento. Os dados referentes ao curso de foram coletados no segundo semestre do ano de 2014. De um total de 485 alunos matriculados regularmente, 245 estavam de acordo em participar da pesquisa. Pode ser observada na Figura 54 a distribuição dos alunos que foram entrevistados.

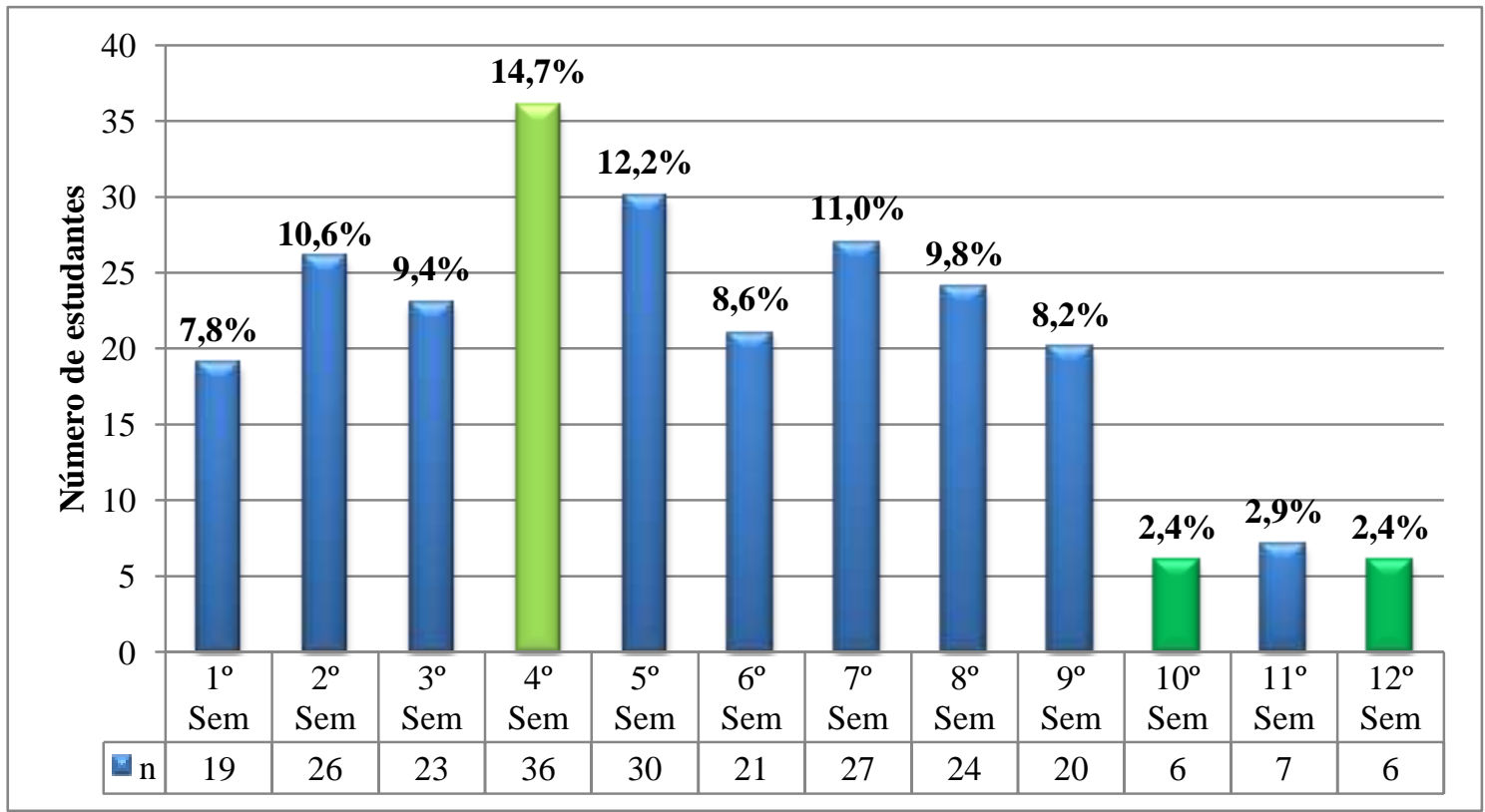

Figura 54. Distribuição percentual dos acadêmicos de Medicina, por semestre, que responderam o instrumento.

Ao se observar a caracterização dos participantes do estudo, descrita na Tabela 51, identifica-se uma predominância de estudantes do sexo masculino $(55,91 \%)$. No que diz respeito à faixa etária, do total de alunos incluídos na pesquisa, mais da metade 
encontram-se entre os 21 e 25 anos (51,02\%), e cerca de $38 \%$ possuem entre 16 e 20 anos. Apenas $1,22 \%$ dos participantes possuem idade igual ou superior a 31 anos. 


\section{Tabela 51}

Caracterização dos acadêmicos de Medicina quanto aos dados sócio-demográficos sexo e faixa etária.

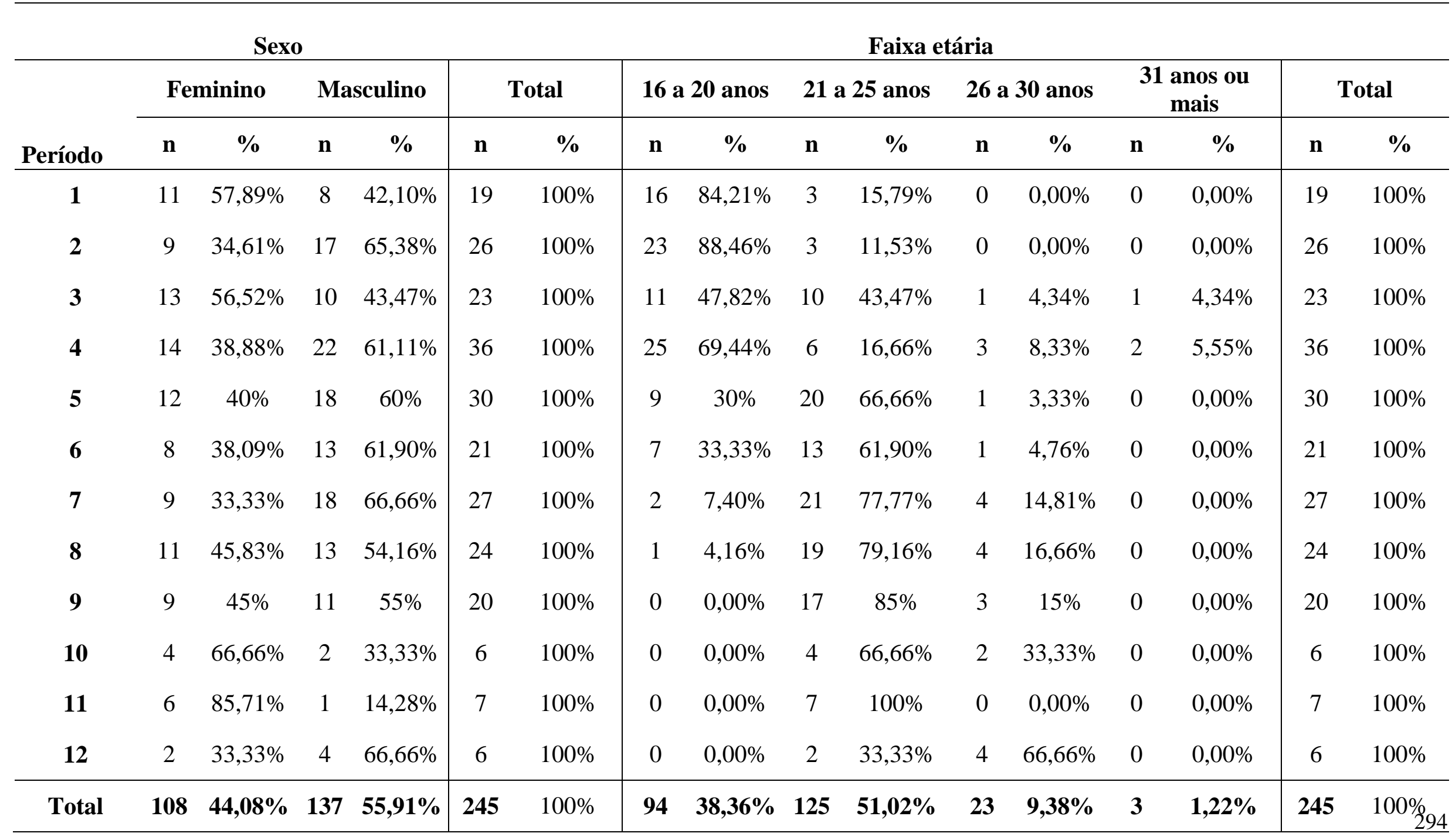


A Figura 55 ilustra o percentual de estudantes que possuem alguma graduação cursada anteriormente em outras áreas. Majoritariamente, representando cerca de 94\%, os participantes não fizeram graduações anteriores. Dos que são graduados, as ciências da saúde foi a área mais escolhida pelos estudantes $(3,7 \%)$, seguida das ciências biológicas e ciências humanas, ambas totalizando 0,8\%.

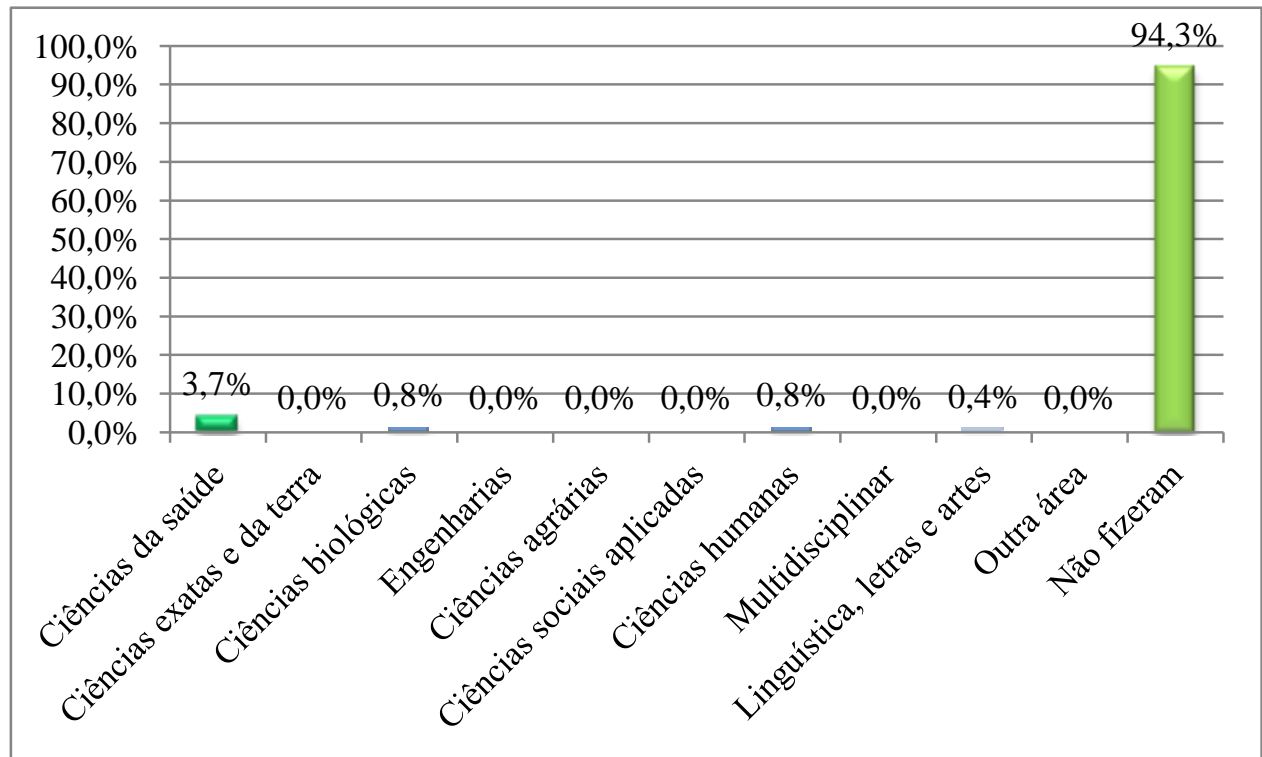

Figura 55. Distribuição percentual dos acadêmicos, segundo graduação concluída em outras áreas.

Do total de alunos participantes da pesquisa, observa-se que $85,2 \%$ deles não são bolsistas do programa Pró-Saúde, enquanto 14,8\% recebem bolsa ou já receberam anteriormente. Os dados podem ser observados na Figura 56. 


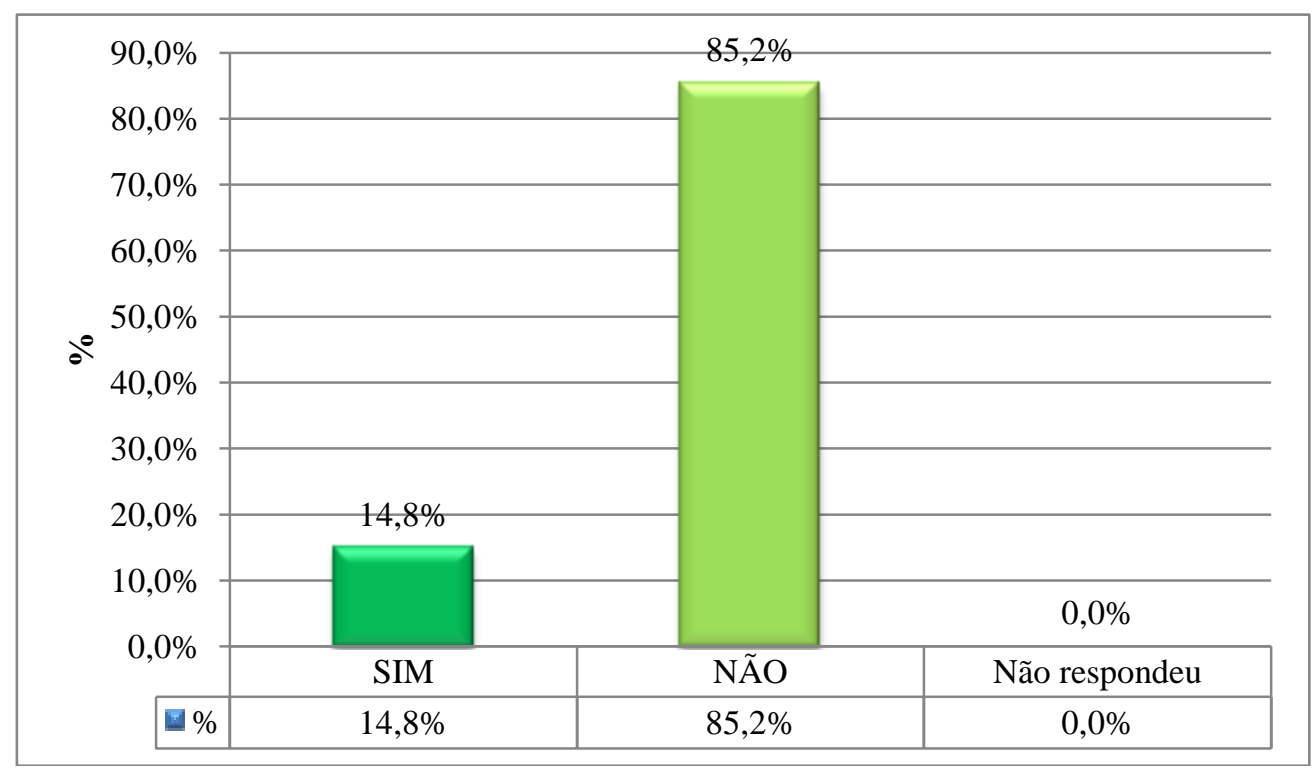

Figura 56. Distribuição percentual dos acadêmicos bolsistas pelo Pró-Saúde.

Dentre os participantes do Programa Pró-Saúde como bolsista, observou-se que a maioria participa do mesmo há mais de 12 meses. Os resultados obtidos neste item estão representados na Figura 57.

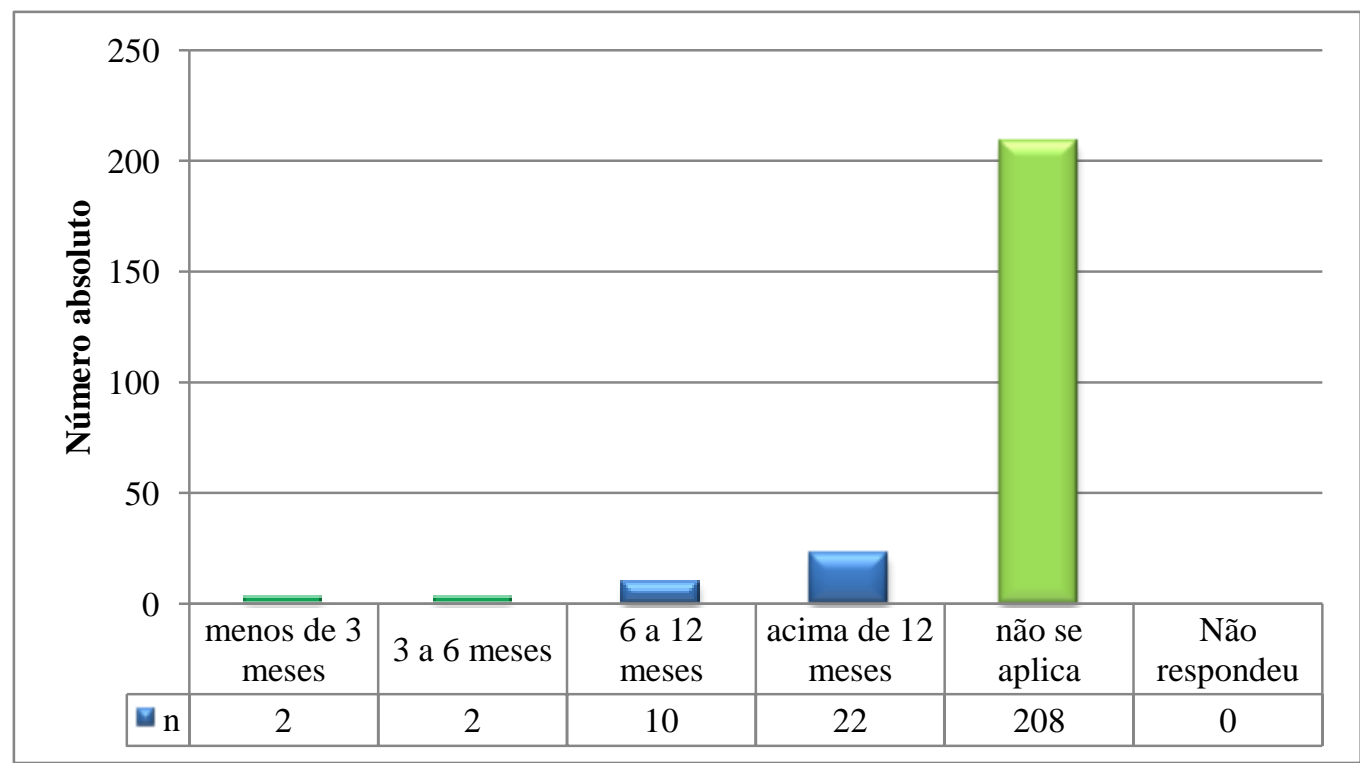

Figura 57. Distribuição dos acadêmicos em números absolutos em relação ao tempo de participação no Pró-Saúde. 
O resumo do perfil sociodemográfico e acadêmico dos estudantes de Enfermagem participantes do estudo encontram-se apresentados na Tabela 52.

\section{Tabela 52}

Perfil sociodemográfico e acadêmico dos estudantes de Medicina participantes do estudo.

\begin{tabular}{|c|c|c|}
\hline Variáveis & $\mathbf{N}$ & $\%$ \\
\hline \multicolumn{3}{|l|}{ Idade } \\
\hline De 16 a 20 anos & 94 & $38,36 \%$ \\
\hline De 21 a 25 anos & 125 & $51,02 \%$ \\
\hline De 26 a 30 anos & 23 & $9,38 \%$ \\
\hline Mais de 30 anos & 3 & $1,22 \%$ \\
\hline \multicolumn{3}{|l|}{ Sexo } \\
\hline Masculino & 137 & $55,91 \%$ \\
\hline Feminino & 108 & $44,08 \%$ \\
\hline \multicolumn{3}{|l|}{ Graduação em outras áreas } \\
\hline $\operatorname{Sim}$ & 14 & $5,71 \%$ \\
\hline Não & 231 & $94,28 \%$ \\
\hline \multicolumn{3}{|c|}{ Participação em atividades acadêmicas } \\
\hline Projeto de iniciação científica & 72 & $29,38 \%$ \\
\hline Projeto de extensão & 60 & $24,48 \%$ \\
\hline Projeto do Pró-Saúde/Pet-Saúde & 31 & $12,65 \%$ \\
\hline Monitoria & 73 & $29,79 \%$ \\
\hline Outros projetos & 36 & $14,69 \%$ \\
\hline Nenhum projeto & 91 & $37,14 \%$ \\
\hline \multicolumn{3}{|l|}{ Conhece o Pró-Saúde } \\
\hline Sim & 189 & $77,45 \%$ \\
\hline Não & 55 & $22,54 \%$ \\
\hline Não opinaram & 0 & $0,0 \%$ \\
\hline \multicolumn{3}{|l|}{ Bolsista do Pró-Saúde/Pet-Saúde } \\
\hline Sim & 208 & $85,24 \%$ \\
\hline Não & 36 & $14,75 \%$ \\
\hline Não opinaram & 0 & $0,0 \%$ \\
\hline
\end{tabular}




\section{Análise descritiva dos dados coletados dos professores na Seção 1 - dados sociodemográficos e profissionais}

Do total de 93 professores do curso de medicina, 19 responderam o instrumento. Entre os participantes, encontra-se uma predominância de pessoas do sexo feminino $(55,6 \%)$. No que diz respeito a faixa etária, a que detém um número maior de docentes é a de 30 a 49 anos, seguida das faixas de 50 a 59 anos e 60 ou mais, que representam um percentual de $25 \%$ cada.

Em relação a formação, identificou-se que $55 \%$ dos entrevistados possuem graduação em Medicina, enquanto que $40 \%$ são graduados em outra área não mencionada. Apenas um professor não respondeu o questionamento.

Quanto ao tempo de formado, a maioria dos entrevistados $(94,4 \%)$, possuem 10 anos ou mais e apenas um profissional possui de 6 a 9 anos de formado. Indagados sobre o grau de formação, $72,2 \%$ dos docentes são doutores e $16,7 \%$ são mestres. Apenas um professor possui especialização e um possui pós-doutorado.

$\mathrm{Na}$ Figura 58, podem ser observados os percentuais dos professores em relação às áreas das disciplinas que ministram. Identifica-se uma homogeneidade em relação ás áreas. As áreas básicas, clínica e social representaram um percentual de $31,6 \%$ cada e apenas 5,3\% dos docentes ministram disciplinas de outras áreas. 


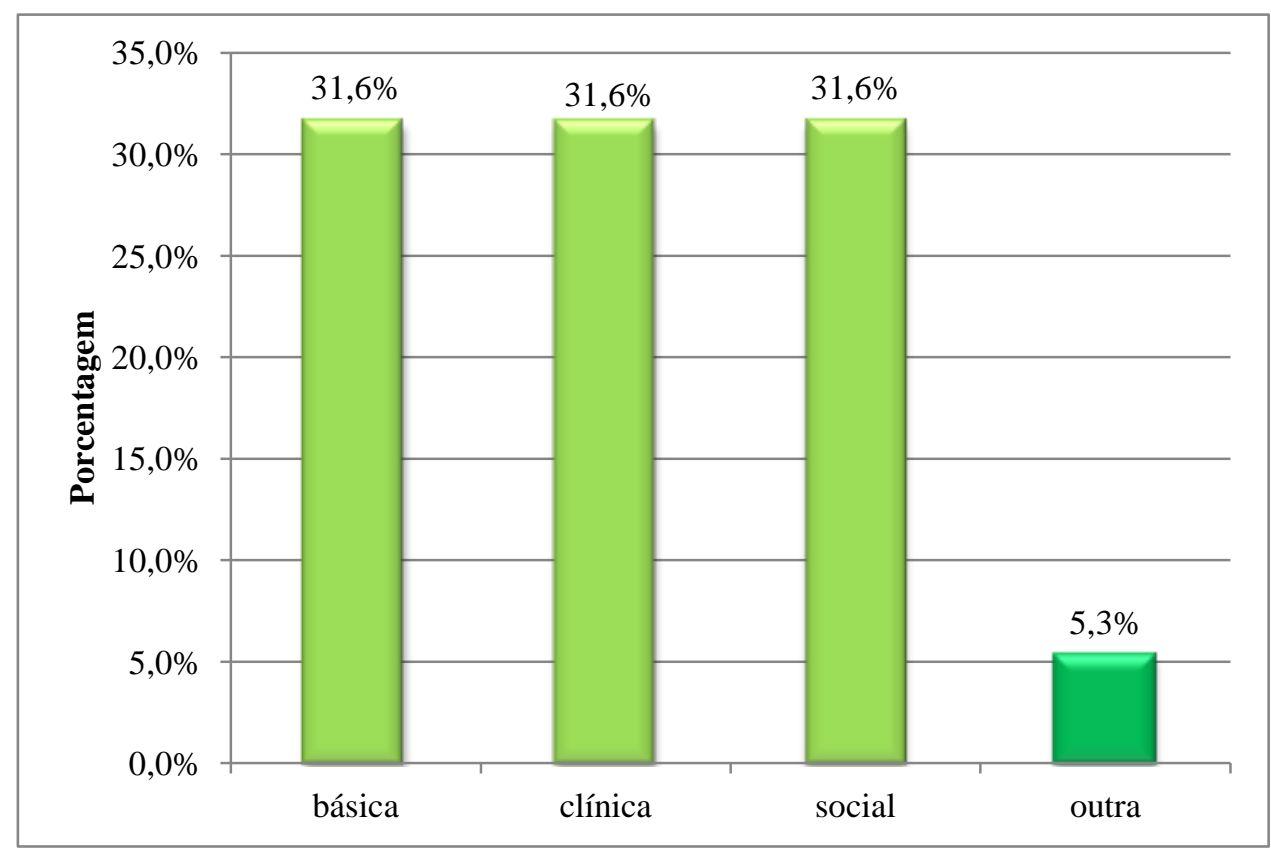

Figura 58. Distribuição percentual dos professores segundo as disciplinas das áreas que ensinam.

Ao serem indagados acerca das atividades que orientam, observou-se que 18,5\% dos participantes orientam atividades relacionadas a iniciação científica e o mesmo percentual de docentes orientam atividades de extensão. As atividades do Pró-Saúde representaram $14,8 \%$ do total de professores, assim como as de monitoria. A maioria dos participantes do estudo orientam outras atividades. A Figura 59 mostra essa distribuição. 


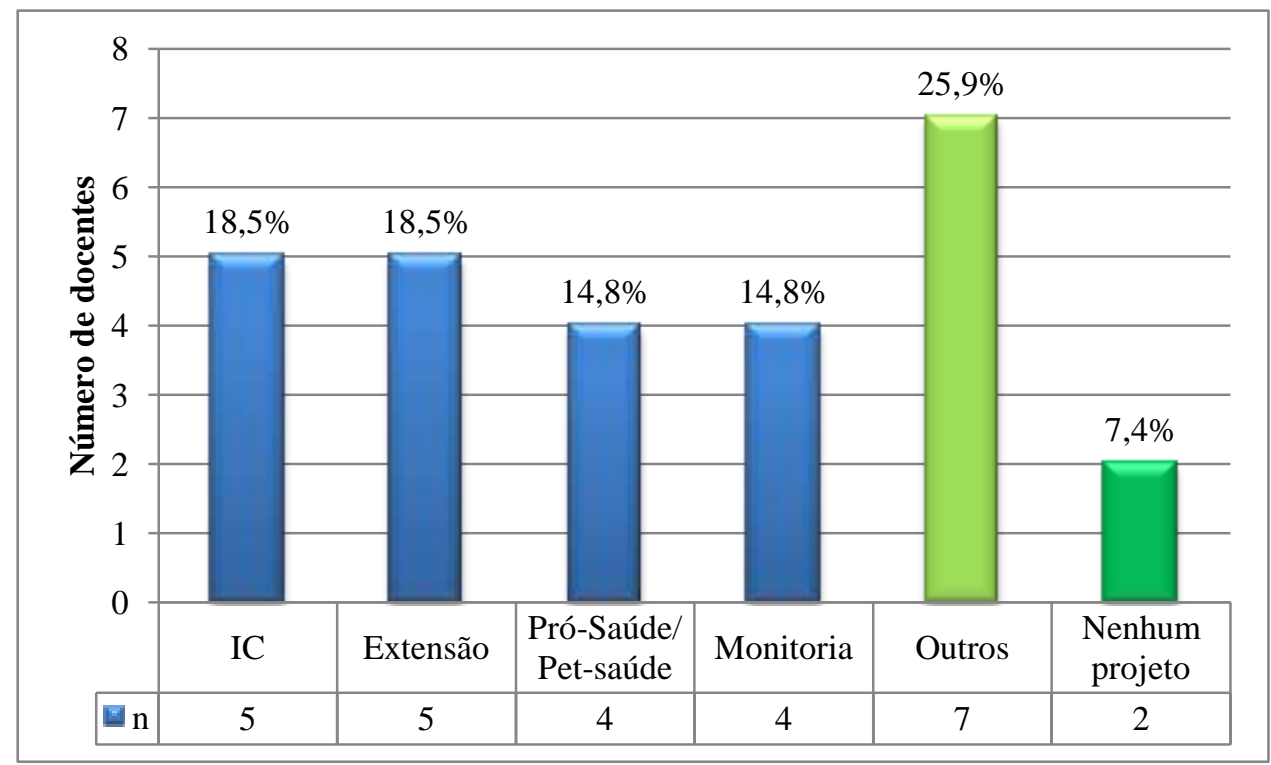

Figura 59. Distribuição percentual dos professores conforme as atividades em que orientam os estudantes.

Quanto ao tempo de participação em disciplinas inseridas na proposta do Pró-Saúde, conforme ilustrado na Figura 60, do total de entrevistados, 25\% não sabem o tempo de participação. Nota-se que 16,7\% estão participando nas disciplinas a menos de 1 ano.

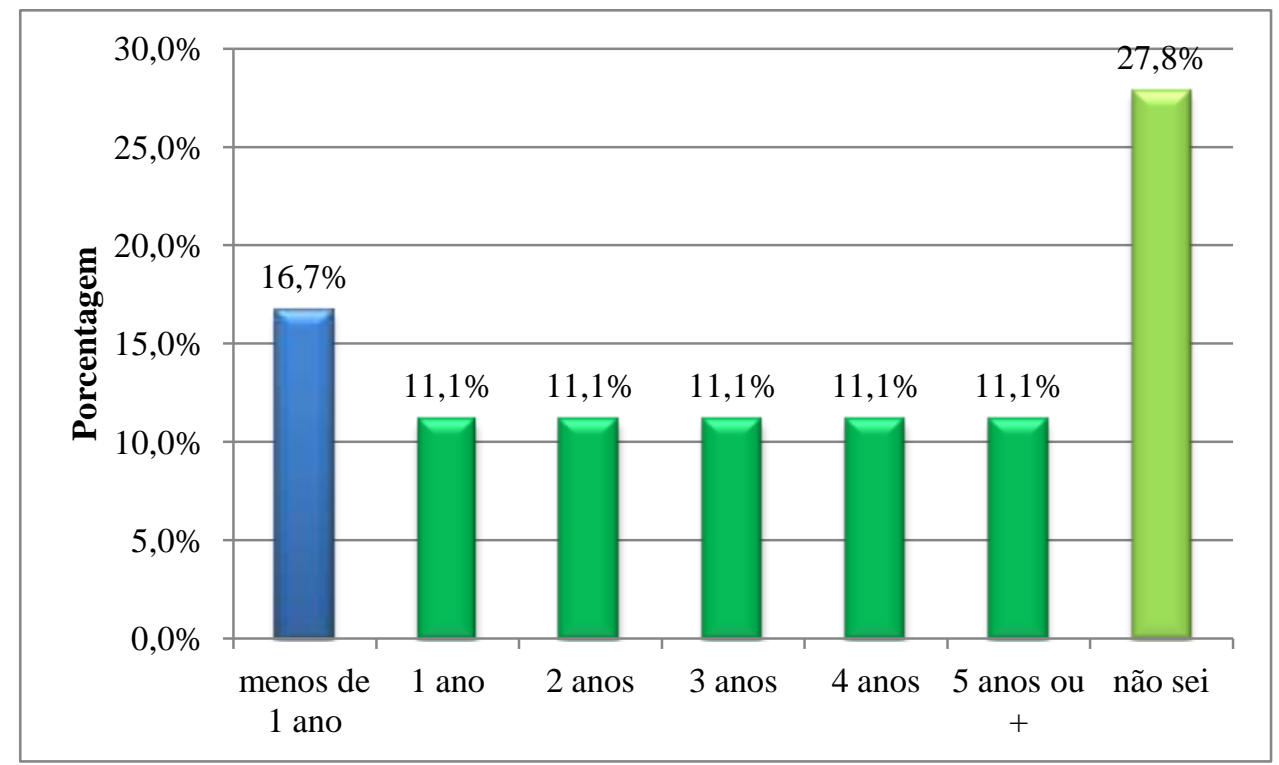

Figura 60. Distribuição percentual dos professores conforme o tempo de participação em disciplinas inseridas na proposta do Pró-Saúde. 
Em relação à tutoria Pró-Saúde/Pet-Saúde, a maioria dos docentes não participam de tutoria do programa, $11,1 \%$ participam como bolsistas e 5,6\% participam como voluntário (Figura 61).

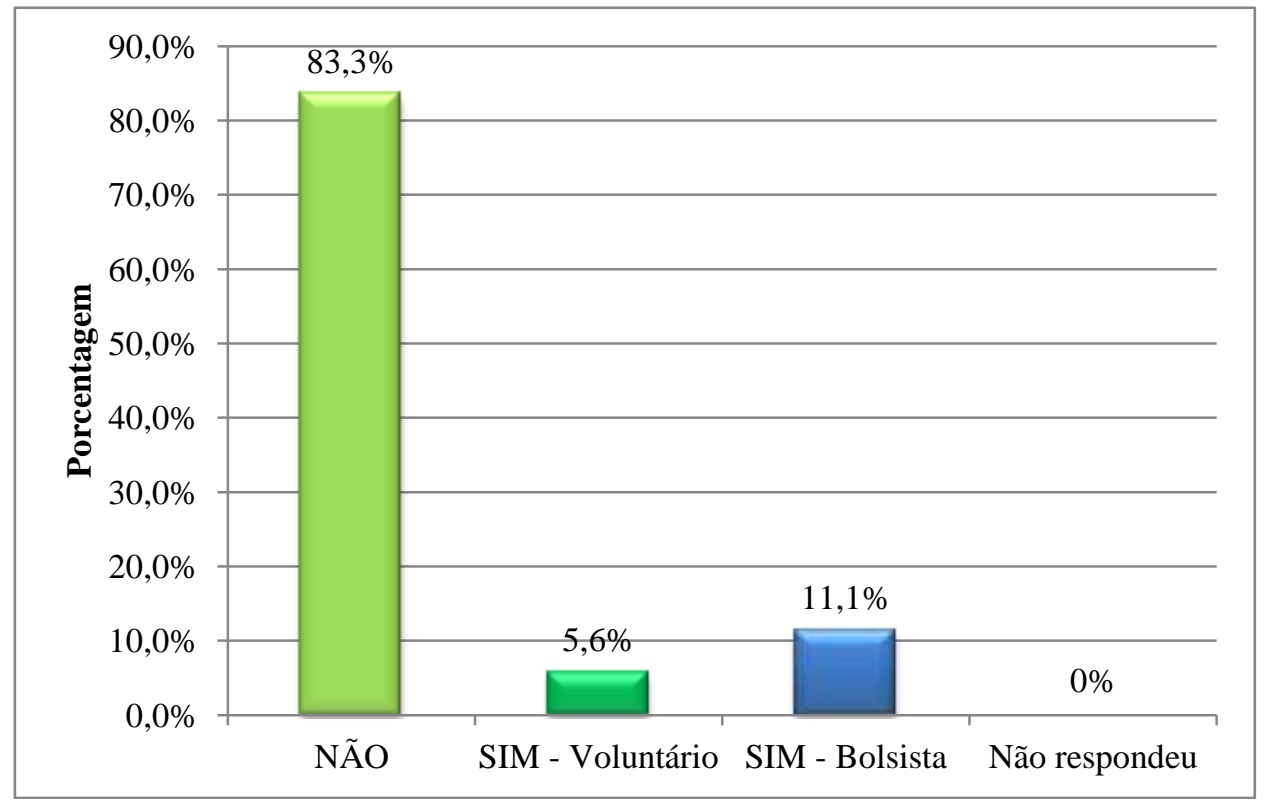

Figura 61. Distribuição percentual dos professores segundo participação em tutoria do Pró-Saúde/Pet-Saúde.

Considerando o tempo de participação em tutoria do Pró-Saúde/Pet-Saúde, a maioria $(64,7 \%)$ dos professores não respondeu a indagação, cerca de $23 \%$ participam a mais de 12 meses e 11,8\% optaram pelo item "não se aplica". Essa distribuição pode ser observada na Figura 62. 


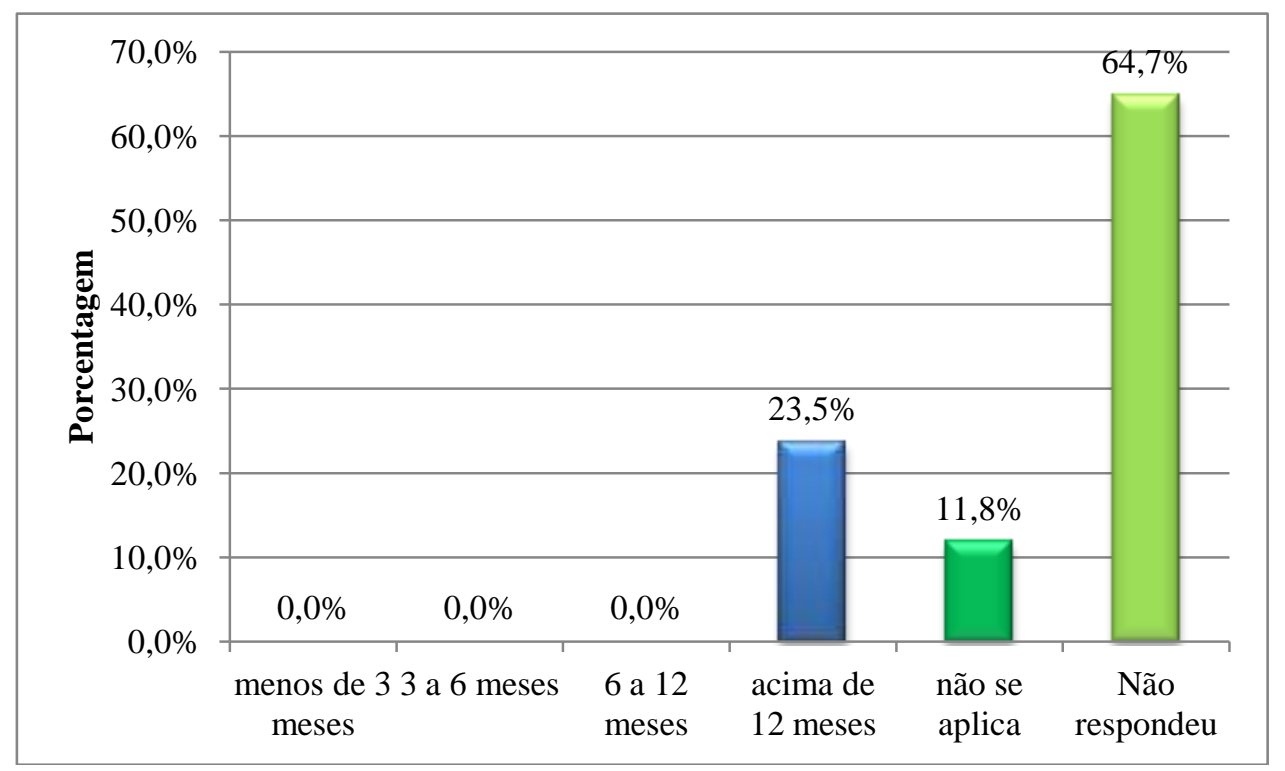

Figura 62. Distribuição percentual dos professores em relação ao tempo de participação em tutoria do Pró-Saúde/Pet-Saúde.

A Figura 63 apresenta o percentual dos professores em relação ao ensino na pósgraduação lato sensu e a área do conteúdo trabalhado. Observou-se que $25 \%$ dos docentes ofertam disciplinas na área básica. As áreas clínica e social detêm $20 \%$ cada dos professores que ministram disciplinas na pós-graduação lato sensu. $\mathrm{O}$ mesmo percentual foi encontrado para aqueles que não ofertam nenhuma disciplina.

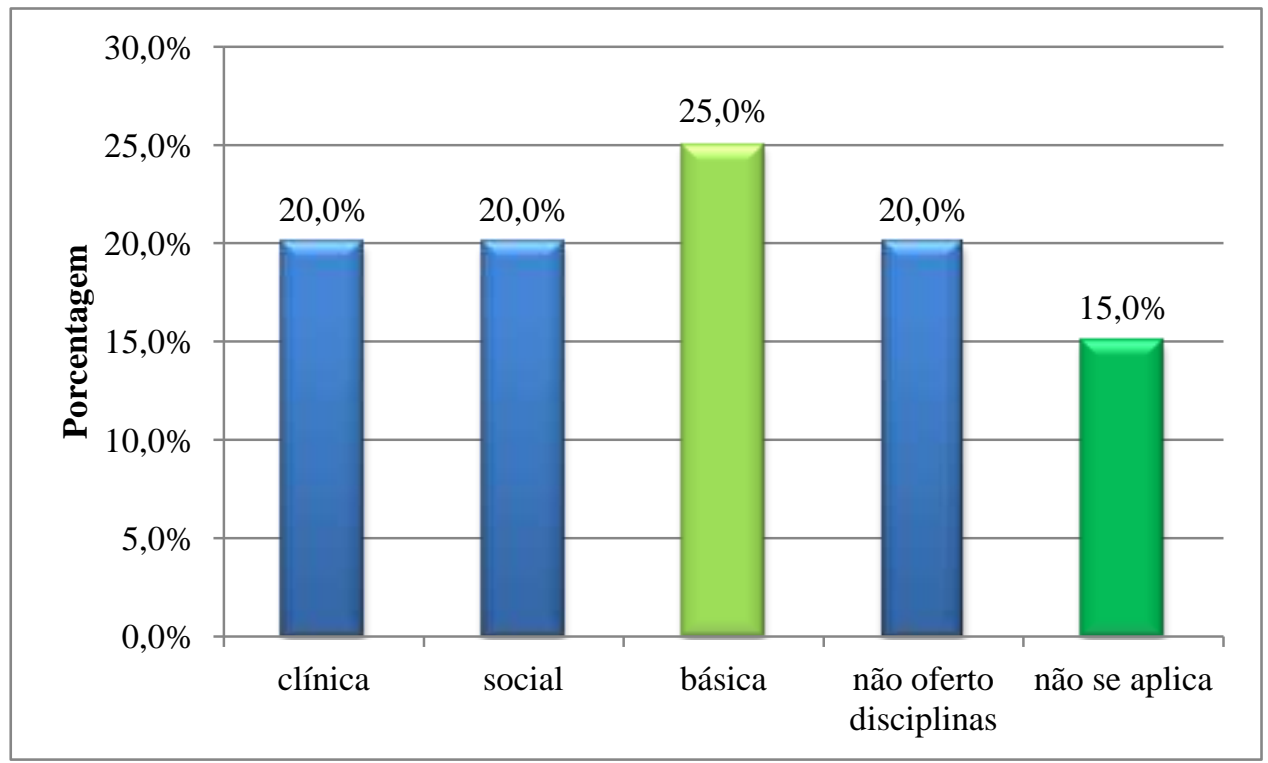

Figura 63 - Distribuição percentual dos professores em relação ao ensino na pós-graduação lato sensu e a área do conteúdo trabalhado. 
Considerando a pós-graduação stricto sensu, cerca de $26 \%$ dos participantes da pesquisa não ministram disciplinas, $21,1 \%$ ofertam disciplinas na área clínica e o mesmo percentual na área social. Essa distribuição é apresentada na Figura 64.

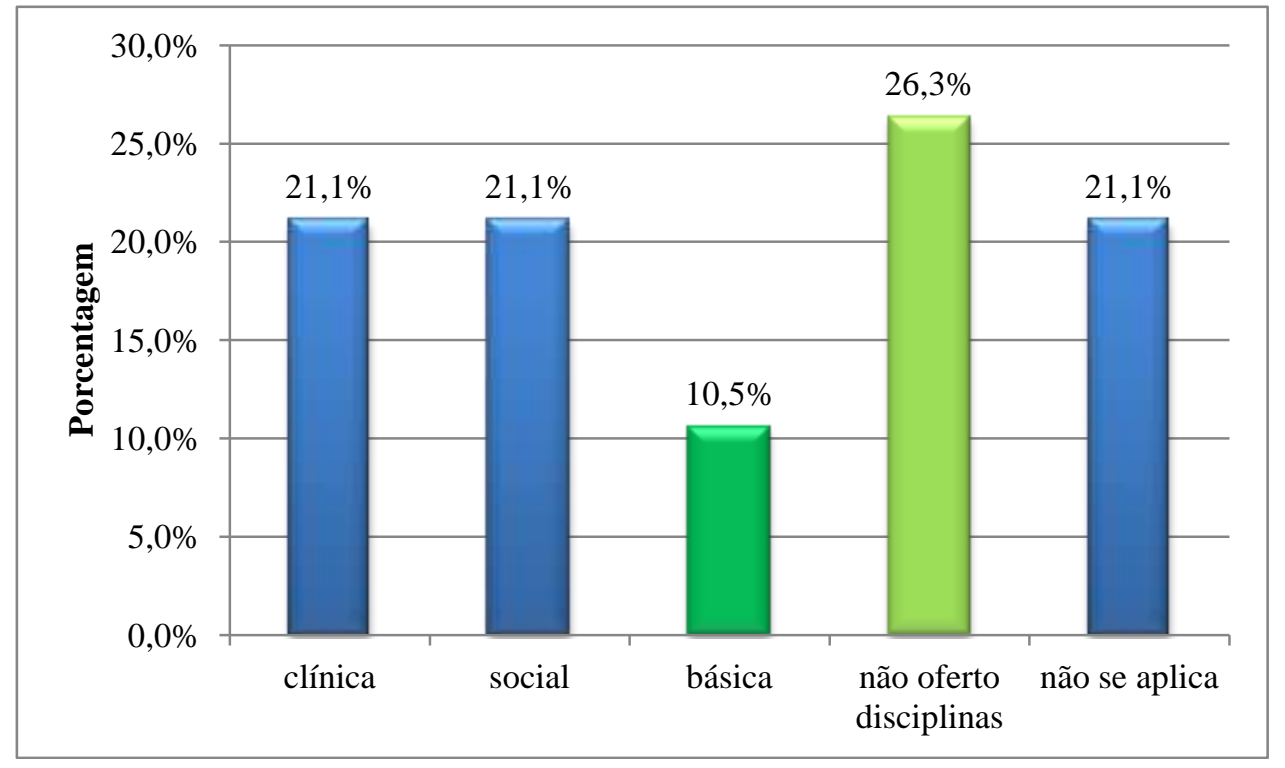

Figura 64. Distribuição percentual dos professores em relação ao ensino na pós-graduação stricto sensu e a área do conteúdo trabalhado.

Na Tabela 53 apresentamos o resumo do perfil sociodemográfico e profissional dos professores de participantes do presente estudo. 


\section{Tabela 53}

Perfil sociodemográfico e profissional dos professores de Medicina participantes do estudo.

\begin{tabular}{|c|c|c|}
\hline Variáveis & $\mathbf{N}$ & $\%$ \\
\hline \multicolumn{3}{|l|}{ Idade } \\
\hline 20 a 29 anos & 0 & $0 \%$ \\
\hline 30 a 49 anos & 8 & $50 \%$ \\
\hline 50 a 59 anos & 4 & $25 \%$ \\
\hline 60 anos ou mais & 4 & $25 \%$ \\
\hline \multicolumn{3}{|l|}{ Sexo } \\
\hline Masculino & 8 & $44,4 \%$ \\
\hline Feminino & 10 & $55,6 \%$ \\
\hline \multicolumn{3}{|l|}{$\begin{array}{l}\text { Graduação em outras } \\
\text { áreas }\end{array}$} \\
\hline Não & 18 & $94,7 \%$ \\
\hline Sim & 1 & $5,2 \%$ \\
\hline \multicolumn{3}{|l|}{$\begin{array}{l}\text { Orientação em } \\
\text { atividades acadêmicas }\end{array}$} \\
\hline $\begin{array}{l}\text { Projeto de iniciação } \\
\text { científica }\end{array}$ & 5 & $18,5 \%$ \\
\hline Projeto de extensão & 5 & $18,5 \%$ \\
\hline $\begin{array}{l}\text { Projeto do } \quad \text { Pró- } \\
\text { Saúde/Pet-Saúde }\end{array}$ & 4 & $14,8 \%$ \\
\hline Monitoria & 4 & $14,8 \%$ \\
\hline Outros projetos & 7 & $25,9 \%$ \\
\hline Nenhum projeto & 2 & $7,4 \%$ \\
\hline Tutoria no Pró-Saúde & & \\
\hline Não & 15 & $83,3 \%$ \\
\hline Sim - voluntário & 1 & $5,6 \%$ \\
\hline Sim - bolsista & 2 & $11,1 \%$ \\
\hline
\end{tabular}

\section{Análise descritiva da Seção 2 - parte específica do instrumento}

\subsection{Dimensão teórica - estudantes}

Analisando conjuntamente as respostas "concordo" e "concordo totalmente" como atitude positiva em relação a um item, verificou-se que em termos de conteúdos ministrados, no item 1, no qual foi avaliada a abordagem de aspectos biológicos, a maioria dos 
acadêmicos respondeu positivamente $(95 \%)$. No item 2, em que aspectos sociais do processo saúde-doença foram abordados, $62 \%$ dos acadêmicos responderam positivamente.

Em relação ao enfoque da produção de conhecimento, inseridas nos itens 4 e 5, a maioria $(49,3 \%)$ entende que a produção científica é focada em investigações sobre aspectos biomédicos ou tecnológicos da atenção à saúde. Nos itens relacionados à ênfase dada nos cursos de pós-graduação (itens 7, 8 e 9) foram obtidos, na sua maioria, a resposta "não sei". A Tabela 54 apresenta os resultados obtidos para essa dimensão.

\section{Tabela 54}

Frequências de respostas obtidas dos estudantes em cada item da dimensão teórica.

\begin{tabular}{|c|c|c|c|c|c|c|}
\hline BLOCO 1 - DIMENSÃO TEÓRICA & $\begin{array}{l}\text { discordo } \\
\text { totalmente }\end{array}$ & discordo & $\begin{array}{c}\text { não } \\
\text { concordo } \\
\text { nem } \\
\text { discordo }\end{array}$ & concordo & $\begin{array}{l}\text { concordo } \\
\text { totalmente }\end{array}$ & não sei \\
\hline $\begin{array}{l}\text { 1- Os conteúdos teóricos ministrados na graduação abordam } \\
\text { aspectos biológicos do processo saúde-doença. }\end{array}$ & 0,8 & 2,0 & 2,0 & 48,2 & 46,9 & 0 \\
\hline $\begin{array}{l}\text { 2- Os conteúdos teóricos ministrados na graduação abordam } \\
\text { aspectos sociais do processo saúde-doença. }\end{array}$ & 2,4 & 13,5 & 22,0 & $\mathbf{5 1 , 8}$ & 10,2 & 0 \\
\hline $\begin{array}{l}\text { 3- Há interação entre as abordagens teóricas das disciplinas das } \\
\text { áreas básicas, clínicas e sociais da graduação. }\end{array}$ & 4,9 & 25,7 & 20,0 & 36,3 & 6,5 & 4,5 \\
\hline $\begin{array}{l}\text { 4- A produção de conhecimento, no que se refere à pesquisa, } \\
\text { está articulada com as demandas do serviço e da comunidade da } \\
\text { Regional de Saúde do Paranoá/Itapoã. }\end{array}$ & 6,1 & 34,3 & 26,5 & 16,3 & 2,4 & 12,7 \\
\hline $\begin{array}{l}\text { 5- A produção científica é focada em investigações sobre } \\
\text { aspectos biomédicos ou tecnológicos da atenção à saúde. }\end{array}$ & 1,2 & 13,9 & 22,9 & 42,0 & 7,3 & 11,0 \\
\hline $\begin{array}{l}\text { 6- A produção de conhecimento, no que se refere à extensão, } \\
\text { está articulada com as demandas do serviço e da comunidade da } \\
\text { Regional de Saúde do Paranoá/Itapoã. }\end{array}$ & 3,7 & 18,8 & 26,5 & 29,4 & 6,1 & 14,7 \\
\hline $\begin{array}{l}\text { 7- A oferta de cursos de pós-graduação é voltada para os } \\
\text { profissionais do SUS. }\end{array}$ & 2,9 & 15,9 & 22,0 & 11,0 & 0,8 & 47,3 \\
\hline $\begin{array}{l}\text { 8- Os cursos de pós-graduação possuem como público-alvo os } \\
\text { profissionais que atuam na rede privada. }\end{array}$ & 3,7 & 17,6 & 18 & 8,6 & 1,6 & 50,2 \\
\hline $\begin{array}{l}\text { 9- Os cursos de pós-graduação são oferecidos de acordo com } \\
\text { interesses ou necessidades do curso. }\end{array}$ & 2,0 & 5,7 & 21,2 & 17,6 & 2,4 & 49,8 \\
\hline $\begin{array}{l}\text { 10- As disciplinas teóricas de conteúdos relacionados às áreas } \\
\text { básicas, clínicas e sociais são ministradas em blocos separados, } \\
\text { sem articulação entre elas. }\end{array}$ & 3,7 & 22,9 & 20,0 & 37,1 & 13,9 & 2,4 \\
\hline
\end{tabular}




\subsection{Dimensão cenário de práticas - estudantes}

Nos itens 1, 2 e 3, em que foi avaliada a percepção dos participantes sobre a integração da universidade com o serviço, e também os benefícios dessa aproximação para a comunidade, para o próprio serviço e para a universidade, os acadêmicos consideraram a aproximação positiva (somatória das frequências "concordo" e "concordo totalmente") em todas as três frentes envolvidas. Em relação à contribuição do curso de Medicina para a organização dos serviços, $41,3 \%$ dos respondentes demonstraram acreditar que a mesma ocorre, seguida de $25,3 \%$ que discordaram e $22 \%$ que se posicionaram de forma neutra ("não concordo nem discordo"). Um total de $35,5 \%$ dos participantes entende que a infraestrutura das unidades utilizadas como cenário de práticas são inadequadas para o processo de ensino e aprendizagem, enquanto 20,4\% não souberam opinar sobre essa questão.

A maior parte dos estudantes $(70,2 \%)$ concordou que as atividades práticas dos primeiros anos do curso ocorrem em laboratórios, e que as atividades práticas clínicas ocorrem dentro do ambiente universitário (75,5\%). Um total de 46,9\% concorda que o PróSaúde contribui para a integração da Medicina com outros cursos da saúde. Todas as frequências obtidas nos itens da dimensão denominada cenário de práticas estão apresentadas na Tabela 55.

\section{Tabela 55}

Frequências de respostas obtidas dos estudantes em cada item da dimensão cenário de práticas.

\begin{tabular}{|c|c|c|c|c|c|c|}
\hline BLOCO 2 - CENÁRIO DE PRÁTICAS & $\begin{array}{l}\text { discordo } \\
\text { totalmente }\end{array}$ & discordo & $\begin{array}{c}\text { não } \\
\text { concordo } \\
\text { nem } \\
\text { discordo }\end{array}$ & concordo & $\begin{array}{l}\text { Concordo } \\
\text { totalmente }\end{array}$ & não sei \\
\hline $\begin{array}{l}\text { 2- A integração da universidade com o serviço de saúde traz } \\
\text { benefícios para o serviço. }\end{array}$ & 0,8 & 4,9 & 9,0 & 42,0 & 40,8 & 1,6 \\
\hline $\begin{array}{l}\text { 3- A integração da universidade com o serviço de saúde traz } \\
\text { benefícios para a universidade. }\end{array}$ & 0,4 & 3,3 & 7,8 & 37,6 & 48,6 & 0,4 \\
\hline
\end{tabular}




\begin{tabular}{|c|c|c|c|c|c|c|}
\hline $\begin{array}{l}\text { 4- O curso de Medicina contribui para a organização dos } \\
\text { serviços da Regional de Saúde do Paranoá/Itapaã. }\end{array}$ & 4,5 & 20,8 & 22,0 & 33,5 & 7,8 & 10,6 \\
\hline $\begin{array}{l}\text { 5- A infraestrutura das unidades de saúde nas quais são } \\
\text { realizadas atividades das disciplinas e/ou ações do Pró-Saúde } \\
\text { são adequadas ao processo de ensino e aprendizagem dos } \\
\text { estudantes. }\end{array}$ & 8,6 & 26,9 & 19,2 & 18,8 & 3,3 & 20,4 \\
\hline $\begin{array}{l}\text { 6- As atividades práticas das disciplinas clínicas são realizadas } \\
\text { nas instalações assistenciais universitárias, a exemplo das } \\
\text { clínicas e hospital universitário. }\end{array}$ & 0,4 & 4,5 & 7,3 & 54,7 & 20,8 & 10,6 \\
\hline $\begin{array}{l}\text { 7- O curso de Medicina está voltado para a formação } \\
\text { especializada do médico. }\end{array}$ & 3,3 & 23,8 & 17,2 & 37,7 & 12,3 & 4,9 \\
\hline $\begin{array}{l}\text { 8- As atividades desenvolvidas nos cenários de práticas do } \\
\text { Paranoá-Itapoã são importantes para a formação do médico. }\end{array}$ & 3,7 & 6,9 & 12,2 & 46,5 & 26,1 & 3,3 \\
\hline $\begin{array}{l}\text { 9- O Pró-Saúde contribuiu para a integração do curso com a } \\
\text { Rede de Serviço de Saúde do Paranoá-Itapoã. }\end{array}$ & 2,0 & 4,1 & 12,2 & 40,8 & 13,5 & 25,3 \\
\hline $\begin{array}{l}10-\text { O curso de Medicina se volta para a formação generalista do } \\
\text { médico. }\end{array}$ & 4,9 & 23,3 & 18,4 & 38,4 & 9,4 & 4,1 \\
\hline $\begin{array}{l}\text { 11- O Pró-Saúde contribuiu para a integração da Medicina com } \\
\text { os demais cursos da área da saúde. }\end{array}$ & 2,4 & 12,2 & 12,2 & 34,7 & 12,2 & 24,1 \\
\hline $\begin{array}{l}\text { 12- As atividades práticas dos primeiros anos do curso ocorrem } \\
\text { em laboratórios da área básica. }\end{array}$ & 1,2 & 10,6 & 12,7 & 58,0 & 12,2 & 3,3 \\
\hline $\begin{array}{l}\text { 13- A inserção dos estudantes de Medicina com atividades } \\
\text { práticas na comunidade ou nos serviços de saúde ocorre desde } \\
\text { os primeiros dois anos do curso. }\end{array}$ & 6,9 & 20,4 & 16,7 & $\mathbf{3 6 , 3}$ & 15,1 & 2,4 \\
\hline
\end{tabular}

\subsection{Dimensão reorientação da formação - estudantes}

No bloco 3, com itens relacionados ao Programa Pró-Saúde, os acadêmicos se posicionaram positivamente na maioria dos itens. No item 1, em que foi abordado o conhecimento dos objetivos do Programa, as opiniões se dividiram, com 38,4\% se posicionando positivamente ("concordo" e "concordo totalmente") e 33,5\% negativamente ("discordo" e "discordo totalmente" ). No item 4, todas as opções de respostas obtiveram percentuais semelhantes. Os acadêmicos entendem que as atividades do Pró-Saúde alteram as rotinas das unidades de saúde (45,7\%). As frequências obtidas nesta dimensão estão descritas na Tabela 56. 


\section{Tabela 56}

Frequências de respostas obtidas dos estudantes em cada item da dimensão reorientação da formação.

\begin{tabular}{|c|c|c|c|c|c|c|}
\hline BLOCO 3 - REORIENTAÇÃO DA FORMAÇÃO & $\begin{array}{l}\text { discordo } \\
\text { totalmente }\end{array}$ & discordo & $\begin{array}{l}\text { não concordo } \\
\text { nem discordo }\end{array}$ & concordo & $\begin{array}{l}\text { Concordo } \\
\text { totalmente }\end{array}$ & não sei \\
\hline 1- Eu conheço os objetivos do Programa Pró-Saúde. & 10,6 & 22,9 & 13,1 & 32,7 & 5,7 & 14,3 \\
\hline $\begin{array}{l}\text { 2- O Pró-Saúde contribuiu com o processo de reforma curricular } \\
\text { do curso de Medicina. }\end{array}$ & 1,2 & 6,9 & 14,7 & 35,9 & 8,6 & 31,8 \\
\hline $\begin{array}{l}\text { 3- A participação do estudante no Pró-Saúde contribui para a } \\
\text { sua maior preparação para atuação profissional na rede pública. }\end{array}$ & 2,0 & 7,8 & 13,5 & 40,0 & 13,5 & 22,4 \\
\hline $\begin{array}{l}\text { 4- A participação do estudante no Pró-Saúde contribui para a } \\
\text { sua maior preparação para atuação profissional na rede privada. }\end{array}$ & 2,4 & 22,0 & 20,8 & 24,9 & 6,5 & 22,0 \\
\hline $\begin{array}{l}\text { 5- As atividades desenvolvidas no contexto do Pró-Saúde nas } \\
\text { unidades de saúde não alteram as rotinas de trabalho e nem as } \\
\text { práticas dos profissionais de saúde no serviço. }\end{array}$ & 5,7 & 40,0 & 10,6 & 12,7 & 0,4 & 28,2 \\
\hline $\begin{array}{l}\text { 6- O Pró-Saúde possibilita a interação entre os profissionais da } \\
\text { área de saúde. }\end{array}$ & 1,2 & 4,9 & 8,6 & 46,9 & 15,1 & 22,0 \\
\hline $\begin{array}{l}\text { 7- As atividades desenvolvidas pelos estudantes de Medicina no } \\
\text { contexto do Pró-Saúde influenciam na qualidade de sua } \\
\text { formação. }\end{array}$ & 1,2 & 4,5 & 12,7 & 43,7 & 17,1 & 19,6 \\
\hline $\begin{array}{l}\text { 8- As atividades desenvolvidas no âmbito do Pró-Saúde } \\
\text { contribuem para a qualificação da prática dos profissionais que } \\
\text { atuam na rede pública de atenção à saúde do Paranoá-Itapoã. }\end{array}$ & 1,2 & 4,1 & 18,0 & 40,0 & 12,2 & 23,3 \\
\hline 9- O Pró-Saúde contribui para o trabalho em equipe. & 0 & 2,0 & 6,5 & $\mathbf{5 0 , 2}$ & 21,2 & 18,8 \\
\hline
\end{tabular}

\subsection{Dimensão pedagógica - estudantes}

Os acadêmicos demonstraram acreditar que não há integração das atividades envolvendo disciplinas básicas e clínicas (item $1=51,4 \%$ ), e que a estrutura do currículo inclui primeiro a teoria e depois a aplicação desta na prática (item $2=72,6 \%$ ); entendem que o currículo está estruturado em ciclo básico e ciclo clínico (item $3=93,9 \%$ ), e que não ocorrem atividades interdisciplinares no processo de ensino e aprendizagem (item $6=43,3 \%$ ). Em contraste, no item 7, pouco mais de metade dos respondentes acreditam haver interação entre a teoria e a prática $(53,9 \%)$. Os dados percentuais dessa dimensão estão apresentados na Tabela 57. 


\section{Tabela 57}

Frequências de respostas obtidas dos estudantes em cada item da dimensão pedagógica.

\begin{tabular}{|c|c|c|c|c|c|c|}
\hline BLOCO 4 - DIMENSÃO PEDAGÓGICA & $\begin{array}{l}\text { discordo } \\
\text { totalmente }\end{array}$ & discordo & $\begin{array}{l}\text { não concordo } \\
\text { nem discordo }\end{array}$ & concordo & $\begin{array}{l}\text { concordo } \\
\text { totalmente }\end{array}$ & não sei \\
\hline $\begin{array}{l}\text { 1- As atividades desenvolvidas nas disciplinas básicas e clínicas } \\
\text { são integradas. }\end{array}$ & $15,1 \%$ & $36,3 \%$ & $18,0 \%$ & $18,8 \%$ & $1,2 \%$ & $9,8 \%$ \\
\hline $\begin{array}{l}\text { 2- A estrutura curricular do curso inclui primeiro o aprendizado } \\
\text { da teoria e na sequência a aplicação da teoria na prática. }\end{array}$ & $2,0 \%$ & $11,4 \%$ & $11,8 \%$ & $57,1 \%$ & $15,5 \%$ & $1,2 \%$ \\
\hline $\begin{array}{l}\text { 3- O curso de Medicina está estruturado em ciclo básico e ciclo } \\
\text { clínico. }\end{array}$ & $0,0 \%$ & $2,4 \%$ & $1,6 \%$ & $48,6 \%$ & $45,3 \%$ & $1,2 \%$ \\
\hline $\begin{array}{l}\text { 5- As estratégias de ensino utilizadas são variadas, a exemplo de } \\
\text { seminários, discussões em grupos tutoriais, estudos de casos, } \\
\text { etc. }\end{array}$ & $4,9 \%$ & $22,9 \%$ & $17,6 \%$ & $42,0 \%$ & $10,6 \%$ & $0,4 \%$ \\
\hline $\begin{array}{l}\text { 8- A interação entre a equipe de profissionais de saúde, } \\
\text { estudantes, professores e comunidade facilita o processo de } \\
\text { ensino e aprendizagem. }\end{array}$ & $0,8 \%$ & $4,1 \%$ & $8,6 \%$ & $52,2 \%$ & $32,7 \%$ & $0,8 \%$ \\
\hline $\begin{array}{l}\text { 9- Atividades práticas envolvendo profissionais das equipes de } \\
\text { saúde são estratégias que pouco acrescentam à formação do } \\
\text { médico, dado as especificidades do curso. }\end{array}$ & $36,3 \%$ & $44,5 \%$ & $4,5 \%$ & $9,0 \%$ & $3,7 \%$ & $1,2 \%$ \\
\hline $\begin{array}{l}\text { 10- As estratégias de ensino-aprendizagem que ocorrem no } \\
\text { ambiente do SUS são avaliadas conjuntamente pelos } \\
\text { profissionais da Rede e docentes. }\end{array}$ & $7,8 \%$ & $19,2 \%$ & $20,8 \%$ & $20,4 \%$ & $5,7 \%$ & $25,3 \%$ \\
\hline
\end{tabular}

\subsection{Dimensão teórica - professores}

A maioria dos docentes se posicionou positivamente sobre a abordagem de aspectos biológicos nos conteúdos teóricos das disciplinas, com a opção "concordo" e "concordo totalmente" totalizando $94,8 \%$ das escolhas. Já em relação à abordagem de aspectos sociais do processo saúde-doença, $68,5 \%$ se posicionaram positivamente. Quanto ao enfoque da produção de conhecimento, inseridas nos itens 4 e 5, um total de 57,9\% entende que o desenvolvimento de pesquisa está articulado com demandas da sociedade. Entretanto, 52,7\% entende que a produção científica é focada em investigações sobre aspectos biomédicos ou tecnológicos da atenção à saúde. Quanto à ênfase da pós- 
graduação, a maioria não acredita que seja voltada para profissionais do SUS, com um total de 47,4\% (somatória de "discordo" e "discordo totalmente"). Os dados percentuais referentes a todos os itens do bloco 1 para professores estão descritos na Tabela 58.

\section{Tabela 58}

Frequências de respostas obtidas dos professores em cada item da dimensão teórica.

\begin{tabular}{|c|c|c|c|c|c|c|}
\hline BLOCO 1 - DIMENSÃO TEÓRICA & $\begin{array}{l}\text { discordo } \\
\text { totalmente }\end{array}$ & discordo & $\begin{array}{l}\text { não concordo } \\
\text { nem discordo }\end{array}$ & concordo & $\begin{array}{l}\text { concordo } \\
\text { totalmente }\end{array}$ & não sei \\
\hline $\begin{array}{l}\text { 1- Os conteúdos teóricos ministrados na graduação abordam } \\
\text { aspectos biológicos do processo saúde-doença. }\end{array}$ & $0,0 \%$ & $5,3 \%$ & $0,0 \%$ & $63,2 \%$ & $31,6 \%$ & $0,0 \%$ \\
\hline $\begin{array}{l}\text { 2- Os conteúdos teóricos ministrados na graduação abordam } \\
\text { aspectos sociais do processo saúde-doença. }\end{array}$ & $0,0 \%$ & $10,5 \%$ & $10,5 \%$ & $47,4 \%$ & $21,1 \%$ & $5,3 \%$ \\
\hline $\begin{array}{l}\text { 3- Há interação entre as abordagens teóricas das disciplinas das } \\
\text { áreas básicas, clínicas e sociais da graduação. }\end{array}$ & $5,3 \%$ & $57,9 \%$ & $15,8 \%$ & $15,8 \%$ & $5,3 \%$ & $0,0 \%$ \\
\hline $\begin{array}{l}\text { 4- A produção de conhecimento, no que se refere à pesquisa, } \\
\text { está articulada com as demandas do serviço e da comunidade da } \\
\text { Regional de Saúde do Paranoá/Itapoã. }\end{array}$ & $\mathbf{0 , 0 \%}$ & $57,9 \%$ & $21,1 \%$ & $15,8 \%$ & $0,0 \%$ & $5,3 \%$ \\
\hline $\begin{array}{l}\text { 5- A produção científica é focada em investigações sobre } \\
\text { aspectos biomédicos ou tecnológicos da atenção à saúde. }\end{array}$ & $0,0 \%$ & $15,8 \%$ & $15,8 \%$ & $47,4 \%$ & $5,3 \%$ & $15,8 \%$ \\
\hline $\begin{array}{l}\text { 6- A produção de conhecimento, no que se refere à extensão, } \\
\text { está articulada com as demandas do serviço e da comunidade da } \\
\text { Regional de Saúde do Paranoá/Itapoã. }\end{array}$ & $0,0 \%$ & $36,8 \%$ & $21,1 \%$ & $21,1 \%$ & $5,2 \%$ & $15,8 \%$ \\
\hline $\begin{array}{l}\text { 7- A oferta de cursos de pós-graduação é voltada para os } \\
\text { profissionais do SUS. }\end{array}$ & $\mathbf{0 , 0 \%}$ & $47,4 \%$ & $26,3 \%$ & $15,8 \%$ & $0,0 \%$ & $10,5 \%$ \\
\hline $\begin{array}{l}\text { 8- Os cursos de pós-graduação possuem como público-alvo os } \\
\text { profissionais que atuam na rede privada. }\end{array}$ & $15,7 \%$ & $36,8 \%$ & $21,1 \%$ & $10,5 \%$ & $0,0 \%$ & $15,8 \%$ \\
\hline $\begin{array}{l}\text { 9- Os cursos de pós-graduação são oferecidos de acordo com } \\
\text { interesses ou necessidades do curso. }\end{array}$ & $0,0 \%$ & $0,0 \%$ & $15,8 \%$ & $63,2 \%$ & $0,0 \%$ & $15,8 \%$ \\
\hline $\begin{array}{l}\text { 10- As disciplinas teóricas de conteúdos relacionados às áreas } \\
\text { básicas, clínicas e sociais são ministradas em blocos separados, } \\
\text { sem articulação entre elas. }\end{array}$ & $0,0 \%$ & $26,3 \%$ & $10,5 \%$ & $52,6 \%$ & $5,3 \%$ & $5,3 \%$ \\
\hline
\end{tabular}

\subsection{Dimensão cenário de práticas - professores}

Em relação aos itens 1, 2 e 3, que avaliava a percepção dos participantes sobre a integração da universidade com o serviço, e sobre os benefícios dessa aproximação para a comunidade, para o próprio serviço e para a universidade, os professores se mostraram positivos (somatória das frequências "concordo" e "concordo totalmente"). Sobre a 
contribuição do curso de Medicina para a organização dos serviços, 52,7\% responderam positivamente, enquanto $26,3 \%$ discordaram. A maioria dos professores

$(78,9 \%)$ entende que a infraestrutura das unidades utilizadas como cenário de práticas são inadequadas para o processo de ensino e aprendizagem. A maior parte dos professores $(73,7 \%)$ concordaram que as atividades práticas clínicas ocorrem dentro do ambiente universitário, e que as atividades práticas dos primeiros anos do curso ocorrem em laboratórios $(47,4 \%)$. Um total de 57,9\% concorda que o Pró-Saúde contribui para a integração da Medicina com outros cursos da saúde (item 11) e 73,6\% concorda que o PróSaúde contribui para a integração do curso com a rede de serviços (item 9). As frequências obtidas nos itens desta dimensão estão apresentadas na Tabela 59.

\section{Tabela 59}

Frequências de respostas obtidas dos professores em cada item da dimensão cenário de práticas.

\begin{tabular}{|c|c|c|c|c|c|c|}
\hline BLOCO 2 - CENÁRIO DE PRÁTICAS & $\begin{array}{l}\text { discordo } \\
\text { totalmente }\end{array}$ & discordo & $\begin{array}{l}\text { não concordo } \\
\text { nem discordo }\end{array}$ & concordo & $\begin{array}{l}\text { concordo } \\
\text { otalmente }\end{array}$ & não sei \\
\hline $\begin{array}{l}\text { 1- A integração da universidade com o serviço de saúde traz } \\
\text { benefícios para a comunidade. }\end{array}$ & $0,0 \%$ & $0,0 \%$ & $0,0 \%$ & $52,6 \%$ & $47,4 \%$ & $0,0 \%$ \\
\hline $\begin{array}{l}\text { 2- A integração da universidade com o serviço de saúde traz } \\
\text { benefícios para o serviço. }\end{array}$ & $0,0 \%$ & $0,0 \%$ & $0,0 \%$ & $52,6 \%$ & $47,4 \%$ & $0,0 \%$ \\
\hline $\begin{array}{l}\text { 3- A integração da universidade com o serviço de saúde traz } \\
\text { benefícios para a universidade. }\end{array}$ & $0,0 \%$ & $0,0 \%$ & $5,3 \%$ & $47,4 \%$ & $47,4 \%$ & $0,0 \%$ \\
\hline $\begin{array}{l}\text { 4- O curso de Medicina contribui para a organização dos } \\
\text { serviços da Regional de Saúde do Paranoá/Itapoã. }\end{array}$ & $0,0 \%$ & $26,3 \%$ & $21,1 \%$ & $47,4 \%$ & $5,3 \%$ & $0,0 \%$ \\
\hline $\begin{array}{l}\text { 5- A infraestrutura das unidades de saúde nas quais são } \\
\text { realizadas atividades das disciplinas e/ou ações do Pró-Saúde } \\
\text { são adequadas ao processo de ensino e aprendizagem dos } \\
\text { estudantes. }\end{array}$ & $10,5 \%$ & $68,4 \%$ & $10,5 \%$ & $10,5 \%$ & $0,0 \%$ & $0,0 \%$ \\
\hline $\begin{array}{l}\text { 6- As atividades práticas das disciplinas clínicas são realizadas } \\
\text { nas instalações assistenciais universitárias, a exemplo das } \\
\text { clínicas e hospital universitário. }\end{array}$ & $0,0 \%$ & $5,3 \%$ & $10,5 \%$ & $68,4 \%$ & $5,3 \%$ & $10,5 \%$ \\
\hline $\begin{array}{l}\text { 7- O curso de Medicina está voltado para a formação } \\
\text { especializada do médico. }\end{array}$ & $0,0 \%$ & $26,3 \%$ & $15,8 \%$ & $\mathbf{5 7 , 9 \%}$ & $\mathbf{0 , 0 \%}$ & $0,0 \%$ \\
\hline $\begin{array}{l}\text { 8- As atividades desenvolvidas nos cenários de práticas do } \\
\text { Paranoá-Itapoã são importantes para a formação do médico. }\end{array}$ & $0,0 \%$ & $0,0 \%$ & $10,5 \%$ & $42,1 \%$ & $47,4 \%$ & $0,0 \%$ \\
\hline $\begin{array}{l}\text { 9- O Pró-Saúde contribuiu para a integração do curso com a } \\
\text { Rede de Serviço de Saúde do Paranoá-Itapoã. }\end{array}$ & $0,0 \%$ & $15,8 \%$ & $10,5 \%$ & $36,8 \%$ & $36,8 \%$ & $0,0 \%$ \\
\hline $\begin{array}{l}\text { 10- O curso de Medicina se volta para a formação generalista do } \\
\text { médico. }\end{array}$ & $0,0 \%$ & $36,8 \%$ & $21,1 \%$ & $36,8 \%$ & $5,3 \%$ & $0,0 \%$ \\
\hline $\begin{array}{l}\text { 11- O Pró-Saúde contribuiu para a integração da Medicina com } \\
\text { os demais cursos da área da saúde. }\end{array}$ & $0,0 \%$ & $10,5 \%$ & $26,3 \%$ & $31,6 \%$ & $26,3 \%$ & $5,3 \%$ \\
\hline
\end{tabular}




\begin{tabular}{|c|c|c|c|c|c|c|}
\hline $\begin{array}{l}\text { 12- As atividades práticas dos primeiros anos do curso ocorrem } \\
\text { em laboratórios da área básica. }\end{array}$ & $0,0 \%$ & $21,1 \%$ & $26,3 \%$ & $47,4 \%$ & $0,0 \%$ & $5,3 \%$ \\
\hline
\end{tabular}

\subsection{Dimensão reorientação da formação - professores}

Neste bloco, os professores se posicionaram positivamente na maioria dos itens. Um percentual de $73,7 \%$ demonstrou conhecer os objetivos do Programa; 68,5\% acreditam que o Pró-Saúde contribuiu para a reforma curricular e $84,2 \%$ se mostraram positivos quanto à contribuição do mesmo para o preparo na formação do acadêmico para atuação na rede pública. Ainda que com frequência menor, $63,1 \%$ dos docentes acreditam que auxilia também no preparo para atuação na rede privada. Os dados obtidos em cada item estão descritos na Tabela 60.

\section{Tabela 60}

Frequências de respostas obtidas dos professores em cada item da dimensão reorientação da formação.

\begin{tabular}{|c|c|c|c|c|c|c|}
\hline BLOCO 3 - REORIENTAÇÃO DA FORMAÇÃO & $\begin{array}{l}\text { discordo } \\
\text { totalmente }\end{array}$ & discordo & $\begin{array}{l}\text { não concordo } \\
\text { nem discordo }\end{array}$ & concordo & $\begin{array}{l}\text { Concordo } \\
\text { totalmente }\end{array}$ & não sei \\
\hline 1- Eu conheço os objetivos do Programa Pró-Saúde. & $5,3 \%$ & $15,8 \%$ & $5,3 \%$ & $\mathbf{5 7 , 9 \%}$ & $15,8 \%$ & $0,0 \%$ \\
\hline $\begin{array}{l}\text { 2- O Pró-Saúde contribuiu com o processo de reforma curricular } \\
\text { do curso de Medicina. }\end{array}$ & $5,3 \%$ & $5,3 \%$ & $10,5 \%$ & $47,4 \%$ & $21,1 \%$ & $10,5 \%$ \\
\hline $\begin{array}{l}\text { 3- A participação do estudante no Pró-Saúde contribui para a } \\
\text { sua maior preparação para atuação profissional na rede pública. }\end{array}$ & $0,0 \%$ & $10,5 \%$ & $5,3 \%$ & $\mathbf{5 7 , 9 \%}$ & $26,3 \%$ & $0,0 \%$ \\
\hline $\begin{array}{l}\text { 4- A participação do estudante no Pró-Saúde contribui para a } \\
\text { sua maior preparação para atuação profissional na rede privada. }\end{array}$ & $0,0 \%$ & $21,1 \%$ & $15,8 \%$ & $52,6 \%$ & $10,5 \%$ & $0,0 \%$ \\
\hline $\begin{array}{l}\text { 5- As atividades desenvolvidas no contexto do Pró-Saúde nas } \\
\text { unidades de saúde não alteram as rotinas de trabalho e nem as } \\
\text { práticas dos profissionais de saúde no serviço. }\end{array}$ & $5,3 \%$ & $63,2 \%$ & $5,3 \%$ & $21,1 \%$ & $0,0 \%$ & $5,3 \%$ \\
\hline $\begin{array}{l}\text { 6- O Pró-Saúde possibilita a interação entre os profissionais da } \\
\text { área de saúde. }\end{array}$ & $0,0 \%$ & $5,3 \%$ & $15,8 \%$ & $\mathbf{5 7 , 9 \%}$ & $21,1 \%$ & $0,0 \%$ \\
\hline $\begin{array}{l}\text { 7- As atividades desenvolvidas pelos estudantes de Medicina no } \\
\text { contexto do Pró-Saúde influenciam na qualidade de sua } \\
\text { formação. }\end{array}$ & $0,0 \%$ & $5,3 \%$ & $5,3 \%$ & $68,4 \%$ & $21,1 \%$ & $0,0 \%$ \\
\hline $\begin{array}{l}\text { 8- As atividades desenvolvidas no âmbito do Pró-Saúde } \\
\text { contribuem para a qualificação da prática dos profissionais que } \\
\text { atuam na rede pública de atenção à saúde do Paranoá-Itapoã. }\end{array}$ & $0,0 \%$ & $10,5 \%$ & $5,3 \%$ & $52,6 \%$ & $31,6 \%$ & $0,0 \%$ \\
\hline 9- O Pró-Saúde contribui para o trabalho em equipe. & $0,0 \%$ & $0,0 \%$ & $5,3 \%$ & $\mathbf{5 7 , 9 \%}$ & $31,6 \%$ & $0,0 \%$ \\
\hline
\end{tabular}




\subsection{Dimensão pedagógica - professores}

Os professores demonstraram acreditar que não há integração das atividades envolvendo disciplinas básicas e clínicas (item $1=73,7 \%$ ), e que a estrutura do currículo inclui primeiro a teoria e depois a aplicação desta na prática (item $2=57,9 \%$ ); entendem que o currículo está estruturado em ciclo básico e ciclo clínico (item $3=84,2 \%$ ). Quanto à ocorrência de atividades interdisciplinares no processo de ensino e aprendizagem (item 6), 42,1\% responderam positivamente e $42,1 \%$ responderam negativamente (soma de "discordo" e “discordo totalmente"). Ainda assim, 73,7\% entende que ocorre interação entre a teoria e a prática $(53,9 \%)$. Os dados percentuais dessa dimensão estão apresentados na Tabela 6'.

\section{Tabela 61}

Frequências de respostas obtidas dos professores em cada item da dimensão pedagógica.

\begin{tabular}{|c|c|c|c|c|c|c|}
\hline BLOCO 4 - DIMENSÃO PEDAGÓGICA & $\begin{array}{l}\text { discordo } \\
\text { totalmente }\end{array}$ & discordo & $\begin{array}{l}\text { não concordo } \\
\text { nem discordo }\end{array}$ & concordo & $\begin{array}{l}\text { concordo } \\
\text { totalmente }\end{array}$ & não sei \\
\hline $\begin{array}{l}\text { 1- As atividades desenvolvidas nas disciplinas básicas e clínicas } \\
\text { são integradas. }\end{array}$ & $5,3 \%$ & $68,4 \%$ & $15,8 \%$ & $10,5 \%$ & $0,0 \%$ & $0,0 \%$ \\
\hline $\begin{array}{l}\text { 2- A estrutura curricular do curso inclui primeiro o aprendizado } \\
\text { da teoria e na sequência a aplicação da teoria na prática. }\end{array}$ & $5,3 \%$ & $15,8 \%$ & $15,8 \%$ & $57,9 \%$ & $\mathbf{0 , 0 \%}$ & $5,3 \%$ \\
\hline $\begin{array}{l}\text { 3- O curso de Medicina está estruturado em ciclo básico e ciclo } \\
\text { clínico. }\end{array}$ & $0,0 \%$ & $10,5 \%$ & $5,3 \%$ & $78,9 \%$ & $5,3 \%$ & $0,0 \%$ \\
\hline $\begin{array}{l}\text { 4- A maior parte dos conteúdos teóricos da(s) disciplina(s) da } \\
\text { graduação que ministro é apresentada na forma de aula } \\
\text { expositiva. }\end{array}$ & $5,3 \%$ & $26,3 \%$ & $0,0 \%$ & $68,4 \%$ & $\mathbf{0 , 0 \%}$ & $0,0 \%$ \\
\hline $\begin{array}{l}\text { 5- As estratégias de ensino utilizadas são variadas, a exemplo de } \\
\text { seminários, discussões em grupos tutoriais, estudos de casos, } \\
\text { etc. }\end{array}$ & $0,0 \%$ & $10,5 \%$ & $5,3 \%$ & $73,7 \%$ & $10,5 \%$ & $0,0 \%$ \\
\hline $\begin{array}{l}\text { 6- O processo de ensino-aprendizagem envolve atividades } \\
\text { interdisciplinares. }\end{array}$ & $\mathbf{0 , 0 \%}$ & $42,1 \%$ & $15,8 \%$ & $36,8 \%$ & $5,3 \%$ & $0,0 \%$ \\
\hline 7- Existe interação entre a teoria ministrada e a prática. & $0,0 \%$ & $15,8 \%$ & $10,5 \%$ & $63,2 \%$ & $10,5 \%$ & $0,0 \%$ \\
\hline $\begin{array}{l}\text { 8- A interação entre a equipe de profissionais de saúde, } \\
\text { estudantes, professores e comunidade facilita o processo de } \\
\text { ensino e aprendizagem. }\end{array}$ & $0,0 \%$ & $0,0 \%$ & $0,0 \%$ & $78,9 \%$ & $21,1 \%$ & $0,0 \%$ \\
\hline $\begin{array}{l}\text { 9- Atividades práticas envolvendo profissionais das equipes de } \\
\text { saúde são estratégias que pouco acrescentam à formação do } \\
\text { médico, dado as especificidades do curso. }\end{array}$ & $33,3 \%$ & $55,6 \%$ & $0,0 \%$ & $11,1 \%$ & $0,0 \%$ & $0,0 \%$ \\
\hline $\begin{array}{l}\text { 10- As estratégias de ensino-aprendizagem que ocorrem no } \\
\text { ambiente do SUS são avaliadas conjuntamente pelos } \\
\text { profissionais da Rede e docentes. }\end{array}$ & $10,5 \%$ & $26,3 \%$ & $21,1 \%$ & $15,8 \%$ & $0,0 \%$ & $26,3 \%$ \\
\hline
\end{tabular}




\subsection{Comentários/sugestões de estudantes e professores sobre os itens}

\section{respondidos no instrumento}

\begin{tabular}{|c|c|}
\hline $3^{\circ}$ Semestre & 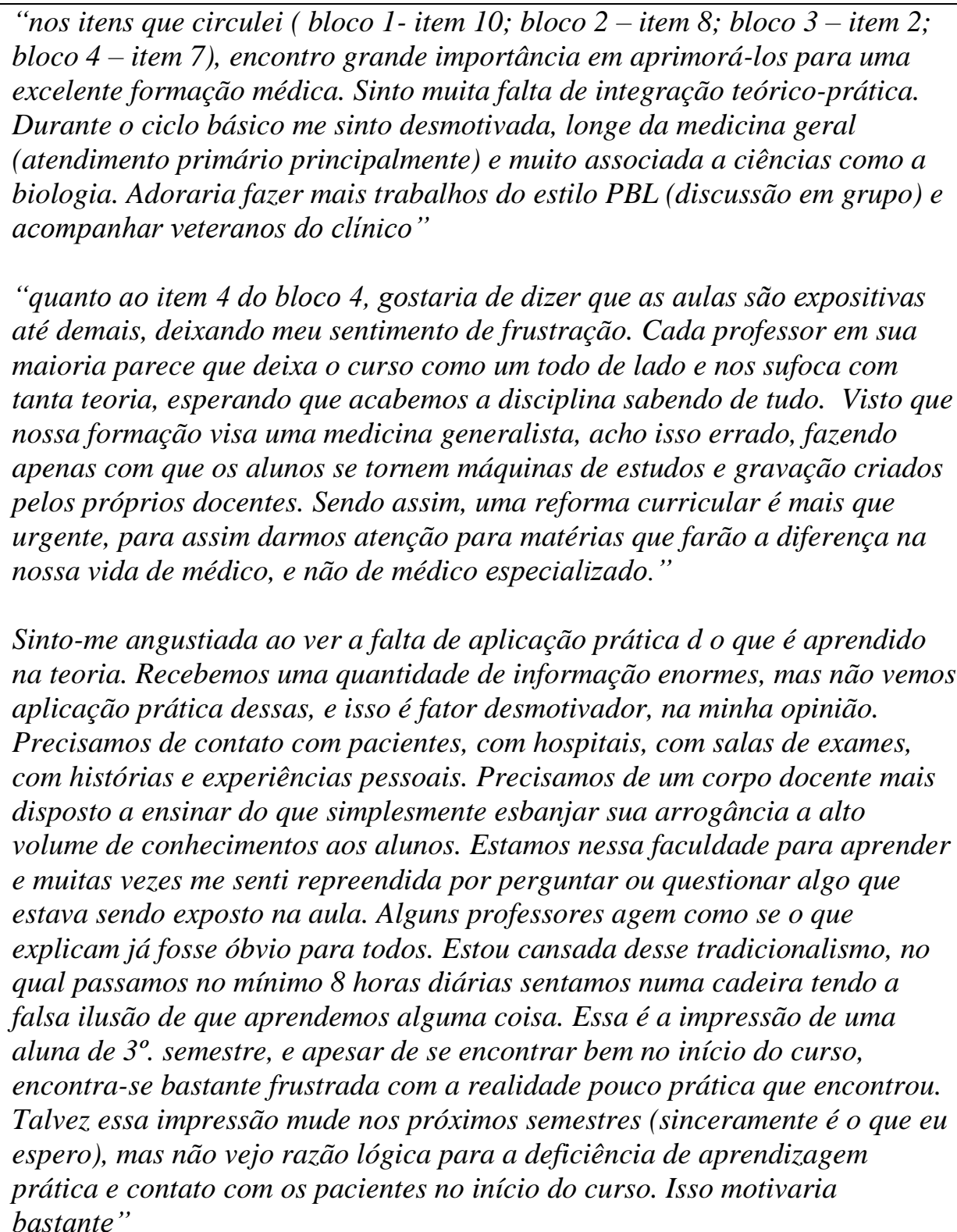 \\
\hline $4^{\circ}$ Semestre & $\begin{array}{l}\text { "o contato com pessoas contribui para a formação profissional, seja na rede } \\
\text { pública ou privada" } \\
\text { "o pouco contato que tive com o projeto impossibilitou uma resposta com } \\
\text { maior opinião" } \\
\text { "bloco 4-item } 8 \text { - interação que nem sempre existe Na verdade, na maioria } \\
\text { das vezes não consegui observar essa interação" } \\
\text { "avaliar as possibilidades de melhoria do ensino-serviço com o projeto Pró- } \\
\text { Saúde não remete ao que de fato é. Por exemplo, existem muitas dificuldades } \\
\text { para integrar as atividades na comunidade quanto à administração local. } \\
\text { Bem, ainda existem dificuldades para consolidar as atividades" }\end{array}$ \\
\hline
\end{tabular}




\begin{tabular}{|c|c|}
\hline & 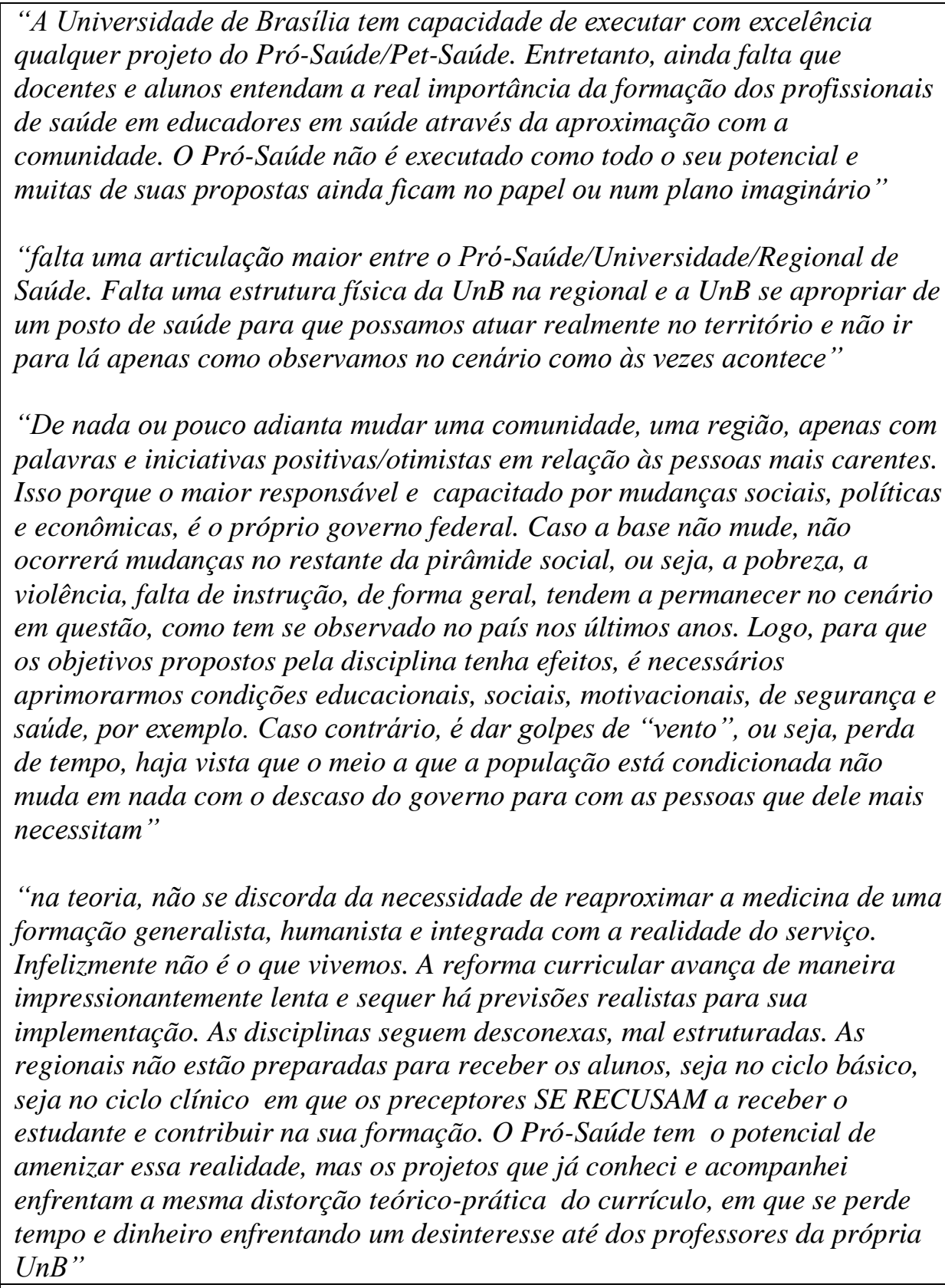 \\
\hline $5^{\circ}$ Semestre & $\begin{array}{l}\text { "a mudança no modelo de formação é urgente, para o bem de todos" } \\
\text { "acredito que as atividade do Pró-Saúde devam ter mais rigor e planejamento } \\
\text { constante porque as falhas nesses campos impossibilitam uma ação realmente } \\
\text { efetiva e transformadora em relação à comunidade de atuação" }\end{array}$ \\
\hline $6^{\circ}$ Semestre & $\begin{array}{l}\text { “Bloco } 3 \text { item } 7 \text { - em sua teoria, o Pró-Saúde atende a todos esses quesitos. } \\
\text { No entanto, pelo que ouvi de outros alunos que participaram do Pró-Saúde, } \\
\text { ele não está nem um pouco organizado. Os alunos apenas dissecaram peças } \\
\text { de cadáveres e não mantiveram contato com a regional. Creio que se esse } \\
\text { projeto fosse melhor, cumprindo seus próprios princípios, haveria maior } \\
\text { adesão dos alunos." } \\
\text { A inserção do curso de medicina no contexto da regional se dá de forma } \\
\text { fragmentada e ineficiente. É necessária uma inserção regular, organizada e } \\
\text { completa, tendo como foco principal as necessidades específicas da } \\
\text { região/comunidade no quesito saúde” }\end{array}$ \\
\hline
\end{tabular}




\begin{tabular}{|c|c|}
\hline $8^{\circ}$ Semestre & $\begin{array}{l}\text { "no curso de medicina, apenas aulas expositivas não suprem as necessidades } \\
\text { de aprendizado complexo" } \\
\text { "apesar da proposta de integração dos serviços no Programa Pró-Saúde, os } \\
\text { subprojetos não possuem estratégias claras de interligação" } \\
\text { "a integração da UnB co ma unidade de saúde representa grande potencial para } \\
\text { uma formação mais generalista, pois a inclusão do ambiente clínico } \\
\text { universitário na regional permite uma maior intervenção sobre o ambiente. É } \\
\text { necessário que a universidade se responsabilize por aquela população, } \\
\text { identificando os principais determinantes do processo de adoecimento para } \\
\text { aquela região e propondo medidas que visem corrigir esses problemas. A } \\
\text { prática no HUB deixa muito a desejar, pois tratam-se de pacientes } \\
\text { selecionados, muitas vezes doenças raras, e que fogem daquilo que nos espera } \\
\text { na prática médica. Por outro lado, entrada na Regional irá demandar um } \\
\text { esforço por parte da faculdade, professores e profissional da regional, pois } \\
\text { deve se conciliar a prática do ensino com a função assistencial. A formação } \\
\text { especializada, por exemplo, não haver uma enfermaria de clínica médica e } \\
\text { poucos ambulatórios, prejudica o aprendizado e forma um profissional que tem } \\
\text { dificuldade para interagir com outras áreas e que consiga resolver os } \\
\text { problemas básicos de uma população" } \\
\text { Sobre o item } 7 \text { da seção 1, apenas conheço o Pró-Saúde de nome, mas não tive } \\
\text { interesse em me aprofundar por seus objetivos" } \\
\text { "a integração dos estudantes de medicina co ma rede de saúde é pequena } \\
\text { durante os ciclos básico e clínico. Acredito que nossa inserção na regional } \\
\text { deveria ser maior, devido as contribuições para a formação do médico } \\
\text { generalista. Portanto, a participação igualmente no HUB e HRPA seria ideal. } \\
\text { Quanto ao internato, o que ouvimos são relatos de falta de preceptoria, algo } \\
\text { fundamental para quem está na graduação. De nada adiantaria os internos } \\
\text { serem obrigados a irem no HRPA sem preceptoria adequada. A solução seria } \\
\text { o estímulo aos professores para realizarem atividades práticas com os alunos } \\
\text { na regional, com orientação e preceptoria adequadas, em todas as fases do } \\
\text { curso" }\end{array}$ \\
\hline $9^{\circ}$ Semestre & $\begin{array}{l}\text { "na seção } 1 \text { questão } 5 \text {, marquei } 3 \text { semestres, mas todas as atividade práticas } \\
\text { fora que fizemos, somadas, não totalizam } 10 \text { ocasiões" }\end{array}$ \\
\hline $\mathbf{1 0}^{\circ}$ Semestre & $\begin{array}{l}\text { "infelizmente não conheço o projeto do Pró-Saúde e não posso colaborar } \\
\text { melhor com o estudo" }\end{array}$ \\
\hline $\mathbf{1 2}^{\circ}$ Semestre & $\begin{array}{l}\text { "bloco } 2 \text { - itens } 1,2 \text { e } 3 \text { - haveria muitos benefícios, caso houvesse de fato } \\
\text { integração, mas esta não existe" }\end{array}$ \\
\hline
\end{tabular}

Figura 65. Comentários /sugestões dos estudantes sobre os itens respondidos. 
"todas as respostas foram baseadas no atual currículo do curso de medicina e não da estrutura pós reforma curricular"

"o Pró-Saúde tem contribuição de forma muito especial para a reorientação da formação dos estudantes de medicina"

"no curso de medicina, durante o estágio probatório, o professor tem que cumprir obrigatoriamente parte de sua carga horária no Pró-Saúde. Essa norma, contudo, é apenas isso: é obrigatória. Não foi criado um programa que receba o professor dentro do Pró-Saúde, na comunidade. Portanto, a maior parte dos professores descobre caminhos que tem por único objetivo cumpri a norma (aulas em igrejas, mini-palestras, etc)"

"Considero fundamental que a UnB oficialize sua parceria com a SES e com a Regional, com bases sólidas. Creio que deveria existir um núcleo de recepção ao novo professor, que o acolha e insira na realidade de um programa de verdade comunitário"

As respostas aos itens acima se referem apenas à nossa experiência com as metodologias ativas de ensino, cujo objetivo é a visão interdisciplinar e multiprofissional de cada disciplina curricular, independente de sua posição na grade curricular. O projeto pedagógico que não insere seu aluno no campo de atuação profissional está na contramão da história, porque não profissionaliza adequadamente. Também acredito que estejamos na contra corrente da formação profissional se resistirmos, ou seja, se não houver por parte do professor uma abertura simpática em relação ao modelo "bancário, jesuítico ou dentre paredes, na educação médica e formação do profissional de saúde"

Figura 66. Comentários /sugestões dos professores sobre os itens respondidos.

\section{Pontuação e codificação dos itens e blocos para interpretação das tendências}

\section{atitudinais}

Seguindo a mesma estratégia empregada nos Estudos 1 e 2, cada item foi pontuado baseado na categorização do mesmo como uma atitude positiva ou negativa em relação ao objeto de estudo, conforme já ilustrado na Figura 10. Para a conversão das médias obtidas nos itens em conceitos, seguiu-se a interpretação já descrita na Figura 36.

Em relação à dimensão teórica (Bloco 1), pode-se observar nas Tabelas 62 e 63 que os resultados de professores e estudantes diferiram. Os professores apresentaram na média geral, uma tendência desfavorável (D) para este bloco, enquanto os estudantes demonstraram uma tendência neutra (NCND). Para os estudantes, isto prevaleceu na 
maioria dos itens, com exceção dos itens 2 e 5, em que a média obtida foi convertida para C e o item 1 para CT.

\section{Tabela 62}

Pontuação dos itens do bloco 1 em relação aos estudantes

\begin{tabular}{|c|c|c|c|c|c|c|c|c|c|c|}
\hline & B1Q2 & B1Q1 & B1Q3 & B1Q10 & B1Q4 & B1Q5 & B1Q7 & B1Q8 & B1Q6 & B1Q9 \\
\hline Sinal & + & - & + & - & + & - & + & - & + & - \\
\hline Soma & 132 & -339 & 34 & -85 & -62 & -99 & -22 & 32 & 38 & -31 \\
\hline Média & 0,54 & $-1,38$ & 0,15 & $-0,36$ & $-0,30$ & $-0,46$ & $-0,17$ & 0,26 & 0,18 & $-0,26$ \\
\hline $\begin{array}{l}\text { Desvio } \\
\text { Padrão }\end{array}$ & 0,93 & 0,71 & 1,07 & 1,10 & 0,95 & 0,91 & 0,88 & 0,95 & 1,00 & 0,88 \\
\hline Moda & 1 & -1 & 1 & -1 & -1 & -1 & 0 & 0 & 1 & 0 \\
\hline Mediana & 1 & -1 & 0 & -1 & 0 & -1 & 0 & 0 & 0 & 0 \\
\hline Conceito & C & CT & ND/NC & ND/NC & ND/NC & C & ND/NC & ND/NC & ND/NC & ND/NC \\
\hline Confirmatório & \multicolumn{2}{|c|}{$-0,84$} & \multicolumn{2}{|c|}{$-0,21$} & \multicolumn{2}{|c|}{$-0,76$} & \multicolumn{2}{|c|}{0,09} & & \\
\hline Conceito & \multicolumn{2}{|c|}{ D } & \multicolumn{2}{|c|}{ ND/NC } & \multicolumn{2}{|c|}{ D } & \multicolumn{2}{|c|}{ ND/NC } & & \\
\hline Bloco & \multicolumn{4}{|c|}{$-0,18$} & \multicolumn{4}{|c|}{ ND/NC } & & \\
\hline
\end{tabular}

Tabela 63

Pontuação dos itens do bloco 1 em relação aos professores

\begin{tabular}{|c|c|c|c|c|c|c|c|c|c|c|}
\hline & B1Q2 & B1Q1 & B1Q3 & B1Q10 & B1Q4 & B1Q5 & B1Q7 & B1Q8 & B1Q6 & B1Q9 \\
\hline Sinal & + & - & + & - & + & - & + & - & + & - \\
\hline Soma & 11 & -23 & -2 & -7 & -16 & -8 & -16 & 11 & -9 & -12 \\
\hline Média & 0,65 & $-1,21$ & $-0,11$ & $-0,39$ & $-0,89$ & $-0,50$ & $-0,94$ & 0,69 & $-0,56$ & $-0,80$ \\
\hline $\begin{array}{l}\text { Desvio } \\
\text { Padrão }\end{array}$ & 1,32 & 0,71 & 2,69 & 0,98 & 0,96 & 0,89 & 1,03 & 0,95 & 1,31 & 0,41 \\
\hline Moda & 1 & -1 & -1 & -1 & -1 & -1 & -1 & 1 & -1 & -1 \\
\hline Mediana & 1 & -1 & -1 & -1 & -1 & -1 & -1 & 1 & -1 & -1 \\
\hline Conceito & C & CT & ND/NC & ND/NC & D & C & D & D & D & C \\
\hline Confirmatório & \multicolumn{2}{|c|}{$-0,56$} & \multicolumn{2}{|c|}{$-0,49$} & \multicolumn{2}{|c|}{$-1,39$} & \multicolumn{2}{|c|}{$-0,25$} & & \\
\hline Conceito & \multicolumn{2}{|c|}{ D } & & 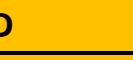 & \multicolumn{2}{|c|}{ DT } & \multicolumn{2}{|c|}{ ND/NC } & & \\
\hline Bloco & \multicolumn{4}{|l|}{$-0,41$} & \multicolumn{4}{|c|}{ D } & & \\
\hline
\end{tabular}

Na dimensão cenário de práticas (Bloco 2), observou-se que os resultados dos

professores e estudantes também diferiram. Os estudantes apresentaram na média geral, uma tendência neutra (NCND). Em relação aos professores, em geral a média do bloco foi 
favorável, com conceito $\mathrm{C}$ (concordo). Na comparação individual dos itens, houve diferença conceitual apenas no item 12, com conceito C para estudantes e NCND para professores. Os dados obtidos estão apresentados nas Tabelas 64 e 65.

\section{Tabela 64}

Pontuação dos itens do bloco 2 em relação aos estudantes

\begin{tabular}{|c|c|c|c|c|c|c|c|c|c|}
\hline & B2Q1 & B2Q2 & B2Q3 & B2Q4 & B2Q5 & B2Q6 & B2Q8 & B2Q13 & B2Q12 \\
\hline Sinal & + & + & + & + & + & - & + & + & - \\
\hline Soma & 311 & 287 & 320 & 47 & -46 & -223 & 207 & 79 & -170 \\
\hline Média & 1,29 & 1,20 & 1,34 & 0,22 & $-0,24$ & $-1,04$ & 0,88 & 0,34 & $-0,73$ \\
\hline \begin{tabular}{|l} 
Desvio \\
Padrão
\end{tabular} & 0,77 & 0,87 & 0,80 & 1,06 & 1,08 & 0,75 & 1,01 & 1,19 & 0,87 \\
\hline Moda & 1 & 1 & 2 & 1 & -1 & -1 & 1 & 1 & -1 \\
\hline Mediana & 1 & 1 & 1 & 0 & 0 & -1 & 1 & 1 & -1 \\
\hline Conceito & CT & CT & CT & ND/NC & ND/NC & C & C & ND/NC & C \\
\hline $\begin{array}{l}\text { Confirmatório } \\
\text { Conceito }\end{array}$ & & & & & & & & \multicolumn{2}{|c|}{$\begin{array}{l}-0,40 \\
\text { ND/NC }\end{array}$} \\
\hline Bloco & 0,36 & & & & & & & & \\
\hline
\end{tabular}

\section{Tabela 65}

Pontuação dos itens do bloco 2 em relação aos professores

\begin{tabular}{|c|c|c|c|c|c|c|c|c|c|}
\hline & B2Q1 & B2Q2 & B2Q3 & B2Q4 & B2Q5 & B2Q6 & B2Q8 & B2Q13 & B2Q12 \\
\hline Sinal & + & + & + & + & + & - & + & + & - \\
\hline Soma & 28 & 28 & 25 & -2 & 5 & -14 & 22 & 0 & -5 \\
\hline Média & 1,47 & 1,47 & 1,32 & $-0,11$ & 0,26 & $-0,82$ & 1,16 & 0,00 & $-0,28$ \\
\hline $\begin{array}{l}\text { Desvio } \\
\text { Padrão }\end{array}$ & 0,51 & 0,51 & 0,95 & 1,37 & 3,51 & 0,64 & 1,21 & 1,41 & 0,83 \\
\hline Moda & 1 & 1 & 1 & 1 & -1 & -1 & 2 & 1 & -1 \\
\hline Mediana & 1 & 1 & 1 & 1 & -1 & -1 & 1 & 1 & -1 \\
\hline Conceito & CT & CT & CT & ND/NC & ND/NC & C & C & ND/NC & ND/NC \\
\hline Confirmatório & & & & & & & & \multirow{2}{*}{\multicolumn{2}{|c|}{$\begin{array}{c}-0,28 \\
\text { ND/NC }\end{array}$}} \\
\hline Conceito & & & & & & & & & \\
\hline Bloco & 0,50 & & & & c & & & & \\
\hline
\end{tabular}

No bloco 3, da dimensão reorientação da formação, a Média dos estudantes para o bloco foi de 0,52 e dos professores 0,57 . Ambos os grupos apresentaram o conceito C (concordo) ao se realizar a conversão, demonstrando tendência atitudinal positiva. Em 
todos os itens considerados negativos em relação ao objeto de estudo, tanto professores quanto estudantes, após as conversões das Médias, apresentaram os conceitos D (discordo) ou neutro (NCND), reforçando a tendência positiva em relação a essa dimensão. Os dados referentes a esse bloco encontram-se descritos nas Tabelas 66 e 67.

Tabela 66

Pontuação dos itens do bloco 3 em relação aos estudantes

\begin{tabular}{|c|c|c|c|c|c|c|c|c|c|c|c|c|c|}
\hline & B3Q1 & B3Q2 & B3Q3 & B3Q4 & B3Q8 & B3Q5 & B3Q6 & B3Q9 & B3Q7 & B2Q10 & B2Q7 & B2Q9 & B2Q11 \\
\hline Sinal & + & + & + & - & + & - & + & + & + & + & - & + & + \\
\hline Soma & 0 & 107 & 135 & -27 & 142 & 93 & 171 & 222 & 174 & 59 & -72 & 146 & 103 \\
\hline Média & 0,00 & 0,65 & 0,72 & $-0,14$ & 0,77 & 0,55 & 0,91 & 1,13 & 0,90 & 0,26 & $-0,31$ & 0,82 & 0,57 \\
\hline $\begin{array}{l}\text { Desvio } \\
\text { Padrão }\end{array}$ & 1,20 & 0,90 & 0,96 & 1,03 & 0,84 & 0,90 & 0,84 & 0,66 & 0,86 & 1,10 & 1,17 & 0,90 & 1,06 \\
\hline Moda & 1 & 1 & 1 & -1 & 1 & 1 & 1 & 1 & 1 & 1 & -1 & 1 & 1 \\
\hline Mediana & 0 & 1 & 1 & 0 & 1 & 1 & 1 & 1 & 1 & 1 & -1 & 1 & 1 \\
\hline Conceito & ND/NC & C & C & ND/NC & C & D & C & C & C & ND/NC & ND/NC & C & C \\
\hline Confirmatório & & & \multicolumn{2}{|c|}{0,57} & \multicolumn{2}{|c|}{1,31} & \multicolumn{2}{|c|}{2,04} & & \multicolumn{2}{|c|}{$-0,06$} & & \\
\hline Conceito & & & \multicolumn{2}{|c|}{ C } & & $\mathbf{T}$ & \multicolumn{2}{|c|}{ CT } & & \multicolumn{2}{|c|}{ ND/NC } & & \\
\hline Bloco & 0,52 & & & & & & & & & & & & \\
\hline
\end{tabular}

Tabela 67

Pontuação dos itens do bloco 3 em relação aos professores

\begin{tabular}{|c|c|c|c|c|c|c|c|c|c|c|c|c|c|}
\hline & B3Q1 & B3Q2 & B3Q3 & B3Q4 & B3Q8 & B3Q5 & B3Q6 & B3Q9 & B3Q7 & B2Q10 & B2Q7 & B2Q9 & B2Q11 \\
\hline Sinal & + & + & + & - & + & - & + & + & + & + & - & + & + \\
\hline Soma & 22 & 22 & 17 & -10 & 18 & 10 & 12 & 21 & 18 & -6 & -6 & 14 & 4 \\
\hline Média & 1,16 & 1,29 & 0,89 & $-0,53$ & 0,95 & 0,56 & 0,63 & 1,17 & 0,95 & $-0,32$ & $-0,32$ & 0,74 & 0,22 \\
\hline $\begin{array}{l}\text { Desvio } \\
\text { Padrão }\end{array}$ & 2,41 & 2,57 & 1,10 & 0,96 & 1,13 & 0,92 & 1,34 & 0,92 & 0,97 & 1,34 & 0,89 & 1,41 & 1,66 \\
\hline Moda & 1 & 1 & 1 & -1 & 1 & 1 & 1 & 1 & 1 & -1 & -1 & 2 & 1 \\
\hline Mediana & 1 & 1 & 1 & -1 & 1 & 1 & 1 & 1 & 1 & -1 & -1 & 1 & 1 \\
\hline Conceito & C & CT & C & C & C & D & C & C & C & ND/NC & ND/NC & C & ND/NC \\
\hline Confirmatório & & & \multirow{2}{*}{\multicolumn{2}{|c|}{$\begin{array}{c}0,37 \\
\text { ND/NC }\end{array}$}} & \multicolumn{2}{|c|}{1,50} & \multicolumn{2}{|c|}{1,80} & & \multicolumn{2}{|c|}{$-0,63$} & & \\
\hline Conceito & & & & & & & & & & \multicolumn{2}{|c|}{ D } & & \\
\hline Bloco & 0,57 & \multicolumn{12}{|c|}{ C } \\
\hline
\end{tabular}


Na dimensão pedagógica (Bloco 4), os resultados diferiram entre professores e estudantes. Os professores demonstraram uma tendência atitudinal mais positiva que os estudantes em relação a esta dimensão, com conceito $C$ após a conversão das Médias. Em três itens negativos em relação ao objeto de estudo, os estudantes obtiveram C ou CT, ou seja, tendência atitudinal negativa.

Os professores apresentaram uma posição neutra (NCND) em relação a dois desses itens negativos (item 2 e item 4) e concordaram com o item 1. Ainda assim, a média geral do bloco para estes foi favorável, com conceito $\mathrm{C}$ (concordo). Os resultados de cada item deste bloco estão descritos nas Tabelas 68 e 69.

\section{Tabela 68}

Pontuação dos itens do bloco 4 em relação aos estudantes

\begin{tabular}{|c|c|c|c|c|c|c|c|c|c|c|}
\hline & B4Q1 & B4Q3 & B4Q7 & B4Q2 & B4Q5 & B4Q4 & B4Q6 & B4Q8 & B4Q9 & B4Q10 \\
\hline Sinal & + & - & + & - & + & - & + & + & - & + \\
\hline Soma & -111 & -335 & 94 & -178 & 75 & -331 & -43 & 274 & 247 & -7 \\
\hline Média & $-0,51$ & $-1,40$ & 0,40 & $-0,74$ & 0,31 & $-1,40$ & $-0,18$ & 1,14 & 1,03 & $-0,04$ \\
\hline $\begin{array}{l}\text { Desvio } \\
\text { Padrão }\end{array}$ & 1,05 & 0,65 & 0,91 & 0,93 & 1,10 & 0,64 & 1,05 & 0,80 & 1,06 & 1,13 \\
\hline Moda & -1 & -1 & 1 & -1 & 1 & -1 & -1 & 1 & 1 & 0 \\
\hline Mediana & -1 & -1 & 1 & -1 & 1 & -1 & 0 & 1 & 1 & 0 \\
\hline Conceito & D & CT & ND/NC & C & ND/NC & CT & ND/NC & C & D & ND/NC \\
\hline Confirmatório & \multicolumn{2}{|c|}{$-1,90$} & \multicolumn{2}{|c|}{$-0,35$} & \multicolumn{2}{|c|}{$-1,08$} & & \multicolumn{2}{|c|}{2,17} & \\
\hline Conceito & \multicolumn{2}{|c|}{ DT } & \multicolumn{2}{|c|}{ ND/NC } & \multicolumn{2}{|c|}{ D } & & \multicolumn{2}{|c|}{ CT } & \\
\hline Bloco & \multicolumn{4}{|c|}{$-0,14$} & \multicolumn{3}{|c|}{ ND/NC } & & & \\
\hline
\end{tabular}

Tabela 69

Pontuação dos itens do bloco 4 em relação aos professores

\begin{tabular}{|l|cc|cc|cc|c|cc|c|}
\hline & B4Q1 & B4Q3 & B4Q7 & B4Q2 & B4Q5 & B4Q4 & B4Q6 & B4Q8 & B4Q9 & B4Q10 \\
\hline Sinal & + & - & + & - & + & - & + & + & - & + \\
Soma & -7 & -15 & 9 & -6 & 14 & -6 & -5 & 23 & 71 & 10 \\
Média & $-0,37$ & $-0,79$ & 0,47 & $-0,33$ & 0,74 & $-0,32$ & $-0,26$ & 1,21 & 3,74 & 0,71 \\
Desvio & 2,63 & 0,71 & 1,22 & 0,97 & 0,99 & 1,06 & 1,28 & 0,42 & 11,48 & 4,08 \\
Padrão & -1 & -1 & 1 & -1 & 1 & -1 & -1 & 1 & 1 & -1 \\
Moda & -1 & -1 & 1 & -1 & 1 & -1 & -1 & 1 & 1 & -1 \\
Mediana & -1 & & & & & & & & &
\end{tabular}




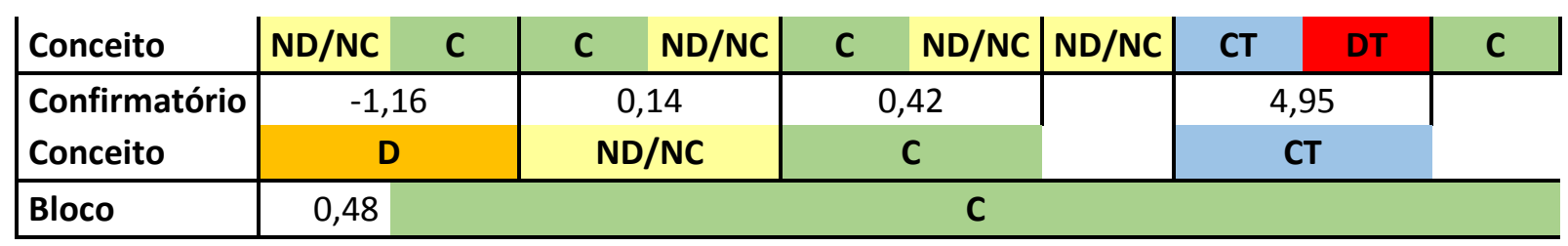

Para a análise comparativa entre estudantes e professores por bloco, calculou-se a soma de cada indivíduo de cada grupo (estudantes e professores). Considerando que havia itens positivos (favoráveis ao Pró-saúde) e negativos (desfavoráveis ao Pró-saúde), a soma indica o quão favorável ao Pró-saúde cada indivíduo é em cada bloco. Na sequência, aplicou-se o Teste H de Kruskal-Wallis, para verificação das diferenças entre as medianas dos grupos. Para rejeitar a hipótese de igualdade, foi considerado nível mínimo de significância de 5\%. A comparação entre Medianas para os dois grupos para os quatro blocos estão apresentadas na Tabela 70 .

\section{Tabela 70}

Comparação entre as medianas para estudantes e professores nos blocos 1, 2, 3 e 4 .

\begin{tabular}{lc|c|c|c|c}
\hline \multicolumn{2}{c|}{ GRUPO } & BLOCO 1 & BLOCO 2 & BLOCO 3 & BLOCO 4 \\
\hline Estudantes & $\mathrm{N}$ & 190 & 190 & 190 & 190 \\
& Mediana & $-2,00$ & 3,00 & 6,00 & $-1,00$ \\
\hline Professores & $\mathrm{N}$ & 18 & 18 & 18 & 18 \\
& Mediana & $-3,50$ & 4,50 & 7,00 &, 00 \\
\hline Total & $\mathrm{N}$ & 208 & 208 & 208 & 208 \\
& $\mathrm{Mediana}$ & $-2,00$ & 3,00 & 6,00 & $-1,00$ \\
\hline
\end{tabular}


Assim como no Estudo 2, o teste de Kruskal-Wallis demonstrou que para os blocos 1, 2, e 3 não ocorreu diferenças significativas entre professores e estudantes. Para o bloco 4, a diferença entre os dois grupos foi estatisticamente significante. A Tabela 71 apresenta o resultado comparativo entre professores e estudantes para as quatro dimensões estudadas, assim como os valores de $p$ e do teste Kruskall Wallis.

\section{Tabela 71}

Comparação dos resultados entre professores e estudantes para as quatro dimensões estudadas.

\begin{tabular}{|c|c|c|c|c|c|c|c|c|}
\hline \multirow[b]{2}{*}{ Grupo } & \multicolumn{2}{|c|}{$\begin{array}{c}\text { Bloco 1 } \\
\text { dimensão teórica }\end{array}$} & \multicolumn{2}{|c|}{$\begin{array}{c}\text { Bloco } 2 \\
\text { cenário de práticas }\end{array}$} & \multicolumn{2}{|c|}{$\begin{array}{c}\text { Bloco } 3 \\
\text { reorientação da } \\
\text { formação }\end{array}$} & \multicolumn{2}{|c|}{$\begin{array}{c}\text { Bloco } 4 \\
\text { dimensão } \\
\text { pedagógica }\end{array}$} \\
\hline & $\begin{array}{c}\text { média } \\
\text { dos } \\
\text { escores }\end{array}$ & Conceito & $\begin{array}{c}\text { média } \\
\text { dos } \\
\text { escores }\end{array}$ & conceito & $\begin{array}{c}\text { média } \\
\text { dos } \\
\text { escores }\end{array}$ & Conceito & $\begin{array}{c}\text { média } \\
\text { dos } \\
\text { escores }\end{array}$ & conceito \\
\hline Estudantes & $-0,18$ & $\begin{array}{c}\text { não } \\
\text { concordo } \\
\text { nem } \\
\text { discordo }\end{array}$ & 0,36 & $\begin{array}{c}\text { não } \\
\text { concordo } \\
\text { nem } \\
\text { discordo }\end{array}$ & 0,52 & concordo & $-0,14$ & $\begin{array}{l}\text { não } \\
\text { concordo } \\
\text { nem } \\
\text { discordo }\end{array}$ \\
\hline Professores & $-0,41$ & discordo & 0,50 & concordo & 0,57 & concordo & 0,48 & concordo \\
\hline $\begin{array}{l}\text { Teste de } \\
\text { Kruskal-Wallis }\end{array}$ & \multicolumn{2}{|c|}{$H(1)=3,314$} & \multicolumn{2}{|c|}{$\mathrm{H}(1)=0,938$} & \multicolumn{2}{|c|}{$\mathrm{H}(1)=1,551$} & \multicolumn{2}{|c|}{$\mathrm{H}(1)=4,703$} \\
\hline Valor de p & \multicolumn{2}{|c|}{$p=0,069$} & \multicolumn{2}{|c|}{$p=0,333$} & \multicolumn{2}{|c|}{$\mathrm{p}=0,213$} & \multicolumn{2}{|c|}{$p=0,030$} \\
\hline
\end{tabular}

\section{Análise de conteúdo das entrevistas}

Um total de oito estudantes e sete professores foram entrevistados. Seguindo a mesma metodologia dos Estudos 1 e 2, os quais foram norteados pela temática reorientação da formação, e possuindo como elemento de análise o Pró-Saúde, as entrevistas geraram, pelo procedimento de caixas (Bardin, 2009) as seguintes categorias: perfil percebido; currículo; processo de ensino e aprendizagem; cenário de práticas e implementação das 
ações. Na Figura 21 foi apresentado o modelo descritivo de forma similar nos estudos dos três cursos propostos para análise.

A partir das categorias, foram estabelecidas subcategorias, e neste momento obtivemos algumas variações entre estudantes e professores, além das variações entre os cursos. Unidades de registro de cada subcategoria estão representadas respectivamente, para estudantes e professores, nas Figuras 67 e 68. 


\begin{tabular}{|c|c|c|}
\hline CATEGORIA & $\begin{array}{c}\text { SUB } \\
\text { CATEGORIAS }\end{array}$ & UNIDADE DE REGISTRO \\
\hline \multirow[t]{2}{*}{$\begin{array}{c}\text { PERFIL } \\
\text { PERCEBIDO }\end{array}$} & Generalista & $\begin{array}{l}\text { "é ter um domínio sobre diversas questões do que é mais prevalente, que realmente necessite de uma } \\
\text { tecnologia menor, que consiga dar conta em um nível de atenção mais primário" (EM1) } \\
\text { "acho que a formação pura não fornece muito embasamento pra você ter muito palpável o que é um } \\
\text { médico generalista; o meu foi um caso pessoal de querer ir atrás mesmo" (EM1) } \\
\text { "generalista é o que vê as doenças mais prevalentes" (EM2) } \\
\text { "deveria se enquadrar em problemas das populações locais e não em várias especialidades, você não tinha } \\
\text { que estar preparado para ver os problemas específicos das pessoas nas áreas delas e sim o quadro geral" } \\
\text { (EM3) } \\
\text { "não necessariamente você te quem saber tudo de tudo e resolver todos os problemas, mas pelo menos } \\
\text { saber pra onde encaminhar" (EM4) } \\
\text { "ter uma visão geral de todos os aspectos da Medicina" (EM5) } \\
\text { "o que mais falta no Brasil para formar o médico generalista é uma formação mais humana, mais } \\
\text { humanística dos profissionais da área da saúde como um todo" (EM5) } \\
\text { "o médico generalista tem que ser o profissional capaz de diagnosticar aquelas doenças mais prevalentes. } \\
\text { De uma maneira geral acho que o curso não te dá uma visão disso" (EM7) } \\
\text { "eu preciso saber lidar com a população em geral" (EM8) }\end{array}$ \\
\hline & Especialista & $\begin{array}{l}\text { "médicos que pensam extremamente em especialidade e desde alunos já pensam em onde vão fazer sua } \\
\text { residência" (EM1) } \\
\text { "no nosso curso a gente vê todas as áreas da medicina, mas todas de ponta, então a gente faz a multi- } \\
\text { especialidade" (EM2) } \\
\text { "eu acho que está lançando um profissional que tem uma capacidade alta de se especializar, de ser um } \\
\text { especialista de ponta" (EM2) } \\
\text { "100\%, não é mais... é todo!" (EM3) } \\
\text { "a expectativa dos alunos é fazer a especialidade" (EM3) } \\
\text { "apesar de ter maior foco na sensibilização para os problemas da sociedade, da comunidade, o curso é prá } \\
\text { especialista (EM3) } \\
\text { "aqui a gente tem uma formação mais técnica e especializada" (EM4) } \\
\text { "um bom médico; a gente se aprofunda em coisas que outras escolas não se aprofundam" (EM4) } \\
\text { "acho que aqui a tendência à especialização enquanto estamos na graduação é muito grande" (EM5) } \\
\text { "eu acho que a gente pende um pouco pra especialidade" (EM7) }\end{array}$ \\
\hline
\end{tabular}




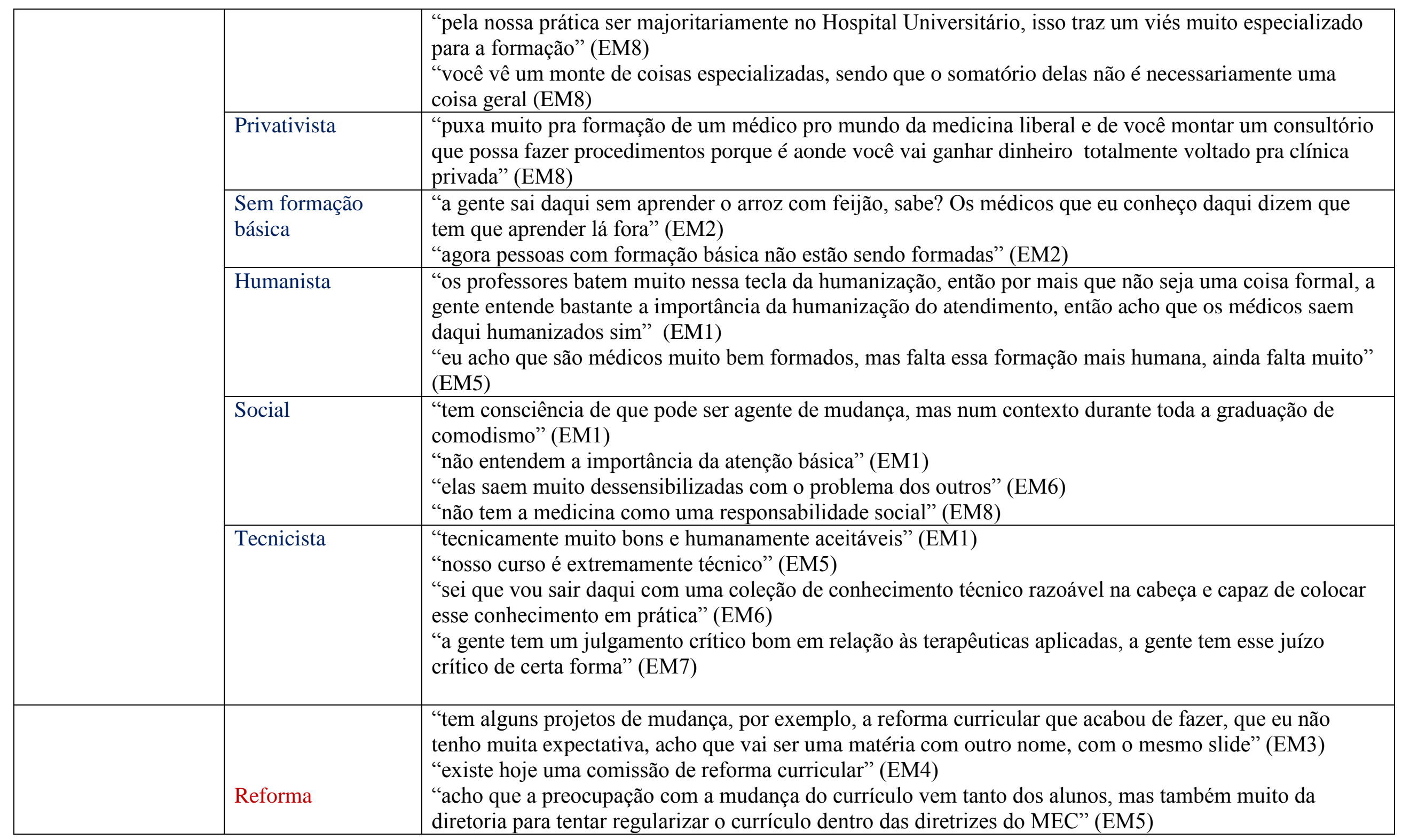




\begin{tabular}{|c|c|c|}
\hline \multirow{4}{*}{ CURRÍCULO } & & $\begin{array}{l}\text { "o que falta no nosso currículo é a parte de geriatria, isso vai ser focado no nosso novo currículo" (EM5) } \\
\text { "a gente está passando por um processo de reforma curricular agora com um protagonismo estudantil } \\
\text { muito grande" (EM8) } \\
\text { "tem uma minoria que está se mobilizando, puxando a reforma curricular, mas na verdade gente não } \\
\text { representa a maioria" (EM8) }\end{array}$ \\
\hline & $\begin{array}{l}\text { Mudança de } \\
\text { estrutura }\end{array}$ & $\begin{array}{l}\text { "com uma metodologia um pouco mais ativa que envolve mais o estudante" (EM4) } \\
\text { "essa discussão é uma parte do centro acadêmico; eu faço parte do CA e nós temos essa preocupação } \\
\text { também" (EM5) } \\
\text { "tem uma proposta de ter uma maior prática lá no serviço e ter experiência de internato lá. Na origem da } \\
\text { faculdade de medicina nós começamos atendendo Sobradinho. Lá era formado o profissional de saúde" } \\
\text { (EM5) } \\
\text { "a gente tenta aproximar o currículo hoje do que tínhamos na fundação do curso, da faculdade de medicina } \\
\text { aqui, que atendia no Hospital de Sobradinho" (EM6) } \\
\text { "vai ser trocado essa coisa de disciplina estanque por módulos de sistemas" (EM8) }\end{array}$ \\
\hline & Dificuldades & $\begin{array}{l}\text { "o que mais sinto falta é no papel do professor. O professor se mostra como um instrutor. Temos muitos } \\
\text { instrutores e poucos professores. O conceito de professor que eu tinha antes de entrar se perdeu. Sempre } \\
\text { tive a ideia do diretor de bateria na capoeira, do mestre que passa valores além de conhecimento técnico. É } \\
\text { isso que gostaria que tivesse aqui na medicina. Às vezes quero conversar com um professor, mas tenho até } \\
\text { medo do que vou ouvir deles. Para a formação básica basta" (EM6) } \\
\text { "a gente nota às vezes resistência de alguns docentes, não de todos, tem muitos que estão engajados" } \\
\text { (EM8) } \\
\text { "eles não foram formados nesse método, então é difícil pra eles" (EM8) }\end{array}$ \\
\hline & $\begin{array}{l}\text { Integração entre } \\
\text { áreas do curso }\end{array}$ & $\begin{array}{l}\text { A integração é bem pequena dentro das disciplinas. Se passa da minha especialidade, a gente não discute } \\
\text { mais essa aula hoje... é muito ruim" (EM1) } \\
\text { "não acontece, a gente sempre vê o mais profundo de cada área" (EM2) } \\
\text { "totalmente separadas" (EM3) } \\
\text { "é bem separado. Prá você ter uma noção, a gente tem uma disciplina que se chama gineco e outra } \\
\text { obstetrícia" (EM4) } \\
\text { "cada professor está puxando para seu lado" (EM5) } \\
\text { "a gente percebe que não há diálogo" (EM6) } \\
\text { "Âs vezes o professor já deu uma disciplina pra gente antes, ele vai dar outra disciplina depois e essa }\end{array}$ \\
\hline
\end{tabular}




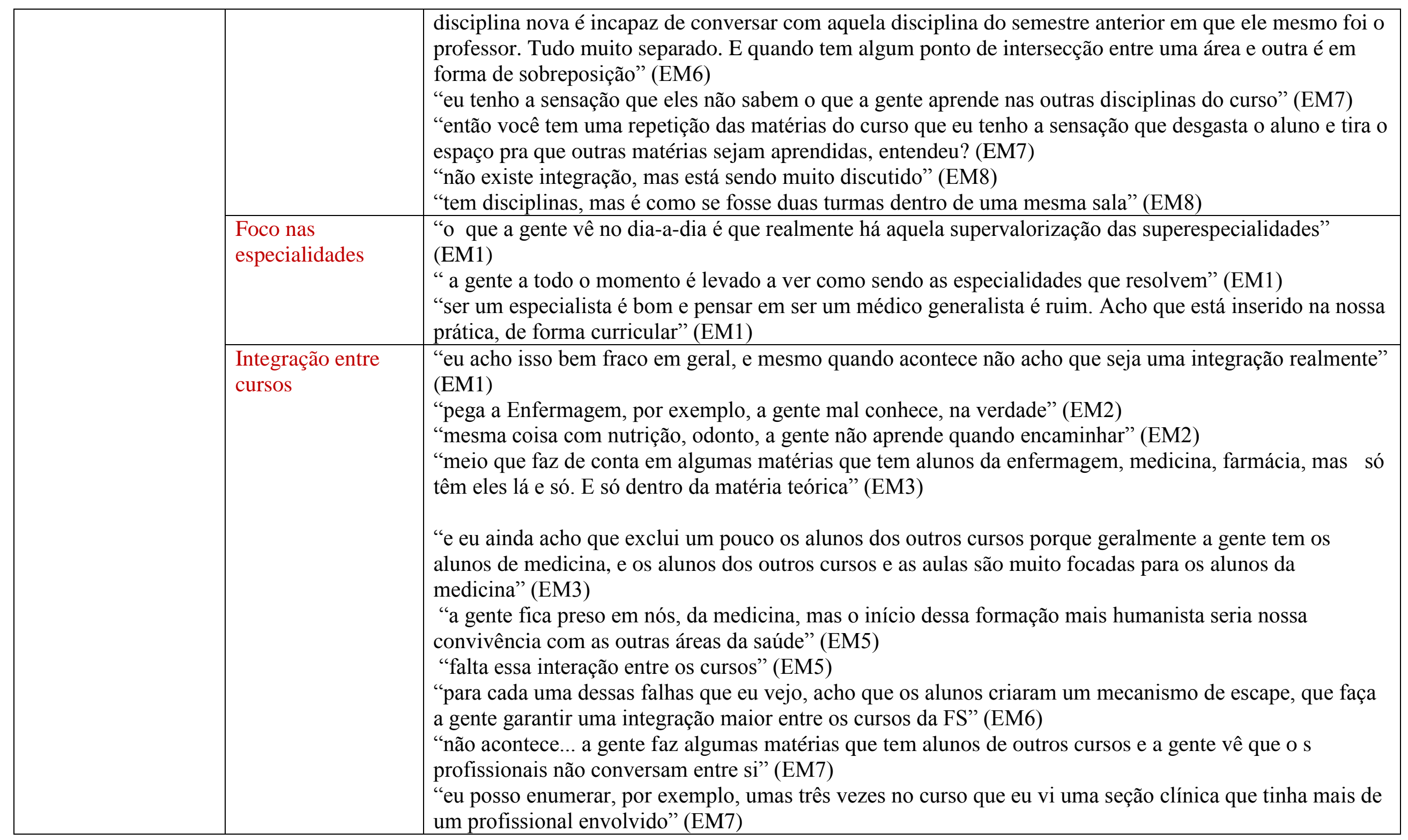




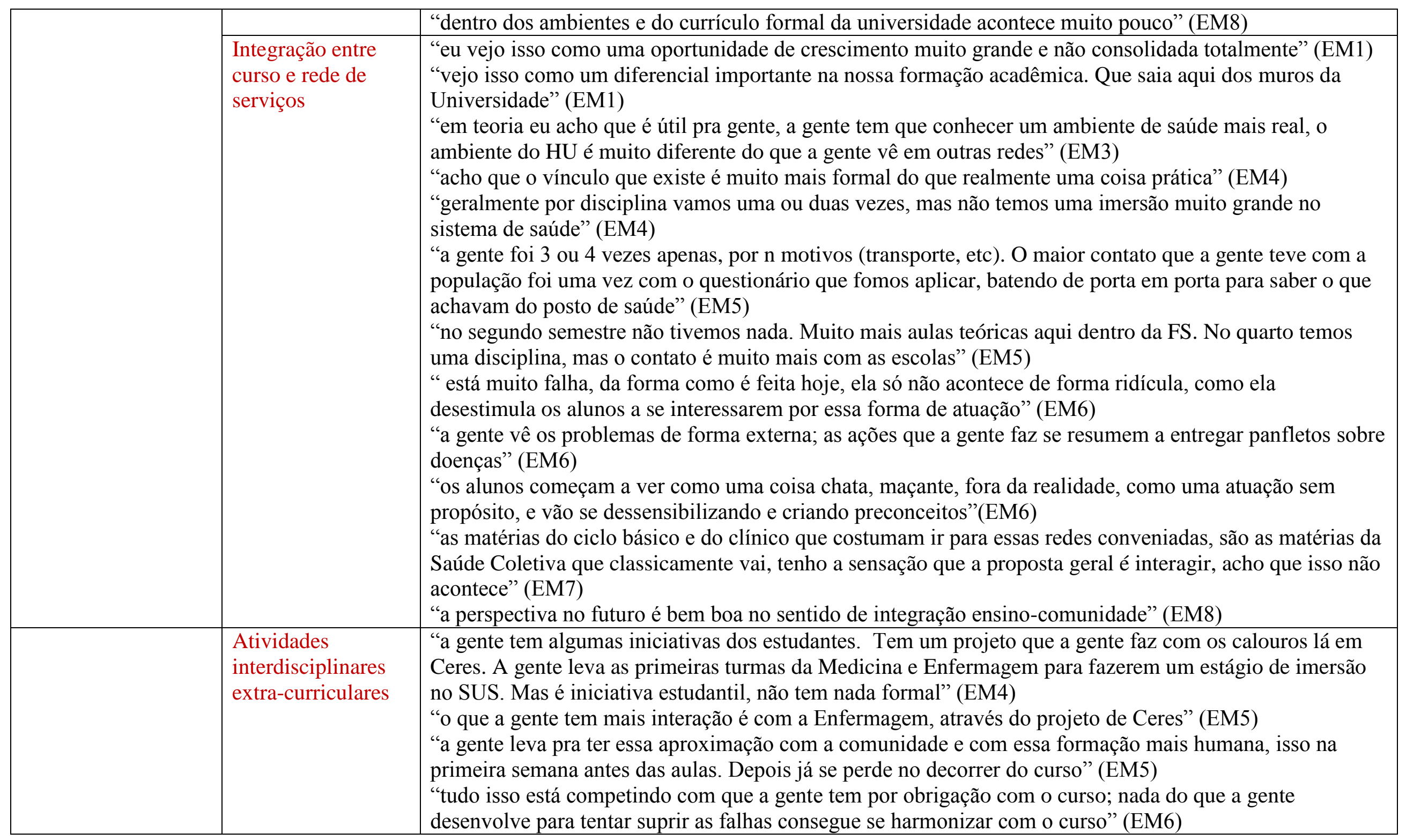




\begin{tabular}{|c|c|c|}
\hline & & $\begin{array}{l}\text { "tem um projeto desenvolvido pelos próprios alunos entre Medicina e Enfermagem que foi iniciativa } \\
\text { deles, muito inovador nesse sentido"... a gente sente que o que ele gera, que é muito positivo, vai } \\
\text { morrendo aos poucos ao longo do curso" (EM8) }\end{array}$ \\
\hline \multirow[t]{2}{*}{$\begin{array}{l}\text { PROCESSO DE } \\
\text { ENSINO E } \\
\text { APRENDIZAGEM }\end{array}$} & $\begin{array}{l}\text { Metodologia } \\
\text { tradicional }\end{array}$ & $\begin{array}{l}\text { "aqui tem uma forma bem tradicional ainda, o professor leva o conhecimento e a gente absorve, isso nas } \\
\text { aulas teóricas" (EM1) } \\
\text { "eu me encaixo bem nesse modelo, se o professor tiver uma boa oratória, boa dinâmica, não acho que seja } \\
\text { uma coisa que me prejudique" (EM1) } \\
\text { "quase todas as nossas aulas são aquelas tradicionais na sala de aula, com slide, o professor na maior parte } \\
\text { do tempo lendo os slides" (EM2) } \\
\text { "eu acho que é bem tradicional... o professor fala e o aluno escuta" (EM3) } \\
\text { "os professores são bem tradicionais, eles estão acostumados com os métodos deles, e não sinto nenhuma } \\
\text { intenção de mudar não" (EM3) } \\
\text { "é bastante tradicional, a gente tem aquela ideia do professor, a cátedra, ele vai na frente, explica, é uma } \\
\text { coisa que envolve pouco a gente" (EM4) } \\
\text { "a gente tem muito a ideia do Flexner: modelo básico, modelo de clínica, depois internato" (EM4) } \\
\text { "nosso currículo atual prega uma metodologia mais tradicional, com teoria por } 2 \text { anos, dois anos e meio de } \\
\text { clínica e um ano e meio de internato" (EM5) } \\
\text { "a parte de preleção convencional, sala de aula, etc" (PM5) } \\
\text { "o ensino é bem tradicional mesmo; a forma como são feitas as avaliações, os objetivos das aulas, às } \\
\text { vezes dissociados dos objetivos das avaliações" (EM6) } \\
\text { "o resto gira em torno disso, ele tem um título e ele projeta slide lá porque ele é um professor doutor } \\
\text { fulano de tal, vai projetar o slide e você lê o livro" (EM7) } \\
\text { "forma de ensinar totalmente tradicional” (EM8) } \\
\text { "muito a visão do professor lá na frente, falar, falar, falar..." (EM8) }\end{array}$ \\
\hline & $\begin{array}{l}\text { Metodologias } \\
\text { ativas }\end{array}$ & $\begin{array}{l}\text { "as aulas práticas são muito boas, eu realmente me sinto instigado, é uma coisa que demanda mais da } \\
\text { gente, a participação e construção de um raciocínio crítico" (EM1) } \\
\text { “os professores esperam que a gente construa... apresentam um caso, aquele baseado em problema, só que } \\
\text { mais nas aulas práticas" (EM1) } \\
\text { "algumas atividades são baseadas no aluno, tentando desenvolver, problematizar; têm disciplinas que } \\
\text { fazem um modelo de aulas práticas, mesmo baseadas no hospital, a ideia é estimular a crítica sobre como }\end{array}$ \\
\hline
\end{tabular}




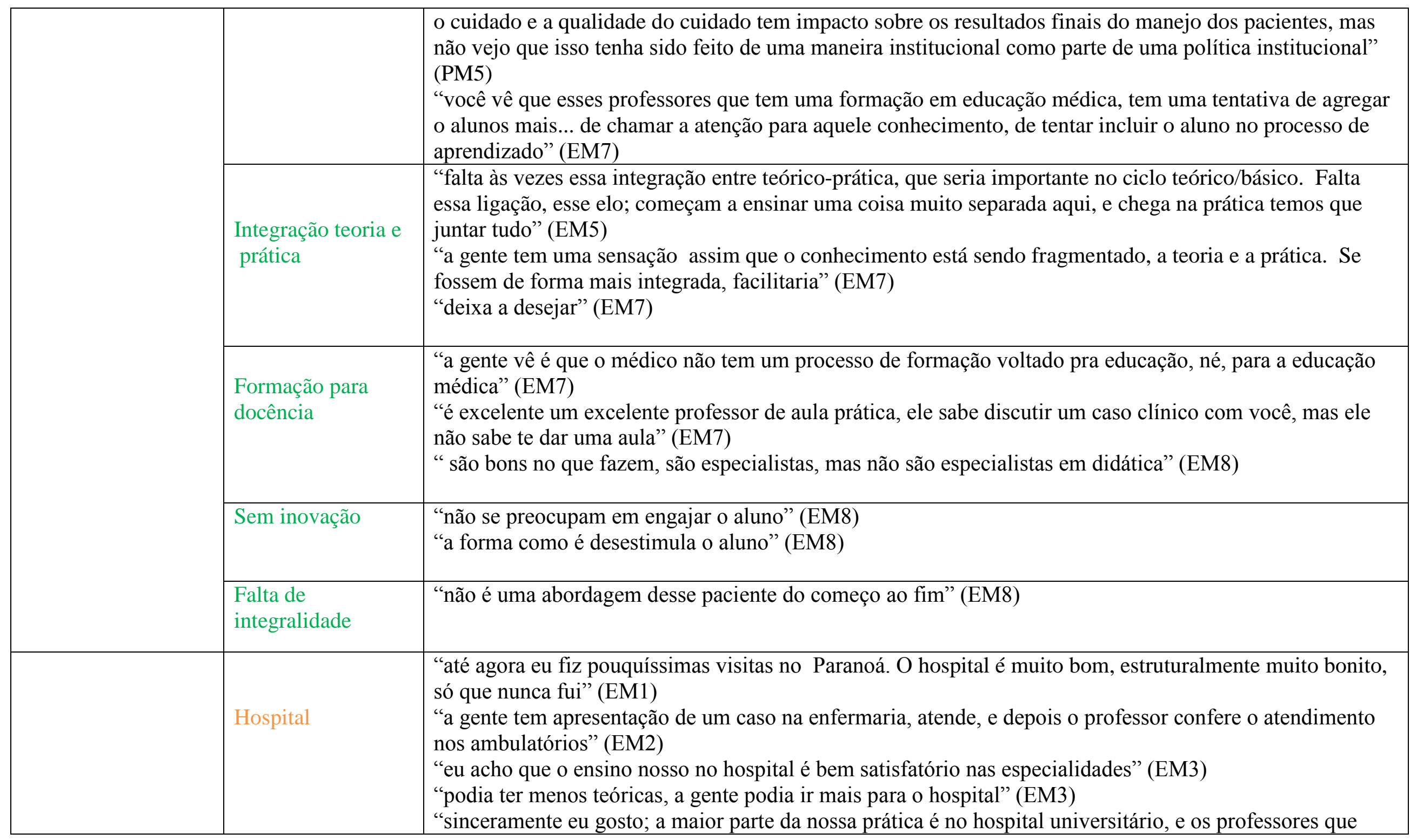




\begin{tabular}{|c|c|c|}
\hline \multirow[t]{4}{*}{$\begin{array}{l}\text { CENÁRIO DE } \\
\text { PRÁTICAS }\end{array}$} & & $\begin{array}{l}\text { estão aqui entendem o que é a ideia de que é uma escola" (EM4) } \\
\text { "tenta cumprir essa demanda do aluno de ver alguma coisa legal, vamos lá no hospital ver como } \\
\text { acontecem exames X, como fazem" (EM8) }\end{array}$ \\
\hline & Rede de serviços & $\begin{array}{l}\text { "as atividades precisam ser repensadas, principalmente as voltadas para a atenção primária" (EM1) } \\
\text { "pensando no que tive até agora, acho que todas foram extremamente sem sentido" (EM1) } \\
\text { "alguns professores tentam estabelecer, mas em geral tem uma resistência do corpo docente de ir levar a } \\
\text { gente, então a gente vai mais nas matérias que falam de saúde pública" (EM2) } \\
\text { "a gente foi lá aprender algumas teorias e não fizemos nada" (EM2) } \\
\text { "eu me lembro de ir lá } 2 \text { vezes durante nove semestres de curso e no hospital, especificamente, foi o único } \\
\text { lugar que a gente foi” (EM3) } \\
\text { "o que você aprende a fazer é clínica; ninguém se sente muito confiante em fazer atenção básica porque } \\
\text { ninguém fez durante o curso. Eu não sei fazer, não tenho nem ideia de como funciona" (EM3) } \\
\text { "tenho expectativa de que no internato mude, porque pouquíssimas vezes a gente foi, teve contato, não } \\
\text { tem preceptor" (EM7) } \\
\text { "existe aquele território lá, a gente pode ir lá e acaba indo uma vez ou outra de uma forma que a gente } \\
\text { chama de zoológico ou safári, que é assim: vai lá, olha e fala - que legal, está vendo essas pessoas, como é } \\
\text { a vida delas, nossa e tal" (EM8) } \\
\text { "acontece em um semestre e acabou... não tem um eixo que comece no primeiro semestre e siga ao longo } \\
\text { do curso que faça criar um vínculo" (EM8) } \\
\text { "está sendo discutido que o internato seja completamente integrado com a Rede" (EM8) }\end{array}$ \\
\hline & Divulgação & $\begin{array}{l}\text { "não é uma coisa muito divulgada" (EM1) } \\
\text { "eu acho que pode estar barrando é uma falha de comunicação mesmo" (EM1) } \\
\text { "tem um problema de divulgação" (EM3) } \\
\text { "o Pró-Saúde surge pra gente de uma maneira obscura, não existe divulgação" (EM4) } \\
\text { "falta um pouco de divulgação também" (EM5) } \\
\text { "eu acho que a divulgação do Programa não é adequada, dentro da universidade e do próprio hospital, } \\
\text { entendeu? Você vê que os profissionais da área não tem uma compreensão de como é o programa" (EM7) }\end{array}$ \\
\hline & Avanços & $\begin{array}{l}\text { "não lembro de ter ouvido alguma coisa que pareça ter sido algo muito transformador" (EM6) } \\
\text { "pelo que tenho visto, parece que está engatinhando mesmo" (EM8) }\end{array}$ \\
\hline
\end{tabular}




\begin{tabular}{|c|c|c|}
\hline \multirow[t]{4}{*}{$\begin{array}{l}\text { IMPLEMENTAÇÃO } \\
\text { DAS AÇÕES } \\
\text { DO PRÓ-SAÚDE }\end{array}$} & Distorções & $\begin{array}{l}\text { "tem uma parte de ensino, uma parte pesquisa, extensão e acaba que sendo tudo acaba não sendo nada" } \\
\text { (EM4) } \\
\text { "as pessoas não entendem bem o que é" (EM4) } \\
\text { "a ideia que tive até hoje é que é um projeto de extensão" (EM6) } \\
\text { "eu vejo que o programa é meio distorcido, como muita coisa no Brasil, então usam um programa legítimo } \\
\text { com uma finalidade política" (EM7) } \\
\text { "as pessoas não entenderam o propósito, do que se trata" (EM8) } \\
\text { "a maioria dos professores que estão participando e fazendo projeto do Pró-Saúde não enxergam o que é o } \\
\text { Programa, enxergam como projetos pontuais, muitos deles" (EM8) }\end{array}$ \\
\hline & Sensibilização & $\begin{array}{l}\text { "falta alguma conscientização das pessoas" (EM1) } \\
\text { "uma forma muito legal seria colocar como as mudanças estão associadas com as consequências tais, tais e } \\
\text { tais para a sociedade" (EM1) } \\
\text { "acho que falta interesse do corpo docente da universidade em relação a aderir ao projeto, a desenvolver e } \\
\text { a fazer acontecer" (EM5) } \\
\text { "principalmente os professores, eles não conversam entre si, não tem aquela conversa - olha gente, o Pró } \\
\text { Saúde, vamos participar, deveria ter esse tipo de conversa, não tem" (EM7) } \\
\text { "falta sensibilizar as pessoas" (EM8) } \\
\text { "promover um debate que faça com que as próprias pessoas percebam" (EM8) }\end{array}$ \\
\hline & Reflexão & $\begin{array}{l}\text { "pegando o exemplo da medicina, acho que as pessoas entram com uma ideia muito imatura do que elas } \\
\text { querem do curso" (EM6) } \\
\text { "ninguém tem o hábito de questionar qual o perfil do egresso da universidade pra poder se engajar em um } \\
\text { projeto pra que tenha a ideia de mudar isso" (EM8) } \\
\text { "fazer a pessoas se questionarem e caírem nas próprias contradições pra daí elas se abrirem pra esse } \\
\text { projeto" (EM8) }\end{array}$ \\
\hline & Barreiras & $\begin{array}{l}\text { "às vezes existe desinteresse ou até mesmo preconceito dos próprios estudantes e relação às políticas que } \\
\text { se proponham à valorização da Atenção Básica, de uma formação generalista" (EM1) } \\
\text { "falta de interesse associada com essa repulsa de que seja uma coisa chata... não veem como isso impacta } \\
\text { a vida do profissional e do estudante" (EM1) } \\
\text { "é um enfrentamento cultural" (EM2) } \\
\text { "pra mim o principal é a cultura hospitalar que tem no curso" (EM2) } \\
\text { "acho que tem um cunho político fortíssimo, influenciando, tem uma influência política nisso muito forte, }\end{array}$ \\
\hline
\end{tabular}




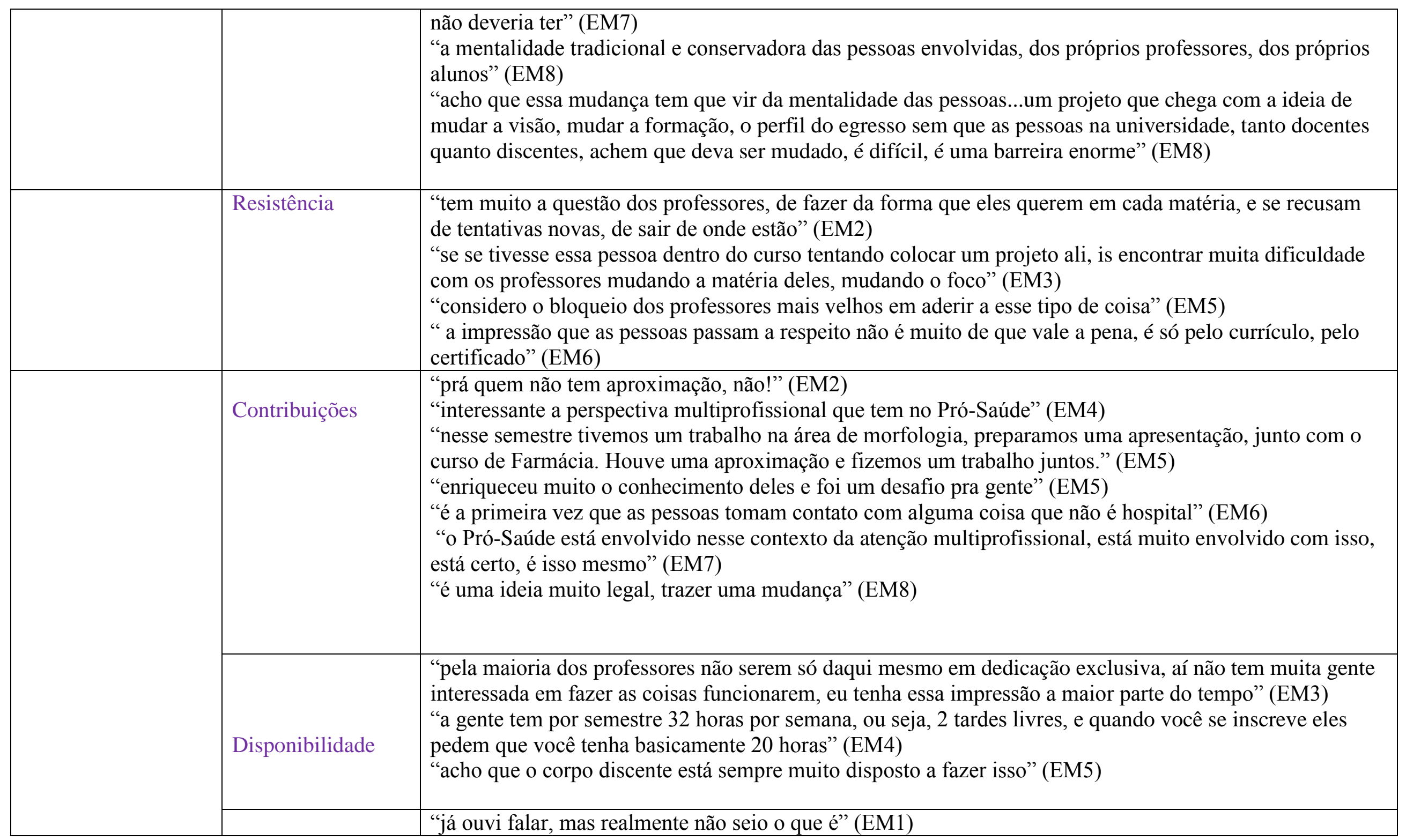




\begin{tabular}{|l|l|l|}
\hline Conhecimento & $\begin{array}{l}\text { "já ouvi falar, mas nunca... ouvi falar inclusive que nossa tendência era atura no Paranoá, no Itapoã, sair } \\
\text { daqui do terciário" (EM2) } \\
\text { "a maioria das pessoas acaba se inscrevendo sem entender o que realmente é o Programa" (EM4) }\end{array}$ \\
\hline
\end{tabular}

Figura 67 - Unidades de registro das subcategorias obtidas na análise de conteúdo das entrevistas dos estudantes de Medicina.

\begin{tabular}{|c|l|l|}
\hline CATEGORIA & \multicolumn{1}{|c|}{$\begin{array}{c}\text { SUB } \\
\text { CATEGORIAS }\end{array}$} & \multicolumn{1}{c|}{ UNIDADE DE REGISTRO } \\
\hline Generalista & $\begin{array}{l}\text { "falta uma identificação do egresso com as práticas generalistas" (PM2) } \\
\text { "essa formação que a gente deseja, que é aquele médico que conhece a integralidade do cuidado, } \\
\text { que enxerga a pessoa da forma holística, que tem uma escuta qualificada, que saiba fazer um } \\
\text { projeto terapêutico singular, que trabalha com a humanização, que enxerga o contexto social da } \\
\text { família, da comunidade" (PM2) } \\
\text { "precisamos ter um equilíbrio, vejo que temos que formar generalistas. Acho que estamos um } \\
\text { pouco nessa crise de identidade, em relação ao perfil. Acho que a graduação não tem essa } \\
\text { responsabilidade de formar um especialista. Ela tem que formar a pessoa com uma visão geral } \\
\text { que seja capaz de aprofundar na sua residência conforme a escolha que fizer" (PM4) } \\
\text { "médico generalista é essencial para a implementação, com sucesso das políticas de saúde que de } \\
\text { fato dão uma cobertura adequada para atender as necessidades da população" (PM5) } \\
\text { "a formação do generalista precisa da visão integrada, né? Ver o ser humano como um todo e } \\
\text { ação da saúde no âmbito coletivo... essas são as necessidades que eu identifico como mais } \\
\text { gritantes" (PM6) }\end{array}$ \\
PERFIL & $\begin{array}{l}\text { PEREBIDO } \\
\text { "você acaba tendo quase um médico especialista no final da graduação; o aluno entra e já vai se } \\
\text { direcionando e estudando apenas os conteúdos que dizem respeito àquela especialidade que ele }\end{array}$ \\
\hline
\end{tabular}




\begin{tabular}{|c|c|c|}
\hline & & $\begin{array}{l}\text { vai escolher no futuro" (PM1) } \\
\text { "um médico pré-especialista" (PM1) } \\
\text { "eu acho que ele sai com o ímpeto de fazer residência em uma especialidade" (PM2) } \\
\text { "médico especialista" (PM3) } \\
\text { "praticamente o que acontece é que todo mundo vai para uma especialidade" (PM4) } \\
\text { "ele se forma com esse foco nas especialidades" (PM6) } \\
\text { "eu creio que forma mais médico especialista, naquele modelo hospitalocêntrico" (PM7) }\end{array}$ \\
\hline & Mercantilista & $\begin{array}{l}\text { "com certeza tem o aspecto financeiro, o pessoal quer saber de tecnologia já pensando no futuro" } \\
\text { (PM3) }\end{array}$ \\
\hline & Tecnicista & $\begin{array}{l}\text { "extremamente competentes, muito bem formados, com os conhecimentos necessários para ser } \\
\text { um bom médico, só que falta um pouco dessa vivência mais real do serviço" (PM2) } \\
\text { "eu acho que é bem parecido com a maioria das escolas. Um profissional com uma qualificação } \\
\text { técnica muito boa, capaz de continuar na seguinte etapa de especialização onde ele adensa } \\
\text { tecnologicamente sua prática, mas com relativa pouca visão do conjunto e dos grandes problemas } \\
\text { de saúde que a comunidade enfrenta" (PM5) }\end{array}$ \\
\hline CURRÍCULO & Reforma & $\begin{array}{l}\text { "vai estar com outro foco, ementas, eixos temáticos principalmente focados na medicina de } \\
\text { família e comunidade" (PM1) } \\
\text { "o modelo que vai ser implementado prevê que a gente tenha, desde a área básica até a última, } \\
\text { que é o internato, com a atenção básica norteando todas as disciplinas, a gente está pensando } \\
\text { numa estrutura de colocar professores integradores entre as áreas" (PM1) } \\
\text { "a reforma prevê a inserção uma inserção desse aluno mais aprofundada no campo, coisa que o } \\
\text { internato já propôs um pouco" (PM1) } \\
\text { "a gente está em processo de reforma curricular" (PM2) } \\
\text { "pro currículo novo, a gente tem muitos planos e eles vão logo se concretizar" (PM2) } \\
\text { "a reforma, ela possibilita um fazer diferenciado, ela nos obriga a conversar" (PM2) } \\
\text { "embora a gente já tenha essa discussão da reforma curricular, algumas pessoas já se organizando } \\
\text { para isso, as pessoas que estão no processo formativo têm uma visão (a maior parte, não todas) } \\
\text { dessa formação especialista. No dia a dia isso se reflete em todas as disciplinas, por exemplo, de } \\
\text { como você aborda o conteúdo" (PM4) } \\
\text { "a gente tem um pequeno grupo que está discutindo isso, a grande maioria entendo que estão } \\
\text { entrando porque é necessário fazer, mas na realidade não compreendem e não acreditam" (PM4) } \\
\text { "a pessoa não acredita nisso. Dentro da faculdade a gente tem uma resistência à reforma" (PM4) }\end{array}$ \\
\hline
\end{tabular}




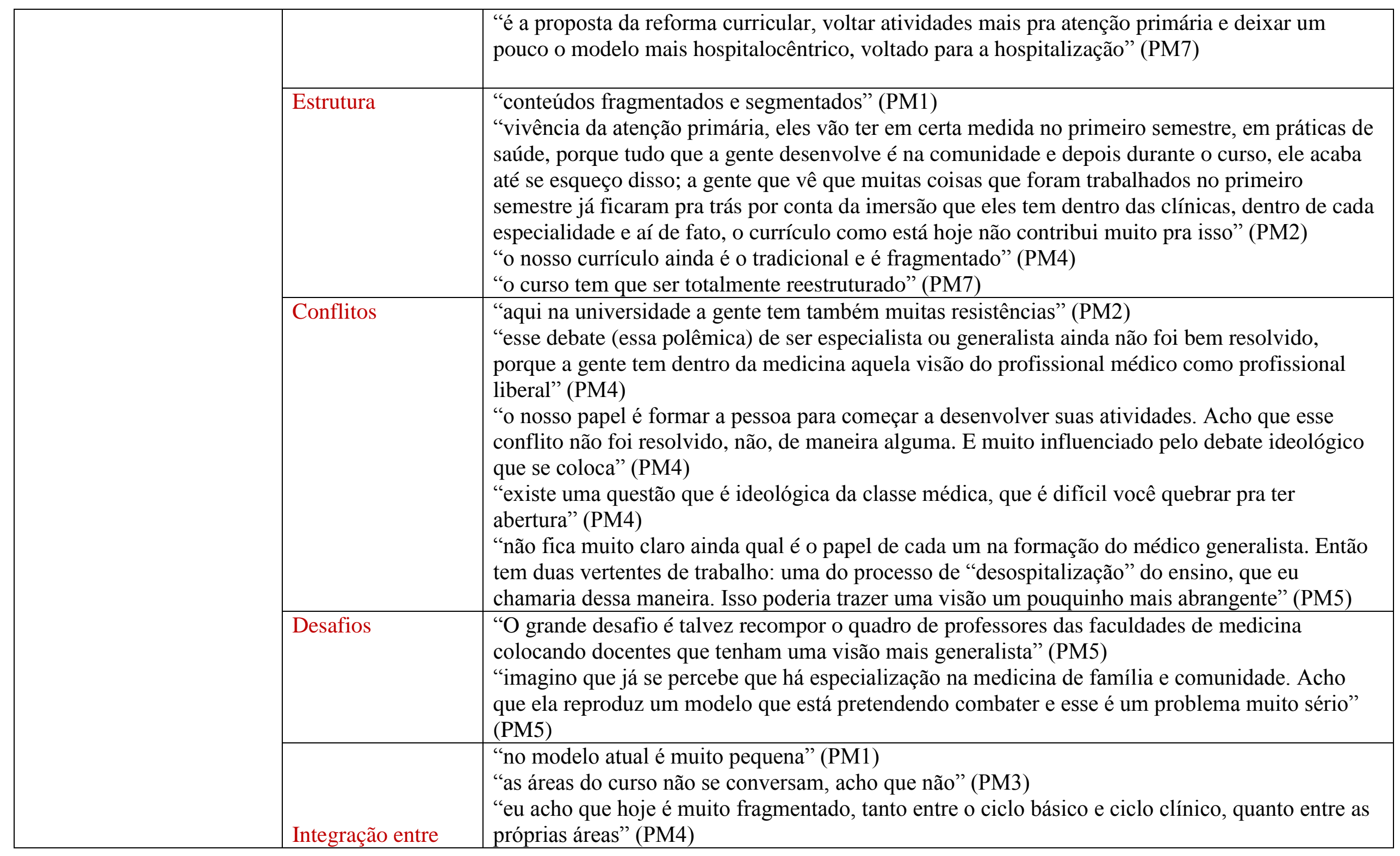




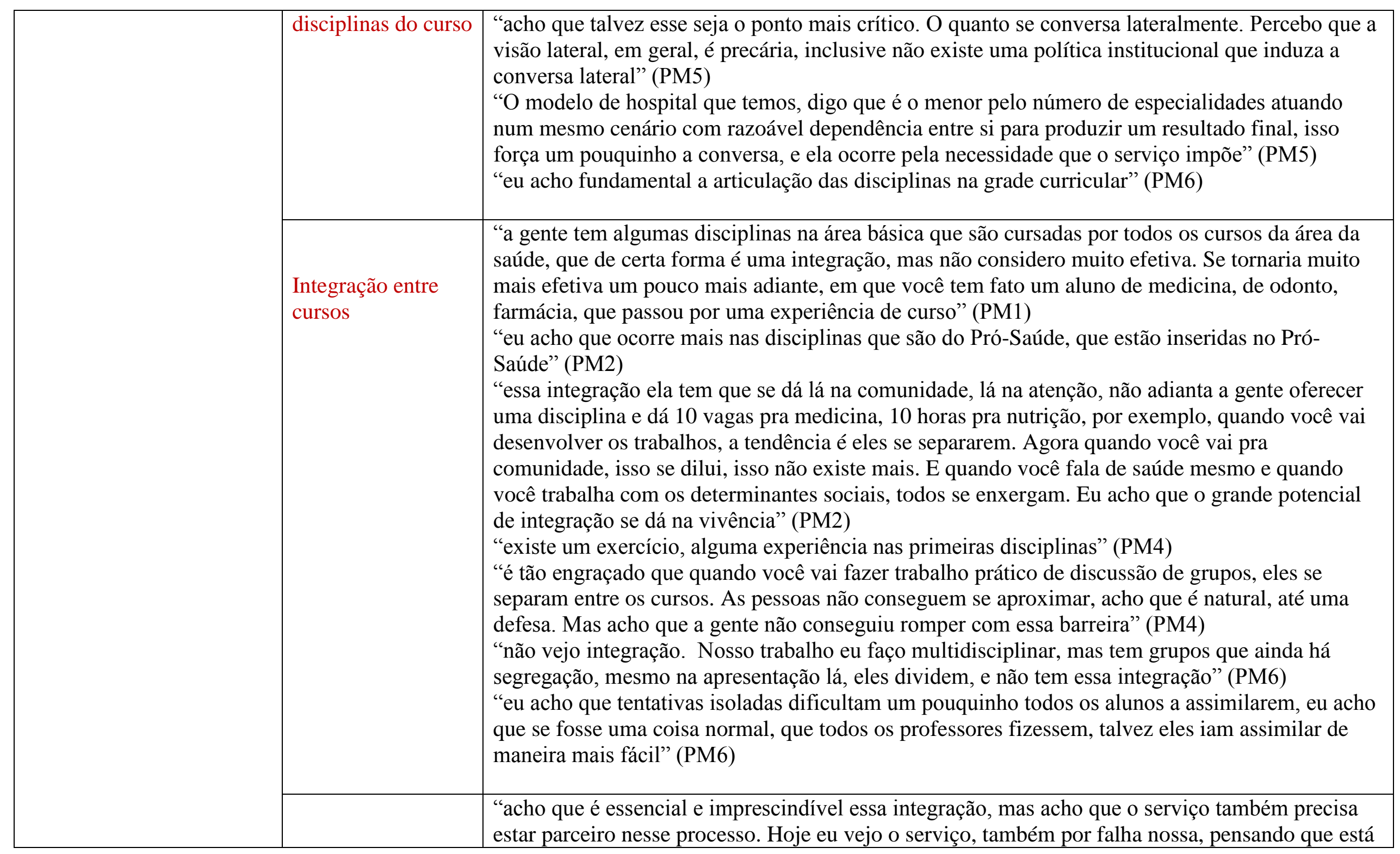




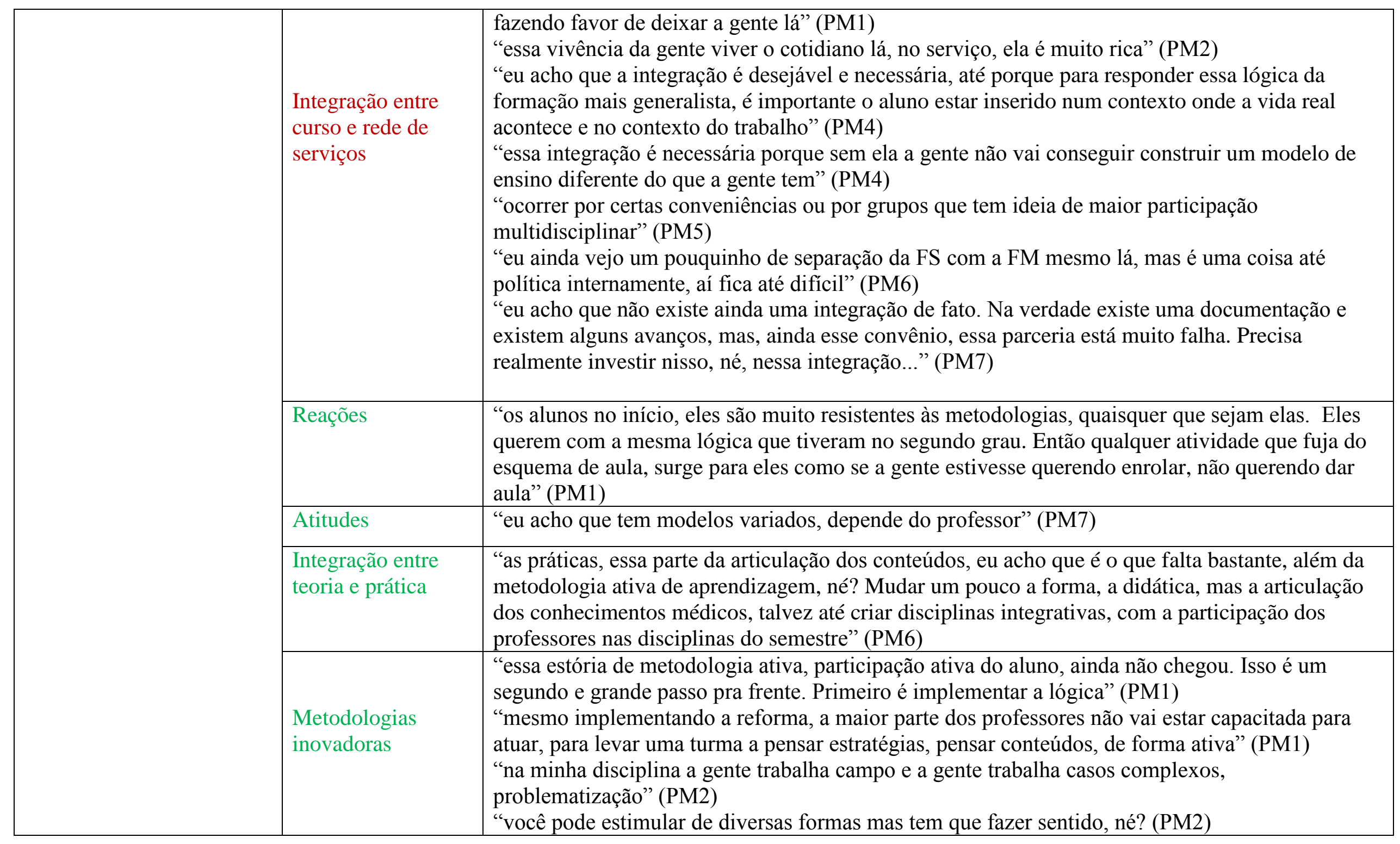




\begin{tabular}{|c|c|c|}
\hline & & $\begin{array}{l}\text { "eu estou tentando ser inovadora, estou tentando ser inovadora" (PM6) } \\
\text { "tem outros professores na medicina que estão tentando inovar, com a inserção de tecnologias, } \\
\text { com vídeos, utilizando plataformas de informação, entendeu?" (PM6) }\end{array}$ \\
\hline & $\begin{array}{l}\text { Metodologias } \\
\text { Tradicionais }\end{array}$ & $\begin{array}{l}\text { "são tradicionais, aula expositiva, pouco dialogada" (PM4) } \\
\text { "uma coisa que a gente tem, que é tradicional também, mas que ajuda na discussão, é que tudo já } \\
\text { é baseado em casos clínicos, o que ajuda um pouco na cotextualização com a realidade, mas ainda } \\
\text { é focando no professor" (PM4) } \\
\text { "é um curso tradicional" (PM5) } \\
\text { "predomina a tradicional, que é a aula expositiva" (PM6) }\end{array}$ \\
\hline & Dificuldades & $\begin{array}{l}\text { "teve uma oficina com representantes dos professores, alunos e rede para debaterem essa questão. } \\
\text { Como a gente não conseguiu organizar, então começa a frustração. Porque nós que estávamos no } \\
\text { ensino tradicional reclamávamos porque tínhamos pouca metodologia ativa. O pessoal que já } \\
\text { nasceu dentro do PBL também reclamava por conta dessa questão de que nem sempre os cenários } \\
\text { estavam prontos para atender e nem sempre atendiam aquela necessidade educacional. Então o } \\
\text { problema não é o método, o problema é de como a gente integra" (PM4) }\end{array}$ \\
\hline \multirow[b]{2}{*}{ CENÁRIO DE PRÁTICAS } & Hospital & $\begin{array}{l}\text { "o cenário de aprendizado desses meninos é } 90 \% \text { no hospital especializado, então esses alunos } \\
\text { focam mais em doenças mais graves, que vêm para cá e necessita de muita tecnologia" (PM3) }\end{array}$ \\
\hline & Rede de serviços & $\begin{array}{l}\text { "temos muito a caminhar para que o cenário da atenção básica seja uma realidade para o } \\
\text { estudante de medicina” (PM2) } \\
\text { "a atuação do cenário de práticas na atenção primária é uma grande preocupação" (PM2) } \\
\text { "estão pouco inseridos no cenário de atenção primária” (PM3) } \\
\text { "a rede também tem que estar preparada para isso, não só da estrutura física, mas dos } \\
\text { profissionais também. Acho que ainda estamos engatinhando nisso" (PM4) } \\
\text { "na minha disciplina precisa ser repensada e a reforma curricular vai favorecer isso, articular } \\
\text { melhor com as unidades de saúde" (PM7) }\end{array}$ \\
\hline
\end{tabular}




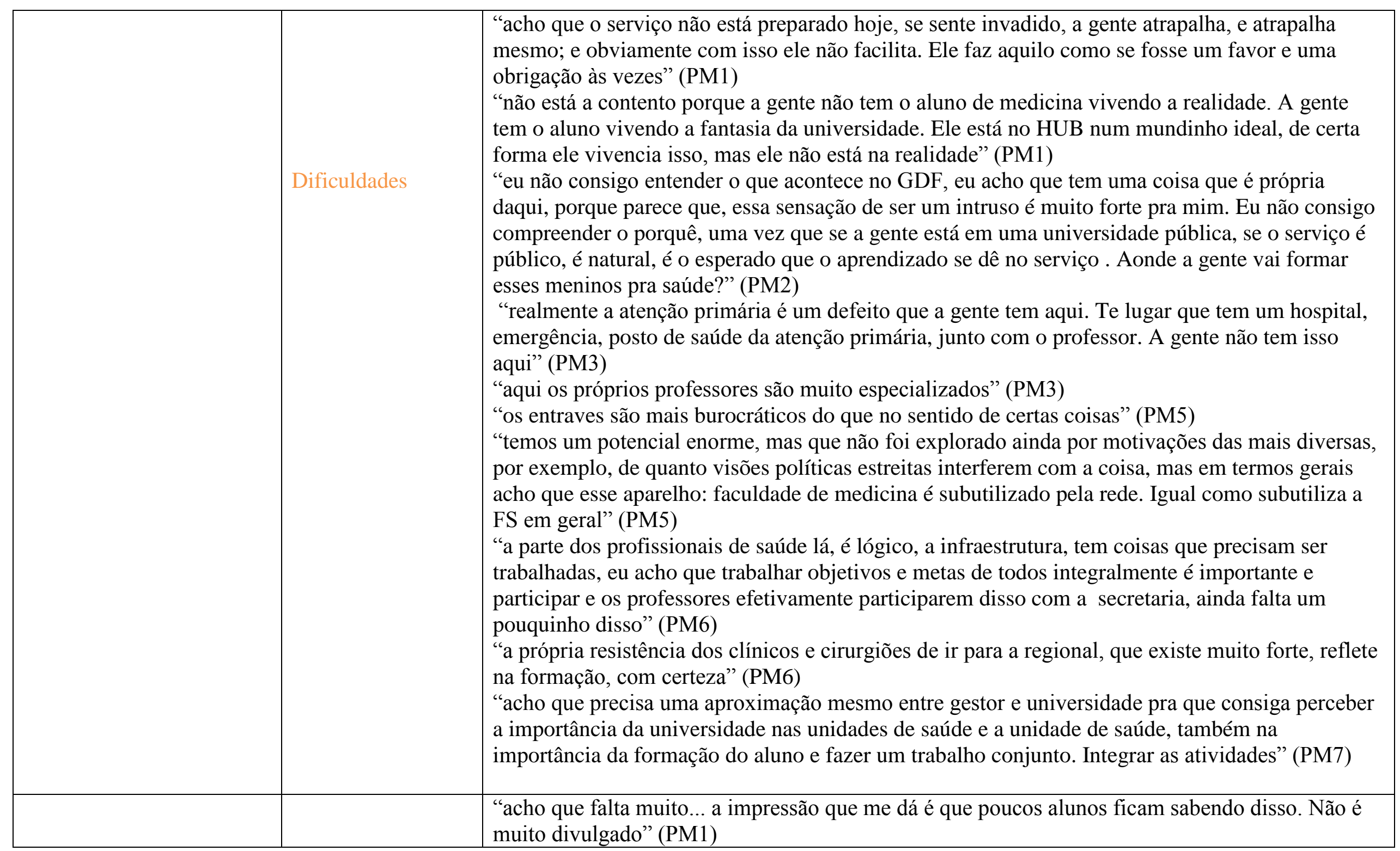




\begin{tabular}{|l|l|l|}
\hline $\begin{array}{l}\text { IMPLEMENTAÇÃO } \\
\text { DAS AÇÕES DO } \\
\text { PRÓ-SAÚDE }\end{array}$ & $\begin{array}{l}\text { "tinha que ter uma referência física, uma sala enorme, uma secretaria, os banners do projeto" } \\
\text { (PM1) } \\
\text { "nós fazemos a apresentação do Pró-Saúde pros alunos, o primeiro passo é a apresentação, ele } \\
\text { não sabe o que é e o que faz isso na formação dele, então pra ele se engajar ele precisa comprar a } \\
\text { ideia não é?" (PM6) } \\
\text { "divulgação, de repente quem participa divulgar os trabalhos que estão sendo desenvolvidos" } \\
\text { (PM7) }\end{array}$ \\
\hline Divulgação & $\begin{array}{l}\text { Barreiras } \\
\text { "as pessoas não se sentem participantes se elas não estão vinculadas a algum grupo tutorial, então } \\
\text { os grupos tutoriais eles tem a sua importância, precisam existir, na minha opinião, mas eles são } \\
\text { mal interpretados e muitos professores mesmos e alunos restringiram o Pró-Saúde aos grupos } \\
\text { PET, é como se só existisse PET, o Pró-Saúde não existisse" (PM2) } \\
\text { "precisa de uma postura política por trás que facilite a execução na prática. Cada vez que se tem } \\
\text { uma barreira burocrática que tem que ser superada para se fazer alguma coisa é um enorme } \\
\text { estímulo para desmotivação das equipes para tentar avançar. Essa é uma enorme fragilidade. } \\
\text { Você dá a receita, mas você não cria os instrumentos para que o contexto seja de fato favorável” } \\
\text { (PM5) }\end{array}$ \\
\hline
\end{tabular}




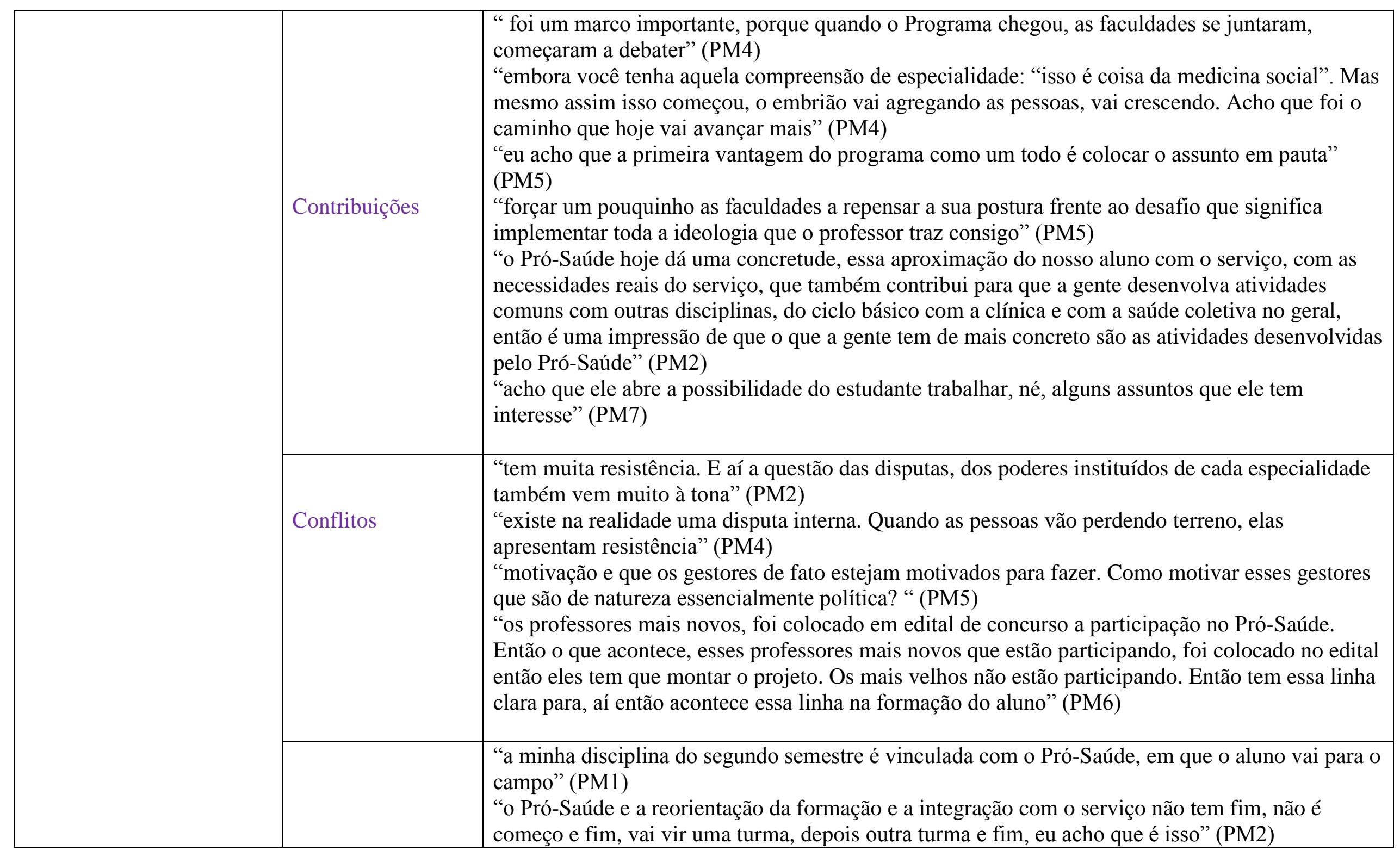




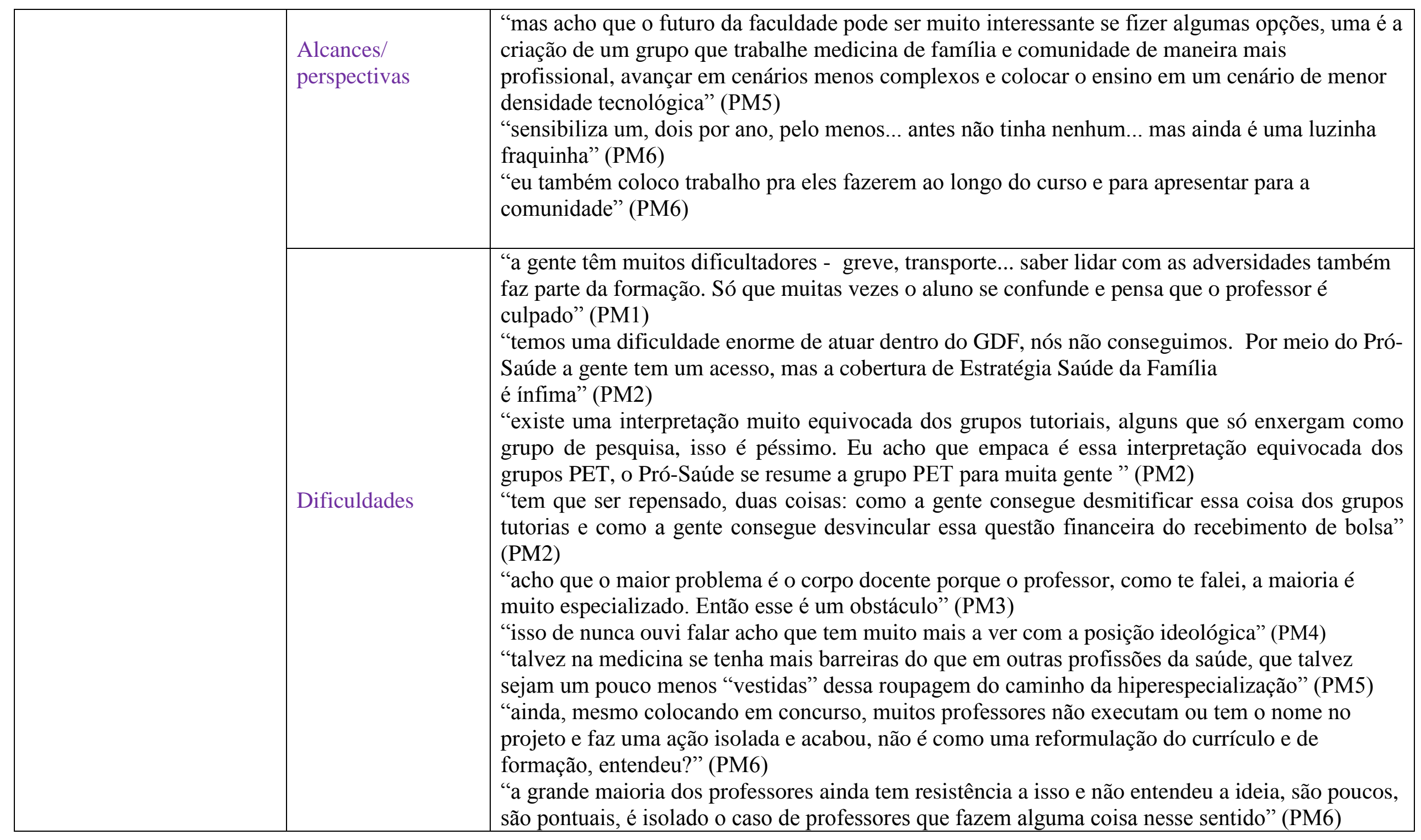

Figura 68 - Unidades de registro das subcategorias obtidas na análise de conteúdo das entrevistas dos professores de Medicina. 